\title{
Cronfa

\section{A case study investigation into a children's rights approach to health services}

Rhian Chamberlain

\section{This thesis is submitted in candidacy for the degree of Doctor of Philosophy Hillary Rodham Clinton School of Law}

Swansea University

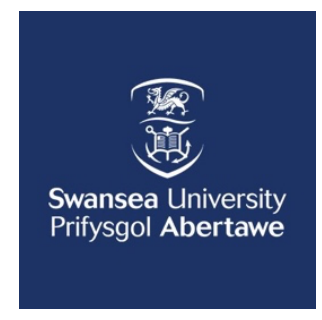

March 2020 


\section{ABSTRACT}

The purpose of this thesis is to contribute knowledge regarding what should be involved in a children's rights approach (CRA) to health services in the Welsh context and to develop tools to monitor the implementation of such an approach using Abertawe Bro Morgannwg University Health Board (ABMU) as a case study. There is no agreed model for a human rights approach, a children's rights approach, human rights approach to health or indeed a CRA to health services. This thesis begins with an examination of the conceptual literature and the international human rights treaty system to determine what should be included in a CRA to health services. It considers what are the barriers and also the mechanisms that support a CRA to health services' implementation in practice and reviews devolved health policy and the agenda for children's rights in Wales.

From this analysis it develops a conceptual framework and monitoring tools to test a health authority's institutional approach to implementing a CRA in the Welsh context. Using ABMU Health Board as the case study it demonstrates how tools were developed to gain a baseline understanding of how far a CRA had been embedded in $A B M U$ health services and what strategies were required to make a CRA fully operational.

The monitoring tools are determined to be effective, non-resource intensive methods that can be used to test a health board's progress on implementing a CRA. The thesis presents opportunities for critical reflections regarding how to better embed and implement a CRA to health services and recommendations regarding future research. 


\section{DECLARATION AND STATEMENTS}

This work has not previously been accepted in substance for any degree and is not being concurrently submitted in candidature for any degree.

Signed:

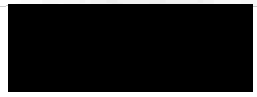

Date: Monday March $30^{\text {th }} 2020$

\section{STATEMENT 1}

This thesis is the result of my own investigations, except where otherwise stated. Where correction services have been used, the extent and nature of the correction is clearly marked in a footnote(s).

Other sources are acknowledged by footnotes giving explicit references. A bibliography is appended.

Signed:

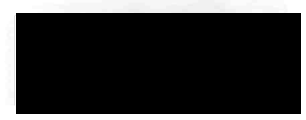

Date: Monday March $30^{\text {th }} 2020$

\section{STATEMENT 2}

I hereby give consent for my thesis, if accepted, to be available for photocopying and for inter-library loan, and for the title and summary to be made available to outside organisations.

Signed:

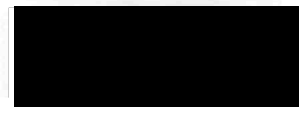

Date: Monday March $30^{\text {th }} 2020$ 


\section{ACKNOWLEDGEMENTS}

Many people have helped me to complete this thesis and I am grateful for all their invaluable support. Special thanks to my first supervisor Associate Professor Simon Hoffman for inviting me to apply to undertake a PhD and for his encouragement, constructive feedback, helpful discussions and patience. He has assisted in helping me to articulate my ideas and thoughts at each stage of the research and offered essential knowledge regarding human rights.

I would like to express my thanks for the financial support provided by Abertawe Bro Morgannwg Health Board and the critical expertise of partner colleagues in particular, Eirlys Thomas, Head of Nursing and Children's Services at Swansea Bay Health Board, Jannine Smith, Manager of the Neath Port Talbot Children's Rights Unit and Jannette Williams, Patient Experience Coordinator at Swansea Bay Health Board. Over the last 3 years I have admired their commitment and dedication to going beyond the confines of their day jobs to try to ensure that all children have their human rights realised when interacting with health services. I also wish to thank them for delivering the research and all the children, young people and professionals who generously gave their time to participate in the surveys.

Thanks to Helen Dale (Lleisiau Bach/Little Voices) who offered invaluable advice concerning children's involvement in the research and the software package that made the surveys possible. Thanks to my long time colleagues, Professor Jane Williams, for our ongoing inspiring discussions to promote the human rights of children and to Emeritus Professor Elspeth Webb at the start of my thesis for her insights and extensive knowledge base on children's rights in health.

Towards the later stages of the PhD, I have also benefited from working closely with my colleagues Rhian Thomas Turner, R\& D Paediatric Lead and Dr Phillip Connor, Consultant Haematologist at the Children's Hospital for Wales, in our mission to ensure the human rights of children with complex health conditions are better realised in Wales.

This PhD would not have been possible without the support of my family - to my husband Ross, who has been my rock, who became the sole breadwinner when 
delays in the ethics process meant my research was delayed by almost a year and has emotionally supported me every step of the way, in particular through various health challenges and latterly with the unanticipated challenges of Covid 19. And to my Mum (Mags) Dad (Pete), Gramma Lyn and Grandpa Ron, Great Auntie Jan, Auntie Leah - my cavalry - who have stepped in to look after our children, to clean our house, to walk our dogs, and other numerous acts of kindness, so that I could finish my write up and inspire me to never give up. Finally, to my three gorgeous children, Nye, Gruff and Catrin who were so very young when I embarked on this journey, thanks for all the cuddles, mummy has finally submitted her $\mathrm{PhD}$, hallelujah let's celebrate! 


\section{LIST OF DIAGRAMS, TABLES, FIGURES AND ILLUSTRATIVE EXAMPLES}

\section{LIST OF DIAGRAMS}

DIAGRAM 1: Map of the seven welsh health boards up to March 2019

DIAGRAM 2: Three tiers of health services delivery

DIAGRAM 3: Overview of the Welsh health system

DIAGRAM 4: Levels of obligations to the child as rights holder

DIAGRAM 5: Five interrelated and overlapping principles of a CRA to health services

\section{LIST OF TABLES}

TABLE 1: A summary of Tobin's principles of a CRA and where they are derived from

TABLE 2: The essential characteristics of human rights

TABLE 3: A CRA to health services should include

TABLE 4: Summary of the 5 principles of a CRA and where they are derived from

TABLE 5: Health authority wide commitment to the UNCRC

TABLE 6: A children's rights strategy

TABLE 7: Raising awareness and training on children's rights for staff

TABLE 8: Undertake children's rights monitoring

TABLE 9: Equality and non-discrimination to children throughout service delivery

TABLE 10: Children can actively participate in their own health 
TABLE 11: Children are directly involved in the development, monitoring and evaluation of service delivery.

TABLE 12: A child friendly advice and complaints mechanism

TABLE 13: Health promotion, children's rights information and advocacy is provided to children and their carers

TABLE 14: Maccat-cr Macarthur competence assessment tool for clinical research

TABLE 15: Examples of age criteria and informed consent to clinical research in other countries (drawn from Hein et al 2014).

TABLE 16: ABMU case study - number of respondents per each sample

\section{LIST OF FIGURES}

FIGURE 1: Number of strategic lead respondents by age category

FIGURE 2: Number of strategic lead respondents by gender

FIGURE 3: Percentage of health professional respondents by gender

FIGURE 4: Percentage of health professional respondents by age category

FIGURE 5: Percentage of health professional respondents by local authority area where they work

FIGURE 6: Percentage of health professional respondents by health service area they work in

FIGURE 7: Percentage of health professional respondents by professional category

FIGURE 8: Percentage of health professional respondents by medical specialisation in child health or special training in providing care for children

FIGURE 9: Percentage of young people respondents by age

FIGURE 10: Percentage of young people respondents by gender 
FIGURE 11: Percentage of young people respondents by number of times they visited a health professional in 2018 and 2019

FIGURE 12: Percentage of young people respondents who responded that they were answering the survey based on visiting a Hospital, GP, Children's centre or Accident and Emergency

FIGURE 13: Percentage of young people respondents by area they live in

FIGURE 14: Percentage of child respondents by age

FIGURE 15: Percentage of child respondents by gender

FIGURE 16: Percentage of child respondents by the area in which they live

FIGURE 17: Percentage of child respondents by number of times they visited a health professional in 2018 and 2019

FIGURE 18: Percentage of children who responded that they were answering the survey based on visiting a Hospital, GP, Children's Centre or Accident and Emergency

FIGURE 19: Distribution of strategic leads to the 5 options rating of the objective SLQ3

FIGURE 20: Distribution of strategic leads to 5 score options rating of objective SLQ4

FIGURE 21: Percentage of health professional respondents that report the children's rights charter is displayed in service areas where they work

FIGURE 22: Percentage of health professional respondents by knowledge rating of the children's rights charter

FIGURE 23: Distribution of strategic leads to 5 score options rating by objective SLQ5

FIGURE 24: Percentage of young people respondents who know their rights when visiting a health professional

FIGURE 25: Percentage of young people respondents who have seen the children's rights charter before 
FIGURE 26: Percentage of child respondents who know their rights when visiting a doctor or nurse

FIGURE 27: Percentage of child respondents who have seen the children's rights charter before

FIGURE 28: Distribution of strategic leads to 5 score options rating by objective SLQ6

FIGURE 29: Percentage of health professional respondents who have access to guidance on implementing the children's rights charter in their area of work

FIGURE 30: Distribution of strategic leads to 5 score options rating by objective SLQ8

FIGURE 31: Percentage of health professional respondents who responded there is a named person in their service area responsible for service delivery complying with the charter

FIGURE 32: Distribution of strategic leads to 5 score options rating by objective SLQ7

FIGURE 33: Distribution of strategic leads to 5 score options rating by objective SLQ9

FIGURE 34: Distribution of strategic leads to 5 score options rating by objective SLQ10

FIGURE 35: Distribution of strategic leads to 5 score options rating by objective SLQ11

FIGURE 36: Distribution of strategic leads to 5 score options rating by objective SLQ12

FIGURE 37: Percentage of health professional respondents by training they have received

FIGURE 38: Percentage of health professionals that would like to receive training on children's rights

FIGURE 39: Distribution of strategic leads to 5 score options rating by objective SLQ13 
FIGURE 40: Distribution of strategic leads to 5 score options rating by objective SLQ14

FIGURE 41: Distribution of strategic leads to 5 score options rating by objective SLQ15

FIGURE 42: Distribution of strategic leads to 5 score options rating by objective SLQ17

FIGURE 43: Distribution of strategic leads to 5 score options rating by objective SLQ5

FIGURE 44: Percentage of health professional respondents who have job descriptions that include performance indicators relating to the children's rights charter

FIGURE 45: Distribution of strategic leads to 5 score options rating by objective SLQ19

FIGURE 46: Distribution of strategic leads to 5 score options rating by objective SLQ20

FIGURE 47: Distribution of strategic leads to 5 score options rating by objective SLQ21

FIGURE 48: Distribution of strategic leads to 5 score options rating by objective SLQ2

FIGURE 49: Distribution of strategic leads to 5 score options rating by objective SLQ23

FIGURE 50: Percentage of health professional respondents who have timely access to professional interpreters

FIGURE 51: Distribution of strategic leads to 5 score options rating by objective SLQ24

FIGURE 52: Percentage distribution of young people respondents when seeing a health professional believe they have been treated unfairly by protected characteristic

FIGURE 53: Percentage of young people respondents who find it difficult to get to see a health professional 
FIGURE 55: Distribution of strategic leads to 5 score options rating by objective SLQ25

FIGURE 56: Percentage of health professional respondents by rating their ability to involve children according to their age and capacity in clinical decisions

FIGURE 57: Percentage of young people respondents that think health professionals are friendly

FIGURE 58: Percentage of young people respondents who think that health professionals only talk to them, only talk to the person they came with, or talk to them and the person they came with

FIGURE 59: Percentage of young people respondents who think that health professionals listen to what they have to say

FIGURE 60: Percentage of young people respondents who think health professionals give them a chance to ask questions

FIGURE 61: Percentage of young people respondents who understand everything health professionals say to them

FIGURE 62: Percentage of young people respondents who help to choose how they can get better

FIGURE 63: Percentage of young people respondents who would tell a health professional if they were worried or upset

FIGURE 64: Percentage of young people respondents who trust health professionals

FIGURE 65: Percentage of young people who said they knew that health professionals have to keep their information private but professionals have to pass their information on if they consider them to be unsafe

FIGURE 66: Percentage of young people respondents who feel safe when they visit a health professional 
FIGURE 67: Percentage of young people respondents who feel their privacy is respected when they visit health professional

FIGURE 68: Percentage of young people respondents who think health professionals ask for their permission before treating them

FIGURE 69: Percentage of child respondents who like visiting the doctor or nurse

FIGURE 70: Percentage of child respondents who think doctors and nurses are friendly

FIGURE 71: Percentage of child respondents who feel safe when they visit a doctor or nurse

FIGURE 72: Percentage of child respondents who are happy to tell the doctor or nurse if they are worried or upset

FIGURE 73: Percentage of child respondents who understand what doctors and nurses say to them.

FIGURE 74: Percentage of child respondents who think that doctors and nurses give them the chance to ask questions

FIGURE 75: Percentage of child respondents who think that doctors and nurses listen to what they have to say

FIGURE 76: Distribution of strategic leads to 5 score options rating by objective SLQ26

FIGURE 77: Distribution of strategic leads to 5 score options rating by objective SLQ27

FIGURE 78: Percentage of health professional respondents who provide children with opportunities to give patient feedback

FIGURE 79: Percentage of young people respondents who have been asked what would make a visit to a health professional better

FIGURE 80: Distribution of strategic leads to 5 score options rating by objective SLQ29 
FIGURE 81: Distribution of strategic leads to 5 score options rating by objective SLQ28

FIGURE 82: Distribution of strategic leads to 5 score options rating by objective SLQ30

FIGURE 83: Percentage of health professional respondents who know how to support a child to make a complaint

FIGURE 84: Number of children health professional respondents supported to make a complaint in 2018

FIGURE 85: Percentage of young people respondents who know how to complain

FIGURE 86: Distribution of strategic leads to 5 score options rating by objective SLQ

FIGURE 87: Distribution of strategic leads to 5 score options rating by objective SLQ32

FIGURE 88: Distribution of strategic leads to 5 score options rating by objective SLQ34

FIGURE 89: The percentage of health professionals who provide health promotion or health rights information by subject categories listed

FIGURE 90: Distribution of young people respondent's responses by where they learn most about being healthily

\section{LIST OF ILLUSTRATIVE EXAMPLES}

Illustrative Example 1: Discrimination because of Race [YP15]

Illustrative Example 2: Discrimination because of Age [YP48]

Illustrative Example 3: Discrimination because of Disability [YP31]

Illustrative Example 4: Discrimination because of: Learning needs [YP9] 
Illustrative Example 5: "Less formal. Ensure you understand. Ask me what I think is wrong" [YP37]

Illustrative Example 6: "I didn't know that I had the right to information in health or the right to have my say. I thought that the doctors word was final." [YP16]

Illustrative Example 7: "Better attitude. They have secretive meetings about my care without me knowing" [YP34]

Illustrative Example 8: "If I didn't need so many blood tests and they told me more what they are doing" [C87]

Illustrative Example 9: "I get scared the reason why i get scared is because $i$ worry about what they gonna do" [C94]

Illustrative Example 10: “More things my age to take my nerves away" [C72]

Illustrative Example 11: "I think that the doctor needs to listen to the children a bit more" [C13]

Illustrative Example 12: “Tell Mam" [YP3]

Illustrative Example 13: Health professionals should "stop looking down on you" [HP4] 


\section{LIST OF ABBREVIATIONS}

ABMU Abertawe Bro Morgannwg Health Board

ACE Adverse Childhood Experience

CAMHS Children and Adolescent Mental Health Services

CCfE Children's Commissioner for England

CCfW Children's Commissioner for Wales

CCH Community Child Health

CEDAW Convention on the Elimination of Discrimination Against Women

CHC Community Health Council

CRA Children's Rights Approach

CIOMS Council for International Organisations of Medical Sciences

CoE Council of Europe

DANIDA Danish Institute for Human Rights

ESCR Economic, Social, Cultural Rights

EU European Union

GAfREC Governance Arrangements for Research Ethics Committees

GOWA Government of Wales Act

HCWP Healthy Child Wales Programme

HEIW Health Education Improvement Wales

HRA Health Research Authority

HRBA Human Rights Based Approach

ICCPR International Covenant on Civil and Political Rights

ICESCR International Covenant on Economic, Social and Cultural Rights

IRAS Integrated Research Assessment System

LHB Local Health Board

MDG Millennium Development Goal 
NHRI National Human Rights Institution

NCB National Children's Bureau

NHS National Health Service

NIHR National Institute for Health Research

NSF National Service Framework

NGO Non-governmental organisation

NORAD Norwegian Agency for Development Cooperation

OECD Organisation for Economic Cooperation and Development

OHCHR Office of the United Nations High Commissioner for Human Rights

PSE Personal Social Education

SDH Social Determinants of Health

SDG Sustainable Development Goal

SEMT Self-Evaluation Model and Tool

SIDA Swedish International Development Cooperation Agency

R\&D Research and Development

RCPCH Royal College of Paediatrics and Child health

UDHR Universal Declaration of Human Rights

UN United Nations

UNCAT UN Convention against Torture and Other Cruel, Inhuman or Degrading Treatment or Punishment

UNCRC United Nations Convention on the Rights of the Child

UNDG United Nations Development Group

UNDP United Nations Development Programme

UNGA UN General Assembly

UNHCR UN Refugees Agency

UNICEF United Nations Children's Fund

WCPPE Wales Centre for Pharmacy Professional Education 
WAG Welsh Assembly Government (1999-2006)

WEDS Wales Deanery, NHS Wales Workforce Education and Development Services WG Welsh Government $(2007+)$

WHSSC Welsh Health Specialised Services Committee

WHO World Health Organization

YPAG Young Person Advisory Group 


\section{CONTENTS}

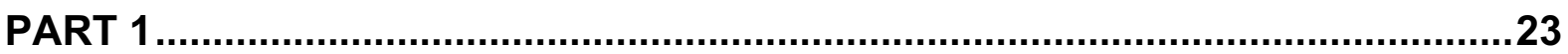

CHAPTER 1 BACKGROUND AND STRUCTURE OF THESIS ............................23

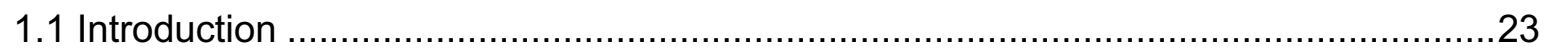

1.1.1 Translating a CRA into practice in health service delivery ...............................26

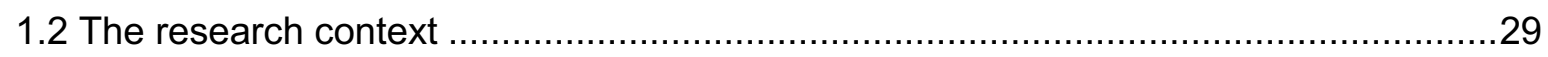

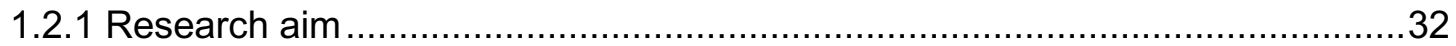

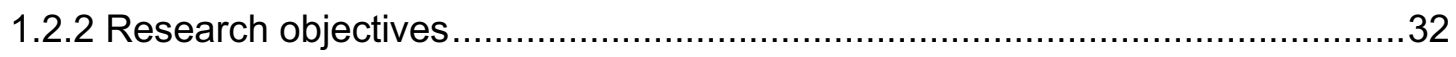

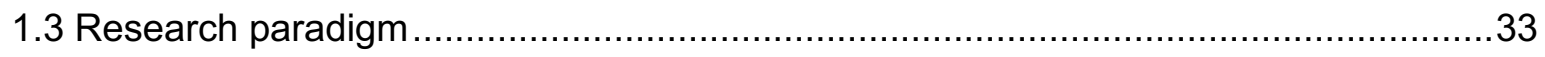

1.3.1 Ontological, epistemological and methodological considerations ....................33

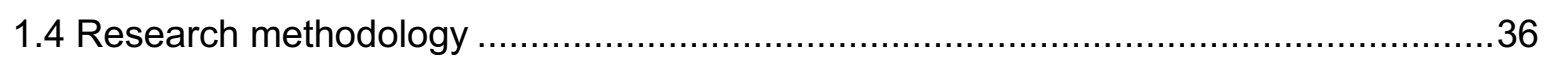

1.4.1 Review and analysis of the international human rights treaty system and literature

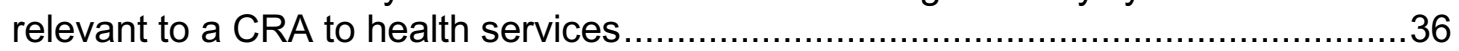

1.4.2 Single organisation case study - testing ABMU's institutional approach to implementing a CRA across their health services .................................................43

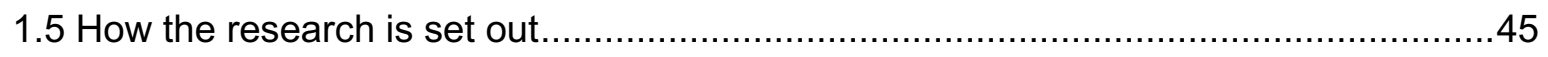

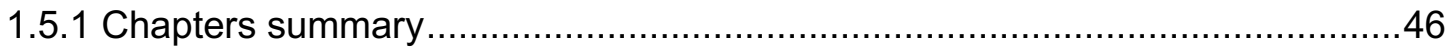

CHAPTER 2 INTRODUCING HUMAN RIGHTS, CHILDREN'S RIGHTS AND THE

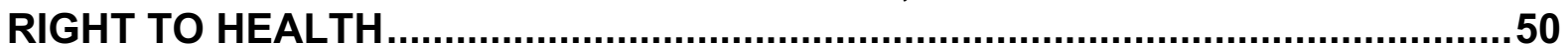

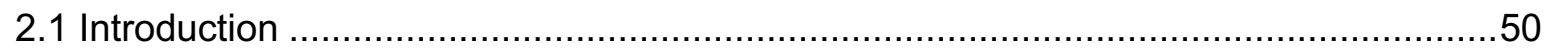

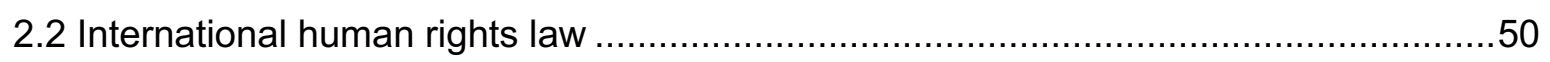

2.3 The International Covenant on Economic, Social and Cultural Rights.......................53

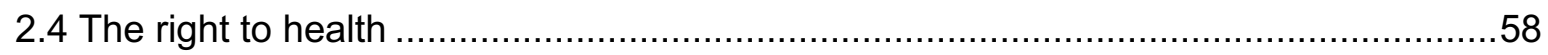

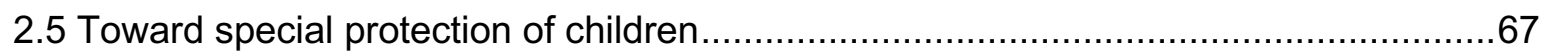

2.6 The United Nations Convention on the Rights of the Child ........................................69

2.6.1 The General Measures of Implementation....................................................71

2.6.2 The General Principles of the United Nations Convention on the Rights of the

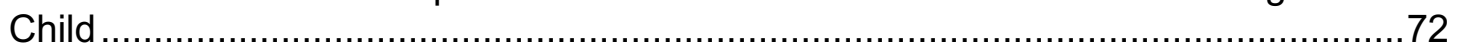

2.6.3 The UN Committee on the Rights of the Child ..............................................73

2.6.4 The UN Committee on the Rights of the Child General Comments...................74

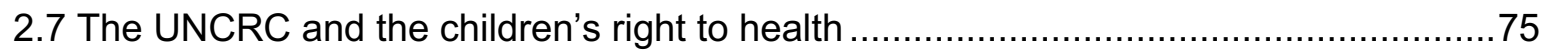

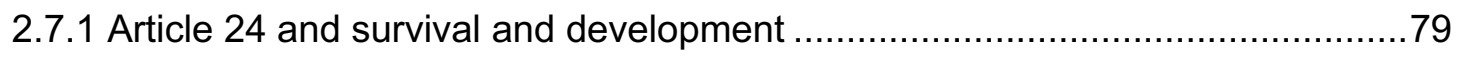

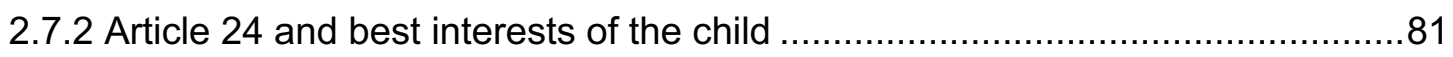

2.7.3 Article 24 and children's right to be heard according to their age and maturity 83

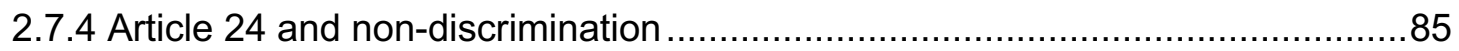

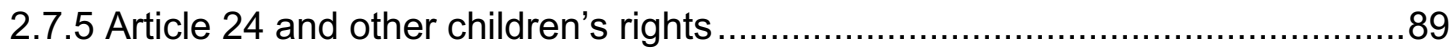

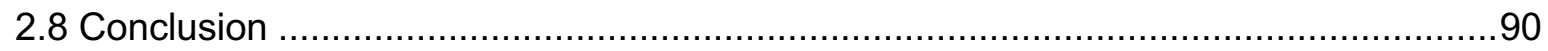



APPROACH

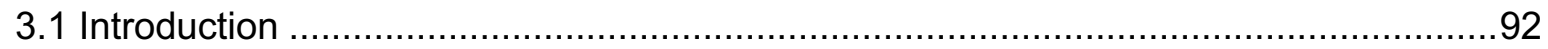

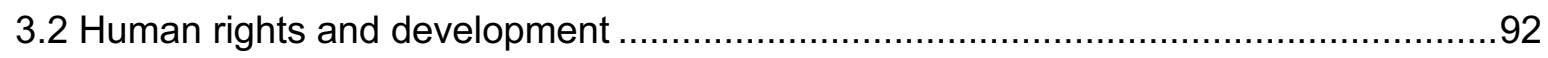

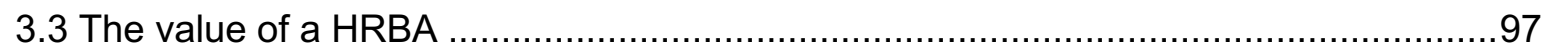

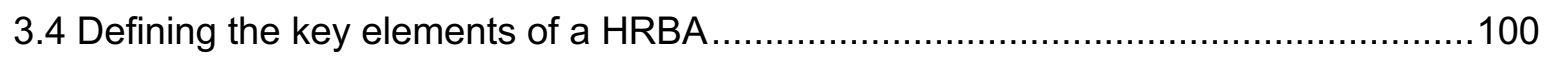

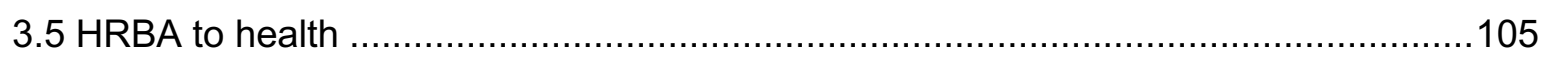

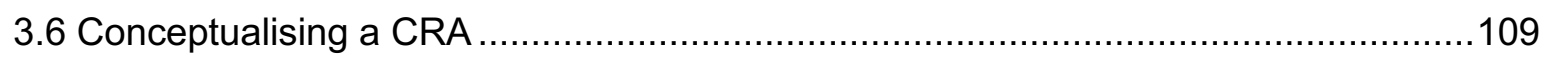

3.7 Organisational learning regarding implementing human rights approaches .............114

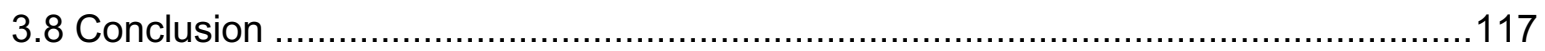

CHAPTER 4 RESEARCH INTO IMPLEMENTATION OF CHILDREN'S RIGHT TO HEALTH IN PRACTICE ......................................................................119

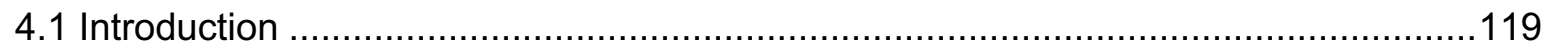

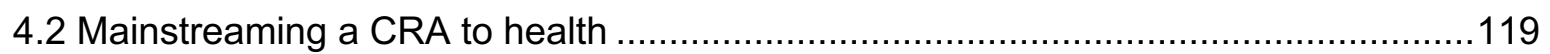

4.2.1 WHO and Office for the High Commissioner on Human Rights: HRBA to Women's, Adolescents and Children's Health …………..................................119

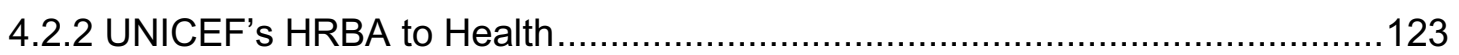

4.2.3 Council of Europe Child Friendly Guidelines to Health Care .........................125

4.2.4 Application of the Child Friendly Approach to Health Care in practice ...........127

4.3 Health professionals limited knowledge of how to deliver a CRA to health care .......129

4.4 Children's right to be heard in medical decision making ........................................132

4.5 Children's autonomous decision-making and consent to treatment in health care

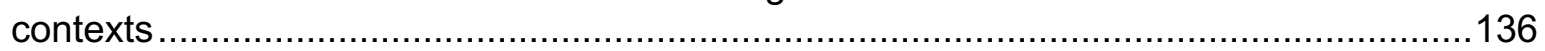

4.6 Children's involvement in the monitoring and evaluation of health services ..............140

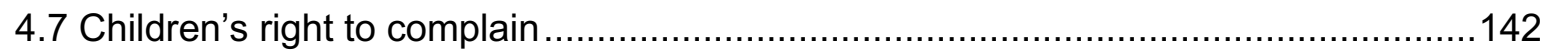

4.8 Design and provision of child friendly health services..........................................144

4.9 Discrimination and inequality impacting on children's right to health .......................146

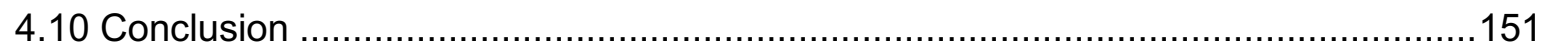

CHAPTER 5 POST DEVOLUTION POLICY AND LEGISLATION IMPACTING ON

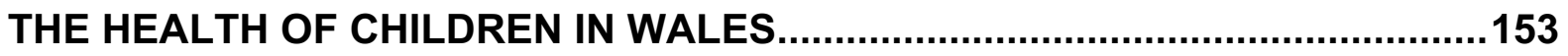

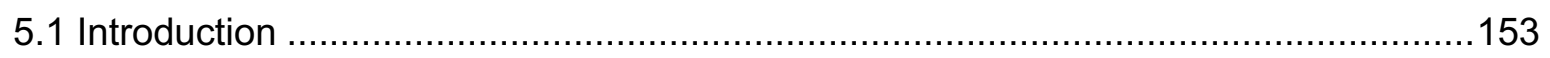

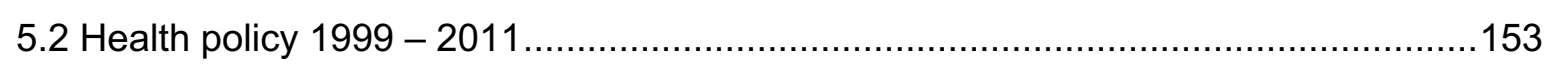

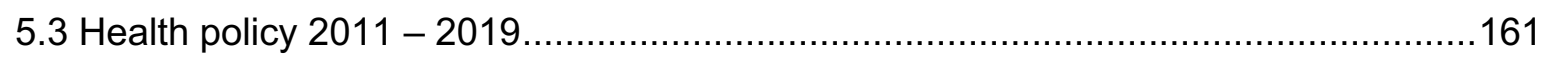

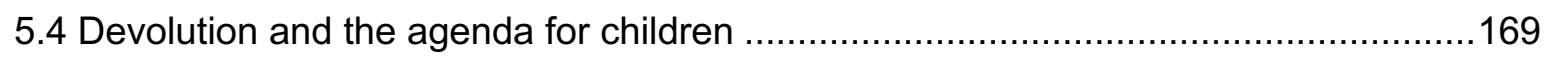

5.4.1 Child poverty: policy underpinned by the UNCRC ....................................171

5.4.2 Child health: policy underpinned by the UNCRC ......................................172

5.4.3 Research and collection of data on children's health and well-being .............174

5.4.4 Children's mental health services ..........................................................177 
5.4.5 Education supporting health and well-being 179

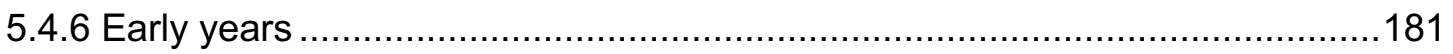

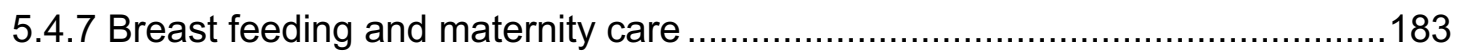

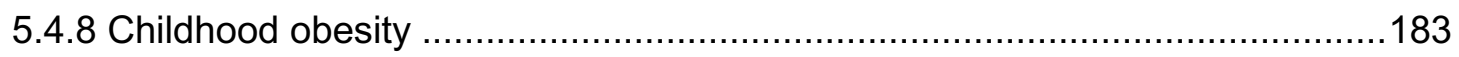

5.4.9 Continued national commitment to children's rights ...................................184

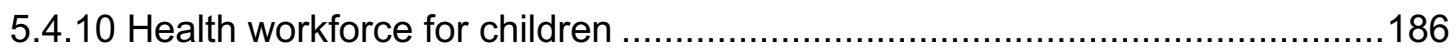

5.5 The implementation gap: analysing the reality of children's health experiences in Wales

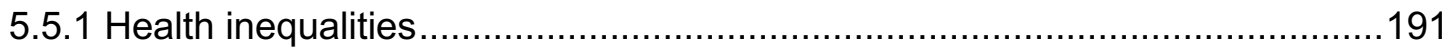

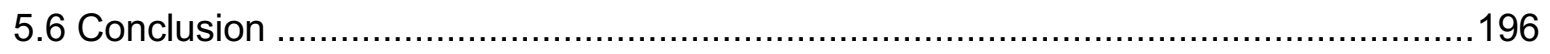

CHAPTER 6 DEVELOPING A CONCEPTUAL FRAMEWORK FOR A CRA TO HEALTH SERVICES IN WALES ..................................................................199

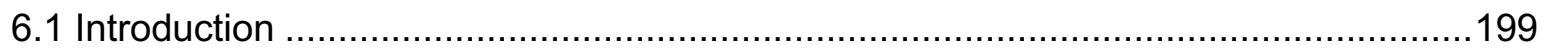

6.2 Understanding the key elements of a CRA to health services ................................199

6.2.1 The essential characteristics of human rights must be understood ...............199

6.2.2 A focus on the human rights of children and the United Nations Convention on

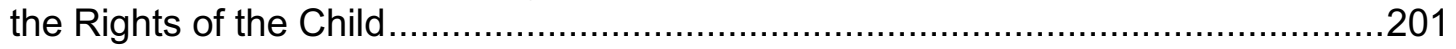

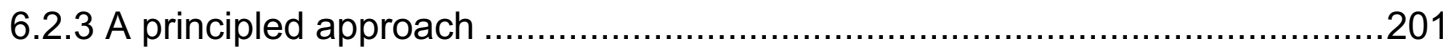

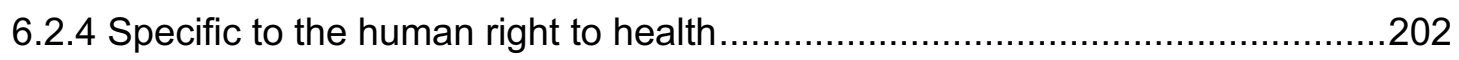

6.3 Five principles of a CRA to health services for the Welsh context ............................204

6.3.1 Examining the theory and importance of the principle, 'Embedding children's

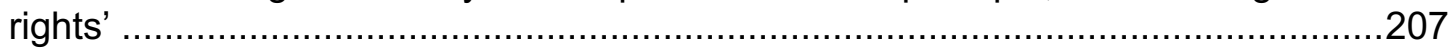

6.3.2 Examining the theory and importance of the principle 'Accountability to children' 215

6.3.3 Examining the theory and importance of the principle of 'Equality and non-

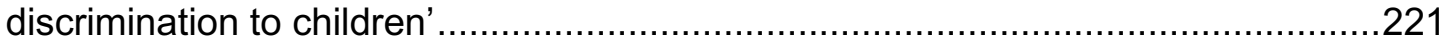

6.3.4 Examining the theory and importance of the principle of 'Participation of children' 230

6.3.5. Examining the theory and the importance of the principle 'Empowering children' .235

6.4 Translation of the principles and key elements of a CRA to health services in practice 252

6.4.1 Health authority wide commitment to the UNCRC ....................................253

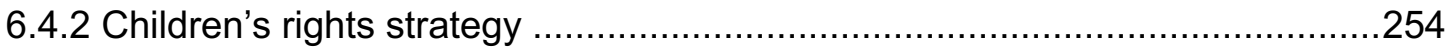

6.4.3 Raising awareness and training on children's rights for staff.......................257

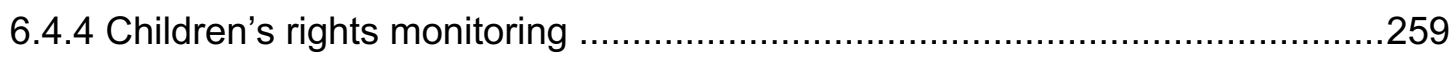

6.4.5 Equality and non-discrimination to children throughout service delivery ........263

6.4.6 Children can actively participate in decisions about their own health .............265

6.4.7 Children should be directly involved in the development, monitoring and

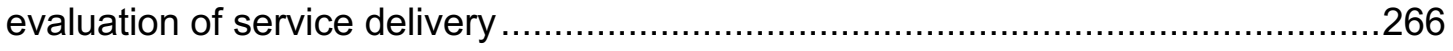


6.4.9 Health promotion, children's rights information and advocacy provided to all

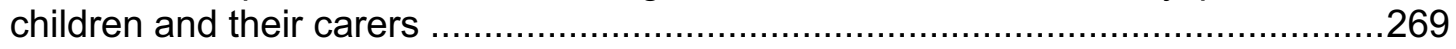

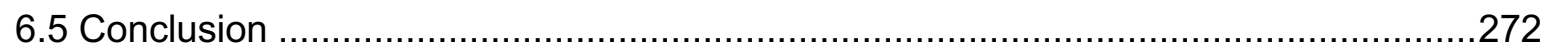

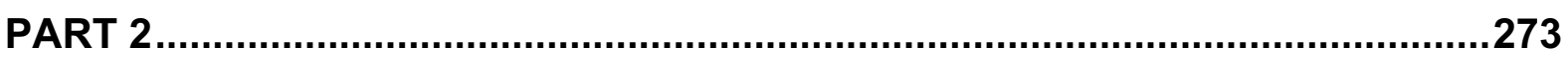

CHAPTER 7 DEVELOPMENT OF RESEARCH METHODS FOR TESTING THE CONCEPTUAL FRAMEWORK FOR A CRA TO HEALTH SERVICES AT ABERTAWE BRO MORGANNWG HEALTH BOARD .....................................273

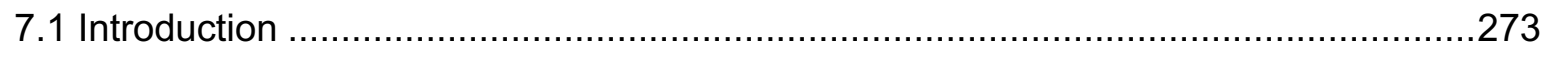

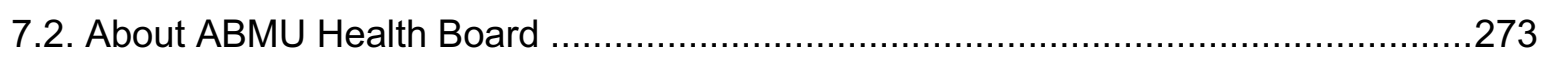

7.2.2 ABMU's commitment to children's rights ............................................274

7.3 The research design: a single organisation case study ....................................277

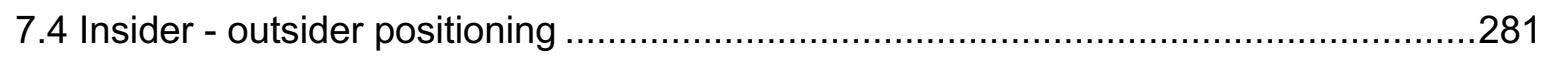

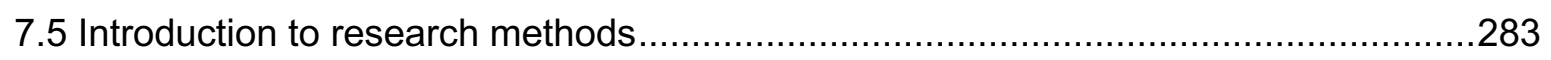

7.5.1 Surveys chosen as the method of analysis.................................................283

7.5.2 Children and young people's surveys ....................................................286

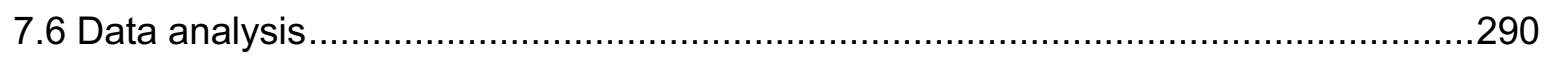

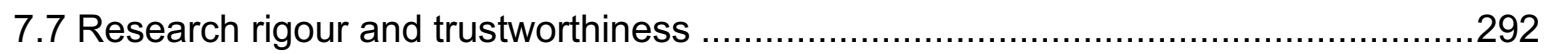

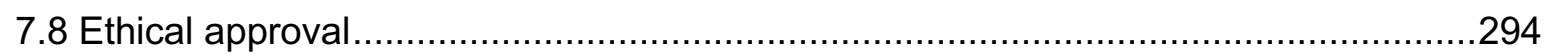

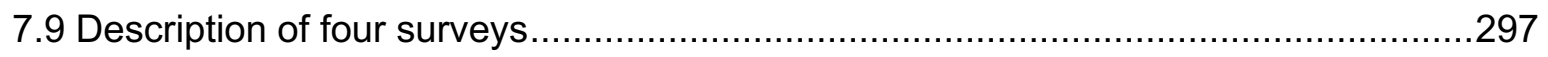

7.9.1 Phase 1 ABMU Strategic Lead's perspective ..........................................297

7.9.2 Phase 2 Health professionals' perspective ................................................. 300

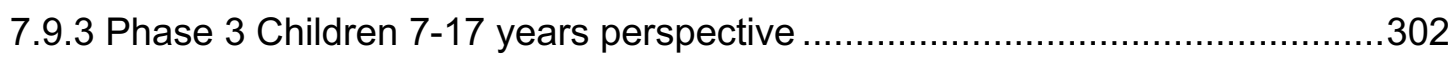

7.10 Integrated conceptual framework including questions from the 4 surveys correlated

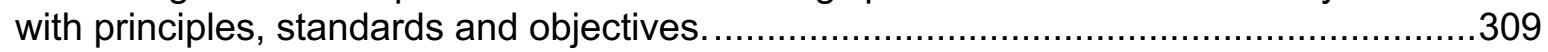

CHAPTER 8 CHILDREN'S RIGHT TO CONSENT TO PARTICIPATE IN RESEARCH IN THE HEALTH SERVICES CONTEXT .........................................................326

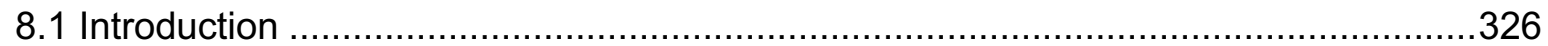

8.2 What does UK law say about children's consent to health research? .......................326

8.3 Are notions of childhood vulnerability guiding decisions regarding children's consent to

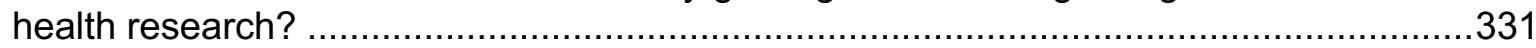

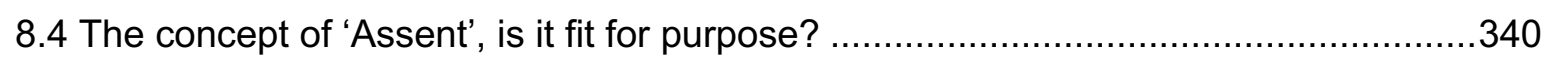

8.5 Should competent children have the right to make autonomous decisions? ..............343

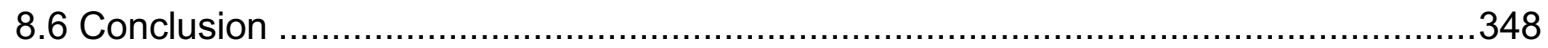

CHAPTER 9 ABMU CASE STUDY - ANALYSIS OF FINDINGS .........................349

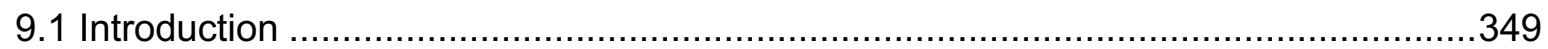

9.2 Describing the samples and reflections regarding improving the monitoring tools in future

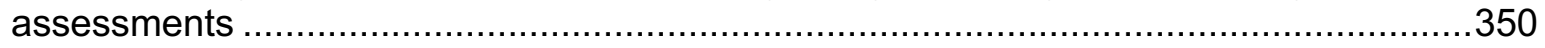

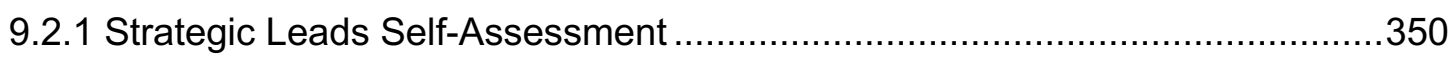


9.2.2 Health professional's survey .353

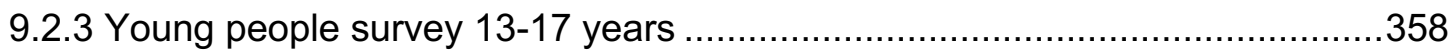

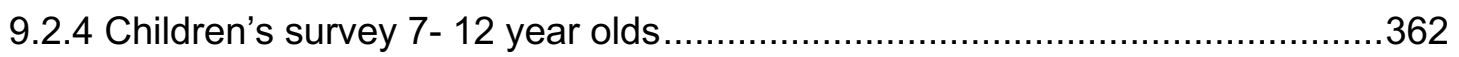

9.3 How successfully has ABMU Health Board embedded a children's rights approach?

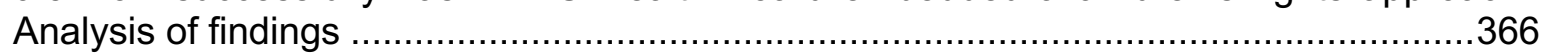

9.3.1 Embedding children's rights: health authority wide commitment ...................367

9.3.2 Embedding children's rights: children's rights strategy ...............................377

9.3.3 Embedding children's rights: children's rights training ...............................385

9.3.4 Accountability to children: children's rights monitoring ................................392

9.3.5 Equality and non-discrimination: equality and non-discrimination to children

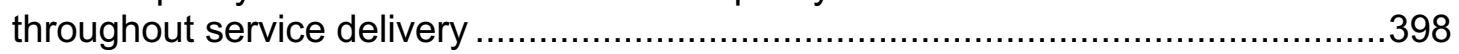

9.3.6. Participation of children: children can actively participate in decisions about their own health.

9.3.7 Participation of children: children involved in the design, monitoring and

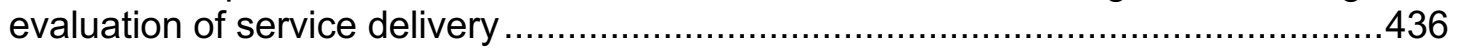

9.3.8 Empowering children: child friendly complaints mechanism .........................446

9.3.9 Empowering children: health promotion and children's rights information and

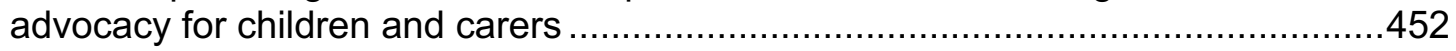

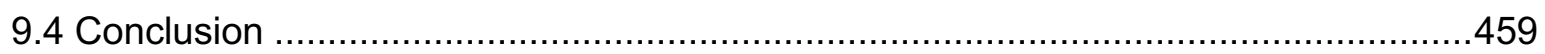

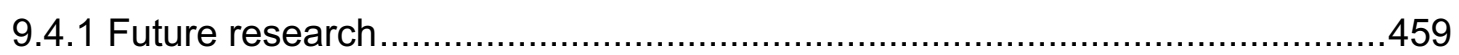

9.4.2 Embedding children's rights: health authority wide commitment, children's rights strategy, children's training, children's rights monitoring ...................................460

9.4.3 Accountability to children: children's rights monitoring ...............................461

9.4.4 Equality and non-discrimination: equality and non-discrimination throughout

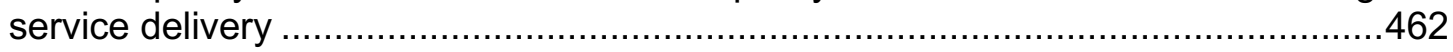

9.4.5 Participation of children: children's participation in their own health ...............462

9.4.6 Participation of children: children's participation in the monitoring, evaluation and

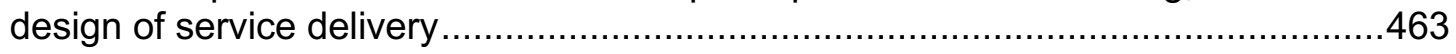

9.4.7 Empowering children: children's rights complaints mechanism ...................463

9.4.8 Empowering children: health promotion and children's rights information and

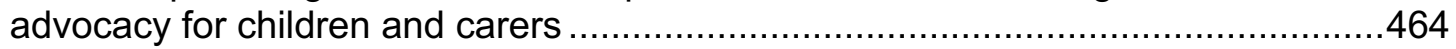

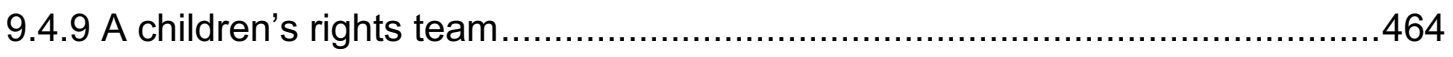

CHAPTER 10 CONCLUSION .....................................................................466

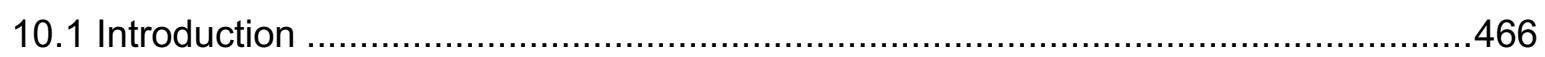

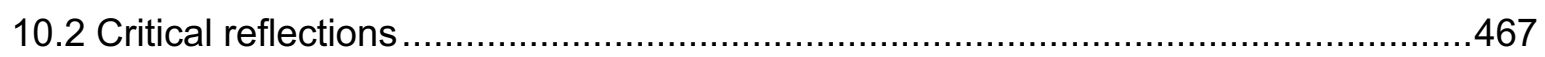

10.2.1 The national policy and legislative environment needs to support a children's rights approach

10.2.2 Embedding a CRA requires leadership, commitment to children's rights training and allocation of resources

10.2.3 Children must no longer be invisible, neglected or devalued in health care decision making 
Appendix 1: Assessing the 5 principles of a CRA and giving consideration to the UNCRC:

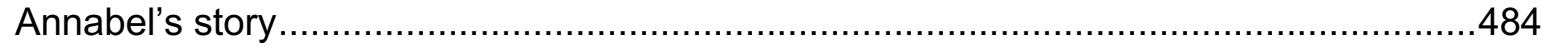

Appendix 2: Strategic Leads children's rights organisational self-assessment...............490

Appendix 3: Health professionals' views - survey ........................................................502

Appendix 4: Young people - Your views on health services - survey..............................508

Appendix 5: Children - Your views on health services - survey .................................514

Appendix 6: College of Law and Criminology Ethics Review Form, Swansea University 518 


\section{A CASE STUDY INVESTIGATION INTO A CHILDREN'S RIGHTS APPROACH TO HEALTH SERVICES}

\section{PART 1}

\section{CHAPTER 1 BACKGROUND AND STRUCTURE OF THESIS}

\subsection{Introduction}

This thesis seeks to establish a conceptual basis for a children's rights approach (CRA) to health services in the Welsh context. It also provides evidence of what this might involve in practice, including through the introduction and testing of tools to monitor the implementation of a CRA in health services. Since the late 1990s, human rights have emerged as a key framework for policy and programmes in public, private and non-governmental settings. ${ }^{1} \mathrm{~A}$ major challenge for all stakeholders and service providers including researchers is how to implement expectations arising from human rights. There is no universally agreed model for a human rights based approach (HRBA) ${ }^{2}$, a $\mathrm{CRA}^{3}$, a human rights approach to health ${ }^{4}$ or indeed a CRA to health

\footnotetext{
${ }^{1} 1986$ United Nations General Assembly adopted the Declaration on the Right to Development; 1993 Vienna Declaration and Programme of Action recognising that development and respect for human rights were interdependent; 1995 Copenhagen Summit on Social Development; 1997 Kofi Annan Secretary General of the UN issued a directive that human rights should be mainstreamed into all activities of UN agencies; 2002 approach was endorsed and expanded by Mary Robinson as UN High Commissioner; 1998 UNICEF first agency to adopt the human rights based approach, followed by other UN agencies; United Nations Office of the High Commissioner on Human Rights, Guiding Principles on Business and Human Rights: Implementing the United Nations "Protect, Respect and Remedy" Framework (United Nations New York and Geneva 2011); Chapter 3 discusses further the adoption of HRBA by other agencies including INGOs and NGOs.

${ }^{2}$ Vandenhole W, 'Failures and Successes of Human Rights-Based Approaches to Development: Towards a Change Perspective,' Nordic Journal of Human Rights, 2014 Vol. 32, No. 4, 291-311

${ }^{3}$ Tobin J, 'Understanding a human rights based approach to matters involving children: conceptual foundations and strategic considerations,' In Invernizzi A and Williams J (eds), The Human Rights of Children: From Visions to Implementation (Farnham: Ashgate 2011)

${ }^{4}$ Gruskin S, Bogecho D, and Ferguson L, 'Rights-based approaches' to health policies and programs: Articulations, ambiguities, and assessment,' Journal of Public Health Policy 31/2 (2010), 129-145
} 
services. ${ }^{5}$ However, the United Nations is explicit that a HRBA places the legal force and the normative framework of international human rights at the heart of service and programme delivery. ${ }^{6}$ This creates a stronger basis for service design and delivery, in which all citizens are empowered to claim their human rights, and places accountability on service providers and policy actors to meet their human rights obligations to all citizens.

The proposal for this research developed from a partnership between Abertawe Bro Morgannwg University Health Board (ABMU), the Observatory on the Human Rights of Children, Swansea University and Neath Port Talbot Children's Rights Unit. The rationale was to raise awareness and understanding of CRAs to health services in Wales; to help achieve greater consistency of practice and to develop a shared sense of what a CRA to health services might involve both conceptually and practically. The partners felt that there was a gap in understanding of children's rights and their implications for improving health services from the perspective of children who are likely to experience barriers in accessing their human rights. The partners were also aware that health service providers do not understand the implications and positive benefits of a CRA to service delivery. ABMU as the partner responsible for delivering health services, wanted support in the development of monitoring tools to examine the extent to which they were implementing a CRA to health services in practice.

The research is particularly significant in the light of the persistence of deep seated children's health inequalities in Wales evidenced by Public Health Wales (PHW)7and the Royal College of Paediatrics and Child Health (RCPCH). ${ }^{8} 29 \%$ of children are living

\footnotetext{
${ }^{5}$ However, the Council of Europe has adopted the Child Friendly Guidelines to Health Care that will be discussed in Chapter 4. Council of Europe, Child Friendly Guidelines to HealthCare (COE 2011) https://rm.coe.int/guidelines-of-the-committee-of-ministers-of-the-council-of-europe-on-c/16808c3a9f accessed January 2020

${ }^{6}$ UN Development Group, UN Statement of Common Understanding on Human Rights based approaches (UNDG 2003) https://unsdg.un.org/sites/default/files/6959-

The_Human_Rights_Based_Approach_to_Development_Cooperation_Towards_a_Common_Underst anding_among_UN.pdf accessed January 2020

${ }^{7}$ Public Health Wales Observatory, Health of Children and Young People (Public Health Wales NHS Trust 2013); Public Health Wales Observatory, Health and its Determinants in Wales - Informing Strategic Planning (2018)

${ }^{8}$ Royal College of Paediatrics and Child Health, Child Health Matters, A Vision for 2016 in Wales (RCPCH 2016); Royal College of Paediatrics and Child Health, State of Child Health: 2017 Recommendations for Wales, (RCPCH 2017); Royal College of Paediatrics and Child Health, One year on Score Card (RCPCH 2018)
} 
in poverty in Wales (when housing costs are taken into account) and these children are most at risk of the negative impact of the wider determinants of health. ${ }^{9}$ As the $\mathrm{RCPCH}$ report, the impact of 'poverty on child mortality rates in Wales is stark: children from the most deprived fifth of the population have a rate of child death 70 percent higher than those in the least deprived fifth'. ${ }^{10}$ Children as a social group bear the burden of neuro-psychiatric disorders, violence and accidents, poor maternal conditions and poverty. ${ }^{11}$ Health in childhood defines wellbeing across the life-course..$^{12}$ The UK ranks $19^{\text {th }}$ in Europe for neonatal mortality and $20^{\text {th }}$ for under 5 mortality dropping significantly from its position in $1990 .{ }^{13}$ Children are born into these conditions and countries with high levels of socio-economic inequality are more likely to experience poorer health outcomes. ${ }^{14}$

Research from a human rights perspective can contribute concretely to health institutions' efforts to tackle health inequalities. A focus on human rights dictates the necessity to strive for equal opportunity for health, for groups of people who have suffered discrimination. It places accountability on service providers to empower and ensure that discriminated against groups, including children, are able to claim their human rights. Research on children's experience of health services across Europe indicates that children are discriminated against with regards to accessing quality

Royal College of Paediatrics and Child Health, State of Child Health 2020: Wales (RCPCH 2020)

${ }^{9}$ Stats Wales, percentage of children living in poverty 2015-16 to 2017-18; Child poverty is set to increase not decrease by 2022, Institute for Fiscal Studies, Living standards, poverty and inequality in the UK: 2017-18 to 2021-22 (Institute for Fiscal Studies 2017)

https://www.ifs.org.uk/uploads/publications/comms/R136.pdf accessed January 2020

${ }^{10}$ Royal of College of Paediatrics and Child Health, State of Child Health: 2017 Recommendations for Wales (RCPCH 2017) 4

${ }^{11}$ Viner R M, Ozer E M, Denny S, Marmot M, Resnick M, Fatusi A, Currie C, 'Adolescence and the social determinants of health', The Lancet 379 (2012): 1641-52

${ }^{12}$ Larkin M, Health and well-being across the life course (2013 Sage Publications)

${ }^{13}$ Office of National Statistics Data 2017

https://www.ons.gov.uk/peoplepopulationandcommunity/healthandsocialcare/childhealth/articles/ukdr opsineuropeanchildmortalityrankings/2017-10-13 accessed January 2020.

${ }^{14}$ Black D, Inequalities in Health (London: Penguin; 1980) Acheson D, Independent Inquiry into Inequalities in Health (London: The Stationery Office; 1998); Marmot M, Allen J, Goldblatt P, Boyce T, McNeish D, Grady M, Geddes I, Fair Society, Healthy Lives: The Marmot Review (Marmot review 2010); Marmot M, Allen J, Boyce T, Goldblatt P, Morrison J, Health equity in England: The Marmot Review 10 years on (London: Institute of Health Equity 2020) 
health services. ${ }^{15}$ Children are significant recipients of health services yet lack a voice in service access and delivery ${ }^{16}$, they are vulnerable to ill treatment by adults and those more powerful than themselves, and can experience consistent and entrenched age discrimination. ${ }^{17} \mathrm{It}$ is apparent that there needs to be more research on the barriers preventing children accessing and exercising their human rights, and how health professionals can be supported to help children to benefit from their human rights.

The UNCRC recognises the human rights of all children ${ }^{18}$ and presents a children's rights perspective on how children should be treated and respected to achieve the highest possible standard of physical and mental health and to ensure that no child is deprived of his or her right of access to quality health care services. ${ }^{19}$ This international treaty entrenches the child's right to health into international law and provides the full range of human rights that can be used to highlight violations where these take place in public services.

\subsubsection{Translating a CRA into practice in health service delivery}

This thesis focuses on the development and implementation of a CRA to health services in the Welsh context. Devolution in Wales has accelerated a commitment to children, with successive Welsh administrations underpinning policy and law with the UNCRC..$^{20}$ The commitment to the human rights of children in Wales culminated in the passing of the Rights of Children and Young Person's (Wales) Measure 2011, a landmark piece of legislation which requires Welsh Ministers to have due regard to the rights, principles, provisions and optional protocols of the UNCRC, in the exercise of

\footnotetext{
${ }^{15}$ Parliamentary Assembly Council of Europe, Ensuring access to healthcare for all children in Europe, Report to Committee on Social Affairs, Health and Sustainable Development Rapporteur: Ms Stella KYRIAKIDES, Cyprus, Group of the European People's Party (2016)

${ }^{16}$ Kilkelly U, Child Friendly Healthcare: The Views and Experiences of Children and Young People in the Council of Europe (Strasbourg: Council of Europe 2011)

${ }^{17}$ Liebel M, 'Adultism and Age Based Discrimination against children,' In Kutsar D and Warming H (eds) Children and non-discrimination, inter-disciplinary textbook (University of Estonia press 2014)

${ }^{18}$ Children's rights in the context of this thesis refer to the human rights of children under the age of 18 years; this is in accordance with Article 1 of the United Nations Convention on the Rights of the Child.

${ }^{19}$ See Article 24 of the United Nations Convention on the Rights of the Child.

${ }^{20}$ Williams J (eds) The UNCRC in Wales (University of Wales Press 2013)
} 
all of their functions. ${ }^{21}$ This made Wales the first country in the UK to incorporate the UNCRC, within the limits of its powers into domestic legislation.

Whilst public authorities (including health authorities) are not directly affected by the due regard duty they are indirectly affected as any legislation or policy introduced by the Welsh Ministers must be developed in the light of the duty. ${ }^{22}$ Flowing from this national legislative and policy commitment to children's rights, a number of public bodies across Wales have pledged their own commitments to the UNCRC. ABMU was the first health board in Wales in 2017 through its Children's Rights Charter to express a strong commitment to complying with the UNCRC when delivering its health services.

Reducing child health inequalities and promoting equality of access to services and helping children to exercise their human rights in health care settings are priorities for ABMU, Welsh Government (WG), PHW and the $\mathrm{RCPCH}$. In the reporting round to the UN Committee on the Rights of the Child in 2015/2016, evidence from the Children's Commissioner for Wales (CCFW) ${ }^{23}$ and the Wales UNCRC Monitoring Group ${ }^{24}$ confirmed that although children's rights underpin national policy and legislation affecting children in Wales, service providers, including health service providers across Wales were struggling to translate children's rights into practice.

My interest in the subject came from coordinating the Wales UNCRC Monitoring Group (2004-2015) a multi-agency group of non-governmental organisations and academic organisations tasked with monitoring and promoting the implementation of the UNCRC in Wales. The Group successfully influenced changes for children's rights at the national legislative and policy level ${ }^{25}$ but realised after gathering evidence for consecutive state of the nation reports on children's rights, the next step was to

\footnotetext{
${ }^{21}$ Rights of Children and Young Persons (Wales) Measure 2011 http://www.legislation.gov.uk/mwa/2011/2/contents accessed January 2020

${ }^{22}$ Williams J (eds) The UNCRC in Wales (University of Wales Press 2013)

${ }^{23}$ UK Children's Commissioners, Report of the UK Children's Commissioners UN Committee on the Rights of the Child Examination of the Fifth Periodic Report of the United Kingdom of Great Britain and Northern Ireland (UK Children's Commissioners 2015)

${ }^{24}$ Croke R and Williams J (eds) Wales UNCRC Monitoring Group report to the UN Committee on the Rights of the Child (Swansea University 2015)

${ }^{25}$ See Aspinwall T and Croke R, 'Policy Advocacy Campaigns: the collective voices of children's NGOs in Wales', In Williams (eds) The UNCRC in Wales (University of Wales Press 2013)
} 
influence change at the service delivery level. ${ }^{26}$ As part of that programme of work I designed a website that developed advice for public sector professionals regarding implementing a CRA in their work. This thesis has given me the opportunity to undertake further research and to learn in more depth about how to translate a children's rights approach into practice at service delivery level.

Additionally, it is important to acknowledge that working with my first supervisor we were commissioned by CCfW in 2016 to develop a CRA statement and guide for public services in Wales. ${ }^{27}$ My previous experience working as the Coordinator of the Wales UNCRC Monitoring Group was critical to the development of the children's rights model for the public services context in Wales, entitled The Rights Way: A Children's Rights Approach. ${ }^{28}$ Since 2017 this has driven CCfW's agenda for working with public bodies and more recently the Future Generations Commissioner. ${ }^{29}$ The Right Way is influencing public bodies across Wales to translate a CRA into their work. ${ }^{30}$

It is also important to recognise in the introduction to this thesis, that there has been no known research to date regarding to what degree children are able to access their human rights in health care settings in Wales, including what are the main barriers to health service providers being able to empower and support children to claim their human rights. This thesis sets out to address this gap in knowledge, by developing understanding of what a CRA to health services looks like in practice and developing a conceptual framework and a range of monitoring tools that can be used to test how

\footnotetext{
${ }^{26}$ Croke R and Williams J (eds) Wales UNCRC Monitoring Group report to the UN Committee on the Rights of the Child 2015 (Swansea University 2015) Croke R (eds) Rights here, right now: What is the reality of children's rights in Wales? (Save the Children UK 2013); Croke R and Crowley A (eds) Stop, look, listen: the road to realising children's rights in Wales (Save the Children UK 2007); Croke $\mathrm{R}$ and Crowley A (eds) Righting the wrongs: the reality of children's rights in Wales (Save the Children UK 2006)

${ }^{27}$ Hoffman S and Croke R, 'Children's Rights Approach Statement and Guide for the Children's Commissioner for Wales' (Swansea University 2016)

${ }^{28}$ Children's Commissioner for Wales, The Right Way: A Children's Rights Approach (2017) https://www.childcomwales.org.uk/wp-content/uploads/2017/04/The-Right-Way.pdf accessed January 2020.

${ }^{29}$ Future Generations Commissioner, The Right Way: A Wales Future Fit for Children (2019) https://futuregenerations.wales/resources posts/the-right-way-a-wales-future-fit-for-children/ accessed January 2020

${ }^{30}$ One very clear example is the Welsh Government in 2018 used the model in their Compliance report on the Rights of Children and Young Persons (Wales) Measure 2011 https://gov.wales/rightschildren-and-young-people-compliance-report accessed January 2020
} 
far health authorities are implementing a CRA across their health services. This thesis had the opportunity to engage with ABMU Health Board to test these monitoring tools and consider how they can be improved. The results and recommendations of this research will therefore be valuable to $A B M U$ when making improvements to service planning and delivery and will present transferrable recommendations to other health authorities in Wales and further afield who are trying to improve health services for children.

\subsection{The research context}

As outlined above, the original research proposal was designed and funded by the partners in the project, $A B M U$, the Observatory on the Human Rights of Children, Swansea University and Neath Port Talbot Children's Rights Unit. The primary research was undertaken at $A B M U$ Health Board. ABMU covered the local authority areas of Swansea, Bridgend and Neath Port Talbot. The seven Welsh Health Boards as they were configured up to 2019, can be seen in Diagram 1.

\section{DIAGRAM 1: Map of the seven Welsh health boards up to 2019}

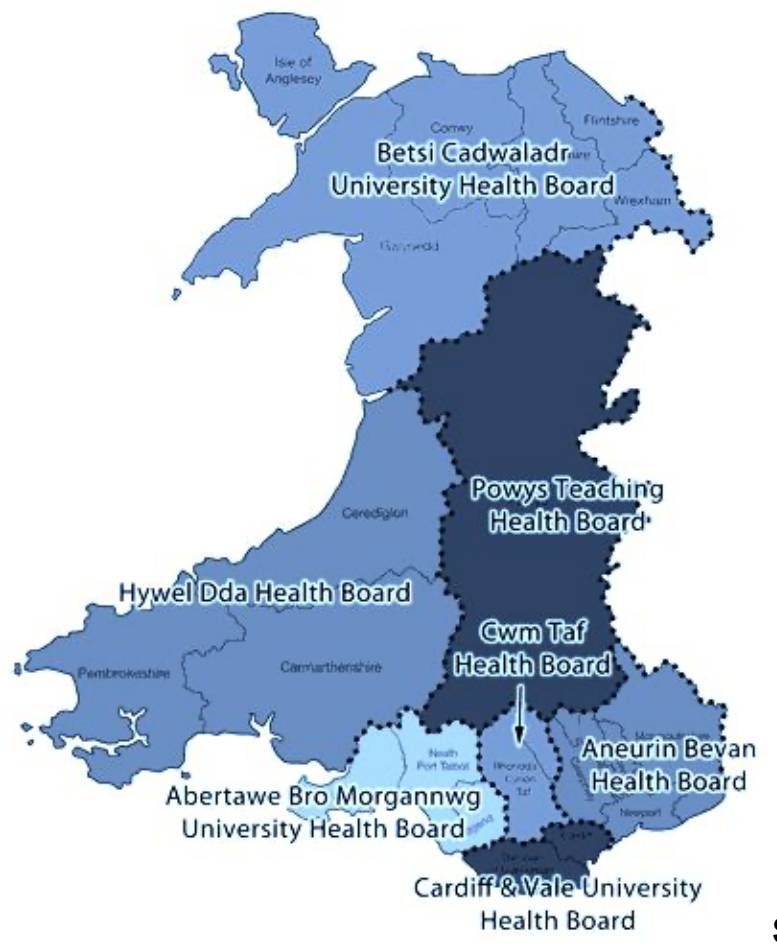

Source: NHS Wales ${ }^{31}$

\footnotetext{
${ }^{31}$ NHS Wales, Health in Wales http://www.wales.nhs.uk/nhswalesaboutus/structure accessed January 2020
} 
The research was conducted before Bridgend local authority area was merged into Cwm Taf health board in April 2019 and Swansea University Bay Health Board became a separate health authority. There were approximately 118,000 children and young people from birth to 18 years ( 2011 census) across ABMU Health Board. Within the ABMU Health Board area, children face a number of health inequalities (these are detailed in Chapter 7) and consequently experience a number of breaches of their human rights. Diagram 2 outlines the three tiers of health service delivery via which children can access health services.

\section{DIAGRAM 2: Three tiers of health service delivery}

Children can access these services:

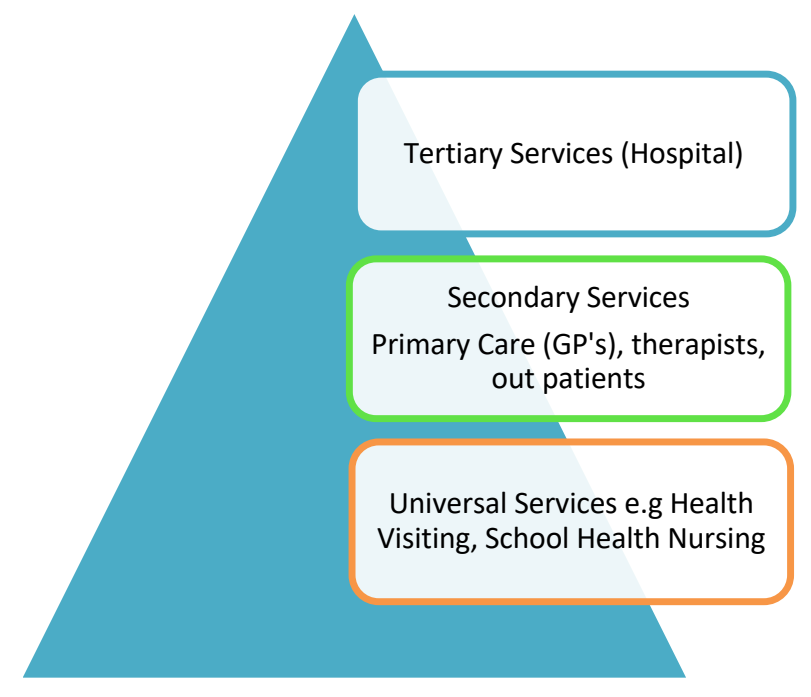

Source: ABMU Children's Strategy 2017

The Health Board had a next expenditure of approximately $£ 1.12$ billion. In 2018, it was reported that most of this went on running its four hospitals (Singleton and Morriston Hospitals in Swansea, Neath Port Talbot Hospital in Port Talbot and the Princess of Wales Hospital in Bridgend) the rest was spent on primary healthcare GPs, dentists, community nurses - while a third portion was spent on independent and private healthcare providers. ${ }^{32}$ There were approximately 16,500 staff reported to

\footnotetext{
32 They exceeded their spending by $£ 234$ million as reported in Youle R, 'This is how a Welsh health board spent £1billion last year,' Wales Online (June 5th 2018)

https://www.walesonline.co.uk/news/health/how-welsh-health-board-spent-14737520 accessed January 2020
} 
be working for $\mathrm{ABMU}$ in $2018 .{ }^{33}$ The largest proportion, were nurses and midwives ${ }^{34}$ and $70 \%$ of staff were reported to be involved in providing direct patient care..$^{35}$

ABMU health board made a health authority wide commitment to the UNCRC through the launch of their Children's Rights Charter in 2017. This was inspired by a senior level commitment to children's rights through discussions the Chair of the Health Board Andrew Davies had with Coordinator of the Observatory on the Human Rights of Children, Professor Simon Hoffman at Swansea University. The Chair of the Health Board tasked the development of the Charter to Eirlys Thomas, Head of Nursing and Children's Services at ABMU who was supported by consecutive managers of the Neath Port Talbot Children's Rights Unit. The Charter includes 10 health-related guarantees identified through consultation with children and young people across the health board area that the ABMU Health Authority must seek to adhere to. ${ }^{36}$

ABMU through their charitable endowment, fund the Neath Port Talbot Children's Rights Unit to support the ABM Youth Advisory Group and to fund the Manager to deliver children's rights training to health professionals at ABMU. ABMU was the first health board in Wales in 2017 to have a young people's advisory group to advise a health board from a young person's perspective.

The project partners wanted to learn more about children's rights approaches to health services globally and to develop a shared understanding of how they could be practically applied in the Welsh context, using ABMU as a case study. Due to the multidisciplinary nature of the research, the thesis was supervised by a team of experts in law and human rights, and health from the Swansea University, ABMU and the Neath Port Talbot Children's Rights Unit:

\footnotetext{
${ }^{33}$ Abertawe Bro Morgannwg Health Board, Annual Quality Statement 2018 (ABMU 2018) http://www.wales.nhs.uk/sitesplus/documents/863/AQS\%202018\%20Final1.pdf accessed January 2020

${ }^{34}$ Youle R, 'This is how a Welsh health board spent £1billion last year,' Wales Online (June 5th 2018)

${ }^{35}$ Abertawe Bro Morgannwg Health Board, Annual Quality Statement 2018 (ABMU 2018)

${ }^{36}$ ABMU's Children's Rights Charter

http://www.wales.nhs.uk/sitesplus/documents/863/Bilingual\%20Children $\% 27 \mathrm{~s} \% 20$ Rights $\% 20$ Charter .pdf accessed January 2020.
} 
- Dr Simon Hoffman, Professor, Hillary Rodham Clinton School of Law, Swansea University (First Supervisor).

- Dr Ann John, Professor, College of Medicine, Swansea University.

- Dr Paul Rees, Associate Professor, Health and Human Sciences.

- Jannine Smith, Manager, Neath Port Talbot Children's Rights Unit

- Eirlys Thomas, Head of Nursing and Children's services.

\subsubsection{Research aim}

The aim of this research was to contribute original and significant knowledge regarding what is required to ensure a CRA to Health Services, particularly in the Welsh context, and to develop tools to monitor the implementation of such an approach using ABMU Health Board as a case study.

\subsubsection{Research objectives}

- Identify what should be involved in a CRA to health services.

- Identify what are the main barriers and the main mechanisms that support the implementation of a CRA to health services.

- Using ABMU as a case study, develop and test a range of tools (as appropriate) to monitor how far a CRA to health services is embedded.

- From the findings of the research make recommendations for

- ABMU health services regarding the better implementation of a CRA,

- future research and,

- transferrable recommendations to other health authorities.

In order to meet the aim and objectives, the research examined the following research questions:

- Is it possible to identify a CRA to health services in the literature?

- If so, what does a CRA to health services involve?

- What are the mechanisms that support a CRA to health services and what are some of the barriers to its effective implementation in practice?

- What monitoring tools need to be developed to provide data to test the effective implementation of a CRA to health services? 
- How can a CRA to health services be better implemented?

\subsection{Research paradigm}

\subsubsection{Ontological, epistemological and methodological considerations}

Over the three-year period of conducting the research, I held regular meetings with the Head of Nursing and Children's Services, the Patient Experience Coordinator at $A B M U$ and the Manager of the Neath Port Talbot Children's Rights Unit. I also met with other practitioners and managers in ABMU and attended ABMU Children's Strategy Group quarterly meetings. ${ }^{37}$ Additionally ABM Youth (Young People Expert Advisory Group) were involved in overseeing the element of the research that was conducted with children and young people. This all contributed to the development of the research design and learning about the delivery of $A B M U$ health services for children. Clark argues that research can have the greatest impact if policy makers are brought in from the start of the research process and an 'iterative process of mutual influence' is supported ${ }^{38}$ As a researcher with a history of advising public bodies regarding implementing children's rights, it is important to acknowledge that this knowledge may have contributed to developments affecting children's rights at ABMU over the three-year period of the thesis.

It is important to also acknowledge that learning and reflection from meetings with partners are included throughout this thesis and influenced the design and analysis of findings. The approach to this relationship and my ontological perspective follows that of Giddens, recognising that there is dialectic interplay between structure and agency. ${ }^{39}$ Structure refers to rules and resources organised as the properties of social systems that humans as agents interact with. ${ }^{40}$ Giddens recognises that agents are

\footnotetext{
${ }^{37}$ Abertawe Bro Morgannwg Health Board, Annual Quality Statement 2018 (ABMU 2018) 28 These were multi-agency meetings attended by managers and practitioners whose work impacted on children in the ABMU Health Board Area from across the statutory and third sector

${ }^{38}$ Clark A, Understanding Research with Children and Young People (Published in association with The Open University 2013) 8

${ }^{39}$ Bryant C G A, and Jary D, 'Coming to terms with Anthony Giddens', In Bryant C G A and Jary D (eds.) Giddens' theory of structuration: A critical appreciation (New York, NY: Routledge 1991).

${ }^{40}$ Giddens A, Central problems in social theory: Actions, structure and contradiction in social analysis (Contemporary Social Theory 1979)
} 
at the 'same time the creators of social systems yet created by them. ${ }^{141}$ In undertaking the research, the work of Bourdieu is also embraced, which rejects the notion that structure and agency are in opposition: that is, practices are not objectively determined or the product of free will, they arise as a result of the interplay between the two..$^{42}$

From observing and engaging in conversation with these various members of the ABMU Health Board, I was able to improve my understanding of their social, cultural and institutional environment. This sensitive contact with their working context, fostered a deepened and more empathetic knowledge base. It should be acknowledged that I will have brought values and biases to the study accumulated through my own cultural and social experiences. As a female researcher with a history of children's rights activism, I will have approached this research with ideas and prejudices that are a consequence of my own standpoint and indeed ethnicity, gender, class and nationality.

According to Hellawell, insiders are considered to be a part of the institution they are conducting the research with, while outsiders are considered outside of or at a distance to the institution they are researching. ${ }^{43}$ Assuming the ontological standpoint introduced above, it is possible to see these two positions as complementary (not in opposition), while acknowledging that there will be a degree of fluidity between the two. My positionality as a researcher and a consideration of my outsider/insider relationship with the health board is discussed further in Chapter 7 .

The content of the overarching research questions was in some respects predetermined because ABMU wanted to learn about a CRA to health, how far they were progressing with their own CRA and were seeking the development of tools to assess this. So, from the outset the research methodology was aimed at addressing these priorities, with the research questions following as a consequence. This approach is

\footnotetext{
${ }^{41}$ Giddens A, 'Structuration theory: past, present and future, In Bryant C.G.A and Jary D (eds) Giddens', Theory of Structuration: A Critical Appreciation (London: Routledge: 1991) 204

${ }^{42}$ Bourdieu P, Distinction: A Social Critique of the Judgment of Taste, translated by R Nice (Harvard University Press 1984 [1979]); Bourdieu P, Language and Symbolic Power (Harvard University Press 1991)

${ }^{43}$ Hellawell D, 'Inside-out: Analysis of the insider-outsider concept as a heuristic device to develop reflexivity in students doing qualitative research', Teaching in Higher Education, 11(4) 2006: 483494
} 
consistent with the 'pragmatist' research paradigm which proposes that researchers should use the best methodological approach to address the problem or issue that has been chosen to be researched. ${ }^{44}$ Pragmatism supports both post-positivist methods i.e., quantitative and deductive reasoning and interpretivist qualitative and inductive reasoning, embracing a reflexive and flexible stance to research design. ${ }^{45}$

This thesis fits well within the 'pragmatist' paradigm because the methodology sought to directly and pragmatically address the research questions posed by the health partners. ${ }^{46}$ The pragmatist approach supports researchers answering research questions that do not sit within an explicitly qualitative or quantitative approach to research methodology. ${ }^{47}$ This paradigm accepts the value of using a 'mixed methods' approach and focuses on the most pragmatic design to answer the research questions as well as promote the impact of the research. ${ }^{48}$ Methods from quantitative and qualitative approaches to collect data can be utilised in a simultaneous or sequential way that address the research questions. ${ }^{49}$ Brewer and Hunter ${ }^{50}$ suggest that data collection approaches can use 'multi-methods' whereas Bryman refers to the 'mixed strategy approach' that uses quantitative and qualitative research strategies, e.g. ethnography and a survey within the same research. ${ }^{51}$

With collaboration with health partners, it was determined that the first phase of the research would concentrate on a review of the literature and the international human

\footnotetext{
${ }^{44}$ Tashakkori A and Teddlie C, Mixed Methodology: Combing Qualitative and Quantitative Approaches (London: Sage 1998)

${ }^{45}$ Morgan D L, 'Paradigms lost and pragmatism regained methodological implications of combining qualitative and quantitative methods,' Journal of mixed methods research 2007 no. 1 (1):48-76; Felizer M, 'Doing Mixed Methods Research Pragmatically: Implications for the Rediscovery of Pragmatism as a Research Paradigm', Journal of Mixed Methods Research January 2010 4(1):6-16

${ }^{46}$ Creswell J W, Research design: Qualitative, quantitative and mixed methods approaches (London: Sage Publications 2003)

${ }^{47}$ Morgan D L, 'Paradigms lost and pragmatism regained methodological implications of combining qualitative and quantitative methods,' Journal of mixed methods research 2007 no. 1 (1):48-76

${ }^{48}$ Biesta G, Pragmatism and the philosophical foundations of mixed methods research. In Handbook of Mixed Methods in Social and Behavioral Research, 2nd ed. Tashakkori A and Teddlie C

(Thousand Oaks: Sage 2010) 95-117; Creswell J W and Plano Clark V L, Designing and Conducting Mixed Methods Research, 2nd Edition (Sage Publications, Los Angeles 2011)

${ }^{49}$ Creswell J W, Research design: Qualitative, quantitative and mixed methods approaches (London: Sage Publications 2003)

${ }^{50}$ Brewer J and Hunter A, Multi-method Research: A Synthesis of Styles (London: Sage 1998)

${ }^{51}$ Bryman A, Quantity and Quality in Social Research (London: Routledge, $1^{\text {st }}$ ed 1998); Bryman (2004) Quantity and Quality in Social Research (London: Routledge, $2^{\text {nd }}$ ed 2004)
} 
rights framework to learn what is involved in CRAs to health globally, and the second phase of the research, an organisational case study concentrated on the ABMU Health Board.

The case study approach allows empirical investigation of a real-life context, the development of detailed knowledge, using multiple methods and sources of evidence. ${ }^{52}$ The original plan was to collect data that could be inferred into the wider population through a large cohort quantitative study. However, as the research project developed, it became apparent that the necessary scale of data collection would not be possible with the limited resources that the health partner had at its disposal. As a result, the research adopts what Brewer refers to as a 'multi-method approach', carrying out quantitative analysis via four surveys to yield primarily descriptive data which is supported by qualitative data drawn from open ended survey questions. ${ }^{53}$ The evidence from the survey therefore offers a picture of a health authority during a fixed period of time, that reveals how it is progressing to embed a CRA and which identifies recommendations and areas of concern for further research. Utilising both quantitative and qualitative data collection methods within a case study, leads to an interpretivist approach to analysis which offers transferrable rather than generalisable findings (this is discussed in more depth in Chapter 7).

The literature review, review of the international human rights framework and the case study were all carried out adopting a flexible and iterative approach to fit with the 'pragmatic' paradigm as the overarching approach to the methodology. The review approach is discussed in the next section followed by an introduction to the ABMU case study research (Section 1.4.2) which will be further discussed in Chapter 7.

\subsection{Research methodology}

\subsubsection{Review and analysis of the international human rights treaty system and literature relevant to a CRA to health services}

To address the research questions, the first phase of the research included a detailed review of the literature and the international human rights treaty system. This review

\footnotetext{
${ }^{52}$ Brewer J and Hunter A, Multi-method Research: A Synthesis of Styles (London: Sage 1989)

${ }^{53}$ Ibid
} 
contributed to the development of the conceptual framework for developing the tools required to provide data to test the implementation of a CRA to health services in practice.

Traditionally legal analysis has not used systematic reviews to summarise the state of knowledge on a given subject. ${ }^{54}$ However, in 2017, Baude et al argued that performing systematic reviews that are specifically tailored to legal analysis should be developed. ${ }^{55}$ They commented that without a systematic review of the existing knowledge it 'makes it difficult for the reader to evaluate the validity of the claim, but also may impede future legal analysis and allow for either conscious or unconscious bias. ${ }^{56}$

The review of the conceptual literature and the international human rights treaty framework was based on a model that was developed by the Overseas Development Institute and the Secure Livelihoods Research Consortium (ODI and SLRC) in 2013.57 This approach was determined to be best suited to an interdisciplinary and multithematic socio-legal study. ODI and SLRC argue for adopting a review approach that complies with certain core systematic review principles, but also leaves enough space for iterative and flexible problem solving and is more appropriate to exploring questions of how and why certain things work, and others do not. This was also considered to be a good fit with the pragmatic research paradigm referred to above.

The literature was examined through focussed reading, deploying a key word search that related to human rights, children's rights, human rights and health, human rights based approaches to health, children's rights approaches and children's rights approaches to health. The review focused on analysis of academic journals, books, government and non-governmental reports and of critical importance, the most relevant international human rights treaties. This analysis thus used legal research

\footnotetext{
${ }^{54}$ A systematic review is a detailed method of summarizing the results of prior literature on a research question. Typically employed in the medical and psychological sciences, but increasingly being used in the social sciences.

${ }^{55}$ Baude W, 'Making Doctrinal Work More Rigorous: Lessons from Systematic Reviews', University of Chicago Law Review (May 2017) 37

${ }^{56}$ Ibid 37

${ }^{57}$ Hagen-Zanker J and Mallett $\mathrm{R}$, How to do a rigorous, evidence focused literature review in international development: A Guidance Note (Overseas Development Institute. London 2013)
} 
methods which involve an engagement with the law and legal concepts including an analysis of academic work, but with a strong focus on treaties and conventions and their jurisprudence..$^{58}$ In particular, the UNCRC and the International Covenant on Economic, Social and Cultural Rights (ICESCR) and the relevant General Comments issued by the UN Committee bodies.

The review considered the mechanisms that support a CRA to health services and what are some of the barriers to its effective implementation in practice. The review also examined the policy and legislative context relating to health and children's rights in Wales. This element of the review was important to contribute to the development of a CRA conceptual framework that could be used effectively in the Welsh context.

From my experience of working for over 15 years in the field of children's rights, I realised that relevant material is often located outside the orthodox peer review channels (academic databases, journals etc) and often what is happening in practice is far out reaching what has been written about within the academic context. This evidence, referred to as 'Grey literature', although not peer reviewed, contributes to advancing knowledge regarding what should be included in a CRA to health services and the challenges to implementing it in practice. Grey literature refers to government and non-governmental reports, working papers, concept notes, policy documents and briefings (Online and hard copy). My experience of working in the NGO sector influencing policy and law reform, certainly aided finding this kind of literature, as well as having a working knowledge of the main children's rights and human rights websites. The review also provided evidence to demonstrate that little has been written that directly addressed the research questions in the academic context. If I had failed to incorporate grey literature in my search strategy this would have excluded materials relevant and necessary to address the research questions.

Google/Google Scholar was a particularly effective way of identifying the grey literature as well as studies and reports that had only recently been released. This may have led me away from the rigidity of a systematic review which allows you to only

\footnotetext{
${ }^{58}$ McConville M and Wing H (eds) Research Methods for Law (Edinburgh University Press 2017) The thesis did not seek to focus on case law, only when a case elucidated more strongly a point in question. It focused primarily on the provisions of the International Human Rights Treaties and their General Comments.
} 
source material from specific channels, but it certainly enhanced the breadth, relevance and the utility of the review. Snowballing was also a critical element of the review which led me to a depth of literature that contributed to addressing the research questions. The stages of the review based on the ODI and SLRC's approach ${ }^{59}$ are outlined below:

\subsubsection{Setting the research questions}

The research questions included, were the ones already set for the research project:

- Is it possible to identify a CRA to health services in the literature?

- If so, what does a CRA to health services involve?

- What are the mechanisms that support a CRA to health services and what are some of the barriers to its effective implementation in practice?

- What monitoring tools need to be developed to provide data to test the effective implementation of a CRA to health services?

- How can a CRA to health services be better implemented?

\subsubsection{Deciding what to include/exclude as part of the review}

In order to ensure that the research remained focused on the above research questions, the following were included in the review:

- Qualitative and quantitative studies

- Academic journals

- International human rights treaties and their jurisprudence

- UN publications

- WHO publications

- Grey literature: Government reports, non- governmental reports, working papers, concept notes, policy documents and briefings, conference proceedings, health board reports, Public Health Wales publications, Royal College of Paediatric and Child Health publications

\footnotetext{
${ }^{59}$ Hagen-Zanker J and Mallett R, How to do a rigorous, evidence focused literature review in international development A Guidance Note (Overseas Development Institute. London 2013)
} 
- Reports from leading global children's rights organisations e.g., Save the Children and UNICEF.

- Literature primarily from 1989 onwards (adoption of UNCRC)

- Studies that included the search strings referred to below.

While there were not specific 'exclusion' criteria, the following were not included in the review:

- Case law

- Non-English language publications (recognition of language bias).

\subsubsection{Identifying 'search strings'}

Search strings included the relevant keywords related to addressing the research questions. The selected key words were:

- Human rights, children's rights, human rights and health, children's rights and health, human rights approaches, human rights approaches to health, children's rights approaches and children's rights approaches to health.

\subsubsection{Retrieval}

Track I: Academic literature search

This involved searching using the key search strings through the following databases:

- Office of the Commissioner on Human Rights Treaty Data Base, Proquest Social Sciences Database, Google Scholar, JSTOR: Journal Storage, Medline, Cochrane Database, Social Science Research Network, SpringerLink, Wiley Online, Brill Online, Oxford Online.

Track II: Snowballing

This included talking to the experts on the supervisory team (academic and health practitioner colleagues) regarding advising on publications that should be referred to within the literature review. The next step was to look at reference lists of those publications and to look for other relevant publications on the same research questions, using the above inclusion/exclusion criteria. Then to download those 
references and thereafter look at the reference lists of those references. This snowballing process presented the opportunity to examine a depth of literature to address the research questions.

Track III: Grey literature capture

Again, using the key search strings, grey literature was identified. Grey literature as referred to above; government and non-governmental reports, working papers, concept notes, policy documents and briefings (Online and hard copy). Google/Google Scholar was a particularly effective way of identifying this literature and identifying studies and reports that had only recently been released as well as searching institutional/organisational websites relating to children's rights and human rights.

\subsubsection{Screening}

Based on the volume of hits, the search strings were recognised to be too wide. So, the search strings were narrowed to only include human rights and health, children's rights and health, human rights approaches, human rights approaches to health, children's rights approaches and children's rights approaches to health.

The basis of all the titles and abstracts were firstly assessed (where there was one, not always the case with grey literature) using the inclusion and exclusion criteria. Studies that met the inclusion criteria were included as relevant. Secondly, the full texts of the documents were downloaded using the same inclusion/exclusion criteria. Although full systematic review protocols tend to require researchers to collect and store details on the excluded studies, the lighter approach suggested by SLRC was adopted. These studies were not documented or stored and the number of hits per data base or number of irrelevant studies was not recorded. This was determined to be the best approach due to time constraints of the $\mathrm{PhD}$ and not having the wider resource of a review team, usually prevalent in systematic scientific reviews. This also gave the opportunity to devote more time to analysing the findings of the relevant studies rather than spending time documenting and reporting all the publications that had been retrieved. 


\subsubsection{Evidence assessment}

The selected studies were then classified with basic descriptive information and then assessed according to their strength and contribution toward addressing the research questions. This included assessing their quality and the overall strength of the body of research/evidence/practice in the article/document. This element of the review was subjective and to a degree influenced by my past experience in the field of children's rights and it must be acknowledged was non-bias free. It was helpful to categorise the studies by way of a simple traffic light system with Green, being the category most pertinent to addressing the research questions and to definitely be included, Amber may or may not be included, and Red will not be included.

\subsubsection{Analysis}

The findings were then summarised and synthesised, with the aim of addressing the research questions. Included studies, were focused on in the analysis and excluded studies were not focussed on. A narrative synthesis approach was adopted to describe and compare findings in detail, as Popay et al explain using:

an approach to the systematic review and synthesis of findings from multiple studies that relies primarily on the use of words and text to summarise and explain the findings of the synthesis. ${ }^{60}$

Even though this thesis is submitted to the academy, the target audience who would benefit most from reading it i.e., partner health practitioners and managers was considered. Thus, the review was made as accessible as possible and the nature of human rights and children's rights, contextualised at the beginning of the review. This was specifically requested by partner colleagues in the Health Board, who wanted to better understand the underpinnings and building blocks of a CRA and was also essential to the development of the conceptual framework.

\footnotetext{
${ }^{60}$ Popay J, Roberts H, Sowden A, Petticrew M, Arai L, Rodgers M and Duffy S, Guidance on the conduct of narrative synthesis in systematic review. A product from the ESRC methods programme (Version 1 Oxford: ESRC 2006) 5
} 


\subsubsection{Single organisation case study - testing ABMU's institutional approach to implementing a CRA across their health services}

The second phase of the research adopted a socio-legal approach which aimed to gain empirical knowledge and an understanding of how the law is working in society. ${ }^{61}$ The socio-legal approach aims to study the realities of the law in action, the social impact of the law and its relationship to social structures. ${ }^{62}$ This interdisciplinary approach uses social science research methods to analyse the relationships between law, legal phenomenon and wider society. ${ }^{63}$

This aspect of the thesis sought to understand how the international human rights treaty the UNCRC was being translated into the practice of a Welsh Health Board. Using the CRA conceptual framework developed in Part 1 of the thesis, a single organisation case study was designed that was multi-phased and sequential, using a mixed methods approach.

There are a number of advantages to using a case study approach:

It allows in-depth focussing on shifting relationships, it captures complexities, it allows a focus on the local and sense of the participants in the case, and it provides readable data that brings research to life that aims to be true to the concerns and meanings under scrutiny. ${ }^{64}$

The case study allows empirical investigation of a real-life context, the development of detailed knowledge, using multiple methods and sources of evidence. ${ }^{65}$ It encourages the triangulation of methods which enables a thorough understanding of the context under consideration and allows for a cross-checking process to enhance

\footnotetext{
${ }^{61}$ Harris D, The development of socio-legal studies in the United Kingdom (Cambridge University Press: January 2018)

${ }^{62}$ Ibid

${ }^{63}$ Nkansah L A, Chimbwanda V, Interdisciplinary Approach to Legal Scholarship: A Blend from the Qualitative Paradigm', Asian Journal of Legal Education. December 24, 2015

${ }^{64}$ Edwards A and Talbot R, The Hard-pressed Researcher: Research Handbook for the Caring Professions (Longman 1994) 48

${ }^{65}$ Robson C, Real world research: a resource for social scientists and practitioner-researchers, Malden, Blackwell Publishing 2002); Yin R K Case study research: Design and methods (Newbury Park, CA: Sage 1984)
} 
the authority and rigour of the research. ${ }^{66}$ Ziebland, Pope and Mays, claim that a 'single case study design may be the most successful way of generating theory'. ${ }^{67}$ However, Robson has concerns about the case study approach with regards to its lack of transferability. ${ }^{68}$ Johnson conversely argues that applying the in depth learning from the case study can be applied to broader issues and the 'macro-sociological context'.69

The case study aimed to link the research questions with the analytical requirements of the research; it did not claim to be statistically generalisable or provide a significant or representative sample size, however it supported learning that was transferrable to similar health service contexts that impact on children. According to Yin, case studies have been particularly useful for informing policy because processes, problems and programmes can be examined to bring about understanding that can affect and even improve practice. ${ }^{70}$ Sensitive research questions or policy recommendations can be applied to other places experiencing similar challenges.

The case study focused on ABMU institutional policies, procedures and practices intended to give effect to its commitment to deliver health services in accordance with a CRA. The research tools that were developed were designed based on the detailed review of the literature and the international human rights framework in Part 1. They aimed to seek a base line understanding from multiple perspectives of 'How far has a CRA been embedded in ABMU health services?' and 'What strategies are required to make a CRA fully operational?'

This evaluation of ABMU health services from a children's rights perspective was intended to be embedded by ABMU and delivered every 2 years to assess progress in the realisation of children accessing their human rights. It was also intended to be

\footnotetext{
${ }^{66}$ Robson C, Real world research: a resource for social scientists and practitioner-researchers, Malden, Blackwell Publishing 2002)174

${ }^{67}$ Pope C, Ziebland S and Mays N, 'Qualitative research in health care: Analysing qualitative data,' BMJ (2000) Jan 8; 320 (7227)115

${ }^{68}$ Robson C, Real world research: a resource for social scientists and practitioner-researchers, Malden, Blackwell Publishing 2002) 179

${ }^{69}$ Johnson J, 'Are children's perspectives valued in changing contexts? Revisiting a rights-based evaluation in Nepal', Journal of International Development (2010) 1076 -1089

${ }^{70}$ Yin R K, Case study research: Design and methods (London: Sage Publications (1989)
} 
used as a baseline to help flag up children's rights issues of concern that require further in-depth research.

The research was targeted at primarily secondary health services impacting on children in the ABMU health authority. To answer the research questions, four surveys were designed to carry out research with: ABMU strategic leads (Executive and NonExecutive Board Members) health professionals, child patients (7-12 years) and young people patients (13-17 years). The multiple perspectives were compared to determine areas of agreement as well as areas of divergence. Surveys were chosen as the method of analysis to continue with the 'pragmatic approach' of responding to the needs and requirements of the health board, who wanted non-resource intensive methods that could be 'picked up off the shelf' and used again by the health authority in the future. A multi-method approach was used that employed some quantitative analysis via four surveys in the form of descriptive statistics, supported by evidence from qualitative data from open ended responses. The reason for the choice of research methods and their limitations are discussed in more detail in Chapter 7 of this thesis and the challenges to conducting the research at health services are also discussed in Chapter 7.

\subsection{How the research is set out}

Part 1 of the thesis (Chapters 2-6) begins with an examination of the conceptual literature and the international human rights treaty system and its jurisprudence, to determine what should be included in a CRA to health services. It also examines what are the mechanisms that support a CRA to health services and what are some of the barriers to its effective implementation in practice. It further considers health policy and the agenda for children's rights in the Welsh context and concludes with an analysis of what a CRA to health services involves conceptually and practically. From this, a conceptual framework is developed to test ABMU's institutional approach to implementing a CRA.

Part 2 of the thesis (Chapters 7-10) is a case study of ABMU's institutional approach to health services for children. It first describes the ABMU Health Board context and how a single organisation case study has been designed that is multi-phased and sequential, using a mixed methods approach to test ABMU's institutional approach to 
implementing a CRA across their health services. The choice of research methods is discussed as well as the rigour and the trustworthiness of the research and the challenges of seeking ethical approval to conduct the research on site at ABMU health services. The thesis then presents the findings from the research, including analysis of the results of the primary research and makes conclusions and recommendations regarding the development of tools for monitoring a CRA and for better implementation in practice.

\subsubsection{Chapters summary}

Hereafter the thesis is set out as follows:

\section{Chapter 2-Introducing human rights and children's rights}

This chapter sets the scene for more in-depth discussion on children's rights. It provides an overview to the roots of our current international human rights law and explains that human rights are universal, inalienable, indivisible and interrelated and recognise the inherent dignity of each individual. It explains the different categorisations of human rights and refers to the importance of social, economic and cultural rights and describes and explains the historical development of the human right to health. This chapter also introduces the development of special protection for children that culminated in the ground-breaking treaty, the United Nations Convention on the Rights of the Child (UNCRC) that has entrenched the right to the highest attainable standard of health for children into international law. It provides an introduction to the critical components of Article 24 of the UNCRC and relevant interrelated human rights and draws our attention to the importance of the UN Committee on the Rights of the Child and its General Comments.

\section{Chapter 3- Human Rights Based Approach (HRBA) and a Children's Rights Approach (CRA)}

This chapter considers the application of human rights in practice and seeks to contribute towards an understanding of the value of a human rights based approach. It focuses on the different elements of a HRBA and a CRA and demonstrates why they offer a sound framework for implementing human rights and children's rights. It gives consideration to a principled approach that argues that any HRBA/CRA should have 
principles rooted in the international human rights framework and coherently link them to the establishment and delivery of standards and objectives across the policy, programming and legislative process. It also considers what should be included in a HRBA to health and the importance of practical guidance. It finally refers to the learning from UNICEF and the Scandinavian Aid agencies regarding the challenge of applying a HRBA into institutional practice. This chapter further contributes to what should be included in a CRA to health services.

\section{Chapter 4 - Research into implementation of a children's right to health in practice}

A review of predominantly UK and European research on the subject of the implementation of children's right to health in practice, identifies a number of key themes that highlights some of the barriers and the mechanisms that support a child's right to health being implemented in practice. The themes that emerged consistently were: the need for better mainstreaming of a children's rights approach to health and training of health professionals; better recognition of children's right to be heard in clinical decision making and the monitoring and evaluation of services; child-friendly complaints systems; children experiencing challenges in accessing health care services; and discrimination towards children in health service delivery. This chapter explores these themes in detail.

\section{Chapter 5 - Post devolution health policy impacting on children in Wales}

A range of different legal and policy initiatives have addressed healthcare, children's health and general children's issues since devolution in Wales. This chapter presents an overview to some of the key developments in law and policy, firstly concerning health policy generally and then more specifically for children in Wales. It then considers the health inequalities that many children face across Wales. Understanding of the legal and policy framework and what is the reality of many children's lives in Wales, is critical to making any conceptual framework for a CRA to health services applicable to the Welsh context. 


\section{Chapter 6 - Developing a conceptual framework for a CRA to health services in}

Wales

The evidence in Chapters 2- 5 present a detailed analysis of the international human rights framework, its jurisprudence and the literature on human rights, children's rights and health and their application in practice and gives consideration to the Welsh context. It is made clear that HRBAs and CRAs benefit from a principled approach and those principles should be drawn from the international human rights framework. The identification of principles and their translation into standards and objectives should help to drive the policy and service delivery process more directly towards the realisation of children's rights. Chapter 6 draws on this evidence and makes recommendations regarding what should be included in a CRA to health services in the Welsh context. It identifies and presents justification for principles best suited to driving the implementation of a CRA to health services in Wales and translates them into standards and objectives to be included in a conceptual framework.

\section{Chapter 7 - Development of research tools for testing the conceptual framework for a CRA to health services: The ABMU Case Study}

This chapter firstly describes the ABMU Health Board context and then explains how a single organisation case study has been designed that is multi-phased and sequential, using a mixed methods approach to test ABMU's institutional approach to implementing a CRA across its health services. The first part of this chapter introduces ABMU health board and its work on children's rights. It then discusses the case study inquiry approach and considers the challenge of researcher insider/outsider postionality. The chapter also outlines the research methods and data analysis technique, considers the rigour and the trustworthiness of the research and the challenges of seeking ethical approval to conduct the research on site at ABMU Health Board. The final section outlines the four surveys in more detail and presents an integrated conceptual framework which includes the research questions correlated with the principles, standards and objectives of the CRA. 


\section{Chapter 8 - Challenges to conducting the research: Securing ethical approval and young people's independent right to consent to participate in the research}

Following discussion concerning the challenges of ethical approval in Chapter 7, this chapter returns to the literature and focuses on the complexity of securing young people's independent right to consent to participating in research at ABMU health services. It aims to interpret what the law is surrounding the right to consent to participate in research in the health context, considers whether notions of children's vulnerability are guiding decision making around consent, the confusion around the concept of 'assent' and whether 'competent' children should be able to make autonomous decisions. It finally makes some recommendations from a children's rights perspective regarding children consenting to research in the health context.

\section{Chapter 9 - ABMU Case Study: Analysis of findings}

The first part of this chapter focuses on describing the four purposive samples, children 7-12 years, young people 13-17 years, health professionals and Strategic Leads (i.e., ABMU Health Board, Executive and Non-executive Members) and then reflects on improving the monitoring tools in future assessments. The second part of this chapter analyses and triangulates the data from the four surveys using the conceptual framework as its interpretative frame for analysis. It gives consideration to how successfully ABMU Health Board has embedded a CRA and makes some recommendations for future research and improvements to service delivery.

\section{Chapter 10 - Conclusions}

This chapter makes conclusions and presents some critical lessons learned from the thesis as a whole. 


\section{CHAPTER 2 INTRODUCING HUMAN RIGHTS, CHILDREN'S RIGHTS AND THE RIGHT TO HEALTH}

\subsection{Introduction}

Before developing a framework for a CRA to health services, it is important to understand the conceptual underpinnings of human rights and to understand the nature of human rights obligations at all levels in society. This chapter provides an overview to the roots of our current international human rights law and explains that human rights are universal, inalienable, indivisible and interrelated and recognise the inherent dignity of each individual. The different categorisations of human rights are introduced, and the importance of social, economic and cultural rights made reference to, because the right to health fits within this categorisation of human rights. The chapter, then goes onto describe the historical development of the human right to health.

This chapter also introduces the development of special protection for children that culminated in the ground-breaking treaty, the United Nations Convention on the Rights of the Child (UNCRC), which has entrenched the right to the highest attainable standard of health for children into international law. It provides an introduction to the critical components of Article 24 of the UNCRC (the Article focuses on the right to health) and relevant interrelated human rights and draws attention to the importance of the UN Committee on the Rights of the Child and its General Comments.

\subsection{International human rights law}

Over the course of the $20^{\text {th }}$ Century, great social change was achieved in the name of human rights, for example in relation to minorities, women's right to vote and the expulsion of colonial rule. World War One and its atrocities spearheaded nations, under the 1919 Treaty of Versailles, into coming together to establish the League of Nations. Enshrined in the League's Charter was a mandate to promote many of the rights which were later included in the Universal Declaration of Human Rights (UDHR). The Geneva Conventions were also developed during the first half of the $20^{\text {th }}$ Century, 
to safeguard people's human rights when in conflict. However, the horrific atrocities continued in World War Two. ${ }^{71}$

The UN General Assembly (UNGA) and the UN Charter were created in 1945 in an attempt to formally bring nations together to ensure that such horrors as the holocaust never happened again and to ensure the human rights of all individuals are safeguarded. Article 1 and Article 55 of the Charter explicitly refer to human rights, demonstrating that the pursuit of human rights was the central reason for the development of the Charter.

Article 1 The purpose of the United Nations are:

(3) To achieve international cooperation in solving international problems of an economic, social, cultural or humanitarian character and in promoting and encouraging respect for human rights and for fundamental freedoms for all without distinction as to race, sex, language or religion. ${ }^{72}$

Article 55 additionally refers to universal respect for human rights and creating the appropriate conditions for well-being, that is higher standards of living, social health, full employment and conditions for economic and social progress.

After the Second World War, the UDHR was adopted by the UN General Assembly in:

recognition of the inherent dignity and of the equal and inalienable rights of all members of the human family is the foundation of freedom, justice and peace in the world. ${ }^{73}$

This document was the culmination of centuries of thinking and understanding across cultures and religions. ${ }^{74}$ Inherent human dignity is generally interpreted as the Kantian

\footnotetext{
${ }^{71}$ For further information regarding the League of Nations, Treaty of Versaille and Geneva Conventions, https://www.un.org/en/sections/history/history-united-nations/ accessed January 2020

${ }^{72}$ UN Charter, Chapter 1, Article 1, June 1945. For further information http://www.un.org/en/charterunited-nations/ accessed May 2019

${ }^{73}$ Preamble to the Universal Declaration of Human Rights, 1948. For further information on the text of the UDHR and for information about its history https://www.ohchr.org/EN/UDHR/Pages/UDHRIndex.aspx accessed May 2019.

${ }^{74}$ The conceptual underpinnings of human rights has been made reference to for thousands of years for example from the Hindu Vedhas, Babylonian Code of Hammurabi, Bible, Koran, Analects of Confucius, Ancient Greek philosophy, Roman Philosophy, in the Bible, Magna Carta, developed in
} 
notion that dignity is the 'inviolable property of all human beings' ${ }^{75}$ and human rights are predicated on the intrinsic value and worth of all human beings. ${ }^{76}$ Human rights are considered to be moral principles that describe certain standards of behaviour commonly understood as inalienable and universal to which a person is entitled simply because they are a human being. ${ }^{77}$ The entitlement to these human rights is not dependent on nation, language, religion, ethnic origin or any other status. They are applicable everywhere and at every time and to everyone. ${ }^{78}$

The UDHR was a declaration, regarded as 'soft law' and not binding on states, however it was the blueprint of what was to be expected across all international human rights treaties. The 1948 UDHR brought together civil and political rights and social, economic cultural rights into one document. Civil and political rights are rights such as, the right to life, freedom from torture and slavery, freedom of expression, of association and peaceful assembly, the right to a fair trial, to privacy, a name and nationality. These are the 'freedom from' rights that protect the individual from abuse by political authorities. They are primarily included in Articles 2-21 of the UDHR.

Social, economic and cultural rights include the right to the highest attainable standard of health and access to medical services, the right to social security and an adequate standard of living, the right to an education and the right to rest and leisure. These

the middle ages by Catholic Philosophers and through the Protest Reformation to the European Enlightenment Era, English Bill of Rights, French Declaration on the Rights of Man, United States Declaration of Independence, US Constitution etc.

${ }^{75}$ Chapman A, 'The Foundations of a Human Right to Health: Human Rights and Bioethics in Dialogue', Health and Human Rights Journal (2015) Vol. 1 Issue 17

https://www.hhrjournal.org/2015/06/the-foundations-of-a-human-right-to-health-human-rights-andbioethics-in-dialogue/ accessed March 202020.

${ }^{76}$ Leibenberg S, 'The value of human dignity in interpreting socio-economic rights', South African Journal of Human Rights (2005), 21 (1) 1-31. The Kantian moral philosophy has been criticised for its conceptualisation of the inherent worth of individuals being based on their capacity as rational beings. This may be seen to exclude children and adults who are mentally incapacitated, see later discussion in Chapter 6.

${ }^{77}$ Madigan J H, Truth, Politics, and Universal Human Rights (Palgrave Macmillan, New York 2007) 45-54

${ }^{78}$ One understanding of the roots of human rights is that they may be found in natural rights. Natural rights belong to a person because they are human beings rather than purely because they are a citizen of a particular country. The social contract between the state and the individual supported the existence of a set of mutual obligations that ensured natural rights, such as the inalienable right to life, liberty and property. These natural rights, it was argued should not be challenged by regulated authority unless there is an infringement of any of the other natural rights (See social philosophers Locke, Hobbes, and Rousseau). 
'freedom to' rights require the intervention of the state, including the allocation of resources, for the purpose of assuring equitable participation in the production and distribution of values. They are primarily included in Articles 22-27 of the UDHR.

The International Covenant on Civil and Political Rights (ICCPR) ${ }^{79}$ and the International Covenant on Social, Economic and Cultural rights (ICESCR) ${ }^{80}$ were the treaties that flowed from the UDHR and were legally binding on all states that ratified them. Together with the UDHR they are commonly referred to as the International Bill of Rights. ${ }^{81}$ They were followed by over 20 principal treaties that were designed to address specific abuses, for example the UN Convention against Torture and other Cruel, Inhuman or Degrading Treatment or Punishment (UNCAT) ${ }^{82}$ and specific vulnerable populations such as women, through the Convention on the Elimination of Discrimination Against Women (CEDAW) ${ }^{83}$ and children, the UNCRC. ${ }^{84}$ UN member states are bound to adhere to the treaties they have ratified. They are expected to agree to comply with their provisions, change their domestic laws to conform to them and report progress against them.

\subsection{The International Covenant on Economic, Social and Cultural Rights}

The 1966 ICESCR ensured that economic, social and cultural rights were expressed as legal rights. The right to health (Article 12 of ICESCR) which is central to the discussion in this thesis is included in the category of economic, social and cultural rights and is classified as a social right. The Committee on Economic and Social and Cultural Rights is the UN Committee charged with overseeing the implementation of the ICESCR. The UN Committee on Economic Social and Cultural Rights is also responsible for monitoring State Parties protection or violation of ESC Rights as well as their role in protecting, respecting and fulfilling them. State Parties that have ratified

\footnotetext{
${ }^{79}$ For the full text of the ICCPR https://www.ohchr.org/EN/ProfessionalInterest/Pages/CCPR.aspx accessed May 2019

${ }^{80}$ For the full text of the ICESCR https://www.ohchr.org/EN/ProfessionalInterest/Pages/CESCR.aspx accessed May 2019

${ }^{81}$ For further history on the establishment of the International Bill of Rights https://www.ohchr.org/Documents/Publications/FactSheet2Rev.1en.pdf accessed May 2019

${ }^{82}$ UNCAT https://www.ohchr.org/EN/ProfessionalInterest/Pages/CAT.aspx accessed May 2019

${ }^{83} \mathrm{CEDAW}$ treaty https://www.ohchr.org/EN/ProfessionalInterest/Pages/CEDAW.aspx accessed May 2019

${ }^{84}$ UNCRC https://www.ohchr.org/EN/ProfessionalInterest/Pages/CRC.aspx accessed May 2019
} 
the ICESCR are obligated to submit reports every 5 years to the Committee detailing their progress regarding implementing ESC rights. Several Rapporteurs have been appointed by the UN to assist in normative interpretation and to monitor the implementation of ESC rights by States.

This Committee has been integral to developing normative definitions of Economic, Social and Cultural Rights and has developed several General Comments. General Comments are a UN Committee's fuller interpretation of an article or provision of a Convention or the internal procedures of a committee and are made reference to throughout this thesis. UN Human Rights Rapporteur, Alston, explains that a General Comment is:

a means by which a UN human rights expert committee distils its considered views on an issue which arises out of the provisions of the treaty whose implementation it supervises ... In essence the aim is to spell out and make more accessible the 'jurisprudence' emerging from its work. ${ }^{85}$

General Comments are generally agreed to provide authoritative guidance and assistance on how to implement a Convention. ${ }^{86}$ Keller and Grover who have reviewed 30 years of human rights committees' General Comments have concluded that no State parties have ever raised an objection to the authority of supervisory treaty bodies in issuing General Comments to State parties. ${ }^{87}$ As Gerber et al explain 'the competence of treaty bodies to issue general comments is now accepted by states'. ${ }^{88}$ Keller and Grove argue that they deliver three functions: legal analysis, policy

\footnotetext{
${ }^{85}$ Alston P, 'The Historical Origins of the Concept of "General Comments” In Human Rights Law,' In Laurence Boisson de Chazournes and Vera Gowlland-Debbas (eds), The International Legal System in Quest of Equity and Universality: Liber Amicorum Georges Abi-Saab (MartinusNijhoff, 2001) 763, 764

${ }^{86}$ Gerber P, KyriaKakis J and O'Byrne K, 'General Comment 16 on State Obligations Regarding the Impact of the Business Sector on Children's Rights: What Is Its Standing, Meaning and Effect?' Melbourne Journal of International Law, Vol. 14, No. 1 (2013)

${ }^{87}$ Keller H and Grover L 'General Comments of the Human Rights Committee and Their Legitimacy,' In Keller H and Ulfstein G (eds), UN Human Rights Treaty Bodies: Law and Legitimacy (Cambridge University Press, 2012) 116, 127

${ }^{88}$ Gerber P, KyriaKakis, J and O'Byrne K 'General Comment 16 on State Obligations Regarding the Impact of the Business Sector on Children's Rights: What Is Its Standing, Meaning and Effect?'

Melbourne Journal of International Law, Vol. 14, No. 1, (2013) 7
} 
recommendations and practice guidance. ${ }^{89}$ Gerber et al, comment that in practice, General Comments have taken the form of a powerful and indispensable juridical tool that assists in reinforcing standards as well as in pushing at the boundaries of the law.'90 The General Comment on the Right to Health and the Child's Right to Health will be referred to in more detail shortly.

There are other secondary legal sources that are regarded as influential on how the ICESCR is implemented such as the Limburg Principles on the Implementation of the International Covenant on Economic, Social and Cultural Rights 1987 and the Maastricht Guidelines on Violations of Economic, Social and Cultural Rights 1997. The Limburg Principles explain by way of examples, how economic and social rights can be violated and make explicit the obligations imposed on States by a reference to a reasonableness criterion as well as offering guidance to the interpretation of the rights listed in the Covenant. ${ }^{91}$ The Maastricht guidelines build on the principles, developing understanding of the legal implications of the violations of economic, social and cultural rights. ${ }^{92}$

It is important in this early chapter, to outline that economic, social and cultural rights are binding international human rights and not just programmatic aspirations. ${ }^{93}$ It is also important to clarify that a human right represents a specific relationship between an individual who has a valid claim and another individual, group, or institution (including the state) with a duty to respect, protect, and fulfil the right. ${ }^{94}$ International Human Rights Law declares that signatories to an International Convention have three types of obligations: to respect, protect, and fulfil. The obligation to fulfil includes obligations to 'facilitate' and

\footnotetext{
${ }^{89}$ Keller H and Grover L, 'General Comments of the Human Rights Committee and Their Legitimacy,' In Keller H and Ulfstein G (eds), UN Human Rights Treaty Bodies: Law and Legitimacy (Cambridge University Press, 2012)

${ }^{90}$ Gerber P, KyriaKakis J and O’Byrne K, 'General Comment 16 on State Obligations Regarding the Impact of the Business Sector on Children's Rights: What Is Its Standing, Meaning and Effect?' Melbourne Journal of International Law, Vol. 14, No. 1 (2013) 11

${ }^{91}$ Limburg Principles on the Implementation of the International Covenant on Economic, Social and Cultural Rights, UN Doc. E/CN.4/1987/17

${ }^{92}$ Maastricht Guidelines on violations of Economic, Social and Cultural Rights (later reissued as UN d ocument E/C.12/2000/13) para 71

${ }^{93}$ UN Committee on Economic and Social Rights, General Comment Number 9 (Nineteenth Session, 1998) Report of the Committee on Economic, Social and Cultural Rights, UN doc. E/1999/22, para 2 $117-121$

${ }^{94}$ Human rights obligations can also attach to private individuals, international organizations and other non-State actors, International Council on Human Rights Policy, Taking Duties Seriously: Individual Duties in International Human Rights Law (1999), www.ichrp.org accessed March 2017
} 
'provide.' The duties described below should be equally applied to all duty-bearers. The primary duty bearer is the State or Government responsible and accountable to fulfilling the rights of a rights holder.

- The Obligation/Duty to Respect requires the duty-bearer to refrain from interfering directly or indirectly with the enjoyment of the right.

- The Obligation/Duty to Protect requires the duty-bearer to take measures that prevent third parties from interfering with the enjoyment of the right.

- The Obligation/Duty to Fulfil (Facilitate) requires duty-bearers to adopt appropriate legislative, administrative, budgetary, judicial, promotional, and other measures towards the full realisation of the right.

- The Obligation/Duty to Fulfil (Provide) requires duty-bearers to directly provide assistance or services for the realisation of the right. ${ }^{95}$

'Respect, Protect and Fulfil' describes the obligation on duty bearers that flow from international human rights law. ${ }^{96}$ This tripartite typology is relevant to economic, social and cultural rights.

The Maastricht Principles state:

Like civil and political rights, economic, social and cultural rights impose three different types of obligations on States: the obligations to respect, protect and fulfil. Failure to perform any one of these three obligations constitutes a violation of such rights. The obligation to respect requires States to refrain from interfering with the enjoyment of economic social and cultural rights. Thus, the right to housing is violated if the State engages in arbitrary forced evictions. The obligation to protect requires States to prevent violations of such rights by third parties. Thus, the failure to ensure that private employers comply with basic labour standards may amount to a violation of the right to work or the right to just and favourable conditions of work. The obligation to fulfil requires States to take appropriate, legislative, administrative, budgetary, judicial and other measures to full

\footnotetext{
${ }^{95}$ Jonsson U, Human Rights Approach to Development Programming (UNICEF 2003) 15

${ }^{96} \mathrm{OHCHR}$ https://www.ohchr.org/EN/ProfessionalInterest/Pages/InternationalLaw.aspx accessed March 202021
} 
realisation of such rights. Thus, the failure of States to provide essential primary health care to those in need may amount to a violation. ${ }^{97}$

Additionally, the UN Committee on Economic and Social Rights in 1998 stated that:

the Covenant norms must be recognised in appropriate ways within the domestic legal order, appropriate means of redress, or remedies must be available to any aggrieved individual or group and appropriate means of ensuring governmental accountability must be put in place. ${ }^{98}$

Progressive realisation is established by Art 2 (1) ICESCR:

[1] Each State Party to the present Covenant undertakes to take steps, individually and through international assistance and cooperation, especially economic and technical, to the maximum of its available resources, with a view to achieving progressively the full realisation of the rights recognised in the present Covenant by all appropriate means, including particularly the adoption of legislative measures.

The ICESCR recognises the concept of 'progressive realisation'. Progressive realisation means that governments 'have a specific and continuing obligation to move as expeditiously and effectively as possible towards the full realisation of social, economic and cultural rights'. ${ }^{99}$ There is an understanding that the full realisation of these rights may not be achieved immediately as the resources may not be available. States must show that they are making every possible effort, within available resources, to better protect and promote their achievement. ${ }^{100}$

\footnotetext{
${ }^{97}$ Maastricht Guidelines on violations of Economic, Social and Cultural Rights (later reissued as UN document E/C.12/2000/13) para 6

${ }^{98}$ Report of the Committee on Economic, Social and Cultural Rights, General Comment Number 9 (Nineteenth Session, 1998) UN doc. E/1999/22, para 2 117-121

${ }^{99}$ UN Committee on Economic, Social and Cultural Rights (CESCR), General Comment No. 3: The Nature of States Parties' Obligations (Art. 2, Para. 1 of the Covenant), E/1991/23 (December 14, 1990)

${ }^{100}$ UN Committee on Economic, Social and Cultural Rights (CESCR), General Comment No. 3: The Nature of States Parties' Obligations (Art. 2, Para. 1 of the Covenant), E/1991/23 (December 14, 1990); UN Committee on Economic, Social and Cultural Rights (CESCR), General Comment No. 14: The Right to the Highest Attainable Standard of Health (Art. 12 of the Covenant), U.N. Doc. E/C.12/2000/4 (Aug. 11, 2000)
} 
This must be demonstrated through adequate and transparent budget analysis. ${ }^{101}$ Available resources refer to those existing within a State, as well as those available from the international community through international cooperation and assistance. The Office of the High Commissioner on Human Rights explains however, that there must not be 'any trade-off that leads to the retrogression of a human right from its existing level of realisation and rules out the non-achievement of certain minimum levels of realisation.' ${ }^{102}$

Another important underlying theme to this thesis, is the acceptance of the indivisibility and interdependence of civil and political rights and economic, social and cultural rights. The Vienna Declaration and Programme of Action at the World Conference on Human Rights in 1993, asserted that:

All human rights are universal, indivisible and interdependent and related.

The international community must treat human rights globally in a fair and equal manner, on the same footing, and with the same emphasis. ${ }^{103}$

The acknowledgement that human rights are indivisible and interdependent will be later discussed in the context of the UNCRC, the international treaty that comprehensively includes civil, political and economic, social and cultural rights in one document. The next section first turns to the international human right to health.

\subsection{The right to health}

The right to health was made a part of the UN framework on human rights in 1948 in the UDHR (Article 25[1]) as a universal minimum standard of health that all individuals are entitled to. The World Health Organization (WHO) defined health in its broader sense in its 1948 constitution as 'a state of complete physical, mental, and social well-

\footnotetext{
${ }^{101}$ UN Committee on the Rights of the Child, General Comment No. 5 on the General Measures of Implementation $\mathrm{CRC} / \mathrm{C} / \mathrm{GC} / 5 / 2003$

${ }^{102} \mathrm{OHCHR}$ Principles and Guidelines for a human rights based approach to poverty reduction (HR/PUB/06/12 2004) para 22

1031993 Vienna Declaration and Programme of Action https://www.ohchr.org/EN/ProfessionalInterest/Pages/Vienna.aspx accessed January 2020
} 
being and not merely the absence of disease or infirmity.' ${ }^{104}$ According to Meier, the WHO then spent:

twenty years shunning human rights discourse.... and..... intentionally neglected human rights discourse during crucial years in the development and implementation of the right to health, projecting itself as a technical organization above legal rights. ${ }^{105}$

It was not until the 1960s that the next significant developments in human rights and health took place, with the ICESCR coming into force in 1966 which included the provision for the right to health under Article 12. The human right to health was included subsequently in a number of other international human rights treaties:

- The 1965 International Convention on the Elimination of All Forms of Racial Discrimination: art. 5 (e) (iv) $)^{106}$

- The 1966 International Covenant on Economic, Social and Cultural Rights: art. $12^{107}$

- The 1979 Convention on the Elimination of All Forms of Discrimination against Women: arts. 11 (1) (f), 12 and 14 (2) (b) ${ }^{108}$

- The 1989 Convention on the Rights of the Child: art. 24109

- The 1990 International Convention on the Protection of the Rights of All Migrant Workers and Members of Their Families: arts. 28, 43 (e) and 45 (c) ${ }^{110}$

- The 2006 Convention on the Rights of Persons with Disabilities: art. 25. ${ }^{111}$

\footnotetext{
${ }^{104}$ WHO Constitution 1948 http://www.who.int/governance/eb/who_constitution_en.pdf accessed January 2020

${ }^{105}$ Meier B, 'Global health governance and the contentious politics of human rights: Mainstreaming the right to health for public health advancement,' Stanford Journal on International Law 46/1 (2010), $1-2$

${ }^{106}$ ICERD https://www.ohchr.org/EN/ProfessionalInterest/Pages/CERD.aspx accessed January 2020

${ }^{107}$ ICESCR https://www.ohchr.org/en/professionalinterest/pages/cescr.aspx accessed January 2020

${ }^{108} \mathrm{CEDAW}$ https://www.ohchr.org/EN/ProfessionalInterest/Pages/CEDAW.aspx accessed January 2020

${ }^{109}$ UNCRC https://www.ohchr.org/EN/ProfessionalInterest/Pages/CRC.aspx accessed May 2019

${ }^{110}$ ICRMW https://www.ohchr.org/EN/ProfessionalInterest/Pages/CMW.aspx accessed January 2020

${ }^{111}$ CRPD

https://www.ohchr.org/EN/HRBodies/CRPD/Pages/ConventionRightsPersonsWithDisabilities.aspx accessed January 2020
} 
The right to health as laid out in the ICESCR is set out in full below:

\section{Article 12 of the ICESCR}

1. The States Parties to the present Covenant recognize the right of everyone to the enjoyment of the highest attainable standard of physical and mental health.

2. The steps to be taken by the States Parties to the present Covenant to achieve the full realization of this right shall include those necessary for:

(a) The provision for the reduction of the still birth-rate and of infant mortality and for the healthy development of the child.

(b) The improvement of all aspects of environmental and industrial hygiene.

(c) The prevention, treatment and control of epidemic, endemic, occupational and other diseases.

(d) The creation of conditions which would assure to all medical service and medical attention in the event of sickness.

Article 12 encompasses and gives equal consideration to physical and mental health and contains both freedoms and entitlements. ${ }^{112}$

By the early 1970s the WHO had returned to the 'promise of international human rights standards as a means to achieve global health policy'113 and an appreciation that public health practitioners needed to re-engage:

\footnotetext{
${ }^{112}$ Rights such as: the right to control one's health and body, such as sexual and reproductive rights and to be free from interference, free from torture and from non-consensual medical treatment and experimentation. Entitlements such as: right to a system of health protection providing equality of opportunity for everyone to enjoy the highest attainable level of health. This further clarification regarding how the right to health is defined is included in the Committee on Economic, Social and Cultural Right's General Comment No.14 on the Right to Health para 8, which is discussed in more detail later in this chapter.

${ }^{113}$ Meier B, 'Global health governance and the contentious politics of human rights: Mainstreaming the right to health for public health advancement,' Stanford Journal on International Law 46/1 (2010) 35
} 
with the underlying determinants of health, drawing on theories of social medicine and recognizing a need for a shift in the balance of effort [to] modification of the conditions which led to disease rather than from intervention in the mechanism of disease after it has occurred. ${ }^{114}$

The WHO documents started to focus on horizontal primary health care and to translate public health discourse into human rights norms, supporting WHO's expanding understanding that obligations to human rights 'could bind states to realise the health of their people'. ${ }^{115}$ Meier argues that this helped to change the language from questions of 'quality of care through medicine to issues of international development and social justice through health systems." ${ }^{116}$

Taking forward the WHO dialogue, the right to health was subject to extended academic discussion in 1978, in a three-day workshop organized by the Hague Academy of International Law and United Nations University. The proceedings were published in 1979 as The Right to Health as a Human Right. ${ }^{117}$ This approach to health rights helped to frame the Declaration of Alma-Ata: ${ }^{118}$

Article I of the Declaration of Alma-Ata states that:

health, which is a state of complete physical, mental and social well-being, and not merely the absence of disease or infirmity, is a fundamental human right and that the attainment of the highest level of health is a most important world-wide social goal whose realization requires the action of many other social and economic sectors in addition to the health sector. ${ }^{119}$

\footnotetext{
${ }^{114}$ Ibid 36

${ }^{115}$ Ibid 37

${ }^{116}$ Ibid 38

${ }^{117}$ Dupuy R (ed), Le Droit à la santé entant que droit de l'homme / The right to health as a human right (Amsterdam: Sijthoff and Noordhoff, 1979)

${ }^{118}$ Meier B, 'Global health governance and the contentious politics of human rights: Mainstreaming the right to health for public health advancement,' Stanford Journal on International Law 46/1 (2010) 39

${ }^{119}$ Declaration of Alma-Ata, International Conference on Primary Health Care, Alma-Ata, USSR, September 1978.
} 
As Meier explains, 'it expanded upon the provisions codified in the ICESCR, laying out specific rights-based governmental obligations for essential aspects of primary health care', including: ${ }^{120}$

(1) education concerning prevailing health problems and methods of preventing and controlling them; (2) promotion of food supplies and proper nutrition; (3) adequate supplies of safe water and basic sanitation; (4) maternal and child health care, including family planning; (5) immunization against major infectious diseases; (6) prevention and treatment of locally endemic diseases; and (7) the provision of essential medicines. ${ }^{121}$

Meier argues that the Declaration of Alma-Ata presented WHO's first unifying framework for promoting public health under the direction of the right to health. ${ }^{122}$ However, like the WHO's Health for All Strategy, its weakness lay in that although its programmatic obligations were based on the human right to health it was not rooted in international treaty law, neither was it operationalised through legal obligations. ${ }^{123}$ Meier claims that the WHO's approach had:

led the right to health to fall from the Universal Declaration of Human Right's promise of lexical rigidity to its current state of aspirational fluidity, rarely legislated or litigated. ${ }^{124}$

Hunt comments that up to 1993, the literature concentrated on the right to health and only in 1993 - 1994 did it begin to focus more on human rights and health. ${ }^{125}$ This he argues was reinforced by the HIVIAIDs context by the development of International Guidelines on HIVIAIDs and Human Rights 1996 which gave reference to a 'human rights approach' and a 'rights based response' and in 1997 in Human Rights and Public Health in the AIDS Pandemic, by Gostin and Lazzarini, which focused on a human

\footnotetext{
${ }^{120}$ Meier B, 'Global health governance and the contentious politics of human rights: Mainstreaming the right to health for public health advancement,' Stanford Journal on International Law 46/1 (2010) 42

${ }^{121}$ Declaration of Alma-Ata, supra note 237, § VII.

122 Ibid 43

${ }^{123}$ Ibid 45

124 Ibid 46

${ }^{125}$ Hunt $\mathrm{P}$ 'Interpreting the International Right to Health in a Human Rights-Based Approach to Health', Health and Human Rights Journal (2016) Dec 18(2): In other words, an understanding of how the right to health is linked to many other human rights
} 
rights approach. ${ }^{126}$ Also in 1993, the WHO published Human Rights in Relation to Women's Health which contributed to three world conferences, ${ }^{127}$ which successfully after a long hiatus put human rights and health back on the agenda of the WHO. In 1997, the WHO held a meeting to specifically address the issue of health and human rights. The meeting report stated:

when inequalities and discrimination contribute to ill-health, health status indicators can highlight underlying human rights violations. Therefore, health status data provide an important indicator of human rights abuses. ${ }^{128}$

Attempts were made to explain the links between human rights and health and in 1999, Toebes wrote, The right to health as a human right in international law. ${ }^{129}$ However, Hunt argues that 'it neither provided a philosophical justification for the right to health nor a clear interpretative methodology. ${ }^{130}$ Despite this criticism Toebes work did offer a significant contribution to the literature. It examined the individual entitlements guaranteed by the right to health and consequent obligations on states and their justifiability. It contributed to the global discussion on the importance of ESC rights and their equality with civil and political rights. Alongside other research and debate it informed the development of the Committee on Economic, Social and Cultural Rights General Comment No. 14 on the right to health published in 2000. ${ }^{131}$

At the turn of the $21^{\text {st }}$ century, support for the right to health and its application was demonstrated by the UN Human Rights Institutions and the UN Special Rapporteurs on the Right to Health. ${ }^{132}$ In 2002 the UN Human Rights Council created the mandate

\footnotetext{
${ }^{126}$ Commission on Human Rights, Guidelines on HIV/AIDS and human rights, UN Doc. E/CN.4/1997/37; Gostin and Z. Lazzarini, Human rights and public health in the AIDS pandemic (New York: Oxford University Press, 1997) xv

${ }^{127}$ World Conference on Human Rights (1993), for which it was written, but also to the International Conference on Population and Development (1994) and Fourth World Conference on Women (1995) ${ }^{128}$ Report of the WHO Informal Consultation on Health and Human Rights (Geneva, December 4-5, 1997) 19

${ }^{129}$ Toebes B, The right to health as a human right in international law (Cambridge: Intersentia 1999).

${ }^{130}$ Hunt $\mathrm{P}$, 'Interpreting the International Right to Health in a Human Rights-Based Approach to Health', Health and Human Rights Journal (2016) Dec 18(2) 103

${ }^{131}$ UN Committee on Economic, Social and Cultural Rights, General Comment No.14: the Right to the Highest Attainable Standard of Health. E/C.12/2000/4

${ }^{132}$ Meier B, 'Global health governance and the contentious politics of human rights: Mainstreaming the right to health for public health advancement,' Stanford Journal on International Law 46/1 (2010),46
} 
of Special Rapporteur on the right of everyone to the highest attainable standard of physical and mental health. Since 2002, rapporteurs have written 32 thematic reports and 23 mission reports on the right to health that provide insights into the interpretation and application of the international right to health. ${ }^{133}$ From 2000 onwards there was a dramatic increase in the academic literature that focused on health and human rights and the right to health. ${ }^{134}$

The right to health increasingly became part of the UN framework, including through General Comments by human rights treaty bodies, i.e. General Comment No 24 of the Committee on the Elimination of Discrimination against Women (1999) ${ }^{135}$, General Comments No. 14 (2000) $)^{136}$ and No. 22 (2016) of the Committee on Economic, Social and Cultural Rights ${ }^{137}$, and General Comment No. 15 of the Committee on the Rights of the Child (2015). ${ }^{138}$ Hunt argues that the General Comments attempt to provide a 'bridge between short legalistic treaty provisions and practice.' 139

The Committee on Economic, Social and Cultural Rights General Comment No.14 addresses 'substantive issues arising in the implementation of the International Covenant on Economic, Social and Cultural Rights', with respect to Article 12 the right to the highest attainable standard of health. ${ }^{140}$ It makes it clear that the right to health is not the unconditional right to be healthy instead it refers to, 'the right to the enjoyment of a variety of goods, facilities, services and conditions necessary for its

\footnotetext{
${ }^{133}$ Office of the High Commissioner for Human Rights Special Rapporteur for Health https://www.ohchr.org/EN/Issues/Health/Pages/SRRightHealthIndex.aspx accessed January 2020 ${ }^{134}$ For further detail of the literature see Hunt P, 'Interpreting the International Right to Health in a Human Rights-Based Approach to Health', Health and Human Rights Journal 2016 Dec 18(2)

${ }^{135}$ CEDAW General Recommendation No. 24: Article 12 of the Convention (Women and Health) Adopted at the Twentieth Session of the Committee on the Elimination of Discrimination against Women, in 1999 (Contained in Document A/54/38/Rev.1, chap. I)

${ }^{136}$ UN Committee on Economic, Social and Cultural Rights, General Comment No.14: the Right to the Highest Attainable Standard of Health. E/C.12/2000/4

${ }^{137}$ UN Committee on Economic, Social and Cultural Rights, General Comment No. 22 on the right to sexual and reproductive health (article 12 of the International Covenant on Economic, Social and Cultural Rights) E/C.12/GC/2016/22

${ }^{138}$ UN Committee on the Rights of the Child, General Comment No. 15 on the right of the child to the enjoyment of the highest attainable standard of health $\mathrm{CRC} / \mathrm{C} / 15 / 2013$

${ }^{139}$ Hunt $\mathrm{P}$, 'Interpreting the International Right to Health in a Human Rights-Based Approach to Health', Health and Human Rights Journal 2016 Dec 18(2) 115

${ }^{140}$ UN Committee on Economic, Social and Cultural Rights, General Comment No.14: the Right to the Highest Attainable Standard of Health. E/C.12/2000/4. 1
} 
realisation. ${ }^{141}$ It describes the right as an inclusive right which includes not only the right to health services, but to the wide range of factors that help us to achieve the highest attainable standard of health. This means that the wider social determinants to health must be addressed, i.e., the conditions in which we are born, we grow and age and in which we live and work. ${ }^{142}$ It focuses on the importance of timely and appropriate health care and to the underlying determinants of health, such as safe and potable water, sanitation, food, housing, health related information and education, and equality. ${ }^{143}$

The importance given to the 'underlying determinants of health'; the factors and conditions which protect and promote the right to health demonstrate that the right to health is dependent on, and contributes to, the realisation of many other human rights. The General Comment draws attention to the fact that health inequalities signify the non-realisation of human rights, and no one should face discrimination on any grounds in accessing their human right to health. ${ }^{144}$ It is also makes clear that the right to health is not just a programmatic aspiration but is a human right standard to be enforced by states. $^{145}$

The General Comment also recognises that there are core obligations to the right to health from which the State cannot derogate. ${ }^{146}$ At the very minimum, immediate obligations include the guarantees of non-discrimination and equal treatment, as well as the obligation to take deliberate, concrete and targeted steps towards the full realisation of social, economic and cultural rights. ${ }^{147}$

\footnotetext{
${ }^{141}$ Ibid para 9

${ }^{142}$ UN Committee on Economic, Social and Cultural Rights, General Comment No.14: the Right to the Highest Attainable Standard of Health, E/C.12/2000/4 para 11; Commission on Social Determinants of Health, Closing the Gap in a Generation: Health Equity through Action on the Social Determinants of Health: Final Report of the Commission on the Social Determinants of Health (WHO and Commission on Social Determinants of Health 2008)

${ }^{143}$ UN Committee on Economic, Social and Cultural Rights, General Comment No.14: the Right to the Highest Attainable Standard of Health. E/C.12/2000/4. para 11

${ }^{144}$ UN Committee on Economic, Social and Cultural Rights, General Comment No.14: the Right to the Highest Attainable Standard of Health. E/C.12/2000/4 paras 18,19

${ }^{145}$ Office of the High Commissioner and Human Rights and the World Health Organisation Fact Sheet No. 31: The Right to Health, 5

${ }^{146}$ UN Committee on Economic, Social and Cultural Rights, General Comment No.14: the Right to the Highest Attainable Standard of Health E/C.12/2000/4 para 47

${ }^{147} \mathrm{OHCHR}$ http://www.ohchr.org/EN/Issues/Health/Pages/SRRightHealthIndex.aspx accessed January 2020
} 
For example, in the context of the right to health, the Committee on Economic, Social and Cultural rights includes in its list of 'minimum core obligations' the duty to ensure access to services health services without discrimination and 'equitable distribution of all health facilities, goods and services', minimum essential food which is nutritionally adequate and safe, freedom from hunger to everyone', 'basic shelter, housing and sanitation, and an adequate supply of safe and potable water', essential drugs; and to adopt through participatory means and implement with independent monitoring of progress a national public health strategy and plan of action. ${ }^{148}$ The Committee also states that there are additional obligations of comparable priority, these are: to ensure reproductive; maternal (pre and post-natal) and child health, immunisation against major infectious diseases; measures to prevent, treat and control epidemic and endemic diseases; education and access to information concerning the main health problems in the community, including methods of preventing and controlling them; and appropriate training for health personnel, including education on health and human rights. ${ }^{149}$

The Committee clarifies that:

In order for a State party to be able to attribute its failure to meet at least its minimum core obligations to a lack of available resources it must demonstrate every effort has been made to use all resources that are at its disposition in an effort to satisfy, as a matter of priority those minimum obligations. ${ }^{150}$

Young is concerned that if we solely focus on the minimum core obligations there is the potentiality of states to neglect the realisation of the other rights within the Convention. ${ }^{151}$ This is why she and others argue that going beyond the realisation of the core obligations means that it is essential that indicators are developed to measure

\footnotetext{
${ }^{148}$ UN Committee on Economic, Social and Cultural Rights, General Comment No.14: the Right to the Highest Attainable Standard of Health. E/C.12/2000/4 para 43

${ }^{149}$ Ibid para 44 a-e

${ }^{150}$ UN Committee on Economic, Social and Cultural Rights (CESCR), General Comment No. 3, para 10

${ }^{151}$ Young K, Constituting Economic and Social Rights (Oxford: Oxford University Press 2012)
} 
progress in the realisation of all economic, social and cultural rights. ${ }^{152}$ The development of indicators will be discussed in later chapters with regards to the realisation of the child's right to health. Additionally, Gearty and Mantouvalou usefully refer to the importance of understanding how to translate social rights into policies, legislation and practice so that they can be realised at the local level having the greatest impact on people's lives. ${ }^{153}$ These rights essentially act as entitlement to services e.g., health care. In order to give effect to these rights, the State party must introduce policy or programmes and make funds available to support service delivery. The challenges of translating social rights into reality will be discussed in later chapters that refer to the application of children's rights in practice. The next section will first focus on the movement towards special protection for children and the adoption into international law of the UNCRC.

\subsection{Toward special protection of children}

Children's rights were not considered a serious topic for rights discourse until the $20^{\text {th }}$ Century. Focus on children was primarily in relation to a parent's duties to the child rather than the child having any rights of their own. In fact, under English common law, they were considered to be the property or chattel of their parents. ${ }^{154}$ Rights of children were also conceptualised more in terms of their protection, originating from the late $19^{\text {th }}$ Century 'child-saving' philosophies with a stronger focus on children's vulnerability and dependency on adults rather than their need for autonomy. ${ }^{155}$

This position began to be challenged as a result of the conflict that broke out in 1914 . Millions of children either died or were made orphans during the First World War and this catalysed Eglatyne Jebb, a British teacher, into action. She founded Save the

\footnotetext{
${ }^{152}$ Green M, 'What We Talk About When We Talk About Indicators: Current Approaches to Human Rights Measurement', Human Rights Quarterly (2001) 23(4): 1062-1097;

Landman, T, 'Measuring Human Rights, Practice and Policy', Human Rights Quarterly (2004) vol. 26: 906-931; de Beco, Gauthier 'Measuring Human Rights: Underlying Approach', 2007 E.H.R.L.R., Issue 3: 266-278; Rosga A and Satterthwaite M

'The Trust in Indicators: Measuring Human Rights', Berkeley Journal of International Law (2009) vol. 27, Number 2: 253-31

${ }^{153}$ Gearty C and Mantouvalou V, Debating Social Rights (Hart Publishing 2010)

${ }^{154}$ Bester, J and Kodish E, 'Children Are Not the Property of Their Parents: The Need for a Clear Statement of Ethical Obligations and Boundaries,' The American Journal of Bioethics Volume 17, 2017 - Issue 11

${ }^{155}$ Archard D, Children's Rights and Childhood (Routledge 2004)
} 
Children and set about drafting the Declaration on the Rights of the Child ${ }^{156}$ which was adopted by the League of Nations in 1924 in an attempt to put pressure on nation states to protect children's rights. ${ }^{157}$ Eglatyne Jebb stated:

I believe we should claim certain rights for the children and labour for their universal recognition, so that everybody - not merely the small number of people who are in a position to contribute to relief funds, but everybody who in any way comes into contact with children, that is to say the vast majority of mankind - may be in a position to help forward the movement. ${ }^{158}$

The idea of children's rights as human rights stem from the philosophy that children are persons, members of society, and citizens of the State and therefore, should be afforded similar rights as other human beings. ${ }^{159}$ Recognition of human dignity and humanity does not just commence when someone reaches the age of maturity. ${ }^{160}$ The Declaration on the Rights of the Child is considered to be the beginning of the drive towards international law on children's rights and a global movement that strove to conceptualise children as subjects of human rights. However, it still saw children primarily in need of 'relief and nurture'. ${ }^{161}$

Once again this changed as a result of global conflict in which children suffered. The Second World War led to many more children's rights being violated. Janusz Korczack (1878-1942) during the Second World War ran an orphanage for Jewish Children in Warsaw, as a kind of children's republic or parliament, with its own court and newspaper. He was a paediatrician, children's author and pedagogue and a passionate believer in children's ability to take responsibility for change in their own lives. He valued and respected children as human beings and recognised both their

\footnotetext{
${ }^{156}$ Text of the Declaration on the Rights of the Child https://blogs.lse.ac.uk/lsehistory/2017/03/08/eglantyne-jebb-and-the-respected-protected-the-rightsof-children-exhibition/ accessed May 2019

${ }^{157}$ Eglatyne Jebb, 1923 recorded in the history of Save the Children UK https://www.savethechildren.org.uk/about-us/our-history accessed January 2020

${ }^{158}$ Ibid

${ }^{159}$ Archard D, Children's Rights and Childhood (Routledge 2004)

${ }^{160}$ Ibid

${ }^{161}$ Hodgson D, 'The historical development and "Internationalisation" of the Children's Rights Movement', Australian Journal of family law quarterly (1992) 25
} 
capacity and competence. Unfortunately, his commitment to the children he cared for took him to the gas camps of Treblinka where he perished. ${ }^{162}$

As noted above, the atrocities of World War Two led to the development of the UDHR and although the rights of children are implicitly included in the UDHR ${ }^{163}$, many considered that the special needs of minors required a separate document. After much debate and deliberation, the Declaration on the Rights of the Child was adopted by the UNGA in 1959. The 1959 UN Declaration on the Rights of the Child like the earlier Geneva declaration of 1924 focused very much on the 'protection and provision' rights and did not include the approach that Jansuck Korczack had fostered in his children's orphanage, i.e., the child's right to autonomy and self-determination. It was also not a legal document and had the limited status of a declaration. ${ }^{164}$

\subsection{The United Nations Convention on the Rights of the Child}

It took a further thirty years for the UNCRC to be adopted in 1989. Discussions started as part of the preparations for the 1979 International Year of the Child based on a draft convention submitted by the Government of Poland. ${ }^{165}$ The United Nations Human Rights Commission group working with NGOs took 10 years to draft the full convention. The UNCRC is the most globally ratified of all the human rights treaties. It covers the human rights of the child (0 to 17 years) and all human rights, from civil and political to social, economic and cultural rights. It is the most important legal source on children's rights. The UNCRC recognises children as 'human beings' in their own right. Prior to the UNCRC, children were less visible in the human rights system. Although, many of their human rights were included in the other international human rights instruments, states argued that there was the need for one comprehensive document

\footnotetext{
${ }^{162}$ Eichstellar G 'JanuszKorczak - His Legacy and its Relevance for Children's Rights Today', The International Journal of Children's Rights, Volume 17, Issue 3, (2009); Arie de Bruin Children's Rights in Health Care and the Legacy of Janusz Korczak, In Children's Rights and Health Care (eds) Doek and Dorscheist (Brill Publications 2018)

${ }^{163}$ The United Nations Universal Declaration of Human Rights (1948) in Article 25(2) recognized the need of motherhood and childhood to "special protection and assistance" and the right of all children to "social protection

${ }^{164}$ Fortin J, Children's Rights and the Developing Law ( $3^{\text {rd }}$ edn Cambridge University Press 2004)

${ }^{165}$ Office of the High Commissioner on Human Rights (1993) Fact Sheet No.10 (Rev.1), The Rights of the Child https://www.ohchr.org/Documents/Publications/FactSheet10rev.1en.pdf accessed January 2020
} 
that was binding in international law. ${ }^{166}$ The international framework of the UNCRC has made children more visible; in some countries it has succeeded in raising children's issues up the political agenda, entitling them to be active citizens in national and local democracy. ${ }^{167}$ It has challenged many governments to invest in children so they can access the health care and nutrition they need to survive and develop, and it has succeeded in promoting the development of stronger frameworks to protect children from violence and exploitation. 168

The UNCRC gives children over 41 fundamental rights while aiming to respect individual traditions and cultures. It is written in such a way that it makes implementation possible in a diverse range of countries with different legal systems. The UNCRC contains 54 sections or 'Articles'. The Articles provide a complete framework of standards, principles and implementation processes developed to respond to the specific needs of childhood. Together these Articles aim to support and ensure each and every child's survival and development, Part 1: Articles 1-41 contain the substantive provisions of the Convention, Part 2: Articles 42-45 are concerned with the implementation and monitoring of the Convention and Part 3: Articles 46-54 contain the final clauses.

The Convention has three 'Optional Protocols'. ${ }^{169}$ These are additional legal mechanisms added to the treaty after its original adoption; the Optional Protocol on the Sale of Children, Child Prostitution and Child Pornography; the Optional Protocol on the involvement of children in armed conflict and the Optional Protocol on a Communications Procedure.

\footnotetext{
${ }^{166}$ Ibid

${ }^{167}$ Cantwell N 'Are children's rights still human?’ In Invernizzi A and Williams J (eds) The Human Rights of Children: From Visions to Implementation (Farnham: Ashgate 2011); Lundy L, Kikelly U, Byrne B, King J, The UN Convention on the Rights of the Child: A Study of Legal Implementation in 12 Countries (Queens University Belfast and UNICEF 2012); Croke R, A new Youth Assembly for Wales? A comparative exploration into the best practice elements of 17 youth parliaments in the UK, Europe and globally (CYPAW 2016)

${ }^{168}$ UNICEF https://www.unicef.org/child-rights-convention/what-is-the-convention accessed January 2020

${ }^{169}$ For further information on the Optional Protocols http://www.ohchr.org/EN/HRBodies/CRC/Pages/CRCIndex.aspx accessed January 2020
} 
The Convention rights are indivisible and interrelated. The Convention both safeguards children's right to be protected (Article 19), but also recognises children's right to be heard in all matters that affect them and influence decisions (Article 12). The Convention recognises that children are different to adults that is, they are smaller and younger human beings, and as is stated in the Convention, 'the child, by reason of his physical and mental immaturity needs special safeguards and care. ${ }^{170}$ The UNCRC takes a life course approach, respects the inherent dignity of the child and recognises that children's capacities develop with age and maturity while still affirming the importance of the family to children (see Article, 5, 18 and preamble to the UNCRC). The UNCRC, by conceptualising children as the subject of human rights, is a ground-breaking legal document because it acknowledges children's agency and that a child's voice must be heard and acted upon. ${ }^{171}$ The rights that are categorised as protection and the rights that are categorised as participation rights should not be seen as dichotomous, but must be delicately balanced in order that the full range of children's rights are realised. ${ }^{172}$ For example, if a child knows how to assert their Article 12 right to be heard they will be better equipped to speak out and claim their human right not to be abused (Article 19). It sets out the minimum standards of provision that all children under 18 years of age are entitled to; from human rights such as access to education, healthcare and social security (Article 28, 24, 26) to all children's rights being interpreted in accordance with their best interests (Article 3 ). It also brings all human rights civil, political and economic, social and cultural rights into one comprehensive document.

\subsubsection{The General Measures of Implementation}

When a State ratifies the UNCRC, it takes on obligations under international law to implement it and to establish effective structures and mechanisms for its implementation. Implementation is the process whereby State parties take action to ensure the realisation of all rights in the Convention for all children in their jurisdiction. These are referred to as the General Measures of Implementation (Articles 4, 42, 44.6)

\footnotetext{
${ }^{170}$ Preamble to the Convention on the Rights of the Child

${ }^{171}$ Archard D, Children's rights and childhood (Routledge 2004) 58

${ }^{172}$ Freeman M, The Value and Values of Children's Rights, in Invernizzi A and Williams J (eds), The Human Rights of Children: From Visions to Implementation (Farnham: Ashgate 2011)
} 
of the UNCRC. ${ }^{173}$ The Committee on the Rights of the Child's General Comment No. 5 presents an explanation of the General Measures of Implementation. ${ }^{174}$

The general measures of implementation are essentially about the development of a children's rights perspective throughout government institutions, parliament and the legislative bodies, as well as the judiciary. ${ }^{175}$ They are required to promote the full enjoyment of all human rights in the UNCRC:

from incorporation of the UNCRC into domestic legislation, to the establishment of coordinating and monitoring bodies (government and independent) to comprehensive data collection, awareness raising and training, monitoring of budgets and the development of plans of action for children and young people rooted in the UNCRC. ${ }^{176}$

These measures are critical to the implementation of the UNCRC at both the national and the local level and will be considered in more detail in later chapters with regards to the implementation of a CRA to health services (see in particular Chapter 6).

\subsubsection{The General Principles of the United Nations Convention on the Rights of the Child}

The General Principles of the UNCRC are seen to be instrumental to the implementation of all the other articles of the UNCRC and together are said to present a children's rights perspective. ${ }^{177}$ Each of the principles are not only rights in themselves but according to the UN Committee on the Rights of the Child should be used in the interpretation and implementation of all the other rights of the UNCRC. ${ }^{178}$ The General Principles are: Article 2: Non-discrimination, no child should be

\footnotetext{
${ }^{173}$ UN Committee on the Rights of the Child, General Comment No. 5 on General Measures of Implementation $\mathrm{CRC} / \mathrm{C} / \mathrm{GC} / 5 / 2003$

${ }^{174}$ For further information on the General Measures of Implementation General Comment No. 5 http://tbinternet.ohchr.org/layouts/treatybodyexternal/Download.aspx?symbolno=CRC\%2fGC\%2f20 $03 \% 2 \mathrm{f} 5 \&$ Lang=en accessed January 2020

${ }^{175}$ Ibid paras 1,12

${ }^{176}$ Ibid para 9

${ }^{177}$ Hammerberg T, Belembaogo A, Children's Rights, turning principles into practice. (Stockholm, Save the Children Sweden 2006)

${ }^{178}$ UN Committee on the Rights of the Child, General Comment No. 12: The right of the child to be heard, $\mathrm{CRC} / \mathrm{GC} / 12 / 2009$ para 2
} 
discriminated against on any grounds; Article 3: Best interests of the child should be a primary consideration in all actions concerning children; Article 6: States must guarantee the child the fundamental right to life and to 'ensure to the maximum extent possible the survival and development of the child; and Article 12: Children's right to be heard must be respected in all matters that affect them and their views given due weight. These general principles will be referred to in this chapter and later chapters.

\subsubsection{The UN Committee on the Rights of the Child}

There is no international court that can try violations against the UNCRC, but since 1991, a global committee of 18 experts have been monitoring the implementation of the UNCRC in countries that have ratified it. The Committee holds regular sessions every year to review State parties' progress made in fulfilling their obligations under the Convention and its Optional Protocols. ${ }^{179}$ As part of the reporting process ${ }^{180}$ to the Committee, NGOs, Children and Independent Human Rights Institutions (NHRIs) are also invited to submit what are known as 'alternative reports' to give the Committee an alternative perspective to what might be happening in a State party. The process of preparing both State party and alternative reports offers an invaluable opportunity to conduct a comprehensive review of the various measures that have been undertaken to harmonise national law and policy with the Convention. ${ }^{181}$ On receiving the State party and alternative reports the Committee holds verbal hearings with the NGOs and NHRIs and children and young people themselves. The Committee can make suggestions and issue recommendations to governments on ways to meet the Convention's objectives by way of 'Concluding Observations.'182 Without the Convention being able to be invoked in a court of law in the UK, holding governments to account is very dependent on the success of civil society collectively using the

\footnotetext{
${ }^{179}$ For further information on the Committee on the Rights of the Child http://www.ohchr.org/EN/HRBodies/CRC/Pages/CRCIndex.aspx accessed January 2020

${ }^{180}$ UN Committee on the Rights of the Child's reporting guidelines http://tbinternet.ohchr.org/ layouts/treatybodyexternal/Download.aspx?symbolno=CRC/C/58/REV.3 \&Lang=en accessed January 2020

${ }^{181}$ UN Committee on the Rights of the Child's reporting guidelines para 3

${ }^{182}$ UN Committee on the Rights of the Child's Concluding Observations http://tbinternet.ohchr.org/ layouts/treatybodyexternal/TBSearch.aspx?Lang=en\&TreatyID=5\&Treat $\mathrm{yID}=10 \&$ Treaty $\mathrm{ID}=11 \&$ DocTypeID $=5$ accessed January 2020
} 
reporting process to challenge the State party to deliver on the Concluding Observations of the UN Committee and the rights of the Convention. ${ }^{183}$

\subsubsection{The UN Committee on the Rights of the Child General Comments}

The Convention has supporting jurisprudence in the form of General Comments. ${ }^{184} \mathrm{~A}$ UNCRC General Comment is a document usually published annually by the Committee on the Rights of the Child. ${ }^{185}$ Art 45(d) of the Convention on the Rights of the Child gives the power to the Committee on the Rights of the Child to 'make suggestions and general recommendations' to States parties and the General Assembly. A General Comment often follows on from a Day of General Discussion. Each year, children, non-governmental organisations (NGOs) and experts are invited to submit documents to be published on-line to inform the Committee's one-day debate with stakeholders (UN agencies, Committee members, NGOs, academics, lawyers, children, etc). As Gerber et al comment, stakeholders coming together to interpret the provisions of the UNCRC, 'can have a critical impact on their capacity to promote coherent and consensus-based interpretations of international human rights law'. ${ }^{186}$

Since the UNCRC was adopted in 1989, the UN Committee has issued 24 General Comments. ${ }^{187}$ These General Comments range from normative interpretation of best interests and the right to be heard, to early childhood, independent human rights institutions and the right to play and the right to health.

This chapter and other chapters throughout this thesis will make reference to a number of the General Comments to assist with a detailed interpretation of the UNCRC and to

\footnotetext{
${ }^{183}$ Aspinwall T and Croke R 'Policy Advocacy Campaigns: the collective voices of children's NGOs in Wales', In Williams J (eds) The UNCRC in Wales (University of Wales Press 2013)

${ }^{184}$ For further information on UNCRC General Comments, to:http://tbinternet.ohchr.org/ layouts/treatybodyexternal/TBSearch.aspx?Lang=en\&TreatyID=5\&Do cTypeID $=11$ accessed January 2020

${ }^{185}$ For the OHCHR explanation of a General Comment https://www.ohchr.org/EN/HRBodies/CRC/Pages/WorkingMethods.aspx para IX accessed January 2020

${ }^{186}$ Gerber P, KyriaKakis J and O’Byrne K, 'General Comment 16 on State Obligations Regarding the Impact of the Business Sector on Children's Rights: What Is Its Standing, Meaning and Effect?'

Melbourne Journal of International Law, Vol. 14, No. 1, (2013) 11

${ }^{187}$ As of January 2020, there were 24 General Comments on the UNCRC http://tbinternet.ohchr.org/ layouts/treatybodyexternal/TBSearch.aspx?Lang=en\&TreatyID=5\&DocT ypeID $=11$
} 
develop a further understanding of a CRA to health services. The next section will make particular reference to the General Comment No.15: The right to the highest possible attainable standard of health, which is critical in considering the development of a CRA to health services. ${ }^{188}$

\subsection{The UNCRC and the children's right to health}

This section introduces the children's right to health. Article 24 of the UNCRC explicitly recognises the child's right to the enjoyment of the highest attainable standard of health and to healthcare. If children are able to realise their right to health it supports children to enjoy the fulfilment of their other human rights. The next section presents a summary of Article 24 followed by an introduction to some of the key articles of the UNCRC that interrelate strongly with Article 24 and refers in particular to the interpretation of the right to health in UN Committee on the Rights of the Child's General Comment No. 15 and other general comments. Article 24 of the UNCRC states:

States Parties recognize the right of the child to the enjoyment of the highest attainable standard of health and to facilities for the treatment of illness and rehabilitation of health. States Parties shall strive to ensure that no child is deprived of his or her right of access to such health care services.

Article 24 is not the unconditional right to be healthy, instead it asserts the right of all children without discrimination to 'the highest attainable standard of health' and to facilities that support the 'rehabilitation of health' and, each child should not be 'deprived of his or her right of access to such health services.' Article 24 'imposes a strong duty of action by States parties to ensure that health and other relevant services are available and accessible to all children, with special attention to under-served areas and populations' and all barriers should be identified and eliminated. ${ }^{189}$ Services

\footnotetext{
${ }^{188}$ UN Committee on the Rights of the Child, General Comment No. 15 on the right of the child to the enjoyment of the highest attainable standard of health CRC/C/15/2013

${ }^{189}$ Ibid paras 28, 29
} 
must be delivered in a timely and appropriate manner ranging from preventative, rehabilitative, palliative, health promotion and curative services. ${ }^{190}$

Article 24 (2) goes further to provide a non-exhaustive list of measures that a State must pursue in order to implement the right:

2. States Parties shall pursue full implementation of this right and, in particular, shall take appropriate measures:

(a) To diminish infant and child mortality;

(b) To ensure the provision of necessary medical assistance and health care to all children with emphasis on the development of primary health care;

(c) To combat disease and malnutrition, including within the framework of primary health care, through, inter alia, the application of readily available technology and through the provision of adequate nutritious foods and clean drinking-water, taking into consideration the dangers and risks of environmental pollution;

(d) To ensure appropriate pre-natal and post-natal health care for mothers;

(e) To ensure that all segments of society, in particular parents and children, are informed, have access to education and are supported in the use of basic knowledge of child health and nutrition, the advantages of breastfeeding, hygiene and environmental sanitation and the prevention of accidents;

(f) To develop preventive health care, guidance for parents and family planning education and services.

${ }^{190}$ Ibid para 2 
3. States Parties shall take all effective and appropriate measures with a view to abolishing traditional practices prejudicial to the health of children.

4. States Parties undertake to promote and encourage international cooperation with a view to achieving progressively the full realization of the right recognized in the present article. In this regard, particular account shall be taken of the needs of developing countries.

This list provides a clear focus to a range of health issues and social determinants of health. The UNCRC's General Comment No.15 reiterates that rights set out in the UNCRC are indivisible and reinforces that the right to health is interconnected to all other rights to the Convention. ${ }^{191}$ It is seen as an 'inclusive' right and includes a range of rights and freedoms that determine children's health, such as the right to access education, freedom from physical and mental violence and to non-discrimination. ${ }^{192}$

The approach to the right to health within the UNCRC supports one of prevention and primary health care and tackling the social determinants that affect health. The General Comment makes reference to both the WHO's definition of health and the importance of the Alma Ata Declaration. ${ }^{193}$ Article 24 (b) conveys the same objective as Alma Ata which reinforces the importance of universal coverage of primary health care for all children matched with an adequate allocation of resources (Article 4) $)^{194}$ and Article 24 (f) preventative health care. It makes reference to the importance of the underlying conditions for health and well-being, such as 'safe water and adequate sanitation, adequate nutritious food and housing, [and] healthy occupational and environmental conditions.' ${ }^{195}$ While Article 24 (c) supports a focus on healthy environmental conditions, and para 50 of the General Comment No. 15 emphasises

\footnotetext{
${ }^{191}$ Ibid para 7

${ }^{192}$ UN Office of the High Commissioner of Human Rights (OHCHR) and World Health Organization (WHO) The Right to Health, Fact Sheet No. 31 www.ohchr.org/Documents/Publications/Factsheet31.pdf accessed January 2018

${ }^{193}$ UN Committee on the Rights of the Child, General Comment No. 15 on the right of the child to the enjoyment of the highest attainable standard of health $\mathrm{CRC} / \mathrm{C} / 15 / 2013$ para 4

${ }^{194}$ Ibid para $73, \mathrm{~b}, \mathrm{c}$,

${ }^{195}$ UN Committee on Economic, Social and Cultural Rights (CESCR) General Comment No. 14 para 45, In Nolan A, Yamin AE and Meier BM, Submission on the Content of a Future General Comment on the right of the child to the enjoyment of the highest attainable standard of health (art. 24) (OHCHR). http://www2.ohchr.org/english/bodies/crc/callsubmissionsCRC received.htm accessed June 202018
} 
that climate change is the 'biggest threat to children's health and exacerbates health disparities' apart from asking that States put child health at the centre of their climate change strategies, this is where the statement ends. Arguably, a General Comment focused on the impact of climate change on children's rights should be developed with urgency $^{196}$ as the OCHCR recognises climate change has disproportionate impact on children. ${ }^{197}$

Article 24 (e) and the General Comment No. 15 are supportive of health promotion and information and acknowledges that all caregivers must be given information on the rights of the child and most importantly, that children themselves have information about how to stay healthy and to access their human rights (Article 42, Article 17). ${ }^{198}$ Article 24 (d) places emphasis on the importance of the pre-natal and post-natal care of mothers. The unborn child is offered some protection in the womb to the highest attainable standard of health through guarantees to the pregnant mother of appropriate pre-natal health care.

Article 24 (3) the abolition of traditional harmful practices has been criticised by Kilkelly ${ }^{199}$ and Fortin ${ }^{200}$ for not specifically naming the different forms of mutilation or cutting carried out for religious, cultural or social reasons and defining them in practice. This, argues DeLaet, opens up competition between parent's human rights to culture and religion and children's rights. ${ }^{201}$

Article 24 (4) recognises the needs of children who live in developing countries obligating states to cooperate, to progressively realise the implementation of Article 24.

\footnotetext{
${ }^{196}$ UN Committee on the Rights of the Child, General Comment No. 15 on the right of the child to the enjoyment of the highest attainable standard of health $\mathrm{CRC} / \mathrm{C} / 15 / 2013$ para 50

${ }^{197}$ Report of the Office of the High Commissioner on Human Rights, Analytical study on the relationship between climate change and the human right of everyone to the enjoyment of the highest attainable standard of physical and mental health A/HRC/32/23 (UN General Assembly May 2016) paras $26-27$

${ }^{198}$ UN Committee on the Rights of the Child, General Comment No. 15 on the right of the child to the enjoyment of the highest attainable standard of health $\mathrm{CRC} / \mathrm{C} / 15 / 2013$ para 59

${ }^{199}$ Kikelly U, 'Health and Children's Rights', In (eds) Vandenhole W, Desmet E, Reynaert D, and Lembrects S, International Handbook of Children's Rights Studies (Routledge 2015) 218

${ }^{200}$ Fortin J, Children's Rights and the Developing Law ( $3^{\text {rd }}$ edn 2009 Cambridge University Press)

${ }^{201}$ DeLaet D, 'Genital Autonomy, children rights and competing rights claims in international human rights law', The International Journal of Children's Rights (2012) 20(4), 554-583
} 


\subsubsection{Article 24 and survival and development}

The implication of Article $6(1)$ is to encourage states to take positive measures:

to protect life, including by increasing life expectancy, diminishing infant mortality and child mortality, combating diseases and rehabilitating health, providing adequate nutritious foods and clean drinking water. And they may further aim at preventing deprivation of life, namely by prohibiting and preventing death penalty, extra legal, arbitrary or summary executions or any situation of enforced disappearance. State parties should therefore refrain from any action that may intentionally take life away, as well as steps to safeguard life. ${ }^{202}$

Article 6 (2) of the UNCRC explains that 'States Parties shall ensure to the 'maximum extent possible'203 the survival and development of the child and this links to the evidence on social determinants. ${ }^{204}$ The UN Committee on the Rights of the Child states that survival and development to the maximum extent possible includes:

the physical, mental, moral, spiritual and social dimensions of their development. The many risks and protective factors that underlie the life, survival, growth and development of the child need to be systematically identified in order to design and implement evidence-informed interventions that address a wide range of determinants during the life course. ${ }^{205}$

\footnotetext{
${ }^{202}$ Pais M, The Convention on the rights of the child, in Manual on Human Rights reporting under six major international human rights instruments, Office of the High Commissioner for Human Rights, Geneva: United Nations 1997 Institute for Training and Research, United Nations Staff College Project Turin. 424 cited In, Newell P and Hodgkin R Implementation handbook for the Convention on the Rights of the Child, (UNICEF 2002) 97

${ }^{203}$ It is important to recognise that enjoyment of Article 6 para 2 as a right is subject to limitation, as it should be read in conjunction with Article 4 of the UNCRC, 'to the maximum extent of the State Party's available resources, Doek J, 'Children's rights in health care and the General Principles of the CRC', In Doek J and Dorscheist M (eds) Children's Rights in Health Care (Brill Publications 2018) 61

${ }^{204}$ Commission on Social Determinants of Health, Closing the Gap in a Generation: Health Equity through Action on the Social Determinants of Health: Final Report of the Commission on the Social Determinants of Health (WHO and Commission on Social Determinants of Health 2008)

${ }^{205} \mathrm{UN}$ Committee on the Rights of the Child, General Comment No. 15 on the right of the child to the enjoyment of the highest attainable standard of health $\mathrm{CRC} / \mathrm{C} / 15 / 2013$ para 16
} 
The UN Committee on the Rights of the Child further outlines the determinants that need to be included to realise the children's right to survive and develop to their fullest potential:

including individual factors such as age, sex, educational attainment, socioeconomic status and domicile; determinants at work in the immediate environment of families, peers, teachers and service providers, notably the violence that threatens the life and survival of children as part of their immediate environment; and structural determinants, including policies, administrative structures and systems, social and cultural values and norms. ${ }^{206}$

Survival and development is not just about preparing a child for adulthood but about the child's development in the here and now. ${ }^{207}$ This right is unique to children because it recognises that children go through a rapid process of development. Every state must take measures:

to create an environment conducive to ensuring to the maximum extent possible the survival and development of the child, including physical, mental, spiritual, moral, psychological and social development, in a manner compatible with human dignity and to prepare the child for an individual life in a free society. ${ }^{208}$

The UN Committee on the Rights of the Child is also concerned with the rise in mental health issues affecting children, and urges:

States to undertake an approach based on public health and psychosocial support to address mental ill-health among children and adolescents and

\footnotetext{
${ }^{206}$ Ibid para 17

${ }^{207}$ Peleg N, 'Reconceptualising the Child's Right to Development: Children and the Capability Approach' The International Journal of Children's Rights, 2013 21(3), 523-542

${ }^{208}$ Reporting Guidelines for Periodic Reports, General Guidelines regarding the form and contents of periodic reports to be submitted by States Parties under Article 44, para (b) of the Convention, adopted by the Committee on the Rights of the Child at its $343^{\text {rd }}$ meeting $\left(13^{\text {th }}\right.$ session $) 11$ October 1996 para 40
} 
to invest in primary care approaches that facilitate the early detection and treatment of children's psychosocial, emotional and mental problems. ${ }^{209}$

However, General Comment No. 15 focuses more on physical health and should arguably pay more attention to children's mental health. General Comment No. 20 regarding implementing children's rights in adolescence also only touches on mental health. ${ }^{210}$ This suggests there is a requirement for the development of a general comment that focuses on children's mental health. The UN Commissioner for Human Rights in 2017 asserted the importance of recognising that children with mental health issues 'have agency, self-determination and rights, which should be protected and respected'. ${ }^{211}$

\subsubsection{Article 24 and best interests of the child}

The General Comment on the right to health promotes the best interests of children individually and collectively in all actions that affect them and recognises that some children are vulnerable and have special needs. The UN Committee on the Rights of the Child asserts that economic considerations must not override children's best interests, ${ }^{212}$ and working in the best interests of the child, assists the resolution of conflict between parents and practitioners. ${ }^{213}$ Best interests must be considered in the development of all policies that may impede the physical and social environments, in which children live, grow and develop ${ }^{214}$, and should guide the withholding, termination or provision of treatment for all children. ${ }^{215}$ Article 3 (3) of the UNCRC, calls upon State

\footnotetext{
${ }^{209} \mathrm{UN}$ Committee on the Rights of the Child, General Comment No. 15 on the right of the child to the enjoyment of the highest attainable standard of health $\mathrm{CRC} / \mathrm{C} / 15 / 2013$ para 38

${ }^{210} \mathrm{UN}$ Committee on the Rights of the Child, General Comment No. 20 on the implementation of the rights of the child in adolescence $\mathrm{CRC} / \mathrm{C} / \mathrm{GC} / 202016$

${ }^{211}$ Annual report of the United Nations High Commissioner for Human Rights and reports of the Office of the High Commissioner and the Secretary-General, Mental and Human Rights. UN General Assembly Human Rights Council (November 2017) A/HRC/34/32 para 34

${ }^{212}$ UN Committee on the Rights of the Child, General Comment No. 15 on the right of the child to the enjoyment of the highest attainable standard of health $\mathrm{CRC} / \mathrm{C} / 15 / 2013$, para 13 (a)

${ }^{213}$ Ibid 13 (b)

${ }^{214}$ Ibid para 13 (c)

${ }^{215}$ UN Committee on the Rights of the Child, General Comment No. 15 on the right of the child to the enjoyment of the highest attainable standard of health $\mathrm{CRC} / \mathrm{C} / 15 / 2013$ para 14; UN Committee on the Rights of the Child, General Comment 14 on best interests of the child, para 15
} 
parties to ensure that institutions and facilities for the care of children (including healthcare) adhere to appropriate standards.

However, Doek and Cantwell are critical of the lack of detailed interpretation of best interests of the children in the context of delivering health care, arguing there is still insufficient guidance for health practitioners and managers to apply the principle of best interests practically in health contexts. ${ }^{216}$ The principle of best interests can often lead to confusion and undermine consistency when professionals are seeking to apply it. Doek refers to the example of a decision to vaccinate a child against infectious disease, explaining that the right to be protected against infectious disease is included in the right to health, consequently the decision to vaccinate a child should not depend on the outcome of an assessment of best interests. He also uses the example of children having access to information on a health issue, explaining that this is a right and should not be perceived as a best interests matter. ${ }^{217}$

A more detailed understanding of the Convention as a whole is required and an understanding of all the rights in the Convention and how they contribute to what is in a child's best interests. For example, as the UN Committee on the Rights of the Child does make clear there can be no correct application of Article 3 if the components of Article 12 (the right to be heard) are not respected. ${ }^{218}$ This suggests the importance of children's rights training, so health professionals gain a more detailed understanding of the Convention and its holistic application to promoting children's right to the highest attainable standard of health. General Comment No. 9, the rights of children with disabilities, also suggests that health professionals should receive training on how to ensure their decision making is UNCRC compliant. ${ }^{219}$

\footnotetext{
${ }^{216}$ Doek J, 'Children's rights in health care and the General Principles of the CRC,' In Doek J and Dorscheist M (eds) Children's Rights in Health Care (Brill Publications 2018); N Cantwell, 'Are the "Best Interests" a Pillar or a problem for Implementing Human Rights of Children?' In T. Liefaard, J. Sloth-Nielsen (eds.): The United Nations Convention on the Rights of the Child. Taking Stock after 25 Years and Looking Ahead, (Leiden/Boston, Brill 2017) 65

${ }^{217}$ Doek J, 'Children's rights in health care and the General Principles of the CRC', In Doek J and Dorscheist M (eds) Children's Rights in Health Care (Brill Publications 2018)

${ }^{218} \mathrm{UN}$ Committee on the Rights of the Child, General Comment No. 12: The right of the child to be heard $\mathrm{CRC} / \mathrm{GC} / 12 / 2009$ para 74

${ }^{219}$ UN Committee on the Rights of the Child, General Comment No. 9: The rights of children with disabilities $\mathrm{CRC} / \mathrm{C} / \mathrm{GC} / 9 / 2006$
} 


\subsubsection{Article 24 and children's right to be heard according to their age and maturity}

The UN Committee on the Rights of the child acknowledges that age cannot be the only criterion for competence and 'children's levels of understanding are not uniformly linked to their biological age'. Instead, the extent to which each child's views are taken seriously should be dependent on their understanding of the issues concerned.220 However, no matter the age of the child, the views of children must always be taken into account in clinical decision making. ${ }^{221}$ The child must be presumed capable of forming their own views and it should be recognised that they have the right to express them. ${ }^{222}$ Article 12 is complemented by other participation rights. For example, Article 13 , freedom of expression which includes the child's freedom 'to seek, receive and impart information ... orally, in writing or in print, in the form of art, or through any other media of the child's choice'. Children should always be provided with information about proposed treatments, including in formats appropriate and accessible to children and children with disabilities. ${ }^{223}$

General Comment No.15 recognises the importance of the child's evolving capacities (discussed in more detail in Chapter 6) and that their opportunities for independent decision making in the health context will increase depending on their developmental stage. The UN Committee states:

Children's right to health contains a set of freedoms and entitlements. The freedoms, which are of increasing importance in accordance with growing capacity and maturity, include the right to control one's health and body, including sexual and reproductive freedom to make responsible choices... ${ }^{224}$

\footnotetext{
${ }^{220} \mathrm{UN}$ Committee on the Rights of the Child, General Comment No. 12: The right of the child to be heard, $\mathrm{CRC} / \mathrm{GC} / 12 / 2009$ para 29

${ }^{221}$ UN Committee on the Rights of the Child, General Comment No. 12: The right of the child to be heard, $\mathrm{CRC} / \mathrm{GC} / 12 / 2009$; UN Committee on the Rights of the Child, General Comment No. 15 on the right of the child to the enjoyment of the highest attainable standard of health $\mathrm{CRC} / \mathrm{C} / 15 / 2013$

${ }^{222}$ Article 12 of the UNCRC

${ }^{223}$ UN Committee on the Rights of the Child, General Comment No. 12: The right of the child to be heard, $\mathrm{CRC} / \mathrm{C} / \mathrm{C} / 12$ para 100

${ }^{224}$ UN Committee on the Rights of the Child, General Comment No. 15 on the right of the child to the enjoyment of the highest attainable standard of health $\mathrm{CRC} / \mathrm{C} / 15 / 2013$ para 24
} 
When a child's consent is required, a child's views should be given due weight. The UN Committee on the Rights of the Child, with respect to adolescents explains:

Before parents give their consent, adolescents need to have a chance to express their views freely and their views should be given due weight, in accordance with article 12 of the Convention. However, if the adolescent is of sufficient maturity, informed consent shall be obtained from the adolescent her/himself, while informing the parents if what is in the best interest of the child' (art. 3). ${ }^{225}$

The UN Committee has welcomed that some States have introduced a fixed age limit in legislation and regulations at which the right to consent transfer to the child. ${ }^{226}$

The UN Committee asserts:

that there are often serious discrepancies regarding such autonomous decision-making, with children who are particularly vulnerable to discrimination often less able to exercise this autonomy. It is therefore essential that supportive policies are in place and that children, parents and health workers have adequate rights-based guidance on consent, assent and confidentiality. ${ }^{227}$

The complexities regarding the age at which children can consent to treatment and to participate in health research will be discussed in further detail in Chapters 4, 6 and 8. The UN Committee asserts across several General Comments that children according to their evolving capacities should also be able to seek confidential counselling and advice independent of their parents. ${ }^{228}$

\footnotetext{
${ }^{225}$ UN Committee on the Rights of the Child, General Comment No.4 Adolescent health and development in the context of the Convention on the Rights of the Child $\mathrm{CRC} / \mathrm{C} / \mathrm{GC} / 4 / 2003$ para 32 ${ }^{226} \mathrm{UN}$ Committee on the Rights of the Child, General Comment No. 12: The right of the child to be heard, $\mathrm{CRC} / \mathrm{C} / \mathrm{C} / 12,2009$ para 102

${ }^{227}$ UN Committee on the Rights of the Child, General Comment No. 15 on the right of the child to the enjoyment of the highest attainable standard of health $\mathrm{CRC} / \mathrm{C} / 15 / 2013$ para 21

${ }^{228}$ UN Committee on the Rights of the Child, General Comment No. 15 on the right of the child to the enjoyment of the highest attainable standard of health $\mathrm{CRC} / \mathrm{C} / 15 / 2013$; UN Committee on the Rights of the Child, General Comment No.4 Adolescent health and development in the context of the Convention on the Rights of the Child CRC/C/GC/4/2003 28; UN Committee on the Rights of the Child, General Comment No. 3: HIV/AIDS and the Rights of the Child CRC/GC/2003/3 which also sets
} 
The General Comment on health states that all children's views should be taken into account in the evaluation of services, what services are needed, what are the barriers to access, the quality of services and the attitudes of health professionals. ${ }^{229}$ It encourages health services to consider increasing children's opportunities for being involved in health service provision for example, as peer-educators. ${ }^{230}$

Additionally, according to Article 12 of the UNCRC, if a child is not happy with any decision that has been made, children should be provided with information and given access to procedures which enable them to question and challenge decision-makers, and the health authority should be transparent and provide reasons for their decisions and actions. Decision makers should always give feedback to children regarding the outcome of a decision-making process and how the child's views were given consideration. ${ }^{231}$ Effective remedies should be accessible to the child where the decision-making process has not adhered to appropriate standards, including child friendly complaints mechanisms. ${ }^{232}$ There must be recourse for rights violations and injustice. Children should be able to turn to independent human rights institutions to help them to deal with complaints. ${ }^{233}$ The importance of children's views being given due weight and their evolving capacity to make decisions in the context of health care decision-making will be discussed in more detail in later chapters.

\subsubsection{Article 24 and non-discrimination}

Article 2 places an obligation on all states to comply with UNCRC rights without discrimination on any grounds. It strongly emphasizes that children's right to health should not be undermined due to reasons of discrimination or the status of the child. ${ }^{234}$ The Convention also offers double protection, with regards to recognising that

\footnotetext{
out that children should be able to consent to HIV/AIDS treatment for themselves, subject to an assessment of their evolving capacities

${ }^{229}$ UN Committee on the Rights of the Child, General Comment No. 15 on the right of the child to the enjoyment of the highest attainable standard of health $\mathrm{CRC} / \mathrm{C} / 15 / 2013$ para 19

${ }^{230} \mathrm{UN}$ Committee on the Rights of the Child, General Comment No. 15 on the right of the child to the enjoyment of the highest attainable standard of health $\mathrm{CRC} / \mathrm{C} / 15 / 2013$

${ }^{231} \mathrm{UN}$ Committee on the Rights of the Child, General Comment No. 12: The right of the child to be heard, $\mathrm{CRC} / \mathrm{C} / \mathrm{C} / 12,2009$ paras 30 and 45

${ }^{232}$ UN Committee on the Rights of the Child, General Comment No. 15 on the right of the child to the enjoyment of the highest attainable standard of health $\mathrm{CRC} / \mathrm{C} / 15 / 2013$ para 119

${ }^{233}$ Ibid para 103

${ }^{234}$ Ibid para 8
} 
discrimination towards parents/guardians impacts on the child. For example, the discrimination a child might experience if their parents are infected with HIVIAIDS. National policies and laws must work to ensure that there is equity, so vulnerable or underserved populations are not disadvantaged. ${ }^{235}$ In addition, health workers must work in a child sensitive manner ensuring that they do not deny children services that they are entitled to. ${ }^{236}$

There is also a clear focus on disability as a prohibited ground for discrimination. Article 23 makes specific reference to the rights of disabled children, in which it includes health services, rehabilitation and preventive care. General Comment No.15 makes it explicit that children with disabilities should, wherever possible be, cared for within a family environment and all measures should be taken to provide basic services for health, education, including early childhood education and care, and social services, and strengthen efforts to achieve inclusive education. ${ }^{237}$ The importance of eliminating discrimination against this group of children is reinforced through General Comment No. 9.238

There is also a specific focus on gender discrimination in General Comment No. 15. All policies and programmes should be rooted in an approach that ensures gender equality, relating to sexual and reproductive health, elimination of all forms of sexual and gender based violence, equal access to information, justice and education. ${ }^{239}$ The UNCRC is the only international human rights treaty that places a specific focus on indigenous children, and this is supported by General Comment No. 11.240 All indigenous children, must have equal access to health care and health services must be culturally sensitive and information should be available in indigenous languages.

\footnotetext{
${ }^{235}$ Ibid para 11

${ }^{236}$ Ibid para 27

${ }^{237}$ Doek J, 'Children's rights in health care and the General Principles of the CRC', In, Doek J and Dorscheist M (eds) Children's Rights in Health Care (Brill Publications 2018)

${ }^{238}$ UN Committee on the Rights of the Child, General Comment No. 9: The rights of children with disabilities $C R C / C / G C / 9 / 2006$

${ }^{239}$ UN Committee on the Rights of the Child, General Comment No. 15 on the right of the child to the enjoyment of the highest attainable standard of health $\mathrm{CRC} / \mathrm{C} / 15 / 2013$ para 10

${ }^{240} \mathrm{UN}$ Committee on the Rights of the Child, General Comment No.11 on the rights of indigenous children $\mathrm{CRC} / \mathrm{C} / \mathrm{GC} / 11 / 2009$
} 
The UNCRC includes the Availability, Accessibility, Acceptability, Quality (AAAQ) Framework. ${ }^{241}$ The AAAQ framework can be linked to the General Principle on Nondiscrimination that is all services must be provided without discrimination and not discriminate against vulnerable or underserved groups of the population. The AAAQ framework (included in General Comment No. 15) states that all children's health services and programmes must comply with the criteria of availability, accessibility, acceptability and quality. In summary:

\section{Availability:}

States should ensure that there are functioning children's health facilities, goods, services and programmes in sufficient quantity. Sufficiency should be measured according to need with particular attention given to underserved and hard to reach populations.

\section{Accessibility}

a) Non-discrimination: Health and related services as well as equipment and supplies must be accessible to all children, pregnant women and mothers, in law and in practice, without discrimination of any kind.

b) Physical accessibility: Health facilities must be within accessible distance for all children, pregnant women and mothers.

c) Economic accessibility/affordability: Lack of ability to pay for services, supplies or medicines should not result in the denial of access.

d) Information accessibility: Information on health promotion, health status and treatment options should be provided to children and their caregivers in a language and format that is accessible and clearly understandable to them.

\section{Acceptability:}

Health-related facilities, goods and services must be designed in a way that takes full account of and is respectful of medical ethics as well as children's

\footnotetext{
${ }^{241} \mathrm{UN}$ Committee on the Rights of the Child, General Comment No. 15 on the right of the child to the enjoyment of the highest attainable standard of health $\mathrm{CRC} / \mathrm{C} / 15 / 2013$ paras 113-116
} 
needs, expectations, cultures, views and languages, paying special attention to certain groups, where necessary.

\section{Quality:}

Health-related facilities, goods and services should be scientifically and medically appropriate and of good quality.

It focuses strongly on ensuring that no child faces discrimination due to their status in accessing health services/programmes, they must be affordable and within an accessible distance and information should be provided in a manner that is accessible to children and their caregivers. It obligates services to be designed to support the specific needs and requirements of children, which forces service providers to consider service design from a children's rights perspective. It recommends that services have an evidence base that ensures that they are of good quality and scientifically and medically appropriate. This presents a useful checklist for the development of standards to support the monitoring of the effectiveness of health service delivery for children and the measure to spend to the maximum extent of available resources (Article 4).

The General Comment emphasises the importance of monitoring health budgets for the proportion of their expenditure on children, carrying out consistent and regular rights based budget analysis and impact assessment. ${ }^{242}$ It also highlights the importance of spending to the maximum extent of available resources (Article 4) and to take immediate action to implement the right to health. ${ }^{243}$

The General Comment also outlines the importance of collecting data on children's lives and of developing indicators that monitor and evaluate the implementation of children's right to health and that States should conduct a 'cyclical process of planning, implementation, monitoring and evaluation'. ${ }^{244}$ The General Comments identify the importance of collecting disaggregated data to identify discrimination against children

\footnotetext{
${ }^{242} \mathrm{UN}$ Committee on the Rights of the Child, General Comment No. 15 on the right of the child to the enjoyment of the highest attainable standard of health $\mathrm{CRC} / \mathrm{C} / 15 / 2013$ para 106

${ }^{243}$ Ibid paras 71 and 72

${ }^{244}$ Ibid para 48
} 
as a social group and specific groups of children. ${ }^{245}$ This is also so that research takes into consideration the changing capacities and needs of children over time so that services are developed appropriately. It references a need to have coordinated service responses and to organise health services around children's needs and expectations. ${ }^{246}$ The importance of a clear strategic policy framework setting out the priorities and the measures necessary to promote, protect and fulfil children's rights in practice is also recommended. ${ }^{247}$

\subsubsection{Article 24 and other children's rights}

In the context of experiencing health services, children must have access to their full range of human rights. So, for example children who come into contact with the healthcare system also have a right to access education (Article 28), to enjoy play, rest and leisure (Article 31), to have contact with and the support of their parents and carers (Articles 9, 18). While receiving healthcare, children have the right to be protected from all forms of harm (Article 19) and exploitation (Article 36) and they are entitled to continue to enjoy their rights to religious freedom (Article 14).

The UNCRC also states that children should be informed of their human right to privacy (Article 16). ${ }^{248}$ This becomes significant with regards to personal hygiene activities, and physical examinations, i.e., before any invasion of bodily privacy informed consent should be acquired. Like all human beings, children's human right to bodily integrity must be respected, as outlined above children must be given the opportunity to express their views and their views be given due weight regarding consenting to or refusing treatment. Children may have different cultural beliefs (Article

\footnotetext{
${ }^{245}$ UN Committee on the Rights of the Child, General Comment No. 5 on General Measures of Implementation $\mathrm{CRC} / \mathrm{C} / \mathrm{GC} / 5 / 2003$ para 48; UN Committee on the Rights of the Child, General Comment No. 15 on the right of the child to the enjoyment of the highest attainable standard of health $\mathrm{CRC} / \mathrm{C} / 15 / 2013$ para 109; UN Committee on the Rights of the Child, General Comment No. 20 on the implementation of the rights of the child in adolescence CRC/C/GC/20 2016

${ }^{246} \mathrm{UN}$ Committee on the Rights of the Child, General Comment No. 15 on the right of the child to the enjoyment of the highest attainable standard of health $\mathrm{CRC} / \mathrm{C} / 15 / 2013$ paras $96-101$

${ }^{247}$ Ibid

${ }^{248}$ UN Committee on the Rights of the Child, General Comment No.4 Adolescent health and development in the context of the Convention on the Rights of the Child $\mathrm{CRC} / \mathrm{C} / \mathrm{GC} / 4 / 2003$ paras 9,11
} 
30) concerning their bodily privacy and treatment decisions must be balanced with regards to what is in their best interests.

Although the Convention is applicable to all children under the age of 18 years, it recognises that a different approach is required and different resources and facilities for children of different age groups and capacities. For example, children of a very young age will need to have a different response to their needs as compared to children who are adolescents. The General Comment No.7 on Early Childhood and the General Comments No. 4 Adolescent Health and Development and No.20 on the implementation of rights during adolescence are good reference points for developing a further understanding on a CRA to these age groups. ${ }^{249}$

\subsection{Conclusion}

This chapter explained that human rights are universal, inalienable, indivisible and interrelated and recognise the inherent dignity of each individual. The concept of a human right implies accountability on behalf of duty bearers to respect, protect and fulfil the human rights of human rights holders. It emphasised the importance of ESC rights that must be recognised as enforceable and not just programmatic aspirations. The chapter referred to the history of the development of the right to health that increasingly challenged public health discourse to incorporate human rights norms, supporting an understanding that obligations to human rights bind states to realise the health of their people. Recognising that health inequalities are in fact human rights violations and the right to health must be progressively realised and its core minimum obligations not derogated from.

This chapter also introduced the development of special protection for children that culminated in the children's rights perspective as conceptualised by the UNCRC. This ground-breaking treaty offers special protection to children balanced with a respect for children's agency as subjects of human rights. The challenge of balancing both is

\footnotetext{
${ }^{249} \mathrm{UN}$ Committee on the Rights of the Child, General Comment No.4 Adolescent health and development in the context of the Convention on the Rights of the Child $\mathrm{CRC} / \mathrm{C} / \mathrm{GC} / 4 / 2003$; UN Committee on the Rights of the Child, General Comment No.7 on implementing the child rights in early childhood CRC/C/GC/2007/Rev.1 2006; UN Committee on the Rights of the Child, General Comment No. 20 on the implementation of the rights of the child in adolescence CRC/C/GC/20 2016
} 
pertinent to the delivery of health services and will therefore be a theme that is focused on in later chapters. This international treaty with its specific focus on children, incorporates civil and political rights and economic, social and cultural rights into one document, and entrenches a child's right to the highest attainable standard of health into international law. This chapter sought to introduce the critical components of Article 24 of the UNCRC and relevant interrelated rights and drew our attention to the importance of several general comments that support this interpretation. It introduced the conceptual underpinnings that will inform the development of a framework for a CRA to health services and will be referred to throughout this thesis. The next chapter will focus on the development of human rights approaches. 


\section{CHAPTER 3 HUMAN RIGHTS BASED APPROACH AND CHILDREN'S RIGHTS APPROACH}

\subsection{Introduction}

This chapter considers the application of human rights in practice and seeks to contribute towards an understanding of the value of a human rights based approach (HRBA). The chapter focuses on the different elements of a HRBA and a CRA and demonstrates why they offer a sound framework for implementing human rights and children's rights. The chapter briefly refers to the emergence of the HRBA, which brought together human rights and development and reviews the literature relating to HRBAs and CRAs. The importance of making explicit connections to the moral and legal basis of the international human rights framework is discussed as well as the importance of empowering rights holders to actively claim their human rights and to hold duty bearers to account to meet their obligations. The chapter acknowledges the strong transformative potential of a HRBA, that is anchored in legal norms but also rooted in an empricisim that draws on evidence from people's experiences of violation of their human rights. The 'principled approach' is given consideration, that argues that any HRBA/CRA should have principles rooted in the international human rights framework and coherently link them to the establishment and delivery, of standards and objectives across the policy, programming and legislative process. The chapter also considers what should be included in a human rights approach to health and the importance of practical guidance for health professionals. Finally, learning from UNICEF and the Scandinavian Aid agencies regarding the challenge of applying a HRBA into institutional practice is made reference to. This chapter further contributes to and makes some conclusions regarding what should be included in a CRA to health services.

\subsection{Human rights and development}

The emergence of a human rights based approach came about because of the coming together of human rights and economic development. In the 1990s it became evident that economic development had failed to address the challenges of poverty and inequality. Theorists such as Sen rejected the traditional economic model of development and placed individuals at the centre of the development journey, arguing 
that respect for human rights and freedoms was critical to economic development. 250 There were a series of world summits in the 1990s where recognition emerged that more was needed than the trickle down of external assistance from the rich 'developed' world to the poorer 'developing' world'. 251252

In 1997, the United Nations Development Programme (UNDP) Secretary General, called for a common understanding to be developed with regards to the mainstreaming of human rights. The UNDP's conceptual basis for a HRBA in 1998 was as follows:

The central goal of development has and will be the promotion of human well being. Given that human rights define and defend human well being, a rights-based approach to development provides both the conceptual and practical framework for the realization of human rights through the development process. ${ }^{253}$

The UNDP Human Development report in 2000 on human rights and development further cemented this evolving approach. ${ }^{254}$ An understanding emerged that holding duty bearers to account and supporting rights holders to claim their human rights could

\footnotetext{
${ }^{250}$ Sen A, Development as Freedom (Alfred A Knopf, New York, 1999) ISBN 0375406190; Darrow, Mac and Tomas, Amparo 'Power, Capture, and Conflict: A Call for Human Rights Accountability in Development Cooperation', Human Rights Quarterly 2005 27; Theis J, Promoting rights based approaches; Experiences and ideas from Asia and the Pacific Bangkok (Save the Children Sweden 2004); Tobin J, 'Understanding a human rights based approach to matters involving children: conceptual foundations and strategic considerations', In Invernizzi A and Williams J (eds), The Human Rights of Children: From Visions to Implementation (Farnham: Ashgate 2011)

${ }^{251} 1986$ United Nations General Assembly adopted the Declaration on the Right to Development; 1993Vienna Declaration and Programme of Action recognising that development and respect for human rights were interdependent; 1995 Copenhagen Summit on Social Development; 1997 Kofi Annan Secretary General of the UN issued a directive that human rights should be mainstreamed into all activities of UN agencies; 2002, approach was endorsed and expanded by Mary Robinson as UN High Commissioner; 1998 UNICEF was the first agency to adopt the human rights based approach, followed by other UN agencies.

${ }^{252}$ Save the Children Sweden Child rights programming: How to apply rights based approaches to programming: A handbook for Save the Children International Alliance Members (Save the Children International 2005) 21

${ }^{253}$ UNDP Section 1 Human Rights and Development: An emerging nexus; human rights and development: the International Framework www.undp.org/rbap/rights/Nexus.htm accessed May 2017

${ }^{254}$ UNDP Human Development Report 2000: Human Rights and Human Development (Oxford University Press. New York 2000)
} 
achieve more success than a narrow focus on development. ${ }^{255}$ Likewise, focussing entirely on human rights obligations and duties would not achieve as much as understanding how these obligations and duties could be actively claimed. ${ }^{256}$ That is empowering rights holders with the capacities to understand their human rights and what resources are required to claim them from the relevant duty bearers. The model of development that had been focused on benevolence and charity, started to focus more on the root causes of poverty and inequality, and to hold development actors and governments accountable for their acts. ${ }^{257}$

In 2003, the United Nations Development Group (UNDG) adopted the 'UN Statement of Common Understanding on Human Rights-Based Approaches to Development Cooperation and Programming'. The purpose behind the Common Understanding was to provide a consistent and coherent definition on a HRBA across all UN agencies, funds and programmes. ${ }^{258}$ The Common Understanding was an attempt at offering some harmonisation of defining what a HRBA should look like and specifically refers to a HRBA to the development cooperation and programming by $U N$ agencies:

1. All programmes of development co-operation, policies and technical assistance should further the realisation of human rights as laid down in the Universal Declaration of Human Rights and other international human rights instruments.

2. Human rights standards contained in, and principles derived from, the Universal Declaration of Human Rights and other international human

\footnotetext{
${ }^{255}$ Nyamu-Musembi C and Cornwall A "What is the "rights-based approach" all about? Perspectives from international development agencies, IDS Working Paper (2004) 234, Brighton: Institute of Developmental Studies

${ }^{256}$ Ibid

${ }^{257}$ Nyamu-Musembi C and Cornwall A "What is the "rights-based approach" all about? Perspectives from international development agencies, IDS Working Paper (2004) 234, Brighton: Institute of Developmental Studies; Uvin P, Human Rights and Development (Kumarian Press 2004); Darrow, Mac and Tomas, Amparo 'Power, Capture, and Conflict: A Call for Human Rights Accountability in Development Cooperation', In Human Rights Quarterly (2005 27) 486-487

${ }^{258}$ UN Development Group, UN Statement of Common Understanding on Human Rights based approaches (UNDG 2003)

https://unsdg.un.org/sites/default/files/6959The Human_Rights Based_Approach to Development Cooperation_Towards_a_Common_Understanding_among_UN.pdf accessed January 2020
} 
rights instruments guide all development cooperation and programming in all sectors and in all phases of the programming process.

3. Development cooperation contributes to the development of the capacities of 'duty-bearers' to meet their obligations and/or of 'rightsholders' to claim their rights. ${ }^{259}$

From this point on, more and more non-governmental agencies (NGOs) adopted HRBA's to their programming work. Save the Children in 2005 reported that:

Bringing the two approaches together, [i.e., Development and human rights] offers the possibility of uniting the best aspects of both approaches, with the 'added value' of the vision, the legal force and the normative framework of the international human rights framework. ${ }^{260}$

The UNDP recognised the importance of human rights to its development work, and human rights were reflected in the Millennium Development Goals, (MDGs) ${ }^{261}$ although Williams argues that some commentators critique that they were not incorporated strongly enough. ${ }^{262}$

The WHO claims that human rights are a core component to their work on health ${ }^{263}$ (critics argue that this was not the case until the 1990s, see chapter 2) they are now clear that, 'promoting and protecting health and respecting, promoting and fulfilling human rights are inextricably linked'. ${ }^{264}$ The WHO Eleventh General Programme of Work (2006-2015) ${ }^{265}$ provided a global health agenda for WHO's Member States, its Secretariat and the international community. This highlighted seven priority areas for

\footnotetext{
${ }^{259}$ Ibid

${ }^{260}$ Save the Children Sweden Child rights programming: How to apply rights based approaches to programming: A handbook for Save the Children International Alliance Members (Save the Children Sweden 2005) 9

${ }^{261}$ UNDP, Human Rights and the Millennium Development Goals (UNDP 2006)

${ }^{262}$ Williams C, 'Editorial: The Post-2015 Development Agenda, Human Rights, Evidence, and OpenAccess Publishing', Health and Human Rights (2013) vol. 15 2, 1-4

${ }^{263}$ WHO website Health Topics http://www.who.int/topics/human rights/en/ accessed $22^{\text {nd }}$ Nov 16

${ }^{264}$ WHO Linkages between health and human rights https://www.who.int/hhr/HHR\%20linkages.pdf accessed January 2020.

${ }^{265}$ WHO, Eleventh General Programme of Work (2006-2015)

https://apps.who.int/iris/bitstream/handle/10665/20611/B117 16-en.pdf?sequence=1\&isAllowed=y accessed January 2020
} 
the international community, including promoting universal coverage, building individual and global health security, promoting health related human rights and gender equality, reducing poverty and its effects on health, tackling the social determinants of health, promoting a healthier environment, building fully functioning and equitable health systems, ensuring an adequate health workforce, harnessing knowledge, science and technology and strengthening governance and leadership. 266 The integration of a HRBA was also specifically addressed in Strategic Objective 7 of the WHO Medium-Term Strategic Plan (MTSP) 2008-2013. ${ }^{267}$ This has been furthered in the Global Strategy for Women, Children and Adolescent Health (2016-2030) which:

envisions a world in which every woman, child and adolescent in every setting realizes their rights to physical and mental health and well-being, has social and economic opportunities, and is able to participate fully in shaping prosperous and sustainable societies. ${ }^{268}$

The human rights focused agenda has also been increasingly supported by NGOs, ${ }^{269}$ international governmental assistance organisations ${ }^{270}$, the $\mathrm{EU}^{271}$ and UN agencies. ${ }^{272}$

\footnotetext{
${ }^{266} \mathrm{Ibid}$

${ }^{267}$ WHO, Medium-Term Strategic Plan (MTSP) 2008-2013

https://apps.who.int/gb/ebwha/pdf files/MTSP2009/MTSP1-en.pdf accessed January 2020

${ }^{268}$ As expressed on webpage at https://www.who.int/life-course/partners/global-strategy/globalstrategy-2016-2030/en/ Every woman, Every Child, The Global Strategy for Women's, Children's and Adolescents' Health, 2016-2030 accessed January 2020

${ }^{269}$ Oxfam, 'Our Commitment to Human Rights', https://www.oxfam.org/en/our-commitment-humanrights accessed January 2020; Care International, 'Accountability and Transparency', https://www.care-international.org/who-we-are-1/accountability-transparency accessed January 2020

${ }^{270}$ SIDA, Human Rights Based Approach at Sida https://www.sida.se/English/partners/methodsmaterials/human-rights-based-approach-at-sida/ accessed January 2020; GTZ German Federal Ministry for Economic Cooperation and Development, Human Rights in German Development Policy - Strategy (BMZ Strategy Paper 4 - 2011); Piron L and Watkins F, DFID Human Rights Review - A Review of How DFID Has Integrated Human Rights Into Its Work (London: Overseas Development Institute, 2004)

${ }^{271}$ Council of the European Union, EU Action Plan on Human Rights and Democracy (Luxembourg 2015)

https://eeas.europa.eu/human_rights/docs/eu_action_plan_on human_rights and democracy_en.pdf accessed January 2020; Joint Statement by the Council and the Representatives of the Governments of the Member States Meeting Within the Council, the European Parliament and the Commission, New European Consensus, 2017/C 210/01, [2017] OJ C210/1

${ }^{272}$ UN Secretary-General MDG Gap Task Force Report 2013, The Global Partnership for Development: The Challenge We Face 2013; UN System Task Team on the Post-2015, UN Development Agenda Towards Freedom from Fear and Want: Human Rights in the Post 2015 Agenda, 2012 Thematic Think Piece by OHCHR; UN General Assembly Report of the Open Working Group of the General Assembly on Sustainable Development Goals, 2014 A/68/970
} 
In the post 2015 development agenda, it is evident that human rights have taken a more prominent role than they did in the MDGs. ${ }^{273}$

\subsection{The value of a HRBA}

What value does a HRBA add to those working to improving the lives of different populations? Nyamu-Musembi et al summarise the value of the approach explaining that human rights put values at the very heart of the policy and development practice:

It is an internationally agreed set of norms backed by international human rights law which provides a stronger basis for citizens to make claims on their states and for holding states to account for their duties to enhance the access of their citizens to the realisation of their rights. ${ }^{274}$

The Office of the High Commissioner on human rights stated that:

Perhaps the most important source of added value in the Human Rights Based Approach is the emphasis it places on the accountability of policy makers and other actors whose actions have an impact on the rights of people. Rights imply duties and duties demand accountability. ${ }^{275}$

Munro also agrees the value of the HRBA is because it provides the moral and legal basis of the universal international human rights framework and if delivered effectively promotes 'accountability, good results and good process. ${ }^{276}$ Whereas needs-based approaches tend to address symptomatic problems of people through providing access to welfare provision, HRBAs address the root causes of human rights violations and empower people, the most deprived and excluded, to participate in achieving their

\footnotetext{
${ }^{273}$ Williams C, 'Editorial: The Post-2015 Development Agenda, Human Rights, Evidence, and OpenAccess Publishing', Health and Human Rights, 2013 vol. 15 2, 1-4

${ }^{274}$ Nyamu-Musembi C and Cornwall A, 'What is the "rights-based approach" all about? Perspectives from international development agencies, IDS Working Paper (2004) 234, Brighton: Institute of Developmental Studies, 1416

${ }^{275}$ Office of the UN High Commission for Human Rights, Draft Guidelines for a Human Rights Approach to Poverty Reduction Strategies, Cited in Nyamu-Musembi C and Cornwall A, 'What is the "rights-based approach" all about? Perspectives from international development agencies, IDS Working Paper (2004) 234, 1417 Brighton: Institute of Developmental Studies, 1417

${ }^{276}$ Munro L A, 'Human Rights Based Approach to Programming: A contradiction in terms,' In (eds) Hickey S and Mitlin D Rights Based Approaches to Development: Exploring the Potentials and the Pitfalls (Kumarian Press 2009 USA) 199
} 
legal entitlements. ${ }^{277}$ People are actively encouraged to claim their human rights from those who have been identified as responsible duty bearers. HRBAs shift the focus of responsibility from the individual to structural inequalities ${ }^{278}$ and promote the equal distribution of resources whereas needs based approaches seek additional resources for services for the vulnerable. ${ }^{279}$ HRBAs recognise both that people are capable human beings and that they have particular needs but rather than starting with generalized assumptions of needs, HRBAs start with agreed declarations of enforceable rights and a commitment to people's participation in achieving these. ${ }^{280}$ 'Needs are met out of charitable intentions, human rights are based on legal obligations'. ${ }^{281}$ As Sen strongly asserts:

\begin{abstract}
A right is something to which I am entitled solely by virtue of being a person. It is that which enables me to live with dignity. Moreover, a right can be enforced before the government and entails an obligation on the part of the government. A need, on the other hand, is an aspiration that can be quite legitimate, but it is not necessarily associated with an obligation on the part of the government to cater to it; satisfaction of a need cannot be enforced. Rights are associated with 'being', whereas needs are associated with 'having'. ${ }^{282}$
\end{abstract}

HRBAs also have a strong transformative potential because they are anchored in legal norms but also rooted in an empiricisim that draws on evidence from the lived

\footnotetext{
${ }^{277}$ Theis J, Promoting rights based approaches - Experiences and Ideas from Asia and the Pacific (Save the Children Sweden 2004)

${ }^{278}$ Pemberton S, Gordon D, Nandy S, Pantazis C, Townsend P, 'Child Rights and Child Poverty: Can the International Framework of Children's Rights Be Used to Improve Child Survival Rates?' PLOS Medicine, Published: October 23, (2007)

${ }^{279}$ Jonsson U, Human Rights Approach to Development Programming (UNICEF 2003; OHCHR Office of the High Commission on Human Rights Human Rights and Poverty Reduction: A conceptual framework (New York: United Nations 2004)

${ }^{280}$ Thomas N, 'Interpreting children's needs: contested assumptions in the provision of welfare'. In Goddard J, McNamee S, James A, James A (eds) The Politics of Childhood: International Perspectives, Contemporary Developments (Palgrave Macmillan 2005)

${ }^{281}$ Nyamu-Musembi C and Cornwall A (2004), "What is the "rights-based approach" all about? Perspectives from international development agencies, IDS Working Paper 234, (Brighton: Institute of Developmental Studies 2, 1417

${ }^{282}$ Sen A, Development as Freedom (Alfred A Knopf, New York 1999) 18
} 
experiences of people. ${ }^{283}$ Piron and Sano reported from their evaluation that a HRBA can be seen as:

providing more analytical rigour; a focus on target groups; power relations; and multi-sectoral activities. It also enables political advocacy and collaborative strategies between Governments and civil society. ${ }^{284}$

So, it not only provides a powerful framework for rights holders to hold duty bearers accountable in the realisation of their human rights, but also a framework for civil society, to hold government to account or to develop collaborative strategies to promote the implementation of human rights.

Darrow et al summarise what human rights bring to development programming:

1. A solid normative basis for values and policy choices that otherwise are more readily negotiable;

2. A predictable framework for action, with the advantages of objectivity, determinacy and the definition of appropriate legal limits;

3. A quintessentially empowering strategy for the achievement of human centred development goals;

4. A ready legal means to secure redress for violations; and

5. A secure basis for accountability not only for the state party concerned but also for a significantly wider range of actors in international development cooperation. ${ }^{285}$

The HRBA therefore provides an internationally accepted accountability framework that all people can use to challenge duty bearers for their violations. The framework when utilised effectively can be incredibly empowering for those who are disempowered, vulnerable or oppressed.

\footnotetext{
${ }^{283}$ Vandenhole W, 'Failures and Successes of Human Rights-Based Approaches to Development: Towards a Change Perspective,' Nordic Journal of Human Rights, (2014) Vol. 32, No. 4, 291-311, 297

${ }^{284}$ Piron L and Sano H (2016) Lessons learned on DANIDA's human rights based approach- An Evaluation (Ministry for Foreign Affairs Denmark/DANIDA 2016)

${ }^{285}$ Darrow, Mac and Tomas, Amparo 'Power, Capture, and Conflict: A Call for Human Rights Accountability in Development Cooperation’, Human Rights Quarterly (2005) 27 486-487
} 


\subsection{Defining the key elements of a HRBA}

The UN Common Understanding outlined the important elements of a HRBA; this section will elaborate further on the elements of a HRBA. Darrow et al comment that it is important not to reduce a HRBA to a simple checklist, instead a minimum list of essential characteristics should be developed around methodologies that can be built up to suit a particular programming context. ${ }^{286}$ Tobin argues that it is all very well to encourage flexibility and supporting application to different contexts but without some streamlining and consistency to what a HRBA looks like in practice how can it be differentiated from any other policy/programming approaches?287 Tobin assesses and critiques the legitimacy of HRBAs and argues that consideration must be given 'to first identifying and then maintaining the principles that underlie this approach'. ${ }^{288}$ Tobin focuses on a 'principles' approach placing attention on how they are identified and derived and their purpose.

A principle as defined by the Oxford Living Dictionary is 'a fundamental truth or proposition that serves as the foundation for a system of belief or behaviour or chain of reasoning.' ${ }^{289}$ In the socio-legal context, Alexy explains that 'principles are norms commanding that something must be realised to the highest degree that is actually and legally possible' and are different to rules which can be seen as definitive commands and do not have clear boundaries. ${ }^{290}$ This is consistent with Sadeleer who sees principles as encouraging the 'underlying values and spirit of the law' to become more central. ${ }^{291}$ The utility of a principled approach may be to shift attention away from formalistic approaches to rights, to a more purposive approach, focussed on what rights are there to achieve. This is what is suggested by Gavrieldes who explains that by focusing more on mainstreaming the principles underlying the UK Human Rights

\footnotetext{
${ }^{286}$ Ibid 482

${ }^{287}$ Tobin J, 'Understanding a human rights based approach to matters involving children: conceptual foundations and strategic considerations' In Invernizzi A and Williams J (eds) The Human Rights of Children: From Visions to Implementation (Farnham: Ashgate 2011)

${ }^{288}$ Ibid 66

${ }^{289}$ Oxford Online Dictionary, https://en.oxforddictionaries.com/definition/us/principle accessed January 2020

${ }^{290}$ Alexy R, 'Rights, Legal Reasoning and Rational discourse', Ratio Juris 51992143 et seq (145)

${ }^{291}$ Sadeleer N, Environmental principles; from political slogans to legal rules (Oxford University Press 2002) 234
} 
Act 1998 and less on its legalistic interpretation, human rights would have been seen to be more relevant by both users and providers of health and social care services. ${ }^{292}$ Darrow et al argue that interpretation of the international legal human rights standards should be in terms of their underlying values and that although these values/principles can be to a certain degree generalisable, one size does not necessarily fit all and there are legitimate variations in national circumstances. ${ }^{293}$

Darrow et al explain that there should not be a false demarcation between principles, values and standards. Human rights principles instead, are the necessary conditions to 'enable the actual enjoyment of human rights through the legislative, policy and practice process. ${ }^{294}$ Such principles help to define human rights objectives, guiding the formulation of policies, laws, budgets and strategies and directing the establishment of corresponding benchmarks or indicators. Human rights principles encourage the incorporation of a HRBA through all stages of the policy, legislative and budgetary process. ${ }^{295}$

The UN Common Understanding is explicit that human rights principles and standards should be linked to and derived from the normative framework of the international human rights instruments. Darrow et al agree that they should be drawn from the international human rights framework and that the:

dominant factors governing the selection of principles should be their functionality - the extent to which they gear the development process more directly towards the realisation of human rights and their practicality, that is to say the extent to which they can provide development practitioners with clear and effective guidance. ${ }^{296}$

\footnotetext{
${ }^{292}$ Gavrieldes T, 'Ethnicity and Inequalities in Health and Social Care' 4.1 (2011) 28-37

${ }^{293}$ Darrow, Mac and Tomas, Amparo 'Power, Capture, and Conflict: A Call for Human Rights Accountability in Development Cooperation', Human Rights Quarterly (2005) 27, 483

${ }^{294}$ Ibid

${ }^{295}$ Ibid 498

${ }^{296}$ Ibid 501
} 
They argue that the list does not need to purport to be comprehensive, it is also not a one size fits all formula, rather it is a framework for understanding how to 'minimise the impacts of discrimination and disempowerment.' 297

Vandenhole conducted research into HRBAs and concludes there is not a universal definition of HRBA. ${ }^{298}$ There are common characteristics such as a focus on process as well as outcomes, that is:

whereas HRBADs are operationally directed to promote and protect human rights as envisaged outcomes, their normative grounding in human rights standards also draws attention to the process through which the outcomes are achieved. 299

In research undertaken by Broberg and Sano they agree there is no one single approach to HRBA and prefer to refer to HRBAs in the plural. ${ }^{300}$ Broberg and Sano also argue that the UN Common Understanding although 'widely quoted is rarely implemented' and prefer to refer to the definition of a HRBA in the OHCHR FAQs:
A human rights-based approach is a conceptual framework for the process of human development that is normatively based on international human rights standards and operationally directed to promoting and protecting human rights. ${ }^{301}$

Broberg and Sano suggest that although this is a 'general definition of a HRBA to development ...... it is simultaneously important to emphasise that no common approach exists as to its implementation.' ${ }^{302}$

\footnotetext{
${ }^{297}$ Ibid 480

${ }^{298}$ Vandenhole W, 'Failures and Successes of Human Rights-Based Approaches to Development: Towards a Change Perspective', Nordic Journal of Human Rights, (2014) Vol. 32, No. 4, 291-311 ${ }^{299}$ Vandenhole W, 'Failures and Successes of Human Rights-Based Approaches to Development: Towards a Change Perspective', Nordic Journal of Human Rights (2014) Vol. 32, No. 4, 293 ${ }^{300}$ Broberg M \& Sano H, 'Strengths and weaknesses in a human rights-based approach to international development - an analysis of a rights-based approach to development assistance based on practical experiences', The International Journal of Human Rights, 2018 22:5, 664-680

${ }^{301}$ Office of the United Nations High Commissioner for Human Rights, Frequently Asked Questions on a Human Rights-Based Approach to Development Cooperation, 15

${ }^{302}$ Broberg M and Sano H, 'Strengths and weaknesses in a human rights-based approach to international development - an analysis of a rights-based approach to development assistance based on practical experiences', The International Journal of Human Rights (2018) 22:5, 669
} 
There is some consistency in the interpretation of which principles should be used from the international human rights framework. Lang et al comment that the UN commonly refers to six standard principles that are essential to human rights based approaches. These are:

- universality and inalienability,

- indivisibility, interdependence and interrelatedness,

- equality and non-discrimination,

- participation and inclusion, and

- accountability and the rule of law. ${ }^{303}$

These principles are fairly consistent across UN bodies and also large NGOs. The $\mathrm{OHCHR}$ has increasingly emphasised the importance of implementing a HRBA into programmes that assist people more effectively to understand how to claim their human rights. ${ }^{304}$ It has been made explicit in addressing inequalities in the post 2015 agenda that the:

Goals and the strategies to pursue them should be rooted in human rights principles and standards, which in turn should influence the identification of specific development outcomes that drive the rights for all. ${ }^{305}$

Human rights principles are often referred to by a range of anacronyms, e.g. PANEL, i.e. Participation, Accountability, Non-discrimination, Empowerment and Linkage to human rights norms, or alternatively PLANET, the T referring to Transparency ${ }^{306}$ and PANEN, the final ' $N$ ' being described as 'normativity', another way of describing

\footnotetext{
${ }^{303}$ Lang R, Kett M, Groce N, Trani J F, 'Implementing the United Nations Convention on the rights of persons with disabilities: principles, implications, practice and limitations', Alter Volume 5, Issue 3, July-September 2011, 206-220

${ }^{304}$ OHCHR Scenario and Talking Points for High Commissioner on Human Rights Event to Launch the Technical Guidance on the Application of a Human Rights Based Approach to the Implementation of Policies 2012; Pillay N, UN High Commissioner for Human Rights Human Rights in the Post-2015 Agenda 2013 Open letter to all Permanent Missions in New York and Geneva ${ }^{305}$ Cited in Williams, C, Editorial: The Post-2015 Development Agenda, Human Rights, Evidence, and Open-Access Publishing, Health and Human Rights, 2013, vol. 152 see original source, UN System Task Team on the Post 2015 UN Development Agenda, Towards freedom from fear and want: Human rights in the post 2015 agenda- Thematic think piece (2012)

${ }^{306}$ SIDA, Human Rights Based Approach at Sida https://www.sida.se/English/partners/methodsmaterials/human-rights-based-approach-at-sida/ accessed January 2020
} 
'linkage to human rights norms. ${ }^{307}$ All these principles can be linked to specific human rights, apart from some do question 'Empowerment' as having any legal equivalent. ${ }^{308}$

In the UK domestic context for example, PANEL has been utilised by a number of statutory agencies to assist in applying human rights approaches as well as application of the Human Rights Act 1998. For example, the Scottish Human Rights Commission, the NHS in Scotland, the Health and Social Care Alliance in Scotland, uses PANEL ${ }^{309}$ other agencies such as NHS England ${ }^{310}$ and the Care Commission ${ }^{311}$, include also the principle of 'Embedding' or 'Mainstreaming' human rights at the heart of services as their first principle to be applied.

Turning internationally for example, the Swedish International Cooperation Agency (SIDA) uses the anacronym PLANET and the Danish Institute for Human Rights (DANIDA) uses similar principles but an alternative anacronym of APE i.e., Accountability and the rule of law, Participation and Inclusion and Equality and Nondiscrimination and a focus on vulnerable groups. What is clear is there is not one single HRBA but a range of organisations referring to similar principles when defining their HRBA.

\footnotetext{
${ }^{307}$ Vandenhole W, 'Failures and Successes of Human Rights-Based Approaches to Development: Towards a Change Perspective', Nordic Journal of Human Rights, (2014) Vol. 32

${ }^{308}$ Ibid 294

${ }^{309}$ Scotland's National Action Plan on Human Rights: Human Rights in Health and Social Care, putting it into practice produced by the Scottish Human Rights Commission, NHS in Scotland, the Health and Social Care Alliance in Scotland http://www.scottishhumanrights.com/media/1408/shrc_case_studies_report.pdf accessed January 2018

${ }^{310}$ Department of Health, Human Rights a Framework for local Action (Department of Health 2008) http://webarchive.nationalarchives.gov.uk/20130124044024/http://www.dh.gov.uk/prod consum dh/ groups/dh_digitalassets/@dh/@en/documents/digitalasset/dh_088972.pdf accessed February 2017

${ }^{311}$ Care Quality Commission, Regulations for Health and Social Care (2014) https://www.cqc.org.uk/sites/default/files/20150416 our human rights approach.pdf accessed January 2020
} 


\subsection{HRBA to health}

There is also no universally agreed definition of a HRBA to health. ${ }^{312}$ However, the essential elements to a HRBA to health were identified in 2010, by Gruskin et $a^{313}$, who carried out a detailed review to determine the common elements of a HRBA in the context of health. Their resulting framework includes a list of principles and standards to translate a HRBA to health into practice. These include the principles of Participation, Non-discrimination, Transparency and Accountability, all of which are common elements of human rights treaties and not distinctive to the right to health and have synergy with the principles referred to in the approaches above. They also referred to the importance of the AAAQ Framework (Availability, Accessibility, Acceptability and Quality, see in Chapter 2 in section on the UNCRC and the Child's Right to Health), primary and preventative health care and the social determinants of health, progressive realization, maximum extent of available resources and international assistance and cooperation. These are all part of the ICESCR's and UNCRC's general human rights obligations referred to in Chapter 2. Gruskin et al argue that if the right to health is to be appropriately applied, consideration must be given to these essential elements. ${ }^{314}$

The human rights approach to health therefore adopts a principled approach, drawing on common principles from international human rights treaties like other HRBAs, but in addition, draws on specific elements directly relevant to the right to health. Hunt argues that there must be appropriate interpretation of the international treaties and the distinctive elements of the right to health should be incorporated into any HRBA to health. ${ }^{315} \mathrm{He}$ cautions that the right to health must be central to a HRBA so that the social, economic and cultural rights are not marginalized, and in particular emphasizes that any approach must give appropriate consideration to the dynamics of poverty and inequality in and across societies. ${ }^{316}$

\footnotetext{
${ }^{312}$ Hunt P, 'Interpreting the International Right to Health in a Human Rights-Based Approach to Health', Health and Human Rights Journal (2016) Dec 18(2)

${ }^{313}$ Gruskin S, Bogecho D, and Ferguson L, 'Rights-based approaches to health policies and programs: Articulations, ambiguities, and assessment,' Journal of Public Health Policy 31/2 (2010), 129-145

${ }^{314}$ Ibid

${ }^{315}$ Hunt P, 'Interpreting the International Right to Health in a Human Rights-Based Approach to Health', Health and Human Rights Journal (2016) Dec 18(2)

${ }^{316}$ Ibid
} 
The OHCHR also comments that the reason that the HRBA is so compelling, is that it has the potential to empower those who experience structural inequalities. ${ }^{317}$ As is now widely recognised, effective strategies to reduce inequality, including health inequality ${ }^{318}$, are not possible without the empowerment of those facing such inequalities. A HRBA to reducing health inequality therefore should emphasise the importance of empowerment.

Once the concept of empowerment is introduced into the context of policymaking, the rationale of eliminating health inequality no longer derives merely from the fact that the people facing health inequalities have needs, but also from the fact that they have human rights-entitlements that give rise to legal obligations on the part of others. The human rights perspective draws attention to the fact that health inequalities signify the non-realization of human rights, so that the adoption of a public health strategy that aims to reduce health inequality is not just desirable but obligatory for States which have ratified international human rights instruments. ${ }^{319}$

Hunt explains 'that duty-bearers are accountable for their right-to-health obligations, including optimal progressivity, as they are for their obligations, for example, under the right to a fair trial.' ${ }^{320}$ All health professionals, argues London, should be aware of what would have been available if the government or public body had taken sufficient legislative, financial, and administrative measures to ensure the realisation of the right to health and be able to provide information that may support a patient to advocate for better access to their human right. ${ }^{321}$

Health care, argues London, should be acknowledged as a human right, instead of a service delivery issue 'requiring technical inputs to reach the best evidence-based

\footnotetext{
${ }^{317} \mathrm{OHCHR}$, Principles and Guidelines for a human rights based approach to poverty reduction (HR/PUB/06/12 2004)

${ }^{318}$ Black D, Inequalities in Health (London: Penguin; 1980) Acheson D Independent Inquiry into Inequalities in Health (London: The Stationery Office; 1998); Marmot M and Wilkinson RG (eds) Social Determinants of Health (Oxford: Oxford University Press; 1999)

${ }^{319}$ Text in this paragraph has been adapted from the OHCHR Principles and Guidelines for a human rights based approach to poverty reduction (HR/PUB/06/12 2004) para 19 to make it pertinent to health inequalities

${ }^{320}$ Hunt P, 'Interpreting the International Right to Health in a Human Rights-Based Approach to Health', Health and Human Rights Journal (2016) Dec 18(2)

${ }^{321}$ London L, 'What is a human rights based approach to health and does it matter?' Health and Human rights (2008) Vol. 10, no. 1, 69
} 
decisions' ${ }^{322}$ She suggests that this represents the current global discourse of public health, which although focussed on achieving social good and social justice, relieves duty bearers of the burden of upholding the right to health and the obligation to progressively realise socio-economic rights. Evidence based decisions are of course important, but they should be part of a framework that recognises health as a human right not merely as a service. ${ }^{323}$

This reinforces the earlier discussion that the power of an effective human rights approach is that it simultaneously anchors itself in enforceable legal standards and also empiricism (i.e., evidence from peoples' lived experiences). London says that this does not need to rely on individual claims against individual health professionals, but instead, she refers to patient rights mechanisms, such as rights charters which can support collective 'claims of users and potential users of health services into claims against health systems'. ${ }^{324}$ Rights mechanisms become integral to health care professionals' practice and a common language and consensus between health care providers, professional managers and service users is generated, regarding human rights standards and objectives for quality health care..$^{325}$

London suggests that even though there are a plethora of international statements, guidelines and ethic codes for health professionals issued by professional bodies, these ethical codes need to integrate stronger human rights language if professional self-regulation is to be more effective. ${ }^{326}$ Hunt also asserts that governance, leadership and training is pivotal in helping professionals to understand their human rights obligations and how to mainstream a HRBA to health in practice. As Hunt claims it is:

unrealistic to expect health policy makers or practitioners to read either a treaty provision or its corresponding general comment and then grasp how

\footnotetext{
${ }^{322}$ Ibid

${ }^{323}$ Ibid 71

${ }^{324}$ Ibid

${ }^{325} \mathrm{Ibid}$

${ }^{326} \mathrm{Ibid}$
} 
they are to operationalise the right to health. More detailed, specific and practical human rights guidance is essential. ${ }^{327}$

Accountability also requires effective monitoring of human rights standards as well as effective remedies where it is shown that organisations fail to meet these standards. Monitoring requires the collection of appropriate information and data, with all organisations being transparent and consistently providing reasons for their decisions and actions. As the WHO and OHCHR advise, there is a necessity to seek to understand each health context, asking key questions:

1. What is happening, where and who is more affected? (assessment) For every health challenge, identify the inter-related human rights standards and the groups suffering from a greater denial of rights.

2. Why are these problems occurring? (causal analysis) Identify the underlying and root causes of exclusion, discrimination and inequality.

3. Who has the obligation to do something about it? (role analysis) Identify individual and institutional duty-bearers and their corresponding obligations.

4. What capacities are needed for those affected, and those with a duty, to take action? (capacity analysis) Identify the skills, abilities, resources, responsibilities, authority and motivation needed by those affected to claim their rights and those obliged to fulfil the right. ${ }^{328}$

These elements of a HRBA to health are reinforced in a short, simple and accessible guide to A Human Rights-Based Approach to Health written by WHO and OHCHR. ${ }^{329}$ This guide presents helpful advice to health policy makers and practitioners when applying a HRBA to health in practice. The next section will focus more specifically on conceptualizing a CRA.

\footnotetext{
${ }^{327}$ Hunt P, 'Interpreting the International Right to Health in a Human Rights-Based Approach to Health', Health and Human Rights Journal 2016 Dec 18 (2)

${ }^{328} \mathrm{WHO}$ and $\mathrm{OHCHR}$, A human rights-based approach to health

https://www.who.int/hhr/news/hrba to health2.pdf accessed February 20172020

${ }^{329}$ Ibid
} 


\subsection{Conceptualising a CRA}

UNICEF and Save the Children International, two of the largest agencies working on issues concerning children claim that human rights underpin all the work that they undertake with children. Tobin critiques UNICEF's approach for not providing any 'cogent conceptual analysis that could generate an internally consistent coherent understanding of a rights-based approach' and agrees with Alston in his critique of the UN Common Understanding for being too 'abstract, untargeted and untested'. ${ }^{330}$ Save the Children also could offer a clearer conceptual analysis of the foundation of their children's rights based approach. ${ }^{331}$ Other lists of principles coming from the UN could also be critiqued for not providing a clear enough explanation of the foundation of their human rights principles. Tobin in his interpretation of principles to be applied to a HRBA to children explains he is aiming to provide an underlying rationale or conceptual framework that seeks to minimise the potential for subjective interpretations and approaches that instead fit organisational agendas. He argues that there should be a consistent and coherent conceptual framework. ${ }^{332}$

Tobin comments that it is important to be clear as to which human rights framework the approach is referring to, i.e., domestic legislation, regional legislation or international human rights treaties. He explains that children are the beneficiaries of human rights as articulated under all the international human rights treaties by virtue of their status as human beings. ${ }^{333}$ The UNCRC represents the most globally ratified international treaty that "has become the accepted international standard against which to measure legislation and policies affecting children'334 and specifically

\footnotetext{
${ }^{330}$ Tobin J, 'Understanding a human rights based approach to matters involving children: conceptual foundations and strategic considerations,' In Invernizzi A and Williams J (eds) The Human Rights of Children: From Visions to Implementation (Farnham: Ashgate 2011) 64 Tobin refers to Alston's 2005 critique.

${ }^{331}$ Save the Children Sweden Child rights programming: How to apply rights based approaches to programming: A handbook for Save the Children International Alliance Members (Save the Children Sweden 2005) 21

${ }^{332}$ Tobin J, 'Understanding a human rights based approach to matters involving children: conceptual foundations and strategic considerations' In Invernizzi A and Williams J (eds) The Human Rights of Children: From Visions to Implementation (Farnham: Ashgate 2011)

${ }^{333}$ Ibid 67

${ }^{334}$ Sachs J, M v The State Case CCT 53/06 (26 September 2007) para 16
} 
designed to realise the human rights of children. ${ }^{335}$ Tobin draws his principles from the UNCRC and other international human rights treaties.

He defines his principles as outlined below:

- Core principle: human rights standards should be integrated into all planned action, including legislation, policies or programs. ${ }^{336}$

- General express principles: those overarching principles that are specifically included within generic international treaties. ${ }^{337}$

- Specific express principles: being those derived from the treaty that aim to protect the rights of a specific group such as children, e.g., UNCRC. ${ }^{338}$

- Implied principles: those that are not expressly included in the treaties but instead represent the fundamental values upon which the international human rights framework is based. ${ }^{339}$

Below is a table (Table 1) which is a synopsis of the conceptual framework Tobin describes in more detail in his 2011 contribution, 'Understanding a Human Rights Based Approach to Matters Involving Children: Conceptual Foundations and Strategic Considerations. 340 This table helps to explain the principles that Tobin thinks are essential to a CRA what type of principle they are, a short description explaining what the principle means and which international treaty they are linked to.

\footnotetext{
${ }^{335}$ Tobin J, 'Understanding a human rights based approach to matters involving children: conceptual foundations and strategic considerations', In Invernizzi A and Williams J (eds) The Human Rights of Children: From Visions to Implementation (Farnham: Ashgate 2011) 68

${ }^{336}$ Ibid 66-67

${ }^{337}$ Ibid $68-72$

${ }^{338}$ Ibid 71-72

${ }^{339}$ Ibid 73-75

${ }^{340}$ Ibid 61-98
} 
TABLE 1: Tobin's principles of a CRA and how they are determined

\begin{tabular}{|c|c|c|c|}
\hline Principle & $\begin{array}{l}\text { Type of } \\
\text { principle }\end{array}$ & Short description & $\begin{array}{l}\text { Link to international } \\
\text { human rights } \\
\text { treaties/UN } \\
\text { institutions }\end{array}$ \\
\hline $\begin{array}{l}\text { Mainstreaming } \\
\text { human rights }\end{array}$ & Core principle & $\begin{array}{l}\text { The process of } \\
\text { assessing the human } \\
\text { rights implications of } \\
\text { any planned action } \\
\text { (legislation, policy, } \\
\text { programs) }\end{array}$ & $\begin{array}{l}\text { - See UN General } \\
\text { Secretary } 1997, \\
\text { paras } 78-9\end{array}$ \\
\hline Accountability & $\begin{array}{l}\text { General } \\
\text { express } \\
\text { principle }\end{array}$ & $\begin{array}{l}\text { Recognition of a } \\
\text { human right entails } \\
\text { the imposition of a } \\
\text { duty on the state, for } \\
\text { which it is } \\
\text { accountable to protect } \\
\text { and secure that right. }\end{array}$ & $\begin{array}{l}\text { - Article } 4 \text { of the } \\
\text { UNCRC } \\
\text { - Article } 18(1) \text { of } \\
\text { the UNCRC } \\
\text { Parents have the } \\
\text { primary } \\
\text { responsibility } \\
\text { Article } 27 \text { (1) of } \\
\text { the UNCRC } \\
\text { States must } \\
\text { support parents in } \\
\text { the delivery of this } \\
\text { responsibility } \\
\text { Accountability is } \\
\text { key component to } \\
\text { all international } \\
\text { human rights } \\
\text { treaties }\end{array}$ \\
\hline
\end{tabular}




\begin{tabular}{|c|c|c|c|}
\hline $\begin{array}{l}\text { Non- } \\
\text { discrimination } \\
\text { and equality }\end{array}$ & $\begin{array}{l}\text { General and } \\
\text { specific } \\
\text { express and } \\
\text { specific } \\
\text { principle }\end{array}$ & $\begin{array}{l}\text { Prohibition of } \\
\text { discrimination on any } \\
\text { grounds and equality } \\
\text { before the law }\end{array}$ & $\begin{array}{l}\text { - Article } 2 \text { of the } \\
\text { UNCRC } \\
\text { - Articles } 2 \text { and } 26 \\
\text { of the ICCPR }\end{array}$ \\
\hline Participation & $\begin{array}{l}\text { General and } \\
\text { specific } \\
\text { express } \\
\text { principle }\end{array}$ & $\begin{array}{l}\text { Every individual has } \\
\text { the right and } \\
\text { opportunity to take } \\
\text { part in the conduct of } \\
\text { public affairs directly } \\
\text { or through freely } \\
\text { chosen } \\
\text { representatives. } \\
\text { For children right to } \\
\text { be heard is slightly } \\
\text { modified and his/her } \\
\text { views are to be } \\
\text { determined in the light } \\
\text { of his/her age or } \\
\text { maturity }\end{array}$ & $\begin{array}{l}\text { - Article } 25 \text { of the } \\
\text { ICCPR } \\
\text { complimented by } \\
\text { Articles } 19,22 \\
\text { - Articles } 12 \text { of the } \\
\text { UNCRC } \\
\text { complimented by } \\
\text { Articles } 13,15,\end{array}$ \\
\hline $\begin{array}{l}\text { Best interests of } \\
\text { the child }\end{array}$ & $\begin{array}{l}\text { Specific } \\
\text { express } \\
\text { principle }\end{array}$ & $\begin{array}{l}\text { Best interests of the } \\
\text { child must be } \\
\text { considered in all } \\
\text { decisions and actions } \\
\text { affecting children }\end{array}$ & $\begin{array}{l}\text { - Article } 3 \text { of the } \\
\text { UNCRC }\end{array}$ \\
\hline $\begin{array}{l}\text { Survival and } \\
\text { development }\end{array}$ & $\begin{array}{l}\text { Specific } \\
\text { express } \\
\text { principle }\end{array}$ & $\begin{array}{l}\text { All children have the } \\
\text { right to survive and }\end{array}$ & $\begin{array}{l}\text { - Article } 6 \text { of the } \\
\text { UNCRC }\end{array}$ \\
\hline
\end{tabular}




\begin{tabular}{|c|c|c|c|}
\hline & & $\begin{array}{l}\text { develop to their full } \\
\text { potential }\end{array}$ & \\
\hline Due deference & $\begin{array}{l}\text { Specific } \\
\text { express } \\
\text { principle }\end{array}$ & $\begin{array}{l}\text { Requirement to } \\
\text { respect parents and } \\
\text { guardians in the } \\
\text { exercise of their } \\
\text { responsibilities for the } \\
\text { care of the child. }\end{array}$ & $\begin{array}{l}\text { - Article } 5 \text { of the } \\
\text { UNCRC }\end{array}$ \\
\hline $\begin{array}{l}\text { Evolving } \\
\text { capacities }\end{array}$ & $\begin{array}{l}\text { Specific } \\
\text { express } \\
\text { principle }\end{array}$ & $\begin{array}{l}\text { Children's capacity } \\
\text { evolves with their age } \\
\text { and maturity }\end{array}$ & $\begin{array}{l}\text { - Article } 5 \text { of the } \\
\text { UNCRC }\end{array}$ \\
\hline Universal dignity & $\begin{array}{l}\text { Implied } \\
\text { principle }\end{array}$ & $\begin{array}{l}\text { All human beings are } \\
\text { born free and equal in } \\
\text { dignity and rights }\end{array}$ & $\begin{array}{l}\text { - Article } 1 \text { of the } \\
\text { UDHR } \\
\text { - Preamble to the } \\
\text { UNCRC }\end{array}$ \\
\hline $\begin{array}{l}\text { Interdependence } \\
\text { and indivisibility }\end{array}$ & $\begin{array}{l}\text { Implied } \\
\text { principle }\end{array}$ & $\begin{array}{l}\text { Realisation of one } \\
\text { right cannot be } \\
\text { divorced from the } \\
\text { realisation of other } \\
\text { rights. It affirms the } \\
\text { equal status of all } \\
\text { human rights (civil } \\
\text { and political and } \\
\text { social, economic and } \\
\text { cultural) and the need } \\
\text { to adopt a holistic or }\end{array}$ & $\begin{array}{l}\text { Vienna } \\
\text { Declaration and } \\
\text { Programme of } \\
\text { Action adopted by } \\
\text { the World } \\
\text { Conference on } \\
\text { Human Rights } \\
1993 .\end{array}$ \\
\hline
\end{tabular}




\begin{tabular}{|l|l|l|l|}
\hline & & $\begin{array}{l}\text { whole of child } \\
\text { response. }\end{array}$ & \\
\hline $\begin{array}{l}\text { Cultural } \\
\text { sensitivity }\end{array}$ & $\begin{array}{l}\text { Implied } \\
\text { principle }\end{array}$ & $\begin{array}{l}\text { Due account of the } \\
\text { importance of the } \\
\text { traditions and cultural } \\
\text { values of each people } \\
\text { for the protection of } \\
\text { their harmonious } \\
\text { development and the } \\
\text { right of children to } \\
\text { enjoy their own } \\
\text { culture. }\end{array}$ & $\begin{array}{l}\text { UNCRC } \\
\text { UNCRC }\end{array}$ \\
\hline
\end{tabular}

Tobin's conceptual framework is useful as it provides an analytical structure around which a CRA can be constructed. Its benefits are that it recommends that any approach should make clear what are the principles that are being used, for what reason and where they are derived from. This breaks ground from all other descriptions of CRAs that do not provide such conceptual clarity. However, it is important to acknowledge that his choices of the principles are not objective, but indeed his own subjective interpretation of what should be drawn from the international human rights framework. Darrow et al argue that although the principles should be explicitly connected to the international human rights framework, they need to be functional, and considered applicable to the context in which they are being chosen to progress and realise human rights. Therefore, the choice of the principles could be changed according to the context in question and must link seamlessly to standards and objectives.

\subsection{Organisational learning regarding implementing human rights approaches}

UNICEF, as an international agency working for the benefit of children offers useful learning with regards to the challenges of implementing a HRBA to its programme. Although it has experienced some challenges to implementing a HRBA and has been 
critiqued by Tobin for not providing sufficient conceptual clarity to its foundations, it is regarded as being one of the more successful applications. ${ }^{341}$ Vandenhole claims that UNICEF:

evolved from a technical organisation with a focus on service provision to one that uses children's human rights as codified in the Convention on the Rights of the Child (CRC) in all its programming. ${ }^{342}$

Instead of just adding children's rights to its operational agenda it sought to transform the organisation as a whole. However, in a global evaluation of the application of HRBA to UNICEF programming in 2012, some challenges were identified, these were: 343

- Staff's limited understanding of HRBA.

- Definition of roles and confusion across disciplines.

- Confusion in understanding the difference between equity approaches and HRBA.

- Human rights being located within the Division on Policy and Practice rather than also in the Programming Division.

- Lack of quality guidance regarding sector specific application of the HRBA.

- Human resources-management practices that did not support competency in HRBA.

- Limited accountability for HRBA.

- HRBA not sufficiently included in performance reviews.

- Insufficient support from senior management.

- Limited systematic reporting on HRBA.

\footnotetext{
${ }^{341}$ Vandenhole W, 'Failures and Successes of Human Rights-Based Approaches to Development: Towards a Change Perspective', Nordic Journal of Human Rights (2014) Vol. 32299

${ }^{342}$ Ibid

${ }^{343}$ Vandenhole W, 'Failures and Successes of Human Rights-Based Approaches to Development: Towards a Change Perspective', Nordic Journal of Human Rights (2014) Vol. 32; UNICEF, 'Global Evaluation of the Application of the Human Rights-Based Approach to UNICEF Programming'. Final Report - Volume I" (UNICEF, 2012), www.unicef.org/policyanalysis/ rights/files/UNICEF_HRBAP_Final_Report_Vol_I_11June_copy-edited_translated.pdf accessed March 2020
} 
- The tension concerning whether the prioritisation of human rights in terms of programming is permissible.

- The tension between short term results focused change or longer-term change focused on human rights goals.

Interestingly in terms of applying the PANEL principles, UNICEF was regarded as strong on incorporating the 'normativity' principle, however a mixed response was reported for the application of the participation and accountability principles and weak on non-discrimination. ${ }^{344}$ In general, the preparatory phase was viewed as strong i.e., the integration of explicit human rights language, but less successful on the implementation, monitoring and evaluation phase. ${ }^{345}$ This was also one of the lessons learned from DANIDA's HRBA that their approach was stronger at the design stage. ${ }^{346}$ The key drivers for UNICEF's change were understood to be committed senior leadership and staff who truly believed the value of a HRBA to their work and internalised and successfully applied it. ${ }^{347}$ In the evaluation of DANIDA they reported the need for a core staff resource and a designated policy lead, to lead on the implementation of a HRBA, in addition more technical and knowledge management support. ${ }^{348}$ They also reported a need for better monitoring and evaluation that tracks the progress of the implementation of human rights principles and standards. ${ }^{349}$

In research undertaken by Broberg and Sano, they suggest that there is a consistent focus on the principles of participation and non-discrimination, but less explicit focus on the principle of accountability. ${ }^{350}$ They argue that interpretation of the HRBA depends on the political, cultural and institutional context, as well as the actors

\footnotetext{
${ }^{344}$ Vandenhole W, 'Failures and Successes of Human Rights-Based Approaches to Development: Towards a Change Perspective', Nordic Journal of Human Rights (2014) Vol. 32

${ }^{345}$ Ibid

${ }^{346}$ Piron L H and Sano H O 'Lessons learned on DANIDA's human rights based approach- An Evaluation' (Ministry for Foreign Affairs Denmark/DANIDA 2016)

${ }^{347}$ Vandenhole W, 'Failures and Successes of Human Rights-Based Approaches to Development: Towards a Change Perspective' Nordic Journal of Human Rights, 2014 Vol. 32

${ }^{348}$ Piron L H and Sano H O, Lessons learned on DANIDA's human rights based approach- An Evaluation (Ministry for Foreign Affairs Denmark/DANIDA 2016)10

${ }^{349}$ Ibid 11

${ }^{350}$ Broberg M \& Sano H 'Strengths and weaknesses in a human rights-based approach to international development - an analysis of a rights-based approach to development assistance based on practical experiences', The International Journal of Human Rights, 2018 22:5, 664-680
} 
involved, e.g., the rights holders, duty bearers. This again reinforces the variability in interpreting and applying a HRBA in practice. ${ }^{351}$

In reporting on NORAD and SIDA's application of a HRBA to children (two Scandinavian Aid Agencies) Tostensen et al summarise succinctly the challenge of adopting a HRBA children:

Mainstreaming is a very ambitious approach indeed. Its underlying rationale is that certain policy issues are of such paramount importance that they need to inform all undertakings. In principle, mainstreaming requires the entire organisation to be capable of implementing it, e.g., the requisite knowledge and practical skills to infuse every intervention with a child rights perspective. At that, the endeavour needs to be continuous to be effective, not a one-off exercise. ${ }^{352}$

This section has introduced the challenge of mainstreaming children's rights into organisations and services. It will be a key theme that runs throughout this thesis and will be discussed in more detail in the next chapter.

\subsection{Conclusion}

The above analysis of the literature concerning HRBAs demonstrates a principled approach rooted in the international human rights framework that coherently links to the establishment and delivery, of standards and objectives across the policy, programming and legislative process is the best approach to pursue. In a review of the literature regarding HRBAs to health, principles were also regarded as the best model but with a specific focus on the right to health. This includes the application of the $A A A Q$ framework, progressive realization and the maximum extent of available resources, promotion of primary and preventative health care and a clear focus on the social determinants of health.

\footnotetext{
${ }^{351} \mathrm{Ibid}$

352 Tostensen A, Stokke H, Trygged S and Halvorsen K, Supporting Child Rights. Synthesis of Lessons Learned in Four Countries (SIDA 2011), 96 www.cmi.no/publications/file/3947-supportingchildrights.pdf accessed January 2020
} 
Access to health care must be understood to be a human right and not solely a service delivery issue. There must be clear mechanisms of accountability established for enforcing the right to health and there must be consistent monitoring of how human rights are being implemented as well as addressing the root causes of why they might be, being violated. With regards to accountability, an explicit connection to the international human rights treaties should be made, as well as holding duty bearers to account. Of critical importance to implementing an effective human rights approach to health is making health service users aware of their human rights and empowering them to be able to claim them.

Tobin's conceptual framework was also examined that clearly links principles to the international human rights treaty system and is one that needs to be considered in developing the framework for a CRA to health services. However, like Darrow et al, the principles, although explicitly linked to the international human rights framework, are not necessarily a one size fits all and should be made specific and relevant to the context they are applied to. This means that when considering a CRA for the health services in the Welsh context, the most relevant principles should be selected for that environment, but also, as Darrow et al recommend a seamless link to the relevant standards and objectives to support their implementation.

Finally, learning from UNICEF and the Scandinavian Aid agencies, demonstrates that there are considerable challenges regarding the applying of any HRBA in practice, and that these should be taken into consideration when introducing a HRBA into any organisation. The next chapter further considers the challenges to implementing children's right to health in practice. 


\section{CHAPTER 4 RESEARCH INTO IMPLEMENTATION OF CHILDREN'S RIGHT TO HEALTH IN PRACTICE}

\subsection{Introduction}

A review of predominantly UK and European research on the subject of the implementation of children's right to health in practice identifies a number of key themes that highlight areas for improvement if the child's right to health and health care are to be realised. The themes that emerged consistently are: the need for better mainstreaming of a children's rights approach to health, human rights in health care and training of health professionals; better recognition of children's right to be heard in clinical decision making; the monitoring and evaluation of services and complaints systems; children experiencing challenges in accessing health care services; and discrimination towards children in health service delivery. This chapter explores these themes in detail.

\subsection{Mainstreaming a CRA to health}

With regards to mainstreaming a CRA to health, human rights are being mainstreamed into health care systems, and many countries internationally are adopting what is referred to as the child friendly approach to health care. The World Health Organisation is also integrating a human rights approach into its child and maternal programmes of health and UNICEF is committed to a HRBA in the delivery of its programme on child health. All of these approaches echo what is included in the UN Committee's General Comment No.15 on health and are discussed briefly below.

\subsubsection{WHO and Office for the High Commissioner on Human Rights: HRBA to Women's, Adolescents and Children's Health}

The High-Level Working Group on Health and Human Rights of Women, Children and Adolescents was established in May 2016 by the WHO and the OHCHR:

to secure political support, both nationally and internationally, for the implementation of the human rights-related measures required by the 
Global Strategy for Women's, Children's and Adolescents' Health (20162030). ${ }^{353}$

The Strategy has three main objectives:

1. Survive: End preventable mortality.

2. Thrive: Enhance health and well-being.

3. Transform: Expand enabling environments.

Efforts to achieve progress on these objectives are interwoven with trying to achieve progress on the Global Sustainable Development Goals (SDGs). Outlined below is SDG Goal 3 relating to health, and the associated goals to the determinants of health: 354

Goal 1: End poverty in all its forms everywhere

Goal 2: End hunger, achieve food security and improved nutrition and promote sustainable agriculture

Goal 3: Ensure healthy lives and promote well-being of all ages

Goal 4: Ensure inclusive and equitable quality education and promote lifelong learning opportunities for all

Goal 5: Achieve gender equality and empower women and girls

Goal 6: Ensure availability and sustainable management of water and sanitation for all

Goal 10: Reduce inequality within and between countries

The SDGS and the Global Strategy are supportive of promoting a HRBA to health, as they seek to address health inequalities and advance the enjoyment of human rights.

In 2017 the High-Level Work Group, produced a report, Leading the realisation of human rights to health and through health with a focus on women, children and

\footnotetext{
${ }^{353}$ Every Child, The Global Strategy for Women's, Children's and Adolescents' Health, 2016-2030 (Every Child 2015) http://www.who.int/countries/moz/areas/human rights/en/ accessed January 2020 ${ }^{354}$ Thomas R, Kuruvilla S, Hinton R, Jensen S L B, Magar V and Bustreo F, 'Assessing the Impact of a Human Rights-Based Approach across a Spectrum of Change for Women's, Children's, and Adolescents' Health and Human Rights Journal 17/2, December 10, (2015)
} 
adolescents. ${ }^{355}$ This report highlights what the authors considered critical to implementing a human rights approach to the health of these groups. The guiding principles of their approach are equality, inclusiveness and non-discrimination, accountability and participation and are influenced by the framework of availability, accessibility, acceptability and quality of health facilities and services (i.e., AAAQ Framework, see Chapter 2). There is also a strong emphasis on the importance of the indivisibility of all human rights and an understanding that the root causes of any health condition must be understood. The High-Level Working Group emphasised the importance of the State in addressing human rights abuses and also highlight the importance of parents and the family in contributing to the well-being of the child. The key elements of their approach, in summary, are:

- The right to health should be upheld as a part of national law (i.e., through national constitutions and other legal instruments, and there should be clear legal remedies).

- There should be a rights based approach to health financing and universal health coverage (i.e., there should be clear timelines to demonstrate achieving universal health coverage, at least $5 \%$ of the GDP should be allocated to public health).

- Human rights should be addressed as determinants of health (and all states should carry out periodic human rights assessments of the health determinants of women, children and adolescent health).

- Social, gender and cultural norms should be removed that prevent the realisation of health rights (i.e., structural and legal barriers must be removed).

- All people should be enabled to claim their rights (i.e., all people should be made aware of their human rights e.g., campaigns and awareness raising activities) and how to claim them through appropriate legal remedies.

- Those who advocate for rights (i.e., defenders, champions and coalitions should be empowered and protected).

\footnotetext{
${ }^{355}$ Report of the High-Level Working Group on Health and Human Rights of Women, Children and Adolescents 'Leading the realisation of human rights to health and through the health', WHO and OHCHR 2017 http://www.ohchr.org/Documents/Issues/Women/WRGS/Health/ReportHLWGhumanrights-health.pdf accessed January 2020
} 
- There should be committed national and local political leadership towards human rights and health.

- All health workers should respect the rights of those they care for.

- All health systems should be designed in accordance with human rights norms, principles and standards.

- There should be national accountability mechanisms (e.g., from courts to patient rights bodies, parliamentary oversight committees, national human rights institutions).

- Rights sensitive data should be collected, and health and human rights should be consistently reported on (i.e. disaggregated data and data that bring the previously invisible to the forefront of policy developments. States should also proactively report on how they are meeting the WHO's Global Strategy). ${ }^{356}$

A report by Bustreo and Hunt into the impact of HRBAs on women and children's health concluded that there is evidence to suggest that a HRBA contributes to improvements in the health of women and children. ${ }^{357}$ Through examining a number of different country contexts that were actively applying a HRBA they were able to demonstrate that international and domestic legislation relating to the right to health were being effectively translated into improving health services. Additionally, principles such as accessibility, quality, participation and accountability were shaping health services and policies that were contributing to improving the health of women and children. ${ }^{358}$ This converges with findings in Chapter 3 regarding the main elements of a HRBA for health.

\footnotetext{
${ }^{356}$ WHO, Informal Consultation on Health and Human Rights, (WHO Geneva, December 4-5, 1997) WHO and OHCHR, Report of the High-Level Working Group on Health and Human Rights of Women, Children and Adolescents (2017) Leading the realisation of human rights to health and through the health $6 \mathrm{http} / /$ www.ohchr.org/Documents/Issues/Women/WRGS/Health/ReportHLWGhumanrights-health.pdf accessed January 2020

${ }^{357}$ Bustreo $\mathrm{F}$ and Hunt $\mathrm{P}$, Women's and Children's health: Evidence of impact of human rights (Geneva: World Health Organization, 2013) 15 http://apps.who.int/iris/bitstre am/10665/84203/1/9789241505420 eng.pdf accessed January 2020

${ }^{358}$ Ibid16
} 


\subsubsection{UNICEF's HRBA to Health}

UNICEF also uses a HRBA in their global programme of work on health and they claim that their policy and programmes are delivered in accordance with human rights norms, standards and principles. UNICEF argues that this approach should promote change at the local, national and international level and should influence the implementation of policies to reduce and eliminate preventable mortality and morbidity for children under the age of 5 years. ${ }^{359}$ UNICEF's approach has a strong focus on 'equity'. As interpreted by their organisation this means 'that all children should have the same opportunities to develop and attain their fullest potential and a fair chance for every child. ${ }^{360}$ The organisation follows an inclusive and holistic strategy that aims to address barriers in the delivery of basic health services to the most deprived and marginalised. UNICEF pushes for legal frameworks that support and strengthen public health efforts and engage duty bearers regarding removing barriers to successful implementation of health services. The organisation focuses on addressing gaps in participation and accountability to promote comprehensive and sustainable solutions, arguing that engagement of all stakeholders is a prerequisite for translating a HRBA into practice.

'UNICEF perceives the rights based approach to be the only credible way to enable children and their families to live a life of dignity.' ${ }^{361}$ This approach has an explicit focus on addressing the SDGs. UNICEF believes that focussing on a holistic approach that addresses many children's needs will help to realise children's right to health, which is cognisant with the earlier discussed focus on prevention, health inequalities and social determinants of health (see Chapter 2). In this respect, the focus is on 5 overarching goals.

These are:

Goal 1: Children survive and thrive Goal 2: All children learning

\footnotetext{
${ }^{359}$ Neefjes P, 'Current Developments in Global Child Health Care: Unicef Data and Experiences' In, Doek and Dorscheist (eds) Children's Rights in Health Care (Brill Publications 2018)

${ }^{360}$ Ibid 39

${ }^{361}$ Ibid 39
} 
Goal 3: All children protected from violence and exploitation

Goal 4: Equity - a fair chance for all children

Goal 5: All children live in secure environments

UNICEF demonstrates how these goals are connected in a complex matrix to the 17 SDGs. ${ }^{362}$ UNICEF has also demonstrated how the SDGs link up to the articles of the UNCRC. This is a very useful interactive document because it links the accountability framework of the UNCRC to the SDGs, so these goals are connected to realisable human rights. ${ }^{363}$ This addresses concerns in Chapter 3 , that earlier organisational HRBAs to children did not make sufficient explicit connections to the international human rights treaties themselves to support enforceability and accountability. ${ }^{364}$

UNICEF has seven strategies for supporting the implementation of their human rights approach. In summary these are: 365

1. Capacity development for system strengthening - this requires attention to implementing human rights standards and principles across a range of programmes internationally and building capacity to develop systems to support this.

2. Research, evidence and knowledge management - developing an evidence base critical to support the case for implementation. UNICEF has country specific and globally based monitoring systems.

3. Policy, dialogue, advocacy and communication, creating opportunities for many stakeholders to not only support programs but to also communicate and replicate them elsewhere.

\footnotetext{
${ }^{362}$ Neefjes P, 'Current Developments in Global Child Health Care: Unicef Data and Experiences' In, Doek and Dorscheist (eds) Children's Rights in Health Care (Brill Publications 2018)

${ }^{363}$ UNICEF, Mapping the UNCRC against the Sustainable Development Goals https://www.unicef.org/media/60231/file accessed January 2020

${ }^{364}$ The Danish Institute of Human Rights has gone further and correlated all of the Sustainable Development Goals with all of the international human rights treaties. This is an excellent web-based tool to aid all organisations when monitoring the Sustainable Development Goals to also understand their connection to human rights in holding duty bearers to account. Danish Institute of Human Rights, The Human Rights Guide to the Sustainable Development Goals http://sdg.humanrights.dk/en/targets2?goal[ $]=72$ accessed January 2020

${ }^{365}$ Neefjes P, 'Current Developments in Global Child Health Care: Unicef Data and Experiences' In, Doek and Dorscheist (eds) Children's Rights in Health Care (Brill Publications 2018) 44
} 
4. South-south triangular cooperation, this strategy takes advantage of regional experience and capacity to promote development.

5. Communication for development, awareness and information sharing is a core element to make changes happen, this strand focuses on campaigns and media influencing.

6. Partnerships, within and across countries to help make rapid changes.

7. Identification and promotion of effective innovation, UNICEF has set up an Innovation Fund that explores links and implements innovations in health care and other services.

As discussed in Chapter 3, UNICEF is transforming itself, into an organisation that promotes a HRBA to its programming work, using a principled approach and human rights standards. It has also developed programmes to build capacity and systems to help understanding of human rights implementation. As an organisation that has global reach, it is attempting to share knowledge on implementation and innovation in health care widely. However, like all organisations there are many challenges to its successful implementation. Learning from the theory of its approach but also the organisation's challenges with regards to its implementation is incredibly useful to the development of a conceptual framework for a CRA to health services in the Welsh context.

\subsubsection{Council of Europe Child Friendly Guidelines to Health Care}

In 2011, the UNCRC and the UNCRC General Comment No.15 was integrated into the Council of Europe (CoE) Child Friendly Guidelines to Health care. In short, the goal of the child-friendly health care approach is:

to embed children's rights in the health care system to ensure that the right things happen, to the right children, at the right time, in the right place, and 
using the right staff having the right support, to achieve the right outcomes, all at the right cost. ${ }^{366}$

CoE member states have pledged commitment to the child friendly health guidelines to embed children's rights into the health care system. The Guidelines are non-legally binding standards for the delivery of healthcare services that fulfil the rights of children and aim to secure better health care in delivery and practice across the CoE member states. ${ }^{367} 368$ It is a child-centred approach that is based on the principles of fundamental rights and specific children's rights, dignity, best interests, participation and equitable access to health care. ${ }^{369}$

According to the CoE Guidelines, it is necessary to integrate the human rights of children with respect to health and health care into a practical framework that 'drives cultural change and consequent improvement in all services which contribute to the health and well-being of children'. ${ }^{370}$ The approach should be 'applicable at the level of policy/planning development, at the service delivery level and at the level of individual children and pushes for efficiency and equity'. ${ }^{371}$

The CoE believes that the training of health care professionals is of primary importance, so that they fully understand the human rights of the child, the child's capacity to understand information about their health care, and to participate in decision making regarding their care and treatments. The Guidelines, state it is necessary to:

\footnotetext{
${ }^{366}$ Council of Europe, Child Friendly Guidelines to HealthCare (COE 2011) para 29

https://rm.coe.int/guidelines-of-the-committee-of-ministers-of-the-council-of-europe-on-c/16808c3a9f accessed January 2020

${ }^{367} \mathrm{CoE}$ level, the "right to protection of health" more generally is also enshrined in the European Social Charter (ETS no. 163) and the "Oviedo Convention" (Convention for the Protection of Human Rights and Dignity of the Human Being with regard to the Application of Biology and Medicine: Convention on Human Rights and Biomedicine; ETSno. 164) requiring from member States to ensure "equitable access to healthcare of appropriate quality" within their jurisdictions.

${ }^{368}$ At EU level, Article 35 of the Charter of Fundamental Rights states that "everyone has the right to access preventive health care and the right to benefit from medical treatment under the conditions established by national laws and practices.

${ }^{369}$ Council of Europe, Child Friendly Guidelines to HealthCare (COE 2011) para 29

$\mathrm{https}: / / \mathrm{rm}$.coe.int/guidelines-of-the-committee-of-ministers-of-the-council-of-europe-on-c/16808c3a9f

${ }^{370}$ Ibid para 20

${ }^{371}$ Ibid para 20
} 
facilitate the incorporation and, where appropriate, the adaptation of the child-friendly health care approach into policies, service planning and practice, coupled with the development of relevant measures to monitor implementation. ${ }^{372}$

The Guidelines, like the UN Committee on the Rights of the Child's General Comment No.15 recommend that all health care professionals including policy makers and managers receive training on children's rights and child development. ${ }^{373}$

\subsubsection{Application of the Child Friendly Approach to Health Care in practice}

Kilkelly and Savage have researched countries that have developed models to implement a child friendly approach in practice. ${ }^{374}$ One of the international models noted in their research as having an impact is the 'Self-evaluation Model and Tool on the Respect of Children's Rights in Hospital'. ${ }^{375}$ In 2004, a Task Force was established as an initiative of the International Network of Healthy Promoting Hospitals and Health Services (WHO). The Task Force consisted of 15 member countries including England, Scotland, Italy, Norway, Austria, Estonia, Portugal, Croatia, Estonia, Spain, Greece, Hungary, Canada, Australia, and the USA. The Task Force carried out a survey of 114 children's hospitals and departments throughout 22 European countries. Their analysis identified a lack of tools to assess children's rights in those hospitals that had adopted Charters. ${ }^{376}$ In 2009, the Task Force designed the Self-Evaluation Model and Tool (SEMT) on the Respect of Children's Rights in Hospital (Task Force

\footnotetext{
${ }^{372}$ Guidelines on child-friendly health care (Adopted by the Committee of Ministers on 21 September 2011 at the 1121st meeting of the Ministers' Deputies) para 57

${ }^{373}$ UN Committee on the Rights of the Child, General Comment No. 5 on the General Measures of Implementation, $\mathrm{CRC} / \mathrm{C} / \mathrm{GC} / 5 / 2003$ paras 66-70; UN Committee on the Rights of the Child (2009) General Comment No. 12: The right of the child to be heard, CRC/GC/12/2009 para 49; UN Committee on the Rights of the Child General Comment No. 15 on the right of the child to the enjoyment of the highest attainable standard of health $\mathrm{CRC} / \mathrm{C} / 15 / 2013$

${ }^{374}$ Kilkelly U and Savage E Child friendly health care: A report commissioned for the ombudsman for children. (Ombudsman for Children 2013)

${ }^{375}$ Simonelli F and Guerreiro A and Task Force on Health Promotion for Children and Adolescents in and by Hospitals and Health Services, The Respect of Children's Rights in Hospital: An Initiative of the International Network of Health Promoting Hospitals and Health Services (Final Report of the implementation process of the implementation of the Self-evaluation Model and Tool on the Respect for Children's Rights in Hospital (International Network of Health Promoting Hospitals and Health Services - WHO Collaborative Centre 2010).

${ }^{376}$ Kilkelly U and Savage E Child friendly health care: A report commissioned for the ombudsman for children (Ombudsman for Children 2013) 47
} 
HPH-CA, 2009). It was based on the UNCRC (UNCRC), the European Association of Children in Hospital (EACH) Charter ${ }^{377}$ and other relevant documents. The SEMT focused on children's right to the highest attainable standard of health care, right to information and to participate in all health care decisions, and the right to protection from all forms of violence. The general principles of the UNCRC non-discrimination, best interests, survival and development and participation were intended to cut across these three areas. ${ }^{378}$

Kilkelly and Savage explain, that the:

... SEMT is used in a cyclical process of quality improvement involving four phases: '(i) mapping the reality of existing practices (i.e. gaps in children's rights in practice) through the implementation of the SEMT; (ii) planning the improvement, though the identification of a set of standards for the respect of children's rights in hospital; (iii) making improvement, through the implementation of specific actions; (iv) evaluating the change, by monitoring progress and gaps. ${ }^{379}$

The SEMT designed self-evaluation tools (questionnaires) for healthcare managers, healthcare professionals and evaluation tools (also questionnaires) were prepared for children aged between 6 and 11 years, children and adolescents aged between 12-18 years and for parents/carers. These were administered across all the hospitals included in the study as referred to above. Based on all the evidence they received from this process, the SEMT developed a Manual on Children's Rights in Hospital and Health Services with the aim of providing tools, which can be used in an 'improvement programme cycle within hospitals and health services, aimed at advancing the respect, protection and fulfilment of children's rights within those institutions'. 380

The Kilkelly and Savage study demonstrates that in many countries children's rights charters and children's rights standards for the health care environment have been

\footnotetext{
${ }^{377}$ For further information regarding EACH, https://www.each-for-sick-children.org/eachcharter.html accessed January 2020

${ }^{378}$ Kilkelly U and Savage E, Child friendly health care: A report commissioned for the ombudsman for children (Ombudsman for Children 2013) 48

${ }^{379}$ Ibid 48

${ }^{380}$ Ibid 50
} 
introduced. However, the study also demonstrates the need for further research on how charters and standards can be made a more effective part of the policy framework, structure of health care systems and how they might be better monitored and embedded into the practice of relevant organisations. It also noted the importance of high-level commitment from senior managers and elected members to embed a child friendly approach to health care for this to be successful from the outset. Kilkelly and Savage advocate for strong leaders and champions for children's rights to be appointed and all health systems to be targeted, including professionals, managers and policy makers and practitioners. ${ }^{381}$ Kilkelly and Savage also emphasised the importance of listening to the views and experiences of children and young people and ensuring that there is clear focus on training and education of health care professionals. ${ }^{382}$ These two themes will be discussed in the next sections.

\subsection{Health professionals limited knowledge of how to deliver a CRA to health care}

The UN Committee on the Rights of the Child believes that the training of health care professionals is of primary importance, so that they fully understand the human rights of the child, the child's capacity to understand information about their health care and to participate in decision making regarding their care and treatments. The UN Committee recommends that all health care professionals including policy makers and managers receive training on children's rights and child development. ${ }^{383}$

According to the international study, health professionals had little knowledge of children's rights in healthcare (SEMT) and there were limited examples of initiatives that focused on education and training of health care professionals. ${ }^{384}$ Further research is required to develop knowledge about the most effective strategies to ensure that

\footnotetext{
${ }^{381}$ Kilkelly U and Savage E, Child friendly health care: A report commissioned for the ombudsman for children (Ombudsman for Children 2013) 4, 60

${ }^{382}$ Ibid 60

${ }^{383}$ UN Committee on the Rights of the Child, General Comment No. 5 on General Measures of Implementation $\mathrm{CRC} / \mathrm{C} / \mathrm{GC} / 5 / 2003$ paras 66-70; UN Committee on the Rights of the Child, General Comment No. 12: The right of the child to be heard CRC/GC/12/2009 para 49; UN Committee on the Rights of the Child, General Comment No. 15 on the right of the child to the enjoyment of the highest attainable standard of health $\mathrm{CRC} / \mathrm{C} / 15 / 2013$ para 27

${ }^{384}$ Kilkelly U and Savage, Child friendly health care: A report commissioned for the ombudsman for children (Ombudsman for Children 2013) 47
} 
health professionals know about and understand children's rights and what this means in practice. Kilkelly and Savage reported that those who specialise in children's health care, are normally situated in secondary and tertiary care services, so children will often be treated by health practitioners at the community level, such as GPs, who do not have a specialism in paediatrics. ${ }^{385}$ However, a child friendly approach aims to mainstream minimum standards for the care of children so that all community-based professionals must consider the rights of the child. ${ }^{386}$

Experience in providing care and communicating effectively with children is an essential element of delivering a CRA to health services impacting on children. Professionals must understand the needs of the client group they are providing a service to. ${ }^{387}$ In the UK, the care of children is part of the core health curriculum objectives. However, training in hospital based paediatrics is currently not a mandatory part of GP training. ${ }^{388} 389$ This has implications for GP's with regards to correct diagnosis of children's conditions and also their ability to communicate effectively with children. In a review undertaken by Kennedy in 2010 in England, it was revealed that GPs had very limited training in the appropriate diagnosis and support of children with mental health conditions and this was set against a mental health epidemic for children and young people. ${ }^{390}$ Additionally, some health professionals reported only being 'able to take an all-or-nothing approach to children's participation in their care, as they do not have the confidence or tools to take a more nuanced approach as the child matures.' 391

\footnotetext{
${ }^{385}$ Ibid 27

${ }^{386}$ Kilkelly U and Savage, Child friendly health care: A report commissioned for the ombudsman for children (Ombudsman for Children 2013) 25

${ }^{387}$ Munro L A, 'Human Rights Based Approach to Programming: A contradiction in terms,' In (eds) Hickey S and Mitlin D Rights Based Approaches to Development: Exploring the Potentials and the Pitfalls. (Kumarian Press USA 2009).

${ }^{388}$ Clements K, Opening the door to better health care: Ensuring General practice is working for children and young people (NCB 2013)

${ }^{389}$ Kennedy I, Getting it right for children and young people: Overcoming cultural barriers in the NHS so as to meet their needs (Department of Health 2010). It was reported in Professor Ian Kennedy's review of the NHS that in many parts of England 40-50\% of GPs had no formal paediatric/child health training; despite the fact $25 \%$ of their patients are children.

${ }^{390}$ Ibid 13

${ }^{391}$ Council for Disabled Children (2011), Managing My way, 22, cited In Clements K, Opening the door to better health care: Ensuring General practice is working for children and young people (NCB 2013) 15
} 
In a qualitative study with Care Leavers in England, young people were very critical of GPs, sometimes feeling that they were medically incompetent and lacked social skills. ${ }^{392}$ In research carried out into young people's views on mental health services in England, young people 'with mental health problems felt that many GPs lacked understanding, awareness, empathy and interest, and were reluctant to provide certain types of support.' 393

Children reported in a study undertaken by the National Children's Bureau (NCB) in 2012 that they wanted health professionals to be skilled, competent, and knowledgeable and have a specialist understanding of their health condition. ${ }^{394}$ It is reported consistently across the literature that children also want professionals to establish positive relationships with them and to be able to communicate, listen and empathise with them in a friendly manner, have a sense of humour and not be overly serious all of the time, to be kind and professional. ${ }^{395} \mathrm{~A}$ study carried out by the National Children's Bureau in 2013 recommended that GPs have 'appropriate training to work with children, including investment in extended initial training for GPs and support and encouragement for existing GPs to develop their expertise'. 396

Health care professionals are aware that due to structural or system problems, such as too few paediatric staff, inaccessible information, not enough time and limited training, implementing children's rights in health care practice is not always adhered to. ${ }^{397}$ Education and training with regards to skills development, review of health and

\footnotetext{
${ }^{392}$ Cameron C, 'Access to health services: Care leavers and young people "in difficulty," ChildRight (2007) 238: 22-25

${ }^{393}$ Lavis P and L Hewson, 'How many times do we have to tell you?' Young Minds Magazine (2010) 109: 30-31

${ }^{394}$ La Valle I, Payne L with Gibb J and Jelicic H, Listening to the views of children, A rapid review of the evidence (NCB 2012); Robinson S 'Children and young people's views of health professionals,' England Journal of Child Health Care (2010)14, 310-326

${ }^{395}$ La Valle I, Payne L with Gibb J and Jelicic H, Listening to the views of children, A rapid review of the evidence (NCB 2012); Kilkelly U, The views and experiences of children and young people in the Council of Europe (Strasbourg Council of Europe 2011); Mainey et al, Children's views of services: a rapid review. (London. National Children's Bureau 2009); Kilkelly U and Donnelly M, The Child's Right to Be Heard in the Health Care Setting (Office of the Minister for Children 2006)

${ }^{396}$ Clements K, Opening the door to better health care: Ensuring General practice is working for children and young people (NCB 2013)

${ }^{397}$ Kilkelly U and Donnelly M, The Child's Right to Be Heard in the Health Care Setting: Perspectives of children, parents and health professionals (Dublin: Office of the Minister for Children 2006)
} 
medical curricula to be compliant with children's rights, and extra resources are critical. More needs to be done to train all health professionals to understand children's rights, child development and how to adopt a children's rights perspective to practice. Critical to ensuring children's rights are respected in health care settings, is ensuring a child's right to be heard in medical decision making, which is discussed further in the next section.

\subsection{Children's right to be heard in medical decision making}

According to Donnelly and Kilkelly, the rights of children to participate in health decision making, only came to the forefront of policy development (as compared to education and family law) relatively recently. ${ }^{398}$ Donnelly and Kilkelly, trace this to a Report of the Bristol Royal Infirmary Inquiry which recommended that:

Healthcare professionals who care for children must be able to listen to children, to respect their needs for information and to be prepared and able to give such information in the right amount and in a way which is suitable for the child's age. ${ }^{399}$

Guidance published by the $\mathrm{RCPCH}$ integrated this principle, requiring that 'paediatricians must listen to children and young people and respect their views'. ${ }^{400}$

This is consistent with the approach as laid out in the UN Committee on the Rights of the Child's General Comment Number 12 which 'stipulates that simply listening to the child is insufficient; the views of the child have to be seriously considered when the child is capable of forming her or his own views.' ${ }^{401}$ As was introduced in Chapter 2, according to the UN Committee the views of children must always be taken into

\footnotetext{
${ }^{398}$ Donnelly M and Kilkelly U, 'Child-friendly health care: delivering on the right to be heard, 'Medical Law Review (2011) Volume 19 Issue 1, Winter

${ }^{399}$ Learning from Bristol: The Report of the Public Inquiry into Children's Heart Surgery at the Bristol Royal Infirmary 1984-1995 Command Paper CM 5207 (Bristol Royal Infirmary Inquiry, Bristol 2001)

${ }^{400}$ Royal College of Paediatrics and Child Health, Good Medical Practice in Paediatrics and Child Health: Duties and Responsibilities of Paediatricians (Royal College of Paediatrics and Child Health, London 2002) para 21

${ }^{401}$ UN Committee on the Rights of the Child, General Comment No. 12: The right of the child to be heard, $\mathrm{CRC} / \mathrm{GC} / 12 / 2009$ para 28
} 
account in clinical decision making. ${ }^{402}$ In any context, not just the health context, Lundy argues that children should be encouraged to actively provide 'input rather than simply acting as a recipient of views if children happen to provide them'. ${ }^{403}$ Listening and encouraging children to express their views leads to a better understanding of the realities of children's lives and to understanding the causes of violated rights.

In Kilkelly's study for the Council of Europe (CoE) children made it clear that they wanted to be included in health care decision making processes that affect them. They wanted health care professionals to proactively engage with them and who were able to contribute to their own development. Research has overwhelmingly highlighted that children value information that is given to them in the healthcare context but are not always satisfied with the quality of the information that is given to them by health care professionals. ${ }^{404}$ Children report that they want information in advance, with regards to procedures and medical treatments. Alderson comments that children are often not informed appropriately regarding what an impending surgery is going to entail, which causes fear and anxiety in the children. ${ }^{405}$ Alderson carried out research with 120 children aged 8-15 years facing orthopaedic surgery, who reported that children become most afraid when they are excluded from decisions about medical procedures. ${ }^{406}$

A 2016 study by Bensted et al demonstrates that although healthcare priorities evolve significantly between childhood and early adolescence; being listened to is the most

\footnotetext{
${ }^{402} \mathrm{UN}$ Committee on the Rights of the Child, General Comment No. 12: The right of the child to be heard, $\mathrm{CRC} / \mathrm{GC} / 12 / 2009$; UN Committee on the Rights of the Child, General Comment No. 15 on the right of the child to the enjoyment of the highest attainable standard of health $\mathrm{CRC} / \mathrm{C} / 15 / 2013$

${ }^{403}$ Lundy L, 'Voice is not enough, conceptualising Article 12 of the United Nations Convention on the Rights of the Child', British Educational Research Journal (2007) 33/6, 934

${ }^{404}$ LaValle I, Payne L with Gibb J and Jelicic H, Listening to the views of children, A rapid review of the evidence (NCB 2012); Coyne I and Gallagher P, 'Participation in communication and decisionmaking: children and young people's experiences in a hospital setting', Journal of Clinical Nursing (2011); Migone M, McNicholas F and Lennon R, 'Are we following the European charter? Children, parents and staff perceptions', Child Care, Health and Development (2008) 34; Kilkelly U and Donnelly M, The Child's Right to be heard in the Healthcare Setting: Perspectives of Children, Parents and Health Professionals. (Dublin: Office of the Minister for Children 2006)

${ }^{405}$ Alderson P, Children's Consent to Surgery (Open University Press, Buckingham 1993) 154-63.

${ }^{406}$ Alderson P, Children's Consent to Surgery (Open University Press, Buckingham 1993); Alderson P 'Competent children? Minors' consent to health care treatment and research' Social Science \& Medicine 65, 2007, 2272-2283
} 
important priority at all ages. ${ }^{407}$ Children want to be able to ask questions and understand what the health care professional is saying to them in plain language and if possible with props, and they do not want to be rushed during the treatment planning process. ${ }^{408}$ Gibson et al comment, as children get older they do not want to be patronised and want to be spoken to in a language that respects their age and understanding. ${ }^{409}$ Kilkelly and Savage report that that there is little evidence of multimedia forms of communication being used in health care contexts. ${ }^{410}$

According to Grootens-Wiegers, Hein and Staphorst:

Meaningful participation in decision making requires an adequate level of understanding of what is at stake. However, a fundamental problem arises as oral communication and textual information are often primarily directed at adults, or aimed at minors but not connected to their perspective. ${ }^{411}$

Consistent with other evidence the International SEMT study revealed that much more needs to be done with regards to children's participation in all decisions involving their healthcare with access to appropriate information. ${ }^{412}$ Children reported not being adequately involved in planning their treatment and care, and health professionals were reported as needing to improve their communication with children and their caregivers. ${ }^{413}$

\footnotetext{
${ }^{407}$ Bensted R, Hargreaves D S, Lombard J, Kilkelly U $\ddagger$ and Viner R M, 'Comparison of healthcare priorities in childhood and early/late adolescence: analysis of cross-sectional data from eight countries in the CoE Child-friendly Healthcare Survey 2011', Child, Care, Health and Development 2015 Jan;41(1):160-5

${ }^{408}$ Kilkelly U and Savage E, Child friendly health care; A report commissioned for the ombudsman for children (Ombudsman for Children 2013)

${ }^{409}$ Gibson F, Aldiss S, Horstman M, Kumpunen S and Richardson A, 'Children and young people's experiences of cancer care: A qualitative research study using participatory methods', International Journal of Nursing Studies, 2010 47, 1397-1407

${ }^{410}$ Kilkelly U and Savage E, Child friendly health care: A report commissioned for the ombudsman for children (Ombudsman for Children 2013)

${ }^{411}$ Grootens-Wieger P, Hein I and Staphorst M, 'Using Children's Voice to Optimize Pediatric Participation in Medical Decision Making', The American Journal of Bioethics (2018) 18:3 14-15 ${ }^{412}$ Simonelli F and Guerreiro, A and Task Force on Health Promotion for Children and Adolescents in and by Hospitals and Health Services The Respect of Children's Rights in Hospital: An Initiative of the International Network of Health Promoting Hospitals and Health Services (Final Report of the implementation process of the implementation of the Self-evaluation Model and Tool on the Respect for Children's Rights in Hospital (International Network of Health Promoting Hospitals and Health Services - WHO Collaborative Centre 2010)

${ }^{413}$ Ibid
} 
O'Malley comments that children's views and lived experiences can contribute to better decision making instead of 'untested adult assumptions'. ${ }^{414}$ Listening to children and acting on their views is particularly challenging in the health care environment, when there are the competing objectives of three parties, the health care professional, the child and the caregiver. Kilkelly and Savage report that health care professionals may not always be skilled in communicating with the child or appreciate the importance of communicating and involving the child and may believe that they should be communicating primarily with the caregiver. ${ }^{415}$ Furthermore, children may already be feeling vulnerable due to being sick and this can additionally exacerbate the anxiety of the adult caregiver. ${ }^{416}$ Young et al comment, that caregivers in an effort to protect their child, can take over the accessing of information and the management of the treatment process. ${ }^{417}$ Additionally, children are given little space to express their views, and some health care professionals are interpreted as intimidating. However, Young et al acknowledge that some parents do encourage children's participation. ${ }^{418}$

Grootens-Wiegers, Hein \& Staphorst reporting from evidence from their own research, explain that:

Children are valuable and essential partners in forwarding our insights for optimizing paediatric participation in medical decision making. It is therefore vital that we, as professionals working in paediatric health care, should take due account of and actively incorporate children's perspectives in paediatric care. $^{419}$

\footnotetext{
${ }^{414}$ O'Malley, Children and Young People Participating in PRSP Processes: Lessons from Save the Children's experiences (London: Save the Children 2004) 9

${ }^{415}$ Kilkelly U and Donnelly M, 'Participation of healthcare the views and experiences of children and young people' International Journal of Children's Rights 19 (2011) 109

${ }^{416}$ Ibid 109

${ }^{417}$ Young B, Dixon-Woods M, Windridge K, and Heney D, 'Managing communication with young people who have a potentially life-threatening chronic illness: Qualitative study of patients and parents', British Medical Journal, (2003) 326, 1-5

${ }^{418}$ Ibid

${ }^{419}$ Grootens-Wieger P, Hein I and Staphorst M, 'Using Children's Voice to Optimize Pediatric Participation in Medical Decision Makin', The American Journal of Bioethics (2018) 18:3, 15
} 
Macleod comments that children's own experiences and views must be taken into account in medical decision making. ${ }^{420} \mathrm{~A}$ focus on children's rights means strong consideration must always be given to seeing the child as an individual with views and feelings of his or her own. Medical professionals may assume they are acting in the child's best interests but respect for a child's Article 12 right to be heard, according to the UN Committee on the Rights of the Child must always be taken into consideration when evaluating what is in a child's best interests. ${ }^{421}$ As Angst and Deatrick comment, children's involvement in goal setting and treatment planning has been demonstrated to have a positive impact on health care treatment outcomes. ${ }^{422}$ As Alderson argues it is critical to recognise that children are human rights holders and experts in the understanding of their own health condition and their own life circumstances. ${ }^{423}$ Children, including young children, should not be seen as passive patients, but active agents who are capable of engaging with medical practitioners and caregivers to help shape their own future. ${ }^{424}$

\subsection{Children's autonomous decision-making and consent to treatment in health care contexts}

The complexities of medical decision-making involving children are of particular significance with regards to consent to health treatment. For example, in the UK, the Law states that 16/17 year olds are assumed competent to consent to medical treatment (Family Law Reform Act 1969, s. 8; Mental Capacity Act 2005, s. 1) and under 16's can consent to medical treatment in their best interests if they are 'Gillick' competent: i.e. if the minor has sufficient understanding and intelligence to enable him or her to understand fully what is proposed. ${ }^{425}$

\footnotetext{
${ }^{420}$ Macleod C M, 'Constructing Children's Rights,' In Drerup J, Graf G, Shickhart C and Shweiger G (eds) Justice, Education and the Politics of Childhood (Springer 2016)

${ }^{421}$ UN Committee on the Rights of the Child, General Comment No. 12: The right of the child to be heard, $\mathrm{CRC} / \mathrm{C} / \mathrm{C} / 12$ para 74

${ }^{422}$ Angst and Deatrick, 'Involvement in health care decisions: Parents and Children with Chronic Illness', Journal of Nursing May 1, 1996

${ }^{423}$ Alderson P, Children's Consent to Surgery (Open University Press, Buckingham 1993) 154-63: which demonstrates children's maturity in the face of making decisions regarding surgery; Alderson P, 'Children's Consent and 'Assent' to Healthcare Research' In Freeman M (eds) Law and Childhood Studies: Current Legal Issues Volume 14 (Oxford Scholarship online 2012).

${ }^{424}$ Ibid.

${ }^{425}$ Gillick v West Norfolk \& Wisbeck Area Health Authority [1986] AC 112 House of Lords
} 
As Lord Scarman stated:

Parental rights ...yields to the child's right to make his or her own decisions when he reaches a sufficient understanding and intelligence to be capable of making up his own mind on the matter requiring decision. ${ }^{426}$

Minors/Under 16 year olds can refuse treatment but when the treatment is life sustaining, the decision may be challenged either on the basis that the child is not competent to make the decision or because, though competent the law permits the decision to be overruled in their best interests by a parent/carer or the court can do so. ${ }^{427}$ This applies even if the minor is $16 / 17$ years of age. This could be interpreted as disrespecting children's autonomous decision making and considered to be more consistent with a paternalistic or protectionist approach. ${ }^{428}$ However, some theorists argue that children's autonomous decision making must be restricted in certain contexts. For example, Eekelaar, argues that a child's right to autonomous decision making should be overridden to support what practitioners consider to be in the child's best interests ${ }^{429}$, and according to Herring, breaching a child's autonomy is justified where there is the potentiality of protecting and maximising the child's future autonomy. ${ }^{430}$

In the UK, it could be argued that the medical profession and the courts place less value on the choices of the child, the choices of the child are only respected as long as they do not override the professional's view of best interests.

On this issue Downie comments:

Where the life of the teenage patient is in danger, it is difficult to disagree with the conclusion that he should not be allowed to bring about his own death, however strong his objections to treatment. However, the application

\footnotetext{
${ }^{426}$ Ibid

${ }^{427}$ Cave E, Young People who refuse life sustaining treatment: A briefing paper on current law and the need for reform (University of Leeds 2013)

${ }^{428}$ Freeman M, Article 3: Best interests of the child (Leiden: Martinus Nijhoff 2007)

${ }^{429}$ Eekelaar J, 'The Emergence of Children's Rights,' Oxford Journal of Legal Studies 6, 1986, no. 2 161; Eekelaar J, 'The Interests of the Child and the Child's Wishes: The Role of Dynamic SelfDeterminism' International Journal of Law Policy and the Family 8, 1994 no. 142

${ }^{430}$ Herring J, Medical Law and Ethics (6 ${ }^{\text {th }}$ edn Oxford: Oxford University Press 2016) 226
} 
of the principle in Re W that the court can always override a refusal of consent even by a Gillick competent minor, means that the assessment of his competence is almost pretence. The court will base its decision on its view of the child's welfare; and it may, therefore, be preferable to avoid the process of finding him incompetent in order to legitimise such a decision. ${ }^{431}$

The UK Department of Health has advised that, where young people are competent, and they are refusing treatment, clinicians do not treat without court authorisation. ${ }^{432}$ There seems to be a great deal of confusion and a lack of coherence with regards to the law in relation to consent, and this is acknowledged by the General Medical Council, which advises on seeking legal advice if a medical professional thinks the treatment is in the best interests of a competent young person who refuses' ${ }^{433}$

The Department of Health 2009 guidance states:

The courts have, in the past, also found that parents can consent to their competent child being treated even where the child/young person is refusing treatment. However, there is no post-Human Rights Act 1998 authority for this proposition, and it would therefore be prudent to obtain a court declaration or decision if faced with a competent child or young person who is refusing to consent to treatment, to determine whether it is lawful to treat the child. ${ }^{434}$

It may be suggested that the law in the UK concerning adolescent decision-making powers over their health is somewhat confusing and often arbitrary. In 2009 Fortin, commented that on the one hand Gillick competence recognises adolescents:

\footnotetext{
${ }^{431}$ Downie A, 'Consent to Medical Treatment -- Whose View of Welfare? Family Law Journal' (1999) 29818 commenting on Re W [1992] 4 All ER 627

${ }^{432}$ Cave E, Young People who refuse life sustaining treatment: A briefing paper on current law and the need for reform (University of Leeds 2013)

${ }^{433}$ Department of Health, Reference Guide to Consent for Examination or Treatment (2nd edn Department of Health 2009) Ch 3, para 15

${ }^{434}$ GMC, GMC 0-18 Guidance (GMC 2007) para 32
} 
capacity for choice and encourages them to take a responsible attitude towards such matters as contraception and other medical procedures that they wish to undergo.

But on the other hand,

...the law attempts to maintain the right to override their choice to refuse all treatment. Whilst it may be comprehensible for the law to refuse them the right to make life-threatening mistakes, it goes much further and enables parents and doctors to correct any decision they consider to be irrational or unreasonable, and not in the patient's best interests. ${ }^{435}$

As Daly, argued in 2020, "Although "Gillick competence" is supposed to be the standard for under-16s in England and Wales, the approach of the courts to assessing capacity can be vague and inconsistent.' ${ }^{\prime 36}$ The tension thus, continues into the present day and could arguably be rooted in age discrimination that results in children being discriminated against, even if they have been deemed to be competent to make decisions. The UN Committee on the Rights of the Child recommends 'if the adolescent is of sufficient maturity, informed consent shall be obtained from the adolescent her/himself, while informing the parents of what is in the best interest of the child' (art. 3). ${ }^{437}$ Interestingly, the Netherlands health care system is one of the most progressive in recognising the important balancing of the child's right to be protected and the child's competence to make decisions. ${ }^{438}$ Children of 12 years of age are presumed to be competent decision makers. ${ }^{439}$ De Vries and Rings, commenting on paediatric practice in the Netherlands said that:

\footnotetext{
${ }^{435}$ Fortin J, Children's Rights and the Developing Law (Cambridge University Press 2009) 182

${ }^{436}$ Daly A, 'Assessing Children's Capacity: Reconceptualising our Understanding through the UN Convention on the Rights of the Child', International Journal of Children's Rights, 2020 Volume 28 Issue 3, 494

${ }^{437}$ UN Committee on the Rights of the Child, General Comment No.4 Adolescent health and development in the context of the Convention on the Rights of the Child $\mathrm{CRC} / \mathrm{C} / \mathrm{GC} / 4 / 2003$ para 32

${ }^{438}$ De Vries M and Rings E, 'Children's Rights in Paediatric Practice,' In, Doek and Dorscheist (eds) Children's rights in Health Care (Brill Publications 2018)

${ }^{439}$ On July 11, 2017, the Court of Appeal in Amsterdam decided in favour of a 12 year-old boy, David, who had a brain tumor, but refused life- sustaining chemotherapy treatment (against the will of his father, but supported by his mother).
} 
Protection rights have always been the essence of paediatrics, since it is the discipline concerned with the medical well-being of children. Furthermore, best interest considerations are always at the core of paediatric work. It is an achievement that Dutch civil law gives formal power of decision-making to competent children in health care from the age of 12. It has made paediatricians mindful of the voice of children, and of the perspective children have on the medical encounter. ${ }^{440}$

The tension between paternalistic approaches and children's capacity for autonomous decision making, will be discussed further as part of considerations for the development of a CRA conceptual framework in Chapter 6. The right to consent to participate in research will be discussed in Chapter 8.

\subsection{Children's involvement in the monitoring and evaluation of health services}

Currently children in Wales are not consistently asked for their perspective regarding their experience of being a patient. ${ }^{441}$ The 2011 CoE study found that the majority of children across Europe had never been asked for their views on their patient experience or health policy making. ${ }^{442}$ With regards to children's primary care experience in England and Wales children under-16 years do not get asked their views in patient experience surveys ${ }^{443}$, available evidence only comes from smaller scale surveys and qualitative research. ${ }^{444}$

In a study undertaken by the NCB, the authors recommended that children and young people's experiences are taken into account when measuring the performance of

\footnotetext{
${ }^{440}$ De Vries M and Rings E, 'Children's Rights in Paediatric Practice' In, Doek J and Dorscheist M (eds) Children's rights in Health Care (Brill Publications 2018) 110

${ }^{441}$ Royal College of Paediatrics and Child Health, State of Child Health: 2017 Recommendations for Wales (RCPCH 2017); RCPCH State of Child Health: 2018 Recommendations for Wales (RCPCH 2018)

${ }^{442}$ Kilkelly U, Child Friendly Healthcare: The Views and Experiences of Children and Young People in the Council of Europe (Strasbourg: Council of Europe 2011)

${ }^{443}$ Royal College of Paediatrics and Child Health, State of Child Health: 2017 Recommendations for Wales (RCPCH 2017) 9

${ }^{444}$ Clements K, Opening the door to better health care: Ensuring General practice is working for children and young people (NCB 2013)
} 
general practice - not just those of adults. ${ }^{445}$ Nolan et al argue that a key component of the right to health, is that children are not only included in individual health decision making but at the systematic level of health policy and service delivery. ${ }^{446}$ According to the UN Committee on the Rights of the Child children should be asked for their views and perspectives on their experiences of health care, if health services are to be better designed to respond to their needs. As introduced in Chapter 2, children according to the General Comment No. 15 on health, should be encouraged to give their views on all:

aspects of health provision, including, for example, what services are needed, how and where they are best provided, barriers to accessing or using services, the quality of the services and the attitudes of health professionals. ${ }^{447}$

This requires children's involvement in the design, development, monitoring and evaluation of services. Children according to research carried out by NCB in 2012 want to have a role to play in shaping policy and the development of services. ${ }^{448}$ This is certainly not happening consistently across health systems in Europe ${ }^{449}$, however, in the last five years pockets of good practice have been emerging across the UK. Some health authorities are establishing Youth Advisory Groups and these are influencing the design and implementation of services. ${ }^{450} \mathrm{NHS}$ England and the British Youth Council have created a bitesize guide to setting up a youth forum in health services across England ${ }^{451}$, and the NHS England Youth Forum has created a range

\footnotetext{
${ }^{445} \mathrm{Ibid}$

${ }^{446}$ Nolan A, Yamin AE and Meier BM 'Submission on the Content of a Future General Comment on the Right of the Child to the Enjoyment of the Highest Attainable Standard of Health (art. 24) (OHCHR).

${ }^{447}$ UN Committee on the Rights of the Child, General Comment No. 15 on the right of the child to the enjoyment of the highest attainable standard of health $\mathrm{CRC} / \mathrm{C} / 15 / 2013$, para 19

${ }^{448}$ La Valle I, Payne L with Gibb J and Jelicic H, Listening to the views of children, A rapid review of the evidence (NCB 2012)

${ }^{449}$ Kilkelly U, Child Friendly Healthcare: The Views and Experiences of Children and Young People in the Council of Europe (Strasbourg: Council of Europe 2011)

${ }^{450}$ Nuffield Council of Bioethics, 'Statement of aspiration: Improving research by involving children and young people' (Nuffield Council of Bioethics 2015) accessed January 2020

${ }^{451}$ NHS England and British Youth Council, A bitesize guide to setting up a youth forum in services across England(NHS England 2015) https://www.england.nhs.uk/wp-content/uploads/2015/02/howto-guid-yth-forum.pdf accessed January 2020
} 
of resources about rights in health care. ${ }^{452}$ Generation $\mathrm{R}$ is a National Network (Generation R Alliance) of Young People's Advisory Group's (YPAGs) based across the UK. ${ }^{453}$ Groups are funded by the National Institute for Health Research (NIHR) and/or other NHS Organisations. The main purpose of the YPAGs is to support the design and delivery of paediatric research in England. Scotland also has its own advisory group which sits under the Scottish Children's Research Network. The Nuffield Council on Bioethics has issued a statement of aspiration in relation to the importance of Youth Advisory Groups influencing the design of paediatric research. ${ }^{454}$ Currently the Wales health infrastructure does not fund youth advisory groups to advise on paediatric research. The Welsh Government has been criticised for not funding such advisory groups. ${ }^{455}$ Although health is a devolved policy area (see Chapter 5 for discussion on devolved health policy) this indicates that there is a disparity in funding across the UK State party. Williams argues 'deficiencies experienced by one young person, and not the other flowing from different policy choices, or structural arrangements [in Wales and England], could be characterised as unequal access to $\mathrm{CRC}$ rights within the State party.' 456 However, two health boards, one being ABMU (see chapter 9 for further discussion) and the other being Cardiff and Vale University Health Board fund youth advisory groups to influence the development of their services.

\subsection{Children's right to complain}

Children must be given an appropriate mechanism to complain, this is recommended by the UN Committee on the Rights of the Child in General Comment No. 12,457 the

\footnotetext{
${ }^{452}$ For further information https://www.england.nhs.uk/participation/get-involved/how/forums/nhsyouth-forum/ accessed January 2020

${ }^{453}$ Generation R, https://generationr.org.uk/about// accessed January 2020

${ }^{454}$ Nuffield Council of Bioethics, 'Statement of aspiration: Improving research by involving children and young people' (Nuffield Council of Bioethics 2015)

${ }^{455}$ National Assembly for Wales Cross Party Group on Medical Research Fourth meeting of 2019, First Inquiry Session: Patient and public involvement, November $19^{\text {th }} 2019$

${ }^{456}$ Williams J, 'Multi-level governance and CRC implementation', In Invernizzi A and Williams J (eds.) The Human Rights of Children: From Visions to Implementation (Farnham: Ashgate 2011) 16 ${ }^{457}$ UN Committee on the Rights of the Child, General Comment No. 12: The right of the child to be heard, $\mathrm{CRC} / \mathrm{GC} / 12 / 2009$
} 
child's right to be heard and in relation to health care by General Comment No. $15 .{ }^{458}$ General Comment No.15 of the UNCRC recommends:

States to put in place functional and accessible complaints mechanisms for children that are community-based and render it possible for children to seek and obtain reparations when their right to health is violated or at risk. ${ }^{459}$

There has been no known research regarding children's ability to complain in health care settings in Wales, however, research in England, suggests that children in health care contexts face multiple barriers to their right to complain. ${ }^{460}$ In a study undertaken by the Children's Commissioner for England (CCfE), of the young people who had reported that they had been unhappy in their last visit to their GP, only a minority of these said they had told anyone about this. ${ }^{461}$ The children reported not knowing how to complain, not thinking that anybody would listen and act on their complaint and others were worried about what the reaction would be. There were also concerns reported regarding professionals handling of complaints, a lack of respect for confidentiality, and a negative perception towards the children who complained and limited training for staff members in how to handle complaints coming from children in an effective manner. ${ }^{462}$ The Children's Commissioner for England reported that services were failing in offering adequate support to ensure that the child's right to be heard and complain, was respected.

As CCfE recommends, good complaints systems help to ensure that services are accountable for their decisions and actions that affect children. ${ }^{463}$ This can help a progressive organisation to reflect on its shortcomings and to strive to improve,

\footnotetext{
${ }^{458} \mathrm{UN}$ Committee on the Rights of the Child, General Comment No. 15 on the right of the child to the enjoyment of the highest attainable standard of health $\mathrm{CRC} / \mathrm{C} / 15 / 2013$ para 119

${ }^{459}$ UN Committee on the Rights of the Child, General Comment No. 15 on the right of the child to the enjoyment of the highest attainable standard of health CRC/C/15/2013, para 119

${ }^{460}$ Children's Commissioner for England Child Friendly Complaints Processes in Health Services, Principles, Pledges and Progress' Children's Commissioner for England (CCfE 2013)

${ }^{461}$ Children's Commissioner for England, It takes a lot of courage - Children and young people's experiences of complaints procedures for services for mental health and sexual health including those provided by GPS' (CCfE 2012) 84-85

${ }^{462}$ Ibid 84-85

${ }^{463}$ Children's Commissioner for England, Child, Friendly Complaints Processes in Health Services, Principles, Pledges and Progress (CCfE 2013)
} 
responding to the needs of children. ${ }^{464}$ Children's complaints should always be investigated and addressed, and children should always be informed within a defined time period of the outcome of any investigation.

As outlined in Chapter 2, the UN Committee on the Rights of the Child, recommends that effective remedies should be accessible to the child where the decision-making process has not adhered to appropriate standards, including child friendly complaints mechanisms. ${ }^{465}$ Children's use of complaints mechanisms will be further discussed in Chapter 5, 6 and 9.

\subsection{Design and provision of child friendly health services}

Research across Europe suggests that children have strong views on their experiences in health care settings. ${ }^{466}$ Adolescents in particular, have called for healthcare environments to be designed in ways that respect their privacy during consultations and procedures, and their right to confidential advice and counselling to be respected. ${ }^{467}$ Offering resources and facilities that support children's human right for play and recreation (Article 31 of the UNCRC) has been highlighted as important to younger children across a range of different health care settings. ${ }^{468}$ In the CoE study, children's access to play and recreation is reported as inadequate ${ }^{469}$ and children

\footnotetext{
${ }^{464}$ Ibid

${ }^{465} \mathrm{UN}$ Committee on the Rights of the Child, General Comment No. 15 on the right of the child to the enjoyment of the highest attainable standard of health $\mathrm{CRC} / \mathrm{C} / 15 / 2013$ para 119

${ }^{466}$ Kilkelly U, Child Friendly Healthcare: The Views and Experiences of Children and Young People in the Council of Europe (Strasbourg: Council of Europe 2011); La Valle I, Payne L with Gibb J and Jelicic H, Listening to the views of children, A rapid review of the evidence (NCB 2012); Tylee A, Haller DM, Graham T, Churchill R, Sanci LA, 'Youth-friendly primary-care services: how are we doing and what more needs to be done?' The Lancet (2007) 269, 1565-73; Boylan P Children's Voices Project: Feedback from Children and Young People about their Experience and Expectations of Healthcare (Commission for Health Improvement National Health Service 2004)

${ }^{467}$ Kilkelly U, Child Friendly Healthcare: The Views and Experiences of Children and Young People in the Council of Europe (Strasbourg: Council of Europe 2011)

${ }^{468}$ La Valle I, Payne L with Gibb J and Jelicic H, Listening to the views of children, A rapid review of the evidence (NCB 2012); Lambert V, Glacken M, and McCarron M, "Visible-ness": the nature of communication for children admitted to a specialist children's hospital in the Republic of Ireland, Journal of Clinical Nursing (2008) 17, 3092-3102; Koller D, Nicholas D, Gearing R and Kalfa O, 'Paediatric pandemic planning: children's perspectives and recommendations', Health and Social Care in the Community' (2010) 18, 396-377

${ }^{469}$ Kilkelly U, Child Friendly Healthcare: The Views and Experiences of Children and Young People in the Council of Europe (Strasbourg: Council of Europe 2011); Migone M, McNicholas F, and Lennon R. 'Are we following the European Charter? Children, parents and staff perceptions', (2008) Child: Care, Health and Development, 34, 409-417
} 
expressed that they experience boredom and anxiety when waiting for appointments. ${ }^{470}$ Children have identified the importance of facilities that are developmentally appropriate, separate adolescent facilities, bright décor and appropriate furniture. Children also report benefiting from organised play activities supervised by play specialists supporting children to alleviate stress and anxiety. ${ }^{471}$

\section{A 2015 study highlighted that:}

The role of play and recreation is significant for all children, who want playful activities and facilities reflected throughout the whole environment. This needs to be appropriate to the age and developmental stage of the child and may require separate facilities to be provided i.e., play room for very young children, play facilities for children in middle childhood and chill out areas for young people that offer recreational activities. ${ }^{472}$

Another factor of significant importance to the majority of children in the CoE study was having their family with them or nearby during treatment to help them feel safe and secure. ${ }^{473}$ Children also want to have access to services that are coordinated and offered as continuum of care. ${ }^{474}$ Children want access to health information and what other services are available to support them. ${ }^{475}$ Children in accordance with their Article 12 UNCRC right to be involved in all decisions that impact on them, should be supported to influence the design of child-friendly health services.

\footnotetext{
${ }^{470}(37.5 \%)$ of the children who participated in the CoE survey reported being bored while they waited for their healthcare appointment, while $19.9 \%$ of children felt anxious and a further $7.9 \%$ said that they were in pain.

${ }^{471}$ Kilkelly U and Savage E, Child friendly health care; A report commissioned for the ombudsman for children (Ombudsman for Children 2013)

${ }^{472}$ NHS England, Healthcare Play Specialist Education Trust Children's Environments of Care Report, Exploring the impact environments have on children and young people's experience of healthcare: a review of the literature for NHS England (NHS England May 2015)

${ }^{473}$ Kilkelly U, Child Friendly Healthcare: The Views and Experiences of Children and Young People in the Council of Europe (Strasbourg: Council of Europe 2011); La Valle I, Payne L with Gibb J and Jelicic H, Listening to the views of children, A rapid review of the evidence (NCB 2012).

${ }^{474}$ Kilkelly U and Savage E, Child friendly health care; A report commissioned for the ombudsman for children (Ombudsman for Children 2013) 27

${ }^{475}$ National Children's Bureau Children and Young People's Views on Health and Health Services: A Review of the Evidence (London: National Children's Bureau 2005)
} 


\subsection{Discrimination and inequality impacting on children's right to health}

Many children face health inequalities due to living in poverty and the area which they live. ${ }^{476}$ Goldhagen and Mercer argue that disparities in health are not the result of 'race, poverty or gender, but racism, classism and sexism' 477 , and Webb who coined the term 'childism' which she describes as discrimination towards children, argues has a dramatic impact on children's health status. ${ }^{478}$ Huber et al report that a children's right to health is challenged by health systems that are unaffordable, inequitable, poor quality and difficult to access. ${ }^{479}$

The Parliamentary Assembly for the CoE argues there needs to be adequate funding for public health systems, improved data collection and a commitment to tackling the social determinants of health. ${ }^{480}$ The CoE Parliamentary Assembly reported that due to the climate of fiscal austerity, children across Europe are experiencing greater difficulty in accessing health care, denying children the right to the highest attainable standard of health. They state that:

Cuts applied to public budgets under austerity programmes regularly ignore the specific needs of children and the short- and long-term consequences that limited support to them may cause for their personal well-being, development and equal opportunities, as well as, in the long-term, for society on the whole. ${ }^{481}$

\footnotetext{
${ }^{476}$ Anwar E, Barr B, Law C, Taylor-Robinson D, 'Poverty and child health in the UK: using evidence for action BMJ Archives of Diseases of Childhood, (2016) Vol 101, Issue 8

${ }^{477}$ Goldhagen and Mercer, 'Child Health Equity: From Theory to Reality, in Invernizzi A and Williams J (eds) The Human Rights of Children: From Visions to Implementation (Farnham: Ashgate 2011) 307

${ }^{478}$ Webb E, 'An exploration of the discrimination-rights dynamic', In Invernizzi A and Williams J (eds) The Human Rights of Children: From Visions to Implementation (Farnham: Ashgate 2011) 290 ${ }^{479}$ Huber M, Stanciole A, Wahlbeck K, Tasma N, Torres F, Jelfs E and Bremner J Equality in and Equality of Access to Health Care Services (Brussels: European Commission 2008)

${ }^{480}$ Parliamentary Assembly CoE Ensuring access to healthcare for all children in Europe, Report 1 Committee on Social Affairs, Health and Sustainable Development Rapporteur: Ms Stella KYRIAKIDES, Cyprus, Group of the European People's Party (2016)

${ }^{481}$ Ibid 4
} 
States have obligations to fulfil the child's right to highest attainable standard of health and to deliver quality health services. According to the CoE Parliamentary Assembly some of the legal, financial, cultural or geographical barriers for certain groups are:

a lack of insurance coverage (in the Welsh context asylum seekers,); the inability of affording the direct costs of care (e.g. for low-income groups); a lack of mobility (e.g. for disabled persons); a lack of language competence (for migrants and ethnic minorities); a lack of access to information (for the poorly educated, migrants or ethnic minorities); time constraints (e.g. for single mothers); specific financial barriers for low-income groups and patients with chronic diseases; health literacy and health beliefs (including certain traditions and cultural practices) of specific social groups, also hindering access to facilities and information on sexual and reproductive health; uneven geographical coverage and lack of healthcare services. ${ }^{482}$

Children's dependency on adult caregivers, their socio-economic status, educational level, health literacy (e.g., understanding of their body, causes, symptoms and implications of diseases) affects their ability to access good health (e.g., healthy living conditions, good nutrition, good lifestyles, non-violent home conditions etc) or quality health care, and ability to navigate and access complex national health systems. ${ }^{483}$ The report by the Parliamentary Assembly, argues that there is a need for further research to determine:

In which ways [children] are they hindered or discriminated against in their access to healthcare? Which are the main categories of children in need of special support in accessing healthcare services? ${ }^{484}$

The report carried out a limited assessment of these questions but stated that a further scoping should be undertaken across Europe. ${ }^{485}$

\footnotetext{
${ }^{482}$ Ibid 7

${ }^{483}$ Ibid 7

${ }^{484}$ Ibid 4

${ }^{485}$ Parliamentary Assembly CoE Ensuring access to healthcare for all children in Europe, Report 1 Committee on Social Affairs, Health and Sustainable Development Rapporteur: Ms Stella

KYRIAKIDES, Cyprus, Group of the European People's Party (2016)
} 
Webb also talks of children's marginalisation, when children are relegated to the status of non-persons and are not even seen as the part of core business or service. ${ }^{486}$ In other words children are often invisible in the development of services and children's needs as service users are not taken into account. For example, in a study undertaken by Clements, into primary health care services in England, service arrangements were not designed around the needs of school age children because services were primarily delivered during school time (primarily close by $6 \mathrm{pm}$ ) and not on the weekend and children were either forced to access out of hours services at a further distance away from their home or take time out of school. Also of concern was the limited availability of consultant paediatricians in acute settings at out of hours time periods. ${ }^{487}$ In a recent report by some of the main children's charities in the UK, services are also currently not appropriately designed to support the needs of vulnerable older teenagers (16/17 year olds) who find themselves slipping through the gap, i.e., not provided effective support by either children's or adults services. ${ }^{488}$ These are just some examples of how services are not designed around the needs of the service user (i.e. the child) and are designed to suit the health professional. ${ }^{489}$ Clement's research suggests that children have poor experiences of health care and that in particular vulnerable groups struggle to make the most of these services. ${ }^{490}$

There is evidence which suggests that children are rarely included in important health decisions ${ }^{491}$ or the setting of budgetary policies, their material needs, and interests are subsumed into the unit of analysis of the household. ${ }^{492} \mathrm{~A}$ children's rights perspective

\footnotetext{
${ }^{486}$ Webb E, 'An exploration of the discrimination-rights dynamic', In Invernizzi A and Williams J (eds) The Human Rights of Children: From Visions to Implementation (Farnham: Ashgate 2011) 291

${ }^{487}$ Clements K, Opening the door to better health care: Ensuring General practice is working for children and young people (NCB 2013) 22

${ }^{488}$ Hill A, 'UK children's health 'harmed by gap with adult services' Guardian Online (28 ${ }^{\text {th }}$ April 2019) https://www.theguardian.com/society/2019/apr/28/uk-childrens-health-harmed-by-gap-with-adultservices accessed January 2020

${ }^{489}$ Clements K, Opening the door to better health care: Ensuring General practice is working for children and young people (NCB 2013) 22

${ }^{490}$ Clements K, Opening the door to better health care: Ensuring General practice is working for children and young people (NCB 2013)

${ }^{491}$ Modi N, 'Top paediatrician says it's time to give parents extra votes for their children' Guardian Online (January $23^{\text {rd }} 2018$ ) https://www.theguardian.com/society/2018/jan/23/top-paediatrician-saysits-time-to-give-parents-extra-votes-for-theirchildren accessed January 2020

${ }^{492}$ Eurochild, 'A Child rights to child poverty: Discussion paper' (2007) [online, Eurochild] https://www.eurochild.org/fileadmin/public/05 Library/Thematic priorities/01_Childrens Rights/Eur ochild/Eurochild_discussion_paper_child_rights_poverty.pdf accessed January 2020
} 
sees children as the units of observation, instead of being rendered invisible in decision making or research. ${ }^{493}$ Children's health services in the UK are consistently allocated the smallest proportion of overall budgets. For example, according to the Children's Rights Information Network, the budget available in the UK for child and adolescent mental health services in 2009 was only $5 \%$ of the total mental health budget even though children represent $25 \%$ of the population. ${ }^{494}$ When the UK Government first developed the National Service Framework (NSF) for Health, children were not included until civil society put pressure on Government. ${ }^{495}$ Even when children were included they were not accompanied with the same resources and investment as the disease-centred NSFs. ${ }^{496}$ A review undertaken by Kennedy in 2010 stated:

Children and young people receive a disproportionately lower priority than adults in the imperatives of management and delivery, in the relative funding allocated, and in the realisation that investment in the care of children and young people will reduce the cost of care later in life. ${ }^{497}$

There is also evidence that children are discriminated against with regards to the accessing of essential medicines. ${ }^{498}$ The prevailing research and development (R\&D) model is ill-prepared to respond to populations such as children with little purchasing/voting power, which sees children neglected in current clinical research. It is argued that the current R\&D model is largely market driven and is not designed to address these challenges. ${ }^{499}$

\footnotetext{
${ }^{493}$ Ibid

${ }^{494}$ CRIN 'Guide to non-discrimination and the CRC' (Child Rights Information Network 2009) http://www.crin.org/Discrimination/CRC/index.asp accessed March 2018

${ }_{495}$ Aynsley-Green A, Barker M, Burr S, Macfarlane A, Morgan J, Sibert J, Turner T, Viner R, Waterston T, Hall D, 'Who is speaking for children and adolescents and for their health at the policy level?’ BMJ (2000) 321

${ }^{496}$ Ibid

${ }^{497}$ Kennedy I, Getting it right for children and young people: Overcoming cultural barriers in the NHS so as to meet their needs (Department of Health 2010) 8

${ }^{498}$ As acknowledged in Chapter 2 of this thesis, access to essential medicines is a minimum core obligation of the right to health. UN Committee on Economic, Social and Cultural Rights, General Comment No.14: the Right to the Highest Attainable Standard of Health. E/C.12/2000/4 para 43

${ }^{499}$ Royal College of Paediatrics and Child Health, Turning the tide-five years on (RCPCH 2018) 7 https://www.rcpch.ac.uk/sites/default/files/2018-03/turning the tide - five years on 2018-03.pdf accessed January 2020
} 
Access to medicines can be a challenging goal for children who are a marginalised group who have limited opportunity to voice their opinion on funding to secure medicines they need. Many medicines essential for treating childhood conditions are not licensed for use in children and very often information about their use is not widely available. ${ }^{500}$ Children are often not in receipt of medicines that are commensurate with their age, physical condition and body weight and can experience inaccurate dosing. ${ }^{501}$ This off label use (i.e. the medicine is being used in a way that is different to that described in the licence) of medicines questions the efficacy and safety of the treatment. This may contribute to negative side effects that would not have the same implications in adults. ${ }^{502}$ Medicines are also not always available in a pharmaceutical format suitable for children. Medicines are often prescribed based on a physician's interpretation of what is appropriate for the child rather than rigorous clinical testing. ${ }^{503}$ Pharmaceutical companies are not as interested in carrying out research into medicines for such small sub-sets of the population due to medicines being appropriate to the different developmental needs of the age groups of children e.g. neonates compared to teenagers. ${ }^{504}$ This means that companies proactively refrain from investing because of low profit return.

In 2018, the UK RCPCH reported that funding for child health research has been decreasing year on year since $2012 .{ }^{505}$ Research in children is critically important as many paediatric interventions still lack the evidence base their adult counterparts take for granted and improvements in health care in children will potentially have the longest (lifetime) impact. In 2007 the EU Paediatric Regulation came into force with the aim of increasing the number of medicines tested for the paediatric population.

\footnotetext{
${ }^{500}$ Report from the Commission to the European Parliament and Council, State of Paediatric Medicines in the EU 10 years of the EU Paediatric Regulation (COM 2017 626) https://ec.europa.eu/health/sites/health/files/files/paediatrics/docs/2017 childrensmedicines report en .pdf accessed January 2020

${ }_{501}$ In 2007 the WHO launched a global programme called 'Make medicines child size' https://www.who.int/childmedicines/en/ accessed January 2020

${ }_{502}$ Report from the Commission to the European Parliament and Council, State of Paediatric Medicines in the EU 10 years of the EU Paediatric Regulation (COM 2017 626)

${ }^{503}$ Ibid 5

${ }^{504}$ Ibid 5

${ }^{505}$ Royal College of Paediatrics and Child Health, Turning the tide-five years on (RCPCH 2018) 26: The proportion of total expenditure on child health research rose to $8.5 \%$ in $2011-12$, but then fell year on year to $5.4 \%$ in $2015-16$.
} 
Prior to the application of this legislation $50 \%$ of all drugs were being prescribed to children without the relevant Marketing Authorisation, this was reported to be as high as $90 \%$ for the neonatal population. ${ }^{506}$ A 10-year report on the Regulation was published in 2018 507 , which showed that although there has been an increase in the number of medicines available for the paediatric population it is disappointing that where diseases are unique or rare to children but could be supported by what is called the European Orphan legislation. This report stated that:

significant therapeutic advances have not happened. For example, the pace of advances observed in adult therapies is so far not mirrored in paediatric patients. In some paediatric cancers the most used medicines date back to the 1990s, if they exist at all. ${ }^{508}$

This is another example of how children can be discriminated against, and their health needs neglected as compared to adults.

\subsection{Conclusion}

Research into the realisation of a children's right to health in practice, illustrates that much needs to be done with regards to mainstreaming the approach and educating and developing the capacity of health professionals and managers to effectively implement it. There is clear agreement that training is pivotal in helping professionals to understand how to mainstream a CRA in practice. Additionally, the process of mainstreaming is more successful if senior leadership is committed to supporting implementation of children's rights across health care settings and if the wider policy and legislative environment is supportive of human rights. There have been examples of international research designed to understand the successes and the challenges of mainstreaming and implementing children's rights in health care contexts. Learning from how these research studies were designed to gather information from health

\footnotetext{
${ }^{506}$ EU working paper 13880/04

${ }^{507}$ Report from the Commission to the European Parliament and Council, State of Paediatric Medicines in the EU 10 years of the EU Paediatric Regulation (COM 2017 626)

${ }^{508}$ Ibid 13
} 
professionals and children are essential to the development of research tools in the Welsh context.

Children's participation in clinical decision making and their influence over the monitoring and design and implementation of services as well as their ability to complain is still limited. However, across the UK there are pockets of good practice emerging that will be useful in the context of progressing a CRA to health services in the Welsh health context.

Children are still being discriminated against with regards to accessing health services and children are still not being empowered to claim their human rights, such as rights to privacy and confidentiality, the right to access essential medicines, the right to play and right to information and access to resources that support the fulfilment of all their health rights.

It is also apparent that there needs to be more research carried out to understand what the barriers are impeding children in accessing their human rights and how we can better assist health professionals to meet their human rights obligations towards children. In a review of the research there were no studies that specifically focused on children's rights and delivery of health services in the Welsh context or as a part of international studies, which makes the case study investigation of a health board in Wales in Part 2 of this thesis an important contribution to the knowledge on this subject. 


\section{CHAPTER 5 POST DEVOLUTION POLICY AND LEGISLATION IMPACTING ON THE HEALTH OF CHILDREN IN WALES}

\subsection{Introduction}

The previous chapters have given consideration to human rights approaches to health and human rights approaches to children and the key elements of such approaches. Children's right to health and children's human rights approaches to health have been considered as well as the key themes from the research concerning their application in practice.

A range of different legal and policy initiatives have addressed healthcare, children's health and general children's issues since devolution in Wales. The following chapter presents an overview to some of the key developments in law and policy, firstly concerning health policy generally and then more specifically for children in Wales. Understanding of the legal and policy framework is critical to making any conceptual framework for a CRA to health services applicable to the Welsh context and mainstreaming a CRA will always be more successful if the legislative and policy environment is supportive of children's rights.

\subsection{Health policy $1999-2011$}

Wales is located to the west of England in the United Kingdom and has a population of approximately 3 million people, of which 633,400 are children (0-17 years). ${ }^{509}$ Between 1965 and 1999, Wales had a health system largely administered through the United Kingdom Government's Welsh Office. Following the 1998 referendum on devolution, Wales had greater opportunity to shape health policies designed specifically to meet the needs of the Welsh people. ${ }^{510}$ The Government of Wales Act 1998 (GOWA 1998) $)^{511}$ granted powers and duties in areas such as agriculture, culture, economic development, education, health, housing, local government, social services

\footnotetext{
${ }^{509}$ Office of National Statistics Wales 2012

${ }^{510}$ Michael P, Public Health in Wales 1800-2000: A brief history. This work was commissioned by the Chief Medical Officer for Wales to mark the Faculty of Public Health Conference held in Cardiff on June 3-5, 2008.

${ }^{511}$ Government of Wales Act (2006) http://www.legislation.gov.uk/ukpga/2006/32/contents accessed February 2020
} 
and planning to be transferred from the UK Government, so that the National Assembly would become responsible for carrying those out in respect of Wales. The key policy document adopted by the Welsh Assembly Government (WAG) was entitled Better Wales. Wales was seen to be disadvantaged in relation to England on a whole range of health indicators. ${ }^{512}$ Better Wales stated that 'the Government wishes to tackle the underlying causes of ill-health through a new approach which recognises and addresses the factors which impact on health.'513 It proposed promoting sustainable health and well-being looking at the social determinants to health and promoting a preventative approach. Within the report was a clear focus on children, with the Welsh Office $^{514}$ making a commitment to focussing on children's health and well-being as an investment for the future, building on their 1997 report The Health of Children in Wales. ${ }^{515}$

Improving Health in Wales: A Plan for the NHS with its partners was launched in 2001, to improve the health service in Wales, to prevent disease and ill health, to promote and strengthen primary care and tackle health inequalities. ${ }^{516}$ It referred specifically to children in the context of access to dental treatment and optometry in the community, as well as concerns that more specialist community nursing and palliative teams were required for children because they historically focused more on the older population. ${ }^{517}$ It promised to modernise hospital services and promote patient involvement. In 2001, to put children at the centre of health services, Lord Carlisle recommended that the WAG 'should produce and disseminate effectively two new NHS children's charters, one aimed at parents and the other at the older range of children themselves'. ${ }^{518}$ In 2020 this has still not happened. ${ }^{519}$

\footnotetext{
${ }^{512}$ Michael P, Public Health in Wales 1800-2000: A brief history.

${ }^{513}$ Welsh Office, Better Health-Better Wales (Welsh Office 1998) para 1 http://www.wales.nhs.uk/publications/greenpaper98 e.pdf accessed June 2018

${ }^{514}$ For several decades in the $20^{\text {th }}$ century Wales was administered through the United Kingdom Government's Welsh Office.

${ }^{515}$ Welsh Office, Better Health-Better Wales (Welsh Office 1998) 19, para 3

${ }^{516}$ NHS Wales, Improving health in Wales: A Plan for the NHS with its Partners (NHS Wales 2001)

${ }^{517}$ Ibid 20

${ }^{518}$ Lord Carlisle, The Review of Safeguards for Children and Young People Treated and Cared for by the NHS in Wales, "Too Serious a Thing" (National Assembly for Wales 2001) 134

http://www.wales.nhs.uk/publications/English text.pdf accessed January 2020

${ }^{519}$ Individual health boards, both ABMU and Cardiff and Vale University Health Board have developed their own Children's Rights Charters in 2017 and 2018 respectively.
} 
The regulator of quality in the NHS was the Commission for Health Improvement until 2004. After 2004 the Healthcare Inspectorate Wales (HIW) was established which regulates the NHS and the independent sector in Wales. NICE however still sets clinical standards. ${ }^{520}$

Following the 2007 Assembly Elections, the newly-formed Labour/Plaid Cymru Coalition Government, produced One Wales ${ }^{521}$ (2007 - 2011), the programme for devolved government in Wales. A Healthy Future, set out six key objectives for the programme of government:

- Reviewing NHS reconfiguration.

- Strengthening NHS finance and management.

- Developing and improving health services in Wales.

- Ensuring access to health care.

- Improving patients' experience,

- Supporting social care. ${ }^{522}$

These objectives built on previous Assembly Governments' strategies, Designed for Life, ${ }^{523}$ published in May 2005, and Improving Health for Wales: A Plan for the NHS with its Partners (2001).

The WAG was developing policies that were distinctively different to England, for example with regards to:

- Ending the internal market.

- Eliminating the use of private hospitals by the NHS in Wales by 2011.

\footnotetext{
${ }^{520}$ For further detail of the regulatory framework for health services in Wales, Longley M, Riley N, Davies P, Hernandez-Quevedo C United Kingdom (Wales), Health system review Health Systems in Transition, Vol 14 (11), 16

${ }^{521}$ Welsh Assembly Government, One Wales: A progressive agenda for the government of Wales (Welsh Assembly Government 27 June 2007)

${ }^{522}$ Health Policy a Topic Brief, National Assembly Research Service 2007

http://www.assembly.wales/NAfW\%20Documents/tb-08-003.pdf\%20-\%2028072009/tb-08-003-

English.pdf accessed February 2020

${ }^{523}$ NHS Wales, Designed for Life, (NHS Wales May 2005)

http://www.wales.nhs.uk/documents/designed-for-life-e.pdf accessed February 2020
} 
- Ruling out the use of Private Finance Initiative in the Welsh NHS during the third term of government.

- Seeking legislative competence in relation to mental health.

- Maintenance of free prescriptions.

- Reforming charges for hospital parking and in-patients' access to telephones and televisions.

- Developing a democratic and localised consultation process for reconfiguration proposals.

- Building up the Community Dental Service and employing more salaried dentists. ${ }^{524}$

Wales chose to abolish the purchaser/provider split, not willing to accept that competition is the best model to support quality improvement. ${ }^{225}$ The system could be described as a 'planned' system based on unified decision making. ${ }^{526}$ The WAG had overarching responsibility for planning of the system. With Local Health Boards (LHBs), Trusts and Local Authorities, responsible for management and operational mechanisms (This system of management changed in 2009, see later section). All 22 local authorities in Wales at this time had Health, Social Care and Well-being strategies, working together with LHBs to deliver health services for their communities. Local authorities in Wales also had responsibilities for delivering initiatives under Health Challenge Wales, the WAG's overarching concept for health improvement policy initiatives and statutory obligations on local government. ${ }^{527}$

Further devolution brought more legislative power regarding health. Under the Government of Wales Act 2006, the National Assembly for Wales could seek legislative competence through Acts of Parliament or Legislative Competence Orders (LCOs) to make a piece of law in the form of an 'Assembly Measure'. Measures could only be made in a specific policy area (or 'Matter') added to one of the 20 'Fields' (or broad subject areas) which were contained in Schedule 5 of the Act. As 'Health and

\footnotetext{
${ }^{524}$ Health Policy a Topic Brief, National Assembly Research Service 2007

${ }^{525}$ Organisation for Economic Co-operation and Development, Reviews of Health Care Quality: United Kingdom (OECD 2016) 186

${ }^{526}$ Ibid 186

${ }^{527}$ Information on Health Challenge Wales (February 1st 2005) http://www.wales.nhs.uk/news/2991 accessed January 2020
} 
health services' was Field 9 of Schedule 5 to the Act, the National Assembly for Wales could seek Measure-making powers in this area. Devolution was furthered in 2011, when the National Assembly gained the competence to make Acts of the Assembly, under schedule 7 all the matters were filled within the fields and the Assembly had full competence. ${ }^{528}$

For example, section 9 of schedule 7 covers:

Health and Health Services:

- Strand 1 - Promotion of health. Family planning.

- Strand 2 -Prevention, treatment and alleviation of disease, illness, injury, disability and mental disorder. Control of disease.

- Strand 3 - Provision of health services, including medical, dental, ophthalmic, pharmaceutical and ancillary services and facilities.

- Strand 4 - Clinical governance and standards of health care. Organisation and funding of the National Health Service. ${ }^{529}$

- The eleven health subject specific exceptions i.e. areas reserved to the UK Government are:

- Abortion.

- Human genetics, human fertilisation, human embryology, surrogacy arrangements.

- Xenotransplantation.

- Regulation of health professionals (including persons dispensing hearing aids).

- Poisons.

- Misuse of and dealing in drugs.

- Human medicines and medicinal products, including authorisations for use and regulation of prices.

- Standards for and testing of, biological substances (that is, substances the purity or potency of which cannot be adequately tested by chemical means).

\footnotetext{
${ }^{528}$ Acts of the Assembly still require Royal Assent to become legislation and section 107 (5) states that the UK Parliament can still make laws for Wales.

${ }^{529}$ Law Wales, Helping you to understand Welsh law https://law.gov.wales/publicservices/healthservices/what-is-devolved-health/?lang=en\#/publicservices/health-services/what-is-devolvedhealth/?tab=overview\&lang=en accessed January 2020
} 
- Vaccine damage payments.

- Welfare foods.

- Health and Safety Executive and Employment Medical Advisory Service and provision made by health and safety regulations. ${ }^{530}$

The NHS (Wales) Wales Act 2006 is the piece of legislation most pertinent to the delivery of the NHS in Wales. ${ }^{531}$ Most of the business of NHS bodies is conducted in accordance with powers contained in the NHS (Wales) Act 2006 and the arrangements set out within the relevant Constitution, Membership and Procedures Regulations. All NHS bodies must also operate within the wider legislative framework governing all UK organisations. The NHS (Wales) Act 2006 consolidates a range of regulatory requirements relating to the promotion and provision of the health service in Wales. It sets out:

- Welsh Ministers' duty to promote health services.

- General power to provide services.

- Provision of particular services.

- Provision of services otherwise than in Wales.

- NHS Contracts.

- Provision of services otherwise than by Welsh Ministers. ${ }^{532}$

With regards to funding for health services, the Welsh Government (WG) receives its funding from a Block Grant from the UK Government, based on per head population allocations made by what is referred to as the Barnet Formula. ${ }^{533}$ The adequacy of this funding allocation was called into question by the WG in 2008 which argued that Wales was underfunded according to its needs, and based on the same formula there was an inequity in the calculations as compared to per head of the population in England. ${ }^{534}$

\footnotetext{
${ }^{530}$ Ibid

${ }^{531}$ NHS Wales Act (2006) http://www.legislation.gov.uk/ukpga/2006/42/contents accessed January 2020

${ }^{532}$ NHS Wales Governance E Manual http://www.wales.nhs.uk/governance-emanual/primarylegislation accessed February 2020

533 Organisation for Economic Co-operation and Development, Reviews of Health Care Quality: United Kingdom (OECD 2016) 190

${ }^{534}$ For a more detailed analysis of the Barnett Formula's impact on funding to Wales, National Assembly for Wales, The Barnett Formula: Funding the Devolved Administrations (NAfW 2008)
} 
The Barnet Formula was more recently challenged in 2019 by a Public Accounts Committee report that argued that there is a lack of transparency about how the funding decisions are made and the lack of detailed information made it challenging for Parliament to scrutinise them. ${ }^{335}$ Other concerns outlined in the report suggested that the UK Treasury does not know whether the block grant reflects the needs of UK citizens, as the funding is usually just rolled forward and does not reflect changes in population. Additionally, the devolved administrations are not always given enough time to review and challenge the Treasury's decisions. ${ }^{536}$

In 2009, the NHS in Wales was reconfigured. NHS Wales became led by the Welsh Government Minister for Health and Social Services, and the Director General for Health and Social Services, the Chief Executive of the NHS Wales supported by the Department of Health and Social Care and governed through seven LHBs and three NHS Trusts (Welsh Ambulance Services Trust, Public Health Wales, Velindre NonSurgical Cancer Trust and Blood Services). Welsh Health Specialised Services Committee (WHSSC), which is accountable to the seven LHBs is responsible for commissioning specialist care. ${ }^{537} \mathrm{LHBs}$ are responsible for coordination of primary and secondary services in their area.

Patient and public involvement is the statutory responsibility of the 8 Community Health Councils $(\mathrm{CHC})$ (that for the most part share the same boundaries as the LHBs). See a helpful diagram below (Diagram 3 ) by Longman et al that visually depicts the Welsh health system and see Diagram 1 for map of the 7 health boards in Chapter 1.538

\footnotetext{
http://www.assembly.wales/NAfW\%20Documents/09-012.pdf\%20-\%2026032009/09-012English.pdf accessed January 2020

${ }^{535}$ UK Parliament, Public Accounts Committee Report (UK Parliament July 2019) https://publications.parliament.uk/pa/cm201719/cmselect/cmpubacc/1751/175102.htm accessed January 2020

${ }^{536}$ Ibid

${ }^{537}$ Specialist services such as highly specialised cancer and mental health services.

${ }^{538}$ For further detail of the regulatory framework for health services in Wales, Longley M, Riley N, Davies P, Hernandez-Quevedo C.United Kingdom (Wales), Health system review Health Systems in Transition, Vol 14 (11)
} 


\section{DIAGRAM 3}

Overview of the Welsh health system

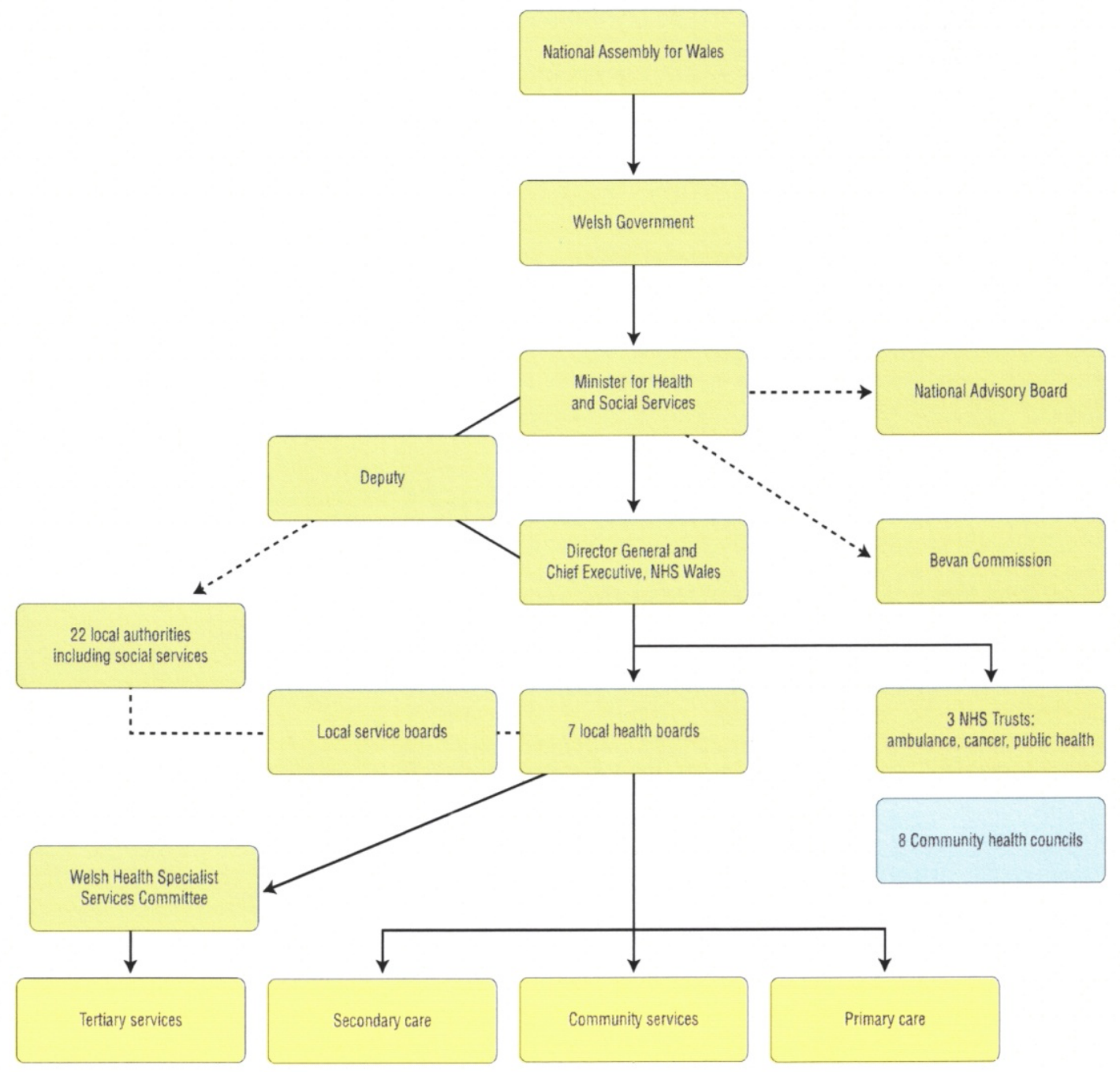

Source: Longley M et al (2012). ${ }^{539}$

The LHBs plan and commission all services locally, the exception being the more specialised Trusts, and Special Services Committees. ${ }^{540}$ The 22 local authorities in Wales and other non-statutory partners have a statutory obligation to work with NHS Wales through local strategic partnerships. ${ }^{541}$ NHS Wales receives the majority of its funding from the Welsh Government to cover running health services on an annual

\footnotetext{
${ }^{539}$ Ibid 10

${ }^{540}$ Organisation for Economic Co-operation and Development, Reviews of Health Care Quality: United Kingdom (OECD 2016)198 and 192

${ }^{541}$ Longley M, Riley N, Davies P, Hernandez-Quevedo C, United Kingdom (Wales), Health system review Health Systems in Transition, Vol 14 (11) 10
} 
basis. This takes the form of revenue allocations to local health boards to secure hospital, community and primary care services for the local populations and capital allocations to local health boards and NHS trusts for operational and strategic developments. ${ }^{542}$

The structural changes in 2009 aimed to improve partnership working between health and social care as well as better integration within healthcare. ${ }^{543}$ The new structure focused on the patient, local planning and transparency. ${ }^{544}$ Also at this time, Our healthy future: A strategic framework for public health in Wales was developed, which included an ambition for organisations and individuals to work together to improve and protect the health of the population. ${ }^{545}$ In 2010, Setting the direction, primary and community service: A strategic delivery programme was established with the aim of using integration to meet the needs of the community. ${ }^{546}$ It proposed achieving this through localities/GP cluster networks ${ }^{547}$, care coordination and multi-disciplinary teams. A report by the OECD recognised these structures as developing a more engaged and coordinated primary sector. ${ }^{548}$

\subsection{Health policy $2011-2019$}

In 2011, the next significant strategy on health was developed for Wales, Together for health, ${ }^{549}$ the WG's five year plan for the NHS, based on putting patients at the centre of care, delivering care closer to home within a more integrated network. In 2012, Working differently, working together: A framework to support the development of a fully integrated healthcare organisation, included planning, financial and services to develop appropriate staffing models across integrated networks of care was

\footnotetext{
${ }^{542}$ Ibid 10

${ }^{543}$ Organisation for Economic Co-operation and Development, Reviews of Health Care Quality:

United Kingdom (OECD 2016)

${ }^{544}$ Ibid

${ }^{545}$ Welsh Government, Our Healthy Future: Technical Working Paper (Welsh Government 2009)

${ }^{546}$ Welsh Government, Setting the Direction: Primary and Community Services Community Delivery Plan (Welsh Government 2010)

547 There are 64 GP Cluster networks across Wales

${ }^{548}$ Organisation for Economic Co-operation and Development, Reviews of Health Care Quality: United Kingdom (OECD 2016)

${ }^{549}$ Welsh Government, Together for Health: A Five Year Vision for the NHS in Wales (2011)
} 
launched. ${ }^{550}$ In 2013, Delivering local healthcare, accelerating the pace of change was developed to support GP cluster networks so they could shape local services. ${ }^{551}$

As well as a focus on the development of effective structures within the NHS, in 2011, the system of complaints was improved through the passing into statute of the NHS Concerns, Complaints, Redress Arrangements Regulations (Wales). In 2017, the framework for complaints 'Putting it right' was revised. ${ }^{552}$ The NHS outline that Putting Things Right is the integrated process for raising the investigation of and learning from concerns. Concerns are identified from patient safety incidents, complaints and, in respect of Welsh NHS bodies, claims about services provided by a responsible body in Wales. The aim is to provide a single, more integrated and supportive process for people to raise concerns which:

- Is easier for people to access.

- People can trust to deliver a fair outcome.

- Recognises a person's individual needs (language, support, etc.).

- Is fair in the way it treats people and staff.

- Makes the best use of time and resources.

- Pitches investigations at the right level of detail for the issue being looked at.

- Can show that lessons have been learnt. ${ }^{553}$

Stats Wales collect data on the number of complaints made against each health board across a number of variables. However, there is no data collected that demonstrates the number of complaints made by children and what their complaints concern. As highlighted in the previous chapter, children in the English context have reported concerns over the handling of their complaints. With no data collected in the Welsh

\footnotetext{
${ }^{550}$ NHS and Welsh Government, Working differently, working together: A framework to support the development of a fully integrated healthcare organisation (NHS and Welsh Government 2012) ${ }^{551}$ Welsh Government, Delivering local healthcare, accelerating the pace of change (Welsh Government 2013) further to this strategy, the plan for primary care services for Wales up to 2018 included a multidisciplinary workforce and further development of GP cluster network

${ }^{552}$ NHS Wales Putting it Right, NHS Wales integrated process for complaints http://www.wales.nhs.uk/governance-emanual/putting-things-right accessed January 2020 ${ }^{553}$ Ibid
} 
context it is impossible to monitor what is happening in this area and to determine if a child's right to complain is being effectively implemented. ${ }^{554}$

Longman et al reported in 2012, that there had been a commitment to develop a Charter for Patients' rights and legislation on NHS redress by the One Wales (an agreement between the Labour and Plaid Cymru groups in the National Assembly for Wales in 2007) but by 2020 , the WG is still to issue a formal statement of patient rights. ${ }^{555}$ Citizens Advice provides general advice about NHS Patient's rights but does not provide information that is relevant and accessible to children. The only information that has a specific focus on children is information concerning children's consent or refusal to treatment. This information correlates with the law concerning children and consent to treatment in England in Wales. ${ }^{556}$

In 2015, the Well-being of Future Generations (Wales) Act 2015 was passed. The legislation aims to make public bodies act more sustainably, including demonstrating how they are maximising their contribution to 'a healthier Wales' and 'a more equal Wales'. All public bodies need to make sure that when making decisions, they take into account the impact they could have on people living in Wales in the future. It focuses public bodies' thinking, to comply with the well-being goals it has set regarding achieving a healthier and more equal Wales. The Act states that:

Each public body must carry out sustainable development. The action a public body takes in carrying out sustainable development must include: a. setting and publishing objectives ("well-being objectives") that are designed to maximise its contribution to achieving each of the well-being goals, and b. taking all reasonable steps (in exercising its functions) to meet those objectives.

\footnotetext{
${ }^{554}$ NHS Performance Complaints https://statswales.gov.wales/Catalogue/Health-and-SocialCare/NHS-Performance/Complaints accessed June 2018

${ }_{555}^{5}$ Longley M, Riley N, Davies P, Hernandez-Quevedo C, United Kingdom (Wales), Health system review Health Systems in Transition, Vol 14 (11), 18

${ }^{556}$ Citizens Advice Bureau, Children's Consent https://www.citizensadvice.org.uk/wales/health/nhshealthcare/nhs-services-in-wales-w/nhs-patients-rights-in-wales-w/\#h-children-and-consent accessed January 2020
} 
[Part 2 'Improving Well-being section 3 'well-being duty on public bodies' paragraphs (1) and (2)] $]^{57}$

This supports a preventative approach and one that aims to reduce inequalities and keep people healthier for longer. The Wales UNCRC Monitoring Group was critical of the draft Future Generations Bill in 2014, claiming that:

it does not give sufficient focus to the enforcement of human rights which we believe is a precondition for sustainable development and a prosperous Wales. Without acknowledging and acting to realise the human rights of people, sustainable development is not possible. We believe that the delivery of public services in Wales must be done through a human rights lens and that the Future Generations Bill presents us with a key opportunity for a human rights framework to be enshrined into law. ${ }^{558}$

Human rights are not on the face of the legislation ${ }^{59}$, however it pleasing to note that the Future Generations Commissioner and CCFW have launched a programme of embedding a CRA to the delivery of the Future Generations Act through public services in 2017.

In 2015, the Welsh Government introduced the Prudent Health Care Principles, overarching principles for all health services across Wales. The principles of prudent healthcare are to:

- Achieve health and well-being with the public, patients and professionals as equal partners through co-production.

- Care for those with the greatest health need first, making the most effective use of all skills and resources.

\footnotetext{
${ }^{557}$ The Well-Being and Future Generations Act (Wales) 2015 http://www.legislation.gov.uk/anaw/2015/2/contents/enacted accessed February 2020

${ }_{558}$ Briefing prepared by Rhian Croke on behalf of the Wales UNCRC Monitoring Group (2014) POLICY BRIEFING 25th Anniversary of the United Nations Convention on the Rights of the Child: Welsh Government action needed to support effective structures and legislation that respects and protects children's human rights

${ }^{559}$ There is a lack of inclusion of human rights within the overarching context of well-being. The UNCRC Monitoring Group argued that there should be a definition of well-being on the face of the Bill, and this should clearly include securing rights and entitlements, in a similar way to section 2 of the Social Services and Well-being (Wales) Act 2014
} 
- Do only what is needed, no more, no less; and do no harm.

- Reduce inappropriate variation using evidence-based practices consistently and transparently. ${ }^{560}$

The OECD review reported in 2016 that the Prudent Health Care Framework needs to be backed up by a 'detailed road map and implementation plan'. ${ }^{561}$ The Prudent Health Care Principles were translated into a 12-month plan in 2016.562 It is hoped that the WG will launch an evaluation of the implementation of the Prudent Health Care Principles so that we can learn how successfully they have shifted health care to be better aligned to them.

The Public Health Wales Act 2016 requires Welsh Ministers to make regulations about the use of health impact assessments by public bodies in certain circumstances. This helps to ensure that before key decisions are made, they are informed by a full consideration of the potential effects on physical and mental health and wellbeing. ${ }^{563}$ This like the Future Generations Act is helping to put health and well-being at the forefront of public body decision making.

In April 2016, the Social Services and Well-being Act (Wales) 2014 came into force with Part Nine creating:

new regional partnership boards at a health board level to drive the integration of health and social services. Statutory and third sector organisations will work collaboratively through these boards, will improve the outcomes and well-being of people, and improve the effectiveness and efficiency of service delivery. ${ }^{564}$

\footnotetext{
${ }^{560}$ Welsh Government and NHS Wales, Prudent Health Care; Securing Health and Well-Being for Future Generations (Welsh Government and NHS Wales 2016)

${ }^{561}$ Organisation for Economic Co-operation and Development, Reviews of Health Care Quality: United Kingdom (OECD 2016)186

${ }^{562}$ Welsh Government and NHS Wales, Prudent Health Care; Securing Health and Well-Being for Future Generations (Welsh Government and NHS Wales 2016)

${ }^{563}$ Public Health (Wales) Act http://www.legislation.gov.uk/anaw/2017/2/contents/enacted16 accessed January 2020

${ }^{564}$ Welsh Government and NHS Wales, Prudent Health Care; Securing Health and Well-Being for Future Generations (Welsh Government and NHS Wales 2016) 9
} 
This better integration of health and social services was furthered in October 2018 by the WG's publication of 'A Healthy Wales: Our Plan for Health and Social care'. In summary, this plan outlines the WG's commitment to a health and social care system, that will aim to:

- Launch new ways of joined up working that will start locally and scale up to the whole of Wales.

- Shift services out of hospital to communities, with more services detecting things earlier, or preventing them altogether.

- Get better at measuring what really matters to people, so that services can work out which services and treatments work well, and which ones need to be improved.

- Make health and social care a good career choice, investing in training and skills, and supporting health and wellbeing at work

- Ensure stronger national leadership, and make sure that decision makers listen- to the people who deliver and use their health and social care services. ${ }^{565}$

This plan is at its inception, and it is hoped that in 3-5 years' time, the priorities it seeks to address will be robustly evaluated and demonstrated to have been implemented successfully.

This raft of policy and legislation since 1999, suggests that devolution in Wales has accelerated an approach to health that is supportive of putting patients first, tackling health inequalities and the social determinants of health, promoting a preventative and primary health care approach to health intervention and one that is based on partnership working and non-privatization. Drakeford and Butler note that WG First Minister Rhodri Morgan, was clear in opting for a model which was non-consumerist, which 'reinforced a set of unconditional universal rights rooted only in citizenship, allowed for a set of relationships based on equality, reciprocity and mutuality.' ${ }^{566}$ This supports Birrel's view of devolution that upheld the principle of universalism; situating

\footnotetext{
${ }^{565}$ Welsh Government, In brief: A Healthier Wales: Our plan for health and social care (Welsh Government 2018) 3 https://gov.wales/docs/dhss/publications/180611ltp-inbriefen.pdf accessed December 2018

${ }^{566}$ Butler 1 and Drakeford M 'Children's rights as a policy framework' in Wales, In Williams J (eds) The UNCRC in Wales (Wales University press 2013) 12
} 
the approach to health within a social democratic paradigm and resonating strongly with the foundations of the welfare state. ${ }^{567}$ George also argues that the Welsh policy approach to health tied directly to the 1980 Black report ${ }^{568}$, that encouraged a focus on reducing health inequalities by tackling health's many and varied social determinants. ${ }^{569}$ This approach was in clear divergence to the approach adopted in England. Greer adds to this explaining that:

Wales...bet on localism. This means integrating health and local government in order to coordinate care and focus on determinants of health rather than just treating the sick. It tries to use localism as the lever to make the NHS into a national health service rather than a national sickness service. ${ }^{570}$

The focus on social determinants is not challenged, however George's research suggests that Wales' divergence was not directed by local government advocates and instead it was directed by political elites who were invested in a statist model of health care, which resulted in the 2009 structural reforms. ${ }^{571}$ George believes that health ministers had the most decisive impact on policy direction and promoted their own vision of the health service. ${ }^{572}$

The Prudent Health Care Principles in 2016 have continued an approach that is preventative, placing emphasis on the social determinants of health and person centred with a focus on patients and the public being equal partners through coproduction. In a Parliamentary Review of Health and Social Care Services in 2018, they recommended:

Put the people in control strengthen individual and community involvement, through voice and control in health and care, and ensuring all ages and

\footnotetext{
${ }^{567}$ Birrell D, The impact of devolution on social policy (Bristol: Policy Press 2009)

${ }^{568}$ Black D, Inequalities in Health (London: Penguin; 1980)

${ }^{569}$ George R L, The NHS in Scotland and Wales: The Ideas and Development of Devolved Health Policy, 1999-2011 (Thesis PhD, Swansea University College of Arts Humanities 2015)

${ }^{570}$ Greer Scott L, Four Way Bet: How Devolution Has Led to Four Different Models for the NHS (February 2004, The Constitution Unit) 4.

571 George R L, The NHS in Scotland and Wales: The Ideas and Development of Devolved Health Policy, 1999-2011 (Thesis PhD, Swansea University. College of Arts Humanities 2015) 438

${ }^{572}$ Ibid 436
} 
communities have equal involvement. The public rightly want a modern service in which they have much better information about health and care, shared decision making in treatment, choice of care and setting, and peer support. ${ }^{773}$

However, there is no evidence to suggest how this objective, will be effectively achieved with children. Indeed, entrenched attitudes that perceive children to be incompetent or vulnerable (see detailed discussion in Chapter 6 ) could become a barrier to children being considered equal partners in coproducing health services with health professionals and in ensuring children's participation in clinical decision making. The importance of children influencing health services will be given consideration in the development of a CRA to health services in later chapters.

The OECD report reviewing the quality of health care in the UK in 2016, reported that:

In Wales, while local autonomy and innovation is encouraged, local Health Boards (established in 2009) do not appear to have sufficient institutional and technical capacity to drive meaningful innovation and quality gains. A stronger central guiding hand is now needed to play a more prescriptive role. ${ }^{574}$

Five years after the establishment of local health boards, the OECD argued they were demonstrating less innovation and radical approaches and advised that the Welsh Government should have a more directing and prescriptive role. The autonomy provided to respond more proactively to the needs of the local population through integrated medium-term plans ( 3 yearly cycle) had not resulted in improved quality health care. As the OECD report outlines, this may be because of a lack of institutional and technical capacity, and a weak accountability framework, with no core standards being centrally driven. ${ }^{575}$ The next section turns to focus on policy and law reform in Wales specific to the health and well-being of children and also examines the reality

\footnotetext{
${ }^{573}$ UK Parliament, Parliamentary Review of Health and Social Care in Wales: A revolution from within: transforming health and care in Wales (UK Parliament January 2018) 8 Recommendation 4

${ }^{574}$ Organisation for Economic Co-operation and Development, Reviews of Health Care Quality: United Kingdom (OECD 2016) 191

575 Organisation for Economic Co-operation and Development, Reviews of Health Care Quality:

United Kingdom (OECD 2016)
} 
of many children's lives that are impacted upon and shaped by the conditions and circumstances in which they and their families live.

\subsection{Devolution and the agenda for children}

Successive Welsh Governments have developed an approach to children's policy which diverges considerably from that of the UK Government. This includes a commitment to children's rights. ${ }^{576}$ As early as 2000, Children and Young People a Framework for Partnership ${ }^{577}$, stated that the 'Assembly believes that the UNCRC should provide a foundation of principle for dealings with children'. ${ }^{578}$ Also in 2000 , the establishment of the post of Children's Commissioner was recommended in a report published by Sir Ronald Waterhouse that presented his inquiry into the abhorrent abuse in children's homes in north Wales. ${ }^{579}$ The UK Parliament subsequently passed legislation for Wales to have the first Children's Commissioner in the UK through the Children's Commissioner for Wales (CCfW) Act $2001 .{ }^{580}$

The Children's Commissioner's primary duties are to safeguard and promote the rights and welfare of children in Wales and have regard to the UNCRC. ${ }^{581}$ Also in the same year, Wales was the first of the UK countries to have a national Child Adolescent Mental Health strategy with the launch in September 2001 of Everybody's

\footnotetext{
${ }^{576}$ Williams J, 'Incorporating children's rights: the divergence in law and policy,' Legal Studies (2007) 27(2), 261-287; Clutton S, 'Devolution and the language of children's rights in the UK', In Invernizzi A and Williams J (eds) Children and Citizenship (London: Sage 2008), 171-81; Croke R and Crowley A 'Human Rights and Child Poverty in the UK', In Invernizzi A and Williams J (eds), The Human Rights of Children: From Visions to Implementation (Ashgate Farnham 2011); Butler I and Drakeford M, 'Children's rights as a policy framework' in Wales', In, Williams J, (eds) The UNCRC in Wales (University of Wales Press 2013)

577 Welsh Assembly Government, Children and Young People: Rights to Action (Welsh Assembly Government 2004)

${ }^{578}$ Welsh Assembly Government, Children and Young People: Rights to Action. Guidance on local cooperation under the Children Act 2004 (Welsh Assembly Government 2004) 10

${ }^{579}$ Department of Health, Lost in care: Report of the Tribunal of Inquiry into the Abuse of Children in Care in the Former County Council Areas of Gwynedd and Clwyd since 1974 (Department of Health 1999)

${ }^{580}$ Children's Commissioner for Wales Act (2001)

http://www.legislation.gov.uk/ukpga/2001/18/contents accessed January 2020

${ }^{581}$ Butler I and Drakeford M, 'Children's rights as a policy framework in Wales' In, Williams J, (eds) The UNCRC in Wales (University of Wales Press 2013),11
} 
Business which outlined a comprehensive, four-tiered model for children's mental health services. ${ }^{582}$

In 2002 the WAG was commended by the Committee on the Rights of the Child in its 2002 UK Concluding Observations for using the Convention as a framework in its strategy for children and young people. ${ }^{583}$ In 2004, this commitment to the UNCRC was furthered by the WAG adopting the UNCRC as an overarching set of principles for all its policy on children, at the same time issuing Rights to Action a policy document which translated the UNCRC into 7 Core Aims for Children:

1. Have a flying start in life.

2. Have a comprehensive range of education and learning opportunities.

3. Enjoy the best possible health and be free from abuse, victimisation and exploitation.

4. Have access to play, leisure, sporting and cultural activities.

5. Be listened to, treated with respect, and have their race and cultural identity recognised.

6. Have a safe home and a community which supports physical and emotional wellbeing.

7. Not be disadvantaged by poverty. ${ }^{584}$

Also in 2004, the WAG guidance for the Children Act 2004, required local authorities and their partners to have regard to the UNCRC. ${ }^{585}$ Policy areas that impacted on children, increasingly became underpinned by the UNCRC. The next sections will first

\footnotetext{
${ }^{582}$ National Assembly for Wales, Health in Wales, Everybody's Business (National Assembly for Wales 2001) http://www.wales.nhs.uk/document/111047/info/ accessed March 2017

${ }^{583}$ UN Committee on the Rights of the Child, Concluding Observations: United Kingdom of Great Britain and Northern Ireland, 9 October 2002, CRC/C/15/Add.188

${ }^{584}$ Welsh Assembly Government, Children and Young People: Rights to Action (Welsh Government 2004)

${ }^{585}$ Welsh Assembly Government, Children and Young People: Rights to Action. Guidance on local cooperation under the Children Act 2004 (Welsh Assembly Government 2004)
} 
consider some of these policy areas and will further discuss the overarching national commitment to children's rights in Section 5.7.8.

\subsubsection{Child poverty: policy underpinned by the UNCRC}

Given the evidence-based links between poverty and child health it is important to consider the policy pertaining to child poverty in Wales.

Child poverty is associated with a wide range of health-damaging impacts, negative educational outcomes and adverse long-term social and psychological outcomes. The poor health associated with child poverty limits children's potential and development, leading to poor health and life chances in adulthood. 586587

In 2005, A Fair Future for Our Children was developed, which was 'built on a set of core values in line with the UNCRC. ${ }^{588}$ In 2010 the Children and Families Measure (Wales) 2010 was passed placing a duty on Welsh Ministers to produce and publish child poverty strategies and also required local authorities and local health boards and other public bodies to include child poverty strategies in their children and young people's plan. ${ }^{589}$ The WG published their Child Poverty Strategy in 2010 with a delivery plan 2011. It clearly followed human rights principles focusing on the most disadvantaged children and reducing inequalities as well as taking account of the interrelated and interdependent dimensions of deprivation that children face. ${ }^{590}$ This was revised in 2015 . One of the 2015 delivery plan's three objectives was to 'tackle health, education and economic inequalities'. ${ }^{591}$ The WG asserted that underlying the objectives 'is a fundamental focus on children's rights as set out in the UNCRC, and

\footnotetext{
${ }^{586}$ Anwar E, Barr B, Law C, Taylor-Robinson D, 'Poverty and child health in the UK: using evidence for action', BMJ Archives of Diseases of Childhood (2016) Vol 101, Issue 8.

${ }^{587}$ Pillas D, Marmot M, Naicker K, et al. 'Social inequalities in early childhood health and development: a European-wide systematic review’, Pediatr Res (2014)76

${ }^{588}$ Welsh Assembly Government, A Fair Future for our Children (Welsh Assembly Government 2005) 9

${ }^{589}$ Children and Families (Wales) Measure 2010

${ }^{590}$ Croke R and Crowley A, Human Rights and Child Poverty in the UK In Invernizzi A and Williams J (eds), The Human Rights of Children: From Visions to Implementation (Farnham: Ashgate 2011), 278-279

${ }^{591}$ Welsh Government, Child Poverty Strategy for Wales (revised) (Cardiff: Welsh Government 2015)
} 
reducing inequalities.' 592 WG has 'consistently reiterated its commitment to the target of eradicating child poverty by 2020 , in fact going further than the rest of the UK in its interpretation of 'eradication'. ${ }^{593}{ }^{594}$ However, the reality for a third of children living in poverty in Wales is not matching this obligation. The Welsh poverty legislation does not give the opportunity to children to claim their individual socio-economic rights; instead, they can only hold the WG to deliver on their 2020 target via judicial review. ${ }^{595}$ WG have consistently argued they do not have enough powers (i.e., tax and benefits) to make significant in-roads into meeting the target.

In 2017, the post of Minister for Communities and Tackling Poverty was abandoned as well as a poverty-specific action plan. There is the Prosperity for All Strategy, however, there are no clear performance targets/progress indicators and ministerial responsibility for delivering on poverty reduction. In 2019, the Children's Commissioner for Wales reported that there should be WG child poverty delivery plan. 596 The WG commissioned a 6-month review in September 2019 to reengineer existing funding programmes to ensure that they have the maximum impact on the lives of children living in poverty. However, the impact of this work has not made sufficient changes to hit the 2020 target and a judicial review could be brought against Welsh Ministers for failing to meet this target as the 2010 legislation still stands.

\subsubsection{Child health: policy underpinned by the UNCRC}

Strategic policy being underpinned by the UNCRC was continued with the development of the National Service Framework (NSF) for Young People and Maternity Services in 2005, this made Wales one of the first countries globally to have a children's strategy for health underpinned by the UNCRC. The development of the

\footnotetext{
592 Ibid

${ }^{593}$ Croke R and Williams J (eds) Wales UNCRC Monitoring Group report to the UN Committee on the Rights of the Child (Swansea University 2015) 36

${ }^{594}$ UK Poverty Act 2010 defined the eradication of child poverty as a reduction in the proportions of children living in households with less than 60 per cent of the median income.

${ }^{595}$ For further discussion on the limitations of legislative target setting see Croke R and Crowley A, 'Human Rights and Child Poverty in the UK' In Invernizzi A and Williams J (eds), The Human Rights of Children: From Visions to Implementation (Farnham: Ashgate 2011), 278-279

${ }^{596} \mathrm{CCFW}$, 2019, Charter for Change: Protecting Welsh Children from the Impact of Poverty, https://www.childcomwales.org.uk/a-charter-for-change-protecting-welsh-children-from-the- impactof-poverty-2/ accessed January 2020
} 
Children's NSF began in September 2002 with the aim of improving quality and equity of service delivery through the setting of national standards. The framework was developed as a partnership between health and social care with links to education, housing, leisure, the voluntary sector and other stakeholders including parents/ carers, children and young people ${ }^{597}$, supporting a holistic and multi-disciplinary response to children, that recognises the full range of their human rights.

The overall aim of the Children's NSF was that 'all children and young people achieve optimum health and well-being and are supported in achieving their potential. ${ }^{598}$ The scope of the Children's NSF includes all children and young people up to 18 years of age, for whom NHS Wales and local social services authorities have a responsibility. Special consideration was given for transition management into adult services beyond the 18th birthday for those requiring support services. The framework contains 21 standards and 203 key actions, based on the 41 Articles of the UNCRC and the Assembly's seven core aims for children and young people. A Self-Assessment Audit Tool was designed as part of a performance measurement system for the Children's NSF for use by all statutory organisations that deliver services for children and young people, including the delivery of maternity services. ${ }^{599}$

In 2007, it was reported by the Wales UNCRC Monitoring Group in a report to the UN Committee on the Rights of the Child that the NSF, 'whilst a welcome development is not accompanied by additional resources, nor are there alternative mechanisms to ensure that NSF standards can be delivered'. ${ }^{600}$ It referred to the lack of ring-fenced budgets for children, the complexity of funding streams and the lack of transparency in spending, 'making children's health budgets vulnerable when resources are scarce'. The Wales UNCRC Monitoring Group commented that it is unsurprising that WAG and local health commissioning targets have largely focussed on adults.' The report also expressed concerns about funding and the prioritising of health services for

\footnotetext{
${ }^{597}$ Welsh Government, National Service Framework for Young People and Maternity Services (Welsh Government 2005) http://www.wales.nhs.uk/sites3/home.cfm?OrgID=441 accessed January 2020

${ }^{598}$ Ibid

${ }^{599}$ Ibid

${ }^{600}$ Croke R and Crowley A (eds) Stop, Look, Listen: the road to realising children's rights in Wales (Save the Children UK 2007)
} 
children in Wales. ${ }^{601}$ As referred to in Chapter 5, this compliments Green's findings regarding the English NSF also not being supported by additional resources and reinforces concerns registered earlier in this chapter in 2001 in Improving health in Wales, that resources were historically focused on the older population. It is not clear from an examination of the literature whether there has been an evaluation of the NSF or if this set of standards and the self-assessment tool are still used consistently in practice.

\subsubsection{Research and collection of data on children's health and well-being}

In 2007, the WG acknowledged the value of the UNICEF Well-being report and commissioned its own report on the well-being of children in Wales. ${ }^{602}$ In 2008, information on children was collated around the 7 core aims and published, with a plan to publish updates every three years to inform service planning at the national and local level. ${ }^{603}$ Another well-being monitor was published in 2011 and one in 2015. However, the Well-being monitor does not collect disaggregated data on children from vulnerable groups, e.g., Gypsy Travellers, Asylum Seekers, disabled children, BME groups which is a requirement of the UN Committee on the Rights of the Child. ${ }^{604}$

There is also still no definitive data on the mental health status of children in Wales. However, the Public Health Wales Observatory can be commended for consistently collecting data relating to child health and health inequality (see next section). In Wales, the Pregnancy and Childhood Surveillance Tool helps in the collation of good data, however according to the RCPCH there:

\footnotetext{
${ }^{601}$ Ibid 32

${ }^{602}$ Croke R and Crowley A, 'Human Rights and Child Poverty in the UK' in Invernizzi A and Williams J (eds), The Human Rights of Children: From Visions to Implementation (Farnham: Ashgate 2011) 267

${ }^{603}$ Welsh Government, Children and young people's wellbeing monitor for Wales 2015: Summary https://gov.wales/sites/default/files/statistics-and-research/2019-07/151211-children-young-peoplewellbeing-monitor-2015-summary-en.pdf accessed January 2020

${ }^{604}$ UN Committee on the Rights of the Child, General Comment No. 5 on the General Measures of Implementation, $\mathrm{CRC} / \mathrm{C} / \mathrm{GC} / 5 / 2003$ para 48 ; UN Committee on the Rights of the Child, General Comment No. 15 on the right of the child to the enjoyment of the highest attainable standard of health $\mathrm{CRC} / \mathrm{C} / 15 / 2013$ para 109; UN Committee on the Rights of the Child, General Comment No. 20 on the implementation of the rights of the child in adolescence CRC/C/GC/20 2016
} 
are some significant gaps in what is captured. For instance the Child Measuring Programme includes four to five year olds, but it does not measure $10.5-11.5$ year olds, creating a barrier to reducing childhood obesity. ${ }^{605}$

The RCPCH also comment, that more needs to be done to collate information across all of childhood, to have integrated statistics on health, social care, youth justice, education and to have data that can be captured and made comparable across all of the UK. ${ }^{606}$

In order to reflect children's rights, indicators would need to be developed that span all the human rights of children 0-18 years and all services for children. The Well-being monitor included the perspective of children as an aspect of its reporting in 2011. The $\mathrm{RCPCH}$ criticises the Healthwise Wales social research project for not collecting the views of under 16 year olds which aims to provide vital evidence to support policy and service decisions in the future. ${ }^{607}$ There has also have been recent criticism that the Welsh health research infrastructure, unlike their English and Scottish counterparts does not fund youth advisory groups to influence the development of paediatric research. ${ }^{608}$ This is contrary to the expectations of the UN Committee on the Rights of the Child General Comment No. 15 that expects children to be included in the design, monitoring and evaluation of all health services and the WG's own Prudent Health Care Principles that expect patients (children being people) to be co-producers of health services.

Although overall research on children's health may be criticised, a more positive assessment highlights Wales' contribution to the UK-wide longitudinal Millennium Cohort Study since it was begun in 2000. The study tracks the lives of 19,000 young people born in UK in 2000-2001, around 1,600 of whom are in Wales. ${ }^{609}$ Data from

\footnotetext{
${ }^{605}$ Royal College of Paediatrics, State of Child Health: 2017 Recommendations for Wales, Royal College of Paediatrics 2017, 5

${ }^{606}$ Ibid

${ }^{607}$ Ibid 5

${ }^{608}$ National Assembly for Wales Cross Party Group on Medical Research Fourth meeting of 2019, First Inquiry Session: Patient and public involvement. November $19^{\text {th }} 2019$

${ }^{609}$ Milennium Cohort Study https://cls.ucl.ac.uk/cls-studies/millennium-cohort-study/ accessed January 2020
} 
many national health and care datasets are stored in an anonymous linked form on the Swansea University SAIL Databank. SAIL presents an additional opportunity to analyse data, that can help researchers to better understand the challenges that many children face and from this evidence contribute to developing better services and outcomes for children. ${ }^{610}$

It is also positive that to support increased investment in research relating to child health, the Children and Young Adults' Research Unit was formally opened at the Noah's Ark Children's Hospital for Wales in October 2017 by the Cabinet Secretary for Health, Wellbeing and Sport. This new facility has state of the art equipment and capacity for child health clinical research and is the first and only dedicated child clinical health research unit of its kind in Wales. Work is underway to develop the research unit as a hub for a Wales-wide child clinical research. However, this has been stalled due to a cut to the health and social care research budget ${ }^{611}$ and Health and Social Care Research Wales making a decision not to fund Wales-wide paediatric research in the 2019 five year round of funding. ${ }^{612}$ The Paediatric Consultant based at the Children's Hospital only has 3.75 hours per week in his work plan to promote Wales-wide clinical research. ${ }^{613}$

Additionally, the Welsh Government Activity Based Funding Model that brings funding into clinical research indirectly discriminates against children because it does not work for low recruiting high complexity studies. The Welsh Government formula pays for each patient recruited into a portfolio study. Portfolio studies are those deemed of sufficient quality to qualify for such recognition and are placed on an all-Wales register of research studies. Studies are categorised in to three bands and funded per patient recruited: interventional (£976), observational (£311) and large sample studies (£89). ABF does not work for low recruiting, high complexity studies that are prevalent in paediatric research.

\footnotetext{
${ }^{610}$ SAIL data bank, https://saildatabank.com/ accessed January 2020

${ }^{611} \mathrm{RCPCH}$ One year on Score Card https://www.rcpch.ac.uk/sites/default/files/2018-

02/state_of_child_health_-_wales_-_one_year_on_scorecard_english_2018-01.pdf accessed December 2018

${ }^{612}$ E-mail communication with Children's Hospital for Wales August 2019

${ }^{613}$ Ibid
} 
Although, the model may not be prima facie discriminatory against children, however when practically applied it results in a discriminatory impact. Due to the studies being low recruiting and high complexity with prohibitive set up costs, children are not receiving equal opportunities to adults with regards to opportunities to participate in clinical studies. This can result in children accessing fewer opportunities to develop critical and age-appropriate medicines, and often pushes children and their caregivers to participate in clinical trials far from home, resulting in negative impacts on household economy, home and family life and access to education.

The ABF is currently under review. Several requests made by the author of this thesis and colleagues to see the children's rights impact assessment on the review of the $A B F$ and the decision of the 5-year funding for the health research infrastructure and as part of scrutiny for a National Assembly Children and Young People and Education Inquiry into children's rights, has been met with silence from the WG. ${ }^{614}$ So consequently, the pattern of child clinical research being under-resourced and represented continues. These factors are all particularly disappointing given that cancer is the leading cause of mortality in children aged 0-9 years in Wales ${ }^{615}$, and dedicated resource to fund paediatric research and the development of tailored medicines may help to prolong life or prevent deaths of children.

\subsubsection{Children's mental health services}

The review into Services for Children and Young People with Emotional and Mental Health Needs in 2009, set out to establish whether services are adequately meeting the mental health needs of children and young people in Wales. Healthcare Inspectorate Wales (HIW) and the Wales Audit Office jointly undertook the review, supported by Estyn and the Care and Social Services Inspectorate Wales (CSSIW). The overall conclusion of the review was that despite some noted improvements; services were still failing many children and young people, reflecting a number of key

\footnotetext{
${ }^{614}$ National Assembly for Wales Children and Young People and Education Committee, Inquiry into Children's Rights http://senedd.assembly.wales/mgIssueHistoryHome.aspx?IId=25724 accessed January 2020

${ }^{615}$ Royal College of Paediatrics and Child Health, State of Child Health 2020: Wales (RCPCH 2020) 11
} 
barriers to improvement. ${ }^{616}$ Breaking the Barriers: Meeting the Challenges. Better Support for Children and Young People with Emotional Wellbeing and Mental Health Needs (2010) was the WG's Action Plan responding to this report. In an Inquiry into CAMHS by the National Assembly's Children and Young Peoples' Education Committee, concerns were expressed regarding the prioritisation of spending on children's services. WG statistics referenced within the Inquiry report showed that $£ 82.75$ was spent per head on general mental illness compared to only £13.94 per head on child and adolescent mental health. ${ }^{617}$ A total of 2,410 under 18 s were waiting for their first outpatient appointment in December 2014 - a rise of 1,300 on December 2010 (although this could be accounted for in part by the extension of the service to 16 and 17 year olds since 2012). ${ }^{618}$ This brings forward further evidence that children were not being prioritised within health budgets.

In 2015, to address the ongoing concerns with the delivery of CAMHS and the mental health status of the child population, further investment was ring fenced for children's mental health and Together for Children and Young People' (T4CYP). ${ }^{619}$ Led by the NHS in Wales, this multi-agency service improvement programme is considering ways to reshape remodel and refocus the emotional and mental health services provided for children and young people in Wales, in line with the principles of Prudent Healthcare. ${ }^{620}$ It is yet to be vigorously evaluated. However, the RCPCH has recommended continued funding of the programme beyond 2021 and integration with the regional partnership boards and locally delivered services. ${ }^{621}$

\footnotetext{
${ }^{616}$ Wales Audit Office, Health Care Inspectorate for Wales, Estyn, CCSIW, Services for Children and Young People with Emotional and Mental Health Needs (Wales Audit Office 2009) https://dera.ioe.ac.uk/11698/1/CAMHS_eng.pdf accessed April 2018

${ }^{617}$ National Assembly for Wales Children, Young People and Education Committee, Inquiry into Child and Adolescent Mental Health Services, November 2014, National Assembly for Wales, 8 http://www.senedd.assembly.wales/documents/s34408/Report\%20November\%202014.pdf accessed March 2018

${ }^{618}$ National Assembly for Wales Children, Young People and Education Committee, Inquiry into Child and Adolescent Mental Health Services, November 2014, National Assembly for Wales, 8 ${ }^{619}$ Together for Children and Young People, http://www.goodpractice.wales/t4cyp accessed January 2018

${ }^{620}$ Prudent Health Care Principles, http://www.prudenthealthcare.org.uk/ accessed January 2018

${ }^{621}$ Royal College of Paediatrics and Child Health, State of Child Health 2020: Wales (RCPCH 2020) 24
} 
In January 2019 , the WG announced that an additional $£ 7.1$ million will be allocated to build on previous investments to improve child and adolescent mental health services (CAMHS) and will also support the whole-school approach to improve mental health and wellbeing in schools.

In March 2020, the RCPCH reported that they were concerned that inpatient provision and community settings for CAMHS patients was comparatively lower in Wales compared to other nations across the UK. ${ }^{622}$ Wales has:

the lowest number of psychiatrists and the second lowest number of community mental health nurses and psychologists (6 and 8 per 100,000), implying lack of capacity as a reason for its low activity rates among both inpatient and community-based care. ${ }^{623}$

This finding indicates there is still much to be done to ensure that investment from WG starts to have an impact on ensuring children across Wales, are able to access the CAMHS provision they require.

\subsubsection{Education supporting health and well-being}

In 2009, A Framework for a School Nursing Service for Wales ${ }^{624}$ was developed to set out the WG's approach to developing a school nursing service for children and young people that is safe, accessible and of a high standard. A key part of the school nurse's role is to contribute either directly or indirectly to a range of educational and health outcomes, which includes positive mental health and wellbeing.

Wellbeing is at the heart of the Schools Effectiveness Framework (SEF) ${ }^{625}$ and is seen as a crucial core element of the work of education settings. It describes the key characteristics required to build on existing good practice and improve children's and young people's learning and wellbeing throughout Wales, and each partner's

\footnotetext{
${ }^{622}$ Royal College of Paediatrics and Child Health, State of Child Health Report 2020: Mental Health Services https://stateofchildhealth.rcpch.ac.uk/evidence/mental-health/services/ accessed March 2020

${ }^{623}$ Royal College of Paediatrics and Child Health, State of Child Health Report 2020: Mental Health Services https://stateofchildhealth.rcpch.ac.uk/evidence/mental-health/services/ accessed March 2020

${ }^{624}$ Welsh Government, A Framework for a School Nursing Service for Wales (Welsh Government 2009)

${ }^{625}$ Welsh Government, School Education Effectiveness Framework (Welsh Government 2008)
} 
contribution to securing that. Thinking positively: emotional health and wellbeing in schools and early years settings (2010) offers:

- A summary overview of the key information and issues for schools and education settings in relation to promoting the emotional health and wellbeing of children and young people, including examples of current practice in Wales.

- Proposals to support schools and local authorities in taking forward their work in promoting emotional health and wellbeing, and for early identification and intervention for children and young people who are experiencing mental health problems.

- Signposting to resources and sources of support.626

To support emotional health and well-being in schools, the WG launched a National Strategy for Counselling in Schools 2008, and 'health and well-being' is one of the 6 areas of the new national curriculum for Wales. ${ }^{627}$ In civil society reports to the UN Committee on the Rights of the Child, it was argued strongly for embedding sex and relationships education into the curriculum. ${ }^{628}$ This was reinforced by a report by the $\mathrm{RCPCH}$ for Wales, expressing urgency for a:

whole-school approach for promoting the health and wellbeing of students, that translates into personal, social and health education as well as sex and relationships, delivered by experienced, credible, influential and relatable people as young people have told us repeatedly that this is what they need. ${ }^{629}$

\footnotetext{
${ }^{626}$ Welsh Government, Thinking positively: emotional health and wellbeing in schools and early years settings (Welsh Government 2010) 1

${ }^{627}$ For information on the school curriculum in Wales: http://gov.wales/topics/educationandskills/schoolshome/curriculum-for-wales-curriculum-forlife/?lang=en accessed January 2020

${ }^{628}$ Croke R and Williams J (eds), Wales UNCRC Monitoring Group to the UN Committee on the Rights of the Child (Swansea University 2015); UK Children's Commissioners' report to the UN Committee on the Rights of the Child 2015

${ }^{629}$ Royal College of Paediatrics, State of Child Health: 2017 Recommendations for Wales, (Royal College of Paediatrics and Child Health 2017) 6
} 
This will be included in the new curriculum which is in the process of being embedded. ${ }^{630}$

\subsubsection{Early years}

There has been an ongoing commitment to give every child a healthy start in life, which fits with the WG's Core Aim 1 in Rights to Action ${ }^{631}$ and is consistent with the 2010 Marmot Review and the earlier Black (1980) and Acheson (1998) report, which all stressed the importance of targeting interventions to reduce health inequalities in the first five years of life. ${ }^{632}$ A number of WG initiatives are aimed at tackling child health inequalities under 5 .

Building a brighter future: early years and childcare plan 2013 aims to bring coherence across different policies and programmes, impacting on and influencing the early years. The key themes are children's health and well-being, supporting families and parents, high-quality early education and childcare, effective primary education, raising standards. ${ }^{633}$

The Flying Start initiative provides early year's provision for children from birth to three years old living in the most deprived communities of Wales, including free, part-time quality childcare for two year olds and enhanced health visitor support and parenting programmes. Evaluation suggests that Flying Start programmes have had the effect of producing parity in some outcomes for families in the most deprived and relatively less deprived areas. ${ }^{634}$ The $\mathrm{RCPCH}$ for Wales recommend the Flying Start project is

\footnotetext{
${ }^{630}$ RCPCH One Year On Score Card (2018) https://www.rcpch.ac.uk/sites/default/files/201802/state_of_child_health_-_wales_-_one_year_on_scorecard_english_2018-01.pdf accessed January 2020

${ }^{631}$ Welsh Assembly Government, Children and Young People: Rights to Action (Welsh Assembly Government 2004)

${ }^{632}$ Black D, Inequalities in Health (London: Penguin 1980); Acheson D, Independent Inquiry into Inequalities in Health (London: The Stationery Office; 1998); Marmot M, Allen J, Goldblatt P, Boyce T, McNeish D, Grady M, and Geddes I, Fair society, healthy lives: Strategic review of health inequalities in England post 2010 (Marmot Review 2010)

${ }^{633}$ Welsh Government, Building a brighter future: early years and childcare plan 2013 (Welsh Government 2013)

${ }^{634}$ National Evaluation of Flying Start: Impact Report, Social Research No. 74/2013 December 2013. However, the report suggests that further investigation is necessary.
} 
extended so all children living in poverty have access to the enhanced services and support it provides. ${ }^{635}$

The Healthy Child Wales Programme (HCWP) started implementation in 2016, across all Welsh health boards. The HCWP is a universal health programme for all families with $0-7$ year old children. It aims to provide a consistent range of evidence based preventative and early intervention measures, and advice and guidance to support parenting and healthy lifestyle choices. It offers an agreed all-Wales approach to child development based on the evidence that investment in the early years of life has significant positive impact on a child's health, social and educational development and their long-term outcomes. This corresponds to a preventative approach to health and one which seeks to address the social determinants of health. The HCWP sets out what planned contacts children and their families can expect from their health boards, from maternity services handover to the first years of schooling. These universal contacts cover three areas of intervention, screening, immunisation, monitoring and supporting child development. ${ }^{636}$

Designed to Smile, introduced by the Welsh Government in 2009, is a preventative programme that involves a wide range of professionals, including health visitors and other early years services. It encourages families to take their children to a dental practice before their first birthday and to develop good habits early. It supports nursery and school-based tooth brushing learning and fluoride varnish programmes to protect children from tooth decay. ${ }^{637}$ In 2020, the RCPCH recommended that the programme's funding was continued and should be supported to do a public health campaign on the factors that contribute to poor oral health. ${ }^{638}$ The RCPCH also recommended that the WG should review the factors that are preventing access to primary, secondary and emergency dental care. ${ }^{639}$

\footnotetext{
${ }^{635}$ Royal College of Paediatrics, State of Child Health: 2017 Recommendations for Wales (RCPCH 2017) 6

${ }^{636}$ NHS Wales and Welsh Government, An overview to the Healthy Child Wales Programme https://gov.wales/sites/default/files/publications/2019-05/an-overview-of-the-healthy-child-walesprogramme.pdf accessed January 2020

${ }^{637}$ Welsh Government, Designed to Smile (Welsh Government 2009)

${ }^{638}$ Royal College of Paediatrics and Child Health, State of Child Health 2020: Wales (RCPCH 2020) 18

${ }^{639}$ Ibid 18
} 


\subsubsection{Breast feeding and maternity care}

In 2020, the WG developed the All-Wales Breastfeeding Plan (2019 - 2024) ${ }^{640}$, and in $2020 \mathrm{RCPCH}$ requested the WG to robustly monitor and evaluate it and provide adequate resources to effectively implement it. ${ }^{641}$ Promoting maternal and infant health is integral to the right to health Article 24, para: 2 of the UNCRC and the promotion of breastfeeding also contributes to the achievement of many of the Sustainable Development Goals. ${ }^{642}$ In 2019, the WG launched the Maternity Care in Wales: A Five Year Vision (2019 - 2024) aiming to offer an equitable approach to maternity care that focuses on the five principles, of family centred care, safe and effective care, continuity of carer, skilled multi-professional teams and sustainable quality services. ${ }^{643}$

\subsubsection{Childhood obesity}

In October 2019, the WG launched Healthy Weight: Healthy Wales to reduce increasing levels of obesity, the strategy sets out 4 themes: Healthy Environments, Healthy settings, Healthy People and Leadership and Enabling Change. ${ }^{644}$

The RCPCH in Wales welcomed the strategy in March 2020 and made several recommendations to WG regarding the actions being implemented at pace and robustly evaluated. In summary:

- Banning advertising, sponsorship of products high in fat, sugar and salt and to lobby UK Government to restrict advertising in broadcast and online settings.

- Review of planning and licensing opportunities e.g., limiting hot food takeaways near schools, leisure centres, parks etc).

\footnotetext{
${ }^{640}$ Welsh Government, All Wales Breast Feeding Action Plan 2019 -2024 (Welsh Government 2019)

${ }^{641}$ Royal College of Paediatrics and Child Health, State of Child Health 2020: Wales (RCPCH 2020)14 and 15

${ }^{642}$ Breast feeding and the Sustainable Development Goals

http://worldbreastfeedingweek.org/2016/pdf/BreastfeedingandSDGsMessaging\%20WBW2016\%20Sh ared.pdf accessed January 2018

${ }^{643}$ Welsh Government, Care in Wales: A Five Year Vision (2019 - 2024)(Welsh Government 2019) 5 https://gov.wales/sites/default/files/publications/2019-06/maternity-care-in-wales-a-five-year-visionfor-the-future-2019-2024.pdf accessed March 2020

${ }^{644}$ Welsh Government, Press Release: Health Ministers Launches ambitious new plan to halt obesity rise in Wales October 172019 https://gov.wales/health-minister-launches-ambitious-new-plan-halt-obesity-rise-wales accessed March 2020
} 
- Building daily physical activity into the school day, in line with the Chief Medical Officer's 2019 Physical Activity Guidelines, and Estyn's commitment to the Whole School approach.

- Providing funding to local authorities to maintain and expand on current sports and leisure facilities.

- Expanding on provision for free breakfast in primary schools and monitoring Healthy Eating in Schools, to ensure that there is compliance across Wales. ${ }^{645}$

\subsubsection{Continued national commitment to children's rights}

In 2009, in response to the UN Committee on the Rights of the Child's UK Concluding Observations 2008, the WG developed a National Action Plan on Children's Rights, with 16 priority areas, none of the priority areas had a specific focus on child health, but many of the priorities for action were ones that contributed to the health and wellbeing of the child population and their right to health. ${ }^{646}$ After an effective lobbying campaign by NGOs and academic experts ${ }^{647}$, the commitment to the human rights of children culminated in the passing of the Rights of Children and Young Person's (Wales) Measure 2011, a landmark piece of legislation which requires Welsh Ministers to have due regard to the principles, provisions and optional protocols of the UNCRC in all of their functions. ${ }^{648}$ This made Wales the first country in the UK to incorporate the UNCRC, within the limits of its powers into domestic legislation. This means that Welsh Ministers must have due regard to the child's right to health and survival and development (Articles 24,6) as well as all the other articles of the Convention in any of their functions. Whilst public authorities (including health authorities) are not directly affected by the due regard duty they will be indirectly affected as any legislation or policy introduced by the Welsh Ministers will need to be developed in the light of the

\footnotetext{
${ }^{645}$ Royal College of Paediatrics and Child Health, State of Child Health 2020: Wales (RCPCH 2020) 17

${ }^{646}$ Welsh Government, National Action Plan on Children's Rights (Welsh Government 2009); Welsh Government, Programme for Government for Children (Welsh Government 2015) included commitments on health and was underpinned by the UNCRC.

${ }^{647}$ Aspinwall T and Croke R, 'Policy Advocacy Campaigns: the collective voices of children's NGOs in Wales' In, Williams J (eds) The UNCRC in Wales (University of Wales Press 2013)

${ }^{648}$ Rights of Children and Young Persons (Wales) Measure 2011,

https://www.legislation.gov.uk/mwa/2011/2 accessed 27 February 2020.
} 
due regard duty. ${ }^{649}$ The Children's Scheme sets out the arrangements that must be taken by Ministers to ensure compliance with the Measure (Section 2.1) ${ }^{650}$, including compelling Ministers (and their support staff) to undertake children's rights impact assessments to assess whether new legislation/policy or legislation/policy that is being reviewed has had due regard to the UNCRC. ${ }^{651}$

Further incorporation occurred, when in 2014, the Social Services and Well-being Wales Act required any persons exercising functions under the Act must have due regard to Part 1 of the UNCRC:

A person exercising functions under this Act in relation to a child falling within section 6(1)(a), (b) or (c) must have due regard to Part 1 of the United Nations Convention on the Rights of the Child adopted and opened for signature, ratification and accession by General Assembly resolution 44/25 of 20 November 1989 ("the Convention").

(3) For the purposes of subsection (2), Part 1 of the Convention is to be treated as having effect-

(a) as set out for the time being in Part 1 of the Schedule to the Rights of Children and Young Persons (Wales) Measure 2011, but

(b) subject to any declaration or reservation as set out for the time being in Part 3 of that Schedule.

(4) Subsection (2) does not apply to the Welsh Ministers (see, instead, the Rights of Children and Young Persons (Wales) Measure 2011).

\footnotetext{
${ }^{649}$ A recent example of the potential significance for public authorities is the homelessness provisions in the Housing (Wales) Act 2014. The discretion given to local housing authorities to disregard intentional homelessness when dealing with applications for assistance from households with children was directly motivated by reference to the Convention (article 27, the child's right to an adequate standard of living, including housing). See Extract from Transcript of the Equalities and Local Government Committee meeting $21^{\text {st }}$ May 2014

${ }^{650}$ Section 2.1 Rights of Children and Young Persons (Wales) Measure 2011, https://www.legislation.gov.uk/mwa/2011/2 accessed 27 February 2020.

${ }^{651}$ Welsh Government, Children's Scheme (Welsh Government 2014)
} 
This legislation also places requirements on LHBs and local authorities to work together to produce population needs assessments which take into account children's needs when determining local service provision.

Additionally, in 2017, through guidance developed by Hoffman and Croke ${ }^{652}$, the Children's Commissioner for Wales launched their guide, The Right Way, to advise public bodies on how to adopt a CRA to their service delivery, and the Future Generations Commissioner also expressed their commitment to encouraging public bodies to adopt a CRA. ${ }^{653}$

However, it seems apparent that in a recent analysis of WG decision making regarding health research delivery, there was no consideration of children's rights and little evidence of compliance with the Rights of Children and Young Persons (Wales) Measure 2011.654 Additionally, when analysing the 2018 Parliamentary Review of Health and Social Care in Wales, the Rights Measure was not referred to once within the document. ${ }^{655}$ This may suggest that the Rights Measure has not been effectively embedded across health care portfolios. Although policy development is referring to ithe Well-Being and Future Generations Act 2015, the Social Services and Well-being Act 2014, and the Prudent Health Care Principles, they are not referring to the Rights Measure and are not honouring their obligations to have due regarding to the UNCRC and to carry out children's rights impact assessments.

\subsubsection{Health workforce for children}

As was explained in the first section to this Chapter, Wales has seven LHBs and these LHBs boards provide a range of paediatric services. Tertiary services are primarily concentrated at the University Hospital of Wales which is overseen by the Cardiff and

\footnotetext{
${ }^{652}$ Hoffman, S and Croke R, 'A Children's Rights Approach Statement and Guide prepared for the Children's Commissioner for Wales' (Swansea University 2016)

${ }^{653}$ The Future Generations Commissioner and Children's Commissioner Guidance is available at: http://www.childrensrightsplanning.wales/wp-content/uploads/2018/06/CCFW-FGCW-ReportEnglish 01.pdf accessed January 2020

${ }^{654}$ See evidence submitted to the National Assembly for Wales: Connor P, Croke R*, Thomas-Turner $\mathrm{R}$, Access to medicines and good quality paediatric research: children's human rights implications and considerations for the Welsh context September 2019 http://senedd.assembly.wales/mgIssueHistoryHome.aspx?IId=25724 accessed January 2020 ${ }^{655}$ UK Parliament, Parliamentary Review of Health and Social Care in Wales: A revolution from within: transforming health and care in Wales (UK Parliament January 2018)
} 
Vale University Health Board. Acute services are concentrated for the most part in larger urban areas. All health boards provide what are referred to as community child health services $(\mathrm{CCH})$.

In 2001, a review of NHS Wales by Lord Carlisle complained about:

The shortage of specialist paediatricians is a basic and unacceptable obstacle to their effectiveness......and that measures be taken to secure a sufficient number of paediatricians to meet the needs of Welsh children. ${ }^{656}$

Currently Wales is still experiencing a serious lack of paediatric consultants, and this is set against a surge in admissions. According to the $\mathrm{RCPCH}$ :

Paediatric consultant whole time equivalent (WTE) growth in Wales between 2015 and 2017 was $2.9 \%$, the lowest of all the UK nations: lower than the England growth of $6.4 \%$ and the UK growth of $6.7 \%$ over the same period. ${ }^{657}$

The RCPCH has argued that according to standards they set out in their report, Facing the Future 3, there needs to be an additional 73.7 whole time equivalent consultants in Wales. ${ }^{658}$ The RCPCH has found that only $6 \%$ of foundation year 1 doctors consider specialising in paediatrics. ${ }^{659}$ There should be a drive to increase the number of paediatric trainees and in addition, $\mathrm{RCPCH}$ says there may be a critical need to ensure that advanced nurse practitioners and physician associates training is developed to support the demands of paediatric services. ${ }^{660}$

\footnotetext{
${ }^{656}$ Lord Carlisle, The Review of Safeguards for Children and Young People Treated and Cared for by the NHS in Wales, "Too Serious a Thing" (National Assembly for Wales 2001) 14 and 33

${ }^{657}$ Royal College of Paediatrics and Child Health (2019) Workforce census: Focus on Wales: An Executive Summary (Royal College of Paediatrics and Child Health 2019)

https://www.rcpch.ac.uk/resources/workforce-census-focus-wales-2019\#downloadBox accessed December 2019

${ }^{658}$ Royal College of Paediatrics and Child Health, Facing the Future: Standards for Paediatric Services (RCPCH 2010)

${ }^{659}$ UK Foundation Programme Office, F2 Career Destinations Report 2018; Royal College of Paediatrics and Child Health (2019) Workforce census: Focus on Wales: An Executive Summary (Royal College of Paediatrics and Child Health 2019) RCPCH explain that young doctors may choose other specialities instead of paediatrics due to the perceived poor life work balance and the desire to work less than full time.

${ }^{660}$ Ibid
} 
There are concerns with regards to the pressure on $\mathrm{CCH}$. It is positive as outlined earlier in this chapter that there is a political emphasis in Wales on preventative health ${ }^{661}$ however this is not correlated with investment in resources at $\mathrm{CCH}$ level. There are currently challenges with increased workload without a corresponding increase in the workforce. ${ }^{662}$ The RCPCH supports the call by the Royal College of General Practitioners for an additional year of GP training to include six months of dedicated child health training for all trainees. ${ }^{663}$ There is also a shortfall of nonpaediatric health professionals, such as psychologists and speech and language therapists, who are essential to multi-disciplinary teams that support the health needs of the child population. ${ }^{664}$ More support for $\mathrm{CCH}$ was identified as early as 2001 , (referred to at the beginning of this Chapter, at the start of the devolution journey). It is distressing that almost 20 years later, research is still evidencing that more resources should be invested to support children's needs at community level.

As expressed earlier in this chapter, there are also concerns regarding clinical research being under-represented and resourced in Wales; one of the reasons for this is insufficient investment in the academic paediatric workforce. ${ }^{665}$ The UN Committee on the Rights of the Child asserts that states must 'ensure an appropriately trained workforce of sufficient size to support health services for all children.'666

\footnotetext{
${ }^{661}$ Welsh Government, A Healthier Wales: Our Plan for Health and Social Care 2018 (Welsh Government 2018)

${ }^{662}$ Royal College of Paediatrics and Child Health and British Association for Community Child Health, Covering all bases - Community Child Health: A paediatric workforce guide (Royal College of Paediatrics and Child Health 2017)

${ }^{663} \mathrm{RCPCH}$, 'Worrying lack of children's doctors in Wales could damage health of future generations, say medical experts' May 102019 https://www.rcpch.ac.uk/news-events/news/worrying-lackchildrens-doctors-wales-could-damage-health-future-generations-say accessed January 2020

${ }^{664}$ Royal College of Paediatrics and Child Health and British Association for Community Child Health, Covering all bases - Community Child Health: A paediatric workforce guide (Royal College of Paediatrics and Child Health 2017)

${ }^{665}$ Evidence submitted to the National Assembly for Wales Children and Young People Education Committee Inquiry into children's rights Connor P, Croke R*, Thomas-Turner R 'Access to medicines and good quality paediatric research: human rights implications and considerations for the Welsh context' http://senedd.assembly.wales/documents/s94526/CYPE5-28-19\%20\%20Paper\%202.pdf accessed January 2020.

${ }^{666} \mathrm{UN}$ Committee on the Rights of the Child, General Comment No. 15 on the right of the child to the enjoyment of the highest attainable standard of health $\mathrm{CRC} / \mathrm{C} / 15 / 2013$ para 27
} 
Additionally, the Royal College of Nursing guidance ${ }^{667}$ states that there must be a children's champion at Executive Board level. However, according to research undertaken by the Royal College of Paediatrics and Child Health, ${ }^{668}$ three out of the seven health boards do not have a Board Level Lead/Champion for children's services, this reduces opportunities for children to have their voice heard and their human rights respected in organisational decision making.

As far back as 2001, Lord Carlisle issued a strong recommendation in his review of the NHS in Wales:

that all staff having access to children should be trained to a full understanding of children's rights and an appropriate level of awareness of the needs of children, and that they should be required by their employers, as a matter of specific contractual obligation to respect and apply those rights rigorously. ${ }^{669}$

$\mathrm{RCPCH}$ as part of a drive to improve the medical workforce for children is targeting Health Education and Improvement Wales (HEIW) which was established in October 2018 with recommendations to improve the workforce for children. ${ }^{670}$

There has been a raft of innovative and radical legislation and policy which has been put in place to further realisation of children's rights in Wales and to support their health and well-being, however, workforce investment and in many contexts health budgets are not prioritising children. Much more needs to be done to support the

\footnotetext{
${ }^{667}$ Royal College of Nursing, The role of children and young people's nurses in commissioning and planning service (Royal College of Nursing 2014)

${ }^{668}$ Royal College of Paediatrics and Child Health (2019) Workforce census: Focus on Wales: An Executive Summary (Royal College of Paediatrics and Child Health 2019)

${ }^{669}$ Lord Carlisle, The Review of Safeguards for Children and Young People Treated and Cared for by the NHS in Wales, "Too Serious a Thing" (National Assembly for Wales 2001) Recommendation 1, 133

${ }^{670}$ HEIW is a special health authority created within NHS Wales which brings together three organisations for health. These are, The Wales Deanery, NHS Wales Workforce Education and Development Services (WEDS) and the Wales Centre for Pharmacy Professional Education (WCPPE). Their principal functions are to improve: education and training, workforce development and modernisation, leadership development, strategic workforce planning, careers, and widening access.
} 
implementation of children's rights in practice. ${ }^{671}$ The reality of many children's health experiences still falls short of the policy and legislative commitments that have been made nationally. The next section will analyse the implementation gap, between policy and the lived experiences of children in Wales.

\subsection{The implementation gap: analysing the reality of children's health experiences in Wales}

Inequalities between children can be affected by a number of different factors, geographical location, socio-economic status, ethnicity, gender and age and combination of these and other factors. ${ }^{672}$ The health of children and young people is shaped by the conditions and circumstances in which they and their families live. In order to improve the health of all children and to eliminate discrimination and reduce health inequalities, the social and environmental determinants of children's health need to be identified and mitigated. ${ }^{673}$ There is an increasing and extensive evidence base that links the social epidemiology of these determinants to children's well-being. The life course sciences have also increased our knowledge on how these determinants affect children's health and impact into the future on adult health

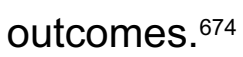

The Welsh Adverse Childhood Experience (ACE) study has brought forth evidence that experiences in childhood, such as abuse and neglect, growing up in households where domestic violence is happening, abusing substances and alcohol can alter child

\footnotetext{
${ }^{671}$ Croke R and Williams J (eds) Wales UNCRC Monitoring Group report to the UN Committee on the Rights of the Child (Swansea University 2015); UK Children's Commissioners, Report of the UK Children's Commissioners UN Committee on the Rights of the Child Examination of the Fifth Periodic Report of the United Kingdom of Great Britain and Northern Ireland (2015)

${ }^{672}$ Black D, Inequalities in Health (London: Penguin 1980); Acheson D, Independent Inquiry into Inequalities in Health (London: The Stationery Office; 1998); Marmot M, Allen J, Goldblatt P, Boyce T, McNeish D, Grady M, and Geddes I, Fair society, healthy lives: Strategic review of health inequalities in England post 2010 (Marmot Review 2010); Marmot M, Allen J, Boyce T, Goldblatt P, Morrison J, Health equity in England: The Marmot Review 10 years on (London: Institute of Health Equity 2020)

${ }^{673}$ World Health Organization and Commission on the Social Determinants of Health, Closing the gap in a generation: health equity through action on the social determinants of health (WHO and Commission on the Social Determinants of Health 2008)

${ }^{674}$ Chandni M J, Baird J, Barker M, Cooper C and Hanson M, The Importance of a Life Course Approach to Health: Chronic Disease Risk from Preconception through Adolescence and Adulthood (Institute of Development Studies, University of Southampton 2017)
} 
brain development, immuniological and hormonal responses, resulting in a greater likelihood of health harming and anti-social behaviours in adolescence and adulthood and in the longer term causing poor health, such as chronic diseases, cancer, cardiovascular diseases etc. and ultimately a lower life expectancy. The first study revealed that more than $47 \%$ of adults have experienced more than one ACE. ${ }^{675}$

\subsubsection{Health inequalities}

\subsubsection{Poverty and inequality}

The UK is one of the most unequal nations in Europe ${ }^{676}$ and according to a 2019 report by the All-Party Parliamentary Group on Inclusive Growth, residents in Blaenau Gwent in south Wales can expect up to 16.4 less years of good health than residents in Wokingham in Berkshire, England. ${ }^{677}$

$29 \%$ of children are living in poverty in Wales (when housing costs are taken into account) and these children are most at risk of the negative impact of the wider determinants of health. ${ }^{678}$ Adults who experienced poverty as children are $50 \%$ more likely to have illnesses which limit their daily life (e.g., arthritis), high blood pressure, respiratory illness, certain disabilities and mental ill health. ${ }^{679}$

Child poverty is set to increase not decrease by $2022 .{ }^{680}$ As the $\mathrm{RCPCH}$ report, the impact of 'poverty on child mortality rates in Wales is stark: children from the most deprived fifth of the population have a rate of child death 70 percent higher than those in the least deprived fifth'681, and as data collected and published by the Public Health

\footnotetext{
${ }^{675}$ Public Health Wales NHS Trust, Welsh Adverse Childhood Experiences Study (Public Health Wales Trust 2015) http://www.cph.org.uk/wp-content/uploads/2016/01/ACE-Report-FINAL-E.pdf accessed January 2020

${ }^{676}$ Partington R, 'Inequality is it rising and can we reverse it?' Guardian Online (September 2019) https://www.theguardian.com/news/2019/sep/09/inequality-is-it-rising-and-can-we-reverse-it accessed January 2020

${ }^{677}$ All Party Parliamentary Group on Inclusive Growth 2019 Report https://www.inclusivegrowth.co.uk/ accessed November 2019

${ }^{678}$ Stats Wales, percentage of children living in poverty 2015-16 to 2017-18

${ }^{679}$ Melhuish E, 'The impact of poverty on child development and adult outcomes: the importance of early years education,' In Judge, L. Ending child poverty by 2020 (Child Poverty Action Group 2012) ${ }^{680}$ Institute for Fiscal Studies, Living standards, poverty and inequality in the UK: 2017-18 to 202122 (Institute for Fiscal Studies 2017)

${ }^{681}$ Royal College of Paediatrics, State of Child Health: 2017 Recommendations for Wales (RCPCH 2017) 4
} 
Wales Observatory reveal the level of health inequality in the Welsh context is concerning. In 2013, it was reported by Public Health Wales that Children aged 0-17 years living in the most deprived parts of Wales were almost twice as likely to die in a given year as those in the least deprived parts of Wales. ${ }^{682}$ Webb comments that hospitalisation rates are higher for socio-economically deprived children, so consequently improving in-patient services will, in theory, benefit sick children from these groups. ${ }^{683}$ The next section briefly outlines the main health inequalities affecting children in Wales.

\subsubsection{Childhood injuries}

In the 2013, Public Health Wales reported that children living in the most deprived areas were more likely be admitted to hospital as an emergency as the result of a pedestrian injury than those children from less deprived areas. ${ }^{684}$ Data from the Public Health Wales Pregnancy and Childhood Surveillance tool show that the rate of emergency hospital treatment for child injury has fallen, from 18.1 to 17.2 per 1,000 between 2006/7 and 2015/16. . $^{2}$

\subsubsection{Dental decay}

Most of the reduction in dental decay of Welsh children has taken place in more affluent groups ${ }^{686}$, with the overall proportion of 5 year olds with a missing, decayed or filled milk tooth reduced from 57.6 per cent to 45.4 per cent between 2007/8 and 2014/15.97.687 However, children in the most deprived fifth of Wales have on average over twice as many decayed, missing or filled teeth than those in the least deprived

\footnotetext{
${ }^{682}$ Public Health Wales Observatory, Health of Children and Young People, (Public Health Wales NHS Trust 2013) 97

${ }^{683}$ Webb, E, 'Health Inequalities,' In Croke R and Crowley A (eds) Righting the wrongs: the reality of children's rights in Wales (Save the Children UK 2006)

${ }^{684}$ Public Health Wales Observatory, Health of Children and Young People, (Public Health Wales NHS Trust 2013) 99

${ }^{685}$ Public Health Wales, Pregnancy and childhood surveillance tool (Public Health Wales Trust 2017)

${ }^{686}$ Public Health Wales Observatory, Health of Children and Young People (Public Health Wales NHS Trust 2013) 99

${ }^{687}$ Welsh Government, Child Poverty Strategy: Assessment of Progress 2016. Summary report, (Welsh Government 2016)
} 
fifth of Wales. ${ }^{688}$ The $\mathrm{RCPCH}$ reported that 6070 children in Wales underwent dental extraction under anaesthetic in $2018 .{ }^{689}$

\subsubsection{Infant mortality and low birth weight}

Socioeconomic status is strongly associated with infant mortality, with increasing risk associated with higher levels of maternal deprivation. ${ }^{690}$ Wales' infant mortality rate (3.6 per 1,000 live births) is higher than Scotland, comparable to England and lower than Northern Ireland. ${ }^{691}$ In the most deprived areas, the highest infant mortality rate rises to 4.7 deaths per 1,000 live births. ${ }^{692}$ The overall percentage of babies born with a low birth weight has remained relatively stable however there is a clear gradient across the deprivation fifths of Wales. ${ }^{693}$

\subsubsection{Childhood obesity}

27.1 per cent of children in Wales in 2016/17 were classified as overweight or obese at the ages of 4-5, compared to only 22.6 per cent in England. ${ }^{694}$ The highest rates of obesity can be found in the most deprived fifths of the population suggesting that socioeconomic deprivation is a strong factor in contributing to obesity. ${ }^{695}$ There are serious concerns regarding children who are obese contracting Type 2 Diabetes, contributing to the development of health conditions such as blindness, amputations and kidney disease and lower life expectancy in later life. There has been a reported $41 \%$ increase in people under the age of 25 years getting the condition in 2016/2017 since

\footnotetext{
${ }^{688}$ Public Health Wales Observatory, Health and its Determinants in Wales - Informing Strategic Planning (Public Health Wales NHS Trust 2018)

${ }^{689}$ Royal College of Paediatrics and Child Health, State of Child Health 2020: Wales, 15 (RCPCH)

${ }^{690}$ Royal College of Paediatrics and Child Health, State of Child Health: 2017 Recommendations for Wales, (RCPCH 2017)

${ }^{691}$ Public Health Wales Observatory, Health and its Determinants in Wales - Informing Strategic Planning (Public Health Wales NHS Trust 2018)

${ }^{692}$ Office of National Statistics, Child mortality in England and Wales 2016

${ }^{693}$ Public Health Wales Observatory, Health and its Determinants in Wales - Informing Strategic Planning (Public Health Wales NHS Trust 2018)

${ }^{694}$ Public Health Wales NHS Trust, Child Measurement Programme for Wales 2016/17 (Public Health Wales NHS Trust 2018) 74

${ }^{695}$ Royal College of Paediatrics and Child Health, State of Child Health 2020: Wales, 16 (RCPCH 2020)
} 
$2013 / 2014 .{ }^{696}$ Those in the most deprived fifths of the population are also the least likely to report eating fruit and vegetables. ${ }^{697}$

\subsubsection{Smoking and alcohol consumption}

One in five deaths in Wales can be attributed to smoking. ${ }^{698}$ Amongst those aged $11-$ 16 years higher percentages of children taking up smoking earlier are found in less affluent groups. ${ }^{699}$ In 2018, '9\% of 15 year olds in Wales self-reported as regular smokers (smoking within the last week), compared to $5.1 \%$ in England and $7 \%$ in Scotland'. ${ }^{700}$ In contrast alcohol consumption is higher in more affluent groups and weekly consumption of alcohol is comparable across England and Wales. ${ }^{701}$

\subsubsection{Teenage conception rates and breastfeeding rates}

Higher teenage conception rates are associated with areas of higher deprivation and areas of higher unemployment. Positively, overall, teenage conceptions in Wales have been falling in recent years in line with the rest of the UK. ${ }^{702} 22 \%$ of babies are breastfed at 10 days in the most deprived fifth of Wales compared with $47 \%$ in the least deprived fifth of Wales. ${ }^{703}$ In 2020, the RCPCH reported that breastfeeding rates at six weeks are lowest in Wales (20.8\%) compared to other UK nations $(30.7 \%$ at 6 8 weeks in Scotland). ${ }^{704}$

\footnotetext{
${ }^{696}$ Data collected by Paediatric Diabetes Units and the Royal College of Paediatrics and Child Health across England and Wales, Campbell D, 'Cases of type 2 diabetes among young people rise $41 \%$ in three years' Guardian Online (18 ${ }^{\text {th }}$ August 2018)

${ }^{697}$ Welsh Government, 2013/14 Health Behaviour in School-aged Children (HBSC) Wales: key findings (Welsh Government 2015)

${ }^{698}$ Public Health Wales Observatory, Tobacco and health in Wales (Public Health Wales Observatory 2012)

${ }^{699}$ Public Health Wales Observatory, Health of Children and Young People, (Public Health Wales NHS Trust 2013) 64

${ }^{700}$ Royal College of Paediatrics and Child Health, State of Child Health 2020: Wales, (RCPCH 2020) 21

${ }^{701}$ Welsh Government, 2013/14 Health Behaviour in School-aged Children (HBSC) Wales: key findings (Welsh Government 2015)

${ }^{702}$ Public Health Wales, Pregnancy and childhood surveillance tool (Public Health Wales Trust 2017)

${ }^{703}$ Public Health Wales Observatory, Health and its Determinants in Wales - Informing Strategic Planning (Public Health Wales NHS Trust 2018)

${ }^{704}$ Royal College of Paediatrics and Child Health, State of Child Health 2020: Wales, (RCPCH 2020)13
} 


\subsubsection{Children as carers}

Wales compared to English regions and England as a whole, had the highest percentage of households with dependent children where one person has a long-term condition or disability. ${ }^{705}$ Compared to the English regions, Wales had the highest percentage of young people providing unpaid care; with growing evidence that this has a detrimental impact on the health of the child carer. ${ }^{706}$

\subsubsection{Mental health}

In 2011, over 40,000 children and young people aged 5-16 were estimated to have a mental health disorder in Wales. ${ }^{707}$ A study undertaken by NHS England, showed one in eight people under the age of 19 in England had a disorder in 2017. ${ }^{708}$ This statistic is likely to be reflected similarly in the Welsh context. Welsh teenagers were reported to have among the poorest life satisfaction rates across the UK in $2017 .{ }^{709}$ There is evidence to suggest that children's mental health is affected by their socio-economic status $^{710}$ and the RCPCH has reported that deprivation and mental health problems increase the risk of death throughout adolescence. ${ }^{711}$ There is very little disaggregated data: data for Wales tends to refer to children generically, ignoring groups within the wider population who have distinct needs and face additional barriers which can lead to further inequalities. The $\mathrm{RCPCH}$ in Wales have recommended that WG should

\footnotetext{
${ }^{705}$ Public Health Wales Observatory, Health of Children and Young People, (Public Health Wales NHS Trust 2013) 35

${ }^{706}$ Croke R and Williams J (eds) Wales UNCRC Monitoring Group report to the UN Committee on the Rights of the Child (Swansea University 2015) 42

${ }^{707}$ Due to a lack of data available on mental health, the estimated number of 5-16 year olds with any mental disorder were produced by applying prevalence estimates $(9.6 \%)$ published by Green et al (2004)19 to the 5-16 year old population of Wales.

${ }^{708}$ NHS Digital, Mental Health of Children and Young People in England, (2017 NHS/PAS)

https://digital.nhs.uk/data-and-information/publications/statistical/mental-health-of-children-andyoung-people-in-england/2017/2017 accessed January 2020

${ }^{709}$ Royal College of Paediatrics of Child Health: 2017 Recommendations for Wales (RCPCH 2017)

${ }^{710}$ Hudson C, 'Socioeconomic Status and Mental Illness: Tests of the Social Causation and Selection Hypotheses,' American Journal of Orthopsychiatry, Foundation (2005) Vol. 75, No. 1, 3-18; Lorant V, Croux C, Weich S, Deliege D, Mackenbach J and Ansseau M, 'Depression and socio-economic risk factors: 7-year longitudinal population study', British Journal of Psychiatry (2007) 190 (4), 293 298

${ }^{711}$ Royal College of Paediatrics and Child Health in Wales https://www.rcpch.ac.uk/resources/statechild-health-1-mortality-indicators accessed January 2020
} 
'collect data on prevalence of mental health conditions in children and young people and report this at a minimum of every three years' ${ }^{712}$

\subsubsection{Access to services for marginalised groups}

NGOs reported to the UN Committee on the Rights of the Child in 2015, that marginalised groups such as looked after children, BME children, refugees and asylum seekers and those children not receiving statutory protection from local authorities (such as homeless children/ children fleeing domestic violence etc.) were struggling to access good quality health care. Marginalised groups were reported to not have a full understanding of what services are available and to find it challenging to navigate systems that are confusing and constantly changing. ${ }^{713}$ There is a dearth of good quality disaggregated data regarding health inequalities and disaggregated groups of children, making it challenging to plan services according to need.

\subsection{Conclusion}

Wales is attempting through policy and law reform to address the socioeconomic determinants of poor child health and to address adverse childhood experiences. However, the above evidence suggests that for those children who face inequality many of their UNCRC rights are being breached.

Post 2011, a focus on children became lost as part of the agenda for integrated service provision for children and adults and resources were not being sufficiently assigned to tackle the full range of children's rights violations. ${ }^{714}$ Fiscal austerity has increased public expenditure cuts, with funding that is often short-term and opportunistic and vulnerable to political re-prioritisation, and insignificant priority has generally been given to ring fencing funding for children's services. ${ }^{715}$ Children's clinical research also continues to be under-resourced and neglected which affects the critical development of medicines tailored to childhood conditions and Welsh Government funding models

\footnotetext{
${ }^{712}$ Royal College of Paediatrics and Child Health, State of Child Health 2020: Wales (RCPCH 2020) 24

${ }^{713}$ Croke R and Williams J (eds) Wales UNCRC Monitoring Group report to the UN Committee on the Rights of the Child (Swansea University 2015)

${ }^{714}$ Ibid

${ }^{715}$ Ibid
} 
indirectly discriminate against children. This is all set against an inadequate paediatric workforce, with Wales currently having a shortfall of 74 paediatric consultants and insufficient investment in the paediatric academic workforce. Additionally, there has been a continued trend of not providing sufficient investment in community child health.

However, there is some evidence of health programmes that have been invested in that focus specifically on the child, i.e., Healthy Child Programme 2016 and the Together for Children and Young People Programme 2015. As they are more recent developments, they are yet to be fully evaluated but it can be hoped that they will have far reaching impacts on children's physical and mental health. It is also positive that an additional $£ 7.1$ million has been invested in children's mental health, given this is an ongoing issue of concern and historically was under-funded compared to adult services.

Where there are general health policies, much more could be done to ensure integration and application to the importance of children's rights e.g., the earlier mentioned Prudent Health Care Principles. The RCPCH commented in 2017 there should be an overarching evidenced based strategy for children's health and wellbeing that covers all of childhood. ${ }^{716}$ They also argue that there should be a 'Child health in all policies' approach to decision-making, policy making and service design'. I would argue that instead there needs to be a children's rights approach to all decision-making and service design, and an overarching strategy for children's rights, with health and well-being an indivisible part of such an approach.

With regards to the UN's interpretation of the right to health, the majority of policies do address some of the important aspects of prevention and the social determinants of health, but none of the policies go far enough to integrate other important aspects of a children's rights approach, i.e., empowering the child, service accountability to children and enforcement of socio-economic rights. Wales does not currently have the strength of the accountability framework of the international human rights framework that visualises access to quality health services in terms of enforceable social and

\footnotetext{
${ }^{716}$ Royal College of Paediatrics, State of Child Health: 2017 Recommendations for Wales (RCPCH 2017)
} 
economic rights and does not sufficiently address how children can be empowered to claim their health rights.

However, it is positive that through guidance developed by Hoffman and Croke $\mathrm{e}^{717}$ with regards to a CRA to public service delivery that the Children's Commissioner for Wales and the Future Generations Commissioner have launched a programme of action to influence all public services to adopt a children's rights approach. This will require public bodies to make children more visible and embed children's rights in public body decision making. This will be examined in more detail in later chapters.

${ }^{717}$ Hoffman S and Croke R, 'A Children's Rights Approach Statement and Guide' prepared for the Children's Commissioner for Wales’ (Swansea University 2016) 


\section{CHAPTER 6 DEVELOPING A CONCEPTUAL FRAMEWORK FOR A CRA TO HEALTH SERVICES IN WALES}

\subsection{Introduction}

The evidence in Part 1 of this thesis (Chapters 1-5) has presented an analysis of the international human rights framework and the literature on human rights, children's rights and health and their application in practice and discussed the policy and health context for children in Wales. This chapter draws on this evidence and with further reflection discusses what should be the principles and standards of a CRA to health services in the Welsh context. It is a long chapter that justifies and explains the conceptual framework that has been developed to inform the design of a methodology for testing how far a health authority has embedded a CRA and their strategies for improvement.

The first section outlines what must be understood and considered in a CRA before moving onto consider the five principles of a CRA to Health Services in the Welsh context and how these principles can be translated into standards and objectives.

\subsection{Understanding the key elements of a CRA to health services}

\subsubsection{The essential characteristics of human rights must be understood}

In the earlier chapters to this thesis, it was demonstrated that there must be a clear acknowledgement that a CRA to health services should be rooted in the international human rights treaty system (See Chapter 2, 3, 4). The essential characteristics of human rights must be understood, that is they are universal, inalienable, indivisible, interrelated and interdependent and support the inherent dignity of each and every individual (See Chapter 2) these are further explained in Table 2. 
TABLE 2: The essential characteristics of human rights

\begin{tabular}{|l|l|}
\hline Dignity & $\begin{array}{l}\text { Human rights are predicated on the } \\
\text { intrinsic value and worth of all human } \\
\text { beings }\end{array}$ \\
\hline Universality & $\begin{array}{l}\text { Human rights are the same for all human } \\
\text { beings, they belong to people simply } \\
\text { because they are human, regardless of } \\
\text { their sex, race, colour, language, } \\
\text { national origin, age, class, religion, or } \\
\text { political beliefs }\end{array}$ \\
\hline Inalienability & $\begin{array}{l}\text { Human rights cannot be taken away; no- } \\
\text { one has the right to deprive another } \\
\text { person of them for any reason. }\end{array}$ \\
\hline Indivisibility & $\begin{array}{l}\text { All human rights have equal status and } \\
\text { cannot be positioned in a hierarchical } \\
\text { order. Denial of one right invariably } \\
\text { impedes enjoyment of other rights. }\end{array}$ \\
\hline Interrelated & $\begin{array}{l}\text { The fulfilment of one right often depends, } \\
\text { wholly or in part, upon the fulfilment of } \\
\text { others. }\end{array}$ \\
\hline
\end{tabular}

Chapters 2-5 emphasised the importance and equal status of Economic, Social and Cultural rights that must be recognised and given effect and not just programmatic aspirations. A CRA promotes the adoption of strategies that aim to respect, protect and fulfil children's human rights (See Chapter 2) recognising that this is not just desirable but obligatory for health authorities in states that have ratified human rights instruments. 


\subsubsection{A focus on the human rights of children and the United Nations Convention on the Rights of the Child}

Munro explains that the value of a human rights approach is that it puts the focus on the 'client'. So, in the school context the focus is on the human rights of the child, 'not the principal, the teacher's union or the local paedophile ring'. ${ }^{718}$ Although, this may seem an obvious approach, the human rights of the client have arguably been absent from the delivery of public services ${ }^{719}$ and this has certainly been the case with children (see Chapter 4).

Tobin comments that it is important to be clear as to which human rights framework the approach is referring to. A CRA to health services has a specific focus on children (0-17 years) and thus should recognise the importance of the UNCRC. The UNCRC which was introduced in Chapter 2, has become the accepted international standard against which to measure legislation and policies affecting children and specifically designed to guarantee the human rights of all children. It covers the full spectrum of human rights, civil and political and economic, social and cultural rights. All the substantive articles of the UNCRC are relevant to a CRA to health, from best interests to survival and development, to the right to health, privacy, protection, play and education and the right to be heard. The UNCRC takes a life course approach, respects the inherent dignity of the child, and recognises that children's capacities develop with age and maturity while still affirming the importance of the family and their carers to children. A CRA for Health Services should aim to put the UNCRC at the core of health practice and ensure children's views and experiences are central to influencing what changes for the better and how.

\subsubsection{A principled approach}

In Chapter 3, it was made clear that human rights and children's rights approaches benefit from a principled approach. Principles should be drawn from the international human rights framework; including the treaty that may be specific to the client group

\footnotetext{
${ }^{718}$ Munro L, 'A Human Rights Based Approach to Programming: A contradiction in terms', In (eds) Hickey S and Mitlin D, Rights Based Approaches to Development: Exploring the Potentials and the Pitfalls (Kumarian Press 2009 USA)

${ }^{719}$ Ibid
} 
under consideration. As Darrow and Amparo make clear, the identification of principles should be driven by their functionality and be clearly understood-they should gear the development process more directly towards the realisation of human rights. There should be a seamless link between principles and objectives that translate the human rights of children into practice, guiding the formulation of policies, laws, budgets and strategies and directing the establishment of corresponding benchmarks or indicators. ${ }^{720}$ Human rights principles, legal standards and norms should be explicitly applied across policy, planning and practice.

\subsubsection{Specific to the human right to health}

In Chapter 3 and 4, it was noted that a CRA for Health Services must give specific consideration to the child's right to health (See the UNCRC and the ICESCR) the AAAQ Framework, Progressive Realization and the Maximum Extent of Available Resources and the importance of implementing and securing socio-economic human rights. Consistent data should be collected on children's lives and indicators developed that monitor and evaluate the implementation of children's right to health. It should aim to address the root causes of children's rights violations, and empower children who experience structural health inequalities, promoting the adoption of public health strategies for children that aim to reduce health inequality, recognising that this is not just desirable but an obligation for States which have ratified international human rights instruments.

There should be universal access for all children to primary health-care services provided as close as possible to where children and their families live, particularly in community settings. Secondary and tertiary level care should also be made available, to the best possible extent, with functional referral systems linking communities and families at all levels of the health system. A holistic approach to health services should be adopted that places the realisation of children's right to health within the broader context of all the human rights of the UNCRC, other international treaties and the

\footnotetext{
${ }^{720}$ Darrow M and Amparo T, 'Power, Capture, and Conflict: A Call for Human Rights Accountability in Development Cooperation', Human Rights Quarterly (2005) 27501
} 
broader framework of working collaboratively with external agencies. What should be included in a CRA to health services is included in the Table 3 below.

TABLE 3: A CRA to health services should include

\begin{tabular}{l} 
An understanding of the essential characteristics of human rights. \\
Have a clear focus on the UNCRC and the human rights of children. \\
\hline $\begin{array}{l}\text { Identify principles that can be translated into objectives/standards relevant to } \\
\text { the context in question and can be explicitly connected to the international } \\
\text { human rights treaties. }\end{array}$
\end{tabular}

Be specific to the right to health, Article 24 of the UNCRC, Article 12 ICESCR but understand the importance of the indivisibility of all human rights.

General Comment No.15 of the UNCRC and General Comment No.14 ICESCR and other relevant General Comments.

Progressive realisation and maximum extent of available resources.

AAAQ Framework i.e., Availability, Accessibility, Acceptability, Quality.

Emphasis on prevention and primary health care.

Emphasis on the social determinants of health/root causes.

A holistic and coordinated approach and one that considers all health systems.

Practical guidance for health professionals. 


\subsection{Five principles of a CRA to health services for the Welsh context}

In order to develop a CRA to health services in the Welsh context, firstly principles must be identified. Hoffman and Croke identify five principles for a CRA to public services in the Welsh context. ${ }^{221}$ The principles are: Embedding children's human rights, Equality and Non-discrimination towards children, Accountability to children, Participation of children, and Empowering children. These principles bear similarities to the principles included in other human rights approaches (See Chapter 3 and 4) and were identified as being the principles best suited to drive the implementation of a CRA for public bodies in Wales. The model developed by Hoffman and Croke was based on a review of CRA/HRBA's in practice and of practices currently in use in the Welsh public sector. The model was not developed from a conceptual framework but offers a practical guide to a CRA.

The five principles were retained as the underpinning framework for the CRA to health services developed in this thesis, as they have been adopted by the CCfW and by public bodies in Wales, including Welsh Government. ${ }^{722}$ The principles are therefore part of the 'child rights consciousness' of public authorities in Wales, and provide a convenient (and familiar) principled and pragmatic framework for practice, including in health services. As discussed in this thesis, the principles are also fully justified by reference to the literature. It is noted that the UN Committee suggest that the 'Best Interests of the Child', (Article 3 of the UNCRC) and 'Survival and Development of the Child' (Article 6 of the CRC) should be amongst the general principles which guide implementation, and therefore would seem appropriate in a CRA. However, for reasons discussed in this thesis (see Chapter 2, Chapter 3, Chapter 4, Chapter 6, Chapter 8 ), it was decided not to include them as principles in the CRA developed by Hoffman and Croke or adopt them as the basis of the CRA put forward for use by ABMU. After careful consideration (see ibid), it was decided these two principles are promoted by application of the 5 principles of the CRA adopted and applied in this thesis.

\footnotetext{
${ }^{721}$ Hoffman S and Croke R, 'Children's Rights Approach Statement and Guide for the Children's Commissioner for Wales' (Swansea University 2016)

${ }^{722}$ One very clear example is the Welsh Government in 2018 used the model in their Compliance report on the Rights of Children and Young Persons (Wales) Measure 2011 https://gov.wales/rightschildren-and-young-people-compliance-report accessed January 2020
} 
This decision was in part influenced by the best interests of the child, first and foremost being interpreted as a 'welfarist principle' in the Welsh context ${ }^{723}$ and the wider UK context. ${ }^{724} 725$ Williams reporting on a study on the UNCRC and the professions in Wales, comments that, professionals often 'reflected a traditional, paternalistic, welfare-orientated conceptualisation of the relationship between the professional and the child. ${ }^{726}$ This interpretative lens perceives children as vulnerable and in need of protection which often results in denying their voice and agency, and also results in adults (practitioners, managers, parents) determining best interests without always giving consideration to the child's view point or considering the child as capable of making decisions in their own right. Research by De Vries suggests that health professionals determine children to be competent to make decisions if the child's decision conforms to their own ideas of what is in the child's best interests ${ }^{727}$, and additionally many practitioners struggle with the vagueness and ambiguity of the concept ${ }^{728} 729730731$ (See also discussion in Chapter 2, Chapter 6, Chapter 8). The risk of legitimising a welfarist approach through the inclusion of the best interest principle amongst the principles included in the CRA to health services used in this thesis, led to the decision to exclude it from the CRA.

\footnotetext{
${ }^{723}$ Williams J, 'The Role of the Professions in Effective Implementation of the CRC', In (eds) Liefaard T and Sloth-Nielsen J (eds) The United Nations Convention on the Rights of the Child: Taking Stock After 25 years (Brill Publishing 2017) 8.

${ }^{724}$ Zermatten J, The Best Interests of the Child: Literal Analysis, Function and Implementation. (Institut International de droits de l'enfants 2009)

${ }^{725}$ Denburg A E, Giacomini M, Ungar W J, Abelson J. 'The Moral Foundations of Child Health and Social Policies: A Critical Interpretive Synthesis', Children. 2021; 8(1):43

${ }^{726}$ Williams J, 'The Role of the Professions in Effective Implementation of the CRC', In (eds) Liefaard T and Sloth-Nielsen J (eds) The United Nations Convention on the Rights of the Child: Taking Stock After 25 years (Brill Publishing 2017) 8

${ }^{727}$ De Vries MC, Wit JM, Engberts DP, Kaspers GJL, Van Leeuwen E. Norms versus Practice: Pediatric Oncologists, Attitudes towards Involving Adolescents in Decision Making concerning Research Participation', Pediatr Blood Cancer. 2010; 55:123-128.

${ }^{728}$ Children's rights knowledge centre, A discussion of commonly encountered tensions and possible solutions based on international best interests and policy strategies since 2004: A study of the Children's Knowledge Centre (Commissioned by the Flemish Government Division of Youth, 2014) ${ }^{729}$ Smeyers P, 'Child rearing in the 'risk' society: on the discourse of rights and the "best interests of a child," Educational Theory (2010) 60 (3), 271-284.

${ }^{730}$ Doek J, 'Children's rights in health care and the General Principles of the CRC', In Doek J and Dorscheist M (eds) Children's Rights in Health Care (Brill Publications 2018)

${ }^{731}$ Cantwell N, "Are the "Best Interests" a Pillar or a problem for Implementing Human Rights of Children?' In Liefaard T and Sloth-Nielsen J (eds.) The United Nations Convention on the Rights of the Child: Taking Stock after 25 Years and Looking Ahead (Leiden/Boston, Brill 2017) 65
} 
'Survival and Development of the Child was not included amongst the principles of the CRA used in this thesis, as once again, it is reflected and promoted by application of the 5 selected principles. In addition, the right to protection of life is protected by the ECHR and given effect in the UK and Wales by the Human Rights Act 1998. The 'right to life and survival and development' of the child is of critical importance, however, it is not apparent why it should be seen as a general principle which informs the implementation of all other rights under the UNCRC, or indeed the practice of health services (see, for example Hanson and Lundy). ${ }^{732}$ The UN Committee on the Rights of the Child's jurisprudence reflects and supports this conclusion, as Article 6 is becoming increasingly absent in the description of the General Principles. ${ }^{733}$ With these considerations in mind, Article 6 may be best described as a substantive right and an outcome arising from the application of a CRA, rather than a principle to be included in a CRA.

While it is vital that children's interests are always given the primary consideration and children's right to life, survival and development should be respected in all circumstances, the overarching interpretative lens of the proposed CRA, is appropriate to ensure that both these rights are properly prioritised. The CRA promotes that:

- all the articles of the Convention should be embedded in any service response and given equal and balanced consideration (Embedding).

- public bodies should be held accountable in respecting, protecting and fulfilling all children's rights (Accountability).

- children as a social group should be treated equally and not discriminated against in public body decision making (Equality and non-discrimination).

- children's views should always be given due weight in accordance with their age and maturity (Participation of the Child).

- children should be empowered to exercise and claim their human rights and presumed capable of making decisions (Empowering the Child).

\footnotetext{
${ }^{732}$ Hanson K and Lundy L, 'Does exactly what it is says on the tin? A critical analysis and alternative conceptualisations of the So-called "General Principles" of the Convention on the Rights of the Child', The International Journal of Children's Rights (2017) (25 (2) 301 ${ }^{733}$ Ibid
} 
This interpretive lens supports a vision of childhood in which children (as active agents and human rights holders) are guaranteed all their human rights.

Hanson and Lundy argue that the terminology of 'principles' should no longer be applied, and instead they favour two categories: 'overall implementing obligations' and 'Cross Cutting Standards'. ${ }^{734}$ While this approach may provide a justifiable approach to implementation of the UNCRC in general, as will be discussed further in this chapter and has been discussed elsewhere in this thesis (see Chapter 3,4 ), when it comes to the practice of children's rights and delivery by authorities such as health boards, implementation may be supported - and promoted - through the application of accessible 'principles'. This approach is considered to support implementing authorities to adopt a way of working which ensures their actions are aimed at respecting, protecting and fulfilling children's rights. A clear set of principles which are aimed at directing practitioners (policy or delivery) to conduct their day-to-day activities is necessary to ensure the UNCRC is central to programmes of work, that impact on all children who use relevant services, including health services. All these reasons informed the decision to retain the principles of the CRA discussed above. The principles which inform the CRA, their justification and conceptual underpinnings in the health context are discussed in further detail in the following sections.

\subsubsection{Examining the theory and importance of the principle, 'Embedding children's rights'}

\subsubsection{Overview}

As noted in Chapter 5, many children in Wales are living in poverty, challenged by health inequalities and not receiving services and the resources they require to be healthy, well-educated and able to develop to the best of their abilities. ${ }^{735}$ In Wales there has been positive progress with regards to the UNCRC underpinning national

\footnotetext{
${ }^{734}$ Hanson K and Lundy L, 'Does exactly what it is says on the tin? A critical analysis and alternative conceptualisations of the So-called "General Principles" of the Convention on the Rights of the Child', The International Journal of Children's Rights (2017) (25 (2) 301

${ }^{735}$ UK Children's Commissioners, Report of the UK Children's Commissioners UN Committee on the Rights of the Child Examination of the Fifth Periodic Report of the United Kingdom of Great Britain and Northern Ireland (2015)

http://www.childrenscommissioner.gov.uk/sites/default/files/publications/UNCRC\%20final 0.pdf accessed March 2018
} 
policy and legislation but it has been suggested that there is a long way to go with regards to a CRA being embedded within public service delivery in Wales. ${ }^{736}$ One way of tackling this lack of a CRA to service delivery is to offer advice to public services regarding how they can mainstream and embed this approach throughout their services. There has been no development to date of a national CRA to health services in the Welsh context although as noted in earlier sections; globally human rights are being mainstreamed into policies and many other countries internationally are adopting a child friendly approach to health care. As referred to in Chapter 4 mainstreaming a child friendly approach to health care was highlighted as an area for improvement by Kilkelly and Savage's study. Many countries have arrived at the point of introducing children's rights charters for the health care environment; however, more research needs to be undertaken with regards to how the charters can become part of the policy framework, structure of health care systems and embedded into the practice of organisations.

\subsubsection{What is the principle of 'Embedding children's rights' and where is it drawn from?}

Children's human rights need to become a permanent and noticeable feature of society and any system affecting children and people's attitudes towards children needs to embed a CRA. The concept of 'Embedding children's rights' although aligned with the definition of 'mainstreaming' which means bringing legislation, policies and practice into the mainstream, has a stronger emphasis on making something rooted and permanent.

The international human rights framework outline that human rights should be integrated into every aspect of decision making. ${ }^{737}$ UN Secretary Kofi Anan describes this principle as:

\footnotetext{
${ }^{736}$ Croke R and Williams J (eds) Wales UNCRC Monitoring Group report to the UN Committee on the Rights of the Child (Swansea University 2015)

https://www.swansea.ac.uk/media/WalesUNCRCReport_v3.pdf accessed March 2018

${ }^{737}$ UNDP Section 1 Human Rights and Development: An emerging nexus; human rights and development: the International Framework www.undp.org/rbap/rights/Nexus.htm accessed May 2017
} 
the process of assessing the human rights implications of any planned action including legislation, policies or programs, in all areas and at all levels. It is a strategy for making human rights an integral dimension of the design, implementation, monitoring and evaluation of policies and programs in political, economic and social spheres. ${ }^{738}$

This principle demands that the impact of policy, budgets, procedure and actions upon individuals must be examined through the lens of human rights, that recognises the entitlements of individuals and the duties of states instead of the alternative paradigms which are based on charity, benevolence and the needs of individuals and in the case of children, often referred to as the welfare approach. ${ }^{739}$

Tobin, comments that embedding human rights supports a proactive process and is preventative as opposed to being purely remedial. ${ }^{740}$ It is not solely based on a compliance model of human rights which is based on an inquiry as to whether a human rights standard has been protected. ${ }^{741}$ This usually results in applying for remedies in a court of law or through an official investigation. Instead, the approach is less restrictive and appreciates the instrumental and powerful role of human rights in shaping policies, legislation and practice. ${ }^{742}$

The UN Committee on the Rights of the Child supports this proactive process and obliges State parties to develop structures and mechanisms to support duty bearers to meet their obligations towards children as human rights holders and to support children to be able to exercise and claim their human rights. The General Measures of Implementation of the UNCRC introduced in Chapter 2, help us to understand what effective structures are required to embed a CRA. State parties are obligated to raise

\footnotetext{
${ }^{738}$ (UN General Secretary 1997, paras 78-9) United Nations, Report of the Secretary-General, Renewing the United Nations: a Programme for Reform, 14 July 1997, UN Index A/51/950

${ }^{739}$ Tobin J, 'Understanding a human rights based approach to matters involving children: conceptual foundations and strategic considerations' In Invernizzi A and Williams J (eds) The Human Rights of Children: From Visions to Implementation (Farnham: Ashgate 2011) 66

${ }^{740}$ Tobin J, 'Understanding a human rights based approach to matters involving children: conceptual foundations and strategic considerations' In Invernizzi A and Williams J (eds) The Human Rights of Children: From Visions to Implementation (Farnham: Ashgate 2011)

${ }^{741}$ Ibid

${ }^{742}$ Darrow M and Amparo T, 'Power, Capture, and Conflict: A Call for Human Rights Accountability in Development Cooperation', Human Rights Quarterly (2005) 27, 486
} 
awareness of the UNCRC, incorporate the UNCRC into domestic legislation and policy, provide provisions for coordinated government with a clear focus on children, monitor human rights standards and facilitate the development of independent human rights institutions. ${ }^{743}$

\section{Under Article 4 of the UNCRC:}

State parties shall undertake all appropriate legislative, administrative, and other measures for the implementation of the rights recognised in the present Convention. With regard to economic, social and cultural rights, State Parties shall undertake such measures to the maximum extent of their available resources and, where needed, within the framework of international cooperation. ${ }^{744}$

The importance of Article 4 is emphasised by both Doek ${ }^{745}$ and Dietrick ${ }^{746}$ who argue it should be included as a general principle of the UNCRC because it introduces obligations applicable to the whole Convention. Hanson and Lundy argue in favour of discarding the general principles in favour of two categories 'overall implementing obligations' and 'cross cutting standards', with Article 4 being recognised as an 'overall implementing obligation'. ${ }^{747}$ This thesis agrees on the importance of the General Measures of Implementation and Article 4 and embraces it, in particular within the principles of Embedding and Accountability.

As outlined in Chapter 2 referring to the ICESCR, there is also an acceptance within Article 4 of the UNCRC that the full realisation of social, economic and cultural rights may not be achieved immediately as resources may not be available. It is the

\footnotetext{
${ }^{743}$ UN Committee on the Rights of the Child, General Comment No. 5 on the General Measures of Implementation, $\mathrm{CRC} / \mathrm{C} / \mathrm{GC} / 5 / 2003$

${ }^{744}$ In international human rights law, there are articles similar to article 4 of the Convention, setting out overall implementation obligations, such as article 2 of the International Covenant on Civil and Political Rights and article 2 of the International Covenant on Economic, Social and Cultural Rights. ${ }^{745}$ Doek J, 'The CRC General Principles' In, 18 Candles: The Convention on the Rights of the Child reaches majority (Geneva: Institut international des droits de l'enfant 2007) 31-32

${ }^{746}$ Dietrick S A, Commentary on the United Nations Convention on the Rights of the Child (The Hague: Brill/Nijhoff 1999)

${ }^{747}$ Hanson K and Lundy L, 'Does exactly what it is says on the tin? A critical analysis and alternative conceptualisations of the So-called "General Principles" of the Convention on the Rights of the Child', The International Journal of Children's Rights (2017) (25 (2) )285-306
} 
responsibility of the State to demonstrate that it has used all resources to the maximum extent and as a matter of priority and that this requires an adequate and transparent budget analysis. The UN Committee needs to know:

what steps are taken at all levels of government to ensure that economic and social planning and decision-making and budgetary decisions are made with the best interests of children as a primary consideration and that children, including in particular marginalized and disadvantaged groups of children, are protected from adverse effects of economic policies or financial downturns. ${ }^{748}$

This way of thinking should also be translated to service delivery level, making clear that children's rights are not an afterthought, but a primary consideration given equal priority with other pressing interests when decisions are taken, and actions carried out. This helps to ensure that the best interests of children are a primary consideration for all organisations that have an influence on children's lives as guaranteed by Article 3 of the UNCRC. ${ }^{749}$

The UN Committee's General Comment No.14 outlines the key elements that a public body should take into account when making the decision. ${ }^{750}$ To ensure the correct implementation of the child's right to have his or her best interests taken as a primary consideration, the public body must implement child-friendly and transparent procedural safeguards..$^{751}$ These should be clear and transparent and identify where children's rights have been taken into account. Best interests places an obligation on decision makers, budget, and law and policy makers and those who deliver services to always consider whether a decision will have an impact on children's lives, to assess

\footnotetext{
${ }^{748}$ UN Committee on the Rights of the Child, General Comment No.5 on the General Measures of Implementation $\mathrm{CRC} / \mathrm{GC} / 2003 / 5$ para 51

${ }^{749}$ 'The very umbrella-like coverage of 3 (1), "in all actions concerning children" - includes actions in which other parties may have equal claims to have their interests considered. However, where the phrase "best interests" is used elsewhere in the Convention, if the focus is on deciding appropriate action for individual children in particular circumstances and requires determination of the best interests of individual children, in such situations, the child's interests are the paramount consideration', Hodgkin R and Newell P, The Implementation of the UNCRC (UNICEF 2002) 44

${ }^{750} \mathrm{UN}$ Committee on the Rights of the Child, General Comment No. 14 on the right of the child to have his or her best interests taken as a primary consideration $\mathrm{CRC} / \mathrm{C} / \mathrm{GC} / 14 / 2013$ 48-84

${ }^{751}$ Ibid paras 85-99
} 
what that impact will be, and to elevate children's interests to the level of a primary consideration in the final decision. ${ }^{752}$ Assessing the impact on children belonging to the most disadvantaged groups is essential to 'protect them against the adverse effects of economic policies and any reduction of budgetary allocations in the social sector'. ${ }^{753}$ Mechanisms such as children's rights impact assessments must be developed by governments at all levels, to assess the impact of proposed policies, legislation or budgets on children and the enjoyment of their human rights. ${ }^{754}$

Article 3 (2) focuses on ensuring 'the well-being of the child', with the specific obligation 'to ensure the child such protection and care as is necessary for his or her wellbeing. ${ }^{755}$ The requirement to take account of the rights and responsibilities of parents and others legally responsible (Article 18) does not prevent the State on occasion from having to intervene without their agreement, recognising that in some instances parents may have an interest in ensuring that children do not exercise their human rights.

Article 3(3) states:

that institutions, services and facilities responsible for the care and protection of children shall conform to the standards established by competent authorities, particularly in the areas of safety, health, in the number and suitability of their staff, as well as competent supervision.

This provision includes not only state-provided institutions, but all those 'responsible' for the care and protection of children. All services and institutions must comply with all provisions of the Convention and therefore the legislative framework that applies to such services and institutions should require comprehensive review. There should

\footnotetext{
${ }^{752} \mathrm{UN}$ Committee on the Rights of the Child, General Comment No. 14 on the right of the child to have his or her best interests taken as a primary consideration $\mathrm{CRC} / \mathrm{C} / \mathrm{GC} / 14 / 2013$ para 99 and also UN Committee on the Rights of the Child (2003) General Comment No.5 on the General Measures of Implementation $\mathrm{CRC} / \mathrm{GC} / 2003 / 5$ paras $45-47$

${ }^{753}$ UN Committee Reporting Guidelines para 20

${ }^{754}$ Hodgkin R and Newell P, The Implementation of the UNCRC (UNICEF 2002) 42; UN Committee on the Rights of the Child, General Comment No. 14 on the right of the child to have his or her best interests taken as a primary consideration $\mathrm{CRC} / \mathrm{C} / \mathrm{GC} / 14 / 2013$ Ibid para $15 \mathrm{a}, \mathrm{b}, \mathrm{d}$

${ }^{755}$ Hodgkin R and Newell P, The Implementation of the UNCRC (UNICEF 2002) 46
} 
also be regular inspection and monitoring of all institutions and services for compliance with the Convention. ${ }^{756}$

The content, meaning and practical application of the best interest's principle has been critiqued to be vague and said to challenge its implementation in practice. Freeman, Children's Rights Knowledge Centre ${ }^{757}$ and Smeyers ${ }^{758}$ argue that an unambiguous interpretation of the principle is almost impossible. This critique complements Doek and Cantwell's concerns (noted in Chapter 2) regarding the lack of a detailed interpretation of this principle, arguing there is still insufficient guidance for health practitioners and managers to apply the principle of best interests practically in health contexts. ${ }^{759} 760$ However, the value of Article 3 is that it does make children more visible and challenges all duty bearers to acknowledge that the interests of children must be considered, this is a critical element of embedding a human rights approach. Best interests of the child has not been chosen to stand alone as a separate principle, it instead is subsumed into all of the principles but in particular the core principle of Embedding. This contributes to our understanding that children's interests have to be a primary consideration in all circumstances and that articles of the Convention must be balanced in any assessment or planning process.

The principle of Embedding argues that all children's rights should be at the core of planning and service delivery and integrated into every aspect of decision-making through procedures and actions. At its most basic, this requires acknowledgement of children's rights as a framework for all services impacting on children. Children's rights should guide decisions and actions having a substantial impact on children's lives in areas such as education, health or social care, but also in other areas such as planning, transport and the environment. According to the UN Committee's General

\footnotetext{
${ }^{756}$ Ibid 48

${ }^{757}$ Children's rights knowledge centre, A discussion of commonly encountered tensions and possible solutions based on international best interests and policy strategies since 2004: A study of the Children's Knowledge Centre (Commissioned by the Flemish Government Division of Youth, 2014) ${ }^{758}$ Smeyers P, 'Child rearing in the 'risk' society: on the discourse of rights and the "best interests of a child,", Educational Theory (2010) 60 (3), 271-284

${ }^{759}$ Doek J, 'Children's rights in health care and the General Principles of the CRC', In, Doek J and Dorscheist M (eds) Children's Rights in Health Care (Brill Publications 2018)

${ }^{760}$ Cantwell N, "Are the "Best Interests" a Pillar or a problem for Implementing Human Rights of Children?' In Liefaard T and Sloth-Nielsen J (eds.) The United Nations Convention on the Rights of the Child: Taking Stock after 25 Years and Looking Ahead (Leiden/Boston, Brill 2017) 65
} 
Comment No. 5 , there should be coordination across departments, and with external organisations to ensure application of the principle. ${ }^{761}$ This approach is endorsed by the $\mathrm{RCPCH}$ in relation to children's health:

Interventions for all children throughout their life course, and particularly the vulnerable and hard to reach groups, require a joined-up approach by health services and other agencies where necessary. For example, children and young people with long term or complex conditions often need care from a variety of health professionals and navigating that system can be daunting and confusing. Integration of care services can prevent duplication and waste as well as making the system more user friendly for children, young people and their families. ${ }^{762}$

States Parties and therefore those who deliver services on behalf of the State also have a critical obligation to undertake to make the Convention widely known and understood 'by appropriate and active means, to adults and children alike. ${ }^{763}$ Raising levels of awareness (Article 42 of the UNCRC) knowledge and understanding of the UNCRC is vital to embedding children's rights and the right to health. Training and capacity building of all those involved is critical:

There must be ongoing-training and education in children's human rights to emphasise the status of the child as a holder of human rights, to increase knowledge and understanding of the Convention and to encourage active respect for all its provisions. The Committee expects to see the Convention reflected in professional training curricula, codes of conduct and educational curricula at all levels. Understanding and knowledge of human rights must, of course, be promoted among children themselves, through the school curriculum and in other ways. ${ }^{764}$

\footnotetext{
${ }^{761}$ UN Committee on the Rights of the Child, General Comment No. 5 on General Measures of Implementation, $\mathrm{CRC} / \mathrm{C} / \mathrm{GC} / 5 / 2003$ paras 37-39

${ }^{762}$ Royal College of Paediatrics, State of Child Health: 2017 Recommendations for Wales (RCPCH 2017) 9

${ }^{763}$ See Article 42 of the UNCRC.

${ }^{764}$ UN Committee on the Rights of the Child, General Comment No. 5 on General Measures of Implementation $\mathrm{CRC} / \mathrm{C} / \mathrm{GC} / 5 / 2003$ para 53; UN Committee on the Rights of the Child, General
} 
This emphasises the importance of human rights education for everyone, professionals and children. Chapter 4 outlined that research is required to learn what are the best strategies for ensuring that health professionals know about and understand children's rights and what this means in practice. Education and training with regards to skills development is required, as well as the review of health and medical curricula to be compliant with children's rights. Furthermore, extra resources for implementation are critical. More also needs to be done to train health professionals to understand children's rights, child development and how to adopt a CRA in practice. As Hunt notes, it is not realistic to expect health practitioners to understand how to operationalise the human rights treaties. ${ }^{765}$

It was also noted in earlier chapters that there must be a high-level commitment from senior managers and elected members to embed a CRA to health services for it to be successful from the outset. Strong leaders and champions for children's rights should be appointed and all health systems must be targeted, including managers and policy makers and practitioners. The importance of workforce development was also emphasised in Chapter 4 and 5. There are insufficient health professionals in Wales with paediatric training and this needs to be urgently rectified if children's rights are to be effectively supported in health care settings.

Embedding is thus a principle that is critical to a CRA because it supports the integration of children's rights and a child sensitive lens to health service delivery.

\subsubsection{Examining the theory and importance of the principle 'Accountability to children'}

\subsubsection{Overview}

As outlined above, children's rights are often overlooked or not properly taken into account in decisions or actions that affect their lives and service providers do not always understand what their obligations are towards children. Children are often

Comment No. 15 on the right of the child to the enjoyment of the highest attainable standard of health $\mathrm{CRC} / \mathrm{C} / 15 / 2013$ para 93

${ }^{765}$ Hunt P, 'Interpreting the International Right to Health in a Human Rights-Based Approach to Health', Health and Human Rights Journal 2016 Dec 18 (2) 
powerless to hold to account decision-makers or those responsible for the delivery of services. Children who have not reached the age of majority and are not deemed competent, and/or face many additional barriers because of their social, economic or cultural background find it incredibly difficult to assert their human rights. As Hoffman and Williams make clear, 'those making the decisions must be called to account if they fail to recognise and fulfil the obligations precedent to those rights. ${ }^{766}$

What seems to be lacking in approaches to health services and indeed other services in the Welsh context (See Chapter 5) are clear frameworks of accountability. Interventions are recommended but without an identification of the duty bearer responsible for implementing them. According to the primarily European and UK wide research (outlined in Chapter 4 ) the majority of health services still do not effectively monitor against children's rights standards. There are ineffective child-friendly complaints systems and limited sanctions for unsatisfactory compliance with children's rights across health services (see Chapter 4,5 ). Wales has made some positive strides in terms of its health services agenda, but it currently does not have the strength of the accountability framework of the international human rights framework that recognises access to quality health services in terms of enforceable social and economic rights.

\subsubsection{What is the principle of 'Accountability to children' and where is it drawn from?}

Firstly, with reference to London:

defining who is a rights holder, who is a duty bearer, and what the nature of the obligation is, allows a much clearer opportunity to establish accountability for the realization of rights and creates a range of mechanisms to hold governments [service providers] accountable. ${ }^{767}$

\footnotetext{
${ }^{766}$ Hoffman S and Williams J, 'Accountability,' In, Williams, J (eds) The UNCRC in Wales, (University of Wales Press 2013) 167

${ }^{767}$ London L, 'What is a human rights based approach to health and does it matter?' Health and Human rights (2008) vol. 10, no. 1,68
} 
Article 4 outlines the importance of accountability towards children to respect, protect and fulfil their human rights. Most scholars in the area of international human rights law only recognise obligations on the part of the state. ${ }^{768}$ The UNCRC is an exception, as Tobin asserts because parents (or other caretakers) are also recognised as dutybearers. ${ }^{769}$ It is important to be clear regarding the accountability placed upon parents or guardians of children. Article 18 (1) of the UNCRC states that:

Parents or, as the case may be, legal guardians, have the primary responsibility for the upbringing and the development of the child,

And according to Article 27 (2)

the parent(s) or others responsible for the child have the primary responsibility to secure, within their abilities and financial capacities, the conditions of living necessary for the child's development.

These articles do not create a demarcation between the accountability of the State and the parent/guardian; they specifically obligate the State to provide support to parents in the performance of their duties. ${ }^{770}$ So while it is the State which takes on obligations under the Convention, its task of implementation - of making a reality of the human rights of children - needs to engage all sectors of society, including public authorities, non-governmental organisations and, parents and guardians and of course, children themselves. ${ }^{771}$ As is depicted in the diagram below (Diagram 4) it must also be understood that the child as a human rights holder has the ability to make claims and the duty bearers have obligations at many different levels of any society.

\footnotetext{
${ }^{768}$ Jonsson U, Human Rights Approach to Development Programming. (UNICEF 2003) 15-16

${ }^{769}$ Tobin J, 'Understanding a human rights based approach to matters involving children: conceptual foundations and strategic considerations' in Invernizzi A and Williams J (eds), The Human Rights of Children: From Visions to Implementation (Farnham: Ashgate 2011) 70

${ }^{770}$ Ibid 70

${ }^{771}$ UN Committee on the Rights of the Child, General Comment No. 5 on the General Measures of Implementation $\mathrm{CRC} / \mathrm{C} / \mathrm{GC} / 5 / 2003$ para 1
} 


\section{Diagram 4: Levels of obligations to the child as rights holder ${ }^{772}$}

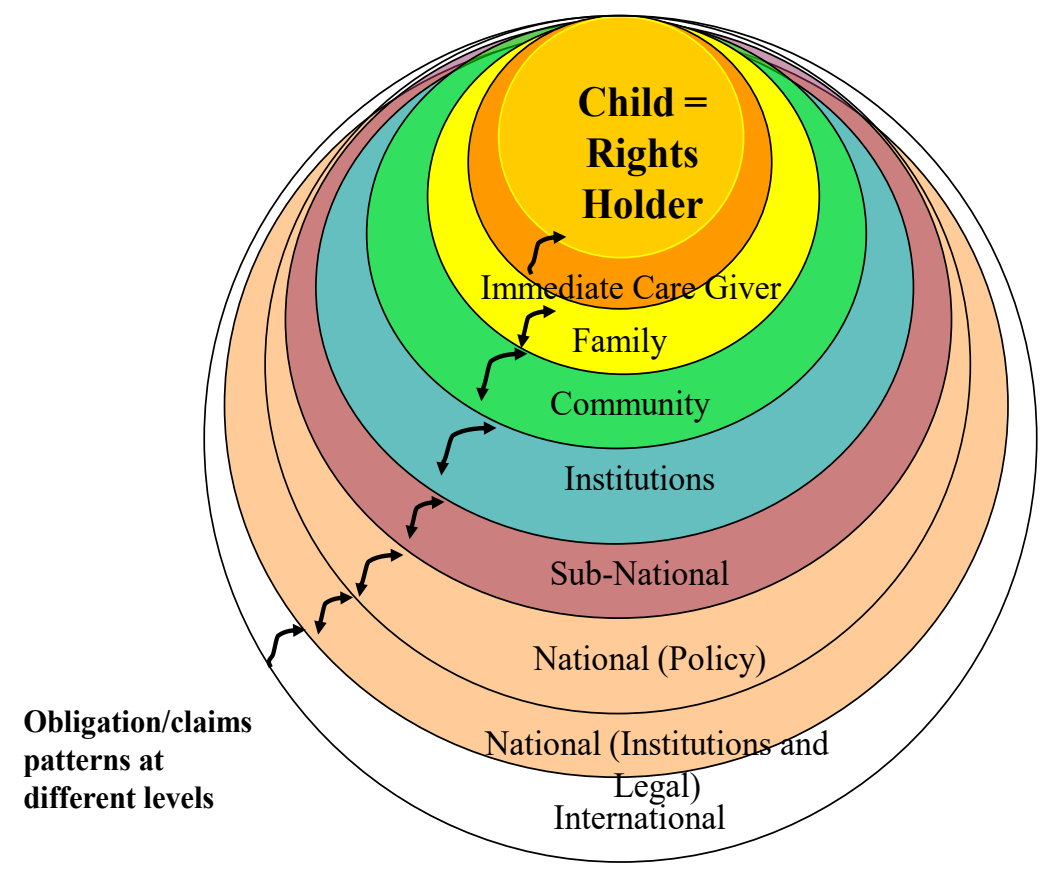

Source: The human rights approach to programming, what have we learnt by Fabio Sabatini

As was made reference to in Chapter 3, London argues that even though there are a plethora of international statements, guidelines and ethic codes for health professionals issued by professional bodies, these ethical codes need to integrate stronger human rights language if professional self-regulation is to be more effective. ${ }^{773}$ Health services should be acknowledged as a right instead of a service delivery issue. The UNCRC should be expressly incorporated into the framework for service planning and delivery in all significant policy statements or other documents setting out the health authority's vision or key objectives, for example in the format of Children's Rights Charters. Health bodies should undertake children's rights impact assessments as part of reviewing existing policy, budgets or service delivery guidance.

Accountability also requires effective monitoring of children's rights standards as well as effective remedies where it is shown that organisations fail to meet these standards.

\footnotetext{
${ }^{772}$ Sabatini F, The Human Rights Approach to Programming; what have we learnt.

${ }^{773}$ Aldersen P and Montgomery J, Health care choices, making decisions with children (IPPR 1996)
} 
Monitoring requires the collection of appropriate information and data, and it requires research into the identification of the root causes of any human rights violations. All organisations must be transparent and consistently provide reasons for their decisions and actions in response to addressing any violation. Joshi helpfully outlines four elements of accountability:

1. setting standards or performance indicators to measure it

2. obtaining information about action taken to meet those standards

3. making judgements about the adequacy of actions measured against those standards

4. imposing sanctions for unsatisfactory performance. ${ }^{774}$

The General Comment No. 15's AAAQ framework ${ }^{775}$, presents a useful basis for developing a checklist or set of indicators (See Chapter 2) for monitoring the effectiveness of health service delivery for children and this will be utilised in the next section with regards to the translation of the principles into standards.

The UN Committee on the Rights of the Child advises that to help enshrine a CRA, the UNCRC should be incorporated into domestic legislation and 'that all legislation and administrative proceedings should be compatible with the UNCRC' ${ }^{776}$

Incorporation should mean that the provisions of the Convention can be directly invoked before the courts and applied by national authorities and that it will prevail where there is a conflict with domestic legislation or common practice. Incorporation by itself does not avoid the need to ensure that all relevant domestic law, including any local or customary law, is brought into compliance with the Convention. ${ }^{777}$

\footnotetext{
${ }^{774}$ Joshi A, Review of impact and effectiveness of transparency and accountability initiatives Annex 1 , Service Delivery (Sussex UK IDS. 2010)

${ }^{775} \mathrm{UN}$ Committee on the Rights of the Child, General Comment No.15 on the right of the child to the enjoyment of the highest attainable standard of health $\mathrm{CRC} / \mathrm{C} / \mathrm{GC} / 15 / 2013$ paras $113-116$

${ }^{776}$ UN Committee on the Rights of the Child, General Comment No. 5 on General Measures of Implementation, $C R C / \mathrm{C} / \mathrm{GC} / 5 / 2003$

${ }^{777}$ Ibid para 20
} 
However, the UNCRC is not incorporated into UK domestic law, so there is no right of remedy in a UK court of law, to enforce the UNCRC. However, as referred to in Chapter 5 there is the Rights of Children and Young Person's (Wales) Measure 2011 that can be described as 'public officer's law'. Welsh Ministers must have due regard to the UNCRC in the exercise of their functions, which can be challenged by way of judicial review in the Administrative Court. So, children can look to the judiciary to hold the Welsh Ministers to account for compliance with the UNCRC/Measure. This is positive on the one hand in that there is an opportunity to challenge Welsh Ministers regarding whether their actions have given due regard to the UNCRC within a court of law, however, to date no child or in fact any adult/institution has sought to do so. There are the practicalities of cost but also how many children are actually aware of or understand this complex channel for challenging the violation of their human rights?

However, public duties are not only enforced in courts of law, but through political and administrative means e.g., complaints procedures, enquiries, elections, parliamentary scrutiny, ombudsmans, media and markets. ${ }^{778}$ As depicted by Diagram 4 and reinforced by Hoffman and Williams, accountability can be fragmented across different levels of government, for example, from the UK Government to Welsh Government to the local authority and externally to the EU and the Council of Europe. Beyond Europe there are institutions established because of the international human rights instruments, the UN and International Human Rights Bodies. ${ }^{779}$ Each of these layers has different and associated structures of accountability.

This indicates the complexity and multi-layered nature of accountability which can make it very difficult for citizens and in particular children, to hold duty bearers to account. It requires the child as the rights holder to be empowered to understand and navigate these complex mechanisms of accountability. So, although human rights give rise to obligations/duties which demand accountability and duty bearers should be respecting, protecting and fulfilling them, children must be supported to be active participants in the process and as claim holders need to be provided with information

\footnotetext{
${ }^{778}$ Dowdle M W, 'Public accountability: conceptual, historical and epistemic mappings', In Dowdle M W (ed) Public Accountability, Designs, Dilemma and Experiences (New York: Cambridge University Press)

${ }^{779}$ Hoffman S, and Williams J, ‘Accountability' In Williams J (eds) The UNCRC in Wales, (University of Wales Press Cardiff 2013) 169
} 
and given access to relevant mechanisms/procedures which enable them to question and challenge decision-makers (See section on Empowering the child).

For example, the UK Human Rights Act 1998 has had limited successes for children's rights and more successes for adults. ${ }^{780}$ Structures of accountability need to be resourced and made effective and accessible to children if they are ever to realise their human rights. For example, in Wales there is acceptance that children have human rights in the very domains that law and policy making take place at the national level, and to a limited degree through the Social Services and Well-being Act 2014 at the local level. A next step on the journey to accountability of public services across Wales, would be to introduce a public sector duty, for all public services (including health services) to have due regard to the UNCRC. However, while we await this to be integrated into legislation, the principle of accountability can be translated into the practice of public services through the implementation of a CRA. The principle of accountability has the potential to drive services towards respecting, protecting and fulfilling human rights and also to services being held to account to meet these obligations.

\subsubsection{Examining the theory and importance of the principle of 'Equality and non- discrimination to children'}

\subsubsection{Overview}

In Part 1, we learned that children are still discriminated against as a group (See Chapter 4) as well as disaggregated groups of children and in Wales children are challenged by many health inequalities (Chapter 5). Fiscal austerity is causing many children difficulties in accessing health services (Chapter 4, 5). It has increased public expenditure cuts and insignificant priority has generally been given to ring fencing funding for children's services (See Chapter 5). Health services across Europe are not being developed that are child friendly and respond to the needs of children (Chapter 4). Children's clinical research in Wales continues to be under-resourced and neglected which affects the critical development of medicines tailored to childhood

\footnotetext{
${ }^{780}$ See Fortin J, Children's Rights and the Developing Law ( $3^{\text {rd }}$ edn. Cambridge University Press 2009)
} 
conditions and Welsh Government funding models indirectly discriminate against children (Chapter 5). It requires a principled response to address this discrimination and to treat children as persons and subjects of human rights. It is important that discrimination towards children is understood if it can ever be challenged in the context of delivering services for children in the health context. The next section seeks to grapple with the complexities of discrimination towards children.

\subsubsection{What is the principle of Equality and non-discrimination and where is it drawn from?}

Attitudes towards children reflect the norms and values of the society that they are embedded within ${ }^{781}$ and children are still often excluded from, or powerless to influence decisions that affect their lives in significant ways. ${ }^{782}$ Many children do not have equal opportunity to develop their talents and potential, and are being discriminated against because of their background, or simply because they are children. ${ }^{783}$ Children experience direct discrimination, because they are 'prevented from having equal status, equal access to resources, equal access to decision-making, or to exercising rights in an equal manner', because they belong to a social group categorised as 'children'. ${ }^{784}$ They experience indirect/institutionalised discrimination 'because certain laws, regulations, measures, social norms, that appear to be neutral and applicable to all persons equally are in fact detrimental to children as a social group.'785 786 Both have

\footnotetext{
${ }^{781}$ Boylan J and Dalrymple J, Understanding Advocacy for Children and Young People (Mcraw Hill Education UK 2009)

${ }^{782}$ Aisling P, Children and International Human Rights Law: The Right of the Child to be heard (Routledge 2013); Liebel M, 'Adultism and Age Based Discrimination against children' In, Kutsar, D \& Warming, $\mathrm{H}$ (eds) Children and non-discrimination, inter-disciplinary textbook. (University of Estonia press. 2014)

${ }^{783}$ Webb E, 'An exploration of the Discrimination-Rights Dynamic' In, in Invernizzi A and Williams J (eds) The Human Rights of Children: From Visions to Implementation (Farnham: Ashgate 2011) ${ }^{784}$ Liebel M, 'Adultism and Age Based Discrimination against children', In, Kutsar D and Warming $\mathrm{H}$ (eds) Children and non-discrimination, inter-disciplinary textbook (University of Estonia press 2014) 120

${ }^{785}$ Liebel M, 'Adultism and Age Based Discrimination against children' In, Kutsar D and Warming H (eds) Children and non-discrimination, inter-disciplinary textbook (University of Estonia press 2014) 120

${ }^{786}$ UN Committee on Economic, Social and Cultural Rights, General Comment No. 20 NonDiscrimination on Economic, Social and Cultural Rights (art 2. Para. 2) E/C.12/GC/20/2009 refers to laws, policies or practices which appear neutral at face value, but have disproportionate impact on the exercise of rights as distinguished by prohibited grounds of discrimination.
} 
consequences for children's rights being violated or left unfulfilled in ways in which those of adults are not. ${ }^{787}$

Children also face multiple discrimination i.e. when a child faces discrimination on more than one ground because of the situation or the circumstances the child finds her/himself in (e.g. a disabled child, belonging to an ethnic minority, who is living in poverty with a parent with mental health problems). ${ }^{788}$ Liebel et al argue that it is important to understand the multi-dimensional nature of discrimination, but not to reduce it to one trait or dimension, e.g. race, gender, class, as this distorts social reality. ${ }^{789}$ It is also important to understand the multiplicity of childhoods that children experience; children live in diverse contexts and are shaped by their family environment, social, economic and political conditions. ${ }^{790}$

Children are often seen as inferior to adults, or to have a lower status, or to be less competent. ${ }^{791}$ Children are seen to be in need of protection and to be dependent on adults and this has been used to put off giving equality to children and conserving the advantage and power that adults have by virtue of their majority status. ${ }^{792}$ Those who conceptualise children primarily as needing protection are described as following the 'caretaker' approach/protectionist approach. ${ }^{793}$ The caretaker/protectionist approach has more heavily influenced legislation and policies in most Western societies, with

\footnotetext{
${ }^{787}$ CRIN 'Guide to non-discrimination and the CRC' (Child Rights Information Network 2009) http://www.crin.org/Discrimination/CRC/index.asp accessed January 2020

${ }^{788}$ The UN Committee on the Rights of the Child has so far identified 53 grounds of discrimination against children based either on their identity or the identity of their parents.

${ }^{789}$ Liebel, Luhamma, Gornischeff, 'The Right to Non-discrimination, Human rights basis and concepts', In Kutsar D and Warming H (eds) Children and non-discrimination, inter-disciplinary textbook (University of Estonia press 2014)

${ }^{790}$ Hart R, Children's participation: the theory and practice of involving young citizens in community development and environmental care (UNICEF and Earthscan1997); Boylan J and Dalrymple J, Understanding Advocacy for Children and Young People (Mcraw Hill Education UK 2009)

${ }^{791}$ Liebel M, 'Adultism and Age Based Discrimination against children,' In Kutsar D and Warming H (eds) Children and non-discrimination, inter-disciplinary textbook. (University of Estonia press 2014) 123; Mayall B, 'The sociology of childhood in relation to children's rights', The International Journal of Children's Rights (2000) 8: 243-259; Jans M, 'Children as citizens: Towards a contemporary notion of child participation,' Childhood, (2004) 11 (1): 27-44

${ }^{792}$ Ibid

${ }^{793}$ Archard D, Children's Rights and Childhood (Routledge 2004)
} 
approaches to children being primarily paternalistic and regulatory and not always supportive of children's voice and agency. ${ }^{794}$

Children are often seen by adults as immature and unfinished, on the road to adulthood as opposed to people in their own right; this is referred to as the 'deficit model of childhood. '795 Policy approaches to children focus on the future adult citizens they are going to become rather than the citizens that they are in the present. ${ }^{796}$ Children are perceived to be relatively powerless and passive and incapable of influencing the society in which they live in, ${ }^{797}$ when in reality their inability is the consequence of an unequal distribution of resources with children often having less political and economic resources to draw on to influence and control their lives than most adults. Children are also perceived as being confined to the private sphere when instead children's lives interface fluidly with the public sphere and are agents and social actors capable of influencing and transforming all structures surrounding their lives. ${ }^{798}$

This lack of recognition of being agents of transformative change can also be linked to 'adultism' a term to describe the abuse of power adults have over children and the assumption ${ }^{799}$ that adults are better than children. ${ }^{800}$ This is seen to have the same power dimension as racism or sexism. ${ }^{801}$

\footnotetext{
${ }^{794}$ Parton N, Safeguarding Childhood: Early Intervention and Surveillance in Late Modern Society. (Basingstoke: Palgrave Macmillan 2006); Freeman M 'Why It Remains Important to Take Children's Rights Seriously', The International Journal of Children's Rights (March 2007) 15 (1): 5-23; Fortin J Children's Rights and the Developing Law ( $3^{\text {rd }}$ edn 2009 Cambridge: Cambridge University Press) ${ }^{795}$ Webb E, 'An exploration of the discrimination-rights dynamic', In Invernizzi A and Williams J (eds) The Human Rights of Children: From Visions to Implementation (Farnham: Ashgate 2011) 292 ${ }^{796}$ Holland S, Renold E, Ross N, Hillman A, Rights 'right on' or the right thing to do? A critical exploration of young people's engagement in participative social work research (Cardiff University ESRC Centre for Research Methods 2008)

${ }^{797}$ Mayall B, 'The sociology of childhood in relation to children's rights,' The International Journal of Children's Rights 8: 243-259, (2000).

${ }^{798}$ Mayall B, 'The sociology of childhood in relation to children's rights,' The International Journal of Children's Rights (2000) 8: 243-259; James A and Prout A (eds) Constructing and Reconstructing Childhood: Contemporary Issues in the Sociological Study of Childhood (London: Falmer,1997)

${ }^{799}$ Flasher J, 'Adultism'. Adolescence (1978) 13 (51): 517-523

${ }^{800}$ Bell J, 'Understanding Adultism: A Major Obstacle to Developing Positive Youth-Adult Relationships', Youth Build USA (1995)

${ }^{801}$ Roche J, 'Children: Rights, Participation and Citizenship', Childhood 1999 6 (4): 475-493
} 
In a survey conducted by the Children's Rights Alliance England and National Children's Bureau 2006/7 (with over 4, 000 children) a total of $43 \%$ of British young people reported experiencing discrimination based on their age, substantially more than other categories of discrimination based on sex $(27 \%)$, race $(11 \%)$, or sexual orientation $(6 \%) .{ }^{802}$

Liebel explains age discrimination against children as individuals or as a social group in terms of four categories, (I have included some of my own examples after Liebel's 4 categories)

1. measures against and punishment of undesired attitudes of children, which are tolerated or seen as normal in adults e.g. curfews, restriction of the use of public space, anti-social behaviour legislation, mosquito devices, corporal punishment etc.

2. measures which are justified by real or assumed children's special needs for protection, but which in the end lead to further disadvantages towards children, e.g. age limits that try to justify the exclusion of working children from minimum wage laws; children who are mentally ill/disabled being locked up, children being medicated due to their hyperactivity etc.

3. the limited access, in comparison to adults, to rights, goods, institutions and $\underline{\text { services }}^{803}$ e.g. calling an ambulance but being refused the service because of being under the age of 18 years, being discharged from children's health services but not being eligible for adult services, etc.

4. the lack of consideration of the social group of children in political decisionmaking which might have negative consequences in the later life of children and that of following generation e.g. Not being consulted on the UK Government's decision to leave the European Union, which could have

\footnotetext{
${ }^{802}$ Willow C, Franklin A and Shaw C, Meeting the obligations of the Convention on the Rights of the Child in England, Children and young people's messages to Government (DCSF 2007)

${ }^{803}$ Protection against age discrimination in services under the Equality Act 2010 only covers adults, according to international human rights treaties children and young people must have their needs met when using services
} 
negative consequences on the future life of children and even for subsequent generations.

These offer compelling examples of how children are discriminated against purely because of their age in their daily lives.

There are different forms of adultism such as 'internalized adultism' when children 'question their own legitimacy, doubt their own ability to make a difference' and perpetuate a 'culture of silence'. ${ }^{804}$ Webb explains that discrimination can be internalised when a group experiencing discrimination adopts and shares the view of the powerful oppressor. 805 'Institutionalized adultism' 'may be apparent in any instance of systemic bias, where formalized limitations or demands are placed on people simply because of their young age' 806 or 'cultural adultism' which is discrimination to children purely based on their young age, as opposed to their ability, comprehension or capacity. ${ }^{807}$

Liebel argues it is important to root any understanding of discrimination against children not just in difference but in structures of inequality and hierarchy that contribute to discriminating consequences. ${ }^{808}$ Children are frequently excluded from decisions that impact on their lives. Nolas in making reference to the Rotherham and Rochdale sexual abuse cases comments that while in services for children their participation remains contested at best and, in certain circumstances, completely absent.' ${ }^{809}$ Landsdown, Lundy, Goldhagen report that the reluctance of services to intervene when the offenders are from an ethnic minority community has 'resulted in ongoing sexual abuse of girls effectively sanctioned by localities', demonstrating

\footnotetext{
${ }^{804}$ Liebel M, 'Adultism and Age Based Discrimination against children' In, Kutsar D and Warming H (eds) Children and non-discrimination, inter-disciplinary textbook (University of Estonia press 2014) ${ }^{805}$ Webb E, 'An exploration of the discrimination-rights dynamic', In Invernizzi A and Williams J (eds) The Human Rights of Children: From Visions to Implementation (Farnham: Ashgate 2011) 295 ${ }^{806}$ Liebel M, 'Adultism and Age Based Discrimination against children', In Kutsar D and Warming H (eds) Children and non-discrimination, inter-disciplinary textbook (University of Estonia press 2014) ${ }^{807}$ Ibid

${ }^{808}$ Liebel, Luhamaa, Gornischeff, 'Introduction', In Kutsar D and Warming H (eds) Children and non-discrimination, inter-disciplinary textbook (University of Estonia press 2014) 28

${ }^{808}$ UN Committee on the Rights of the Child, General Comment No. 5 on General Measures of Implementation $\mathrm{CRC} / \mathrm{C} / \mathrm{GC} / 5 / 2003$ para 12

${ }^{809}$ Nolas M, 'Children's Participation, Childhood Publics and Social Change: A Review,' Children and Society, Volume 29, (2015) 160
} 
entrenched patterns of institutional discrimination to children. ${ }^{810}$ In other service delivery contexts, Parton comments that it is positive in some places that children are being placed at the centre of policies and practices, however concerns over safeguarding vulnerable children has heightened their control over children and reduced children's agency. ${ }^{811}$

Children are often prevented from forming groups or associations and/or are excluded from participating in the development of policy or legislation that has an impact on them and in most societies are unable to vote until they are 18 years of age. Wall argues that:

Children remain the poorest and most exploited social group because they lack the political franchise to assert their own interests and demand political accountability. For example, if children could vote, legislators would be more likely to properly fund schools, improve playgrounds and recreation spaces, respect children's voices and agency, and strengthen laws against children's discrimination and abuse. ${ }^{812}$

Children have unequal access to courts and therefore to justice as compared to adults ${ }^{813}$ and are often powerless to hold to account decision-makers or those responsible for the delivery of services. Children in most societies lack a voice and face systemic and entrenched discrimination, simply because they are children.

The international human rights instruments challenge this discrimination and offers a framework to realise children's right to equality and to not be discriminated against:

\footnotetext{
${ }^{810}$ Lansdown, Lundy, Goldhagen, 'The UN Convention on the Rights of the Child: relevance and application to paediatric clinical bioethics perspectives in biology and medicine', Baltimore 58.3 (summer 2015)

${ }^{811}$ Parton, N, Safeguarding Childhood: Early Intervention and Surveillance in Late Modern Society. (Basingstoke: Palgrave Macmillan 2006)

${ }^{812}$ Wall J, 'Democratising democracy: the road from women to children's suffrage', International Journal Human Rights: Vol 18 (2014) Issue 6

${ }^{813}$ Fortin J, Children's Rights and the Developing Law, ( $3^{\text {rd }}$ edn Cambridge University Press 2004)
} 
The general principle of equality and non-discrimination penetrates and pervades all conventions, treaties, declarations and resolutions that were drafted after the creation of the United Nations. ${ }^{814}$

Article 1 of the Universal Declaration on Human Rights recognises that 'all human beings are born free and equal in dignity and rights'. This is also affirmed in the preamble to the UNCRC which recognises 'the inherent dignity of every individual'. The foundation of equality is the prohibition of direct or formal discrimination and this prohibition is present in all of the international human rights treaties. Article 7 of the UDHR established the right to equality as follows: 'All are equal before the law and are entitled without any discrimination to equal protection of the law. ${ }^{815}$ The United Nations Human Rights Committee 1989 para 1, states:

Non-discrimination together with equality before the law and equal protection of the law without any discrimination, constitute a basic and general principle relating to the protection of human rights. ${ }^{816}$

This is supported by the text of the International Covenant on Civil and Political Rights (ICCPR) Articles 2 and 26 and Article 2 of the International Covenant on Economic, Social and Cultural Rights (ICESCR) demands that rights under the treaty must be enjoyed without any discrimination, whereas the right to equality law is considered to be an autonomous right of general application.

As introduced in Chapter 2, the UNCRC forcefully challenges any discrimination against children and disaggregated groups of children:

\section{UNCRC Article 2:}

1. States Parties shall respect and ensure the rights set forth in the present Convention to each child within their jurisdiction without discrimination of any

\footnotetext{
${ }^{814}$ Naskou - Perraki P, 'An Introduction to International Protection of Human Rights, In Kutsar D and Warming H (eds) Children and non-discrimination, inter-disciplinary textbook (University of Estonia press 2014) 33

${ }^{815}$ Article 7 of the Universal Declaration on Human Rights

${ }^{816}$ Office of the Commission on Human Rights, Human Rights Committee Thirty-seventh session Adopted: 10 November 1989 General Comment No. 18 Non-discrimination HRI/GEN/1/Rev.9/1998 (Vol. I) para 1
} 
kind, irrespective of the child's or his or her parent's or legal guardian's race, colour, sex, language, religion, political or other opinion, national, ethnic or social origin, property, disability, birth or other status.

2. States Parties shall take all appropriate measures to ensure that the child is protected against all forms of discrimination or punishment on the basis of the status, activities, expressed opinions, or beliefs of the child's parents, legal guardians, or family members.

Children must not be discriminated against solely because they are children and the UN Committee on the Rights of the Child confirms the 'equal status of children as subjects of rights. ${ }^{317}$ The UNCRC principle of non-discrimination emphasises all children and vulnerable groups of children should not be discriminated against in any policy, planning and practice decisions and is pertinent to all polices and practice concerning children from health care, education social care, to transport planning and the environment. Landsdown, Lundy and Goldhagen argue that:

legitimate differences in treatment between children are acceptable if these are for example applied in order to advance health equity. An example would be providing school-based health services to children with disabilities that are not available to other children to enable them to attend school. However, any differentiation between children can only be justified if it is in the child's best interests. ${ }^{818}$

Vulnerable groups are deserving of special measures of protection and additionally there must also be protection against discrimination between different groups of

\footnotetext{
${ }^{817}$ UN Committee on the Rights of the Child, General Comment No. 5 on General Measures of Implementation $\mathrm{CRC} / \mathrm{C} / \mathrm{GC} / 5 / 2003$ para 66 ; See also second paragraph to the preamble to the Convention that indicates that all children irrespective of age have the same dignity as adults ${ }^{818}$ Lansdown G, Lundy L, Goldhagen J, 'The UN Convention on the Rights of the Child: relevance and application to pediatric clinical bioethics perspectives in biology and medicine', Baltimore 58.3 (summer 2015)
} 
children. Arguably, those children that are the most disadvantaged in enjoying their rights require the highest standard of protection. ${ }^{819}$

Non-discrimination is referred to across many articles of the UNCRC, and the Committee on the Rights of the Child emphasises the importance of an active approach to its implementation. ${ }^{820}$ It should be written into legislation and discrimination against children should be challenged in courts. It should apply equally to private institutions as it does to individuals and the state. It is regarded as insufficient that the principle is just enshrined in law but there must be a pro-active approach to challenging discriminatory attitudes and practices. ${ }^{821}$ All states and public bodies should collect disaggregated data and transparently identify acts of discrimination, develop comprehensive strategies to tackle it and deliver information and awareness raising campaigns. Action against discrimination against children should not be limited by budgetary constraints and the maximum extent of available resources should be spent on eliminating discrimination. ${ }^{822}$ The principle of Equality and Non-discrimination is an essential principal of a CRA.

\subsubsection{Examining the theory and importance of the principle of 'Participation of children'}

\subsubsection{Overview}

There has been a long history of children being 'seen and not heard' and this lack of voice has recently been reflected in great numbers of adults coming forward seeking justice for appalling abuses they suffered as children. ${ }^{823}$ Despite being experts on their own lives, children are not routinely involved in decisions that affect them and are often

\footnotetext{
${ }^{819}$ Croke R and Crowley A, 'Human Rights and Child Poverty in the UK,' In Invernizzi A and Williams J (eds), The Human Rights of Children: From Visions to Implementation (Farnham: Ashgate 2011)

${ }^{820}$ Newell P and Hodgkin R, Implementation handbook for the Convention on the Rights of the Child, (UNICEF 2002)

${ }^{821}$ Ibid

${ }^{822}$ Newell P and Hodgkin R, Implementation handbook for the Convention on the Rights of the Child (UNICEF 2002); UN Committee on the Rights of the Child, General Comment No. 5 on General Measures of Implementation $\mathrm{CRC} / \mathrm{C} / \mathrm{GC} / 5 / 2003$

${ }^{823}$ Aisling P, Children and International Human Rights Law: The Right of the Child to be heard (Routledge 2013) 1; Independent Inquiry into the Sexual Abuse of Children, https://www.iicsa.org.uk/ accessed January 2020.
} 
treated as invisible members of society, denied any meaningful voice in the matters that affect them. ${ }^{824}$ Children strongly reported across the research on health services in Chapter 4 that they want to participate and have a right to participate in clinical decision making and in the monitoring, evaluation and design of service delivery. Children are not routinely involved in the health decisions that affect them. Many health professionals are not skilled in communicating with children or appreciate the importance of communicating and involving children. Children are often not informed appropriately regarding what an impending treatment is going to entail which causes fear and anxiety and children report wanting to ask questions and be involved in their clinical care from the outset. Although, there have been some strides in recognising the importance of children's right to be heard in Wales in national policy and legislation, there is limited evidence as yet regarding how this principle is being respected in health services (See Chapter 5).

\subsubsection{What is the principle of 'Participation of children' and where is it drawn} from?

The UNCRC vigorously challenges the out-dated concept that children should be 'seen and not heard', by the provision of Article 12, the fundamental right for all children to be heard. Over the last two decades, the principle that children are entitled to be heard in all matters affecting them, has been given greater recognition across the world and has become a legal norm firmly entrenched in the UNCRC, it has spear headed a 'new vision for children'. ${ }^{825}$

Article 12 of the UNCRC states that:

1. States Parties shall assure to the child who is capable of forming his or her own views the right to express those views freely in all matters affecting the child, the views of the child being given due weight in accordance with the age and maturity of the child.

\footnotetext{
${ }^{824}$ Aisling P, Children and International Human Rights Law: The Right of the Child to be heard (Routledge 2013)

${ }^{825}$ Santos Pais M, Child Participation Documentacao e DireitoComparado, nos 81/82 (2000) 93
} 
2. For this purpose, the child shall in particular be provided the opportunity to be heard in any judicial and administrative proceedings affecting the child, either directly, or through a representative or an appropriate body, in a manner consistent with the procedural rules of national law.

Article 12 guarantees all children the right to be heard without discrimination in all matters that affect them, and to give due weight to their views once expressed. State parties should not assume that a child is incapable of expressing his/her own views, but instead should presume that every child has the capacity to form and express them and their views should be given due weight. It is also not the responsibility of the child to first prove his/her capacity. ${ }^{826}$

The UN Committee on the Rights of the Child has criticised any State that attempts to dilute children's right to influence decision making because of the qualifying phrase 'in accordance with the age and maturity of the child'. ${ }^{827}$ All children have a right to dignity and the right to influence decision-making, in particular with regards to their own bodily integrity which has to be taken very seriously, no matter the age of the child. Most adults will give the views of teenagers greater weight than those of a younger child, whether in family, legal or administrative decisions, but children's capacity for influencing decision-making can develop at a very young age, provided children are given opportunities to experience this process. ${ }^{828}$ Even young babies have been proven to be capable of expressing a view in their own way. ${ }^{829}$ Both Alderson and Hart claim from their own research that children from birth are able to influence events and express themselves. ${ }^{830}$ The UN Committee on the Rights of the Child acknowledges that age cannot be the only criterion for competence and 'children's levels of

\footnotetext{
${ }^{826}$ UN Committee on the Rights of the Child (2009) General Comment No. 12: The right of the child to be heard, $\mathrm{CRC} / \mathrm{GC} / 12 / 2009$ para 20

${ }^{827}$ Marshall K, Children's Rights in the Balance: The Participation- Protection Debate (Stationary Office 1997)

${ }^{828}$ Lansdown G, The evolving capacities of the child, Innocenti Research Centre (UNICEF/Save the Children, Florence 2005)

${ }^{829}$ Alderson P, Hawthorne J and Killen M, 'The participation rights of premature babies', International Journal of Children's Rights (2005) 13/1-2

${ }^{830}$ Alderson P, Hawthorne J and Killen M, 'The participation rights of premature babies', International Journal of Children's Rights (2005) 13/1-2; Hart R A, Children's Participation - From Tokenism to Citizenship (Florence, Italy: UNICEF 1992) 4
} 
understanding are not uniformly linked to their biological age'. ${ }^{831}$ The extent to which a child's views are taken seriously should be dependent on their understanding of the issues concerned. ${ }^{832}$ To determine each individual child's maturity or capacity to express a view, consideration must be given on a case by case basis. ${ }^{833}$ The UN Committee 'discourages States parties from introducing age limits either in law or in practice which would restrict the child's right to be heard'. ${ }^{834}$

Article 13, freedom of expression, guarantees the right to hold and express opinions and to seek and receive information through any media. As such, the obligation it imposes on governments is to refrain from interference in the expression of those views, or in access to information, while protecting the right of access to means of communication and public dialogue. To be able to influence decisions, children must be given access to appropriate information and support to increase their understanding about their human rights and access to resources and opportunities to enable them to make use of their human rights in their everyday lives. It is essential that any barriers to children accessing information or resources are removed.

Articles 14 and 15 respectively protect the right to freedom of thought, conscience and religion and to freedom of assembly from interference or control by the State. Article 15 supports children's freedom to create and join associations and to assemble peacefully, supporting children's opportunities to collectively express their opinions and engage in political processes and participate in decision making.

Those responsible for hearing the child must ensure that the child is informed about her/his right to express her/his opinion in all matters affecting the child and that they are given a safe space, opportunities and adequately prepared and supported to participate in any decision making process, that may have an impact upon them. ${ }^{835}$ The UN Committee on the Rights of the Child explains that the context should always

\footnotetext{
${ }^{831} \mathrm{UN}$ Committee on the Rights of the Child, General Comment No. 12: The right of the child to be heard, $\mathrm{CRC} / \mathrm{GC} / 12 / 2009$ para 20

${ }^{832}$ Aisling P, Children and International Human Rights Law: The Right of the Child to be heard (Routledge 2013) 36

${ }^{833}$ UN Committee on the Rights of the Child, General Comment No. 12: The right of the child to be heard, $\mathrm{CRC} / \mathrm{GC} / 12 / 2009$ para 29

${ }^{834}$ Ibid 21

${ }^{835}$ Ibid para 41
} 
be enabling and encouraging and the adult (s) must demonstrate a willingness to listen and to seriously consider what the child has decided to communicate. ${ }^{836}$

The recognition and greater importance given to respect for a child's right to be heard can be evidenced by the propagation of several models which have been proposed to assist people's understanding of the different degrees or levels of participation. ${ }^{837}$ For example, Hart ${ }^{838}$ used the analogy of a ladder, Treseder ${ }^{839}$ used the image of a circle, Shier ${ }^{840}$ a series of pathways and Landsdown, ${ }^{841}$ three levels of participation. Crowley argues that although there are many different models and an increasing number of participation projects that support the importance of child participation, children's voice has had little impact on changing policy. ${ }^{842}$ Parkes in her critical analysis of the above models, comments that none of the models directly refer to the individual requirements of Articles, 12, 13, and 15 of the UNCRC. ${ }^{843}$ She argues that Lundy's 2007 model of participation seems to be the closest in achieving this. Parkes argues that any model of child participation should be UNCRC compliant and at the very minimum 'encapsulate the essential requirements of Article 12'. ${ }^{844}$

Lundy in her model of participation, refers to four aspects of participation, 'space: opportunities should be provided for children to express their views' and 'Voice: children must be facilitated to express their views.' Lundy goes further to suggest that children should have a 'right of audience' or as she explains 'a guaranteed opportunity to communicate views to an identifiable individual or body with responsibility to listen'

\footnotetext{
${ }^{836}$ Ibid para 42

${ }^{837}$ Aisling P, Children and International Human Rights Law: The Right of the Child to be heard (Routledge 2013)

${ }^{838}$ Hart R, Children's Participation: From Tokenism to Citizenship (Innocenti Essays, Unicef, Florence, Italy 1992).

${ }^{839}$ Treseder P, Empowering Children \& Young People: Training Manual: Promoting Involvement in Decision-making (Save the Children 1997)

${ }^{840}$ Shier H, Pathways to participation: openings, opportunities and obligations, Children and Society Vo1. 15 Issue 2. April (2001) 107-117

${ }^{841}$ Landsdown G, 'The Realisation of Children's Participation Rights - Critical Reflections' In Percy Smith B. and Thomas N (eds), A Handbook of Children and Young People's Participation:

Perspectives from Theory and Practice (London and New York, 2010) 11

${ }^{842}$ Crowley A, 'Is anyone listening? The impact of children's participation on public policy', International Journal of Children's Rights (2014(23(3):571-590.

${ }^{843}$ Aisling P, Children and International Human Rights Law: The Right of the Child to be heard (Routledge 2013) 16

${ }^{844}$ Ibid 24
} 
and she refers to 'Influence: consideration must be given to have the children's views acted upon'. ${ }^{845}$ This, she argues, supports the giving of 'due weight' to a child's views in the decision-making process.

Lundy ${ }^{846}$, and Parkes ${ }^{847}$ are clear in their commentary that the definition of a child's right to be heard if properly understood in the context of the UNCRC, is concerning the 'voice' of the child and their views and opinions to influence decisions as guaranteed by Article 12, and not the child's capacity to make decisions and make choices. Donnelly and Kilkelly argue that it is important to understand the difference between children's participation in decision making and autonomous decision making by children. ${ }^{848}$ To support children as active subjects of rights it may be necessary to go above and beyond the participation provisions of the UNCRC, empowering children to act autonomously, recognising their evolving capacity to make choices and take decisions. ${ }^{849}$ Freeman as early as 1992 argued that 'We must get beyond Conventions to "empowerment". ${ }^{850}$ The importance of the principle of 'Empowering the child' will be discussed in the next section.

\subsubsection{Examining the theory and the importance of the principle 'Empowering children'}

\subsubsection{Overview}

Empowering children to act autonomously to take decisions and to claim their human rights and achieve their fullest potential is identified by the research as an area that requires health professionals receiving training and support regarding what this means in practice (See Chapter 2, 4, 5). Even if health professionals deem a child to be

\footnotetext{
${ }^{845}$ Lundy L, 'Voice is not enough, conceptualising Article 12 of the United Nations Convention on the Rights of the Child', British Educational Research Journal (2007) 33/6, 937

${ }^{846}$ Ibid 937

${ }^{847}$ Aisling P, Children and International Human Rights Law: The Right of the Child to be heard (Routledge 2013)

${ }^{848}$ Donnelly M and Kilkelly U, 'Child-friendly health care: delivering on the right to be heard', Medical Law Review (2011) Volume 19 Issue 1, Winter

${ }^{849}$ Aisling P, Children and International Human Rights Law: The Right of the Child to be heard (Routledge 2013) 25

${ }^{850}$ Freeman M, 'Beyond Conventions - towards Empowerment', In Freeman M (ed) The Moral Status of Children: Essays on the Rights of the Child (The Hague, The Netherlands The Kluwer Law International 1997)
} 
competent, evidence suggests that health professionals still often decide what is in the child's best interests instead of empowering the child to make decisions themselves (Chapter 4). Children are also not being made aware of their human rights or how to claim their human rights in health care settings (Chapter 4,5). These complexities and challenges are discussed further in this section.

\subsubsection{What is the principle of 'Empowering children' and where is it drawn from?}

To introduce the principle of 'Empowering children' it is first important to return to considerations of what it means to be a human rights holder. Conceptualising children as human rights holders challenges discriminatory attitudes towards children as a social group. To be a human rights holder, each individual has a claim against others: individuals; the State or the family unit. For every claim holder, there has to be at least one duty bearer who is responsible in meeting duties/obligations to respect, protect and fulfil that claim holder's human rights (See Accountability section). To understand children's status as human rights holders it is important to refer to the two prominent theories of rights,' Will or Choice theory' and 'Interest theory' that help us to understand further what it means to be a rights holder. Interest theory refers to the 'right to have an important interest protected', so anyone who has important interests can have rights. ${ }^{851}$ 'Will or Choice theory' expounds that a 'right is the protected exercise of choice', so only those who are capable of making choices have rights. ${ }^{852} 853$ 'Will theory' can be challenged because in the case of a young child, who is yet unable to exercise choice, it would deem them not capable of being a rights holder. However, a Will theorist would argue that a young child who lacks capacity can still have rights because the choices that their rights protect can be exercised by their representatives (e.g., parents, caregivers, the State). ${ }^{854}$ Some argue that the dichotomy between 'Will 'and

\footnotetext{
${ }^{851}$ Archard D, Children's rights and Childhood (2nd edn Routledge 1993) 54

${ }^{852}$ Ibid 54

${ }^{853}$ Influential Will Theorists are Kant, Savigny, Hart, Kelsen, Wellman, and Steiner. Influential Interest Theorists are Bentham, Ihering, Austin, Lyons, MacCormick, Raz, and Kramer

${ }^{854}$ Hart HLA, 'Bentham on Rights', In Simpson AW (ed.) Oxford Essays in Jurisprudence, (Oxford, Oxford University Press, 1973) 184, fn 86
} 
'Interest theory' is a false one and there cannot be a single conceptualisation of what it means to have a right. ${ }^{855}$

In the 1960s, a new movement for children's rights started to develop that promoted children as rights holders and in particular a child's right to autonomy and selfdetermination. This approach is derived from liberal political philosophies that assert the importance of promoting an individual's freedom to make rational autonomous decisions. ${ }^{856}$ The Child Liberationists (e.g. Holt, Farson, Cohen) ${ }^{857}$ and what is labelled the Liberationist Approach holds the view that a child's right to self-determination is fundamental to all the rights to which children are entitled. ${ }^{858}$ Radical child liberationists argue that children should have equal rights to adults. ${ }^{859}$ Holt argued that children should have the right to vote, to decide where to live, (and whom to live with) economic independence and sexual freedom. He challenged the assumption that children do not have the capacity for rational autonomy. Franklin suggests that childhood and incompetence should not be seen as synonymous. ${ }^{860}$ Franklin, although not as radical as Holt promoted the view that even young children are capable of competent thought and decision making as compared to many adults. ${ }^{861}$ Schrag, in making reference to being able to vote, commented that adults do not lose voting rights if they become senile, mentally ill or just plain thoughtless, whereas children by virtue of being perceived as immature and not yet adults are not given the right to vote. Many adult human beings are less capable than others and have variations in intelligence and strength, just as children have varying capacities dependent on their developing maturity. ${ }^{862}$ This, the Liberationists argue, does not mean children's capacity for making choices should be taken away.

\footnotetext{
${ }^{855}$ Van Duffel S, 'In Defense of the Will Theory of Rights', Res Publica 2012 18: 231-31; Hayward T, 'On Prepositional Duties', Ethics (2013) 123: 264-91

${ }^{856}$ See Archard D, Children Rights and childhood (2nd edn London: Routledge 2004)

${ }^{857}$ Holt J, Escape from Childhood: the needs and rights of children (Boston: E. P. Dutton.1975); Farson, R Birthrights Mcmillan1974); Cohen H, Equal Rights for children (Rowman and Littlefield 1980)

${ }^{858}$ Archard D, Children's Rights and Childhood (Routledge 2004)

${ }^{859}$ Holt J, Escape from Childhood (Boston: E. P. Dutton.1975)

${ }^{860}$ Franklin B, 'Children's political rights', In Franklin B (ed) The rights of children (New York Basil Blackwell 1986)

${ }^{861}$ Ibid

${ }^{862}$ Schrag F, 'Children and Democracy: Theory and Policy', Politics, Philosophy and Economics no. 3 (2004): 371
} 
Other theorists follow a middle ground they respect children's agency and autonomy but do not call for complete equality, not for young children or even for teenagers. Freeman explains that the integrity of the child and his decision making capacities should be recognised, but at the same time the dangers of complete liberation should be acknowledged. ${ }^{863} \mathrm{He}$ argues it is okay to defend laws that were developed to protect children, for example, preventing children from going down the mines and the factories in the $19^{\text {th }}$ century or laws that today prevent children from being sexually abused. ${ }^{864}$ These laws were put in place to safeguard children's opportunity to develop to their fullest potential and as their capacity develops to retain the opportunity to become fully autonomous. Freeman comments that to respect children's right to autonomy is to 'treat children as a person and as a rights holder' and to 'treat them as persons entitled to equal concern and equal respect, entitled to have both their present autonomy recognised and their capacity for future autonomy safeguarded'. ${ }^{865}$ It is about finding an acceptable balance between respecting children's choices and when necessary to collaborate to reach a decision if the choice that is being made by the child could be damaging to their future development. Freeman talks about a false dichotomy between a child's right to be protected versus their increasing right to autonomy. ${ }^{866}$ However, he argues that the importance of the liberationist project was that they addressed discrimination against children and put forward the importance of autonomy. ${ }^{867}$

Feinburg ${ }^{868}$ comments that children should be considered to have a 'right to an open future' and Eekelaar refers to it as 'dynamic self-determinism', which he explains is intended to "bring a child to the threshold of adulthood with the maximum opportunities to form and pursue life-goals which reflect as closely as possible an autonomous

\footnotetext{
${ }^{863}$ Freeman M, 'The Value and Values of Children's Rights', In Invernizzi A and Williams J (eds), The Human Rights of Children: From Visions to Implementation (Farnham: Ashgate 2011) 31 ${ }^{864}$ Freeman M, The Moral Status of Children: Essays on the Rights of the Children $\left(1^{\text {st }}\right.$ ed Springer, 1997) 39

${ }^{865}$ Freeman M, 'The Value and Values of Children's Rights', In Invernizzi A and Williams J (eds), The Human Rights of Children: From Visions to Implementation (Farnham: Ashgate 2011) 6 ${ }^{866}$ Freeman M, 'The Value and Values of Children's Rights', In Invernizzi A and Williams J (eds), The Human Rights of Children: From Visions to Implementation (Farnham: Ashgate 2011) 33; Freeman M, 'Upholding the Dignity and Best Interests of Children: International Law and the Corporal Punishment of Children' (2010) 73 Law and Contemporary Problems, 213-53.

${ }^{867}$ Freeman M, The Moral Status of Children: Essays on the Rights of the Children $\left(1^{\text {st }}\right.$ ed Springer, 1997) 52

${ }^{868}$ Feinburg J, Rights, Justice and the bounds of liberty (Princeton University Press 1980)
} 
choice'. ${ }^{869}$ Lindsay describes this middle ground interpretation as the 'pragmatic approach' that is children should have the opportunity to express their own views as their capacity for taking decisions for themselves develops. ${ }^{870}$

Conceptualising the child as an active subject of human rights recognises the importance and the necessity of balancing a child's right to be protected and their capacity for greater autonomy, understanding that both are equally important in helping children to realise all of their human rights. This perspective is one to a certain extent that underpins the provisions of the UNCRC ${ }^{871}$, and the challenge of balancing protectionist/caretaker and liberationist approaches, is a theme that arises throughout this thesis, coming to the forefront of discussions with regards to health care decision making.

The tension between these approaches is embraced within the concept first introduced by the UNCRC of 'evolving capacities,' that is children's ability to form and express their opinions is understood to develop with experience and to be determined in the light of their age or maturity. This presents a radical departure from previously held conceptualisations of childhood or even how children were conceptualised in other international human rights treaties, as being first and foremost vulnerable, incompetent and in need of protection. ${ }^{872}$ Evolving capacities of the child perceives the child as having a diminishing need for protection as their capacity to make decisions develops. ${ }^{873}$

Under Article 5 of the UNCRC:

\footnotetext{
${ }^{869}$ Eekelaar J, 'The Interest of the Child and the Child's Wishes: The Role of Dynamic Selfdeterminism', International Journal of Law and the Family (1994) 42, 53

${ }^{870}$ Lindsay M, Highlight: An Introduction to Children's Rights (London: National Children's Bureau 1992)

${ }^{871}$ Freeman M, The Moral Status of Children: Essays on the Rights of the Children $\left(1^{\text {st }}\right.$ ed Springer, 1997) 53

${ }^{872}$ Varadan S, 'The Principles of Evolving Capacities under the Convention on the Rights of the Child', International Journal of Child Rights (2019) Volume 27 Issue 2; Tobin J, 'Understanding Children's Rights: A Vision beyond Vulnerability', Nordic Journal of International Law (2015) (28) 155-182; Van Bueren G, 'The International Law on the Rights of the Child', In The International Law on the Rights of the Child (Leiden: Brill Nijhoff 1995)

${ }^{873}$ Lansdown G, The evolving capacities of the child Innocenti Research Centre (UNICEF/Save the Children, Florence 2005)
} 
States Parties shall respect the responsibilities, rights and duties of parents or, where applicable, the members of the extended family or community as provided for by local custom, legal guardians or other persons legally responsible for the child, to provide, in a manner consistent with the evolving capacities of the child, appropriate direction and guidance in the exercise by the child of the rights recognized in the present Convention.

The concept of 'evolving capacities', as referred to within Article 5 of UNCRC introduces the idea that children should be able to exercise their human rights as they acquire the capacity to do so, rather than when they reach a certain age albeit under the direction of their parents/guardians. This corresponds with the earlier mentioned 'Will theory' that argues that rights are the protected exercise of choice and young children can still have rights because the choices that their rights protect can be exercised by their representatives. It requires parents or legal guardians to guide children appropriately and respect the extent to which they can exercise their human rights for themselves. As Landsdown emphasises, parental authority has shifted to include parental responsibility to help children to achieve their rights and to provide appropriate direction and guidance in the exercise of those rights. ${ }^{874}$ This is said not to undermine the rights of parents and the UNCRC recognises the family as 'the natural environment for the growth and well-being of its members'. ${ }^{875}$

Varadan argues that the concept of evolving capacities has evolved since the UNCRC was first drafted. ${ }^{876}$ Evolving capacities was first drafted more as a right of children to receive appropriate guidance and direction from parents and guardians in a manner consistent with their evolving capacities. ${ }^{877}$ Since drafting, evolving capacities has been referred to over 80 times across General Comments and is referred to, not just under the framework of parental guidance but across the whole Convention. ${ }^{878}$

\footnotetext{
${ }^{874} \mathrm{Ibid}$

${ }^{875}$ See preamble to the UNCRC.

${ }^{876}$ Varadan S, 'The Principles of Evolving Capacities under the Convention on the Rights of the Child', International Journal of Child Rights (2019) Volume 27 Issue 2

${ }^{877}$ Ibid

${ }^{878}$ Ibid
} 
For example, in General Comment No. 20, with reference to Article 14, the Committee has confirmed that:

it is the child who exercises the right to freedom of religion, not the parent and the parental role necessarily diminishes as the child acquires an increasingly active role in exercising choice throughout adolescence. ${ }^{879}$

And with reference to Article 13, the UN Committee is clear that,

the obligation of parents and caregivers to provide appropriate guidance in accordance with the evolving capacities of adolescents should not interfere with adolescents' right to freedom of expression. ${ }^{880}$

In line with the developing concept of evolving capacities in the context of health care decision making, once a child is competent to understand the nature and implications of their treatment, they should be entitled to exercise an autonomous choice as to whether to give consent to it taking place. This understanding of children as rights holders does demand the question 'who decides what is in the 'best interests' of the child?' Tobin explains that the best interests of the child are so often overshadowed by the interests of adults who are the principal decision makers in society. The interests of others - such as parents ${ }^{881}$, the community and the state - should not be the overriding concern, even though they may influence the final decision. ${ }^{882} \mathrm{~A}$ children's rights perspective emphasises that the best interests of the child must always be balanced with children's views being given due weight, ensuring that children are not ignored or remain invisible in the decision making process. ${ }^{883}$ Additionally, 'the evolving capacities of the child must be taken into consideration when

\footnotetext{
${ }^{879}$ UN Committee on the Rights of the Child, General Comment No.20 on the implementation of the rights of the child during adolescence $\mathrm{CRC} / \mathrm{C} / \mathrm{GC} / 20 / 2016$ para 43

${ }^{880}$ Ibid para 42

${ }^{881}$ Art 18 explains that best interests should be parents and legal guardian's basic concern in their responsibility for the upbringing and development of the child.

${ }^{882}$ Tobin J, 'Understanding a human rights based approach to matters involving children: conceptual foundations and strategic considerations' In Invernizzi A and Williams J (eds) The Human Rights of Children: From Visions to Implementation (Farnham: Ashgate 2011) 89

${ }^{883} \mathrm{UN}$ Committee on the Rights of the Child, General Comment No. 14 on the right of the child to have his or her best interests taken as a primary consideration $\mathrm{CRC} / \mathrm{C} / \mathrm{GC} / 14 / 2013$; UNHCR, Guidelines on Determining the Best Interests of the Child (UNHCR 2018)
} 
the child's best interests and the right to be heard are at stake'.... as the child matures, his or her views shall have increasing weight in the assessment of best interests' ${ }^{884}$

The jurisprudence of the General Comments noted by Varadan articulates a concept of evolving capacities that is broader than the term as it first appeared in Article 5 and she argues should be presented as an 'enabling principle', Varadan explains it serves four functions:

1. It affirms the child as a rights holder under international law, recognising that as children grow and develop and mature, they acquire capacities to exercise increasing levels of agency over their rights.

2. It supports and recognises children's agency in decision making.

3. It recognises that all children, even very young children should be engaged as agents in the promotion and protection of their own rights.

4. It crystallises the role of parents and legal guardians as duty-bearers to their children, proving guidance and direction to support their child's exercise and enjoyment of rights under the UNCRC. ${ }^{885}$

Doek, ${ }^{886}$ Detrick $^{887}$, Hanson and Lundy ${ }^{888}$ have all argued that Article 5 should be included as a general principle because it is relevant to the whole of the UNCRC. Hanson and Lundy go further to argue that Article 6 (Survival and Development) should be discarded in favour of Article 5.

\footnotetext{
${ }^{884} \mathrm{UN}$ Committee on the Rights of the Child, General Comment No. 14 on the right of the child to have his or her best interests taken as a primary consideration CRC/C/GC/14/2013 para 44

${ }^{885}$ Varadan S, 'The Principles of Evolving Capacities under the Convention on the Rights of the Child', International Journal of Child Rights (2019) Volume 27 Issue 2, 317

${ }^{886}$ Doek J, 'The CRC General Principles' In (eds) Connors J, Zermatten J, Panayotidis A, 18 Candles: The Convention on the Rights of the Child reaches majority (Geneva: Institut international des droits de l'enfant 2007) 31-32

${ }^{887}$ Dietrick S A, Commentary on the United Nations Convention on the Rights of the Child (The Hague: Brill/Nijhoff 1999)

${ }^{888}$ Hanson K and Lundy L, 'Does exactly what it is says on the tin? A critical analysis and alternative conceptualisations of the So-called "General Principles" of the Convention on the Rights of the Child,' The International Journal of Children's Rights 2017 (25 (2) 285-306
} 
Varadan comments that a plain reading of Article 5 however does not support an understanding of 'evolving capacities' as a broader principle.889 The wider jurisprudence of the General Comments instead supports an understanding of what evolving capacities actually means. The Committee in the majority of its references delinks its interpretation of 'evolving capacities' from Article 5 and it is this understanding of evolving capacities that should arguably be embraced into any crosscutting principle. It is this conceptualisation that also challenges notions of children being first and foremost vulnerable and in need of protection and instead envisions children as human rights holders who are capable of making autonomous decisions.

Tobin and Varadan also point out that the Committee refer to evolving capacities not just as an enabling principle, but a 'policy principle and an 'interpretative principle.' They state:

The committee's use of the principle of evolving capacities could be said to fall into three broad categories: (a)'evolving capacities as an enabling principle' in which the child is enabled in the exercise of his or her rights under the Convention; (b) 'evolving capacities as an interpretative principle' in which a child's evolving capacities is enlisted as a tool to interpret provisions under the Convention; and (c) 'evolving capacities as a policy principle' in which the concept of the children's evolving capacities is used to navigate policy issues related to children's agency and autonomy in the exercise of their right. ${ }^{890}$

This thesis seeks to build on Tobin and Varadan's research and indeed the developing jurisprudence of the UNCRC's general comments and instead articulates a principle of empowering children as human rights holders, including the most deprived and excluded, to participate in achieving their human rights and hold those who deliver services to account to meet their obligations. There will be an acceptance that children are rights holders because, like adults, they have important interests that must be

\footnotetext{
${ }^{889}$ Varadan S, 'The Principles of Evolving Capacities under the Convention on the Rights of the Child', International Journal of Child Rights (2019) Volume 27 Issue 2

${ }^{890}$ Tobin J and Varadan S, 'Article 5: The Right to Parental Direction and Guidance Consistent with a Child's Evolving Capacities,' In Tobin J (ed.) The UN Convention on the Rights of the Child: A Commentary (Oxford: Oxford University Press 2019) 78
} 
protected but also the choices that their rights protect can be exercised by themselves when they have capacity and by their representatives when they do not have the capacity to make a choice. Therefore, there is recognition of the dynamic nature of human rights, in that the State has a duty to protect the important interests of and/or not interfere in the important interests of any child and any child who has capacity can be an active agent, capable of claiming their human rights and if they do not have the capacity, their representatives will exercise their right to claim their human right on their behalf. The chosen principle of 'Empowering the Child' for this CRA framework recognises the importance of children being presumed capable of being decision and choice makers and the importance of empowering them to be agents of their own and others social transformation.

Empowering children to act autonomously to take decisions and to claim their human rights and determine what is in their own best interests is identified by the research in Chapter 4 as an area that requires health professionals receiving training and support regarding what this means in practice. It requires in depth training in understanding how to judge the maturity of the child, and any judgements should not be based solely on age. As Archard and Skivenes argue the reasons to doubt a child's decision making ability should not be different to the reasons to doubt an adult. ${ }^{891}$ The Children's Rights Knowledge Centre argue that the knowledge and communication skills of the professional that determines what is in the best interests of the child may be more important than any tool that is provided for an assessment, as well as professionals being given the necessary competences to assess what is in a child's best interests in the most holistic way. ${ }^{892}$ It also requires a shift in attitudes towards children that have traditionally been evidenced to conceptualise children as incompetent, vulnerable, and unable to make autonomous decisions (See above discussion under principle of Discrimination and Chapter 4 and 5).

\footnotetext{
${ }^{891}$ Archard D and Skivenes M, 'Deciding best interests: general principles and the cases of Norway and the UK', Journal of Children's Services (2010) 5 (4), 43-54

${ }^{892}$ Children's rights knowledge centre, $A$ discussion of commonly encountered tensions and possible solutions based on international best interests and policy strategies since 2004 (A study of the Children's Knowledge Centre, Commissioned by the Flemish Government, Division of Youth 2014) 33
} 
The 'principle of empowerment' pushes beyond the constraints of the 'participatory rights of the UNCRC' and Article 5 and is instead drawn from the ethos of the UNCRC, the jurisprudence of the General Comments and the international human rights framework. Using Tobin's own terminology, it can be described as an implied principle, not a principle found expressly in the provisions of international treaties. ${ }^{893}$ Empowerment is an implied principle found in the values on which UDHR is based upon. The UDHR supports the idea each individual, including children, should have the freedom to pursue and achieve a life of his/her choice, this freedom transforms into the right of each and every human to be able to access opportunities for accomplishment of such a life. Empowerment can be described as a principle that provides such development opportunities through supporting the fulfilment of all human rights. ${ }^{894}$

The principle of 'Empowering the child' is very much about emphasising the importance of enhancing children's capacities as individuals, so they are better able to take advantage of their human rights, and to engage with, influence and hold accountable, organisations that affect their lives. It also embraces Article 6, which understands that children go through a process of rapid development, and it is critical to:

to create an environment conducive to ensuring to the maximum extent possible the survival and development of the child, including physical, mental, spiritual, moral, psychological and social development, in a manner compatible with human dignity and to prepare the child for an individual life in a free society. ${ }^{995}$

In order to successfully be able to claim human rights, all individuals need to be supported to develop the relevant capacities. How can rights become real if children

\footnotetext{
${ }^{893}$ Tobin J, 'Understanding a human rights based approach to matters involving children: conceptual foundations and strategic considerations', In Invernizzi A and Williams J (eds), The Human Rights of Children: From Visions to Implementation (Farnham: Ashgate 2011).

${ }^{894}$ See Universal Declaration on Human Rights

${ }^{895}$ Reporting Guidelines for Periodic Reports, General Guidelines regarding the form and contents of periodic reports to be submitted by States Parties under Article 44, para (b) of the Convention, adopted by the Committee on the Rights of the Child at its $343^{\text {rd }}$ meeting $\left(13^{\text {th }}\right.$ session $) 11$ October 1996 para 40
} 
are not given the relevant capacities to realise them? It is not just about accessing resources; it is about children's capacities being developed and obstacles removed to support access to resources or commodities and about being given the real opportunities and freedom of choice to navigate access to resources and formal human rights. Understanding how to support children to develop their own capacities helps public services to consider the best possible options for translating a CRA from theory into practice, and how to effectively implement children's rights.

Empowering children, means that adults should hand over some or all power to children, or share power with children, so that children can better control and direct their lives, in areas where this ability was previously unavailable to them. The diversity of children's experience must always be taken into consideration, there cannot be a narrow view of what childhood is supposed to mean, based on adult assumptions and social theory ${ }^{896}$ and children's subjective reality (s) must be valued. ${ }^{897}$ Federle summarises succinctly by stating that:

...rights have a transformative aspect because they have the potential to reduce victimization and dependence by changing the rights holder into a powerful individual who commands the respect of those in the legal system...rights create mutual zones of respect, challenging those who want to act in the best interest of children to promote the empowerment of children instead. ${ }^{898}$

Additionally, as Stoecklin suggests, children's agency cannot just be a slogan, it must become an operational concept connected to an explicit theory of action. ${ }^{899}$ It needs to be understood in the context of social structure and power relationships but also in connection to the development of every child's internal capacities to influence the direction of their own lives.

The challenges presented by this conceptualisation will be discussed in more detail when faced with the practical challenge of securing young teenagers right to

\footnotetext{
${ }^{896}$ Archard D, Children: Rights and childhood (2nd edn. London: Routledge 2004)

897 Alanen L, Brooker E, Mayall, B (eds.) Childhood with Bourdieu (Palgrave, Macmillan 2015)

${ }^{898}$ Federle K H, 'Rights, Not Wrongs', International Journal of Child Rights (2009) 17, 321

${ }^{899}$ Stoecklin D, Bonvin, J M (eds) Children's rights and the capabilities approach (Springer 2014)
} 
independently consent to the primary research at health services at $A B M U$ and with respect to the analysis of the primary research results (Chapters 8 and 9).

The five principles are interrelated and aim to bring the values and spirit of the international human rights framework alive and an understanding that children as human rights holders should be central to service delivery. In summary and visually described in Diagram 5:

DIAGRAM 5: Five interrelated and overlapping principles of a CRA to health services

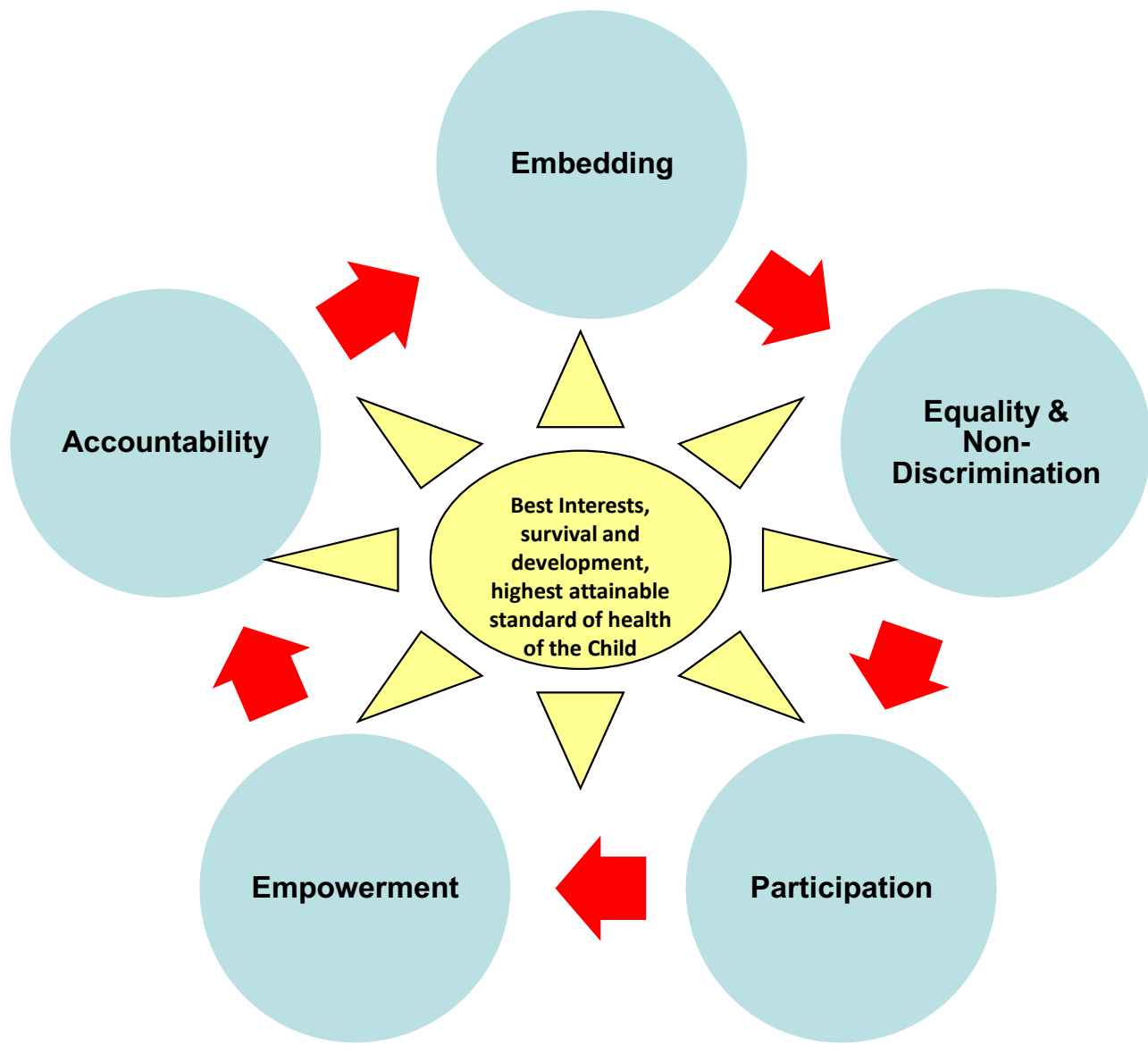

Understanding how to support what is in a child's best interests, ensuring their survival and development and achieving the highest attainable standard of health requires an understanding on behalf of health service providers regarding how to implement all 5 principles of a CRA.

The principle of embedding is critical to a children's rights approach, it is regarded as a core human rights principle, explaining that human rights must become embedded 
across societies and integral to any legislation, policy or service delivery (see Chapter 3). It is also very relevant in the Welsh context because although there has been the development of policies and legislation in Wales regarding children's rights, there is a policy to implementation gap and services are struggling to translate children's rights into practice (Chapter 6). Additionally, what seems to be lacking in approaches to health service delivery in the Welsh context is the principle of accountability i.e., interventions are recommended but without an identification of the duty bearer responsible for implementing them. The principle of accountability has the potential to drive services/ organisations towards respecting, protecting and fulfilling human rights and to being held to account to meet these obligations.

Children strongly report across the UK and European research that they want to participate and have a right to participate in clinical decision making and, in the monitoring, evaluation and design of service delivery (See Chapter 4). Although there have been some significant strides in recognising the importance of children's right to be heard in Wales, in national policy and legislation, there is no evidence yet regarding how this principle is being respected in health services (Chapter 5). Across the research we have learned that children are still discriminated against as a group (See Chapter 4,5 ) as well as disaggregated groups of children and in Wales many children continue to be challenged by health inequalities (Chapter 5 ). It requires a principled response to address this discrimination and to treat children as persons and subjects of human rights, to challenge the discriminatory attitudes of service providers towards children and discrimination that limits children's equal access to services.

Empowering children to act autonomously to take decisions and to claim their human rights and achieve their fullest potential is identified as an area that requires health professionals receiving training and support regarding what this means in practice (See Chapter 3, 4, 5). The principle of 'Empowering the Child' has been included to ensure that at every stage of service delivery the evolving capacities of children to make autonomous decisions and claim their human rights is supported and encouraged.

These principles help to support a vision of childhood which recognises children as active agents and human rights holders able to take advantage of their human rights and hold service providers to account. 
Table 4 is adapted from Tobin's conceptual framework first introduced in Chapter 3 and offers a helpful summary of where the chosen principles are derived from. The principles must be understood to be interrelated and overlapping.

TABLE 4: Summary of the 5 principles of a CRA and where they are derived from

\begin{tabular}{|c|c|c|c|}
\hline Principle & $\begin{array}{l}\text { Type of } \\
\text { principle }\end{array}$ & Short description & $\begin{array}{l}\text { Link to international } \\
\text { human rights } \\
\text { treaties/UN } \\
\text { institutions }\end{array}$ \\
\hline $\begin{array}{l}\text { Embedding } \\
\text { children's } \\
\text { human rights }\end{array}$ & Core principle & $\begin{array}{l}\text { Children's rights } \\
\text { should become } \\
\text { embedded within and } \\
\text { across societies. They } \\
\text { need to become an } \\
\text { integral dimension of } \\
\text { the design, } \\
\text { implementation, } \\
\text { monitoring and } \\
\text { evaluation of } \\
\text { legislation, policies and } \\
\text { practice. }\end{array}$ & $\begin{array}{l}\text { - See UN General } \\
\text { Secretary } 1997, \\
\text { paras } 78-9 \\
\text { - See UN Common } \\
\text { Understanding } \\
\text { - General Commen } \\
\text { No. } 5 \text { of the } \\
\text { UNCRC } \\
\text { - Article } 3 \text { of the } \\
\text { UNCRC } \\
\text { - Article } 4 \text { of the } \\
\text { UNCRC } \\
\text { - Article } 42 \text { of the } \\
\text { UNCRC }\end{array}$ \\
\hline $\begin{array}{l}\text { Accountability } \\
\text { to children }\end{array}$ & $\begin{array}{l}\text { General } \\
\text { express } \\
\text { principle }\end{array}$ & $\begin{array}{l}\text { Human rights give rise } \\
\text { to obligations which } \\
\text { demand accountability. } \\
\text { All duty bearers should } \\
\text { be accountable to } \\
\text { children for their } \\
\text { decisions and actions } \\
\text { which affect their lives. }\end{array}$ & $\begin{array}{l}\text { - Accountability is } \\
\text { key component to } \\
\text { all international } \\
\text { human rights } \\
\text { treaties } \\
\text { - Article } 4 \text { of } \\
\text { UNCRC } \\
\text { - Article } 18 \text { (1) } \\
\text { Parents have the }\end{array}$ \\
\hline
\end{tabular}




\begin{tabular}{|c|c|c|c|}
\hline & & & $\begin{array}{l}\text { primary } \\
\text { responsibility } \\
\text { - } \text { Article } 27 \text { (1) } \\
\text { States must } \\
\text { support parents in } \\
\text { the delivery of this } \\
\text { responsibility } \\
\text { - General Comment } \\
\text { No. } 5 \text { of the } \\
\text { UNCRC }\end{array}$ \\
\hline $\begin{array}{l}\text { Equality and } \\
\text { non- } \\
\text { discrimination } \\
\text { to children }\end{array}$ & $\begin{array}{l}\text { General and } \\
\text { specific } \\
\text { express } \\
\text { principle }\end{array}$ & $\begin{array}{l}\text { Equality is about } \\
\text { ensuring that every } \\
\text { child has an equal } \\
\text { opportunity to make } \\
\text { the most of their lives } \\
\text { and fulfil their potential, } \\
\text { and no child should } \\
\text { endure poor life } \\
\text { chances because of } \\
\text { discrimination. All } \\
\text { discrimination on any } \\
\text { ground is prohibited by } \\
\text { international human } \\
\text { rights law. }\end{array}$ & $\begin{array}{l}\text { UDHR Article 7, } \\
\text { ICCPR Articles } 2 \\
\text { and } 26 \\
\text { - Article } 2 \text { of the } \\
\text { UNCRC }\end{array}$ \\
\hline $\begin{array}{l}\text { Participation } \\
\text { of children }\end{array}$ & $\begin{array}{l}\text { General and } \\
\text { specific } \\
\text { express } \\
\text { principle }\end{array}$ & $\begin{array}{l}\text { At a minimum, } \\
\text { participation means } \\
\text { listening to children } \\
\text { and taking their views } \\
\text { meaningfully into } \\
\text { account. Opportunities } \\
\text { must be given to }\end{array}$ & $\begin{array}{l}\text { - } \text { Article } 25 \text { ICCPR } \\
\text { complimented by } \\
\text { Articles } 19,22 \\
\text { - UNCRC articles } \\
\text { 12, complimented } \\
\text { by Articles } 13,14 \text {, } \\
15,\end{array}$ \\
\hline
\end{tabular}




\begin{tabular}{|c|c|c|c|}
\hline & & $\begin{array}{l}\text { children to influence } \\
\text { decisions about their } \\
\text { lives and children } \\
\text { should be involved in } \\
\text { all decisions that affect } \\
\text { them. }\end{array}$ & $\begin{array}{l}\text { - General Comment } \\
\text { No.12 }\end{array}$ \\
\hline $\begin{array}{l}\text { Empowering } \\
\text { children }\end{array}$ & $\begin{array}{l}\text { Implied } \\
\text { principle }\end{array}$ & $\begin{array}{l}\text { Empowerment means } \\
\text { enhancing children's } \\
\text { capacities as } \\
\text { individuals, so they are } \\
\text { better able to take } \\
\text { advantage of their } \\
\text { human rights, and to } \\
\text { engage with, influence } \\
\text { and hold accountable } \\
\text { those individuals and } \\
\text { institutions that affect } \\
\text { their lives. It is also } \\
\text { about enabling children } \\
\text { to take autonomous } \\
\text { decisions and make } \\
\text { choices to affect } \\
\text { positive outcomes for } \\
\text { themselves. }\end{array}$ & $\begin{array}{l}\text { - Found in the } \\
\text { values on which } \\
\text { the Universal } \\
\text { Declaration of } \\
\text { Human Rights is } \\
\text { based upon and all } \\
\text { international } \\
\text { treaties. } \\
\text { This principle also } \\
\text { supports the } \\
\text { developing } \\
\text { jurisprudence } \\
\text { across the UNCRC } \\
\text { General } \\
\text { Comments on } \\
\text { 'Evolving } \\
\text { Capacities' and } \\
\text { embraces UNCRC } \\
\text { Article 6, survival } \\
\text { and development. }\end{array}$ \\
\hline
\end{tabular}


Please also see Appendix 1, an illustrative example of a child's life story adapted from the BBC "When I Worry About Things" which is a collection of animated films that use personal testimony to explore mental health issues from the perspective of children. ${ }^{900}$ Annabel faced mental health challenges and the adapted story describes her experience of using health services and suggests what should have been considered if a CRA was being implemented. It uses the lens of the 5 principles of a CRA.

The next section considers how the five principles and the key elements of a CRA can be translated into standards and objectives that can later (Chapter 7 ) be integrated into a conceptual framework for testing how far a health authority has embedded a CRA to health services and its strategies for improvement.

\subsection{Translation of the principles and key elements of a CRA to health services in practice}

To deliver on a CRA the following organisational standards and objectives have been developed to translate the above principles and key elements of a CRA into action across health services/health authorities. These standards have been developed based on the evidence reviewed in Chapters $2-5$ and the discussion above. In particular, they draw on the UN Committee's General Comments, with a strong focus on General Comment No. 15 and also the Council of Europe Child Friendly Guidelines. An attempt has been made to keep them simple and accessible and to the point so that they can be easily translated into the practice of a health authority. They focus on the optimum standards for integrating and infusing a CRA into systems of a health authority. This is a corporate wide approach applied to all service areas that impact on child health across the life course, from pre-natal and neo-natal, to the early years, adolescent health and transition.

\section{The main standards for implementing a CRA throughout health services:}

- Health authority-wide commitment to the United Nations Convention on the Rights of the Child (UNCRC).

\footnotetext{
${ }^{900}$ BBC Teach 'When I worry about things'

https://www.bbc.co.uk/programmes/articles/5QM6H01X6b3jTQF85GLgbFl/when-i-worry-aboutthings accessed January 2020
} 
- Develop a children's rights strategy.

- Raise awareness and deliver training on children's rights.

- Undertake monitoring of children's rights.

- Ensure equality and non-discrimination to children throughout service delivery.

- Ensure children can actively participate in decisions about their own health.

- Ensure children are directly involved in the development, monitoring and evaluation of service delivery.

- Develop a child-friendly advice and complaints mechanism.

- Ensure there is health promotion, children's rights information and advocacy for all children and their caregivers.

\subsubsection{Health authority wide commitment to the UNCRC}

The health authority should make express reference to the UNCRC as a framework for service planning and delivery in all significant policy statements or other documents setting out the health authority/services vision or key objectives (e.g. Clear Mission Statement or Children's Rights Charter). The UNCRC should become the standard against which to measure health authority policies and practice affecting children and children's views and experiences should become central to influencing what changes for the better and how. Staff, children and their carers should be made aware of and understand this commitment (See Table 5). 
TABLE 5: Health authority wide commitment to the UNCRC

\begin{tabular}{|c|c|c|c|}
\hline $\begin{array}{l}\text { CRA } \\
\text { Principle }\end{array}$ & $\begin{array}{l}\text { Organisation } \\
\text { standard }\end{array}$ & \begin{tabular}{|l|} 
UNCRC \\
Article/General \\
Comment \\
\end{tabular} & Organisation Objective(s) \\
\hline Embedding & $\begin{array}{l}\text { Health Authority } \\
\text { wide } \\
\text { commitment to } \\
\text { the UNCRC }\end{array}$ & $\begin{array}{l}\text { Articles 1-42, } \\
\text { GC No. } 5, \\
\text { No.14, No. } 15 .\end{array}$ & $\begin{array}{l}\text { - Express reference has } \\
\text { been made to the } \\
\text { UNCRC as the framework } \\
\text { for service planning and } \\
\text { delivery in all significant } \\
\text { policy statements or other } \\
\text { documents setting out the } \\
\text { health authority's vision or } \\
\text { key objectives (e.g. } \\
\text { Children's Human Rights } \\
\text { Charter). } \\
\text { Leaders and staff, who } \\
\text { are required to put the } \\
\text { commitment into practice, } \\
\text { are aware of this } \\
\text { commitment and familiar } \\
\text { with the UNCRC. } \\
\text { Children as service users } \\
\text { and their carers are made } \\
\text { aware of the commitment } \\
\text { to the UNCRC. }\end{array}$ \\
\hline
\end{tabular}

\subsubsection{Children's rights strategy}

A strategy should be developed that is adequately resourced regarding how the UNCRC will be incorporated into every aspect of decision making, procedures and actions (See Table 6). There should be an initial assessment of the health authority's institutional capacity and the availability of human, financial, and technical resources. There must be a clear commitment to ensuring adequate resources are allocated to support the health authority to implement children's rights, including key individuals or 
a team with responsibility to promote children's rights across the health authority. All stakeholders, including children, should be consulted on the development of the strategy. Any strategic plan should:

set out how children's human rights will be integrated and contribute to a 'continuum of care' extending across the traditional boundaries of primary, secondary and tertiary health care organisations, involving health, education, social care and justice systems etc. whether in the public, private or voluntary sectors. The strategy should be applicable at the level of policy/planning, service delivery and to the individual child and families. ${ }^{901}$

The strategic plan should be communicated to all staff, external agencies, the public, including children, explaining the health authority's strategy for integrating the UNCRC into every aspect of their practice. The strategy should include how they will protect children's rights throughout the commissioning cycle. ${ }^{902}$

Any strategy must include the cycle, of monitoring, raising awareness, planning and evaluation and:

- $\quad$ map the reality of existing practices (i.e., gaps in children's rights in practice);

- plan the improvement, through the identification of a set of standards for the respect of children's human rights in health services;

- raise awareness of children's rights and children's rights standards;

- make improvement, through the implementation of specific actions;

- evaluate the change, by monitoring progress and gaps. ${ }^{903}$

${ }^{901}$ Council of Europe, Child Friendly Guidelines to HealthCare (COE 2011) para.20

https://rm.coe.int/guidelines-of-the-committee-of-ministers-of-the-council-of-europe-on-c/16808c3a9f accessed January 2020

${ }^{902}$ UN Committee on the Rights of the Child, General Comment No. 15 on the right of the child to the enjoyment of the highest attainable standard of health $\mathrm{CRC} / \mathrm{C} / 15 / 201377$ 'to ensure compliance by any partners who deliver services on their behalf'

${ }^{903}$ Kilkelly U and Savage E, Child friendly health care: A report commissioned for the ombudsman for children (Ombudsman for Children 2013) 48 referring to the stages involved in the SEMT process 
TABLE 6: A children's rights strategy

\begin{tabular}{|c|c|c|c|}
\hline $\begin{array}{l}\text { CRA } \\
\text { Principle }\end{array}$ & $\begin{array}{l}\text { Organisation } \\
\text { standard }\end{array}$ & \begin{tabular}{|l} 
UNCRC \\
Article/General \\
Comment \\
\end{tabular} & Organisation Objective(s) \\
\hline Embedding & $\begin{array}{l}\text { Develop a } \\
\text { children's rights } \\
\text { strategy }\end{array}$ & $\begin{array}{l}\text { Articles 1-42, } \\
\text { GC No. 5, No. } \\
15 .\end{array}$ & $\begin{array}{l}\text { - A strategy has been } \\
\text { developed to ensure the } \\
\text { UNCRC is taken into } \\
\text { account at all levels of } \\
\text { decision-making across } \\
\text { all health services and } \\
\text { there is clear coordination } \\
\text { with other agencies. } \\
\text { - Protection of children's } \\
\text { rights has been prioritised } \\
\text { through the } \\
\text { commissioning cycle. } \\
\text { - Key individuals and/or a } \\
\text { team with responsibility to } \\
\text { promote children's rights } \\
\text { within the health authority } \\
\text { has been established } \\
\text { There is clear and } \\
\text { transparent evidence to } \\
\text { demonstrate that the } \\
\text { maximum extent of } \\
\text { available resources has } \\
\text { been allocated to support } \\
\text { the organisation to } \\
\text { implement the children's } \\
\text { rights strategy. }\end{array}$ \\
\hline
\end{tabular}




\subsubsection{Raising awareness and training on children's rights for staff}

The Children's Rights Team referred to above should carry out an initial and on-going evaluation of levels of knowledge and understanding of children's rights amongst staff. A communication plan for staff should be developed setting out how the health authority intends to raise awareness and understanding of implementing children's rights.

Health professionals and managers should receive training to understand children's rights, child development and how to adopt a CRA in practice. ${ }^{904}$ There should be mandatory training on children's rights for all staff, with the intensity of training appropriate to context and role that a member of staff performs. This should be delivered to staff members across the health authority.

Training should include, for example: 905

- All staff should receive training on child health and caring for children.

- Training on children's rights.

- Communicating with children, including:

- Addressing children directly during the consultation process.

- Supporting children to express their views freely, to ask questions if they do not understand and to ensure their views are always taken into account and given due weight.

- Sharing diagnoses with children, explaining fully to children (in ways they understand) about their condition, i.e., what is happening to them, which treatments are proposed, options that are available, implications of all the options, treatment side effects, likelihood of discomfort and how to give 'bad news.'

\footnotetext{
${ }^{904}$ UN Committee on the Rights of the Child, General Comment No. 5 on the General Measures of Implementation $\mathrm{CRC} / \mathrm{C} / \mathrm{GC} / 5 / 2003$ para 53; UN Committee on the Rights of the Child, General Comment No. 15 on the right of the child to the enjoyment of the highest attainable standard of health $\mathrm{CRC} / \mathrm{C} / 15 / 2013$ para 93

${ }^{905}$ This section draws on International Institute for Child Rights and Development, CRED Pro Child Rights Curriculum for Health Professionals (IICRD2008) and Landsdown G, Every Child's Right to be Heard: A resource guide to the UN Committee on the Rights of the Child's (UNICEF 2011), Article 12 and General Comment No.12
} 
- Presuming that children first and foremost are capable of making informed decisions and choices about their health care and treatment.

- Using play strategies and props during health care practice for younger children.

- Explaining to children how to access their human rights in health care (e.g., right to play, right to privacy and confidentiality, right to be heard, rights in mental health etc.).

- Recognising and tackling discrimination against children and specific groups of children.

All staff should be responsible for raising the awareness and understanding of all child service users, and their carers, of their human rights (See Table 7).

TABLE 7: Raising awareness and training on children's rights for staff

\begin{tabular}{|c|c|c|c|}
\hline $\begin{array}{l}\text { CRA } \\
\text { Principle }\end{array}$ & $\begin{array}{l}\text { Organisation } \\
\text { standard }\end{array}$ & $\begin{array}{l}\text { UNCRC } \\
\text { Article/General } \\
\text { Comment }\end{array}$ & Organisation Objective(s) \\
\hline Embedding & $\begin{array}{l}\text { Raise } \\
\text { awareness and } \\
\text { deliver training } \\
\text { on children's } \\
\text { rights }\end{array}$ & $\begin{array}{l}\text { Articles 1-42, } \\
\text { GC No. } 5 \text {, No. } \\
14 \text {, No. } 15 .\end{array}$ & $\begin{array}{l}\text { - Initial and on-going } \\
\text { evaluation of levels of } \\
\text { knowledge and } \\
\text { understanding of } \\
\text { children's rights amongst } \\
\text { staff at all levels has been } \\
\text { carried out. } \\
\text { - A communication plan for } \\
\text { staff has been developed } \\
\text { setting out how the health } \\
\text { authority intends to } \\
\text { develop awareness and } \\
\text { understanding of } \\
\text { implementing children's } \\
\text { rights. } \\
\text { - Training on children's } \\
\text { rights for all staff is }\end{array}$ \\
\hline
\end{tabular}




\begin{tabular}{|l|l|l|}
\hline \multirow{5}{*}{} & & $\begin{array}{l}\text { mandatory, with the } \\
\text { intensity of training }\end{array}$ \\
& & appropriate to context and \\
& role that a member of staff \\
& performs has been \\
& prioritised. \\
\hline
\end{tabular}

\subsubsection{Children's rights monitoring}

Children's rights monitoring should be consistently carried out against children's rights standards, including developing applicable children's rights indicators which are made relevant to policy or service areas. Children's rights monitoring should include:

in-depth analysis of the current situation in terms of health problems and responses, and the identification and implementation of evidence-informed interventions and policies that respond to key health determinants (in consultation with children when appropriate). ${ }^{906}$

Understanding the situation of children and young people in each service area is not a one-off process. It should be built up over time. It is first important to carry out an initial, and then a regular audit of all significant policy statements or other documents and budgets to make sure they comply with the UNCRC. Impact assessment of children's rights in any equality impact assessment (treating age as a protected characteristic), should be included where there is no separate procedure for a Children's Rights Impact Assessment (CRIA). As General Comment No. 14 makes clear, children should be involved in the proofing of all policy and budgets that have a direct or indirect impact on them, using a Children's Rights Impact Assessment ${ }^{907}$ or as part of an Equality Impact Assessment.

All health budgets should be transparent and demonstrate the proportion of expenditure on children and if spending is to the maximum extent of available

\footnotetext{
${ }^{906} \mathrm{UN}$ Committee on the Rights of the Child, General Comment No. 15 on the right of the child to the enjoyment of the highest attainable standard of health $\mathrm{CRC} / \mathrm{C} / 15 / 2013$ para 32

${ }^{907} \mathrm{UN}$ Committee on the Rights of the Child, General Comment No. 14 on the right of the child to have his or her best interests taken as a primary consideration $\mathrm{CRC} / \mathrm{C} / \mathrm{GC} / 14 / 2013$ para 99
} 
resources. ${ }^{908}$ All departments should be proofed for their compliance with the UNCRC, and not just Child Health Services because decisions about allocation of spending on adult health services impacts on the allocation of spending on child health. The health authority should take account of the impact of decisions on future generations, including any discriminatory impacts in all health policy decision making. ${ }^{909}$

Children's rights monitoring also involves mapping rights violations and includes an analysis of the underlying causes of the violations of children's human rights and the social determinants of health. Key questions to be asked could be:

- Which human rights are being violated or unfulfilled?

- Which groups of children are most affected by the problem?

- What are the causes (immediate, underlying, fundamental) of the human rights violations?

- Who has the obligation to do something about it?

- What capacities are required for those who have a duty to take action?

- How can we support children as rights holders to have the relevant capacities to claim their human rights? ${ }^{910}$

The General Comment No.15 also outlines the importance of collecting data on children's lives and of developing indicators that monitor and evaluate the implementation of children's right to health that supports the 'cyclical process of planning, implementation, monitoring and evaluation'. 911 Annual reports should be published on performance against children's rights indicators, and the findings disseminated widely. ${ }^{912}$ There should also be external monitoring of performance

\footnotetext{
${ }^{908}$ UN Committee on the Rights of the Child, General Comment No. 15 on the right of the child to the enjoyment of the highest attainable standard of health $\mathrm{CRC} / \mathrm{C} / 15 / 2013$ para 106

${ }^{909}$ Council of Europe, Child Friendly Guidelines to HealthCare (COE 2011) para 64

${ }^{910}$ Adapted from WHO and OHCHR, A human rights-based approach to health https://www.who.int/hhr/news/hrba to health2.pdf accessed January 2020.

${ }^{911}$ UN Committee on the Rights of the Child, General Comment No. 15 on the right of the child to the enjoyment of the highest attainable standard of health $\mathrm{CRC} / \mathrm{C} / 15 / 2013$ para 108

${ }^{912}$ UN Committee on the Rights of the Child, General Comment No. 5 General Measures of Implementation $\mathrm{CRC} / \mathrm{C} / \mathrm{GC} / 5 / 2003$ para 49
} 
against children's rights standards, including by involving children in monitoring and/or external review or inspection. ${ }^{913}$

Monitoring also includes ensuring that performance indicators are developed which reflect children's rights. Staff should understand their responsibilities and obligations to children by making this explicit in any strategic plans, policies governing the conduct of staff and service guidelines. ${ }^{914}$ Staff supervision and performance management should include individual responsibility for children's rights, including by use of individual performance indicators as appropriate (See Table 8).

TABLE 8: Children's rights monitoring

\begin{tabular}{|c|c|c|c|}
\hline $\begin{array}{l}\text { CRA } \\
\text { Principle }\end{array}$ & $\begin{array}{l}\text { Organisation } \\
\text { Standard }\end{array}$ & $\begin{array}{l}\text { UNCRC } \\
\text { Article/General } \\
\text { Comment }\end{array}$ & Organisation Objective(s) \\
\hline Accountability & $\begin{array}{l}\text { Undertake } \\
\text { children's } \\
\text { human rights } \\
\text { monitoring }\end{array}$ & $\begin{array}{l}\text { Articles 1-42, in } \\
\text { particular } \\
\text { Article } 2,3,4 \text {, } \\
12, \text { GC } 5,14 \\
\text { and } 15 \text {, and } \\
\text { AAAQ } \\
\text { Framework. }\end{array}$ & $\begin{array}{l}\text { - An initial and then regular } \\
\text { audit of all significant } \\
\text { policy statements or other } \\
\text { documents has been } \\
\text { carried out to assess } \\
\text { compliance with the } \\
\text { UNCRC. } \\
\text { - Annual reports are } \\
\text { published on performance } \\
\text { against children's rights } \\
\text { indicators and the } \\
\text { findings disseminated } \\
\text { widely. } \\
\text { There is external } \\
\text { monitoring of } \\
\text { performance against }\end{array}$ \\
\hline
\end{tabular}

${ }^{913}$ Article 3 (3) of the UN Convention on the Rights of the Child

${ }^{914}$ London L, 'What is a human rights based approach to health and does it matter? Health and Human rights' (2008) Vol. 10, no. 1 


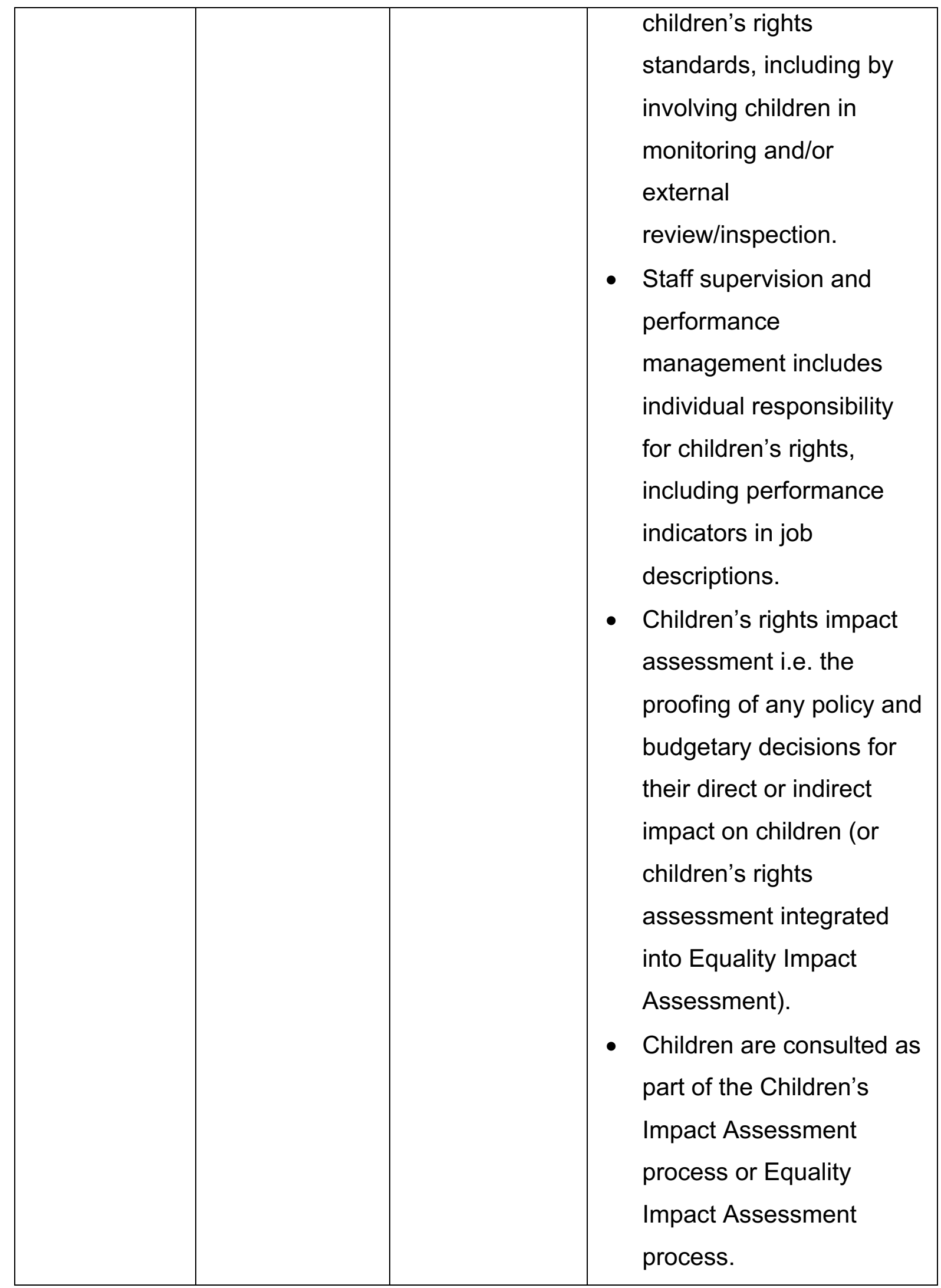




\subsubsection{Equality and non-discrimination to children throughout service delivery}

All staff should be delivering patient-centred care, which recognises not only the child's individuality, dignity and diverse circumstances and needs, but also those of his or her parents or carers. ${ }^{915}$ All staff should be made aware that discrimination (and have received training) can lead to unfair and unequal outcomes and should make the implications of discrimination against children widely understood by staff, service users and children themselves.

Relevant data should be collected, including disaggregated data, to enable identification of discrimination or inequalities in the realisation of children's rights to identify children who are being or may be discriminated against. Services and resources should be reviewed to identify barriers to children's access, including in collaboration with children as service users, in particular in relation to services to excluded/marginalised or disadvantaged social groups. ${ }^{916}$

Appropriate priorities, targets and programmes of action should then be developed to reduce discrimination against excluded, socially marginalised, disadvantaged and vulnerable groups and to promote equality for these groups. With reference to the General Comment No.15's AAAQ Framework:

- Health facilities, goods and services must be accessible to all children especially the most vulnerable or marginalized sections of the population, without discrimination on any grounds.

- Health facilities, goods and services must be within safe physical reach for all children.

- Health services, should be affordable for all, including socially disadvantaged groups of children.

\footnotetext{
${ }^{915}$ Council of Europe, Child Friendly Guidelines to HealthCare (COE 2011)

${ }^{916}$ UN Committee on the Rights of the Child, General Comment No. 15 on the right of the child to the enjoyment of the highest attainable standard of health $\mathrm{CRC} / \mathrm{C} / 15 / 2013$ paras 117-118
} 
- Health services must be culturally, age, disability and gender sensitive. ${ }^{917}$ (See Table 9)

TABLE 9: Equality and non-discrimination to children throughout service delivery

\begin{tabular}{|c|c|c|c|}
\hline $\begin{array}{l}\text { CRA } \\
\text { Principle }\end{array}$ & $\begin{array}{l}\text { Organisation } \\
\text { standard }\end{array}$ & $\begin{array}{l}\text { UNCRC } \\
\text { Article/General } \\
\text { Comment }\end{array}$ & Organisation Objective(s) \\
\hline $\begin{array}{l}\text { Equality and } \\
\text { Non- } \\
\text { Discrimination }\end{array}$ & $\begin{array}{l}\text { Equality and } \\
\text { non- } \\
\text { discrimination } \\
\text { to children } \\
\text { throughout } \\
\text { service } \\
\text { delivery }\end{array}$ & $\begin{array}{l}\text { Articles } 1-42 \text {, in } \\
\text { particular } \\
\text { Article } 2 \text { and } \\
24, \text { GC } 15 \text { and } \\
\text { AAAQ } \\
\text { Framework. }\end{array}$ & $\begin{array}{l}\text { Relevant data is collected, } \\
\text { including disaggregated } \\
\text { data, to enable } \\
\text { identification of } \\
\text { discrimination or } \\
\text { inequalities in the } \\
\text { realisation of children's } \\
\text { rights to identify children } \\
\text { who are being, or may be } \\
\text { discriminated against. } \\
\text { Services and resources } \\
\text { are reviewed to identify } \\
\text { barriers to children's } \\
\text { access, including in } \\
\text { collaboration with children } \\
\text { as service users, in } \\
\text { particular in relation to } \\
\text { services to } \\
\text { excluded/marginalised or } \\
\text { disadvantaged social } \\
\text { groups. } \\
\text { Appropriate priorities, } \\
\text { targets and programmes }\end{array}$ \\
\hline
\end{tabular}

${ }^{917}$ UN Committee on the Rights of the Child, General Comment No. 15 on the right of the child to the enjoyment of the highest attainable standard of health $\mathrm{CRC} / \mathrm{C} / 15 / 2013$ paras 112-116 drawn from the AAAQ Framework. 


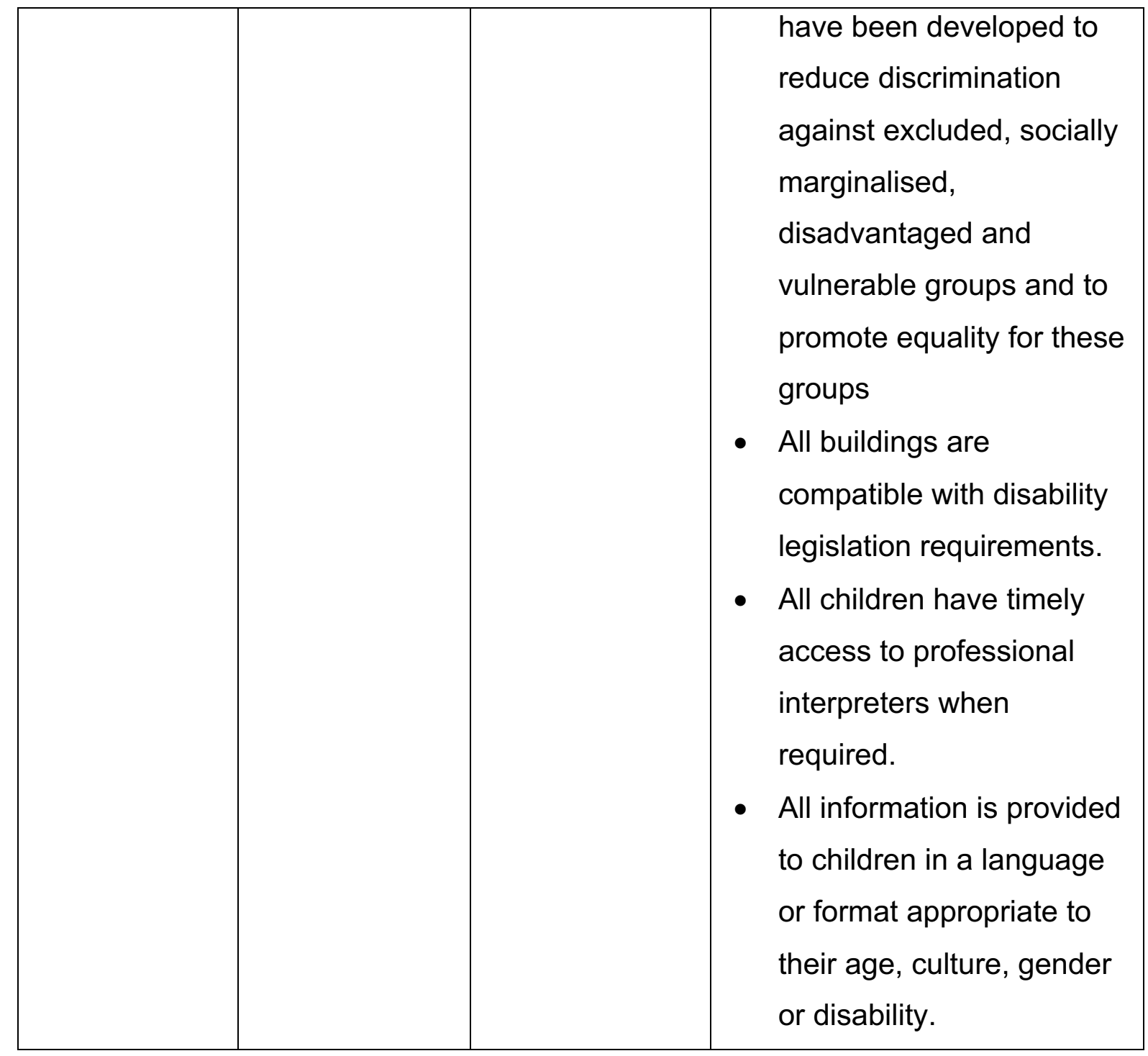

\subsubsection{Children can actively participate in decisions about their own health}

Children should be encouraged to exercise their right to be heard and make decisions about their health or condition, encouraged to express their views freely, to ask questions if they do not understand and their views should always be taken into account and given due weight (See Table 10). Such 'involvement is particularly important in the cases of long-term conditions so that children are fully prepared to play an active role in managing their condition'. ${ }^{918}$ All staff members should be made aware that there can be no correct application of the assessment of what is in the best interests of the child (Article 3 of the UNCRC) unless the components of Article 12 (the

${ }^{918}$ Council of Europe, Child Friendly Guidelines to HealthCare (COE 2011) para 35 
right to be heard) are respected. ${ }^{919}$ All children (and this should not be restricted to biological age) should be presumed capable and asked for their opinion and given opportunities to consent or refuse treatment. ${ }^{920}$ Children should feel that they are in a safe environment (Article 19 of the UNCRC) which supports them to participate in the decisions that affect them. They should also be able to participate in a manner which makes them feel comfortable, for example supporting younger children to engage through the medium of play. Also as emphasised above the training of health professionals in how they communicate with children is essential to achieving the principle and standard (See 6.4.3).

TABLE 10: Children can actively participate in decisions about their own health

\begin{tabular}{|c|c|c|c|}
\hline CRA Principle & $\begin{array}{l}\text { Organisation } \\
\text { Standard }\end{array}$ & $\begin{array}{l}\text { UNCRC } \\
\text { Article/General } \\
\text { Comment }\end{array}$ & Organisation Objective(s) \\
\hline $\begin{array}{l}\text { Participation of } \\
\text { children }\end{array}$ & $\begin{array}{l}\text { Children can } \\
\text { actively } \\
\text { participate in } \\
\text { decisions about } \\
\text { their own health }\end{array}$ & $\begin{array}{l}\text { Articles } 2,3,4 \\
5,6,12,13,14 \\
15,19,24, G C \\
12, \text { GC } 15, G C \\
20 .\end{array}$ & $\begin{array}{l}\text { - Children are encouraged } \\
\text { to exercise their right to } \\
\text { participate in the } \\
\text { decisions being made } \\
\text { about their health or } \\
\text { condition, encouraged to } \\
\text { express their views } \\
\text { freely, ask questions and } \\
\text { their views are given due } \\
\text { weight. }\end{array}$ \\
\hline
\end{tabular}

\subsubsection{Children should be directly involved in the development, monitoring and evaluation of service delivery}

Children and not just adults should be 'regularly engaged on what services are needed, how and where they are best provided, the quality and attitudes of health

\footnotetext{
${ }^{919} \mathrm{UN}$ Committee on the Rights of the Child, General Comment No. 12: The right of the child to be heard $\mathrm{CRC} / \mathrm{GC} / 12 / 2009$ para 74

${ }^{920}$ UN Committee on the Rights of the Child, General Comment No. 12: The right of the child to be heard CRC/GC/12/2009; UN Committee on the Rights of the Child, General Comment No. 15 on the right of the child to the enjoyment of the highest attainable standard of health $\mathrm{CRC} / \mathrm{C} / 15 / 2013$
} 
professionals, and other issues related to the improvement of healthcare services'. ${ }^{921}$ Children (and carers) should be given the opportunity to provide feedback on their experience after they have used services. 'Implementation will require the development of assessment of both patient-reported outcome and patient-reported experience and different methods of involving them in the process (individually and with peers).' ${ }^{922}$

Feedback should be consistently given to children and staff on the outcomes of children's involvement, proactively highlighting any changes and/or benefits brought about by their participation. ${ }^{923}$ Children according to Article 12 of the UNCRC should be involved in all decisions that affect them. This means that children should be involved in the recruitment of all staff who have responsibilities that impact on children. Children should also be given opportunities to act collectively to develop ideas and proposals, to take action and to influence decisions in accordance with Article 15 of the UNCRC (e.g., Youth Advisory Board).

TABLE 11: Children are directly involved in the development, monitoring and evaluation of service delivery

\begin{tabular}{|l|l|l|l|}
\hline CRA Principle & $\begin{array}{l}\text { Organisation } \\
\text { Standard }\end{array}$ & $\begin{array}{l}\text { UNCRC } \\
\text { Article/General } \\
\text { Comment }\end{array}$ & Organisation Objective(s) \\
\hline Participation & $\begin{array}{l}\text { Children should } \\
\text { be directly } \\
\text { involved in the } \\
\text { development, } \\
\text { monitoring and } \\
\text { evaluation of } \\
\text { service delivery }\end{array}$ & $\begin{array}{l}5,6,12,13,14,4,24, \mathrm{GC} 12, \\
\text { GC 15, GC 20. }\end{array}$ & $\begin{array}{l}\text { A process has been } \\
\text { established in all health } \\
\text { and act on } \text { Child Patient } \\
\text { Feedback. }\end{array}$ \\
& & $\begin{array}{l}\text { Children are involved in } \\
\text { the recruitment of staff }\end{array}$ \\
\hline
\end{tabular}

\footnotetext{
${ }^{921} \mathrm{UN}$ Committee on the Rights of the Child, General Comment No. 15 on the right of the child to the enjoyment of the highest attainable standard of health $\mathrm{CRC} / \mathrm{C} / 15 / 2013$, para 19

${ }_{922}$ Council of Europe, Child Friendly Guidelines to HealthCare (COE 2011) para 42 ii

${ }^{923} \mathrm{UN}$ Committee on the Rights of the Child, General Comment No. 12: The right of the child to be heard, $\mathrm{CRC} / \mathrm{GC} / 12 / 2009$ paras 30 and 45
} 


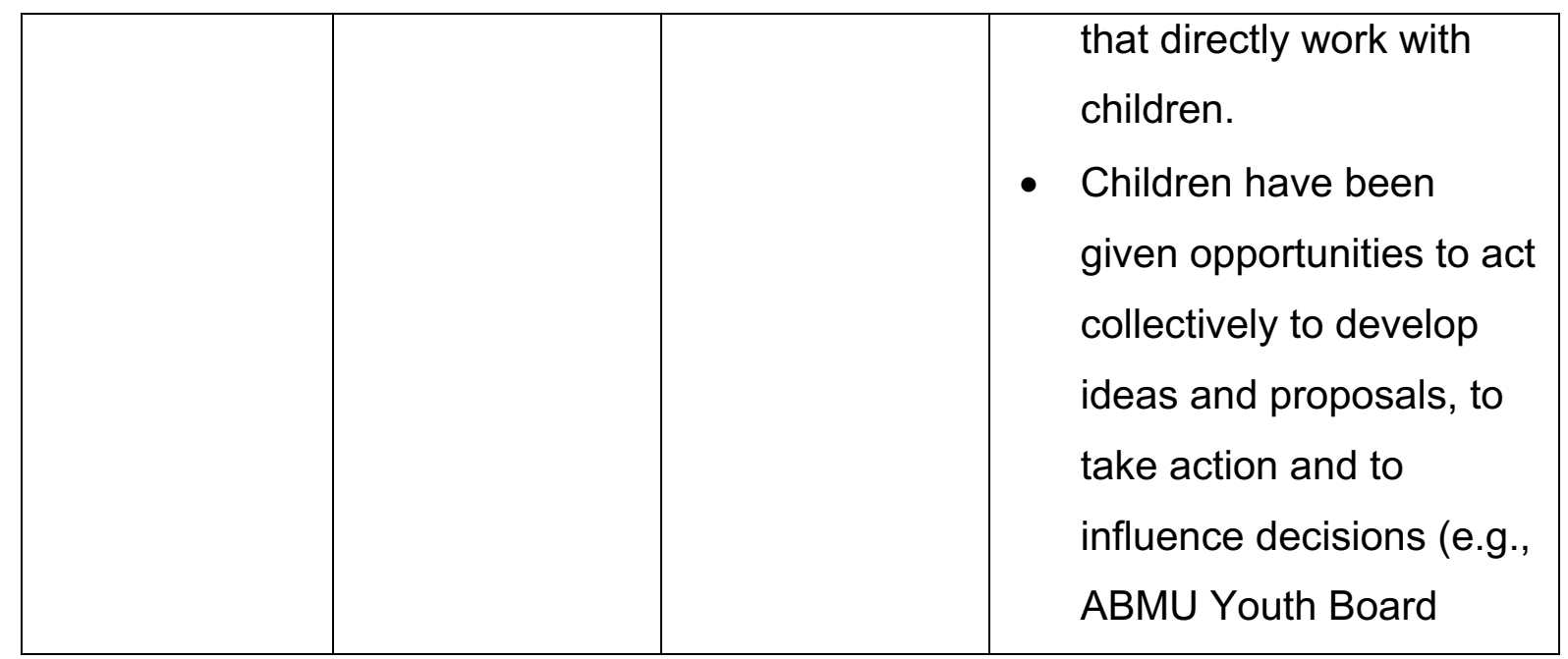

\subsubsection{Child friendly complaints mechanisms}

Children should be provided with accessible information on mechanisms and the process for making complaints, and for holding the authority, or individual staff, to account. This is recommended by General Comment No. 12: The child's right to be heard. ${ }^{924}$ Research suggests that children in health care contexts face multiple barriers to their right to complain. ${ }^{925}$ General Comment No.15 recommends that:

States to put in place functional and accessible complaints mechanisms for children that are community-based and render it possible for children to seek and obtain reparations when their right to health is violated or at risk. ${ }^{926}$

Good complaints systems help to ensure that services are accountable for their decisions and actions that affect children. They also provide evidence of where a service may have failed or offered inadequate support to a child. This can help progressive health authorities to reflect on their shortcomings and to strive to improve, responding to the needs of children. ${ }^{927}$ Children's complaints should always be investigated and addressed. Children should always be informed within a defined time period of the outcome of any investigation (See Table 12). Children should be

\footnotetext{
${ }^{924} \mathrm{UN}$ Committee on the Rights of the Child, General Comment No. 12: The right of the child to be heard, $\mathrm{CRC} / \mathrm{GC} / 12 / 2009$

${ }^{925}$ Children's Commissioner for England, Child Friendly Complaints Processes in Health Services, Principles, Pledges and Progress (Children's Commissioner for England 2013)

${ }^{926} \mathrm{UN}$ Committee on the Rights of the Child, General Comment No. 15 on the right of the child to the enjoyment of the highest attainable standard of health $\mathrm{CRC} / \mathrm{C} / 15 / 2013$ para 119

${ }^{927}$ Children's Commissioner for England, Child Friendly Complaints Processes in Health Services, Principles, Pledges and Progress
} 
empowered throughout the complaints process, according to their evolving capacities, to make autonomous decisions, claim their human rights and hold service providers to account. ${ }^{228}$

TABLE 12: A child friendly complaints mechanism

\begin{tabular}{|c|c|c|c|}
\hline $\begin{array}{l}\text { CRA } \\
\text { Principle }\end{array}$ & $\begin{array}{l}\text { Organisation } \\
\text { standard }\end{array}$ & $\begin{array}{l}\text { UNCRC } \\
\text { Article/General } \\
\text { Comment }\end{array}$ & Organisation Objective(s) \\
\hline $\begin{array}{l}\text { Empowering } \\
\text { the child }\end{array}$ & $\begin{array}{l}\text { Develop a } \\
\text { child-friendly } \\
\text { advice and } \\
\text { complaints } \\
\text { mechanism }\end{array}$ & $\begin{array}{l}\text { Articles 1-42, } \\
\text { GC No. 5, 12, } \\
15\end{array}$ & $\begin{array}{l}\text { Children and their carers } \\
\text { are provided with } \\
\text { accessible information on } \\
\text { the process for making } \\
\text { complaints, and for } \\
\text { holding the authority, or } \\
\text { individual staff, to } \\
\text { account. }\end{array}$ \\
\hline
\end{tabular}

\subsubsection{Health promotion, children's rights information and advocacy provided to all children and their carers}

Children should be given information about how they can stay healthy and take action to become healthy. Health promotion is referred to specifically in Article 24 (e) of the UNCRC which focuses on supporting parents and children to have basic knowledge on nutrition and child health. Children should be actively involved in any health promotion activities. There should be information made available to children in every service area. General Comment No.15 reinforces that information should be in a language and format with is age, gender, disability and culturally appropriate. ${ }^{929}$ Article 17 acknowledges the importance of information being made available in a variety of formats. Health promotion can cover a wide range of health issues, so numerous

\footnotetext{
${ }^{928}$ Developing jurisprudence of the General Comments, see in particular UN Committee on the Rights of the Child, General Comment No.20 on the implementation of the rights of the child during adolescence $\mathrm{CRC} / \mathrm{C} / \mathrm{GC} / 20 / 2016$, and Varadan S, 'The Principles of Evolving Capacities under the Convention on the Rights of the Child'. International Journal of Child Rights (2019) Volume 27 Issue 2

${ }^{929} \mathrm{UN}$ Committee on the Rights of the Child, General Comment No. 15 on the right of the child to the enjoyment of the highest attainable standard of health $\mathrm{CRC} / \mathrm{C} / 15 / 2013$, para $114 \mathrm{~d}$
} 
articles of the Convention could be applicable. The UN Committee summarises the importance of health promotion succinctly and recommends that:

Children require information and education on all aspects of health to enable them to make informed choices in relation to their lifestyle and access to health services. Information and life skills education should address a broad range of health issues, including: healthy eating and the promotion of physical activity, sports and recreation; accident and injury prevention; sanitation, hand washing and other personal hygiene practices; and the dangers of alcohol, tobacco and psychoactive substance use; understanding issues concerning mental health, sex education and healthy relationships. Information and education should encompass appropriate information about children's right to health, the obligations of health authorities, and how and where to access health information and services. Information and education should be provided as a core part of the school curriculum, as well as through health services and in other settings for children who are not in school. Materials providing information about health should be designed in collaboration with children and disseminated in a wide range of public settings. ${ }^{930}$

The UN Committee also recommends that health promotion is provided to parents or carers and the extended family that supports the child. ${ }^{931}$ Health promotion information should also include helping children to understand their right to health and the full range of their rights in health care settings. Children should also be provided with accessible information on how to access advice, such as advisory services, human rights advocacy services or professional legal advice (See Table 13).

\footnotetext{
${ }^{930}$ Ibid para 59

${ }^{931}$ Ibid para 61
} 
TABLE 13: Health promotion, children's rights information and advocacy is provided to children and their carers

\begin{tabular}{|c|c|c|c|}
\hline $\begin{array}{l}\text { CRA } \\
\text { Principle }\end{array}$ & $\begin{array}{l}\text { Organisation } \\
\text { standard }\end{array}$ & $\begin{array}{l}\text { UNCRC } \\
\text { Article/General } \\
\text { Comment }\end{array}$ & Organisation Objective(s) \\
\hline $\begin{array}{l}\text { Empowering } \\
\text { the child }\end{array}$ & $\begin{array}{l}\text { Health } \\
\text { promotion, } \\
\text { children's rights } \\
\text { information and } \\
\text { advocacy is } \\
\text { provided to } \\
\text { children and } \\
\text { their carers }\end{array}$ & $\begin{array}{l}\text { Articles } 2,3,5, \\
6,12,13,17, \\
24,28,29,42, \\
\text { GC } 12,15\end{array}$ & $\begin{array}{l}\text { Children and their carers } \\
\text { are able to access age, } \\
\text { gender, disability and } \\
\text { culturally appropriate } \\
\text { information about how to } \\
\text { stay healthy and how to } \\
\text { take action to become } \\
\text { healthy. } \\
\text { Children and their carers } \\
\text { are given information that } \\
\text { is age, gender, culture } \\
\text { and disability appropriate } \\
\text { regarding how to access } \\
\text { their rights in health care. } \\
\text { Materials providing } \\
\text { information about health } \\
\text { should be designed in } \\
\text { collaboration with } \\
\text { children. } \\
\text { Children and their carers } \\
\text { are provided with } \\
\text { accessible information on } \\
\text { how to access advice, } \\
\text { such as advisory } \\
\text { services, human rights } \\
\text { advocacy services or } \\
\text { professional legal advice. }\end{array}$ \\
\hline
\end{tabular}




\subsection{Conclusion}

In Part 2, the above conceptual framework will be used to test ABMU's institutional approach to implementing a CRA across their policies, practices and procedures. Using the five principles, the UNCRC and the organisational standards outlined above; a number of research objectives and research tools (to deliver this conceptual framework) will be developed to learn from strategic managers, health professionals and children themselves how far they are embedding such an approach. This is the first time that such research has been carried out in the Welsh context and using a principled CRA framework that has been developed based on a critical examination of the literature and the international human rights framework. The results of the primary research will present an original contribution to the field of knowledge because there is limited information regarding children's experience of accessing their human rights and service providers' perception of how far children's rights have been implemented in the health care environment. 


\section{PART 2}

\section{CHAPTER 7 DEVELOPMENT OF RESEARCH METHODS FOR TESTING THE CONCEPTUAL FRAMEWORK FOR A CRA TO HEALTH SERVICES AT ABERTAWE BRO MORGANNWG HEALTH BOARD}

\subsection{Introduction}

This chapter explains how a single organisation case study was designed, that was multi-phased and sequential, to test Abertawe Bro Morgannwg Health Board's (ABMU) institutional approach to implementing a CRA across their health services. In Part 1 of this thesis, a CRA conceptual framework was designed based on a critical examination of the literature and the international human rights framework to be used by health services. This conceptual framework is used as the platform to develop research questions and objectives that are integrated into the conceptual framework found in Section 7.10.

The first part of this chapter introduces ABMU health board and its work on children's rights. It then discusses the single organisation case study and considers the challenge of researcher insider-outsider postionality. The research methods and data analysis techniques are then introduced, with consideration given to the rigour, trustworthiness and integrity of the research and the challenges of seeking ethical approval to conduct the research on site at ABMU Health Services. The final section outlines the four surveys in more detail and presents the integrated conceptual framework.

\subsection{About ABMU Health Board}

Up until April 2019, ABMU was the largest health board in Wales and covered the regions of Swansea, Bridgend and Neath Port Talbot (See Diagram 1, Chapter 1). The research was conducted before Bridgend local authority area was merged into Cwm Taf health board in April 2019 and Swansea University Bay Health Board became a separate health authority. There were approximately 118,000 children and young people from birth to 18 years (2011 census) across the ABMU Health Board. 
Within the ABMU Health Board area children faced a number of heath inequalities:932

- The rate of low-birth-weight babies was 1.7 times higher in ABMU's most deprived communities compared to the least deprived communities. The ABM University Health Board area local authority rates were not significantly different from the Wales and England averages.

- In recent years Bridgend had seen the lowest reduction in teenage conceptions and across the ABM University Health Board a number of wards had rates significantly higher than the Welsh average.

- Breast feeding initiation rates in Wales and ABM University Health Board area remain low. There was a $29 \%$-point difference in breastfeeding initiation between mothers living in the least and most deprived areas.

- Across all three ABM University Health Board local authorities the percentage of overweight and obese children aged 4-5 years fell between 2011-2012 and 2013-2014.

- Consistent with other health boards across Wales, ABM University Health Board saw an increase in the uptake of routine vaccinations for children aged 1-5 years. However, the uptake of routine childhood vaccinations was lower in ABMU's most deprived communities.

- In ABM University Health Board nearly 1 in 5 children aged 3 years had at least one tooth affected by decay.

- In 2013-2014 around 4\% of ABM University Health Board area's children and young people aged 18 years and under were referred to social services with the largest number of children being referred in Neath Port Talbot.

- National studies indicate that over $50 \%$ of children in socially deprived areas may start school with impoverished speech, language and communication skills, and this was reflected locally across the ABMU area.

\subsubsection{ABMU's commitment to children's rights}

ABMU was the first health board in Wales in 2017 through its Charter on Children's Rights to express a strong commitment to complying with the UNCRC when delivering

\footnotetext{
${ }^{932}$ This information is drawn from ABMU's Children and Young Person's Strategy published in September 2017, 24-25
} 
its health services. This was inspired by a commitment to children's rights through discussions with the Chair of ABMU Health Board, Andrew Davies, had with Coordinator of the Observatory on Human Rights of Children, Professor Simon Hoffman, Swansea University. The programme of development of the Charter was led by Eirlys Thomas Head of Nursing and Children's Services at ABMU and supported by consecutive managers of the Neath Port Talbot Children's Rights Unit.

Due to senior level commitment to children's rights, Eirlys Thomas was tasked with the development of the Children's Rights Charter in 2014. Through a collaborative partnership led by the Observatory on Human Rights of Children, ABMU developed a working partnership with the Neath Port Talbot Children's Rights Unit, a charitable organisation supporting the promotion of children's rights in the Neath Port Talbot local authority area. ${ }^{933} \mathrm{~A}$ first draft of the Children's Rights Charter was launched for consultation at a conference in 2014. Thereafter, consultation with children across health services, youth councils, school councils, schools and tertiary colleges was conducted to make it a child friendly charter. Approximately 300 children were consulted on its development. The draft was changed based on the feedback from children and then signed off internally at ABMU.

Implementation of the Charter had already begun but the final Charter was launched in 2017. ${ }^{934}$ The Charter includes 10 health related guarantees that mirror, albeit through young people friendly language, rights that are included in the UNCRC. It is a challenge to reduce the UNCRC to fewer rights. However, the Charter successfully focuses on health-related guarantees that contribute to a CRA to health services that can be understood by young people and their caregivers. The language is not accessible to younger children. The 10 health guarantees are laid out below in the young people friendly version of the Charter. Each guarantee is demonstrated to correspond to Articles of the UNCRC. The intention is that the health board must seek to raise awareness of these identified guarantees with staff, child service users and

\footnotetext{
${ }^{933}$ Neath Port Talbot Children's Rights Unit is a project set by Neath Port Talbot local authority to help to ensure that children and young people's rights are respected and protected. The unit aims to make the UNCRC a reality for children, young people and their families living in Neath Port Talbot ${ }^{934}$ Information received on development of the Charter from discussions with Eirlys Thomas, Head of Nursing and Children's Services, ABMU.
} 
their caregivers and seek to comply with them. See the Charter below: NHS in Wales ABMU Children's Rights Charter ${ }^{935}$

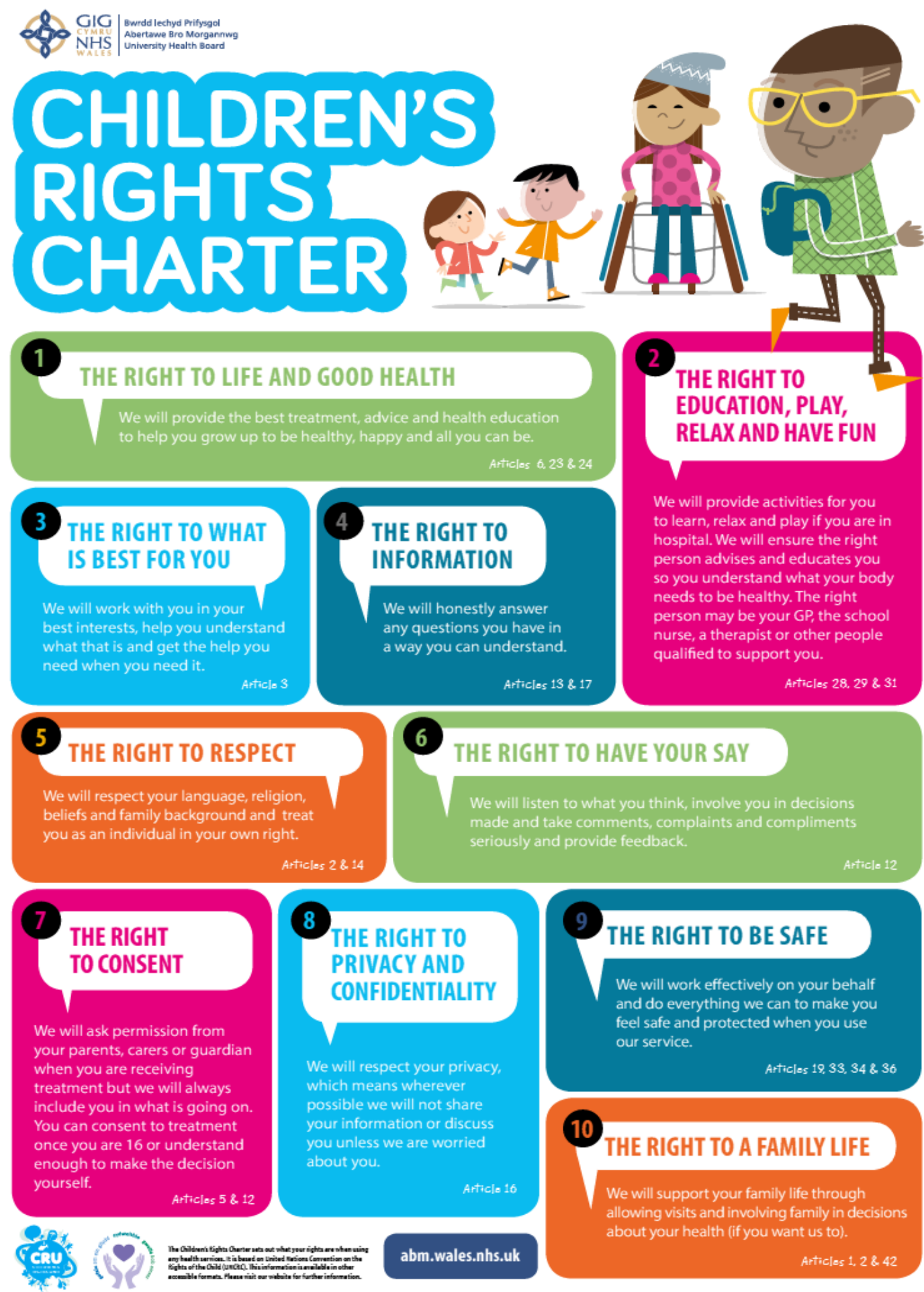

${ }^{935}$ NHS in Wales ABMU Children's Rights Charter

http://www.wales.nhs.uk/sitesplus/documents/863/Bilingual\%20Children\%27s\%20Rights\%20Charter.pdf 
ABMU through their charitable endowment fund the Neath Port Talbot Children's Rights Unit to support the ABM Youth Advisory Group and to fund the Unit Manager to deliver children's rights training to health professionals at $A B M U$. ABMU was the first health board in Wales to have a young people's advisory group to advise a health board from a young person's perspective. ABM Youth are one of the mechanisms in the authority for raising awareness of the Charter and supporting its implementation (discussed further in Chapter 9).

The funding for this $\mathrm{PhD}$ thesis, as outlined in the introduction, came from the same partners who were involved in the development of the Charter, i.e., ABMU, Observatory on the Human Rights of Children and Neath Port Talbot Children's Rights Unit. The PhD thesis was part funded by the ABMU endowment fund as well as the Hillary Rodham Clinton School of Law at Swansea University. The Neath Port Talbot Children's Rights Unit offered in kind supervisory support and advice. The research proposal and research methods were developed with the oversight of ABMU health services staff members, Neath Port Talbot Children's Rights Unit as well as academic supervisors.

\subsection{The research design: a single organisation case study}

As introduced in Chapter 1, the research methodology uses a case study as its strategy of inquiry. A case study can be described as:

a qualitative approach in which the investigator explores a real-life, contemporary, bounded system ... or multiple bounded systems ... through detailed, in-depth data collection involving multiple sources of information. ${ }^{936}$

The case study offers a bridge to understanding, dynamic and complex processes within an authentic setting, in this case a health authority. ${ }^{937}$ Butler describes the case study inquiry as being an effective research approach to acquiring new information

\footnotetext{
${ }^{936}$ Creswell J W, Qualitative inquiry and research design (3rd ed) (Thousand Oaks, CA: Sage Publications 2013) 97

${ }^{937}$ Butler D L, 'Investigating self-regulated learning using in-depth case study', In Zimmerman B J and Schunk D H (eds.), Handbook of self-regulation of learning and performance (346-360) (New York, NY: Routledge 2011)
} 
and to bridge theory and practice. ${ }^{938}$ It also offers the opportunity to 'study things in their natural settings, attempting to make sense of or interpret phenomena in terms of the meanings people bring to them.' ${ }^{939}$ Through multiple sources of evidence, it is an empirical interactive inquiry approach which aims to contribute rich descriptions of a bounded setting. 940 Sources of evidence should include descriptions of the relevant characteristics of the organisation and its participants, and the justification for their selection. ${ }^{941}$

As outlined in Chapter 1, the research paradigm was 'pragmatic', responding to the research questions that were requested to be investigated by the ABMU health authority and partners. The case study was designed to focus on ABMU's institutional policies and practice, intended to give effect to its commitment to deliver health services in accordance with a CRA. The primary research question, the health authority partners wanted to address was 'How far has a CRA been embedded in ABMU health services policies and practice?' The secondary research question asked, 'What strategies are required to make a CRA fully operational?' This evaluation of ABMU health services from a children's rights perspective was intended to be used as a baseline to assess progress and to flag up children's rights issues of concern that may require further in-depth research. The evaluation was also intended to be embedded by ABMU and delivered every 2 years to assess progress in the implementation of a CRA.

The research was targeted at secondary health services (out-patients, GPs, therapists etc) impacting on children in the ABMU health authority. It was decided to focus primarily on secondary services because to date there has been more research done in the hospital environment and less research with outpatients and children's experience of primary health care (See Diagram 2, Chapter 1 Three Tiers of Health

\footnotetext{
${ }^{938}$ Ibid

${ }^{939}$ Denzin N K and Lincoln Y S, Introduction: The discipline and practice of qualitative research, In Denzin NK and Lincoln Y S (eds.) The Sage handbook of qualitative research (4th ed 1-20)

(Thousand Oaks, CA: Sage Publications 2011) 3

${ }^{940}$ Merriam S B, 'Qualitative research: A guide to design and implementation. Revised and expanded from qualitative research', Practical Assessment, Research \& Evaluation, Vol 25 No 2 2009; Yin R K, Case study research: Designs and methods (5th ed) (Thousand Oaks, CA: Sage Publications 2014)

${ }^{941}$ Duran R P, Eisenhart M A, Erickson F D, Grant C A, Green J L, Hedges L V, Schneider B L, 'Standards for reporting on empirical social science research in AERA publications', American Educational Research Association. Educational Researcher, 2006 35(6), 33-40
} 
Services). It also reflected concerns in Part 1 that there was less resource and specialist support for paediatrics in secondary services.

Although, the original aim was to collect data that could be inferred into the wider population, through the course of implementing the research, it became evident, that this scale of data collection was not possible with the limited resources that health partners had at their disposal. So, the research uses, as Brewer describes a multimethod approach that does some quantitative analysis via four surveys in the form of descriptive statistics, supported by evidence from qualitative data generated from open ended responses. ${ }^{942}$

The research is primarily qualitative in orientation, supporting evidence from multiple realities from the researcher and participants. ${ }^{943}$ The meaning of the participant's experiences that were time and context dependent were captured to understand what was particular to the health authority between December 2018 and April 2019. The participants and the researcher can be seen to construct meaning from personal experiences, defining both what is known and what can be considered to be true..$^{944}$ The participants voices are represented wherever possible verbatim. ${ }^{945}$ It is however, important to acknowledge that it is the researcher who acts as the 'prime filter and interpreter' ${ }^{946}$, being most intimately involved in the data analysis. As Drisko comments the researcher aims to translate 'experiences and understandings across different social groups. ${ }^{947}$ The researcher interprets surroundings and the social situation goes through a process of metamorphosis, the social reality takes on a different meaning, from observation, to the researcher's mind to written text. ${ }^{948}$ Bourdieu argues that we

\footnotetext{
${ }^{942}$ Brewer J and Hunter A, Multi-method Research: A Synthesis of Styles (London: Sage 1998)

${ }^{943}$ Denzin N K and Lincoln Y S, Introduction: The discipline and practice of qualitative research. In

K. Denzin NK and Lincoln Y S (eds.) The Sage handbook of qualitative research (4th ed 1-20) (Thousand Oaks, CA: Sage Publications 2011) 3

${ }^{944}$ Peel K L, 'A beginner's guide to applied educational research using thematic analysis'. Practical Assessment, Research \& Evaluation 2020 25(2)

${ }^{945}$ Slevin E, 'Enhancing the truthfulness, consistency, and transferability of a qualitative study: using a manifold of two approaches', Nurse Res 2002; 7:79-197.

${ }^{946}$ Goodwin W L and Goodwin L D, Understanding quantitative and qualitative research in early childhood education (New York, NY: Teachers College Press 1996) 111

${ }^{947}$ Drisko J W, 'Constructivist research in social work', In A. E. Fortune, Reid W J and Miller R L (eds) Qualitative research in social work (pp. 81-106) (New York, NY: Columbia University Press 2013) 85

${ }^{948}$ Bourdieu P, Language and Symbolic Power (Harvard University Press 1991)
} 
must be aware that when we textualise data the process of transformation and translation must be seen to be subjective interpretations that objectify social situations and fix actions in time and space. ${ }^{949}$ Following this logic, while it may not be possible to discover 'the truth' the researcher can at least seek to understand (albeit imperfectly and from a particular perspective) how social institutions work and how people, in a specific place and time, interact with those institutions both individually and collectively. ${ }^{950}$ As Peel argues:

Therefore, the conclusions, subjective through their construction and interpretation, include multiple perspectives such as existing knowledge, the voices of the participants, the researcher's standpoint and the readers' constructions as the personal meaning makers. By acknowledging that all knowledge is interrelated and value-laden, rather than being objective truths, researchers can provide a comprehensive account of the issue of investigation relative to their perspective. ${ }^{951}$

It must be acknowledged that my background experiences, beliefs and values will inevitably have biased the selection of the research questions and the conceptual foundation of the inquiry as well as the findings. I view children through a children's rights lens biased by my long history of activism and professional experience in children's rights. It is also important to acknowledge that children as well as other key stakeholders in this research project, were seen as social actors, with their own understandings, motivations and ideas. ${ }^{952}$ Children were viewed as Lundy promotes, as active agents and not through the lens of 'pity' or 'protection'. ${ }^{553}$ However, as acknowledged in Chapter 6, it is also necessary to understand that the research was conducted within a social world that so often defines childhood as a time of dependency and protection and children as 'not-yet-citizens'. ${ }^{954}$

\footnotetext{
${ }^{949}$ Ibid

${ }^{950}$ Ibid

${ }^{951}$ Peel K L, 'A beginner's guide to applied educational research using thematic analysis. Practical Assessment', Research \& Evaluation 2020 25(2) 4

${ }_{952}$ Mason J and Hood S, 'Exploring issues of children as social actors in research', Children and Youth Services Review, Volume 33, Issue 4, April 2011, 490-49

${ }^{953}$ Lundy L, 'A Lexicon for Research on International Children's Rights in Troubled Times', International Journal of Children's Rights. Volume 27 Issue 42019

${ }^{954}$ Holland S, Renold E, Ross N, Hillman A, Rights 'right on' or the right thing to do? A critical exploration of young people's engagement in participative social work research (Cardiff University
} 


\subsection{Insider - outsider positioning}

Qualitative research usually involves a close relationship between the participants and the researcher. ${ }^{955} \mathrm{As}$ a researcher, I developed a close relationship with my immediate health partners, who offered a gateway to understanding the health authority context and a gateway to undertaking the primary field research. Over the three-year period I held regular meetings with the Head of Nursing and Children's Services, the Patient Experience Coordinator at ABMU and the Manager of the Neath Port Talbot Children's Rights Unit. I also met with other practitioners and managers in ABMU and attended ABMU Children's Strategy Group quarterly meetings. ${ }^{956}$ Additionally, ABM Youth were involved in overseeing the element of the research that was conducted with children and young people. Having a relationship with health partners from the outset of the research certainly had its benefits. ${ }^{957}$ This relationship supported opportunities to access rich information to develop understanding of how far the health authority was embedding a CRA, and to support the development of the research questions and methods.

In terms of my positionality to the research, I could be deemed an outsider to the health services context, as firstly I am not a health practitioner and secondly, I did not work for the health authority. However, my positioning as an outsider diminished over time, through regularly meeting with health colleagues, learning about and sharing their frustrations regarding implementing a CRA, developed my understanding of health services. Rapport and trust also developed because of a shared commitment to progressing a CRA. This could have the perceived disadvantage of becoming too close to the research topic inhibiting so called objectivity. ${ }^{958}$ If one is firmly positioned

ESRC Centre for Research Methods 2008) Webb E, 'An exploration of the discrimination-rights dynamic', In Invernizzi A and Williams J (eds) The Human Rights of Children: From Visions to Implementation (Farnham: Ashgate 2011) 292; Mayall B, 'The sociology of childhood in relation to children's rights', The International Journal of Children's Rights 8: 243-259, (2000)

${ }^{955}$ Corbin Dwyer S and Buckle J L, 'The Space Between: On Being an Insider-Outsider in Qualitative Research', Sage Journals, March 1, 2009

${ }^{956}$ Abertawe Bro Morgannwg Health Board, Annual Quality Statement 2018 (ABMU 2018) 28

These were multi-agency meetings attended by managers and practitioners whose work impacted on children in the ABMU Health Board Area from across the statutory and third sector.

${ }_{957}$ Clark A, Understanding Research with Children and Young People (Published in association with The Open University 2013) 8

${ }_{958}$ Brannick T and Coghlan D, 'In Defense of Being "Native": The Case for Insider Academic Research', Sage Journals, January 12007 
as an outsider, Hellawell argues, that a researcher is able to be more objective and critical. ${ }^{959}$ An outsider is able to challenge the biases or false beliefs the inside group may possess. ${ }^{960}$ However, building trust and rapport, supported opportunities to meet regularly with health partners, be a part of health authority meetings and ultimately secure a commitment to the research progressing and not floundering over the threeyear period.

Becoming more of an insider enables the researcher to access information the outsider finds difficult to obtain. ${ }^{961}$ The strength of the relationship ensured that even with consistent obstacles and delays to the field research (discussed in Section 7.8) health staff did not lose commitment to the research project. Becoming more of an insider enabled me to formulate relevant questions and develop research methods, most pertinent and pragmatic to meeting the challenges of the health services context. Woods suggests that 'familiarity and empathy mixed with a sense of alienation or distancing provides the ideal situation for the researcher to engage with participants'. ${ }^{962}$ Hellawell refers to an in-between relationship ${ }^{963}$ and as Woods explains researchers:

may slide between facets of insiderness and outsiderness as the situation itself changes, participants change, the project itself evolves or the researchers own life experiences change. ${ }^{964}$

Woods comments that the literature is dichotomous regarding the insider outsider perspective. ${ }^{965}$ However, as with my ontological standpoint (referred to in Chapter 1) it

\footnotetext{
${ }^{959}$ Hellawell D, 'Inside-out: Analysis of the insider-outsider concept as a heuristic device to develop reflexivity in students doing qualitative research', Teaching in Higher Education, 11(4) 2006: 483494.

${ }^{960}$ Corbin Dwyer S and Buckle J L, 'The Space Between: On Being an Insider-Outsider in Qualitative Research', Sage Journals, March 1, 2009

${ }^{961}$ Woods H, Examining the implications of Insider- Outsider Positioning. Published by Heather W June 2019, https://heatherawoods.ca/research/examining-the-implications-of-insider-outsiderpositioning/ accessed December 2020

962 Ibid

${ }^{963}$ Hellawell D, 'Inside-out: Analysis of the insider-outsider concept as a heuristic device to develop reflexivity in students doing qualitative research', Teaching in Higher Education, 11(4) 2006: 483494.

${ }^{964}$ Woods H, Examining the implications of Insider- Outsider Positioning. Published by Heather W June 2019, https://heatherawoods.ca/research/examining-the-implications-of-insider-outsiderpositioning/ accessed December 2020

${ }^{965}$ Ibid
} 
was accepted that there is a fluid interplay between the two perspectives. As a researcher, I could never be a complete insider and due to my increasing familiarity with the health partners and the research topic, I could never be a complete outsider. Recognising my 'in between' or fluid relationship, helped me to be more reflexive and acknowledge my own biases when reporting the findings, enhancing the rigour of the research..$^{966}$

As the principal researcher, working with a team of health practitioners who could be interpreted as insiders, I was the person in the middle, the 'in between'967and this approach or model of working is one that has been reflected on elsewhere. Thomas et al conclude that teams that include members from both inside and outside organisations can make valuable contributions. ${ }^{968}$ The diverse range of experience and perspectives that contributed to this study also enhanced the trustworthiness of the findings (further discussed in Section 7.8).

\subsection{Introduction to research methods}

\subsubsection{Surveys chosen as the method of analysis}

To answer the research questions, surveys were designed to be carried out with Strategic Leads (ABMU Executive and Non-Executive Members) health professionals and child patients (7-17 years). The questions in the surveys were based on evidence collated in Part 1 of the thesis and aligned to the Conceptual Framework in Chapter 6. The questions are thus derived from the 5 principles of a CRA, standards and objectives of a CRA, the ABMU Charter and ultimately, all grounded in the UNCRC. The questions are included in an integrated conceptual framework that can be seen at the end of this Chapter in Section 7.10

The four stakeholder groups, Strategic Leads, Health Professionals, Young People and Children, were selected to gain the perspectives of the stakeholders most

\footnotetext{
${ }^{966}$ Berger R, 'Now I see it, now I don't: Researcher's position and reflexivity in qualitative research', Qualitative Research, 15(2), 2013 219-234.

${ }^{967}$ Hellawell D, 'Inside-out: Analysis of the insider-outsider concept as a heuristic device to develop reflexivity in students doing qualitative research', Teaching in Higher Education, 11(4) 2006: 483494.

${ }^{968}$ Thomas M D et al, 'Utilising insider-outsider research teams in qualitative research,' Qualitative Health Research 2000 Nov.
} 
impacted by the delivery of health services. The multiple perspectives were compared and contrasted to determine areas of agreement as well as areas of divergence. The benefit of this approach is:

increasing confidence in research data, creating innovative ways of understanding a phenomenon, revealing unique findings, challenging or integrating theories, and providing a clearer understanding of the problem. ${ }^{969}$

Triangulation of the data also supports reducing researcher subjectivity and bias as the data is interrogated from a number of different perspectives. However, as was earlier acknowledged, it is impossible to completely eliminate the researcher's voice. There was a need for continuous reflexivity and an acknowledgment that the researcher is a part of the process of discovering meaning.

Surveys were chosen as the method of analysis to continue with the pragmatic approach' of responding to the needs and requirements of the health board, who wanted non-resource intensive methods that could be 'picked up off the shelf' and used again by the health authority in the future. It is important to acknowledge the limitations of surveys, recognising that respondents will not always report their attitudes or beliefs correctly, either because of bias or because of their own internal characteristics. ${ }^{970}$ Respondents may also misinterpret questions or respondents may not treat responding to the questions seriously. ${ }^{971}$ With regards to children, even if they do not know the answer they may still respond to the question. There are biases such as the impact of the context, social desirability and acquiescence bias. ${ }^{972}$

However, surveys can provide a straightforward and standardised approach to the study of attitudes, values, beliefs and motives. ${ }^{973}$ They also are one of the easiest ways of retrieving information from a large set of people, and are efficient at providing a lot

\footnotetext{
${ }^{969}$ Thurmond V A, 'The point of triangulation', The Journal of Nursing Scholarship (2001) Volume 33 Issue 3, 254

${ }^{970}$ Robson C, Real World Research (2 ${ }^{\text {nd }}$ Edn) (Blackwell Publishing 2002).

${ }^{971}$ Ibid

${ }^{972}$ Scott J, 'Children as Respondents. The Challenge for Quantitative Methods', In P. Christensen and A. James (eds) Research with Children. Perspectives and Practices, 98-119 (London: Routledge Falmer 2000).

${ }^{973}$ Ibid
} 
of data, in a short period of time, at low cost. ${ }^{974}$ Hill argues, that children also may find it easier to respond to surveys independently, rather than face to face with a stranger. ${ }^{975}$ To enrich the data, open ended questions were added throughout all the surveys, to increase opportunities for 'thick descriptions' ${ }^{976}$ and illustrative examples were collated from the individual responses to questionnaires.

An in-depth ethnography or semi-structured interviews may have added more nuance and richer qualitative data, but these were considered more complex methods, that required more in-depth training of health staff, more time and indeed resources. If there was a dedicated children's rights researcher role, this kind of in-depth research may be possible in the future. However, to serve the purposes of embedding a nonresource intensive method that health staff could deliver, surveys were deemed to be more accessible, and to yield more information quickly across the four stakeholder groups.

It had been hoped to conduct the research questions with Strategic Leads collectively as a focus group, however this was met with resistance due to time pressures and the Strategic Leads finding the time in diaries to meet together as a group. The Strategic Leads expressed that they preferred to respond to the questions via individual online surveys. For consistency, an online survey approach was also considered most practical for health professionals. Finally, it was understood to be too challenging to bring together a cross section of child out-patients as a focus group and the health partners wanted to capture the children's individual perspectives wherever possible, immediately after their appointments.

The adult participants contributing to data collection were not deemed vulnerable and were participating in their capacity as strategic leads/professionals, however consideration was given to the time taken to participate in the research and this is one of the reasons non-resource intensive methods were designed. The online surveys were designed to be quick to respond to, neither survey exceeding 10 minutes, to

\footnotetext{
${ }^{974}$ Ibid

${ }^{975}$ Hill M, 'Research Review: Participatory research with children', Child and Family Social Work 2: 1997 171-183

${ }^{976}$ Geertz C, Thick description: Toward an interpretive theory of culture. In The interpretation of cultures: Selected essays, 3-30 (New York: NY: Basic Books 1973)
} 
ensure that the burden on the strategic leads/health professional's time was minimal. Likewise, the children and young people's surveys were quick and simple to respond to and did not exceed eight minutes. Any risks to child research participants and ethical issues were considered and outlined in Section 7.9.

The online surveys were designed using Survey Monkey and were handed over to ABMU Head of Nursing and Children's Services. I only had access to secondary anonymous data from both staff and children so did not have direct contact with either staff or children. To support a process of embedding a CRA and the research becoming a two-yearly commitment to monitor progress, the intention was that ABMU staff would take responsibility for the administering of the children and young people surveys on site at health services. The surveys with children and young people were intended to be delivered as part of the ongoing child-patient satisfaction programme that was delivered by ABMU to learn about child patient experience of ABMU's health services.

\subsubsection{Children and young people's surveys}

The reason that children were asked for their perspective was because they are the group most impacted by whether ABMU were successfully delivering a CRA to their service delivery and are the experts on how services can be improved from a children and young person's perspective. As Scott explains:

the best people to provide information about the child's perspective, actions and attitudes are the children themselves. Children provide reliable responses if questioned about events that are meaningful to their lives. ${ }^{977}$

As reiterated throughout Part 1 this is also a requirement of Article 12 of the UNCRC and a standard of the CRA. ${ }^{978}$

\footnotetext{
${ }^{977}$ Scott J, 'Children are respondents: The Challenge for Quantitative Methods' In, (eds) Christensen $\mathrm{P}$, and James A, Research with Children: Perspectives and Practices $\left(2^{\text {nd }}\right.$ edn Routledge London and New York 2008) 88

${ }^{978}$ UN Committee on the Rights of the Child, General Comment No. 15 on the right of the child to the enjoyment of the highest attainable standard of health $\mathrm{CRC} / \mathrm{C} / 15 / 2013$
} 
ABM Youth were involved in the design of the children and young people's surveys. Due to constraints of time, ethical challenges and limitations of staff research skills, (see Section 7.8) it was not possible to conduct a study that involved children in all aspects of the research, including data generation and overall research design. This could be regarded as a limitation to the research process, as others have argued for research to be truly children's rights based, that children be empowered to coproduce the research from the start of the process. As Charles and Haines argue 'young people should be active in the research process and integrally involved, not just as participants, but as designers and leaders'. ${ }^{979}$ Larkin et al also comment that for the children's rights research community to have a strong contribution to achieve influence through their actions; there is an imperative need to start from children's self-identified concerns and then identify the relevant range of moral, legal, political or economic rights that may provide resources for their activism. ${ }^{980}$ Quennerstedt comments that:
'Instead of prioritising the universal and a top-down approach in research, where the urgent research questions spring from universal claims, the opposite position is taken, priority is given to context, particularity and a bottom-up approach.'981

Additionally, in academic research, both the substantive and procedural requirements of the Convention have stimulated increased use of methods which involve children as active participants or co-producers. ${ }^{982}$ There is debate about whether academic research 'on' children should now normally be done 'with' or even 'by' children.983

\footnotetext{
${ }^{979}$ Charles A \& Haines K, 'Engaging young people as partners for change: The UR Community project', International Journal of Children's Rights, 2019 27, 7

980 Larkins C, Thomas N, Carter B, Farrelly J, Judd D, Beatrice D and Lloyd J,

'Support for Children's Protagonism: Methodological Moves towards Critical Children Rights

Research Framed from Below', International Journal of Children's Rights 201523 (2) 34

${ }^{981}$ Quennerstedt A, 'Children's Rights Research Moving into the Future - Challenges on the Way Forward', The International Journal of Children's Rights 2013 21(2), 244

982 Boyden, J and Ennew J, Children in Focus - a manual for participatory action research with children, (Radda Barnen, Swedish Save the Children, Stockholm 1997); Kirby P, Involving children in research, In The New Handbook of Children's Rights: Comparative Policy and Practice, Franklin B (ed.) (London: Routledge 2002)

${ }_{983}$ Chae-Young K, Sheehy K, Kerawalla L, Developing children as researchers: A practical guide to help children do social research (London: Routledge 2017)
} 
Researching 'with' or 'by' rather than 'on' children is seen as supportive of implementation of children's rights. ${ }^{984}$

More and more, children are involved in different elements of the research process, from designing the methodology, to development of research questions, analysis of data and writing of recommendations. ${ }^{985}$ In this study, due to the challenges of gaining ethical approval (See section 7.8) as well as the limitations of time, funding, and health partners' research skills, young people were only involved in the development of questions for the children and young people surveys. This may be considered a limitation of the research and contrary to my ontological perspective that children as social actors and rights holders should be integrally involved. However, as well as young people being involved in the development of questions for the children and young people surveys, wherever possible children and young people's voices were captured verbatim in the discussion of findings (Chapter 9) to try to give authenticity to their perspective. Furthermore, it may be considered a strength, that as the principal researcher, my own voice, presented a consistency of interpretation from research design to research questions, to data analysis of the four surveys, and write up of reflections and recommendations. ${ }^{986}$

The surveys asked the children and young people questions that were directly about their experience of visiting a health professional. As Scott suggests it is best to ask children questions that are relevant and relate to their own experiences. ${ }^{987}$ Morgan et al comment children will only respond with limited responses to questions that are not pertinent to them. ${ }^{988}$ It was decided to have two surveys for children, one for 7-12 year

\footnotetext{
${ }^{984}$ Beazley H, Bessell S, Ennew J \& Waterson R. 'The right to be properly researched: research with children in a messy, real world' Children's Geographies 2009, 7:4, 365-378; Kellett M, Small Shoes, 'Big Steps! Empowering Children as Active Researchers', Journal of Community Psychology 2010 Vo1.46. Issue 1-2; Lundy L, McEvoy L, \& Byrne B, 'Working With Young Children as CoResearchers: An Approach Informed by the United Nations Convention on the Rights of the Child', Early Education and Development, 2011 22(5), 714-736

${ }^{985}$ Coad J and Evans R, 'Reflections on Practical Approaches to Involving Children and Young People in the Data Analysis Process', Children and Society 2008 22(1): 41-5

${ }^{986}$ Goodwin W L and Goodwin L D, Understanding quantitative and qualitative research in early childhood education (New York, NY: Teachers College Press 1996) 111

${ }^{987}$ Scott J, 'Children as Respondents. The Challenge for Quantitative Methods', In Christensen P and James A (eds) Research with Children. Perspectives and Practices, 98-119 (London: Routledge Falmer 2000)

${ }^{988}$ Morgan M, Gibbs S, Maxwell K, and Britten N, 'Hearing children's voices: methodological issues in conducting focus groups with children aged 7-11 years', Qualitative Research 2002 2(5): 5-20
} 
olds and one for 13-17 year olds. This was based on a similar approach undertaken by the international SEMT study (as discussed in Chapter 4) designed to support the presumed developmental capacity and needs of both age groups. The lower age threshold at age 7 was selected as it corresponded with the age in Wales that children transition into Key Stage 2 of their school education. It was considered that any younger that children may struggle to read and understand the questions. This was supported by research undertaken by de Leeuw who explains that:

Below the age of 7 years children do not have sufficient cognitive skills, to be effectively and systematically questioned. The age of 7 is a major development point, in the cognitive and social maturation of the child, and with care children can be interviewed, with structured questionnaires and complete self-reports, from 7 years onwards, depending on their development. . $^{989}$

The young person's survey with the lower age threshold of 13 years was selected to support a process of independent consent to participate which was based on detailed research and through discussions with the partner health professionals at ABMU (The challenges of securing independent consent of young people to participate in the research warranted an additional chapter to the thesis, please see Chapter 8).

The draft surveys drew learning from the templates of the SEMT surveys but were fundamentally based on ABMU's own Children's Rights Charter and the five principles, standards and objectives of a CRA. The surveys went through several drafts and the young people ABM Youth representatives had several opportunities to meet and collectively discuss the questions and to make suggested amendments. The young people were adamant that the surveys should be reduced in size as much as possible, in particular for the younger age group. Consequently, they are shorter in length than the original SEMT surveys. The young people were concerned that children and young

\footnotetext{
989 de Leeuw E D, Improving data quality when surveying children and adolescents cognitive social development and its role in questionnaire construction and pre-testing (Report prepared for the annual meeting of the academy of Finland: Research Programmes, Public Health Challenges and Health and Welfare of Children and Young People 2011)
} 
people would lose interest if the surveys were too long in length. As Mauthner ${ }^{990}$ argues it may be unsuitable to ask too many questions and as Alderson advises it is important to not use words that are too complex or words that are oversimplified that reduce children to trivial responses. ${ }^{991}$ The young people's amendments were accepted and integrated into the final surveys.

Due to the challenges of resources, time and limitations of health partner's research skills, children under the age of 7 years were not selected for the study. As outlined above, a self-complete survey would not have been an appropriate research method ${ }^{992}$ 993, for children under the age of 7 years and it is advised that a participatory research method is designed for this age group for future research. Children over the age of 17 years were not included in the study because the UNCRC is only applicable to children under the age of 18 years and this international treaty was chosen to underpin the conceptual framework and indeed underpins ABMU's Children's Rights Charter and national policy and legislation for children in Wales.

\subsection{Data analysis}

Using the conceptual framework, as the interpretative frame of analysis, descriptive statistics were reported on against the standards of a CRA which presented a snapshot of how the health authority was progressing as perceived by the four groups of stakeholders during December 2018 - April 2019. The descriptive statistics were analysed using the Survey Monkey software package.

The data generated from research participant's additional comments and responses to open-ended questions across all four surveys was analysed manually using

\footnotetext{
${ }^{990}$ Mauthner M, 'Methodological Aspects of Collecting Data from Children: Lessons from Three Research Projects', Children \& Society 1997 11: 16-28

${ }^{991}$ Alderson P, 'Children as Researchers. The Effects of Participatory Rights on Research Methodology', In Christensen P and James A (eds) Research with Children. Perspectives and Practices, 241-257. (London: Routledge Falmer 2000)

${ }^{992}$ Scott J, 'Children are respondents: The Challenge for Quantitative Methods', In (eds) Christensen $\mathrm{P}$, and James A, Research with Children: Perspectives and Practices $\left(2^{\text {nd }}\right.$ edn Routledge London and New York 2008)

${ }^{993}$ de Leeuw E D, Improving data quality when surveying children and adolescents cognitive social development and its role in questionnaire construction and pre-testing (Report prepared for the annual meeting of the academy of Finland: Research Programmes, Public Health Challenges and Health and Welfare of Children and Young People 2011)
} 
thematic analysis. Thematic analysis is one of the most common forms of analysis in qualitative research. It focuses on examining, and recording 'themes' within data. ${ }^{994}$ Themes are essentially patterns identified across data that are important to the description of a phenomenon and are associated to a specific research question. ${ }^{995}$ Braun and Clarke's method of thematic analysis provided the required flexibility, complexity and structure to scrutinise comprehensively and to interpret systematically the themes coming from the qualitative data. ${ }^{996}$ The approach also supported moving between the concrete descriptions informed by the data and the interpretations informed by the literature reviewed in Part 1.997 Following Braun and Clark's approach to data analysis the steps taken were:

Step 1 - Data familiarisation: generating an initial understanding of the data set as a whole across the four surveys, searching for patterns, making initial notes to how they interrelated, complemented or indeed challenged each other.

Step 2- Assigning preliminary codes: the development of an initial set of coding categories that helped to describe the content. This helped to organise the data into meaningful groups.

Step 3 - Searching for themes: the coding categories constituted the basis for further analysis by mapping the data in a way that facilitated a process of identifying, describing and interpreting themes from across the codes and sub codes.

Step 4 - Reviewing the themes: the themes were then re-examined and interrogated by considering the standards and objectives of a CRA, the ABMU Children's Rights Charter and the UNCRC and its General Comments and indeed the wider conceptual literature on the subject. Therefore, using a deductive thematic approach, that viewed

\footnotetext{
${ }^{994}$ Braun V and Clarke V, Thematic Analysis; Handbook of Research Methods in Health Social Sciences (Springer 2019) 843-860

${ }^{995}$ Ibid

${ }^{996}$ Peel K L, 'A beginner's guide to applied educational research using thematic analysis', Practical Assessment, Research \& Evaluation 2020 25(2)

${ }^{997}$ Merriam S B, 'Qualitative research: A guide to design and implementation. Revised and expanded from qualitative research', Practical Assessment, Research \& Evaluation, Vol 25 No 2 2009; Yin R K, Case study research: Designs and methods (5th ed) (Thousand Oaks, CA: Sage Publications 2014).
} 
the data through the conceptual framework developed in Part 1 of the thesis. ${ }^{998}$ This essentially provided the interpretative frame that guided the analysis and interpretation.

Step 5 - The themes were described and named: capturing what was important about the data in relation to the research questions and the CRA framework.

Step 6 - Write up: throughout this process conclusions and recommendations about the data were formulated, examined and challenged. The analysis of the four surveys was presented under each of the principles and standards of the CRA to aim to demonstrate in an accessible and triangulated way how far ABMU had successfully embedded a CRA to health services from the four perspectives, i.e., Strategic Leads, Health Professionals, Young People and Children.

The evidence from the descriptive statistics was interwoven with the themes coming from the open-ended responses and the overall analysis presented in alignment to the conceptual framework.

\subsection{Research rigour and trustworthiness}

Research rigour and trustworthiness was reinforced by the integrated conceptual framework. The framework utilised systematic procedures for collecting data, then analysing the data and generating codes and themes. Specific research methods and processes for data collection and thematic analysis to answer the research questions were introduced in Section 7.6 and considered in more detail in Section 7.9. The integrated conceptual framework (see Section 7.10) demonstrates the alignment of the research questions to the principles, standards; the ABMU Children's Rights Charter and ultimately the UNCRC and helps to reinforce the trustworthiness of the methods. The transparency and the logic of the inquiry demonstrate there was a sequential pathway of identifying the research questions and objectives, to establishing the methods for collecting data and analysis. This also demonstrates that the methods could be applied to another organisational context or utilised by the health authority in the future.

\footnotetext{
${ }^{998}$ Clark V, Braun V and Hayfield N, 'Thematic Analysis', In Smith J A (eds) Qualitative Psychology: A Practical Guide to Research Methods (Sage 2015)
} 
Surveys as referred to above were chosen so that health partners had access to a non-resource intensive method that could be 'picked up off the shelf' and replicated in the future, to help with the embedding of a process that monitored progress of children's rights implementation on a 2-year basis to be conducted by health staff. The data in Chapter 9 is analysed using the same conceptual framework which further substantiates the sources of evidence and ultimately the findings, to attempt to assure the reader of the rigour of the knowledge claims. ${ }^{999}$ The case study yielded sufficient evidence to justify the findings, and the transparent integrated conceptual framework helped to further explain the logic of the inquiry. ${ }^{1000}$

Throughout the research process, a meticulous record of interpretations of the data was collated, ensuring consistency and transparency and clarity of thought processes. The data was interrogated seeking out similarities and differences across stakeholder accounts to ensure different perspectives were represented. ${ }^{1001}$ Using data triangulation $^{1002}$, descriptive statistics complemented with qualitative data, helped to produce a wide-ranging set of findings. ${ }^{1003}$ As part of the write up of the research, bias in sampling was acknowledged and continually reflected upon in Chapter 9. ${ }^{1004}$

As outlined earlier, the nature of this inquiry is context specific and time bounded. The findings may only be interpreted by the reader and made applicable to their own contexts. ${ }^{1005}$ However, writing using, 'thick descriptions' allows the reader to enter the research world and to bring forth transferable lessons and generation of new

\footnotetext{
${ }^{999}$ Merriam S B, 'Qualitative research: A guide to design and implementation. Revised and expanded from qualitative research', Practical Assessment, Research \& Evaluation, Vol 25 No 2 2009; Yin R K, Case study research: Designs and methods (5th ed) (Thousand Oaks, CA: Sage Publications 2014) ${ }^{1000}$ Duran R P, Eisenhart M A, Erickson F D, Grant C A, Green J L, Hedges L V, Schneider B L, Standards for reporting on empirical social science research in AERA publications: American Educational Research Association. Educational Researcher, 2006 35(6), 33-40.

${ }^{1001}$ Morse J, Barrett M, Mayan M, et al 'Verification strategies for establishing reliability validity in qualitative research', Int J Qual Res 2002; 1:1-19

${ }^{1002}$ Sandelowski M, 'Rigor or rigor mortis: the problem of rigor in qualitative research revisited', $A d v$ Nurs Sci 1993; 16:1-8.

${ }^{1003}$ Dura Kuper A, Lingard L, Levinson W, 'Critically appraising qualitative research', BMJ 2008;337

${ }^{1004}$ Sandelowski M, 'Rigor or rigor mortis: the problem of rigor in qualitative research revisited', $A d v$ Nurs Sci 1993; 16:1-8.

${ }^{1005}$ Peel K L, 'A beginner's guide to applied educational research using thematic analysis', Practical Assessment, Research \& Evaluation 2020 25(2)
} 
theories. ${ }^{1006}$ The analysis of the data using participant's voices and illustrative examples from the children and young people's data, in Chapter 9 provides snapshots, which 'present opportunities for collective interpretations that act as a validity filter for acceptance of findings'. ${ }^{1007}$ The snapshots also support the potential transferability of the case study's findings from the vantage point of the reader who relates to the research through the descriptive findings. It must be acknowledged that the smallscale nature of a case study inquiry could be regarded as a limitation. However, it was always the intention of the research partners to have a focused evaluation of their health authority and to situate it in the wider Wales and global context, through developing understanding of the conceptual literature and jurisprudence of the UNCRC. A focused case study has supported the opportunity to investigate a complex issue that traverses disciplines in depth. The development of the integrated conceptual framework can be utilised in the future and successfully produced a set of findings that can help the health authority learn how far they have progressed a CRA, consider strategies for improvement and recommendations for further research.

\subsection{Ethical approval}

Even though a positive working relationship was established with immediate health partners at the health board, gaining Health Board consent and approval to undertake the field research became fraught with bureaucratic challenges. With immediate health partners, it was determined that the research was a single organisation case study and in health services terms a focused 'service evaluation'. However, when the research proposal was shared with $A B M U$ Research and Development (R\&D) Team they responded that the study was in fact 'research' and would require R\&D's approval. It was additionally recommended that an NHS Rec Review be conducted because children would be involved in completing the surveys.

According to the NHS guidance, there is a difference between carrying out an internal service evaluation and research that can be considered generalisable. ${ }^{1008}$ The R \& D

\footnotetext{
${ }^{1006}$ Geertz C, Thick description: Toward an interpretive theory of culture. In The interpretation of cultures: Selected essays (pp. 3-30) (New York: NY: Basic Books 1973)

${ }^{1007}$ Peel K L, 'A beginner's guide to applied educational research using thematic analysis', Practical Assessment, Research \& Evaluation 2020 25(2)

${ }^{1008}$ Health Research Authority, Health Authority Decision Making Tools
} 
Team did not accept that it was solely a service evaluation they believed that the findings would be generalisable to similar contexts and therefore it should be classified as 'research' and therefore must go through the NHS Integrated Research Assessment System (IRAS). ${ }^{1009}$

Additionally, it was decided the research with children would have to go through what is called an NHS Rec Review. ${ }^{1010}$ The IRAS is a central assessment portal for research that is undertaken in NHS health services across the UK. It supports a system for applying for and managing research approvals. This system was adopted in 2016 by the Health Research Authority (HRA) to streamline and better integrate legal compliance and ethical review on a UK wide basis, instead as previously occurred locally at each NHS organisation. ${ }^{1011}$ NHS Ethics Review which is integrated as part of this process is undertaken for all research with vulnerable populations. Children under the age of 16 years are categorised as having a vulnerable status. ${ }^{1012}$ The questions in the IRAS were developed in such a way, that it would have been easier to collect children's human tissue rather than encouraging staff to collect children's perspectives on accessing their rights at health services.

As a postgraduate researcher, based in a non-clinical academic department, no-one in my own department or other university departments had encountered the NHS application system first-hand or indeed my health partners. This, therefore required being pro-active in terms of finding out how the lengthy application process worked and what was required to gain ethical approval. This involved setting up meetings with $R \& D$ and NHS Ethics and ultimately responding to a detailed assessment process and development of a research protocol that met the IRAS requirements. After completing the process, which included the research being considered by an English

\footnotetext{
http://www.hra decisiontools.org.uk/research/docs/DefiningResearchTable Oct2017-1.pdf accessed January 2018

${ }^{1009}$ Integrated Research Assessment Application system https://www.myresearchproject.org.uk/ accessed January 2018

${ }^{1010}$ Health Research Authority, Research Ethics Committee Review, What approvals and decisions do I need https://www.hra.nhs.uk/approvals-amendments/what-approvals-do-i-need/research-ethicscommittee-review/ accessed January 2018

${ }^{1011}$ Health Research Authority, Health research approval one year on (HRA 2017) https://www.hra.nhs.uk/about-us/news-updates/hra-approval-one-year/

${ }^{1012}$ When reading the guidance to the IRAS notions of children's vulnerability come through strongly in the wording throughout.
} 
Ethics Committee, the Committee decided on initial read of the application that the study was in fact a 'service evaluation' and in which case REC review committees were not expected to consider such applications. The Committee instructed me to refer to their guidance and decision-making tools ${ }^{1013}$, and provide justification for regarding the study as 'research'. With immediate health partners and academic supervisors, as earlier outlined, we also had considered the research to be a single organisation study or service evaluation which was not generalisable only transferrable. Over six months after starting the process, the English Ethics Review Committee concluded that the study did indeed fall outside of the definition of 'research' within the 'defining research table.'1014 They further explained that they were not expected to consider such projects, under Governance Arrangements for Research Ethics Committees (GAfREC) and suggested that the application for ethics review be withdrawn.

There was obviously a difference in the interpretation of what qualified as 'research' or 'service evaluation' between the R \&D Committee in Wales and the NHS Rec Review Committee in England. This suggests that the 'streamlined system' the Health Research Authority was hoping to embed across the UK was not working effectively in all cases. ${ }^{1015}$ One could question whether the difference in interpretation could be to do with the study falling out with the usual parameters of health/clinical research usually submitted to the IRAS, so it caused confusion because it did not fit the 'normal templates' of the studies they expect to be undertaken.

Perhaps one could surmise that because there is a policy and legislative landscape in Wales for children that is framed by the UNCRC; the ABMU R\&D Committee automatically considered the study to have important learning and generalisabliity to other contexts. Whereas in England, the UNCRC is not as embedded into the national policy and legislative framework, so embedding a CRA may not have such significance. ${ }^{1016}$ Or it may be that R\&D ABMU followed a more precautionary approach

${ }^{1013}$ Health Research Authority Defining Research Table http://www.hradecisiontools.org.uk/research/docs/definingresearchtable_oct2017-1.pdf http://hra-decisiontools.org.uk/ethics/" accessed January 2018

${ }^{1014}$ Ibid

${ }^{1015}$ Health Research Authority, HRA Approval https://www.hra.nhs.uk/about-us/news-updates/hraapproval-one-year/ accessed March 2018

${ }^{1016}$ Williams J, 'General legislative measures of implementation: individual claims, 'public officer's law' and a case study on the UNCRC in Wales', The International Journal of Children's Rights 2012 
to any studies undertaken as it was ultimately their own health board that would have been subject to the burden of risk.

Nevertheless, it can be concluded that the challenges of navigating this complex assessment process, caused a considerable delay to the primary research. However, the research methodology and methods were critically reviewed by R \& D Committees in both Wales and England which further helped to ensure the rigour, integrity and trustworthiness of the research. Please see Appendix 6 for the College of Law Research Ethics Form.

The next section of this chapter outlines the different phases of the research process and the research methods developed to respond to the research questions. The time frame for all the surveys to be completed was between December 2018 and April 2019

\subsection{Description of four surveys}

This section describes the four surveys in more detail. It outlines each survey's objective, the method, the sampling strategy and the exclusion criteria, how the questions were developed, how the participants were recruited, the process of informed consent, risks and burdens to participants, the benefits to participants and the time frame for the conducting the survey. The integrated conceptual framework is included in Section 7.10.

\subsubsection{Phase 1 ABMU Strategic Lead's perspective}

This phase of the research was designed to determine how far children's rights are embedded in policy and practice from the perspective of the strategic level professionals who were executive or non-executive members of the ABMU Health Board. It was considered necessary to gain the perspective of senior management to develop a corporate wide understanding of how children's rights were being implemented across the health authority.

20 (2), 224-240; Rees O and Williams J, 'Framing Asymmetry: Devolution and the United Kingdom's Four Children's Commissioners', The International Journal of Children's Rights 24(2), 408-433 
Research objective: To determine how far children's rights are embedded in policy and practice from the perspective of ABMU Strategic Leads and their recommendations for improvement.

Research method: The self-assessment tool was a questionnaire designed to ask questions relating to the CRA conceptual framework (See Appendix 2) with the inclusion of a 5 options rating/Likert scale per each organisational standard. The benefit/relevance of the data was that it informed the analysis of ABMU policies and practice from the perspective of Strategic Leads who have an understanding of how policies and practice are implemented corporate-wide. The 5 options rating was developed using a Likert Scale, to support a rating of 5 degrees or levels of implementation, from objectives at the one end of the scale not being actioned at all, to them not only being fully developed but the highest standard of them being fully developed and operational at the point of service delivery. ${ }^{1017}$ This scale was designed to understand from a Strategic Lead's perspective, how effective they were in translating children's rights into policies and practice.

The 5 options rating was:

1. No action taken

2. Under development

3. Developed but requiring refinement

4. Fully developed

5. Fully developed and operational

The self-assessment tool was intended to be completed collectively by the ABMU Executive and Non-Executive members so that they could decide together and agree on the options rating per each standard. However, Strategic Leads, due to time commitments preferred to respond to a separate electronic questionnaire. This presented interesting results (discussed in more detail in Chapter 9) demonstrating

1017 Sullivan GM, and Artino JR AR, ‘Analyzing and Interpreting Data From Likert-Type Scales', $J$ Grad Med Educ. 2013 Dec; 5(4): 541-542. 
that there was often disagreement between the Strategic Leads with regards how far an objective had been implemented. This data was analysed using Survey Monkey. The Strategic Leads were also invited to give additional evidence to support their rating. This data was analysed manually using thematic analysis (see the Braun and Clark approach above).

Sample: Strategic Leads identified were, ABMU Health Board: Executive \& NonExecutive Members. This was a purposive sample of experts who had a corporate wide understanding of health services delivery at ABMU. All members were invited to respond voluntarily to the self-assessment via an on-line self-assessment tool that was designed using Survey Monkey. A maximum of 20 Strategic Leads were anticipated to respond to the survey.

Developing the questions for the Strategic Leads: The questions developed for the Strategic Leads were to directly ask them what options rating they would give to each objective included in the conceptual framework (See Appendix 2/Integrated conceptual framework). They were also asked to provide evidence or comments to support their rating.

Exclusion criteria: All Strategic Leads that work at a corporate level that have an impact on children were included; those who did not fall into the ABMU Executive and Non-Executive Board were not included.

Recruitment of participants: The Strategic Leads were contacted directly via e-mail and asked to voluntarily respond to the organisational self-assessment tool electronically. The Chair of the Health Board also brought the Strategic Leads' attention to the importance of the self-assessment. Information about the research project, their involvement in it and informed consent was also given as part of the introduction to the online self-assessment tool. Reminders were sent out at appropriate times as agreed with the Head of Nursing and Children's Services.

Informed consent: After reading and understanding the Participant Information Sheet (which was on the front page of the electronic survey) all Strategic Leads had the opportunity to give their informed consent. 
Confidentiality: To ensure that the research participants were able to answer freely it was made clear to each staff member that all data collected was anonymous, the data from the questionnaire was aggregated and anonymised for analysis purposes and individual participants were not identified. ABMU Staff members collected the data via the on-line survey monkey tool. Once the survey was closed, ABMU gave me consent to acquire the data via password access to the survey monkey tool. I was the sole person responsible for analysing the data on my home computer with password access only. The data was archived and stored electronically in compliance with UK data protection legislation, for a period of 3 years after finalisation of the research.

Risks and burdens for research participants: The survey did not include any subjects that were of a personal nature that could be deemed sensitive, embarrassing or distressing to the participant. The adult participants contributing to the data collection were not deemed vulnerable and were participating in their capacity as Strategic Leads. No risks to research participants were foreseen. Survey Monkey calculated it would take participants, 8 minutes to complete the survey.

Benefits to research participants: It was made clear to the participants that recommendations coming from the research would help to support new and improved services for children from a children's rights perspective.

Arrangements to comply with Welsh Language requirements: The survey was provided in the Welsh language on request by staff members.

\subsubsection{Phase 2 Health professionals' perspective}

This phase of the research was designed to determine how far children's rights were embedded in policy and practice from the perspective of health professionals working at the front line of service delivery at ABMU. This encompassed health professionals including doctors, nurses and therapists who primarily worked in secondary level services (as referred to above). It was considered necessary to gain the perspective of health professionals working at the frontline of service delivery to determine how far they believed children's rights were being embedded in policy and practice across their own service areas. 
Research objective: To determine how far a CRA is embedded in policy and practice from the perspective of ABMU health professionals.

Research method: An on-line survey (See Appendix 3) was designed to ask questions relating to the CRA conceptual framework of health professionals delivering services that impact on children. The benefit/relevance of the data was to inform analysis of $A B M U$ policies and practice from the perspective of health professionals at the delivery end of services, for compliance with a CRA to health services. The survey was open from December 2018 to end of April 2019. Data was collected using Survey Monkey. The survey was disseminated via the ABMU Staff intranet and Staff Facebook web page. The data generated from the health professional's additional comments was analysed manually using thematic analysis (see the Braun and Clark approach above).

Sample: All ABMU health professionals were invited to participate in the survey if their services impacted on children. A total maximum sample of 40 health professionals was anticipated to respond to the survey. This was considered to give opportunity to test the tool and for sufficient data to make exploratory findings and reflections and generate questions for further research.

Developing the questions for health professionals: These questions were developed with reference to the five principles, the standards and objectives of the conceptual framework with a stronger focus on health services delivery. Reference was also made to the questions for health professionals in the SEMT study. The number of questions was kept shorter than the SEMT study based on advice from ABMU colleagues who advised that health professionals would not be inclined to participate in the study if the number of questions were not reduced.

Exclusion criteria: Health professionals were invited to participate in the survey if their services impacted on children.

Recruitment of participants: As well as disseminating the survey via Facebook, the intranet and the ABMU website, also some targeted e-mailing to staff members was driven by the Head of Nursing and Children's Services and the Patient Experience Coordinator. The e-mail included a description of the research project and information about informed consent. Reminders were sent out at appropriate times as agreed with 
the Head of Nursing and Children's Services. The survey required a resource commitment of staff of an estimated 7 minutes (by Survey Monkey) of their time to fill in the survey.

Informed consent: After reading and understanding the Participant Information on the front page of the survey all health professionals had the opportunity to give their informed consent.

Confidentiality: To ensure that the research participants could answer the questions freely it was made clear to each staff member that all data collected was anonymous and the data from questionnaires was to be aggregated and anonymised for analysis purposes and individual participants not identified in the PhD submission. ABMU Staff members collected the data via an on-line survey monkey tool. Once the surveys were closed, I acquired the data from ABMU via password access only to the survey monkey tool. The data was archived and stored electronically in compliance with UK data protection legislation, for a period of 3 years after finalisation of the research.

Risks and burdens for research participants: The survey did not include any subjects that were of a personal nature that could be deemed sensitive, embarrassing or distressing to the participant. The adult participants contributing to data collection were not vulnerable and were participating in their capacity as health professionals. No risk to research participants was foreseen. It was anticipated that the survey would take 8 minutes to complete, and they were given a 4-month period within which to complete it with reminders along this time frame.

Benefits to research participants: Health professionals were made aware that recommendations coming from the research would support new and improved services for children from a children's rights perspective.

Arrangements to comply with Welsh Language requirements: The survey was provided to the health professionals in the Welsh language on request.

\subsubsection{Phase 3 Children 7-17 years perspective}

This phase of the research was designed to determine how far children's rights were embedded in policy and practice from the perspective of children and young people. 
As discussed in the introduction to the research methods (Section 7.5) the best people to provide information about the child's perspective are the children themselves. ${ }^{1018}$ This is also an important aspect of respecting Article 12 of the UNCRC and was a key standard of the CRA conceptual framework.

Research objective: To determine how far a CRA is embedded in policy and practice from the perspective of children aged 7-17 years in ABMU Health Services and their recommendations for improvement.

Research method: This included two anonymised generic surveys (7-12 years and 13-17 years, (see Surveys, Appendices 4 and 5) administered by ABMU staff and disseminated on site at health services and in the community online to gauge the effectiveness of ABMU's institutional approach to children's rights from a children and young person's perspective. These surveys were designed to gain a children and young people's perspective as to whether ABMU was successfully complying with a CRA and presented children's recommendations for improvement. The surveys were designed with the input of ABM Youth who helped with the design of the questions and agreed that akin to the International SEMT study (see chapter 4) the survey needed to be split and the language adapted to the two age bands to ensure that children across the age group understood the questions appropriately. The analysis of results chapter therefore uses the word 'children' to refer to the 7-12 age category and 'young people' to refer to the 13-17 age category. As referred to above, the lower age threshold at age 7 was selected as it corresponded with the age in Wales that children transition into Key Stage 2 of their school education. It was considered that any younger, that children may struggle to read and understand the questions. The young person's survey with the lower age threshold of 13 years was selected to support a process of independent consent to participate which was based on detailed research and through discussions with the partner health professionals at ABMU (Please see Chapter 8 that discusses the complexities surrounding young people's independent consent).

\footnotetext{
${ }^{1018}$ Scott J, 'Children are respondents: The Challenge for Quantitative Methods' In, (eds) Christensen $P$, and James A, Research with Children: Perspectives and Practices $\left(2^{\text {nd }}\right.$ edn Routledge London and New York 2008)
} 
These surveys were primarily administered at health services by Ipad. The surveys were also disseminated in the community via the internet by ABMU, the Children's Rights Unit and partner organisations e.g., Swansea University's Children's Legal Centre and Lleisiau Bach/Little Voices project. Survey Monkey was used to collect the data. The data generated from the children and young people's additional comments and response to open-ended questions was analysed manually using thematic analysis (see the Braun and Clark approach above).

Sample: Two purposive samples one targeting children between the ages of 7-12 years and one targeting young people 13-17 years with direct experience of the services defined in the research. A total minimum sample size of 75 children and a sample size of 75 young people was anticipated. The sample sizes were not sufficient to make inferences into the total patient population in the ABMU area. ${ }^{1019}$ However, they were considered sufficient to test the tool and to generate data to make exploratory findings and reflections, and questions for further research. A larger children and young people quantitative survey that would have been capable of making inferences into the general population would have been the preferred option (Please see for example NHS England Children and Young People's Survey), ${ }^{1020}$ however due to the limited and time bound resources of ABMU and the research project, and staff administering the survey in addition to their daily health care activities, this was unfortunately not possible on this occasion.

Developing the questions for the children and young people: The questions were developed based on the principles and standards of the conceptual framework and the Children's Rights Charter. Questions were developed that related to all 5 principles. It became apparent that more of the questions suitable for children were connected to the principles of Participation and Empowerment. Reference was made to the SEMT study and the Council of Europe 2011 study in the development of questions. However, it was advised by both ABMU health professionals and the ABM

\footnotetext{
${ }^{1019}$ With calculations based on confidence interval data, a sample size of over 380 children would have been necessary to infer into the child patient population of the ABMU Health Board area. ${ }^{1020}$ NHS England, Children and Young People's Survey http://www.cqc.org.uk/publications/surveys/children-young-peoples-survey-2016 accessed January 2020
} 
Youth, that fewer questions would be responded to more favourably by children across the age group. The questionnaires went through several drafts and were critically appraised by ABM Youth, who amended questions, added questions or asked for questions to be removed. Questions were included that asked children whether they believed health professionals to be friendly or if they trusted health professionals. Although, these questions cannot be explicitly connected to the UNCRC or the Charter, the young people expressed, that the way in which health professionals communicate to them is essential to gaining meaningful responses during consultations and contributes to the young people feeling both safe and comfortable. This was considered to contribute to a CRA and was supported by the research in Chapter 4 and reinforces what was included in the conceptual framework in Chapter 6 . The young people also gave clear advice regarding what they considered to be age appropriate and whether the questions were clear and made sense.

Exclusion criteria: Children under the age of 7 years and children using service areas were not selected for the study. Not carrying out research with children under the age of 7 years was purely for pragmatic reasons. The study was constrained by resources and time and was not able to undertake research meaningfully with the younger age group as part of this study.

Recruitment of participants: Out-patient services were contacted in advance to inform them that the surveys would be carried out in their service area and services were informed that the research was an extension of the child-patient experience/satisfaction programme. Staff recruited child and young people patients to voluntarily participate in the survey post their clinic appointments at location at each service. Recognisable as ABMU staff members with visible ID, children and caregivers were not surprised to be approached by them. Staff informed the children and young people about the research and invited them to take part in the research. Other children and young people learned about the survey online in the community and took the opportunity to respond to the survey independently online.

I had no direct contact with patients. The recruitment of child patients on site at health services required a resource commitment from staff to invite children to complete the survey within 4 months (December 2018 - April 2019). Questionnaires took approximately 5-8 minutes to complete on an iPad at location. To reduce staff 
influence and bias, each child/young person was encouraged to respond to the questionnaire independently of the staff member who recruited the participant and with the support of a parent/carer if under the age of 13 years.

Informed consent: For the purposes of the research if children were above the age of 13 years, they were deemed Gillick competent ${ }^{1021}$ and therefore capable of giving consent, (See Chapter 8 that refers to Consent in further detail) it was considered that the majority of 13-year-olds will have sufficient understanding and maturity (and/or be capable of seeking further information from staff) to: Understand the purpose and nature of the research, i.e.

- 'Understand what the research involves, its benefits (or lack of benefits), risks and burdens.

- Understand the alternatives to taking part.

- Be able to retain the information long enough to make an effective decision.

- Be able to make a free choice.

- Be capable of making this particular decision at the time it needs to be made.'1022

- 'Opt in consent' was only sought from parents/caregivers of children under the age of 13 years. If children were under the age of 13 years, parents were asked to give their consent to their child to participate in the study as well as the child.

Consideration was given by staff that consent to participate is voluntary and not subject to any coercion. Staff were instructed to fully understand they are in a position of power and influence in relation to all research participants. A briefing was given to all staff members undertaking the research, by the Head of Nursing and Children's Services, regarding carrying out the recruitment of children to participate in the survey appropriately.

${ }^{1021}$ Gillick v West Norfolk \& Wisbeck Area Health Authority [1986] AC 112 House of Lords, 'The parental right to determine whether or not their minor child below the age of 16 will have medical treatment terminates if and when the child achieves a sufficient understanding and intelligence to enable him or her to understand fully what is proposed' [Lord Scarman on the Gillick Case, House of Lords].

${ }^{1022}$ Health Research Authority, Qualitative Protocol Tool (HRA 2016) 5 https://www.hra.nhs.uk/documents/324/qualitative-protocol-develop 
Information about the research was included on the first page of the on-line survey (Please, Appendices 4 and 5). The information was kept short and simple and to the point, using clear language, given the target group's presumed age and level of understanding. Child participants and their carers were able to consent to participate in the survey when they press 'OK'. Young people 13 years and over, after they had read and understood the information about the research were able to give their own consent to participate by pressing 'OK'.

Confidentiality: There was no personally identifiable data. Anonymous data was collected by ABMU staff by two anonymous online surveys which were voluntary to complete. The data from questionnaires was aggregated and anonymised for analysis purposes and individual participants were not identified in the PhD submission. I sought consent from $A B M U$ to acquire the secondary anonymous data. Once the surveys were closed, I acquired the data from ABMU via password access only to the survey monkey tool, for use on my computer and committed to secure the data for a minimum of 3 years.

Risks to research participants: The survey did not include any subjects that were of a personal nature that could be deemed sensitive, embarrassing or distressing to the participant. However, if a child was worried or upset about anything that arose from the child or young person learning about their human rights for the first time, the survey included a list of organisations' contact details that the child/parent or caregiver could be sign posted to and staff were always accessible to all children for any support, sign posting, or dealing with complaints for those children who participated at health services. Any disclosures were to be handled appropriately via the ABMU child safeguarding policy.

Potential benefits for research participants: There is a long-term benefit to the research participants that services may be improved from a children's rights perspective. Additionally, children's participation in research regarding their access to human rights tends to have the beneficial impact of providing children with information resources and support opportunities which enhance their well-being.

Arrangements to comply with Welsh Language requirements: The on-line survey was offered bilingually. 
The integrated conceptual framework for research at health services is outlined below. This builds on the conceptual framework developed in Chapter 6, integrating standards and questions from the four surveys for this evaluation, Strategic Leads, Health professionals, Young People and Children and correlates them to the 5 principles of a CRA and the standards outlined in Chapter 6 and with the ABMU Children's Rights Charter. 


\subsection{Integrated conceptual framework including questions from the 4 surveys correlated with principles, standards}

and objectives.

\section{Overarching research questions}

1. How far has a CRA been embedded in ABMU health services policies and practices?

2. What strategies are required to make a CRA fully operational

\begin{tabular}{|c|c|c|c|c|c|}
\hline $\begin{array}{l}\text { Organisation } \\
\text { principle }\end{array}$ & $\begin{array}{l}\text { Organisation } \\
\text { standard } \\
\text { - ABMU Charter No. }\end{array}$ & $\begin{array}{l}\text { Organisation } \\
\text { Objective (Strategic } \\
\text { Leads) } \\
1=\text { No action taken } \\
2=\text { Under } \\
\text { development } \\
3=\text { Developed but } \\
\text { requiring refinement } \\
4=\text { Fully developed } \\
5=\text { Fully developed } \\
\text { and operational } \\
\\
\text { What } \\
\text { evidence/comments do } \\
\text { you have to support } \\
\text { this rating? }\end{array}$ & $\begin{array}{l}\text { Health } \\
\text { Professionals } \\
\text { questions }\end{array}$ & $\begin{array}{l}\text { Young people } \\
\text { questions (13-17 } \\
\text { yrs) }\end{array}$ & \begin{tabular}{|l|} 
Children's \\
questions (7-12 yrs)
\end{tabular} \\
\hline
\end{tabular}




\begin{tabular}{|c|c|c|c|c|c|}
\hline 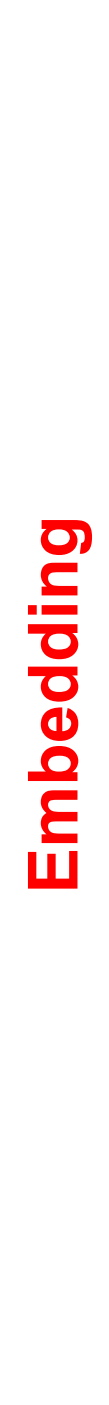 & $\begin{array}{l}\text { Health authority } \\
\text { wide commitment } \\
\text { to the UNCRC } \\
\text { ABMU Charter } 1-10\end{array}$ & $\begin{array}{l}\text { Reference has been } \\
\text { made to the United } \\
\text { Nations Convention on } \\
\text { the Rights of the Child } \\
\text { as the framework for } \\
\text { service planning and } \\
\text { delivery in all } \\
\text { significant policy } \\
\text { statements or other } \\
\text { documents setting out } \\
\text { the health authority's } \\
\text { vision or key objectives } \\
\text { (e.g. a Children's } \\
\text { Rights Charter). } \\
\text { Leaders and staff, who } \\
\text { are required to put the } \\
\text { Children's Rights } \\
\text { Charter into practice, } \\
\text { are aware of this } \\
\text { commitment. } \\
\text { Children as service } \\
\text { users and their carers } \\
\text { have been made } \\
\text { aware of the Children's } \\
\text { Rights Charter and } \\
\text { what it means for them }\end{array}$ & $\begin{array}{l}\text { Is the ABMU } \\
\text { Children's Rights } \\
\text { Charter displayed } \\
\text { in the service area } \\
\text { where you work? } \\
\text { How would you } \\
\text { rate your } \\
\text { knowledge of the } \\
\text { ABMU Children's } \\
\text { Rights Charter? }\end{array}$ & $\begin{array}{l}\text { Do you know what } \\
\text { your rights are when } \\
\text { you visit a health } \\
\text { professional? } \\
\text { Have you seen this } \\
\text { poster before today? } \\
\text { (ABMU Children's } \\
\text { Rights Charter } \\
\text { poster) }\end{array}$ & $\begin{array}{l}\text { Do you know what } \\
\text { your rights are when } \\
\text { you see a doctor or } \\
\text { nurse? } \\
\text { Have you seen this } \\
\text { poster before? } \\
\text { (ABMU Children's } \\
\text { Rights Charter } \\
\text { poster) }\end{array}$ \\
\hline
\end{tabular}




\begin{tabular}{|c|c|c|c|c|c|}
\hline 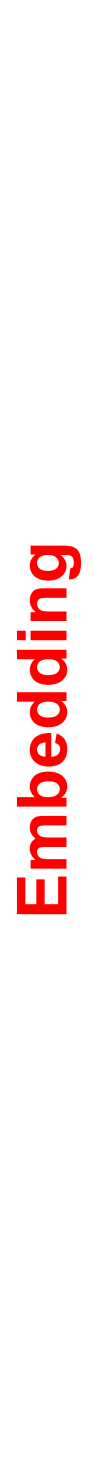 & $\begin{array}{l}\text { Develop a } \\
\text { children's rights } \\
\text { strategy }\end{array}$ & $\begin{array}{l}\text { A strategy has been } \\
\text { developed to ensure } \\
\text { the Children's Rights } \\
\text { Charter is taken into } \\
\text { account at all levels of } \\
\text { decision-making } \\
\text { across all health } \\
\text { services and there is } \\
\text { clear coordination with } \\
\text { other agencies. } \\
\text { Protection of children's } \\
\text { rights has been } \\
\text { prioritised through the } \\
\text { commissioning cycle. } \\
\text { Key individuals and/or } \\
\text { a team with } \\
\text { responsibility to } \\
\text { promote } \\
\text { implementation of } \\
\text { children's rights within } \\
\text { the health authority has } \\
\text { been established. } \\
\text { There is clear and } \\
\text { transparent evidence } \\
\text { to demonstrate that the } \\
\text { maximum extent of } \\
\text { available resources }\end{array}$ & $\begin{array}{l}\text { Do you have } \\
\text { access to guidance } \\
\text { on how the ABMU } \\
\text { Children's Rights } \\
\text { Charter can be } \\
\text { implemented in } \\
\text { your area of work? } \\
\text { Is there a named } \\
\text { person in your } \\
\text { service area } \\
\text { responsible for all } \\
\text { service delivery } \\
\text { complying with the } \\
\text { ABMU Children's } \\
\text { Rights Charter? } \\
\text { What do you } \\
\text { consider to be the } \\
\text { main challenges to } \\
\text { complying with the } \\
\text { ABMU Children's } \\
\text { Rights Charter in } \\
\text { your service area? } \\
\text { What do you think } \\
\text { are the main } \\
\text { strategies required } \\
\text { to implement the }\end{array}$ & $\begin{array}{l}\text { No questions } \\
\text { included for this age } \\
\text { group }\end{array}$ & $\begin{array}{l}\text { No questions } \\
\text { included for this age } \\
\text { group. }\end{array}$ \\
\hline
\end{tabular}




\begin{tabular}{|l|l|l|l|l|l|}
\hline & $\begin{array}{l}\text { has been allocated to } \\
\text { implement the } \\
\text { Children's Rights } \\
\text { Charter. }\end{array}$ & $\begin{array}{l}\text { ABMU Children's } \\
\text { Rights Charter? }\end{array}$ & & \\
& & & \\
\hline
\end{tabular}




\begin{tabular}{|c|c|c|c|c|c|}
\hline 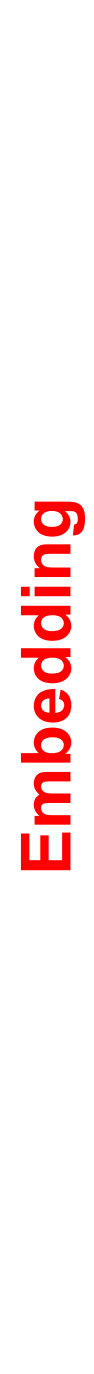 & $\begin{array}{l}\text { Raise awareness } \\
\text { and deliver training } \\
\text { on children's rights } \\
\text { to professionals } \\
\text { ABMU Charter }(1-10)\end{array}$ & $\begin{array}{l}\text { Initial and on-going } \\
\text { evaluation of levels of } \\
\text { knowledge and } \\
\text { understanding of } \\
\text { children's rights } \\
\text { amongst all staff at all } \\
\text { levels has been carried } \\
\text { out } \\
\text { A communication plan } \\
\text { for staff has been } \\
\text { developed setting out } \\
\text { how the health } \\
\text { authority intends to } \\
\text { develop awareness } \\
\text { and understanding of } \\
\text { implementing the } \\
\text { Children's Rights } \\
\text { Charter. } \\
\text { Training on children's } \\
\text { rights for all staff } \\
\text { (appropriate to context } \\
\text { and role that a member } \\
\text { of staff performs) has } \\
\text { been prioritised }\end{array}$ & $\begin{array}{l}\text { Do you have a } \\
\text { medical } \\
\text { specialisation in } \\
\text { child health or } \\
\text { special training in } \\
\text { providing care for } \\
\text { children? } \\
\text { Please tick which } \\
\text { training you have } \\
\text { received below: } \\
\text {-Children's rights } \\
\text {-Children's } \\
\text { informed consent } \\
\text { to treatment } \\
\text {-Supporting } \\
\text { children with } \\
\text { mental health } \\
\text { issues } \\
\text {-Ensuring } \\
\text { children's views } \\
\text { are always taken } \\
\text { into account and } \\
\text { given due weight }\end{array}$ & $\begin{array}{l}\text { No questions } \\
\text { included for this age } \\
\text { group }\end{array}$ & $\begin{array}{l}\text { No questions } \\
\text { included for this age } \\
\text { group. }\end{array}$ \\
\hline
\end{tabular}




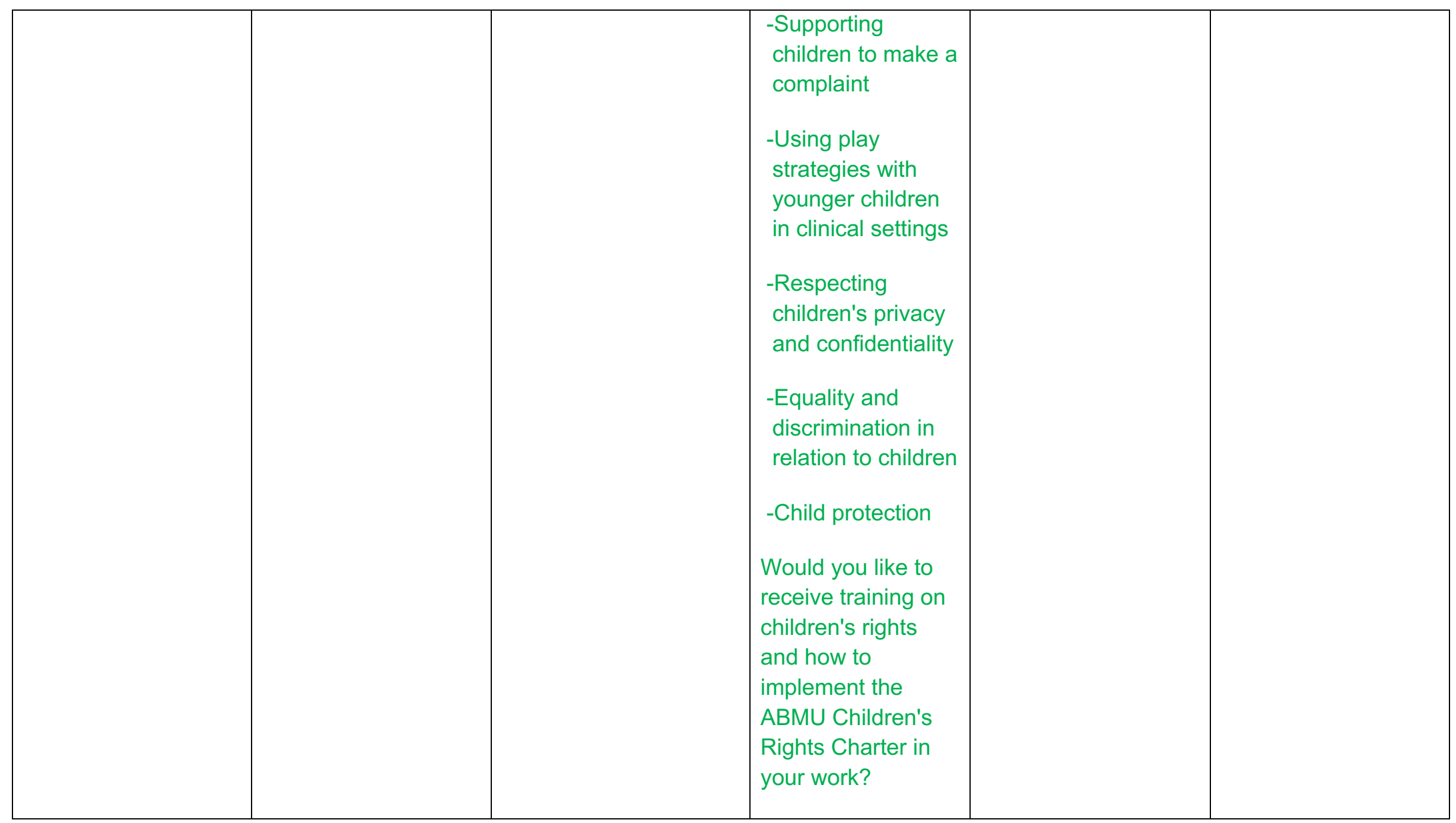




\begin{tabular}{|c|c|c|c|c|c|}
\hline 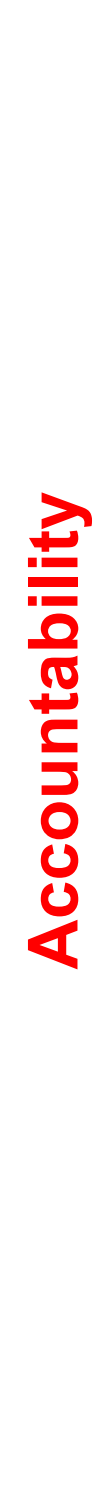 & $\begin{array}{l}\text { Undertake } \\
\text { children's rights } \\
\text { monitoring }\end{array}$ & $\begin{array}{l}\text { An initial and then } \\
\text { regular audit of all } \\
\text { significant policy } \\
\text { statements or other } \\
\text { documents has been } \\
\text { carried out to assess } \\
\text { compliance with the } \\
\text { Charter. } \\
\text { Annual reports are } \\
\text { published on } \\
\text { performance against } \\
\text { children's rights } \\
\text { indicators and the } \\
\text { findings disseminated } \\
\text { widely. } \\
\text { There is external } \\
\text { monitoring of } \\
\text { performance against } \\
\text { children's rights } \\
\text { standards, including by } \\
\text { involving children in } \\
\text { monitoring and/or } \\
\text { external } \\
\text { review/inspection. } \\
\text { Staff supervision and } \\
\text { performance } \\
\text { management includes }\end{array}$ & $\begin{array}{l}\text { Does your job } \\
\text { description include } \\
\text { performance } \\
\text { indicators relating } \\
\text { to implementation } \\
\text { of the ABMU } \\
\text { Children's Rights } \\
\text { Charter? }\end{array}$ & $\begin{array}{l}\text { No questions } \\
\text { included for this age } \\
\text { group }\end{array}$ & $\begin{array}{l}\text { No questions } \\
\text { included for this age } \\
\text { group }\end{array}$ \\
\hline
\end{tabular}




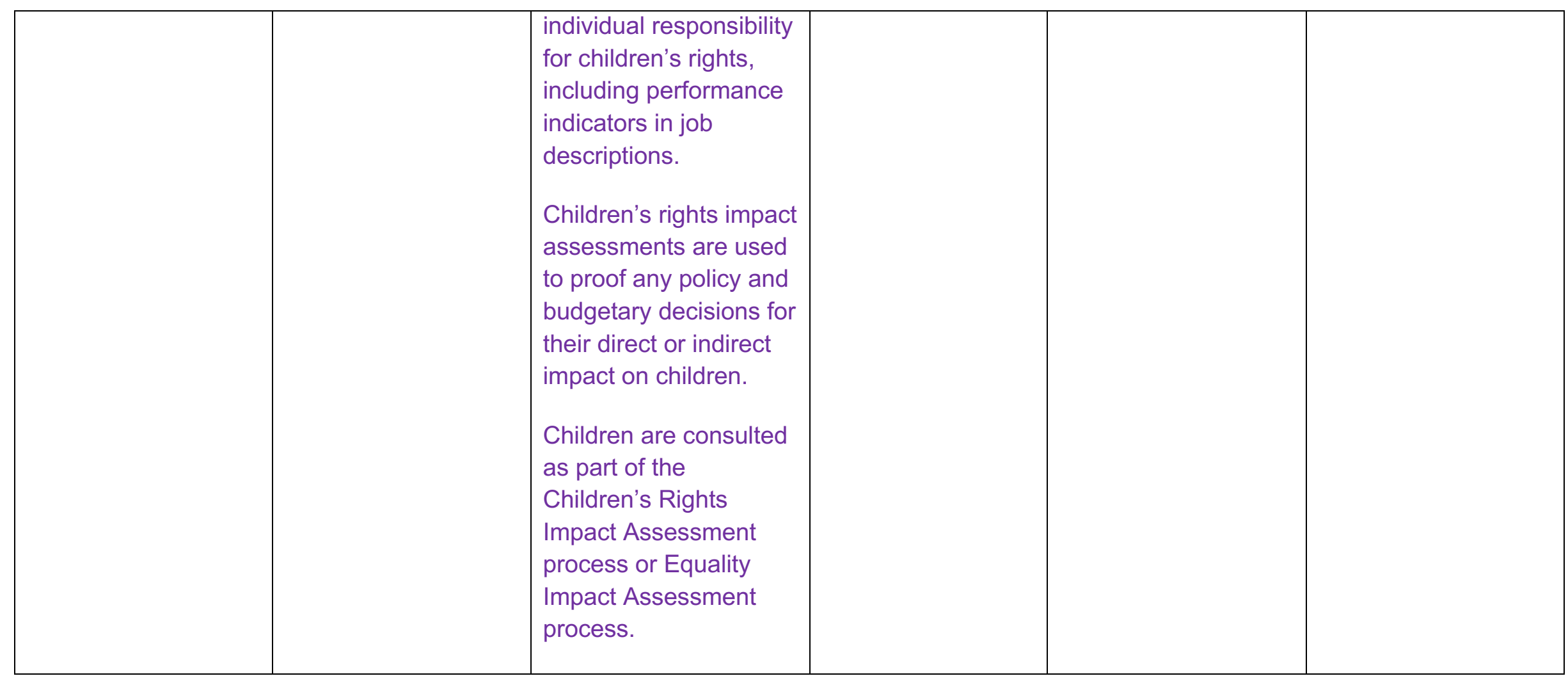




\begin{tabular}{|c|c|c|c|c|c|}
\hline 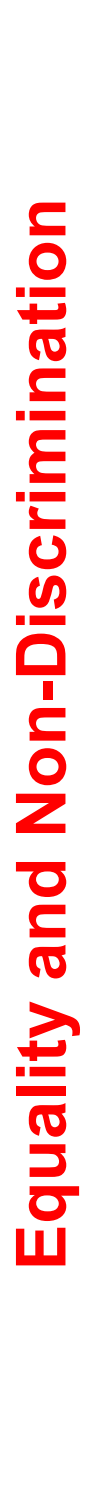 & $\begin{array}{l}\text { Equality and non- } \\
\text { discrimination } \\
\text { throughout service } \\
\text { delivery } \\
\text { ABMU Charter (5) }\end{array}$ & $\begin{array}{l}\text { Data is collected, } \\
\text { including } \\
\text { disaggregated data, to } \\
\text { enable identification of } \\
\text { discrimination or } \\
\text { inequalities in the } \\
\text { realisation of children's } \\
\text { rights to identify } \\
\text { children who are being } \\
\text { or may be } \\
\text { discriminated against. } \\
\text { Services and } \\
\text { resources are reviewed } \\
\text { to identify barriers to } \\
\text { children's access, } \\
\text { including in } \\
\text { collaboration with } \\
\text { children as service } \\
\text { users, in particular in } \\
\text { relation to services to } \\
\text { excluded/marginalised } \\
\text { or disadvantaged } \\
\text { social groups. } \\
\text { Appropriate priorities, } \\
\text { targets and } \\
\text { programmes have } \\
\text { been developed to } \\
\text { eliminate discrimination }\end{array}$ & $\begin{array}{l}\text { Do you have } \\
\text { access to } \\
\text { professional } \\
\text { interpreters when } \\
\text { needed? } \\
\text { Do you ensure that } \\
\text { all the information } \\
\text { you provide to } \\
\text { children is in a } \\
\text { language or format } \\
\text { appropriate to their } \\
\text { age, culture, } \\
\text { gender or } \\
\text { disability? } \\
\text { If no, please } \\
\text { specify why you } \\
\text { find this } \\
\text { challenging? }\end{array}$ & $\begin{array}{l}\text { When seeing a } \\
\text { health professional } \\
\text { have you ever been } \\
\text { treated unfairly } \\
\text { because of: } \\
\text { - Your age } \\
\text { - Your gender } \\
\text { - Your race (this } \\
\text { includes, your } \\
\text { colour, ethnic or } \\
\text { national origin) } \\
\text { - Your language } \\
\text { - Your sexual } \\
\text { orientation } \\
\text { (heterosexual, } \\
\text { lesbian, gay, } \\
\text { bisexual } \\
\text { - Where you live } \\
\text { - Your religion or } \\
\text { belief } \\
\text { - Asylum or refugees } \\
\text { status }\end{array}$ & $\begin{array}{l}\text { No questions } \\
\text { included for this age } \\
\text { group }\end{array}$ \\
\hline
\end{tabular}




\begin{tabular}{|c|c|c|c|}
\hline & $\begin{array}{l}\text { against excluded, } \\
\text { socially marginalised, } \\
\text { disadvantaged and } \\
\text { vulnerable groups and } \\
\text { to promote equality for } \\
\text { these groups. } \\
\text { All buildings are } \\
\text { compatible with } \\
\text { Disability Legislation } \\
\text { requirements. } \\
\text { All children have } \\
\text { access to professional } \\
\text { interpreters when } \\
\text { required. } \\
\text { All information is } \\
\text { provided to children in } \\
\text { a language or format } \\
\text { appropriate to their } \\
\text { age, culture, gender or } \\
\text { disability. }\end{array}$ & 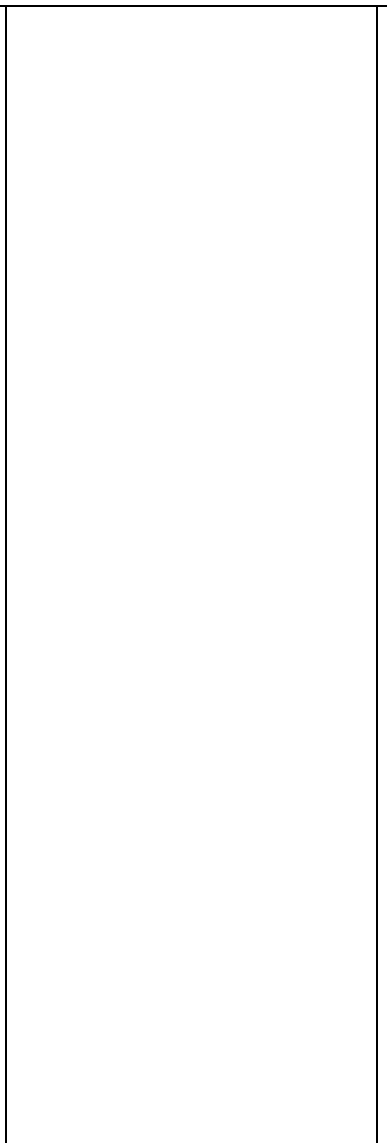 & $\begin{array}{l}\text { - You live in care } \\
\text { - You are in a } \\
\text { juvenile offender } \\
\text { institution } \\
\text { - Other } \\
\text { If you would like to } \\
\text { say why you were } \\
\text { treated unfairly, } \\
\text { please say why in } \\
\text { the box below } \\
\text { Do you find it difficult } \\
\text { to get to see a } \\
\text { health professional? }\end{array}$ \\
\hline
\end{tabular}




\begin{tabular}{|c|c|c|c|c|c|}
\hline $\begin{array}{l}\frac{c}{0} \\
\frac{0}{0} \\
\frac{0}{0} \\
\frac{0}{0} \\
\frac{0}{0} \\
0\end{array}$ & $\begin{array}{l}\text { Children can } \\
\text { actively participate } \\
\text { in decisions about } \\
\text { their own health } \\
\text { ABMU Charter }(3,4 \text {, } \\
7,6)\end{array}$ & $\begin{array}{l}\text { Children are } \\
\text { encouraged to exercise } \\
\text { their right to participate } \\
\text { in the decisions being } \\
\text { made about their } \\
\text { health or condition, } \\
\text { encouraged to express } \\
\text { their views freely, ask } \\
\text { questions and their } \\
\text { views are given due } \\
\text { weight. }\end{array}$ & $\begin{array}{l}\text { How would you } \\
\text { rate your ability to } \\
\text { involve children in } \\
\text { clinical decisions } \\
\text { according to their } \\
\text { age and capacity } \\
\text { that affect them? }\end{array}$ & $\begin{array}{l}\text { Are health } \\
\text { professionals } \\
\text { friendly? } \\
\text { When you are talking } \\
\text { to a health } \\
\text { professional do you } \\
\text { think that? (please } \\
\text { tick one) } \\
\text { - They mostly talk to } \\
\text { you } \\
\text {-They mostly talk to } \\
\text { the person that you } \\
\text { came with } \\
\text {-They talk to you and } \\
\text { the person that you } \\
\text { came with } \\
\text {-I go by myself } \\
\text { Do health } \\
\text { professionals listen } \\
\text { to what you have to } \\
\text { say? } \\
\text { Do health } \\
\text { professionals give }\end{array}$ & $\begin{array}{l}\text { Do you like visiting } \\
\text { the doctor or nurse? } \\
\text { Are doctors and } \\
\text { nurses friendly? } \\
\text { Do you understand } \\
\text { everything doctors } \\
\text { and nurses say to } \\
\text { you? } \\
\text { Do doctors and } \\
\text { nurses give you the } \\
\text { chance to ask } \\
\text { questions? } \\
\text { Do doctors and } \\
\text { nurses listen to what } \\
\text { you have to say? } \\
\text { Do you have the } \\
\text { chance to play when } \\
\text { you visit the doctor or } \\
\text { nurse? } \\
\text { Do you feel safe } \\
\text { when you visit a } \\
\text { doctor or a nurse? }\end{array}$ \\
\hline
\end{tabular}




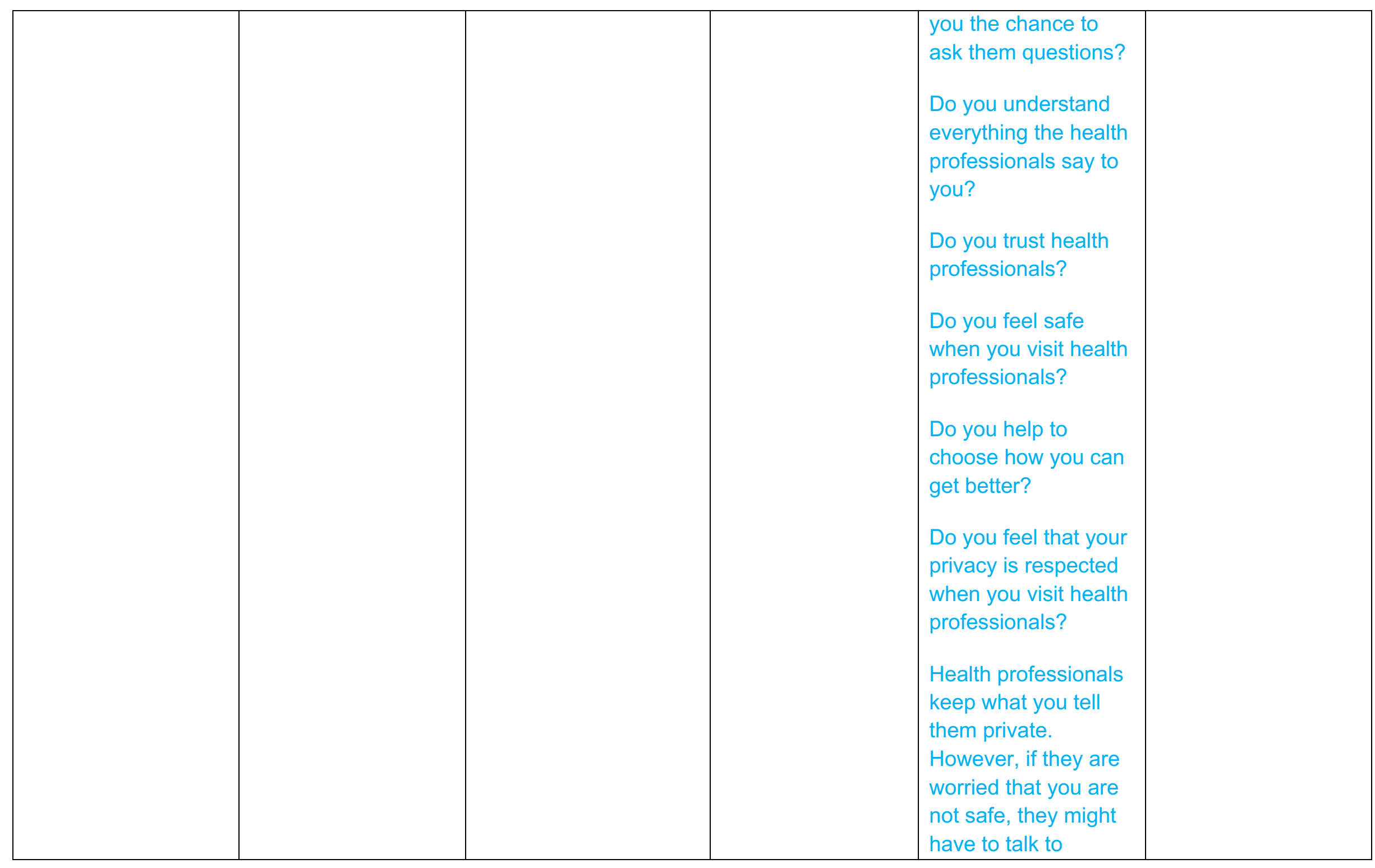




\begin{tabular}{|l|l|l|l|l|}
\hline & & & & $\begin{array}{l}\text { someone else about } \\
\text { what you have told } \\
\text { them. Did you know } \\
\text { this? } \\
\text { Do health } \\
\text { professionals ask for } \\
\text { your permission } \\
\text { before treating you? } \\
\text { (i.e., your consent) }\end{array}$ \\
\hline
\end{tabular}




\begin{tabular}{|c|c|c|c|c|c|}
\hline $\begin{array}{l}\frac{c}{0} \\
\frac{10}{0} \\
\frac{0}{0} \\
\frac{0}{0} \\
\frac{10}{0} \\
0\end{array}$ & $\begin{array}{l}\text { Children are } \\
\text { directly involved in } \\
\text { the development, } \\
\text { monitoring and } \\
\text { evaluation of health } \\
\text { service delivery } \\
\text { ABMU Charter (4 } \\
\text { and 6) }\end{array}$ & $\begin{array}{l}\text { A process has been } \\
\text { established in all } \\
\text { ABMU health services } \\
\text { areas to collect and act } \\
\text { on Child Patient } \\
\text { Feedback. } \\
\text { Children have been } \\
\text { given opportunities to } \\
\text { act collectively to } \\
\text { develop ideas and } \\
\text { proposals, to take } \\
\text { action and to influence } \\
\text { decisions e.g., ABM } \\
\text { Youth Board } \\
\text { Children are involved } \\
\text { in the recruitment of } \\
\text { staff that directly work } \\
\text { with children. }\end{array}$ & $\begin{array}{l}\text { Do you provide } \\
\text { children with } \\
\text { opportunities for } \\
\text { child patient } \\
\text { feedback? } \\
\text { If you answered } \\
\text { Yes, do you have } \\
\text { any examples of } \\
\text { how child patient } \\
\text { feedback has } \\
\text { improved services } \\
\text { for children? }\end{array}$ & $\begin{array}{l}\text { Has a health } \\
\text { professional ever } \\
\text { asked you question } \\
\text { number } 24 \text { before? } \\
\text { (What do you think } \\
\text { would make a visit to } \\
\text { see the health } \\
\text { professional better? } \\
\text { (open-ended) }\end{array}$ & $\begin{array}{l}\text { What do you think } \\
\text { would make a visit to } \\
\text { see the doctor or } \\
\text { nurse better? Please } \\
\text { tell us your ideas. }\end{array}$ \\
\hline
\end{tabular}




\begin{tabular}{|l|l|l|l|l|l|}
\hline & $\begin{array}{l}\text { Develop and } \\
\text { implement a child } \\
\text { friendly complaints } \\
\text { mechanism }\end{array}$ & $\begin{array}{l}\text { Children and their } \\
\text { carers are provided } \\
\text { with accessible } \\
\text { information on the } \\
\text { process for making } \\
\text { complaints, and for } \\
\text { holding the authority, } \\
\text { or individual staff to } \\
\text { account. }\end{array}$ & $\begin{array}{l}\text { Do you know how } \\
\text { to support a child to } \\
\text { make a complaint? } \\
\text { How many children } \\
\text { have you } \\
\text { supported to make } \\
\text { a complaint in } \\
2018 ?\end{array}$ & $\begin{array}{l}\text { Would you be happy } \\
\text { to tell a health } \\
\text { professional if you } \\
\text { were worried or } \\
\text { upset? }\end{array}$ & $\begin{array}{l}\text { Are you happy to tell } \\
\text { a doctor or a nurse if } \\
\text { you are worried or } \\
\text { upset? } \\
\text { health professional } \\
\text { and something } \\
\text { happened that you } \\
\text { didn't like, would you } \\
\text { know how to } \\
\text { complain? }\end{array}$ \\
\hline
\end{tabular}




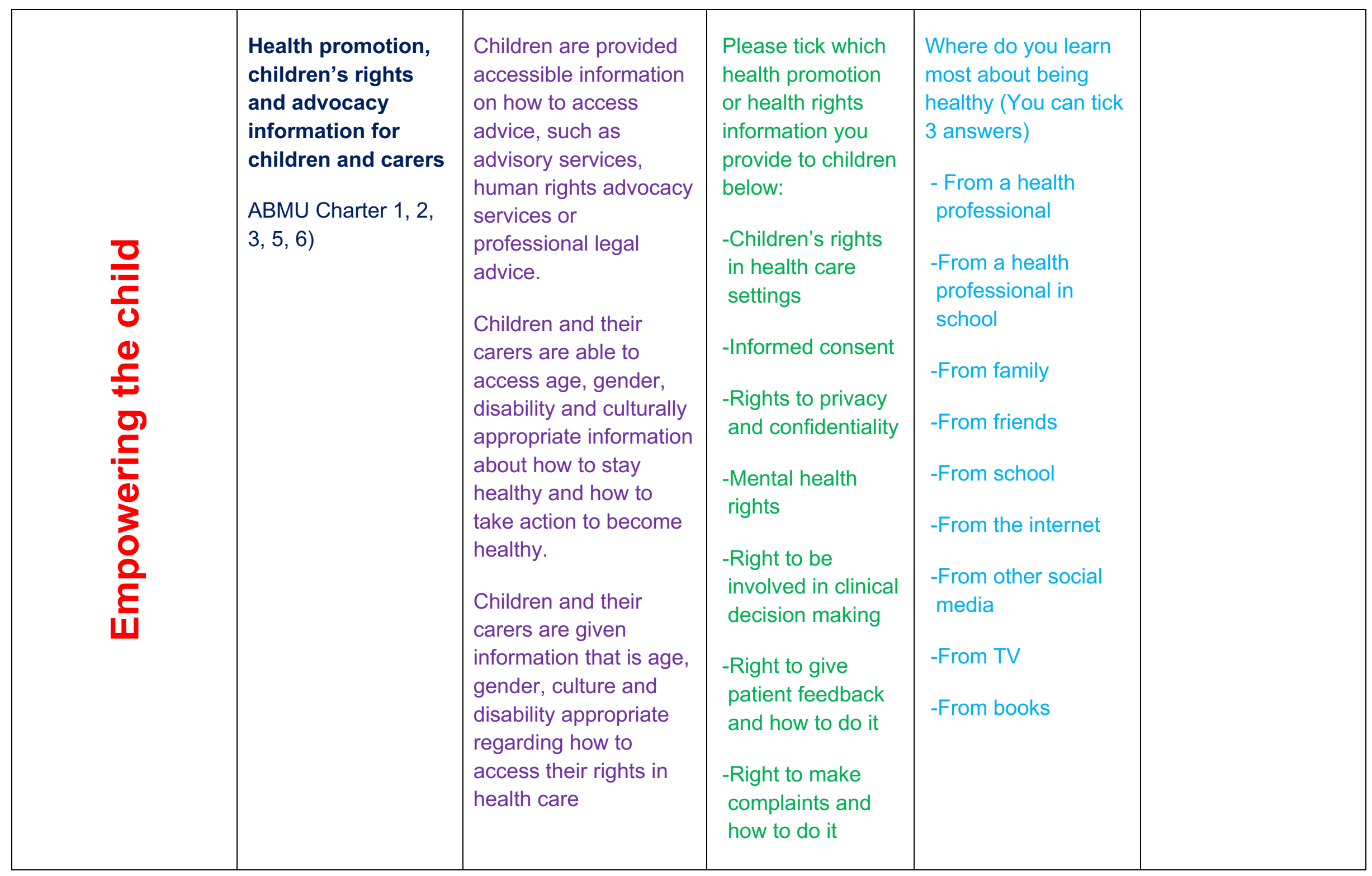




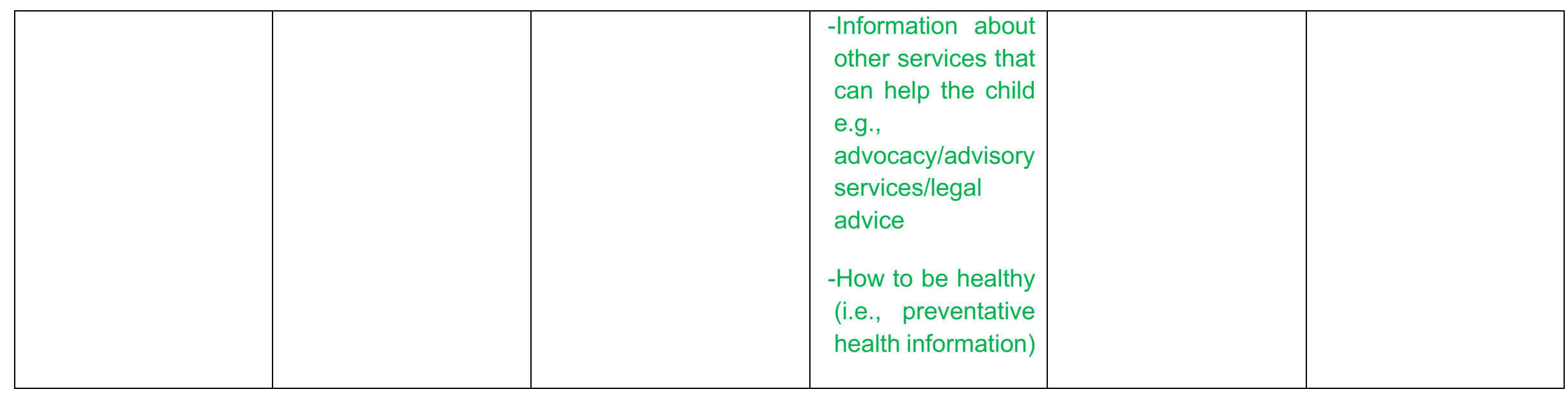




\section{CHAPTER 8 CHILDREN'S RIGHT TO CONSENT TO PARTICIPATE IN RESEARCH IN THE HEALTH SERVICES CONTEXT}

\subsection{Introduction}

Following on from navigating the complex NHS IRAS and NHS Ethics this section focuses on the complexity of children's right to consent to participate in research in the health context. The journey interrogating these issues started whilst navigating the NHS approval systems and awaiting the new UK Data Protection Legislation. Messages were received from Swansea University reminding post graduate researchers of the importance of gaining opt-in consent from parents when carrying out research with children in schools following the new data protection rules. I considered what this meant for my own research. The age of the child it was referring to and whether it was just relevant to research with children in schools. Including an 'opt in consent' for parents/carers for the 13-17 years survey did not sit comfortably with me. This chapter, therefore, aims to interpret the law surrounding children's right to consent to participate in research in the health context. The chapter considers whether notions of children's vulnerability are guiding decision making around consent, the confusion around the concept of 'assent' and whether 'competent' children should be able to make autonomous decisions. Conclusions are made regarding informing $A B M U$ decision making concerning the age at which young people could independently consent to the research.

\subsection{What does UK law say about children's consent to health research? ${ }^{1023}$}

As discussed in Chapter 4, 16/17 year olds are assumed competent to consent to medical treatment (Family Law Reform Act 1969, s. 8; Mental Capacity Act 2005, s. 1). ${ }^{1024}$ Under 16 year olds can consent to medical treatment in their best interests if

\footnotetext{
${ }^{1023}$ This chapter is referring to research clinical and non-clinical that does not constitute a clinical trial of an investigational medicinal product. Most research submitted to ethical review falls into this category.

${ }^{1024}$ However, under the common law in England and Wales, parents do not relinquish their power to give consent to treatment on behalf of their children until the age of 18: 'parents' and children's powers to consent thus coexist up to that point'. If a 16- or 17-year-old refused to consent to treatment, consent can still be obtained from their parents, or from a court, if treatment was held to be in their best interests
} 
they are considered Gillick competent ${ }^{1025}$ that is, if the minor has 'sufficient understanding and intelligence to enable him or her to understand fully what is proposed.' ${ }^{1026}$

As Alderson argues, so called Gillick competency goes slightly further than the UNCRC because as well as supporting a children's right to be informed, to express a view and have that view taken into account when decisions are made, when children are deemed competent they should be the 'main decision maker about a proposed intervention'. ${ }^{1027}$ I therefore presumed that Gillick competency would be applicable to children's involvement in health research and that based on my survey questions, the majority of 13 year olds upwards would have sufficient understanding and intelligence to answer the questions.

However, with my strong desire for the research to get through NHS Ethics I initially decided to err on the side of caution and pursue what Alderson refers to as the 'safest course' and seek both the young person's and the parent's/caregiver's consent. ${ }^{1028}$ I amended the young people's survey 13-17 years to include 'opt in consent' from parents and caregivers the same as the survey to be carried out with 7-12 years. Considering it was better to return some data collection even if I had to account for parental/carer influence in responses. The survey prior to going to NHS Ethics was sent to health partners for their consideration. They questioned why parents have to give consent to young people (especially in the older age group) taking part, arguing that it may form part of ethical approval, but they did not believe that it followed Fraser Guidelines. ${ }^{1029}$

\footnotetext{
${ }^{1025}$ Gillick $v$ West Norfolk \& Wisbeck Area Health Authority [1986] AC 112 House of Lords. ${ }^{1026} \mathrm{Ibid}$

${ }^{1027}$ Alderson P, 'Children's Consent and 'Assent' to Healthcare Research' In Freeman M (eds) Law and Childhood Studies: Current Legal Issues Volume 14 (Oxford Scholarship online 2012) 178

${ }^{1028}$ Alderson P, Listening to children: children, ethics and social research (London: Barnardos) 22. The safest course, is to ask for parental consent and also to ask for children's consent, when they are able to understand

${ }^{1029}$ It is important to emphasise that Frazer guidelines should not be subsumed into Gillick competence. Fraser Guidelines were based on Lord Fraser's advice as part of the Gillick case and have a narrower focus in relation to a young person's advice surrounding contraception. However, in this case and generally it appears health services conflate Frazer Guidelines with the larger concept of Gillick. Gllick competence and Fraser should not be seen to be interchangeable; for further discussion Wheeler R, 'Gillick or Fraser? A plea for consistency over competence in children-Gillick and Fraser are not interchangeable', 807 BMJ volume 3328 April (2006)
} 
I decided to find further information on the new Data Protection Legislation and found a useful draft guide written by the Information Commissioner. This document stated that:

If you are relying on consent as your lawful basis for processing personal data, when offering an online service directly to a child, only children aged 13 or over are able provide their own consent. ${ }^{1030}$

We allow competent children to exercise their own data protection rights. ${ }^{1031}$

Considering my research was not requesting any personal data, I considered there would be less of a risk to the children involved in the research than children being requested for personal data as a part of online services. I followed this up with an email to NHS Ethics to check if 13 years of age was a threshold at which children could independently consent to research before, I submitted my Research Protocol to the NHS Ethics Review, citing Gillick competence. NHS Ethics responded that if the data protection guidelines did not give a clear answer, then parental consent would be the safe option, however, they clarified that they should not be considered experts in relation to children and were not familiar with the Information Commissioner's guidance. They advised that I consult an expert in children's law.

I decided to seek clarity on the issue from the main advisory organisations working on this issue to try to determine where there was a clear legal standpoint on children's consent to involvement in health research. A Working Party from the RCPCH in 2014 stated:

The acquisition of capacity is a developmental continuum, and children over 12-14 years of age may have near-adult capacity. This poses potential difficulties in law. The legal test for capacity as it applies to medical treatment for those under 16 years of age, is the ability to understand what

\footnotetext{
${ }^{1030}$ Information Commissioner, Consultation Children and the GDPR Guidance 2017 https://ico.org.uk/media/about-theico/consultations/2172913/children-and-the-gdpr-consultationguidance-20171221.pdf accessed February 2018

${ }^{1031}$ Information Commissioner, General Data Protection Regulation for Children https://ico.org.uk/for-organisations/guide-to-the-general-data-protection-regulationgdpr/applications/children/ accessed May 2018
} 
is involved and the consequences (so-called Gillick or Fraser competence). As there is no direct case or statute law in the UK covering non-clinical trial research, ${ }^{1032}$ it has been presumed that the test of Gillick competence applies. In most instances, the child's assent or consent should be underpinned by parent consent, but this can be problematic where sensitive subjects, such as sexual health, contraception, and adolescent behavioural studies are involved, and there is a duty to preserve confidentiality. In such cases, the need for parental assent or consent should be carefully considered. ${ }^{1033}$

This fits with international guidance from the Council for International Organisations of Medical Sciences (CIOMS) in association with the WHO guidance in 2002, refers to children specifically and outlines that research can only happen if 'a parent or legal representative of each child has given permission', and 'the agreement of each child has been obtained to the extent of the child's capabilities.' 1034 If the child dissents to taking part in the research this should be respected. The explanation supporting the guidance suggests that although children over 12 or 13 years are usually considered capable of understanding what is required for informed consent, their consent should be supported by parental consent, even if the law of their jurisdiction does not require

1032 'Whilst competent children can consent to clinical treatment, children entering clinical trials of medicines within the UK and many other countries are not legally permitted to give informed consent for themselves (Medicines for Human Use (Clinical Trials) Regulations 2004).' In Madden L, Woolfall K, Sowden E, Smyth, R L, Williamson P R, Young B 'Questioning assent: how are children's views included as families make decisions about clinical trials?' Child: Care, Health and Development Volume 2016 42, Issue 6

${ }^{1033}$ Working party of the Royal College of Paediatrics Guidance on clinical research involving infants, children and young people: an update for researchers and research ethics committees (RCPCH 2014). The document also states that: Research should ideally carry no greater than minimal or low risk. However, research that involves greater than minimal risk may be acceptable if the interventions involve diagnostic procedures or treatments that are important for the individual child ${ }^{1034}$ The Declaration of Helsinki developed by the World Medical Association in 1964 outlines the medical principles to be applied to medical research involving human subjects. It is a clear statement that human subjects who are capable of giving their informed consent to research participation must be voluntary. If a human subject is not capable of giving their informed consent then their consent must be given by a legally authorised representative. However, if the research subject is considered not capable of giving their informed consent their assent must be sought as well as the consent of the legally authorised representative and the subject's dissent should be respected. No specific reference is made in the Declaration to 'minors' or 'children'. The distinction is made between those deemed capable and those deemed incapable to give consent. There is also no clarity with regards to how 'assent should be understood' https://www.wma.net/policies-post/wma-declaration-of-helsinkiethical-principles-for-medical-research-involving-human-subjects/ accessed January 2020 
this. However, there is the caveat that with regards to certain forms of research e.g., adolescent sexual health, illegal drugs, child abuse, domestic violence, parental permission may be waived if considered appropriate. It also suggests that children, who are already living independently, are parents or married, may be able to give consent without the permission or even knowledge of their parents.

At the local level, WG Guidance 2017, outlined that Gillick competent children under the age of 16 years may be able to consent to research:

\begin{abstract}
The case of Gillick determined that children who have sufficient understanding and intelligence to enable them to understand fully what is involved in a proposed intervention, will have the capacity to give their consent to that intervention. This is sometimes described as being 'Gillick competent'. A child under 16 years of age may 'be Gillick competent to consent to medical treatment, research, donation or any other activity that requires their consent. ${ }^{1035}$
\end{abstract}

As the RCPCH and the WG guidance illustrates because there is no UK Statute law covering children's involvement in research, as I suspected, the presumption is that the Gillick competence test applies.

The most recent case law where the question of the confidentiality owed to minors who do not wish to involve their parents in aspects of their healthcare was furthered in the case of $R$ (on the application of Axon) $v$. Secretary for State for Health and Another [2006] EWHC 37. ${ }^{1036}$

However, there is still a lack of clarity with regards to the older age group of children, with a presumption, like in the international guidance that young people's consent should be underpinned by parental consent.

\footnotetext{
${ }^{1035}$ Welsh Government, Patient Consent to Examination and Treatment - Revised Guidance, Welsh Health Circular (WHC 2008,10, February 29)

${ }^{1036}$ For further discussion see Modi N, Vohra J, Preston J et al, 'Guidance on clinical research involving infants, children and young people: an update for researchers and research ethics committees', Archives of Disease in Childhood (2014) 99(10): 887-91
} 
It is good practice for parental consent to be obtained as well as obtaining consent from a competent child. ${ }^{1037}$ [Welsh Government]

When a young person is believed to be competent, consent from those with parental responsibility is not legally necessary. However, the involvement of parents in decision-making is encouraged in most circumstances. [Health Research Authority]

So, I decided to return to an interrogation of the literature on this issue, relating to children's consent in research.

\subsection{Are notions of childhood vulnerability guiding decisions regarding children's consent to health research?}

An article written by Ballen et al resonated with my own complexities to securing young people's independent right to consent to participate in the research. Ballen et al note that services conceptualise children as 'active beings' and were available to children without parental knowledge or permission, whereas research ethics and gate-keeping systems were conceptualising children as 'human becomings', as dependent and in need of protection and only allowing children to participate in research if the parent's consent was also obtained. ${ }^{1038}$

Ballen et al ask the question 'In what circumstances does adult gate keeping become interference in the rights of children to impart information and ideas through their participation in research?'1039 There is a significant body of literature that says that research gate keeping systems are essentially adult centred and conceptualise children as both first and foremost 'vulnerable' and dependent. ${ }^{1040}$ It suggests that

\footnotetext{
${ }^{1037}$ Welsh Government, Patient Consent to Examination and Treatment - Revised Guidance, Welsh Health Circular, (WHC 2008,10, February 29)

${ }^{1038}$ Balen R, Blyth E, Calabretto H, Fraser C, Horrocks C, and Manby M, Involving children in health and social research: 'Human becomings' or 'active beings'? Childhood, 2006 13(1), 29-48.

${ }^{1039}$ Ibid 32

${ }^{1040}$ Morrow V, and Richards M, 'The ethics of social research with children: an overview', Children \& Society (1996) 10, 90; Hood S, Kelley P and Mayall B, 'Children as research subjects: a risky enterprise', Children and Society (1996) 10, 117-128; Miller S, 'Researching children: issues arising from a phenomenological study with children who have diabetes mellitus', Journal of Advanced Nursing (2000) 31, 1228-1234; Masson, J 'The legal context', In Fraser S, Lewis V, Ding S, Kellett $\mathrm{M}$ and Robinson C (Eds.), Doing research with children and young people,(London: Sage
} 
children need to be protected from questions that are construed to be upsetting or worrying and can result in children's views on issues being almost silenced, marginalised or reduced. This silencing is disturbing; for example, considering the issue of physical punishment children may offer an alternative viewpoint to their parents ${ }^{1041}$ and it is the physical punishment, inflicted on the child that is more distressing not necessarily the research carried out to find their independent views on the issue. Mason, although respecting the important function of parents and gatekeepers protecting children, points out they can also use their power to censor children's voices. ${ }^{1042}$

It also became apparent from a further review of the literature that even if a young person is deemed to be competent to give consent, in the majority of cases parental consent has to be sought ${ }^{1043}$ and children find themselves excluded from research if parents did not give consent but they consented to participate. ${ }^{1044}$ Children under the age of 16 years are regularly accessing services, such as counselling, that recognises them as autonomous individuals and attending without the consent of their parents. ${ }^{1045}$ Ballen et al revealed that there is often a higher age threshold for children to participate independently in research than to participate in services. ${ }^{1046}$ Also, other research notes that if you look at the reality of children's lives, many children are looking after siblings,

Publications 2004) 43-58; Hill M, Davis J, Prout A, and Tisdall K, 'Moving the participation agenda forward', Children and Society (2004) 18, 77-96; Balen R, Blyth E, Calabretto H, Fraser C, Horrocks $\mathrm{C}$, and Manby M, 'Involving children in health and social research: 'Human becomings' or 'active beings'? Childhood, 13(1), 36; Powell M, and Smith A B, 'Children's participation rights in research', Childhood (2009) 16, 124-142

${ }^{1041}$ Evidence suggests that adults are much more likely to have a different perspective on the removal of the defence of physical punishment of children. See Dobbs, T \& Duncan J 'Children's Perspectives on Physical Discipline: A New Zealand Example', Journal Child Care in Practice (2004) Volume 10, 2004 - Issue 4

${ }^{1042}$ Mason J, 'The Legal Context', In Fraser S, Lewis V, Ding S, Kellett M and Robinson C (eds)

Doing Research with Children and Young People (London: Sage Publications 2004)

${ }^{1043}$ Morrow V, and Richards M, The ethics of social research with children: an overview, Children \& Society (1996) 10, 90-105; Greig A and Taylor J, Doing Research with Children (London: Sage 1999); Mullender A, Hague G, Imam U, Kelly L, Malos E and Regan L, Children's Perspectives on Domestic Violence (London: Sage 2002)

${ }^{1044}$ Goodenough T, Williamson E, Kent J and Ashcroft R, 'What did you think about that?

Researching children's perceptions of participation in a longitudinal genetic epidemiology study,' Children and Society (2003) 17, 113-125.

${ }^{1045}$ Balen R, Blyth E, Calabretto H, Fraser C, Horrocks C, and Manby M. (2006) Involving children in health and social research: 'Human becomings' or 'active beings'? Childhood, 13(1)

${ }^{1046} \mathrm{Ibid}$ 
caring for parents, and in many cases looking after the household, so why should they be deemed too young to make decisions about being involved in research? ${ }^{1047}$ Research undertaken by Powell et al, demonstrates that even very young children or children with learning difficulties are capable of consenting to research. ${ }^{1048}$ As Gallagher et al makes clear, excluding them from the research process only serves to reinforce the viewpoint that they are both incompetent and dependent. Instead, the researcher could as Gallagher et al suggest, creatively adapt to the capabilities of the children to best support the process of informed consent. ${ }^{1049}$

Additionally, as the Working party from the Royal College of Paediatrics point out:

The age of criminal responsibility also provides an interesting point of comparison: in England and Wales, for example, it is currently set at age ten and in Scotland at age eight. ${ }^{1050}$ Young children in the UK are thus deemed capable, in the context of criminal behaviour, of assuming a level of responsibility with respect to their own actions at a time when it is implicitly assumed they cannot take responsibility for even very minor decisions about research that may have few if any long-term consequences for them. ${ }^{1051}$

With reference to research examining children's participation in democracy, this presents further evidence that children are increasingly taking on advising roles across public services and are engaging and influencing UN treaty monitoring processes from

\footnotetext{
${ }^{1047}$ Cheah P Y, and Parker M 'Research consent from young people in resource-poor settings', Archives of Disease in Childhood (2015) 100(5): 438-40

${ }^{1048}$ Powell M A, Fitzgerald R M, Taylor N, Graham A, International literature review: ethical issues in undertaking research with children and young people (Southern Cross University ePublication@SCU 2012)

${ }^{1049}$ Gallagher M, Haywood S, Jones M, and Milne S, 'Negotiating informed consent with children in school-based research: A critical review,' Children and Society (2010) 24, 471482

${ }^{1050}$ To be acknowledged that Scotland changed their age of criminal responsibility to 12 years of age in 2019; Age of Criminal Responsibility Act (2019)

http://www.legislation.gov.uk/asp/2019/7/contents/enacted accessed January 2020

${ }^{1051}$ Nuffield Bioethics, Children and Clinical Research: Ethical Issues, (Nuffield Bioethics 2015) para 263

http://nuffieldbioethics.org/wpcontent/uploads/Children-and-clinical-research-Chapter-2.pdf accessed January 2017
} 
the age of 7 years upwards. ${ }^{1052}$ So there is a tension in both legislation and policy for children, in the understandings surrounding when children should be deemed competent to make decisions.

Over thirty years ago, Grisso and Vierly ${ }^{1053}$ published a review of developmental psychology research relevant to the capacity of minors and concluded that there is little evidence to suggest that young people aged 15 and above are less competent to give consent than are adults and a survey by Leiken ten years later reached a similar conclusion. ${ }^{1054}$ In recent research, in 2015 , by Hein et al using an assessment tool with the 4 relevant criteria, of 'understanding, appreciation, reasoning and choice,' have concluded that the majority of children from 11.2 years can be deemed decision making competent and 'assuming that children older than 11.2 years cannot provide competent consent appears to have no ground. ${ }^{1055}$ Additionally, children as young as 9.6 years can be considered decision making competent on a case by case basis with regards to involvement in clinical research. ${ }^{1056}$ Hein et al's findings are summarised in Table 14 below.

\footnotetext{
${ }^{1052}$ Croke R and Williams J, Our rights, our parliament: The story of the campaign for the children and young people's assembly for Wales 2014-2018 (Swansea University 2018)

${ }^{1053}$ Grisso T and Vierling L, 'Minors' Consent to Treatment: A Developmental Perspective' ProfPsych (1978) 9: 412-427

${ }^{1054}$ Leikin SL, 'A Proposal Concerning Decisions to Forgo Life Sustaining Treatment for Young People', JPediatr (1989) 108:17-22; Weithorn L.A. and Campbell S.B, 'The Competency of Children and Adolescents to Make Informed Treatment Decisions', Child Dev (1982) 53: 1589-1598 ${ }^{1055}$ Hein I M, De Vries M C, Troost P W, Meynen G, Johannes B, Van Goudoever J B and Lindauer $\mathrm{R} \mathrm{J} \mathrm{L}$, 'Informed consent instead of assent is appropriate in children from the age of twelve: Policy implications of new findings on children's competence to consent to clinical research' BMC Med Ethics (2015) 16: 76

${ }^{1056}$ Ibid
} 
TABLE 14: MacCAT-CR MacArthur Competence Assessment Tool for Clinical Research

\begin{tabular}{|l|l|}
\hline 11.2 years and above & $\begin{array}{l}\text { Decision making competent and able to } \\
\text { give informed consent }{ }^{1057}\end{array}$ \\
\hline 9.6 years and 11.2 years & $\begin{array}{l}\text { Transition period, some capacities but } \\
\text { maturity not pervasive, case by case } \\
\text { assessment }\end{array}$ \\
\hline Under 9.6 years & Decision making incompetent \\
\hline
\end{tabular}

At this juncture, the neuro-science literature regarding the adolescent brain needs some discussion because this paradigm suggests that human brains are not fully developed until they are 25 years of age. Neuroscience using functional MRI testing has revealed that there are marked changes in brain activity during adolescence associated with impulse control ${ }^{1058}$, resisting immediate rewards ${ }^{1059}$ and emotional processing. ${ }^{1060}$ Neuroscience presents evidence that cognitive systems involved with decision making and impulsivity don't develop in their entirety until humans are 25 years of age. Neuroscientists use this evidence to support the so-called heightened risk-taking behaviour stereotypical to adolescents.

However, there have been challenges to the field of neuroscience with cross-cultural evidence that the characterisation of adolescence as one of 'psychological turmoil is not an inevitable aspect of adolescence driven by the brain.' ${ }^{1061}$ Choudhury

\footnotetext{
${ }^{1057}$ Ibid 5: 'In special research populations where there are reasons to doubt children's decisionmaking capacities (e.g., intellectual disabled children or paediatric patients with a psychiatric disorder that diminishes competence), a research protocol could include a standardized competence assessment of participants.'

${ }^{1058}$ Liston C, Watts R, Tottenham N, Davidson MC, Niogi S, Ulug Am, Casey BJ 'Frontostriatal microstructure modulates efficient recruitment of cognitive control', Cereb Cortex (2006) Apr 16(4):553-60. Epub 2005 Jul 20; Velanova K, Wheeler M E and Luna B, 'Maturational Changes in Anterior Cingulate and Frontoparietal Recruitment Support the Development of Error Processing and Inhibitory Control', Cereb. Cortex 18 (2008) 2505-2522

${ }^{1059}$ Olson E A, Collins P F, Catalina H J, Muetzel R, 'White Matter Integrity Predicts Delay Discounting Behavior in 9- to 23-Year-Olds: A Diffusion Tensor Imaging Study', Journal of Cognitive Neuroscience 21, (2009) 1406-1421

${ }^{1060}$ Burnett S, Bird G, Moll J, Frith C and Blakemore S J, 'Development during adolescence of the neural processing of social emotion', Journal of Cognitive Neuroscience (2009) 1736-1750

${ }^{1061}$ Choudhury S, Culturing the adolescent brain: what can neuroscience learn from anthropology? Social Cognitive and Affective Neuroscience, (2010) Volume 5, Issue 2-3, 1 June 2010, 159-167
} 
demonstrates through a detailed examination of historical and ethnographic research that increased risk-taking is not common to all cultures and therefore neurobiology cannot be the universal cause of this behaviour in adolescents. It is instead important to consider the many socialisation processes that contribute to how adolescents are defined, and to thus understand that adolescence is a socially and culturally defined category. Buchen also argues when examining the criminal behaviour of adolescents:

Focusing on biology draws attention away from socioeconomic, educational and cultural drivers of criminal behaviour. After all, most teenagers do not commit murder, despite their fledgling frontal cortices. ${ }^{1062}$

Buchen refers to the case of Miller, explaining that the child had experienced a catalogue of abuse and violence in his early life leading up to his adolescence when he himself committed murder. Social policy should be addressing the denial of his human rights he faced in his early life not just accepting the framework of neuroscience that would like to argue that he committed murder because of his fragile, less competent, risk taking adolescent mind.

As outlined in Chapter 6, Tobin cautions that it can no longer be assumed 'that decision makers, parents, teachers, doctors, judges, institutions or government officials, will automatically know what is in the best interests of the child'. ${ }^{1063}$ It is additionally concerning that a 2010 study by De Vries et al, demonstrated that doctors and researchers tend to judge a child to be competent if the child's decision conforms to their own ideas of what is in the child's best interest. ${ }^{1064}$ This means, as Hein et al

\footnotetext{
${ }^{1062}$ Buchen L, 'Science in court: Arrested development', Nature News, International weekly journal of science (2012) Volume 484, Issue 7394

${ }^{1063}$ Tobin J, 'Understanding a human rights based approach to matters involving children: conceptual foundations and strategic considerations', In Invernizzi A and Williams J (eds), The Human Rights of Children: From Visions to Implementation. (Farnham: Ashgate 2011)89

${ }^{1064}$ Hein I M, De Vries M C, Troost P W, Meynen G, Johannes B, Van Goudoever J B and Lindauer R J L, 'Informed consent instead of assent is appropriate in children from the age of twelve: Policy implications of new findings on children's competence to consent to clinical research' BMC Med Ethics (2015) 16: 76; De Vries MC, Wit JM, Engberts DP, Kaspers GJL, Van Leeuwen E. Norms versus Practice: Pediatric Oncologists' Attitudes towards Involving Adolescents in Decision Making concerning Research Participation. Pediatr Blood Cancer. 2010;55:123-128.
} 
argue, 'that competence is gauged by the outcome of the decision rather than by the process of reasoning in deciding about participation.' 1065

Hein et al when referring to Article 3 of the UNCRC comment:

If a child possesses all the required decision-making capacities which means that it understands the relevant information, is able to appreciate the consequences of the decision, capable of reasoning and of expressing a choice, in other words if a child is considered competent to give informed consent, that would mean that a child is capable of acting in its best interest. ${ }^{1066}$

If the child demonstrates this decision making capacity and the professional deems them not competent based on the child's different interpretation of what is in their best interests, it could be said to be a decision based on age discrimination that makes assumptions that minors should be treated differently to adults. ${ }^{1067}$ These assumptions go contrary to the empirical research relating to age-based competence and the recommendation of the original Gillick ruling that children much younger than 16 and 17 years are for the most part competent decision makers. It is also contrary to the developing jurisprudence from the UN Committee on the Rights of the Child in relation to evolving capacities that Varadan draws our attention to and was discussed in Chapter 6. ${ }^{1068}$ Coyne also argues that often assumptions that children are unable to understand the risks, benefit and purpose of research apply equally to adults. ${ }^{1069}$ Coyne presents evidence that suggest "parents often find it difficult to comprehend and absorb the implications of the research for their child. '1070

\footnotetext{
${ }^{1065}$ Hein I M, De Vries M C, Troost P W, Meynen G, Johannes B, Van Goudoever J B and Lindauer $\mathrm{R} \mathrm{J} \mathrm{L}$, 'Informed consent instead of assent is appropriate in children from the age of twelve: Policy implications of new findings on children's competence to consent to clinical research', $B M C \mathrm{Med}$ Ethics (2015) 16: 76, 4.

${ }^{1066}$ Ibid

${ }^{1067}$ Liebel M, 'Adultism and Age Based Discrimination against children' In, Kutsar, D \& Warming, H (eds) Children and non-discrimination, inter-disciplinary textbook (University of Estonia press 2014) 123

${ }^{1068}$ Varadan S, 'The Principles of Evolving Capacities under the Convention on the Rights of the Child', International Journal of Child Rights (2019) Volume 27 Issue 2

${ }^{1069}$ Coyne I, Accessing children as research participants: examining the role of gatekeepers.

Childcare, health and development Vol 36 Issue 4 (2010)

${ }^{1070}$ Ibid
} 
The UN Committee on the Rights of the child acknowledges that age should not be the only criterion for competence' and 'children's levels of understanding are not uniformly linked to their biological age'. ${ }^{1071}$ Instead, the extent to which each child's views are taken seriously should be dependent on their understanding of the issues concerned in accordance with the evolving capacity of each child. According to the $\mathrm{RCPCH}$ :

Children's ability to consent develops as they learn to make increasingly complex and serious decisions. Ability may relate to experience rather than to age, and even very young children appear to understand complex issues. They should therefore be informed as fully as possible about the research in terms they can understand. ${ }^{1072}$

Hein et al comment, there is the risk with a 'set age-limit, some incompetent individuals above the limit will unjustly be deemed competent and some competent individuals below the limit unjustly deemed incompetent.'1073 However, without some kind of framework, we are left to the subjective judgements of health professionals, who as the recent evidence suggests, push their own perspective of what is in the best interests of the child. Instead of a framework which supports younger decision-making competent children giving their own informed consent to what they consider is in their

${ }^{1071}$ UN Committee on the Rights of the Child (2009) General Comment No. 12: The right of the child to be heard, $\mathrm{CRC} / \mathrm{GC} / 12 / 2009$ para 29

${ }^{1072}$ McIntosh N and Hull D, 'Guidelines for the ethical conduct of medical research involving children, Royal College of Paediatrics, Child Health: Ethics Advisory Committee', Archives of Diseases of Childhood Volume 82, 180

${ }^{1073}$ Hein I M, De Vries M C, Troost P W, Meynen G, Johannes B, Van Goudoever J B and Lindauer R J L, 'Informed consent instead of assent is appropriate in children from the age of twelve: Policy implications of new findings on children's competence to consent to clinical research', BMC Med Ethics (2015) 16: 76. 
best interests. ${ }^{1074}$ Should the framework be changed to be comparable to that of adults; instead of a presumption of incompetence, a presumption of competence? ${ }^{1075} 1076$

It is apparent from the regulation of clinical research, via international ethical declarations, to national law which spans out and influences non-clinical research, they conceptualise children in contrast to autonomous adults as distinctly vulnerable. ${ }^{1077}$ This has had the impact of influencing clinicians, researchers and review bodies to drive an approach that sees children first and foremost as vulnerable and also unable to make decisions and therefore in need of protection, instead of supported to have their voice heard. ${ }^{1078} \mathrm{It}$ is arguable that there needs to be a balance between the two approaches rather than seeing them dichotomously, that researchers/clinicians/review bodies are always aware of the possibility of vulnerability, but this has to be balanced with the benefits of a child's right to have their voices heard in issues that affect them through participation in a research process. ${ }^{1079}$

Recent reports by the Nuffield Council on Bioethics and RCPCH challenge ethics committees' traditional conceptualisations of childhood vulnerability and are pushing for a more balanced approach:

from a young age, children have a role in determining their own lives and should be seen as active participants in research. The assumption that all

\footnotetext{
${ }^{1074}$ Further to De Vries et al (2010), the Case of NHS Trust v. Baby X and others [2012] EWHC 2188; Ian Kennedy, has criticised the use of the language of 'best interests' also in this context, on the basis that it simply serves to legitimise decisions based on instinct (a form of 'ad hocery') with the 'empty rhetoric of best interests', Kennedy I, Treat me right: essays in medical law and ethics (Oxford: Clarendon Press 2001) 395

${ }^{1075}$ In the majority of jurisdictions children are presumed 'incompetent' whereas adults are presumed competent. 'American Academy of Pediatrics Committee on Bioethics, 'Informed consent, parental permission, and assent in pediatric practice' Pediatrics (1995) 95:314-317

1076 'It is not up to the child to first prove her or his capacity.' UN Committee General Comment No.12 2009: para 20

${ }^{1077}$ Nuffield Council of Bioethics, Children and Clinical Research: Ethical Issues (Nuffield Council do Bioethics 2015) 34, 35 and Chapter 4, 453

${ }^{1078}$ Nuffield Council of Bioethics, Children and Clinical Research: Ethical Issues (Nuffield Council do Bioethics 2015) Chapter 4, 453 and Nuffield Council of Bioethics Summary, 28

${ }^{1079}$ There can be no correct application of the assessment of what is in the best interests of the child (article 3 of the UNCRC) unless the components of article 12 (the right to be heard) are respected. All children (and this should not be restricted to biological age) should be asked for their opinion and given opportunities to consent or refuse treatment or to participate in research. This is a clear recommendation of the UN Committee on the Rights of the Child in their General Comment No.14 on Best Interests.
} 
children are necessarily vulnerable may prevent worthwhile research from going ahead. ${ }^{1080}$ [Nuffield Council of Bioethics 2015]

Children require considered protection, but this should not preclude the claim of other rights, including the right to the highest standard of health care, and to be informed, express their views, and influence decisions made about them (UNCRC 1989). ${ }^{1081}$ [RCPCH 2014]

However, even though both bodies are pushing for a more balanced approach to notions of children's vulnerability, they still defer to the safest course, i.e., seeking parental consent as well as children's consent or assent.

\subsection{The concept of 'Assent', is it fit for purpose?}

There is also the complexity surrounding the concept of "assent", which medical councils globally do not have a shared agreement to its meaning. ${ }^{1082}$ In the UK,

'assent' refers to acquiescence... [RCPCH]

affirmative agreement to participate. Failure to object should not be construed as assent but later on "Does the child actively object?" and if no, "research may proceed" [Medical Research Council]

With regards to children who are deemed not legally competent, researchers/health professionals are required to seek a child's affirmative agreement to participate. However, if the parents and child's response is incompatible and for example the child dissents and the parent consents, then arguably assent has no role because the parent's decision to consent overrides that of the child. Assent additionally does not have the legality and power of consent. ${ }^{1083}$ Baines argues that 'the concept of assent

${ }^{1080}$ Nuffield Council on Bioethics Summary of report Children and clinical research: ethical issues (Nuffield Council of Bioethics 2015).

${ }^{1081}$ Working party of the Royal College of Paediatrics, Guidance on clinical research involving infants, children and young people: an update for researchers and research ethics committee, (Working party of RCPCH 2014) 2

${ }^{1082}$ Baines P, 'Assent for children's participation in research is incoherent and wrong', Archives of Diseases in Childhood, Volume (2011) 96 Issue 10

${ }^{1083}$ Oulton K, Gibson F, Sell D, Williams A, Pratt L, Wray J, 'Assent for children's participation in research: why it matters and making it meaningful. Child Care, Health and Development' (2016) Vol. 42, Issue 4, 589 
is ill thought-out, confused and harmful' he contests that 'decisions should be made for incompetent children by their parents' and that children who are competent should be able to give their informed consent and considers there is no meaningful space for assent in the research process. ${ }^{1084}$

However, others argue that assent allows children to be involved in decision making and although they may not have a complete understanding of the research and what it entails, they can demonstrate an active agreement to their participation. ${ }^{1085}$ Oulton et al, while agreeing that it may be ill thought out suggest that it has a 'valuable educative process that has important consequences for children's participation in research, including the likelihood of reducing the risks of promoting open discussion and establishing trust.' ${ }^{1086}$ They also report:

Congruent with the latest guidance from the Nuffield Council on Bioethics (2015), our emphasis is that wherever possible, a decision about taking part, or not, should be a shared decision between a child/young person and their parents/carers. We support their view that assent is valuable in situations where a child is able to communicate what they think about research but is not able to make a decision independently of their parents. ${ }^{1087}$

Is this not a matter of terminological application; the UNCRC promotes an approach that all children, no matter their age, have an Article 12 right to influence decisions that affect them. This should be done in a manner that is meaningful and accords their views due weight. Those responsible for hearing the child must ensure that the child

\footnotetext{
${ }^{1084}$ Baines P, 'Assent for children's participation in research is incoherent and wrong', Archives of Diseases in Childhood. Volume (2011) 96 Issue 10, 962 and see also Alderson P 'Children's Consent and 'Assent' to Healthcare Research' In Freeman M (eds) Law and Childhood Studies: Current Legal Issues Volume 14 (Oxford Scholarship online 2012)

${ }^{1085}$ Giesbertz N A A, Bredenoord A L and Delden van J J M, 'Clarifying assent in pediatric research', European Journal of Human Genetics (2014) volume 22, 266-269; Waligora M, 'Is a requirement of personalised assent realistic? A case from the GABRIEL project, European Jounal of Human Genetics Volume 22, (2014) 855; Wilkson D, 'Dissent about assent in paediatric research, Journal of Medical Ethics (2012) 38(1):2

${ }^{1086}$ Oulton K, Gibson F, Sell D, Williams A, Pratt L, Wray J, 'Assent for children's participation in research: why it matters and making it meaningful', Child Care, Health and Development' (2016)

Vol. 42, Issue 4, 589

${ }^{1087}$ Ibid 590
} 
is informed about her/his right to express her/his opinion in all matters affecting them and that they are given a safe space, opportunities and adequately prepared and supported to participate in any decision making process that may have an impact upon them. ${ }^{1088}$ The Committee on the Rights of the Child explains that the context should always be enabling and encouraging and the adult (s) must demonstrate a willingness to listen and to seriously consider what the child has decided to communicate, with their views given due weight ${ }^{1089}$ (see Lundy's Model Chapter 6). The child should be able to express an opinion freely and without the expectation that their decision must be in compliance with that of the adults. ${ }^{1090}$

Interestingly, Oulton et al who believe that 'assent' is an important element of securing participation in the research process, did not carry out any research with children. Instead, the research was carried out with 48 adult health professionals. ${ }^{1091}$ A great deal has been written about the concept of assent, but there has been limited empirical work to 'involve children to inform these ideas and whether they resemble children's decision making practice'. ${ }^{1092}$ In research where children were included in the study about the assent process, it was noted that parents play a 'substantial mediating role in producing their children's decisions' and 'whilst children valued their parents' role, a case study of child-parent disagreement indicated how children can struggle to be heard'. ${ }^{1093}$ Assent being reached independently of the family environment is not always the case, although the biomedical literature likes to suggest that decisions by children are predominantly made, separate from their parents. ${ }^{1094}$ It would be good practice to

${ }^{1088}$ UN Committee on the Rights of the Child, General Comment No. 12: The right of the child to be heard, $\mathrm{CRC} / \mathrm{GC} / 12 / 2009$ para 41

${ }^{1089}$ Ibid para 42

${ }^{1090}$ Balen R, Blyth E, Calabretto H, Fraser C, Horrocks C, and Manby M, 'Involving children in health and social research: 'Human becomings' or 'active beings'? Childhood, 2006 13(1),44 ${ }^{1091}$ Oulton K, Gibson F, Sell D, Williams A, Pratt L, Wray J 'Assent for children's participation in research: why it matters and making it meaningful', Child Care, Health and Development', (2016) Vol. 42, Issue 4

1092 Madden L, Woolfall K, Sowden E, Smyth, R L, Williamson P R, Young B 'Questioning assent: how are children's views included as families make decisions about clinical trials?' Child: Care, Health and Development Volume 2016 42, Issue 6,901

${ }^{1093}$ Ibid 904

${ }^{1094}$ Tait A, Voepel-Lewis T, Malviya S, 'Do they understand? (Part II) Assent for children participating in clinical anesthesia and surgery research', Anaesthesiology 2003; 98; Hein I M, De Vries M C, Troost P W, Meynen G, Johannes B, Van Goudoever J B and Lindauer R J L, 'Informed consent instead of assent is appropriate in children from the age of twelve: Policy implications of new findings on children's competence to consent to clinical research', BMC Med Ethics (2015) 16: 76. 
find out from children whether they consider it helpful or indeed fair when they make one decision and then an adult says something contrary, and their decision is consequently vetoed. This has the potential to be disempowering and silencing instead of a child feeling empowered and believing they have a voice that is heard in the process.

\subsection{Should competent children have the right to make autonomous decisions?}

If a child is decision making competent should a child's decision be respected and the child's autonomous decision to consent to research be the overriding decision? If the child is determined competent, why should they have to make a shared decision to consent with an adult? Gillick competency should then be respected whereby children when deemed competent should be the 'main decision maker about a proposed intervention.'1095

The Nuffield Council on Bioethics 2015 argue that there is a:

morally significant difference between 'competent children' and 'adults' which they consider may justify differential treatment. Children, however intellectually capable, do not have full adult powers - and the corollary of that is that they also do not have full adult responsibilities. Parents are there, both ethically and legally, to share that responsibility until the agreed threshold of adulthood is reached. ${ }^{1096}$

Additionally, Hein et al although agreeing that 'assent' is not a useful concept argue that:

To achieve a balanced consideration between the legal position of the child and that of the parents, a dual consent procedure (child and parent) is recommended for minors from the age of 12 until the age they are allocated rights for independent consent. Even if we establish a child's decision-

\footnotetext{
1095 Alderson P, 'Children's Consent and 'Assent' to Healthcare Research', In Freeman M (eds) Law and Childhood Studies: Current Legal Issues Volume 14 (Oxford Scholarship online 2012) 178

${ }^{1096}$ Nuffield Council on Bioethics, Summary and Conclusions: Children and clinical research: ethical issues (Nuffield Council of Bioethics 2015) para 31
} 
making competence regarding the medical decision at hand, a dual consent procedure will do justice to developmental aspects of children and the specific characteristics of the parent-child dyad. The parental role is needed to offer extra protection by creating the context for the child's competent decision-making and by facilitating the child's long term autonomy. ${ }^{1097}$

The dual consent procedure advocates for quite a significant shift from the current legal context of 'assent' and recognises the legality of a young person's right to give consent. However, Hein et al lean towards a dual consent procedure seems to go contrary to their own research which deems children as young as 11.2 years to be decision making competent and indeed other research which presents contrasting evidence that parent's themselves struggle to make informed decisions. ${ }^{1098}$ It does not recognise competent children as autonomous decision makers.

Returning to informed consent to clinical research, which influences all other research in the health context, as can be seen in the Table 15 below, there is jurisdictional diversity in the age criteria regarding informed consent. From the extreme end in the US, 18 years of age, to Canada and Switzerland having the most liberal approach, whereby anybody who is deemed capable can give their informed consent. This approach would seem to be the least discriminatory approach that treats children as subjects of human rights, equal to adults with competence determined on a case-bycase basis.

${ }^{1097}$ Hein I M, De Vries M C, Troost P W, Meynen G, Johannes B, Van Goudoever J B and Lindauer R J L, 'Informed consent instead of assent is appropriate in children from the age of twelve: Policy implications of new findings on children's competence to consent to clinical research,' BMC Med Ethics (2015) 16: 76, 6

${ }^{1098}$ Coyne I, Accessing children as research participants: examining the role of gatekeepers. Childcare, health and development Vol 36 Issue 4 (2010) 
Table 15: Examples of age criteria and informed consent to clinical research in other countries (drawn from Hein et al 2014)

\begin{tabular}{|l|l|}
\hline US & 18 years \\
\hline UK & $\begin{array}{l}16 / 17 \text { years deemed competent, under } \\
16 / 17 \text {-year-olds on a case by case basis } \\
\text { deemed competent, but } \\
\text { parents/guardians having the right to } \\
\text { refuse informed consent up to the age } \\
\text { of } 18 \text { years. }\end{array}$ \\
\hline Denmark & $\begin{array}{l}15 \text { years } \\
\text { Netherlands }\end{array}$ \\
\hline Canada & $\begin{array}{l}\text { Anyone who is capable can give } \\
\text { informed consent, whereby competence } \\
\text { is evaluated on a case-by-case basis } \\
\text { (dependent on which Canadian } \\
\text { province). }\end{array}$ \\
\hline Switzerland & $\begin{array}{l}\text { Anyone who is capable can give } \\
\text { informed consent, whereby competence } \\
\text { is evaluated on a case-by-case basis. }\end{array}$ \\
\hline
\end{tabular}

The UK is currently a distance away from this more liberal approach; it therefore may be useful to have an age-based framework that is based on the current research, a presumption of children's competence for autonomous decision making and right to give independent consent from 12 years as an interim arrangement to convince medical professionals/research ethics committees over time, that the younger age group do have capacity before moving to a case-by-case approach. As Alderson points out health professionals after years of working with children increasingly respected children's ability to make decisions at younger ages. ${ }^{1099}$ The limitations of a pure case by case approach is that it would be based on professionals' determining competence and what is in the best interests of the child and as recent research

\footnotetext{
${ }^{1099}$ Alderson P, 'Children's Consent and 'Assent' to Healthcare Research', In Freeman M (eds) Law and Childhood Studies: Current Legal Issues Volume 14 (Oxford Scholarship online 2012) 185
} 
suggests, the outcome is usually determined wholly by the professionals' view of best interests and not the views of the child.

The results of Hein et al's research relating to children's competence to participate in clinical research from age 11.2 years provide a useful starting point for further research in the Welsh context to challenge policymakers to reconceptualise notions of children's vulnerability across all areas of research as well as at the same time contribute to an evidence-based underpinning of proposals that ultimately aim to modify the age competence requirements for children's informed consent.

From the collaborative discussion with health partners, it was agreed that children from the age of 13 years upwards would be able to participate in the surveys for this research without the consent of their parents, but ABMU would be interested in facilitating further discussions at the national level in Wales, to debate competence from the age of 12 years. With children under the age of 13 years for the purposes of the primary research, the concept of 'assent' was rejected, and a dual consent procedure was adopted, whereby children and parents/carers were both asked to consent before participating in the research. This supported a shared decision-making process, intended to respect the right of the younger child to choose to dissent to participate in the research and the important developmental role of the parent/carer if they also chose to dissent. If either party dissented, then the child would not participate in the research; both parties had to agree in order to proceed.

Based on all the evidence I developed a statement (see below) concerning children's informed consent to participate in research utilising the 5 principles of a CRA for use by ABMU Health Board.

\section{A Children's Rights Approach statement for ABMU - children's right to consent to participate in research}

Embedding children's rights: Children's rights should never be an afterthought but a primary consideration when dealing with the right to consent to participate in research. Children's rights to integrity of body, mind and personal identity must be respected. A children's rights perspective on the right to consent should be shared with all health professionals, researchers, ethic review committees, parents/guardians and children. 
Equality and non-discrimination: Every child should be treated fairly, providing them with the resources and opportunities according to their individual needs, age and maturity, equal to others during the process of negotiating consent. Children should not be discriminated against just because they are a child, or because they are a child from a particular socioeconomic, cultural background, disability, other status or position of perceived vulnerability.

Empowering the child: Children should be enabled and given the capabilities wherever possible to make choices that affect their lives; this includes decisions around consenting or refusing to participate in research. Barriers to information or resources to enable children to understand and exercise their right to consent should be removed. Right to consent brings into the forefront, the complexity of adult - child power relationships and adults should wherever possible be willing to hand over power to children so that children can better control and direct the decision to consent to/refuse to participate in research. For further discussion with key stakeholders, all children should be presumed to be decision making competent (unless proven otherwise) from the age of 12 years upwards and on a case by case basis under the age of 12 years. If children who are deemed not decision making competent consistently dissent, this decision should be respected.

Participation of children: All children's views no matter the age (0-17 years) of the child must be given serious consideration and not ignored, corresponding with their evolving capacity for maturity and understanding. The child's view must always be taken into account and given due weight in light of their age and maturity, but young age or relative immaturity is no reason for discounting children's opinions or for giving them less attention in the decision-making process. All children have a right to accessible information to influence decisions that affects them; this includes developing a detailed understanding of the risks, burdens and also the benefits of consenting to research. All health professionals should be given 
training regarding children's meaningful participation in decisions surrounding consent.

Accountability to children: If a child is not happy with the decision that has been made, children should be provided with information and given access to procedures which enable them to question and challenge decision-makers. Health authorities need to be transparent and provide reasons for their decisions and actions. Effective remedies and childfriendly complaints mechanisms should be accessible to the child where the decision-making process surrounding consent has not adhered to appropriate standards.

\subsection{Conclusion}

This chapter made reflections regarding the challenges to securing ethical approval for young people to independently consent to participating in the research at ABMU Health Services. It returned to the literature and the international human rights framework to demonstrate that younger teenagers from age 13 years should be presumed capable to consent to participate in the primary research at ABMU. It also concluded upon a dual consent procedure for younger children aged 7-12 years with both parents/carers with children sharing the decision to consent to participate in the research. The health board also agreed to promote further discussions nationally regarding children's consent to participate in research. The next chapter focuses on the findings of the primary research. 


\section{CHAPTER 9 ABMU CASE STUDY - ANALYSIS OF FINDINGS}

\subsection{Introduction}

The first part of this chapter focuses on describing the four purposive samples, children 7-12 years, young people 13-17 years, health professionals and Strategic Leads (i.e., ABMU Health Board, Executive and Non-executive Members) and then reflects on improving the monitoring tools in future assessments. The four purposive samples are laid out in Table 16 to illustrate the different population groups that contributed to the study.

The second part of this chapter analyses and triangulates the data from the four surveys, giving consideration to how successfully ABMU Health Board has embedded a CRA and makes recommendations for future research and improvements to service delivery. The analysis of the four surveys is presented under each of the principles and standards of the CRA, continuing with the logic of the inquiry established by the conceptual framework. The evidence from the descriptive statistics is interwoven with the themes coming from the open-ended responses and the overall analysis presented with reference to the CRA, the literature and the jurisprudence of the CRC.

TABLE 16: ABMU CASE STUDY - Number of respondents per each sample

\begin{tabular}{|l|l|}
\hline ABMU Case Study & \\
\hline Sample & Number of respondents \\
\hline Children $7-12$ years & $\begin{array}{l}\mathrm{N}=98(100 \% \text { of } \\
\text { anticipated respondents) }\end{array}$ \\
\hline $\begin{array}{l}\text { Young people } 13-17 \\
\text { years }\end{array}$ & $\begin{array}{l}\mathrm{N}=50 \text { (67\% of anticipated } \\
\text { respondents) }\end{array}$ \\
\hline Health professionals & $\begin{array}{l}\mathrm{N}=37(93 \% \text { of anticipated } \\
\text { respondents) }\end{array}$ \\
\hline $\begin{array}{l}\text { Strategic Leads (ABMU } \\
\text { Executive and Non- } \\
\text { Executive Members) }\end{array}$ & $\begin{array}{l}\mathrm{N}=9 \text { (45\% of anticipated } \\
\text { respondents) }\end{array}$ \\
\hline Total & $\begin{array}{l}198 \text { (94\% of anticipated } \\
\text { respondents) }\end{array}$ \\
\hline
\end{tabular}




\subsection{Describing the samples and reflections regarding improving the monitoring tools in future assessments}

\subsubsection{Strategic Leads Self-Assessment}

This self-assessment tool is a questionnaire designed to ask questions relating to the CRA conceptual framework using the 5 options rating per organisational objective. The benefit/relevance of the data was to inform analysis of ABMU policies and practice from the perspective of Strategic Leads who have an understanding of how these are implemented corporate-wide. Strategic leads identified were, ABMU Health Board: Executive \& Non-Executive Members. This was a purposive sample of experts who were considered to have a corporate wide understanding of health services delivery at ABMU. All members were invited to respond voluntarily to the self-assessment via an on-line self-assessment tool that was designed using Survey Monkey. The 5 options rating is outlined again below (see earlier Chapter 7 on Research Methods), and Strategic Leads were invited to give additional evidence to support their rating.

The 5 options rating:

1. No action taken

2. Under development

3. Developed but requiring refinement

4. Fully developed

5. Fully developed and operational 


\subsubsection{Describing the sample}

FIGURE 1: Number of strategic lead respondents by age category

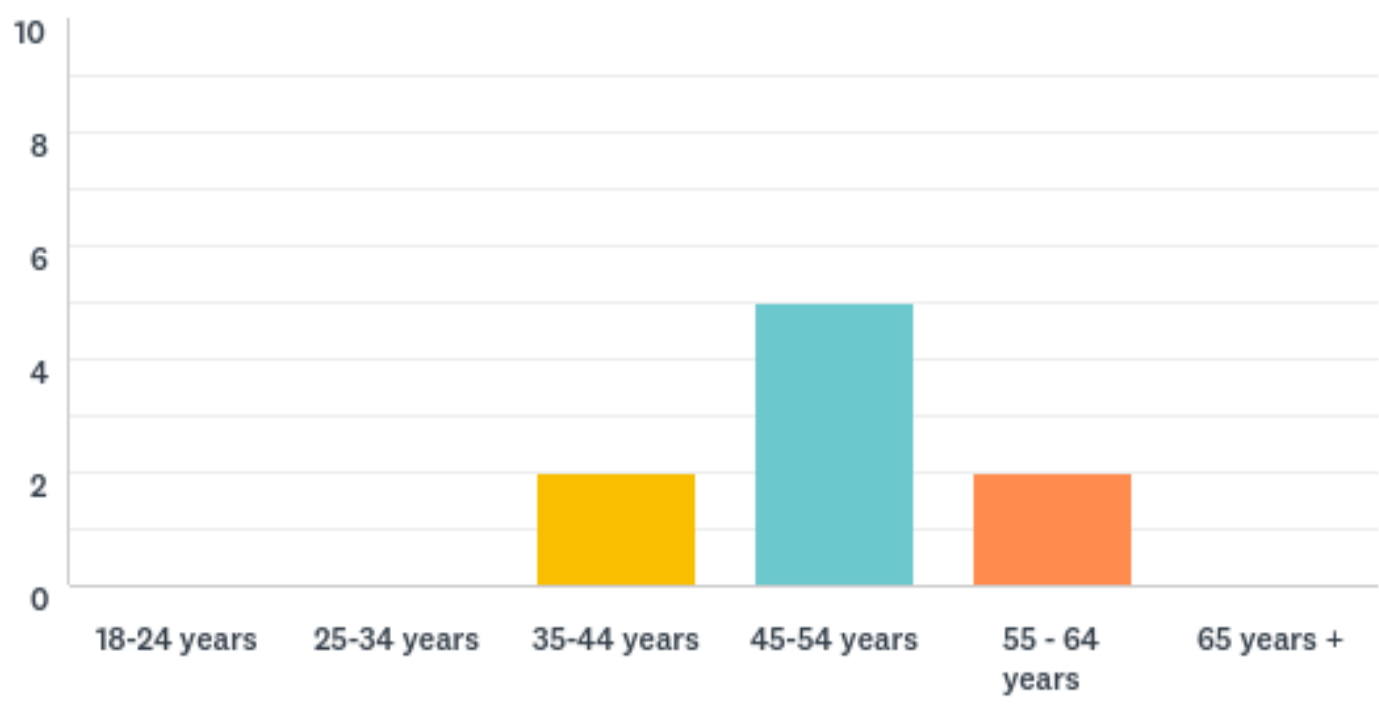

FIGURE 2: Number of strategic lead respondents by gender

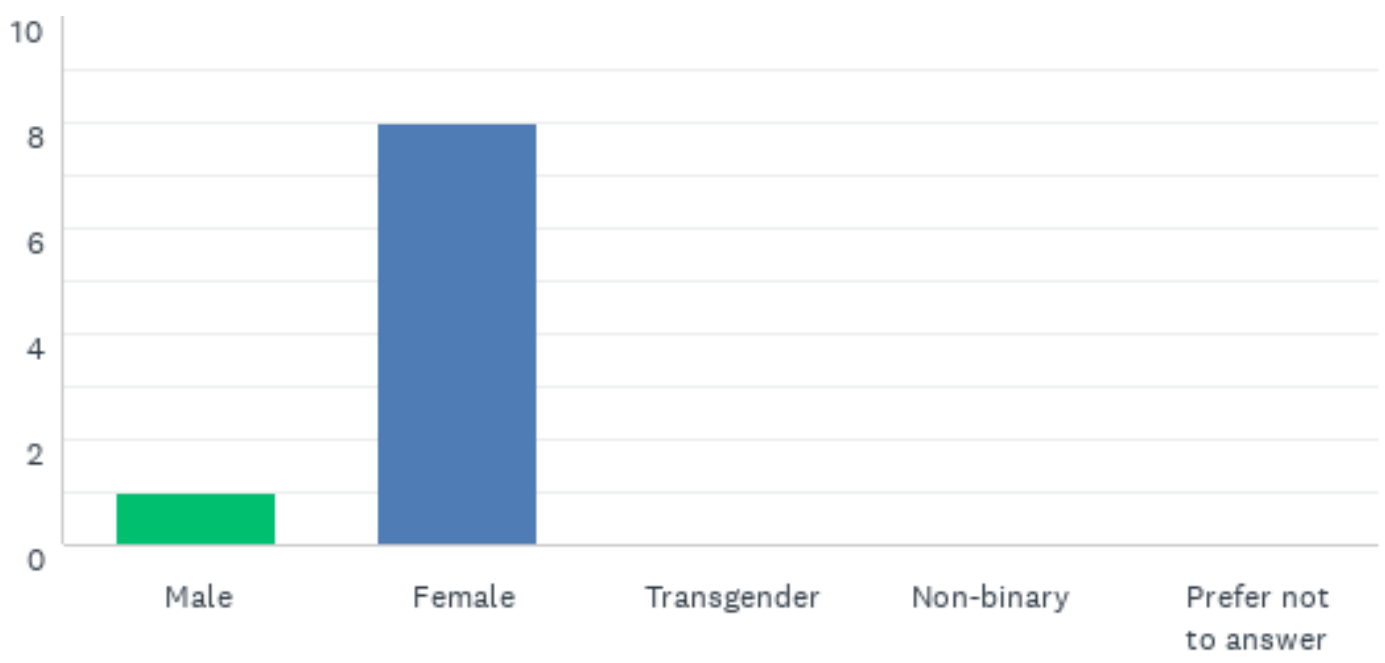

9 Strategic Leads from the ABMU Executive and Non-Executive Board responded to the survey after being requested directly via e-mail by the Chair of the health board. The strategic leads that responded were all over the age of 34 years and the majority were female.

\subsubsection{Reflections on improving the self assessment monitoring tool}

The tool worked effectively with the members rating all standards and offering additional evidence to back up their rating in almost all responses. The survey monkey 
tool recorded that on average, the survey took a maximum of 8 minutes to complete. Only 9 out of a potential of 20 members responded to the survey. This may have been due to the significant infrastructural challenges the Health Board was facing at the time of the research, and the constraints on member's time or they did not place importance on services for children as compared to adult services.

The self-assessment tool was designed and intended to be completed collectively by the ABMU Executive and Non-Executive members so that they could decide and agree on the score rating per each standard. However, Strategic Leads, due to time commitments, preferred to respond to it as a separate electronic questionnaire. This however presented interesting findings because it demonstrated that there was often disagreement between the Strategic Leads with regards how far a standard/objective had been implemented. This was also supported by the data they provided to evidence their score rating. It suggested that there was not a corporate-wide agreement to how far a CRA was being embedded at directorate level and a lack of knowledge and communication between senior members regarding what was happening at the time of the research regarding the implementation of a CRA across the Health Board. This also coincided with the time period when the Children's Strategy Group ${ }^{1100}$ had been disbanded so the sharing and dissemination of information that was offered by this Group to the Health Board was no longer available.

The 5 options rating was developed to support 5 degrees or levels of implementation, from standards at the one end of the scale not being actioned at all, to them not only being fully developed but the highest standard of them being fully developed and operational at the point of service delivery. However, the Likert 5 options rating tool may have been too wide in its span, and perhaps there would have been less noticeable disagreement if the rating tool had been based on a simpler traffic light system of Red, Amber, Green, or 3 score rating tool.

This leads to the conclusion that the self -assessment tool should also be conducted by the Health Board Executive and Non-Executive members to collectively ascertain if they would be able to agree on rating each of the standards when in a group. This

\footnotetext{
${ }^{1100}$ These were multi-agency meetings attended by managers and practitioners whose work impacted on children in the ABMU Health Board Area.
} 
discussion would generate an opportunity for agreeing on actioning each of the standards and developing an overall plan of implementation. Also, carrying out the self-assessment tool as part of a Board meeting would help to ensure that all members respond to the self-assessment.

However, due to identified constraints on staff time, the electronic version (maybe with some adaptation to the Likert scale) worked well because it was easy to use and accessible. It can be argued it is an effective non resource intensive method that can be routinely (every 2 years) used to collect data regarding how far a health board is successfully embedding a CRA.

\subsubsection{Health professional's survey}

This survey was designed to determine how far a CRA is embedded in policy and practice from the perspective of ABMU health professionals. An on-line survey was designed to ask questions relating to the CRA conceptual framework of health professionals delivering services that impact on children. The survey was disseminated via the ABMU Staff intranet and Staff Facebook web page.

\subsubsection{Describing the sample}

37 health professionals responded to the survey ( $\mathrm{N}=37$ ). Only $5.4 \%$ (2) of respondents were male, $94.6 \%$ (35) respondents were female. Over two thirds $(67.5 \%, 25)$ of the respondents were between the ages of 35 and 54 years of age. $40.5 \%$ (15) of respondents delivered health services in Swansea, 32.4\% (12) in Bridgend and 27\% (10) in Neath Port Talbot. The majority of respondents 27 (73\%) worked in Children's Services only, $13.5 \%$ (5) in Children's and Adults Services and 2.7\% (1) in Child, Adolescent and Mental Health Services (CAMHS). It had been hoped to have a sample of at least 40 health professionals, however, even with a series of e-mails, advertising on the staff intranet page and Facebook page, as well as the survey being brought to the attention of staff at various meetings, only 37 health professionals responded.

The majority of respondents were nurses $(78.4 \%, 29$,$) only 4(10.8 \%)$ doctors responded and $4(10.8 \%)$ therapists. It is likely that the majority of responses came from nurses because the survey was primarily promoted with nurse colleagues by the 
Head of Nursing and Children's Services and the Patient Experience Coordinator. However, there was a fairly even spread of respondents across the three local authority areas. Due to the small sample sizes, it is not possible to make statistical or generalisable inferences from the survey results but instead the data can generate exploratory questions for further research and recommendations specific to the context in question. The Figures 3-8 below describe the sample of 37 health professionals.

FIGURE 3: Percentage of health professional respondents by gender

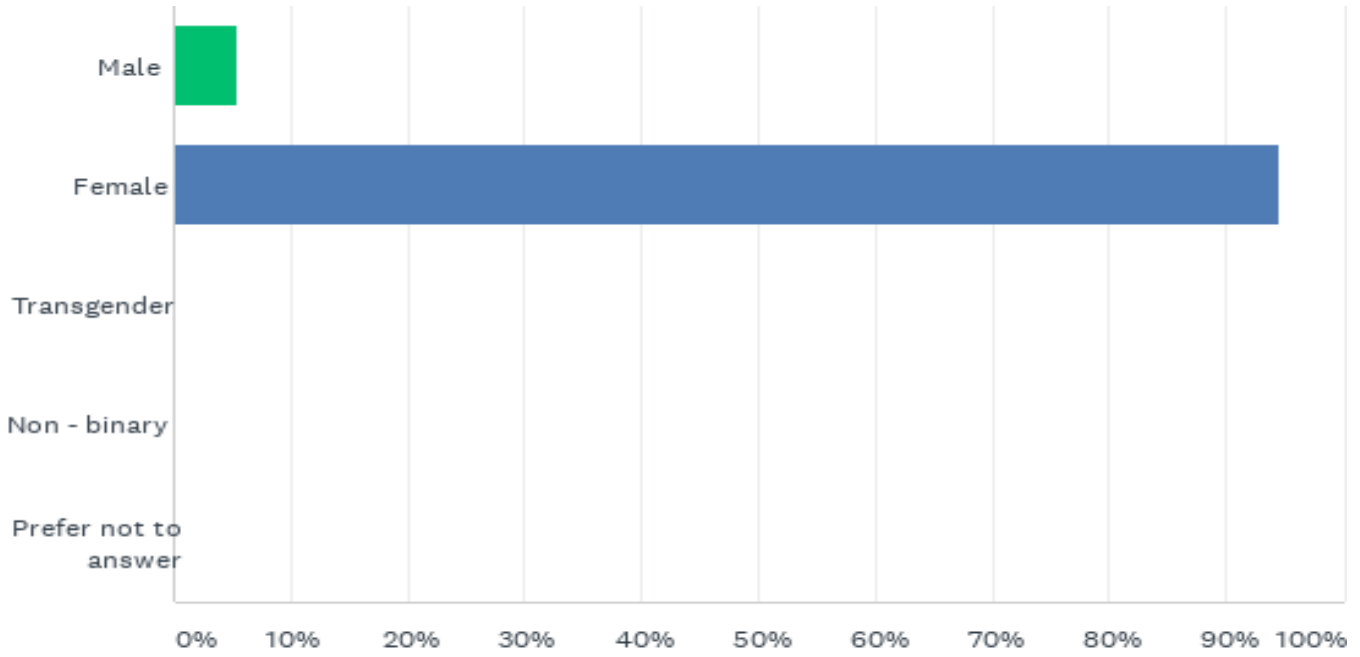

FIGURE 4: Percentage of health professional respondents by age category

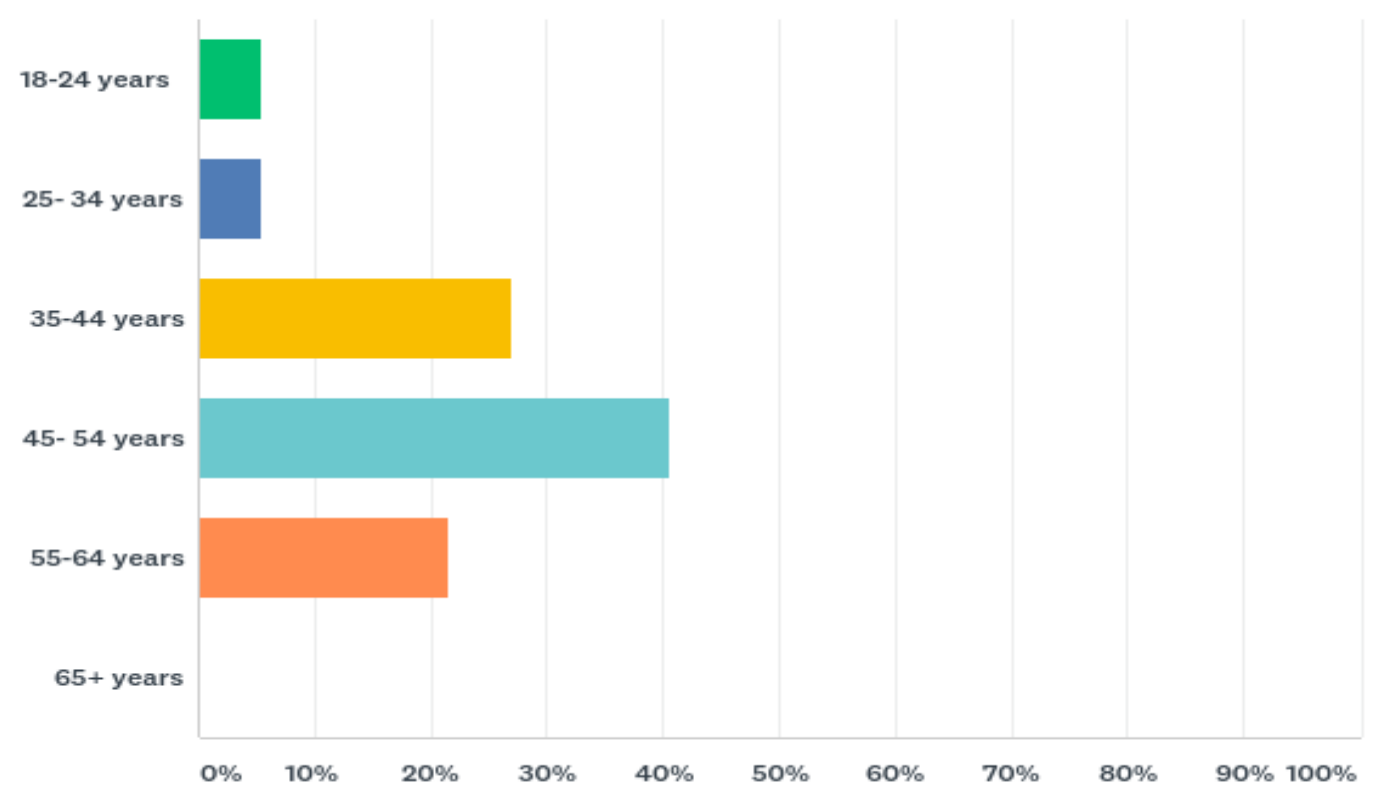


FIGURE 5: Percentage of health professional respondents by Local Authority area where they work

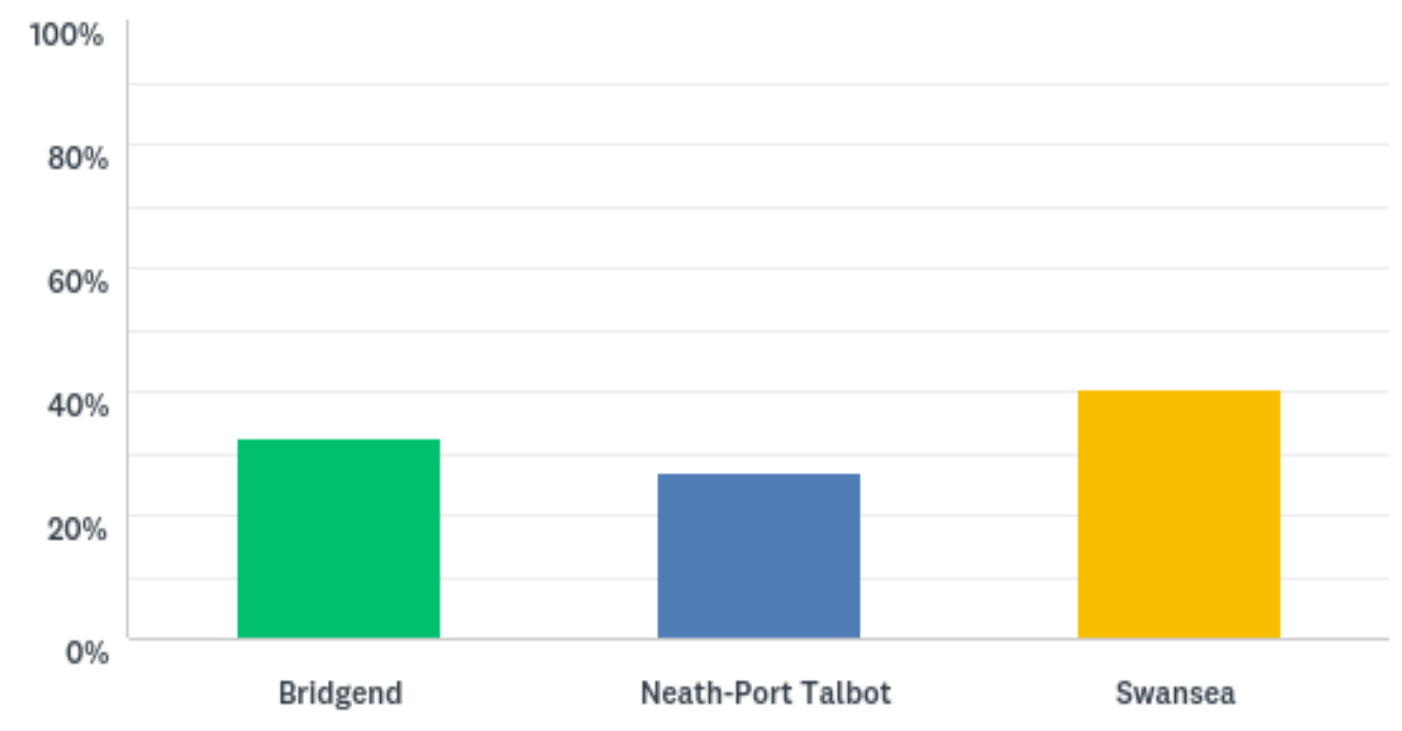

FIGURE 6: Percentage of health professional respondents by health service area where they work

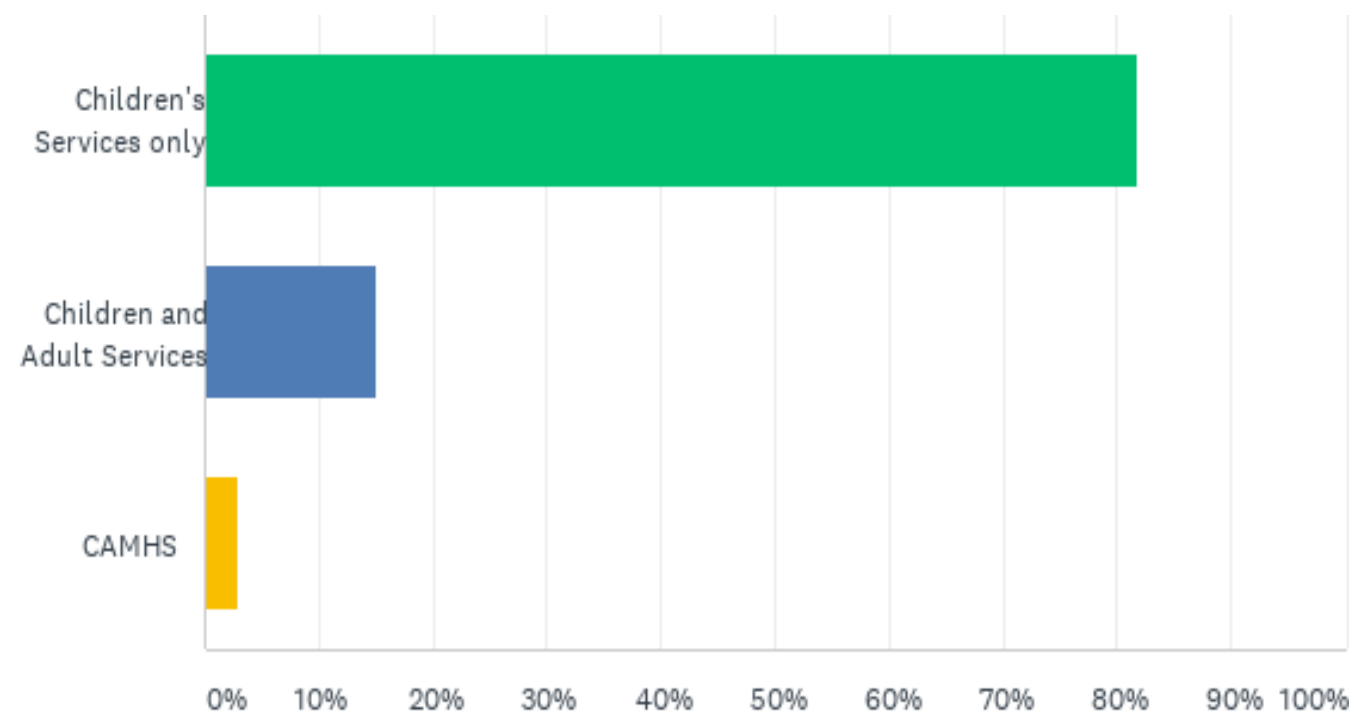


FIGURE 7: Percentage of health professional respondents by professional category

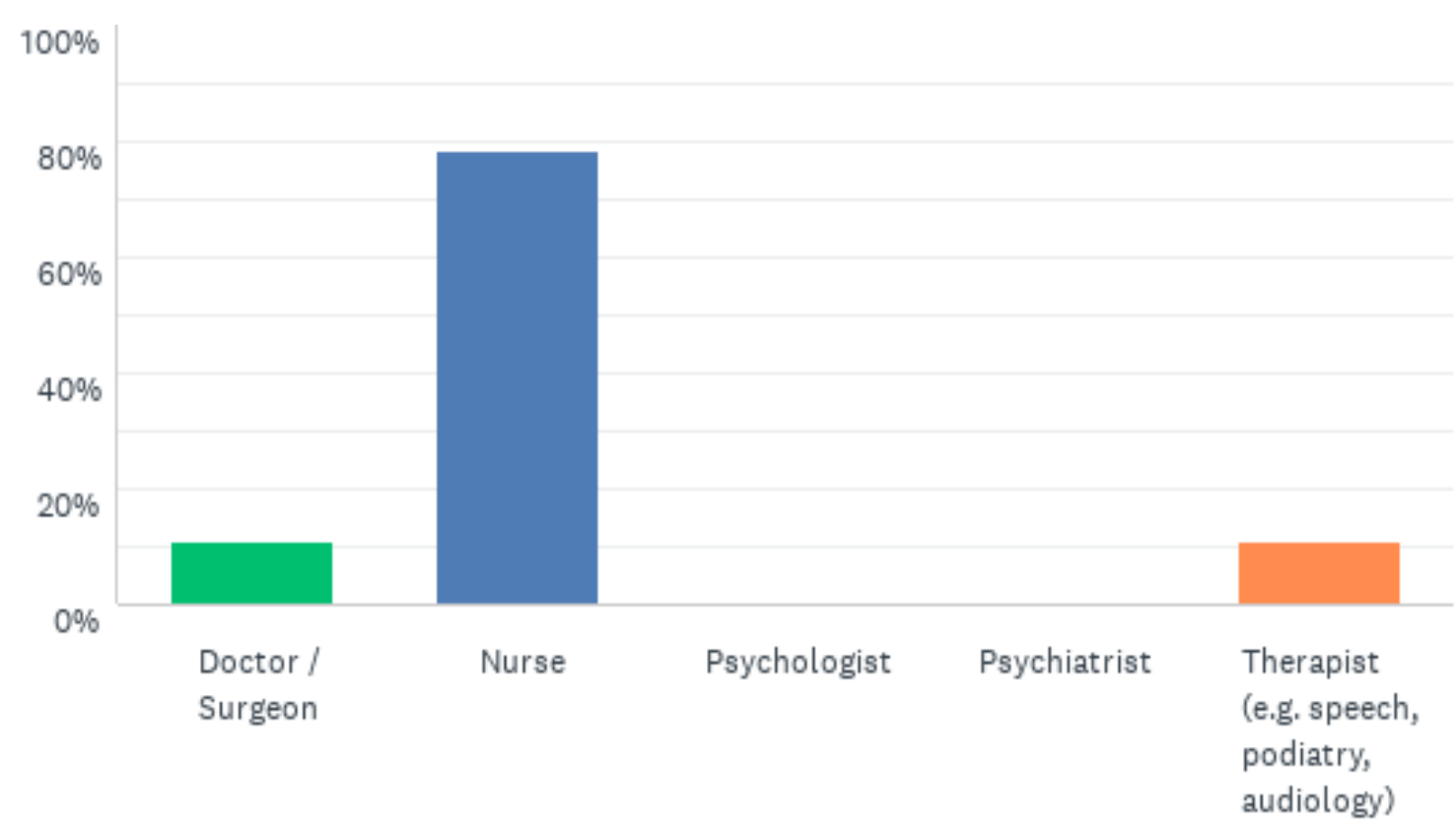

FIGURE 8: Percentage distribution of health professional respondents by medical specialisation in child health or special training in providing care for children

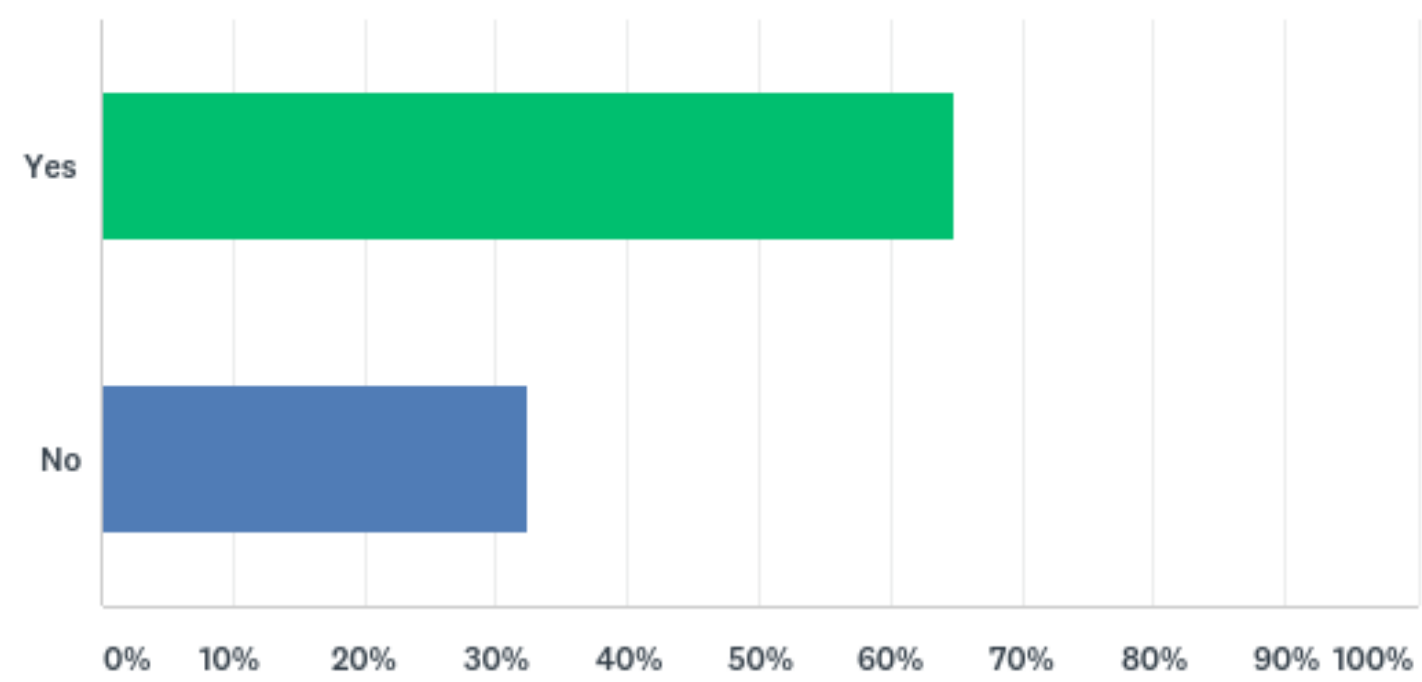

Over two thirds of the respondents said that they had medical specialisation in child health or special training in providing care to children (see Figure 8 above). In the additional comments, staff responded that their specialisation in children came from: 
- Nursing Degree

- Specialist Community Public Health Nurse - School Nurse

- Children's community nursing degree

- British Dietetic Association accredited courses

- Registered Sick Children Nurse

- Registered paediatric nurse

- Paediatric Dietician

- Registered Mental Health Nurse, ongoing mental health courses with CAMHS

- Paediatric anaesthetist with diploma in Child Health

\subsubsection{Reflections on improving the health professional's monitoring tool}

This survey was estimated to only take 7 minutes to complete and nearly all questions were answered by all 37 respondents. It was important that all questions offered health professionals the opportunity to add further comments that supported their response. The questions worked effectively to generate the data that was needed to respond to the research questions.

Primarily nursing staff responded to the survey. It is suggested by senior staff that more health professionals would have responded, however, given the timing that the survey was made available to health professionals; staff morale was particularly low due to the changes being made to the Health Board (Bridgend was in the process of being merged with Cwm Taf Health Board). These changes and this transitional period had brought about additional pressures to staff that were already under significant pressure. It was also the busiest time of year (due to it being the winter period) responding to the survey was thus considered to be an additional expectation given pressures of workload.

This research was intended to act as a framework for future monitoring, so the survey tool is one that can be easily adhered to by the Health Board and monitored against in future assessments. Akin to the Strategic Leads assessment tool, this tool successfully provided the Health Board with a non-resource intensive method that can be routinely used every 2 years to assess health professionals' perspectives on how far a CRA is being successfully embedded. Future research should seek to target a 
wider span of health professionals and also health professionals working in the community.

\subsubsection{Young people survey 13-17 years}

This survey was designed to gain a young person's (13-17 years) perspective to present young people's insights as to whether ABMU was successfully complying with a CRA and present young people's recommendations for improvement. Between December 2018 and April 2019, staff recruited young person patients to voluntarily participate in the survey post their clinic appointments at location, primarily at outpatient services. Staff informed the young people about the research and invited them to take part independently on an Ipad. Other young people learned about the survey online in the community and took the opportunity to respond to the survey independently online. The survey was offered bilingually in Welsh and English.

\subsubsection{Describing the sample}

50 young people responded to the young people survey $(\mathrm{N}=50)$. There was a fairly good span of ages responding across the age range (13-17 years) (See Figure 9 below) and a fairly equal distribution between boys and girls responding (Girls $48 \%$, 24 ) and (Boys 52\%, 26) see Figure 10.72.9\% (35) of young people responded that they had seen a health professional 4 or more times in 2018-19 (see Figure 11).

The majority of the young people $(84 \%, 42)$ answered that they were responding to the survey based on their experience of visiting a health professional in a hospital (See Figure 12). The young people's survey was primarily administered via Ipad at hospital outpatient's services, due to staff who were administering the survey being based in hospital out-patient services. Only 5 young people responded from their experience of visiting a GP, 1 from visiting Accident and Emergency and one from visiting a Children's Centre. 41.7\% (20) of young people who responded lived in the local authority area of Bridgend, $41.7 \%$ (20) Swansea and 12.5\% (6) Neath Port Talbot, one said they had travelled from Llanelli, and two from Ammanford, and 2 children did not respond to this question. Please see Figures 9-13 below that support this narrative description. 
FIGURE 9: Percentage of young people respondents by age in years

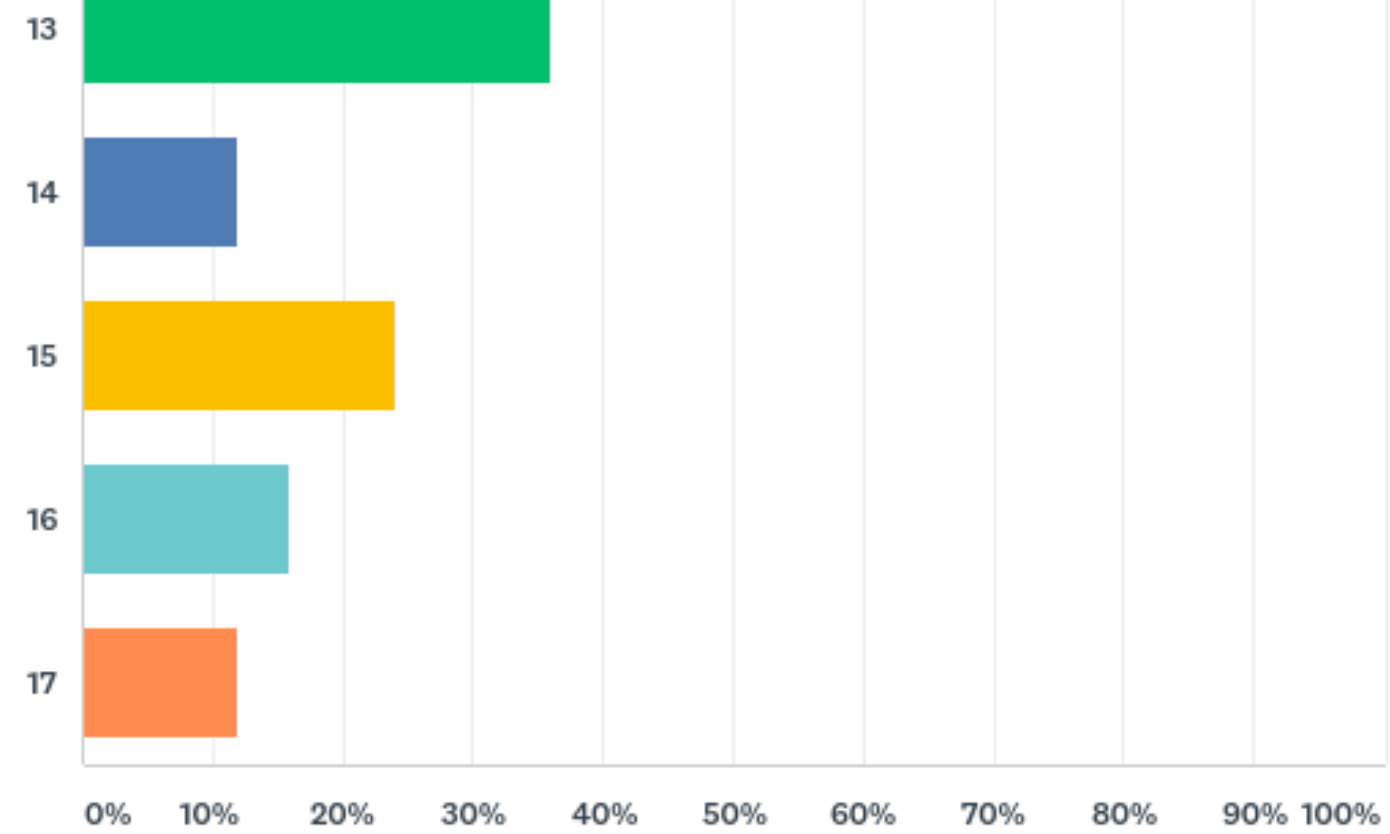

FIGURE 10: Proportion of young people respondents by gender

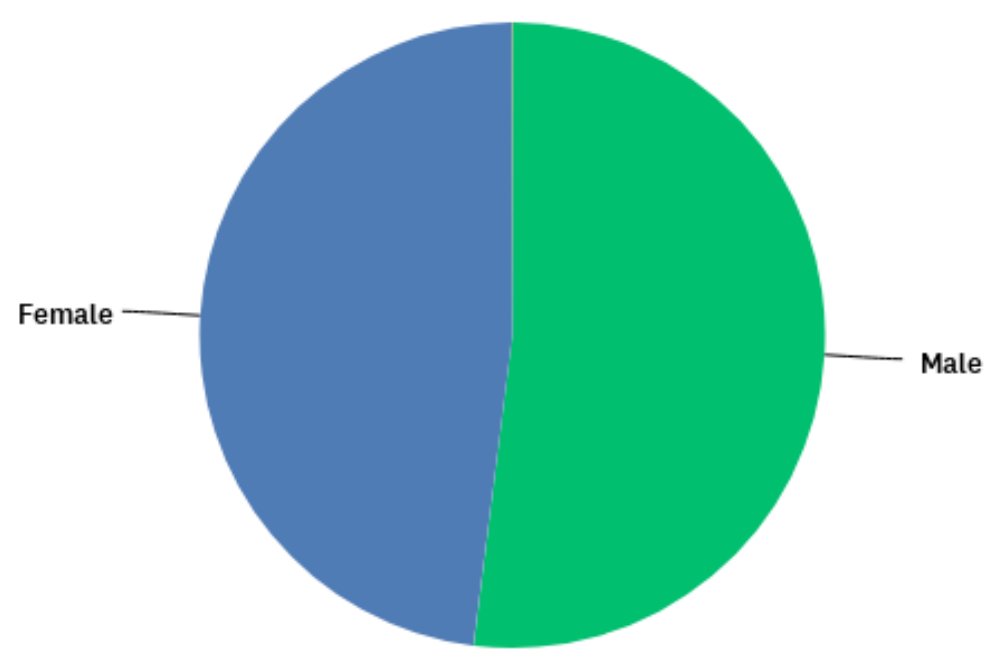


FIGURE 11: Percentage of young people respondents by number of times they visited a health professional in 2018 and/or 2019

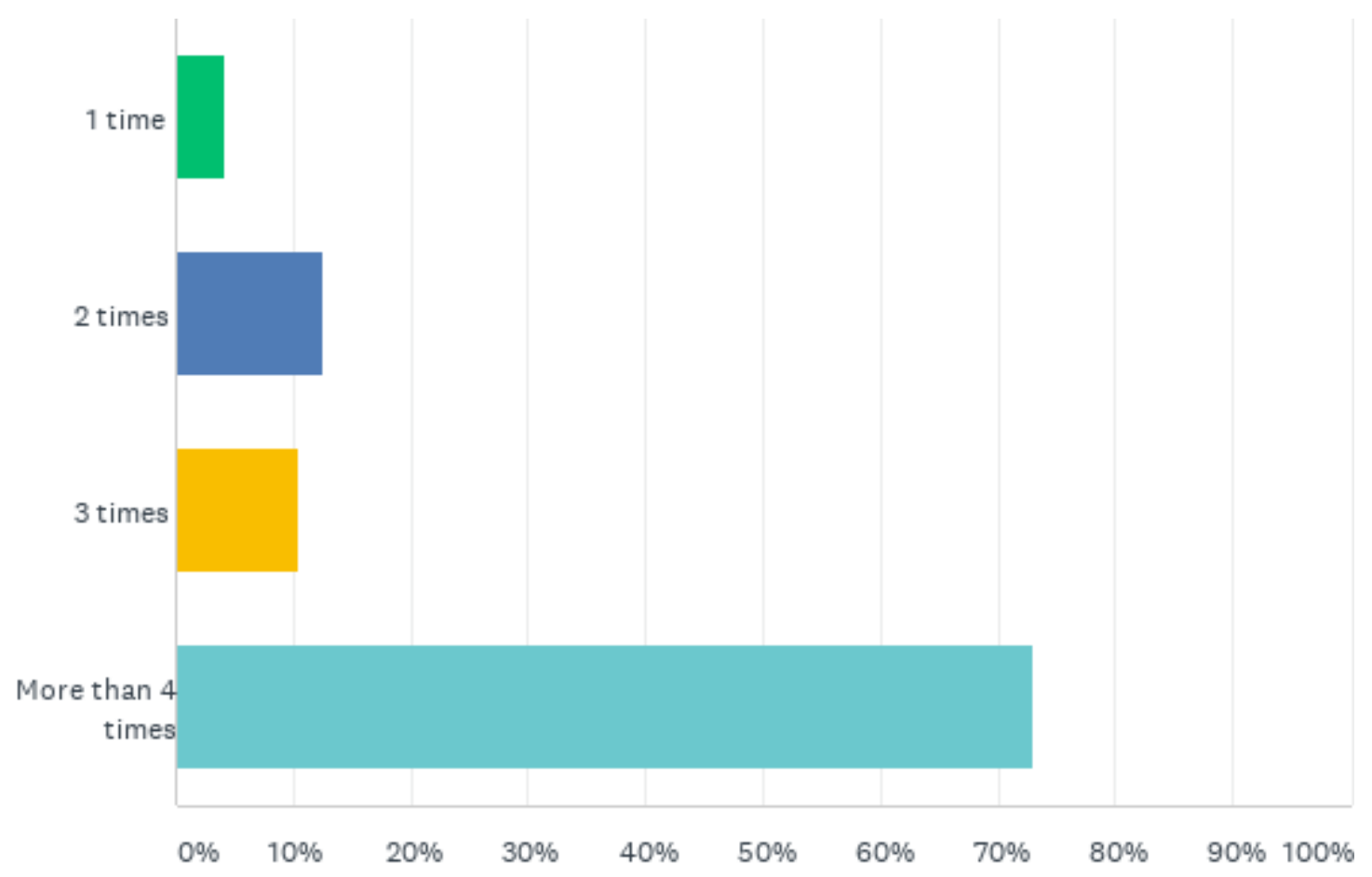

FIGURE 12: Percentage of young people respondents who responded that they were answering the survey based on visiting a hospital, GP, children's centre or accident and emergency

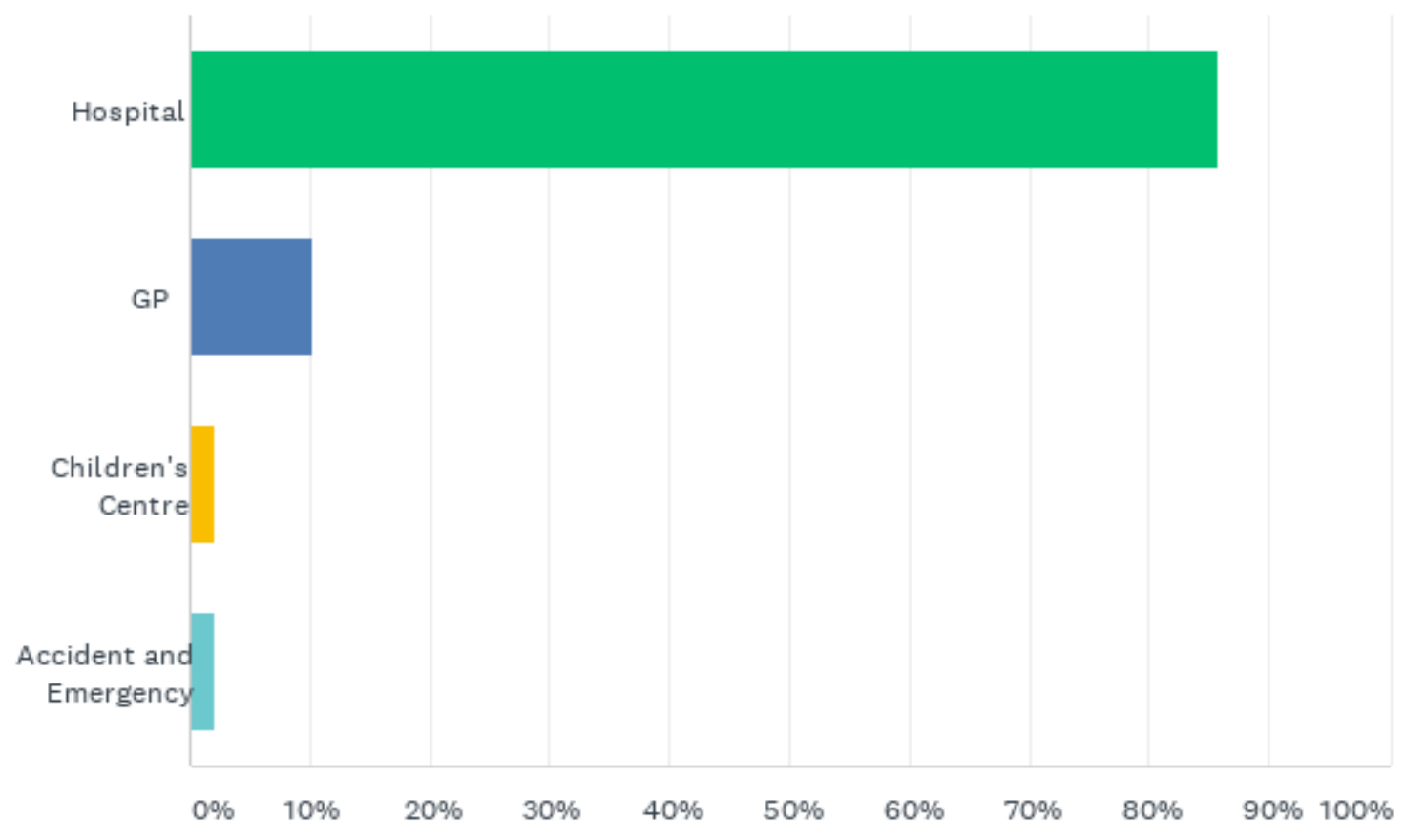


FIGURE 13: Percentage of young people respondents by area where they live

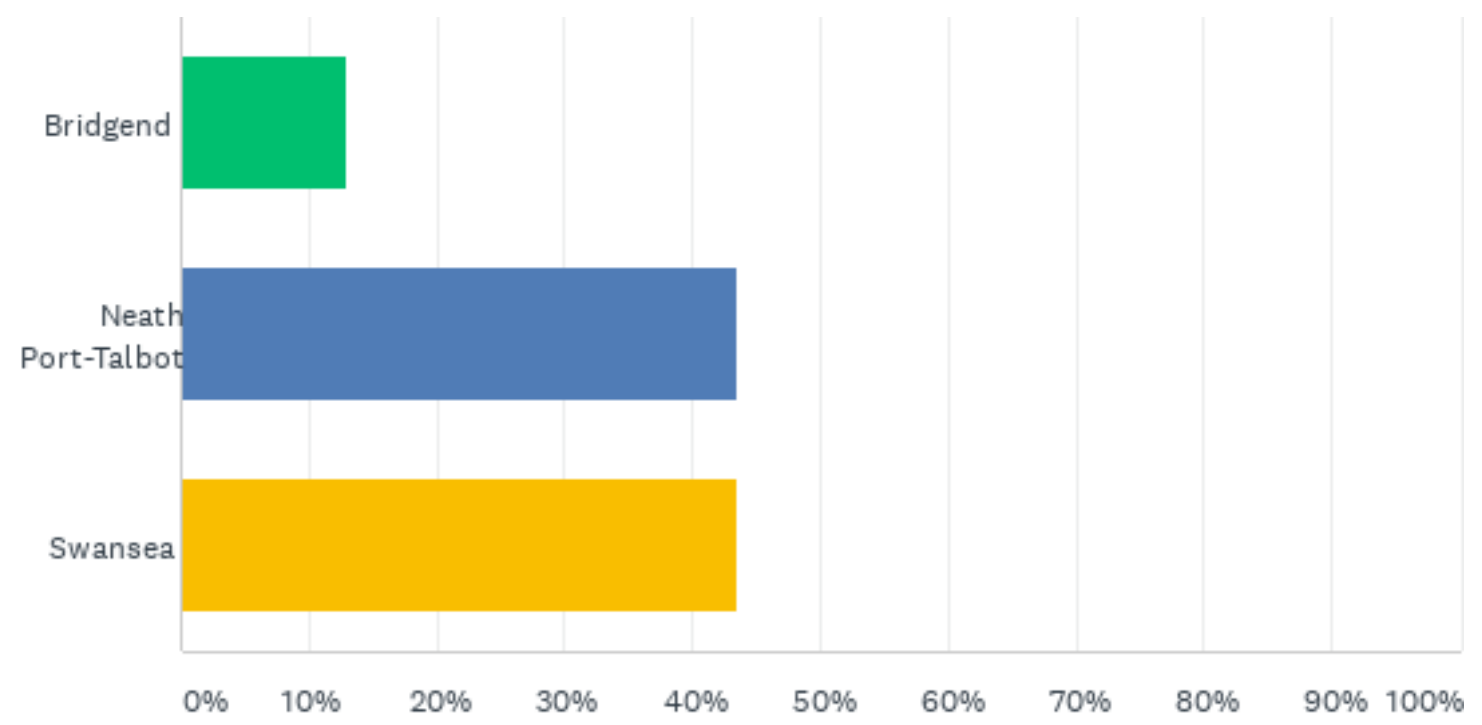

\subsubsection{Reflections on improving the young people's monitoring tool}

The young people seemed to enjoy the experience of independently answering the questions privately and being given the opportunity to answer them via a device that they were familiar with i.e., an iPad. The Head of Nursing reported since using iPads as part of child patient experience, children's and young people's willingness to engage had increased. Nobody questioned the young people's independent right to consent to participate in the survey. The survey worked as intended and presented useful data, data that generated a baseline of information regarding a young person's perception of how far the health authority was embedding a CRA and complying with the Children's Charter. It also highlighted areas of concern that may require further research.

Feedback from the staff who administered the tool onsite at health services, suggested that the number of questions should be reduced because young people struggled to finish the survey during the time they had post appointments. Less young people responded to the young people's survey as compared to the children's survey. This is principally because less young people presented at out-patient services and not all young people had time (because it was a longer survey) to finish the survey during the time they had post appointments. It was suggested that the survey should be 
shortened to take into consideration the constraints of time on patients. Staff also gave feedback that children with cognitive impairment or learning difficulties struggled to answer some of the questions without support and it was recommended that a survey or different research tool should be developed to support young people with these specific needs.

\subsubsection{Children's survey 7-12 year olds}

This survey was designed to gain a child's perspective (7-12 year olds) as to whether $A B M U$ was successfully embedding a CRA and to present their recommendations for improvement. Between December 2018 and April 2019 staff recruited child patients to voluntarily participate in the survey post their clinic appointments at location, primarily at out-patient services. Like the young person's survey, staff informed the children about the research and invited them to take part independently on an Ipad with the consent of their caregivers. Other children learned about the survey online in the community and took the opportunity to respond to the survey online. The survey was offered bilingually in Welsh and English.

\subsubsection{Describing the sample}

98 children responded to the survey $(\mathrm{N}=98)$. There was a good span of ages responding across the age range (Please see Figure 14 below) and a fairly equal distribution between boys and girls responding (Girls - 44.9\%, 44) and (Boys - $55.1 \%$, 54) (See Figure 15 below).

Over half of the children who responded to the survey $(61.8 \%, 60$ children) lived in areas that attend health services in Swansea local authority, 23.7\% (23) Neath Port Talbot local authority and $11.3 \%$ (11) Bridgend local authority. The question focused on where the children lived, as we believed they would find it more difficult to identify the area they were visiting the health service in. However, some children had come from out of the local authority area to visit the service, so the option was given to write this in the 'other' category. The reason why over half the children responded to the survey in the Swansea local authority area was because the staff who administered the survey primarily deliver services in Swansea and this is where most of the recruitment took place. 
92.8\% (90) of the children said they were responding to the survey from their experience of visiting a doctor or nurse in a hospital and $7.2 \%$ (7) from visiting a doctor or nurse in a GP surgery. The reason why the survey became primarily focused on hospital out-patients was because this is where the staff who administered the survey deliver services. It became apparent that due to bureaucratic challenges, even securing meetings with the head of the GP cluster networks to discuss the proposed research taking place at GP services was incredibly challenging.

$59.8 \%$ (59) of children had visited a health professional 4 or more times in 2018/19, $15.5 \%$ (15) children 3 or more times, $16.5 \%$ (16) children 2 or more times and $8.3 \%$ (8) of children one time.

See Figures 14-18 below that support this narrative description.

FIGURE 14: Percentage of child respondents by age in years

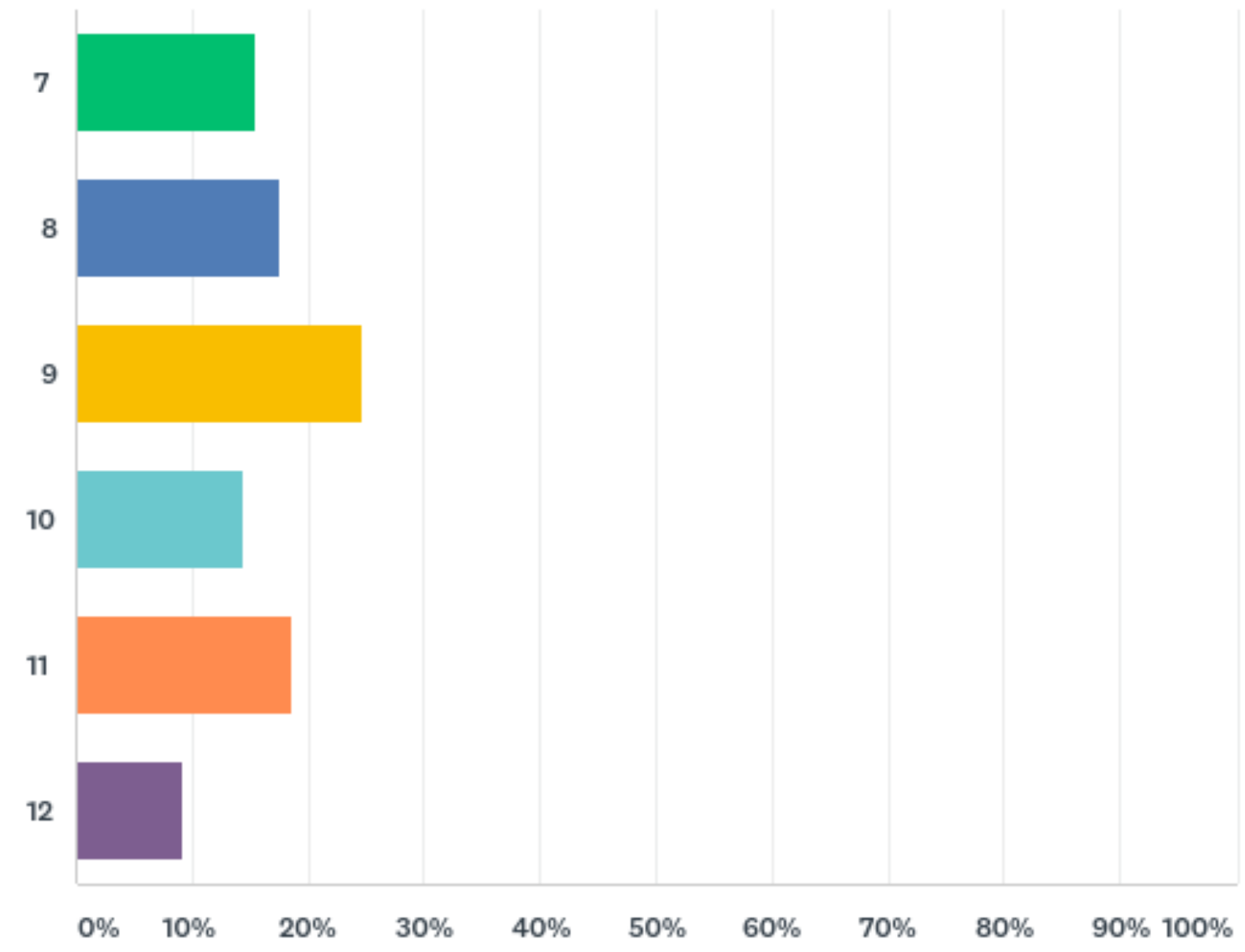


FIGURE 15: Percentage of child respondents by gender

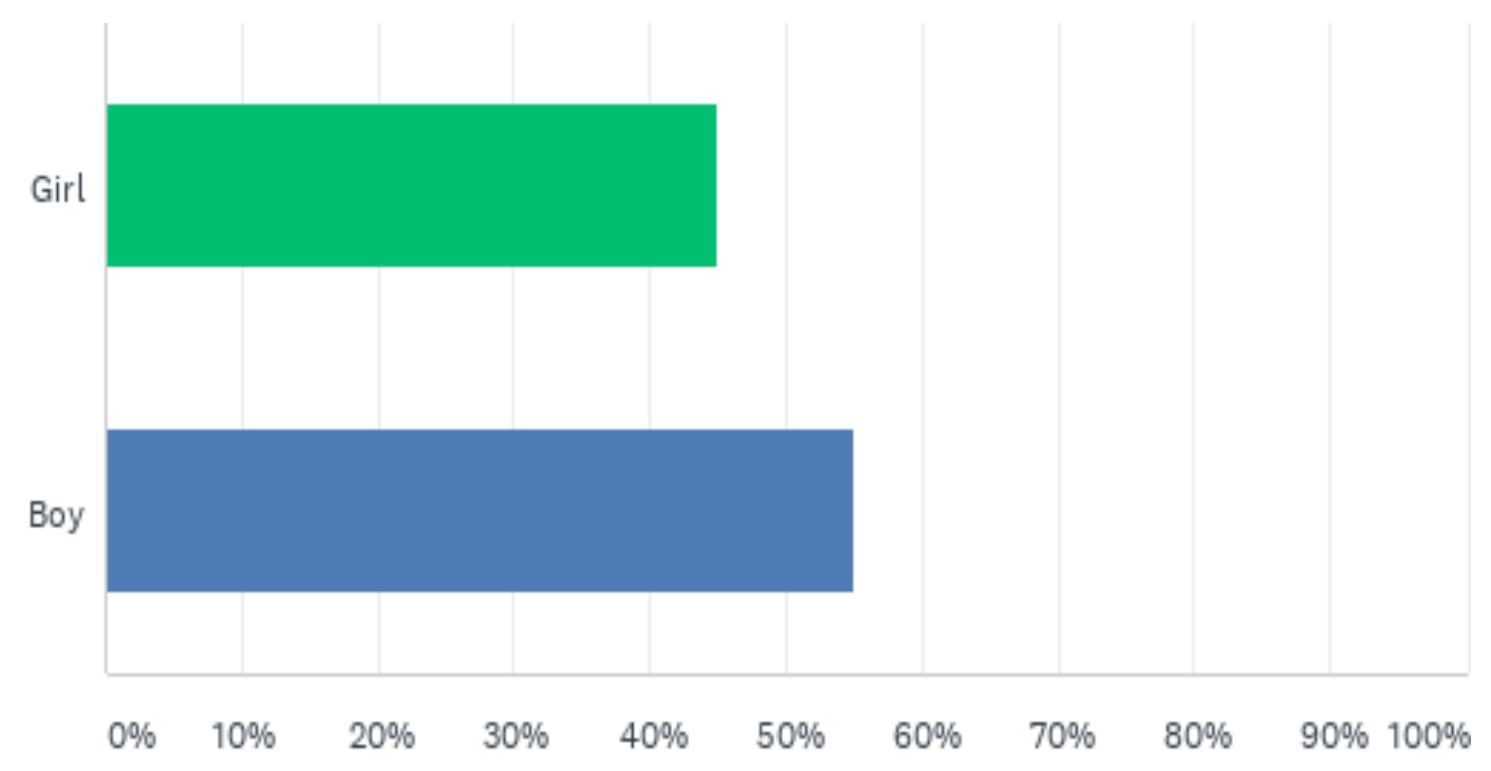

FIGURE 16: Percentage of child respondents by area in which they live

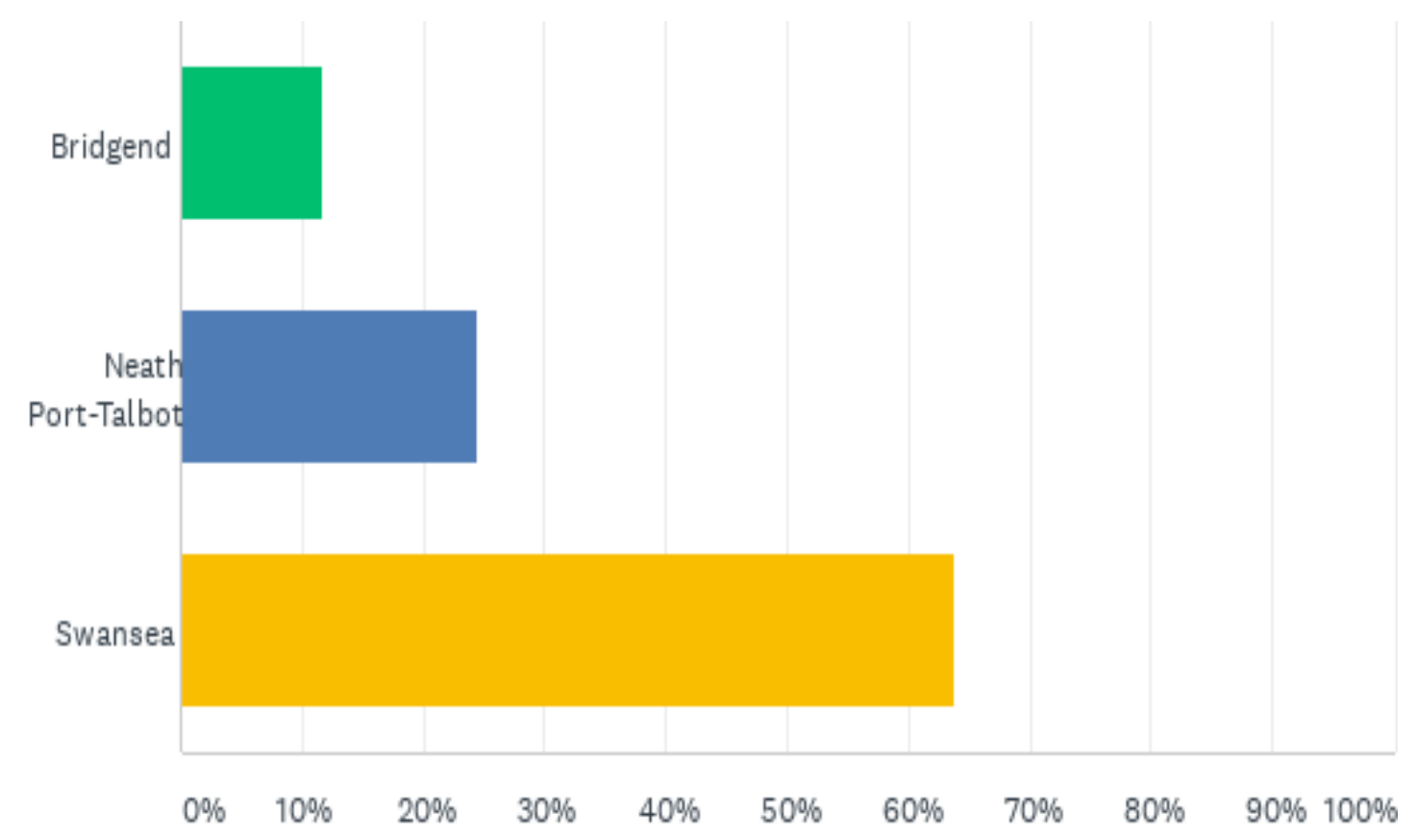


FIGURE 17: Percentage of child respondents by number of times they visited a health professional in 2018 and or 2019

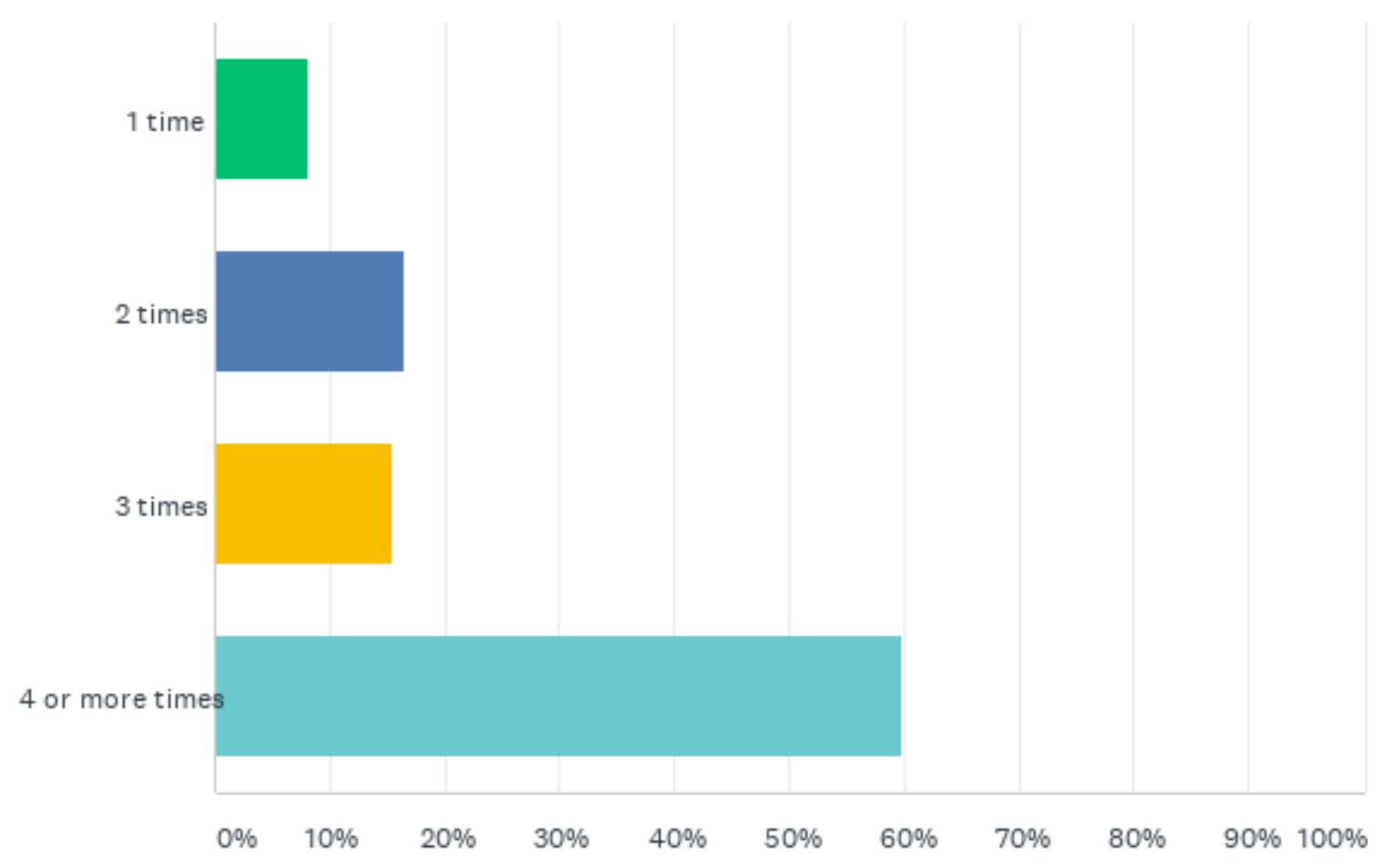

FIGURE 18: Percentage of children who responded that they were answering the survey based on visiting a hospital, GP, children's centre or accident and emergency

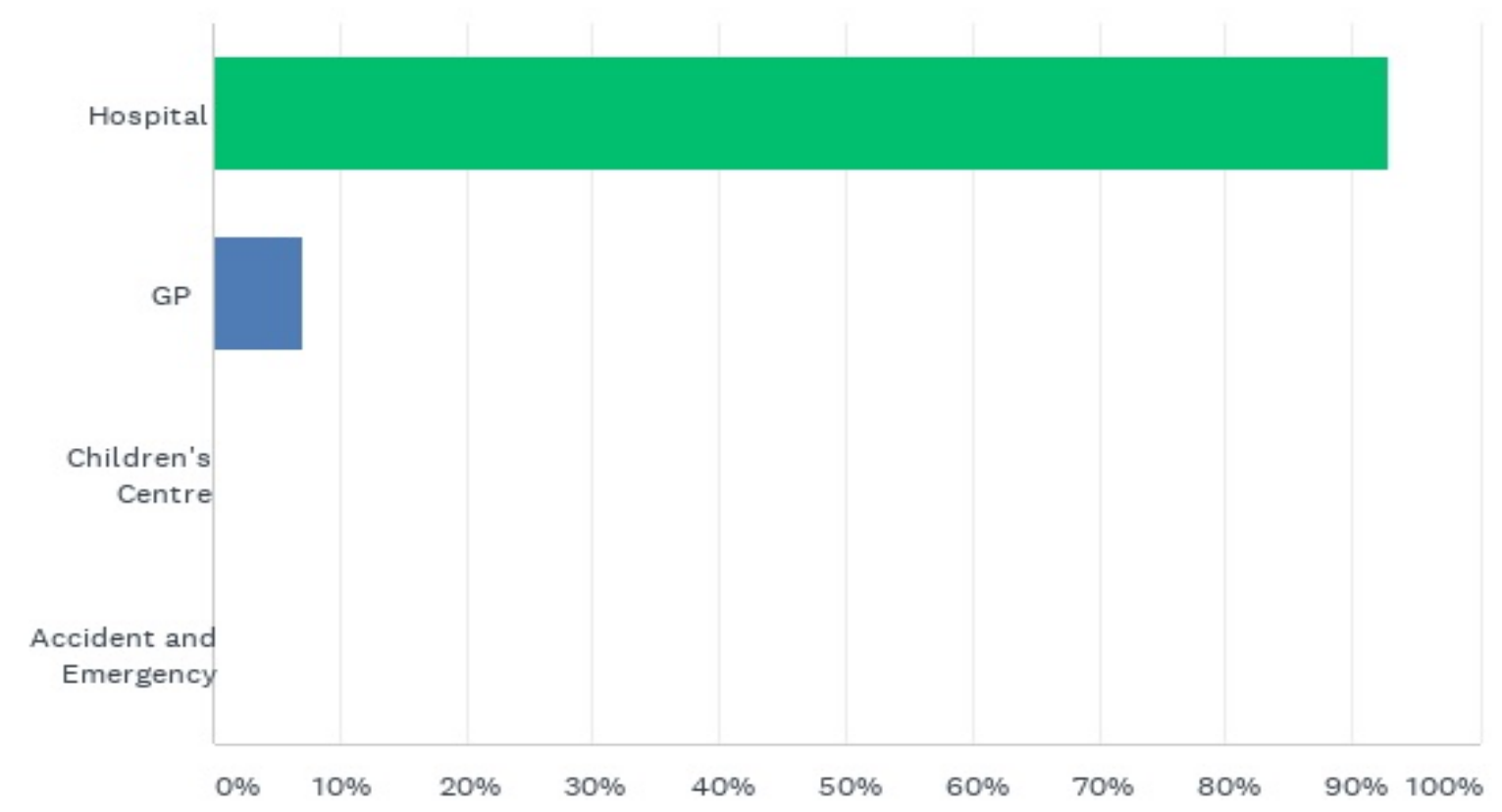




\subsubsection{Reflections regarding improving the children's monitoring tool}

Staff reported that the children enjoyed answering the survey and there was sufficient time to respond to all of the questions post appointment. The children did not report finding the questions difficult to answer and the majority were observed to answer the questions independently without the help of caregivers. It was noted that although the survey was designed to be as simple as possible and not to create too many opportunities for this younger age category having to write in open ended responses, this age group seemed to want the opportunity to write additional comments. In a revised tool each question should have the option to write additional comments, this would in effect give more freedom for children to add how they felt, provide their perceptions on services and also provide richer qualitative data. A number of children also reported that they appreciated being able to answer the questionnaire in Welsh which was their first language. Akin to the other surveys it was an effective nonresource intensive method for staff to administer with children on site at health services or children to undertake independently online.

It was critical that in order to generate a sufficient number of respondents to this survey and the young people survey that staff were given the time to go out into health services to recruit child and young people out-patients to respond to it. The recruitment of young people and children to participate in the survey was primarily supported by the Neath Port Talbot Children's Rights Manager and the Patient Experience Coordinator. They struggled to deliver on the administration of this survey in addition to their day jobs and it is advisable that in future the Health Board recruits a dedicated researcher/child patient experience coordinator. This post holder would be responsible for ensuring that the views and experiences of child/young person patients are gathered consistently and effectively and feed into ongoing changes being made at health board level and become an embedded part of monitoring health services delivery.

\subsection{How successfully has ABMU Health Board embedded a children's rights approach? Analysis of findings}

This next section triangulates the evidence from Strategic Leads, Health Professionals, Young People and Children's surveys and analyses how successfully 
the Health Board is in embedding a CRA to health services. It concludes with some recommendations for further research and improvements to services.

The analysis has been conducted within the framework of the 5 principles of CRA and the standards that have been identified to fit within each of the principles.

\subsubsection{Embedding children's rights: health authority wide commitment}

As outlined in Chapter 7, the ABMU Health Board made a health authority wide commitment to the UNCRC through the development of their Children's Rights Charter in 2017. The Charter includes 10 children's rights guarantees relating to health that the ABMU Health Authority must implement. As indicated by Kilkelly and Savage's research, many country's health authorities have introduced Charters, but have not successfully embedded them. ${ }^{1101}$ Although a good starting point, to embed a CRA to health services delivery, much more has to happen than the adoption of a Charter.

The evidence presented by the Strategic Leads suggest firstly that there was not always agreement between them with regards to how far a CRA had been implemented across services in the ABMU Health Board area. This difference of opinion may suggest there is a lack of a corporate-wide strategy to the delivery of a CRA and there needs to be more senior level direction and support to the delivery of such an approach.

\footnotetext{
${ }^{1101}$ Kilkelly U and Savage E, Child friendly health care: A report commissioned for the ombudsman for children (Ombudsman for Children 2013)
} 


\section{FIGURE 19: Distribution of strategic leads to the $\mathbf{5}$ options rating of the}

objective SLQ 3 - Reference has been made to the United Nations Convention on the Rights of the Child as the framework for service planning and delivery in all significant policy statements or other documents setting out the health authority's vision or key objective s (e.g. a children's rights charter)

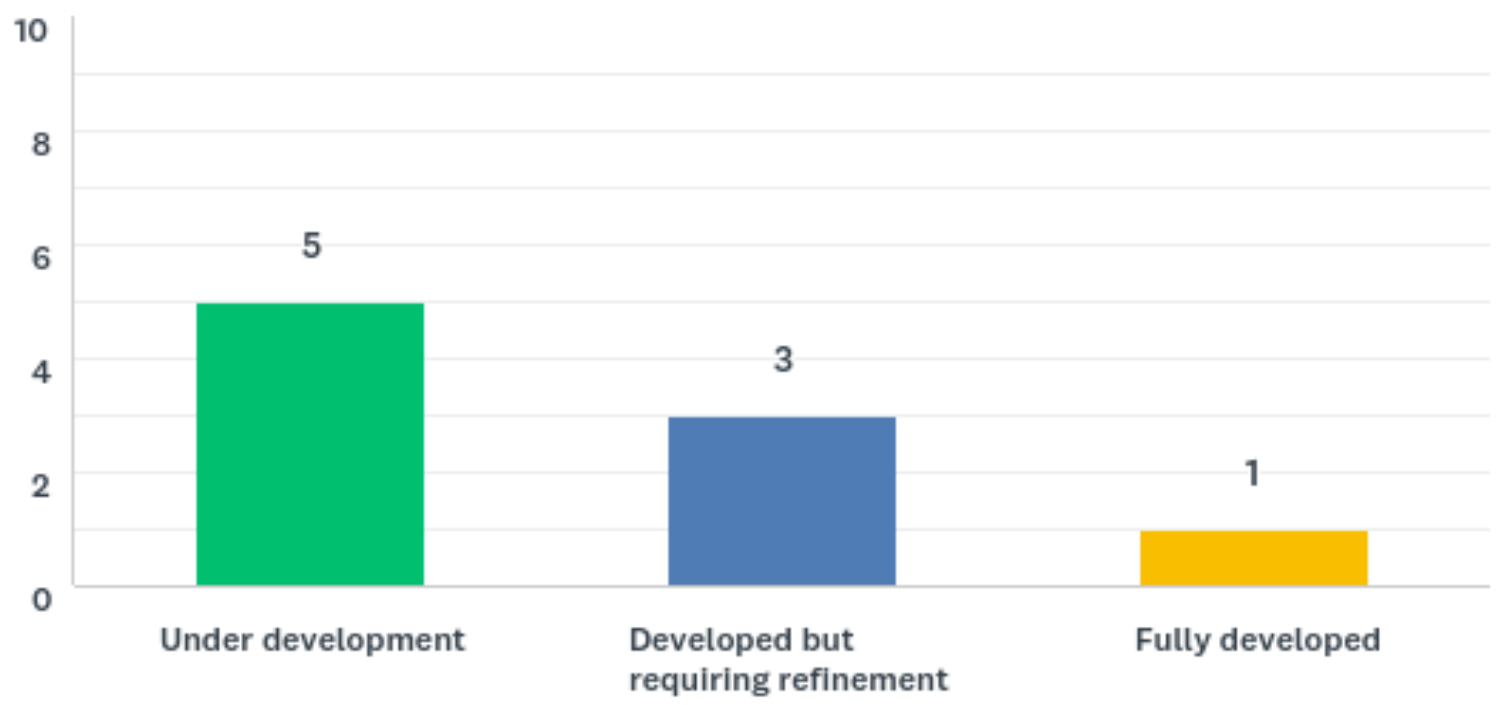

There was a difference of opinion with regards to the implementation of the standard: 5 strategic leads considered that this standard was under development, 3 developed but requiring refinement, and one considered it to be fully developed.

Strategic leads were concerned that although the Charter is in existence it is "Not in place in all areas children \& young people access" [SL5]. Another was concerned that there has been a "Lack of focus on the community setting" [SL4].

"This charter is not solely for 'Children's Services' but it is the responsibility of the whole organisation. Areas like therapy services, primary care, general surgery, ENT, orthopaedic do not sit within Children's Services and yet many Children use their services however there is little evidence that they are committed to this Charter" [SL8]

"Ensuring that this is spread over all children's services within ABMU not just hospital based - that it includes Community nursing, children's clinics and therapy centres, primary care etc." [HP32] 
"It continues to have an acute focus but there is a huge appetite to develop this out in the community/ children's centres/ therapies also." (SL4)

As another Strategic Lead recommended,

"Community services and children's centres etc would benefit from champions i.e., greater support to embed this."

The above quotes are examples of Strategic Leads and health professionals evidencing their concerns that there may have been progress in children's services, but this was not the case for all health services that have an impact on children. Kilkelly and Savage also reported from their research, those who specialise in children's health care, are normally situated in secondary and tertiary care services, so children will often be treated by health practitioners at the community level, such as GPs, therapists, who do not have a specialism in children. More work needs to be carried out at the community level to ensure that community-based health services deliver on the minimum standards of a CRA. ${ }^{1102}$ However, this must be set against the finding by the RCPCH that community-based services in Wales face a considerable lack of investment in the workforce. ${ }^{1103}$ One of the Strategic Leads references the importance of champions for community services and children centres. Kilkelly and Savage advocated for strong leaders and champions for children's rights to be appointed and all health systems to be targeted, including professionals, managers and policy makers and practitioners. ${ }^{1104}$ As referred to in Chapter 5, Royal College of Nursing guidance states that there must be a children's champion at Executive Board level (although this is also not always adhered to). It may also be advisable that there are Children's Rights Champions in all health service areas. ${ }^{1105}$

\footnotetext{
${ }^{1102}$ Kilkelly U and Savage E Child friendly health care: A report commissioned for the ombudsman for children (Ombudsman for Children 2013) 25

${ }^{1103}$ Royal College of Paediatrics and Child Health and British Association for Community Child Health, Covering all bases - Community Child Health: A paediatric workforce guide (Royal College of Paediatrics and Child Health 2017)

${ }^{1104}$ Kilkelly U and Savage E Child friendly health care: A report commissioned for the ombudsman for children. (Ombudsman for Children 2013) 4

${ }^{1105}$ Royal College of Nursing, The role of children and young people's nurses in commissioning and planning service (Royal College of Nursing 2014)
} 
Strategic Leads were also concerned that children's rights were not as yet embedded across all strategic documents. As one Strategic Lead expressed strongly,

"Although we have the Children's Rights Charter it is not fully embedded in

all policy statements/documents throughout the organisation." [SL8]

One Strategic Lead pointed out "The rights are not mentioned in recent strategic documents" [SL3.] As discussed in Chapter 6 for any CRA to be fully embedded, children's rights must be embedded into all policies of an organisation. However, one Strategic lead evidenced the full development of the Charter by the fact there is a "Children and Young People's Strategy" [SL6] (See discussion on Children's Rights Strategy).

FIGURE 20: Distribution of strategic leads to $\mathbf{5}$ score options rating of objective SLQ 4 - Leaders and staff, who are required to put the Children's Rights Charter into practice, are aware of this commitment

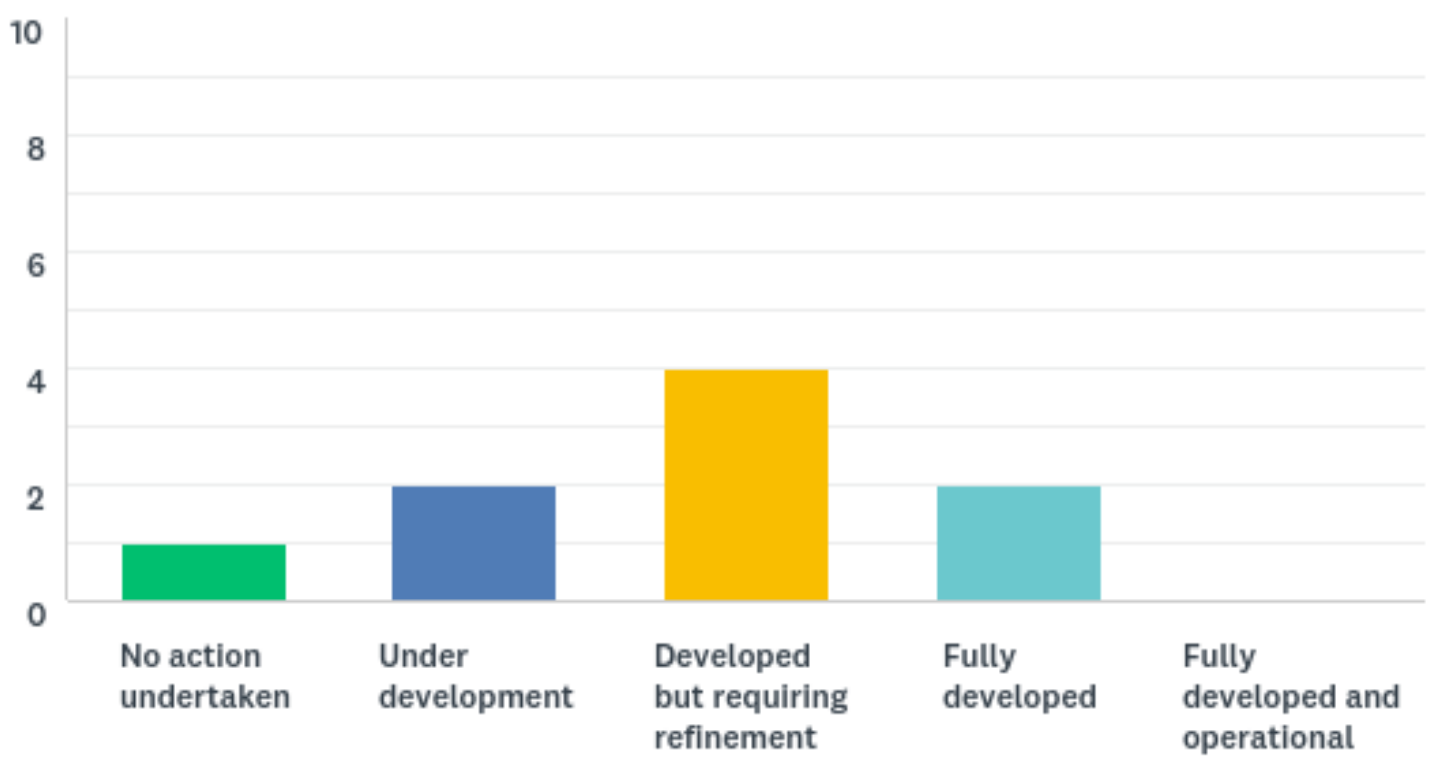

Again, as can be seen in Figure 20 there was a difference of opinion with regards to the implementation of the objective that Leaders and Staff who are required to put the Charter into practice are aware of their commitment to children's rights and the Charter. 
Three Strategic Leads added their comments,

"Within Children's Services the leaders and staff put this Charter into practise HOWEVER, this is not so for other areas in the organisation." [SL8]

"Many staff still require Children's Rights training in adult focused areas." [SL5]

"Outside of child health, staff are unaware of the requirements the rights make of them." [SL3]

These comments reinforced the findings above that outside of children's services little progress has been made with regards to the implementation of a CRA.

\subsubsection{Health professional perspectives}

FIGURE 21: Percentage of health professional respondents who report the Children's Rights Charter is displayed in service areas where they work

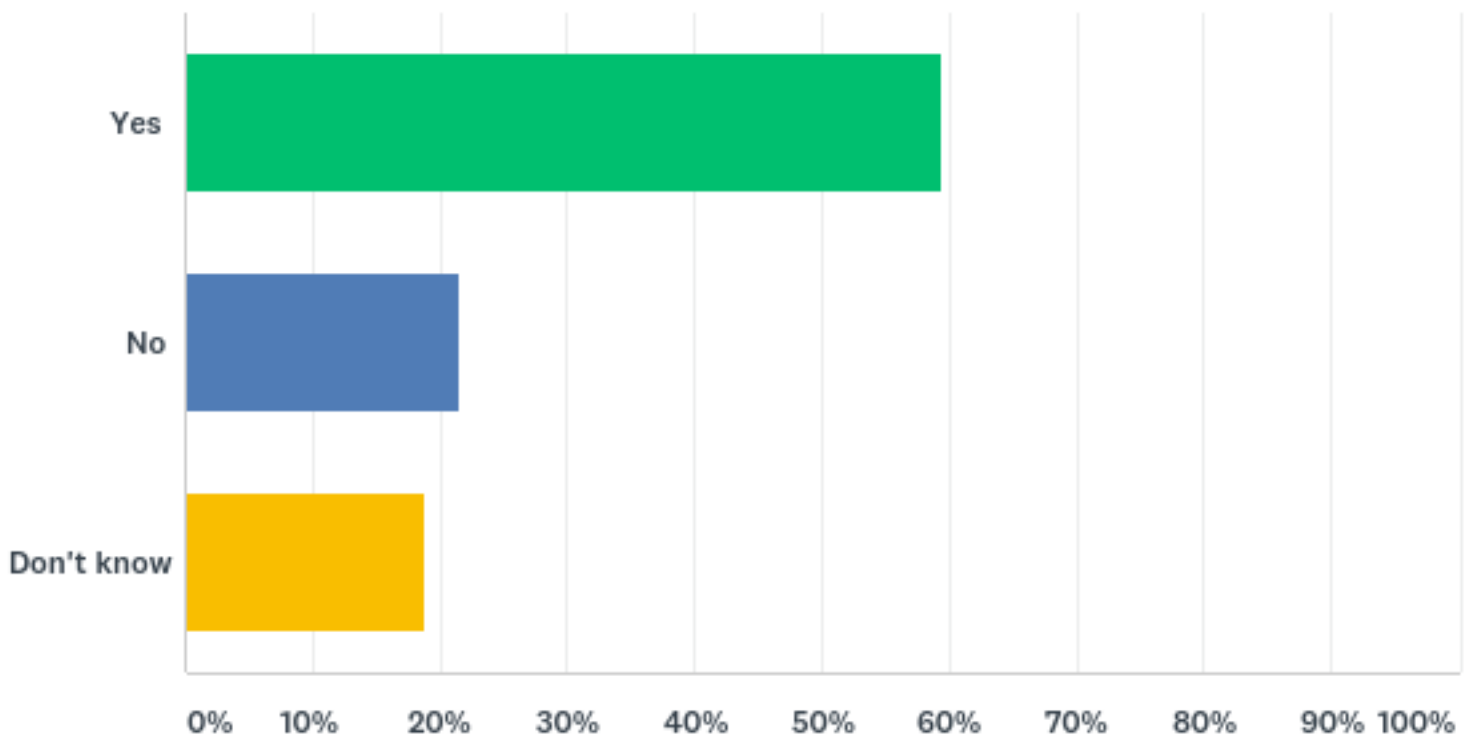


FIGURE 22: Percentage of health professional respondents by how they rate their own knowledge of the ABMU Children's Rights Charter

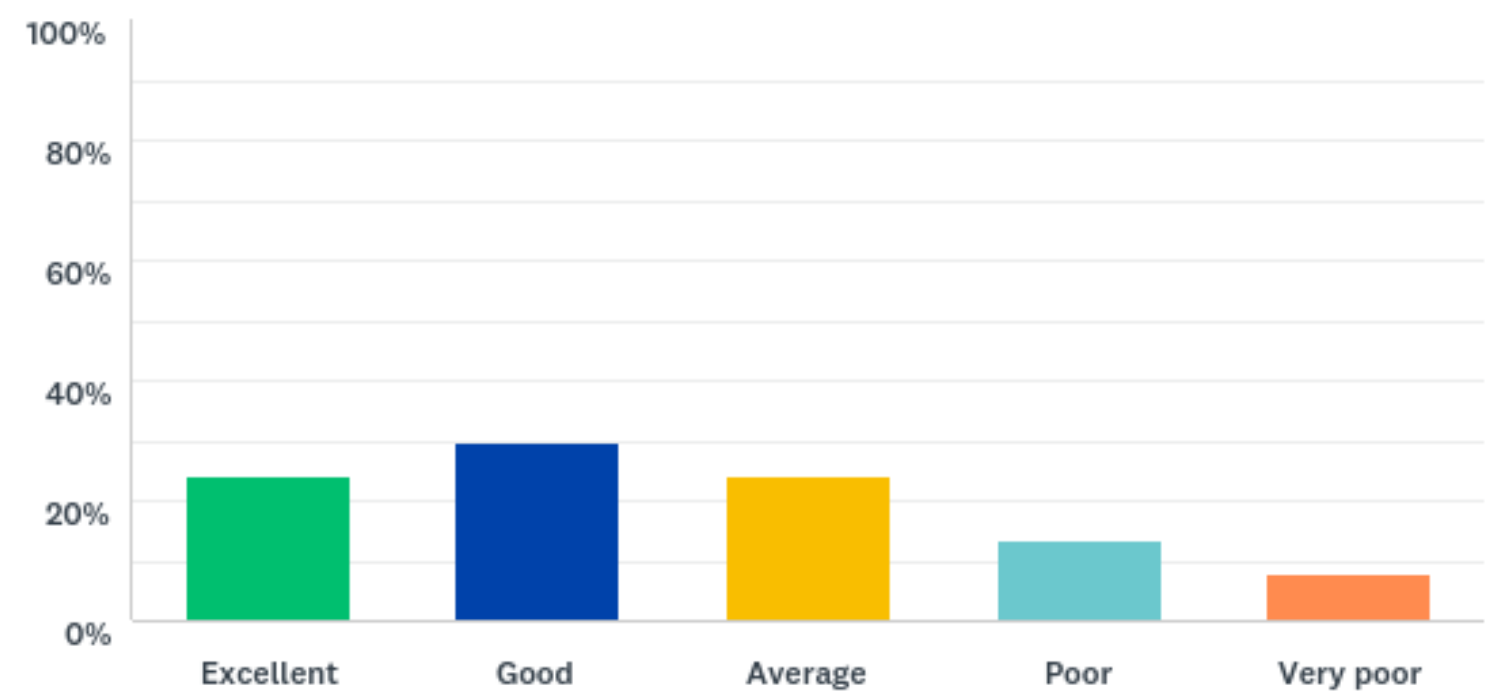

$59.5 \%$ (22) of the health professional respondents answered that the Children's Rights Charter is displayed in the area where they work (Figure 21) and only $24.3 \%$ (9) of respondents responded that their knowledge of the Charter was Excellent (Figure 22). The Charter was only launched in 2017, however, one would expect by 2019 that the Charter would have been displayed in all areas of ABMU health services and that the majority of health professionals had a least a 'good knowledge' of the Charter. One would hope in 2021 when the research is conducted again that $100 \%$ of health professionals have at least a 'Good' knowledge of the Charter and $100 \%$ of health professionals report that it is displayed across all health services. 
FIGURE 23: Distribution of strategic leads to $\mathbf{5}$ score options rating by objective

SLQ 5 - Children as service users and their carers have been made aware of the Children's Rights Charter and what it means for them

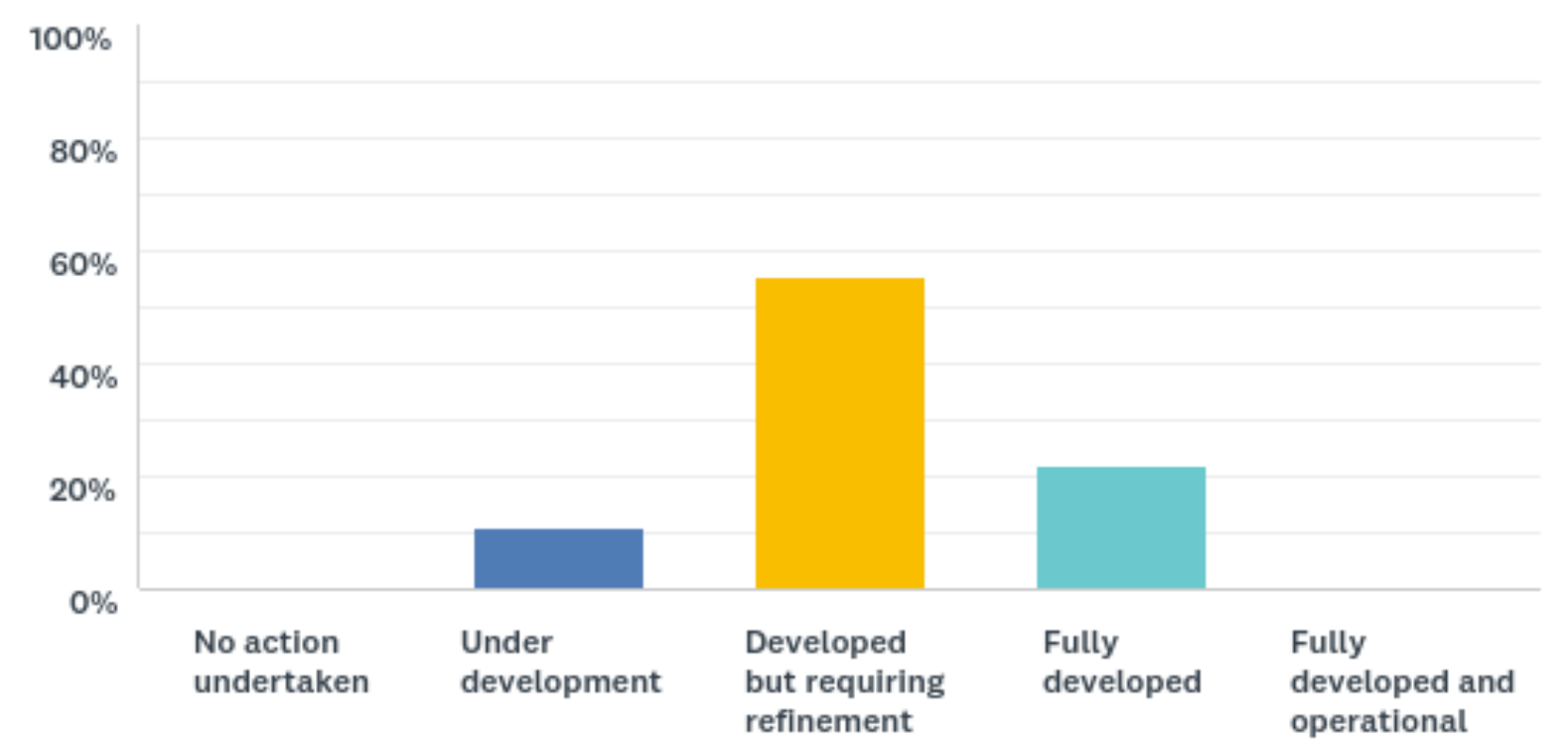

With regards to children and carers being made aware of children's rights and the charter Figure 23) one Strategic Lead thought that this was under development, 5 Strategic Leads thought that the standard was developed but requiring refinement, 2 believed the standard to be fully developed.

One Strategic Lead commented,

"Those children/families using the areas Children's Services are responsible for are aware, fully developed and operational but again children/families accessing services outside the responsibility of Children's Services either no action is taken or this is under development." [SL8]

This was supported by other Strategic Leads saying that the Charter was "In place but not utilised in all areas yet" [SL5] and there is a "Lack of focus on community setting" [SL4]. However, one Strategic Lead believed that the "Charter is available in all areas" [SL6]. 
9.3.1.2 Young people's perspectives 13-17 years

FIGURE 24: Proportion of young people respondents who know their rights when visiting a health professional

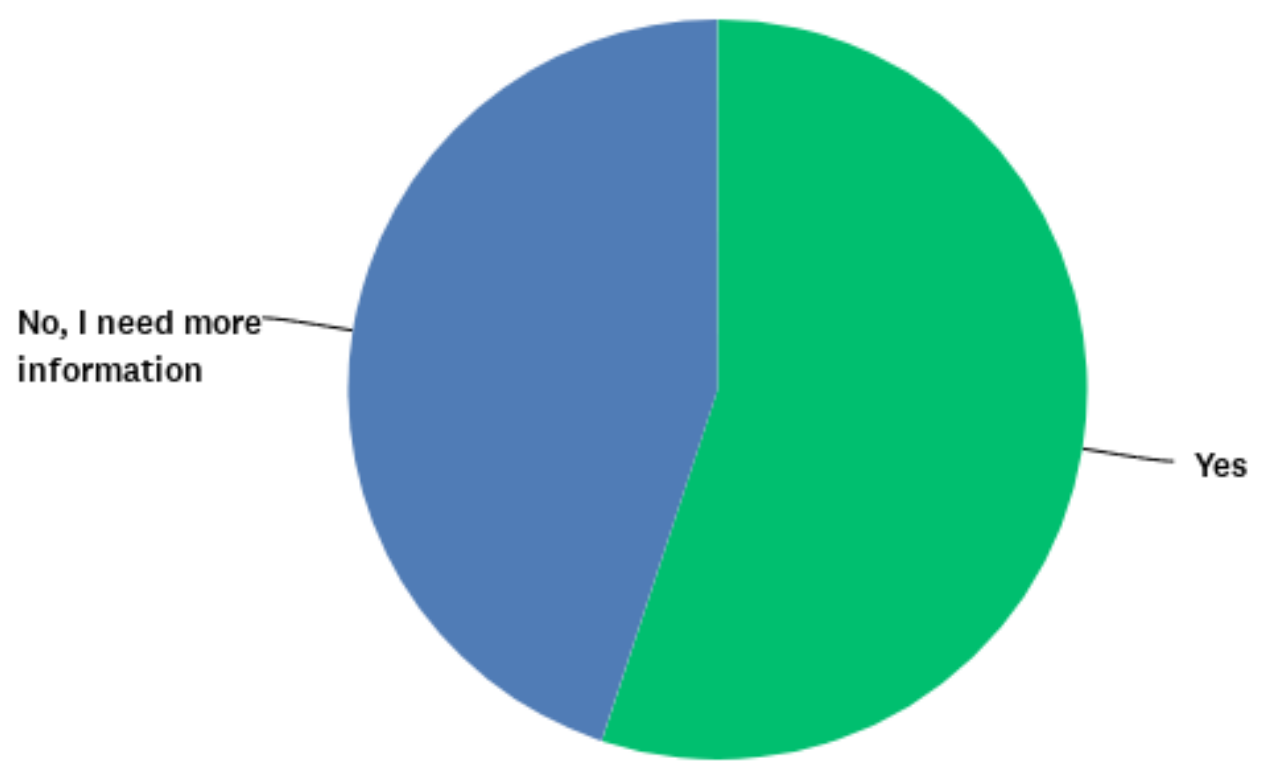

FIGURE 25: Percentage of young people respondents who have seen the Children's Rights Charter before

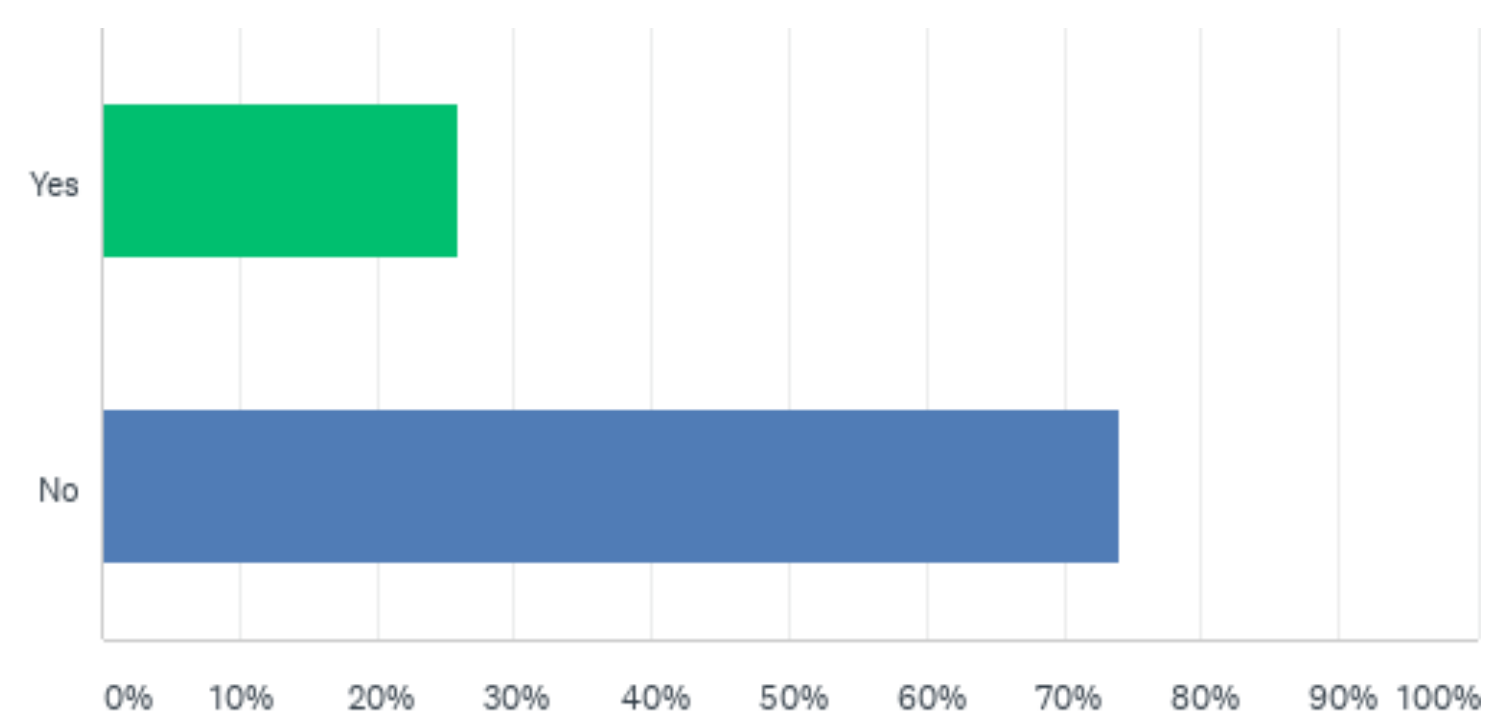


$44.9 \%$ of (22) young people responded that they did not know what their rights were when visiting a health professional (Figure 24) and needed more information and the majority of young people $(74 \%, 37)$ had not seen the Children's Rights Charter before (Figure 25).

\subsubsection{Children's perspectives 7-12 years}

FIGURE 26: Proportion of child respondents who know their rights when visiting a doctor or a nurse

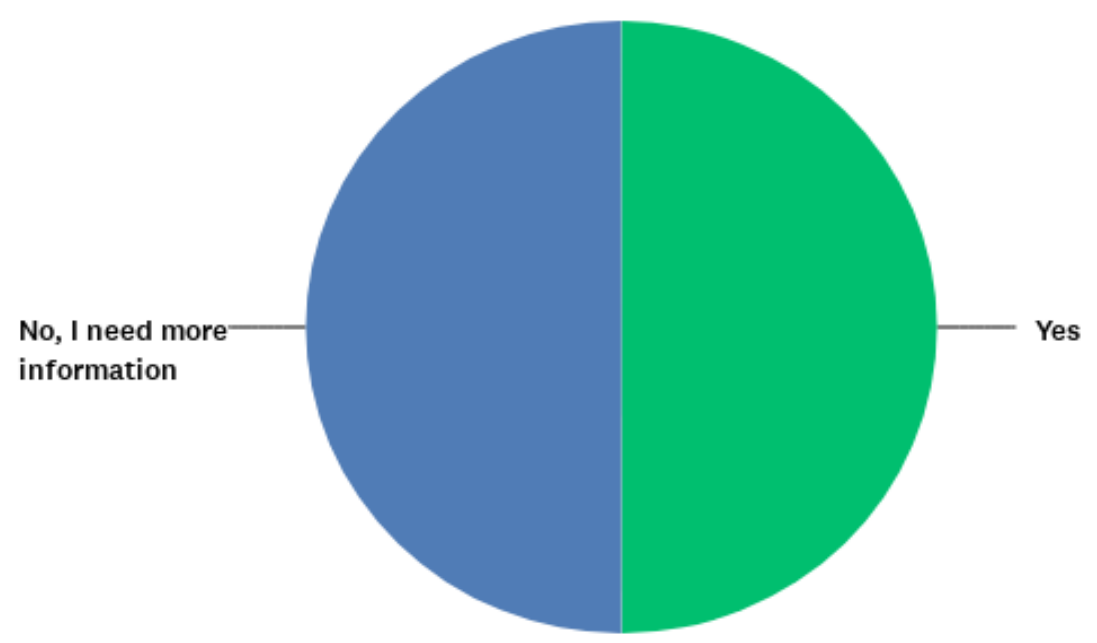

FIGURE 27: Proportion of child respondents who have seen the Children's Rights Charter before

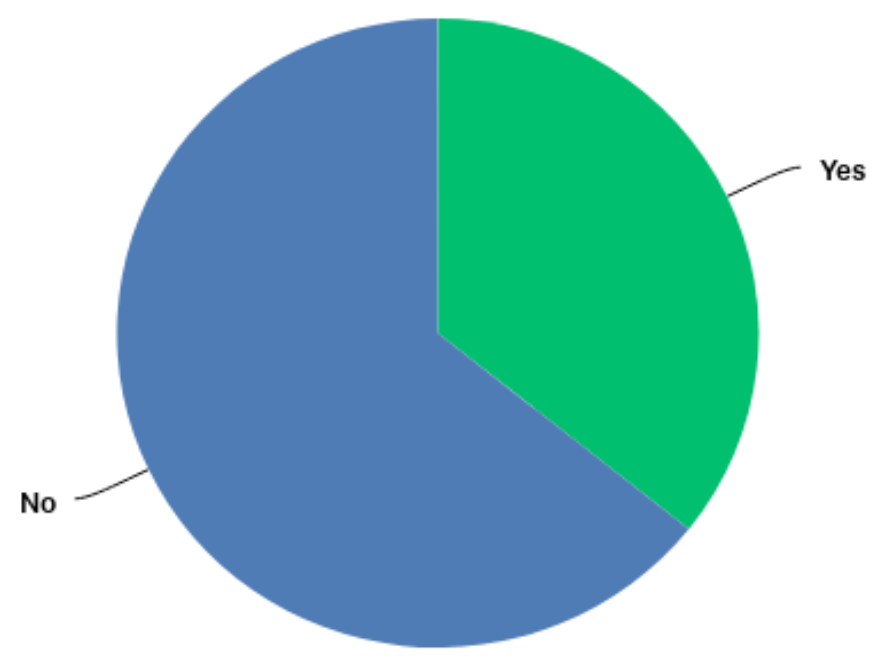


$50 \%$ (49) of the children said they did not know their rights when visiting a health professional and needed more information (Figure 26). 64.3\% (63) of the children said they had not seen the Charter poster before (Figure 27). Of the $35.7 \%$ (35) of children who had seen it before, some added additional comments, 11 children said they had seen it in school and 4 children said they had seen it in hospital.

\subsubsection{Reflections}

The data generated by the Strategic Leads demonstrates that most of the work to raise awareness and embed the Charter has happened in Children's Services and more work needs to happen to raise awareness and embed the Charter in the community setting and also in adult focused health service areas. Strategic Leads and health professionals consistently noted their concern that this was not happening effectively. As the UN Committee on the Rights of the Child makes clear, effective implementation of the UNCRC requires visible coordination to recognise and realise children's rights across all departments working for children. ${ }^{1106}$

Some of the Strategic Leads commented that although they have the Charter it has not been embedded in recent strategic policy statements/documents. There is a certainly a recognised need for senior level direction to ensure that this happens across all future Health Board strategies and documents as a matter of course. As other research has indicated a charter is only a starting point and other processes and structures must be established in order that a CRA becomes fully embedded. ${ }^{1107}$

The data revealed that the Charter is not yet displayed across all health services and the health professional respondents should have a better knowledge of the Charter. With two thirds of children not having ever seen the Charter and the majority of young people also not having seen the charter; these findings suggest that more work needs to be done to raise awareness of the Charter with professionals and children. It should be displayed across all health services and made available to children and young people when attending health services and in educational institutions. As one health

\footnotetext{
${ }^{1106}$ UN Committee on the Rights of the Child, General Comment No.5 on General Measures of Implementation, $\mathrm{CRC} / \mathrm{GC} / 2003 / 5$

${ }^{1107}$ Kilkelly U and Savage E, Child friendly health care: A report commissioned for the ombudsman for children (Ombudsman for Children 2013)
} 
professional explained when referring to the Charter there needs to be; "Access to it and knowing it," [HP25] and as one Strategic Lead commented, staff need to be aware of the requirements the rights make of them [SL3]. This promotes implementation of Article 42 of the UNCRC, which requires the principles and provisions of the Convention to be widely known, by appropriate and active means, to adults and children alike'. This will be discussed further in the section, Children's Rights Training.

\subsubsection{Embedding children's rights: children's rights strategy}

As outlined in Chapter 6, a strategy should be developed regarding how the UNCRC will be incorporated into every aspect of decision making, procedures and actions that is adequately resourced. The UN Committee on the Rights of the Child advises that a cyclical process of planning, implementation, monitoring and evaluating children's rights should become integral to the work of the health authority. ${ }^{1108}$ Furthermore, a need to have coordinated service responses and to organise health services around children's needs and expectations. This should be placed within a clear strategic policy framework setting out the priorities and the measures necessary to fulfil children's rights in practice. ${ }^{1109}$ As laid out in the objectives of the CRA there must be adequate resources allocated to support the health authority to implement children's rights, including key individuals or a team with responsibility to promote children's rights across the health authority. The surveys were designed to ascertain to what degree this was happening across ABMU health services.

\footnotetext{
${ }^{1108}$ UN Committee on the Rights of the Child, General Comment No. 15 on the right of the child to the enjoyment of the highest attainable standard of health $\mathrm{CRC} / \mathrm{C} / 15 / 2013$ para 48

${ }^{1109}$ UN Committee on the Rights of the Child, General Comment No. 15 on the right of the child to the enjoyment of the highest attainable standard of health $\mathrm{CRC} / \mathrm{C} / 15 / 2013$ paras $96-101$
} 
FIGURE 28: Distribution of strategic leads to $\mathbf{5}$ score options rating by objective SLQ 6 - A strategy has been developed to ensure the Children's Rights Charter is taken into account at all levels of decision-making across all health services and there is clear coordination with other agencies

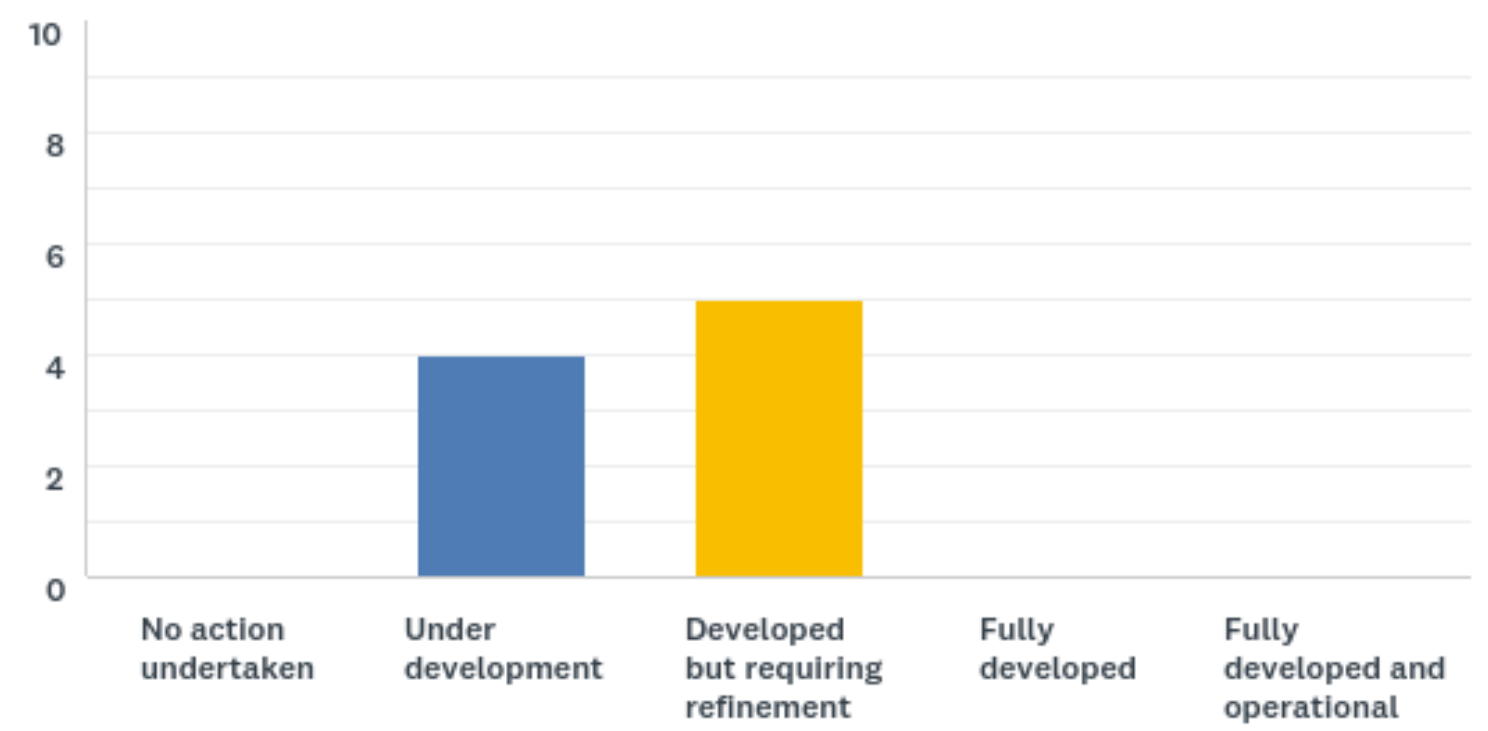

There was general agreement with regards to the standard to establish a Strategy to ensure the Charter is taken into account at all decision making. 4 Strategic Leads believed it to be under development and 5 Strategic Leads believing it to be developed but requiring refinement (Figure 28).

Interestingly one Strategic Lead believed that "More development has taken place within health rather than other agencies" [SL8]. General Comment No. 5 and General Comment No.15 advocate that for children's rights to be implemented successfully, there should be coordination across all governmental agencies working for children. ${ }^{1110}$ The Charter was launched by the health authority and this comment suggests that more work should be undertaken to share information and guidance regarding the implementation of the Charter with other agencies.

${ }^{1110}$ UN Committee on the Rights of the Child, General Comment No. 5 on General Measures of Implementation, CRC/GC/2003/5 para 27, UN Committee on the Rights of the Child, General Comment No. 15 on the right of the child to the enjoyment of the highest attainable standard of health $\mathrm{CRC} / \mathrm{C} / \mathrm{GC} / 15$ para $96-101$ 
Another Strategic Lead stated that, "Community settings and multi-agency approaches not always reflecting this clearly" [SL4] and another was aware of the ABMU Children's Strategy but thought that; "Strategy not finalised /published as far as I am aware" [SL5] and finally one Strategic Lead commented that "Very little evidence of this" (i.e., strategy developed to take account of the Charter at all levels of decision making) [SL3].

The Head of Nursing and Children's Services indicated that alongside the development of the Charter, a Children's Strategy had been developed that was consulted on, as a part of the Children's Strategy Group that ran for two years between 2016 and 2018. Children's Strategy meetings were run quarterly with strategic managers across the Health Board. Representatives from the three local authorities and public health were invited to attend to meet and discuss learning regarding children's health issues and challenges in the Health Board area and to discuss learning from child patient stories. The Children's Strategy was signed off by the ABMU Executive board and published in September 2017 and a 5-year implementation plan, with key priorities was at that time being developed. This suggests that again more work needs to be done to support multi-agency working and the implementation of a CRA in health settings in the community. It seems inadequate that there is a lack of awareness of the Strategy and an action plan across all health services has not yet been finalised and made available to those who have to implement it. 
FIGURE 29: Percentage of health professional respondents that have access to guidance on implementing the Children's Rights Charter in their area of work

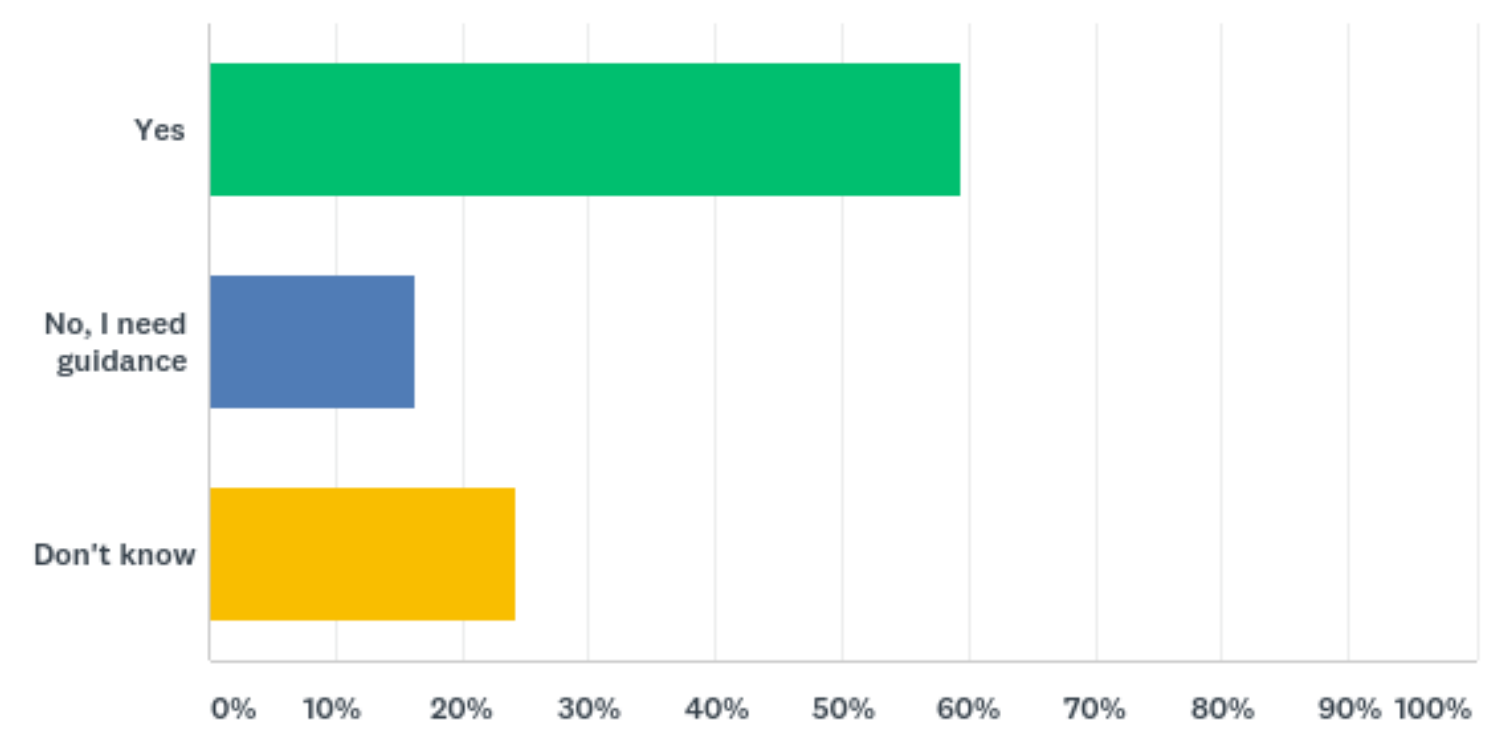

$54.4 \%$ (22) of health professional respondents answered that they had accessed guidance on the Charter (Figure 29). By 2021 it should be expected that $100 \%$ of health professionals are able to access guidance on the implementation of the Charter.

FIGURE 30: Distribution of strategic leads to $\mathbf{5}$ score options rating by objective SLQ 8 - Key individuals and/or teams with responsibility to promote implementation of children's rights within the health authority has been established

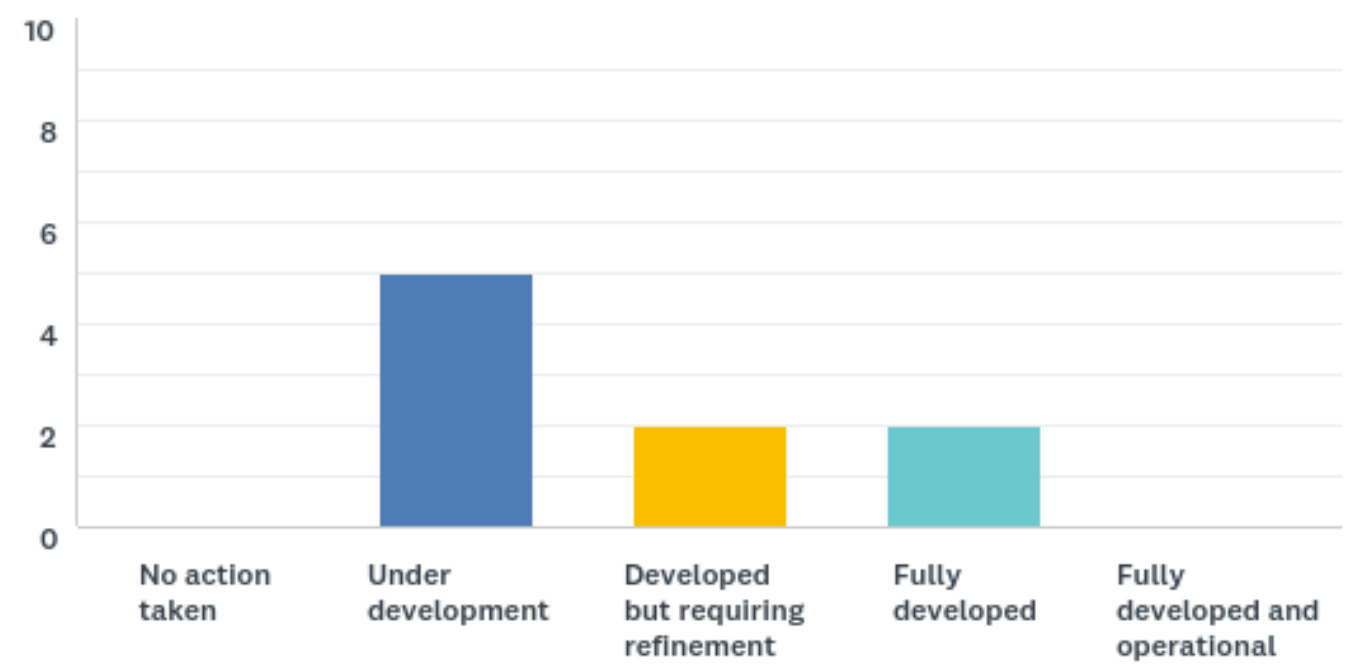


5 Strategic Leads believed that key individuals/team to promote implementation of children's rights within the health authority was under development, 2 developed but requiring refinement and 2 fully developed (Figure 30).

Again, the concern was reiterated that it is currently only seen to be the commitment of Children's Services,

"There is a general attitude that it is the responsibility of Children's Services to undertake this work other areas of the organisation do not see it as their responsibility." [SL8]

This was reinforced by another Strategic Lead, "Needs development in areas outside CYP services" [SL6] with again the concern noted regarding "Lack of input into community setting, rehabilitation, therapy etc" [SL4]. Finally, one individual explained that "The team is developing. Limited representation" (i.e., limited representation of staff from all service areas) [SL3].

The Head of Nursing and Children's Services made it clear that there is no dedicated team or core funding for delivering on children's rights implementation or implementation of the Charter or the Strategy. The Head of Nursing tries to lead on the delivery of all these elements in addition to her day job and is supported by the Manager of the Neath Port Talbot Children's Rights Unit, the Patient Experience Coordinator and ABM Youth (see later section on ABM Youth). 
FIGURE 31: Percentage of health professional respondents that respond there is a named person in their service area responsible for service delivery complying with the charter

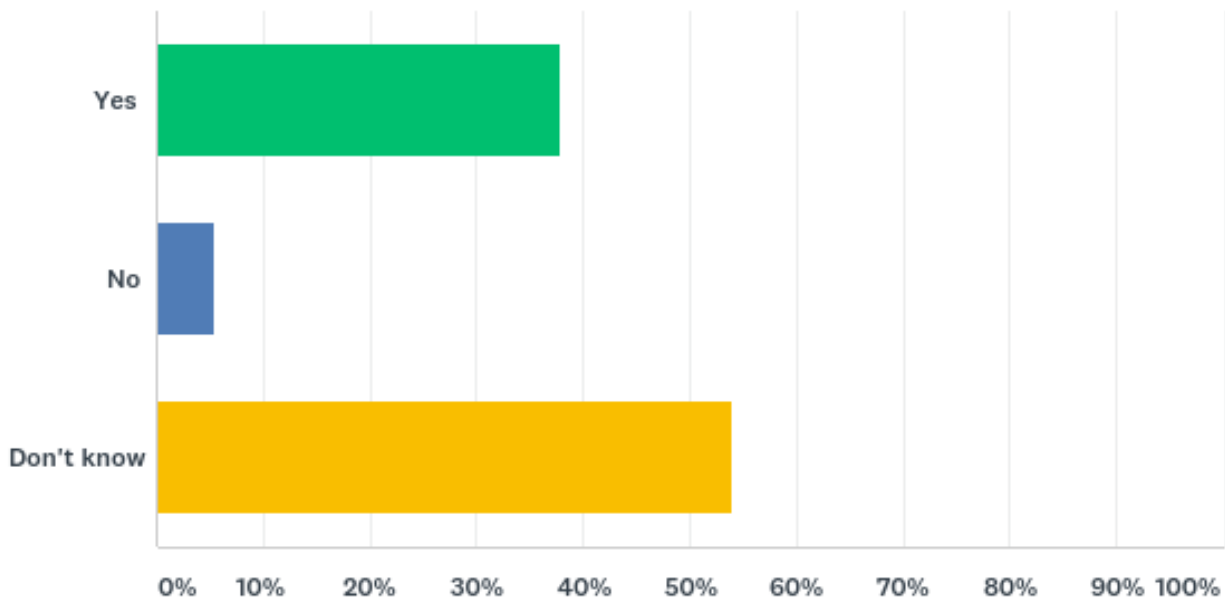

$54 \%$ (20) of health professionals responded that they did not know if there was named person responsible for the delivery of the Charter in their service area (Figure 31). Two health professionals added additional comments to say that "We are all responsible" [HP18] and "We are all responsible in my areas of responsibility to uphold children rights and advocate for them" [HP9].

FIGURE 32: Distribution of strategic leads to $\mathbf{5}$ score options rating by objective SLQ 7 - Protection of children's rights has been prioritised through the commissioning cycle

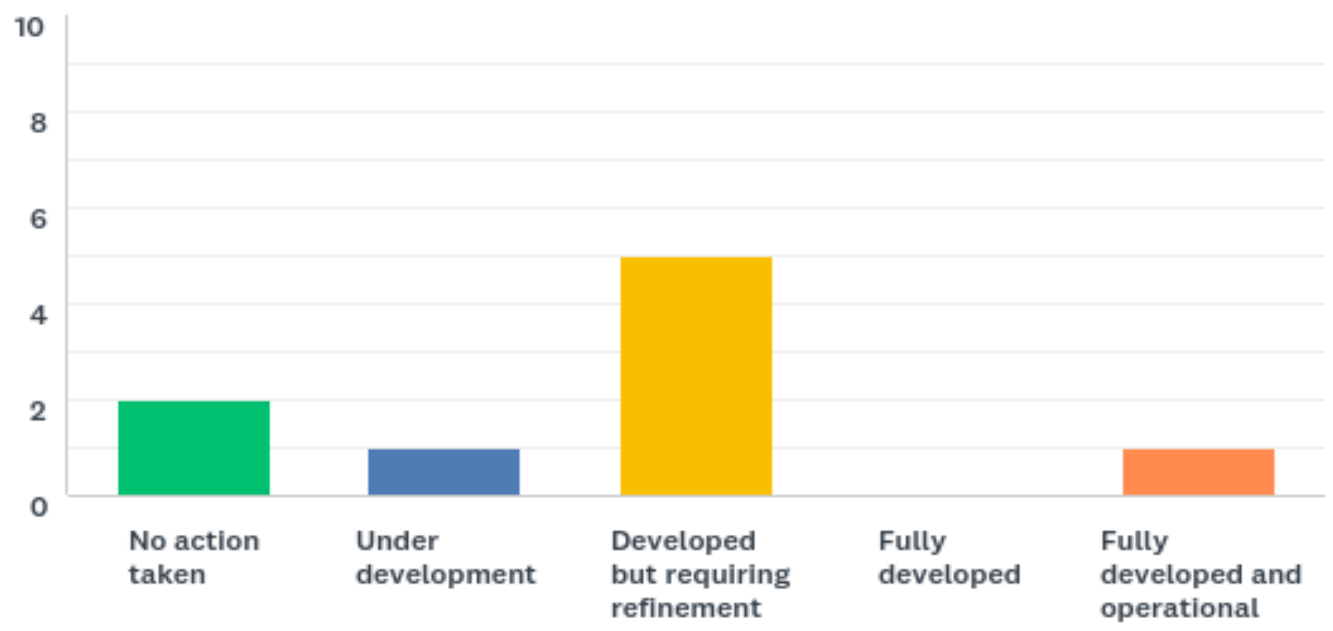


The Strategic Leads were in general agreement that this was an area that required more work and expressed the view that although there was some inclusion of children's rights through commissioning services that this was not consistently applied (Figure 32). Three Strategic Leads added their comments; "There is some protection of children's rights through the commissioning cycle in some areas more than others not consistent throughout" [SL8] and another Strategic Lead agreed "Not assured that this is the case for all service areas" [SL5].

One Strategic Lead [SL6] offered the ABM Youth Board as an example of services being commissioned in a way that demonstrate ABMU's commitment to children's rights (see later discussion on ABM Youth Board). Considering the Health Board commissions a range of services, it should be anticipated that these services are contractually obligated to adhere to the same standards as the health authority to comply with children's rights and is a requirement of the UN Committee on the Rights of the Child. ${ }^{1111}$

FIGURE 33: Distribution of strategic leads to $\mathbf{5}$ score options rating by objective SLQ 9 - There is clear and transparent evidence to demonstrate that the maximum extent of available resources has been allocated to implement the Children's Rights Charter

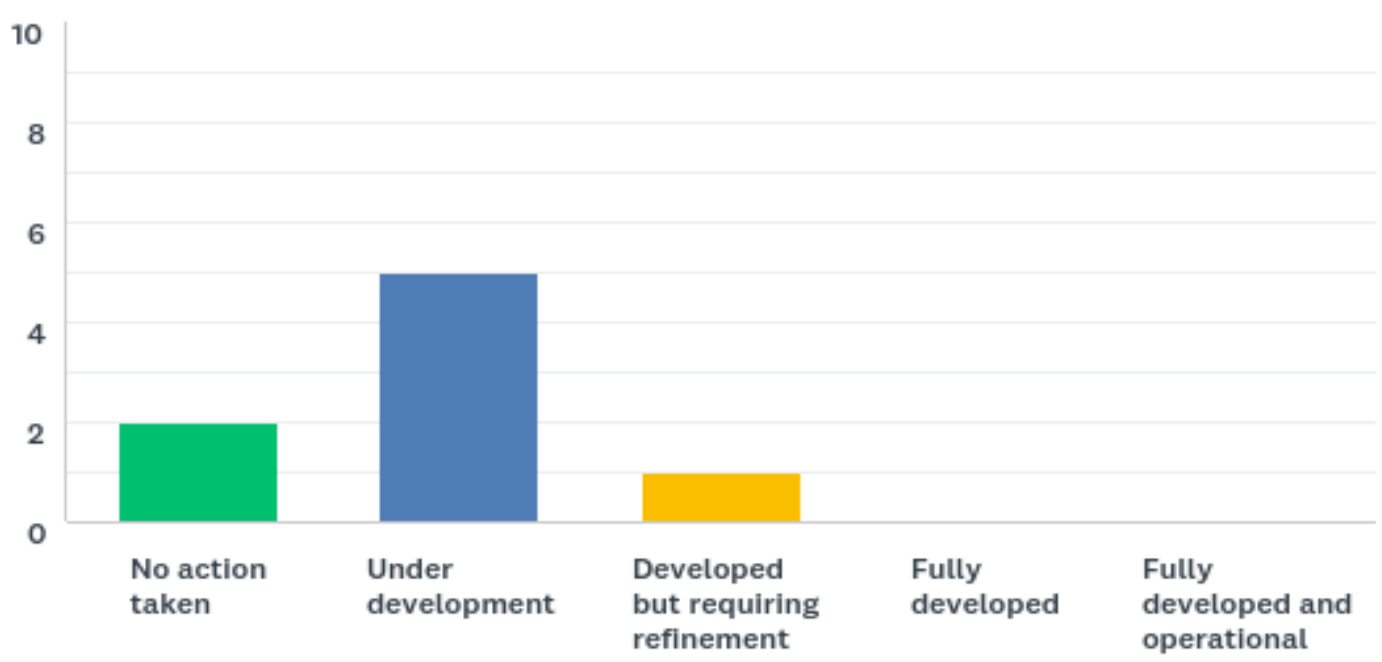

${ }^{1111}$ UN Committee on the Rights of the Child, General Comment No. 15 on the right to the highest attainable standard of health $\mathrm{CRC} / \mathrm{C} / \mathrm{GC} / 15 / 2013$ para 77 
With regards to the clear and transparent evidence to demonstrate that the maximum extent of available resources has been allocated to implement the Charter. There was general agreement that this was an area where no action had been taken or required more work (See Figure 33). One Strategic Lead, said they had, "No evidence I am aware of to support this statement" [SL5] with another believing that there is a "Need to develop a programme of support" [SL6] and stating "I would suggest that there has been minimum resources allocated to the implementation of the Children's Rights" [SL8].

\subsubsection{Reflections}

It is identified as a weakness that the delivery of the Charter and a CRA to service delivery is not better supported and a 5 -year implementation plan for all health services has not as yet been published and resourced. It is in accordance with a CRA that children's rights should be every health professional's responsibility, but without infrastructural support such as a designated Children's Champion, a Children's Rights Implementation Team, a clear corporate-wide Children's Rights Strategy and sufficient allocation of resources; children's rights will not succeed in becoming embedded. The Strategic Leads' evidence suggests that spending on the delivery of the Charter is currently not happening to the 'maximum extent of available resources' on children, therefore breaching Article 4 of the UNCRC. This requires further research to learn what proportion of the health authority's expenditure is being spent to realise the human rights of children across the health authority. The UNCRC General Comment on Health emphasises the importance of monitoring health budgets for the proportion of their expenditure on children, carrying out consistent and regular rights-based budget analysis and impact assessment. ${ }^{112}$ In accordance with the UN Committee on the Rights of the Child, duty bearers are required to demonstrate transparency and whether budgetary decisions are in compliance with the CRC. ${ }^{1113} 1114$ Transparent evidence on spending on children in relation to health services is an essential tool in

\footnotetext{
${ }^{1112}$ UN Committee on the Rights of the Child, General Comment No. 15 on the right of the child to the enjoyment of the highest attainable standard of health $\mathrm{CRC/C} / 15 / 2013$ para 106

${ }^{1113}$ UN Committee on the Rights of the Child, General Comment No. 5 on General Measures of Implementation $\mathrm{CRC} / \mathrm{C} / \mathrm{GC} / 5 / 2003$

${ }^{1114}$ UN Committee on the Rights of the Child, General Comment No.19 on public budgeting for the realisation of children's rights $\mathrm{CRC} / \mathrm{C} / \mathrm{GC} / 19 / 2016$
} 
meeting this obligation. Including evidence of whether planned spending and/or spending cuts are impacting the health outcomes of children. ${ }^{1115}$

Also, as the Committee on the Rights of the Child makes clear, is essential that children's rights are part of the contractual obligations of parties that are commissioned to deliver services. ${ }^{1116}$ These findings again reinforce the need for senior leadership and a commitment to resources for implementation.

\subsubsection{Embedding children's rights: children's rights training}

The questions in the surveys were designed to find out how successfully the Health Board was with regards to raising awareness and understanding of children's rights and if training is being delivered on children's rights. The UN Committee on the Rights of the Child in General Comment No. 5 and 15 and the Council of Europe Child Friendly Guidelines recommends that all professionals (including health professionals, policy makers and managers) who work directly or indirectly with children should receive training in children's rights. ${ }^{1117}$ According to the (SEMT) international study (referred to in Chapter 4) health professionals had little knowledge of children's rights in healthcare and there were limited examples of initiatives that focused on education and training of health care professionals. ${ }^{1118}$

\footnotetext{
${ }^{1115}$ Ibid

${ }^{1116}$ UN Committee on the Rights of the Child, General Comment No. 15 on the right to the highest attainable standard of health $\mathrm{CRC} / \mathrm{C} / \mathrm{GC} / 15 / 2013$ para 77

${ }^{1117}$ UN Committee on the Rights of the Child, General Comment No. 5 on General Measures of Implementation $\mathrm{CRC} / \mathrm{C} / \mathrm{GC} / 5 / 2003$ 53; UN Committee on the Rights of the Child, General Comment No. 15 on the right to the highest attainable standard of health $\mathrm{CRC} / \mathrm{C} / \mathrm{GC} / 15 / 2013$ para 93

${ }^{1118}$ Simonelli F and Guerreiro A and Task Force on Health Promotion for Children and Adolescents in and by Hospitals and Health Services, The Respect of Children's Rights in Hospital: An Initiative of the International Network of Health Promoting Hospitals and Health Services (Final Report of the implementation process of the implementation of the Self-evaluation Model and Tool on the Respect for Children's Rights in Hospital. (International Network of Health Promoting Hospitals and Health Services - WHO Collaborative Centre 2010)
} 
FIGURE 34: Distribution of strategic leads to $\mathbf{5}$ score options rating by objective SLQ 10 - Initial and ongoing evaluation of levels of knowledge and understanding of children's rights amongst staff at all levels has been carried out

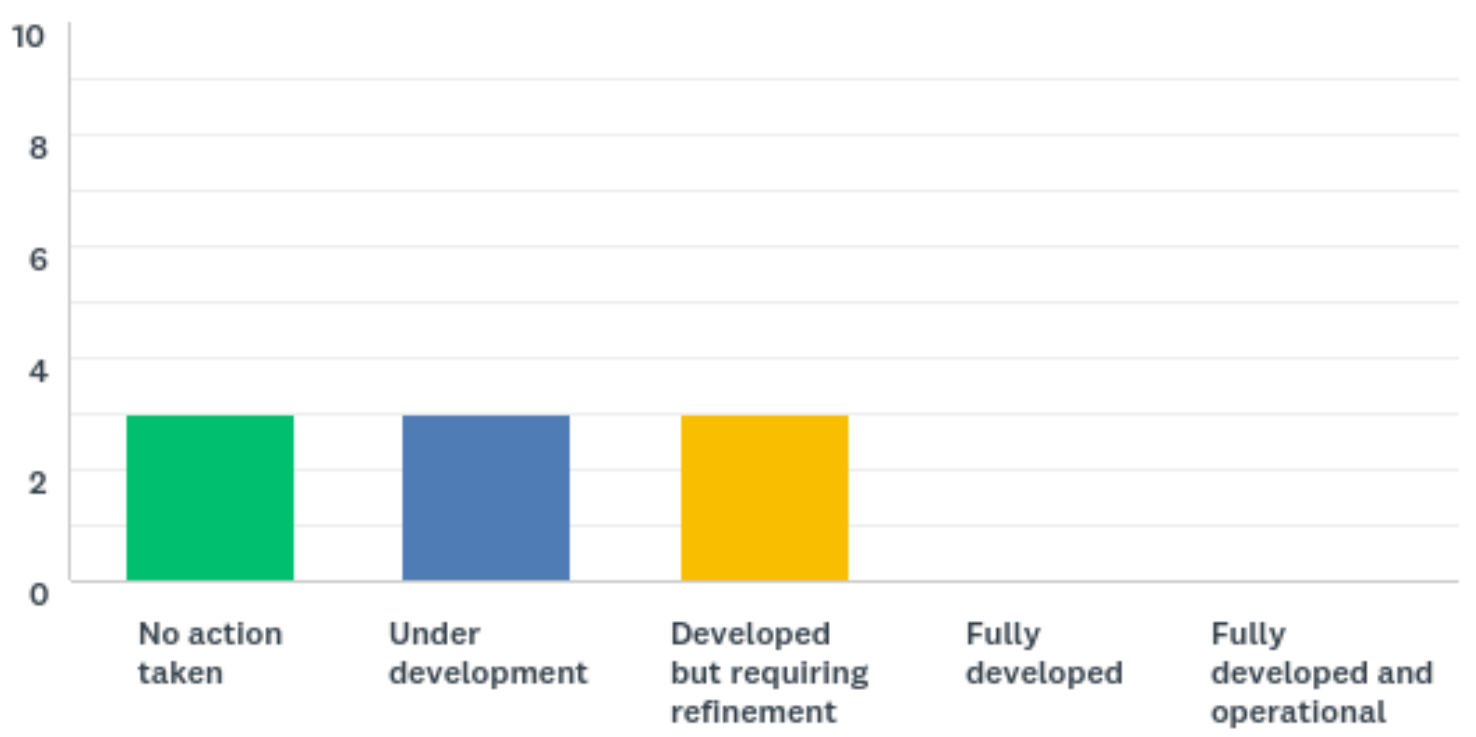

This evaluation of levels of staff knowledge of children's rights was another objective where the strategic leads agreed that little action had been taken and further development was required (See Figure 34). Three Strategic Leads commented on the implementation of this standard. One Strategic Lead believed that, "Good knowledge achieved within children's services" [SL8] but others, iterated their concerns, "I don't think this has been addressed in community / children's centres" [SL4] and "Further work is required" [SL6]. 
FIGURE 35: Distribution of strategic leads to $\mathbf{5}$ score options rating by objective

SLQ 11 - A communication plan for staff has been developed setting out how the health authority intends to develop awareness and understanding of implementing the Children's Rights Charter

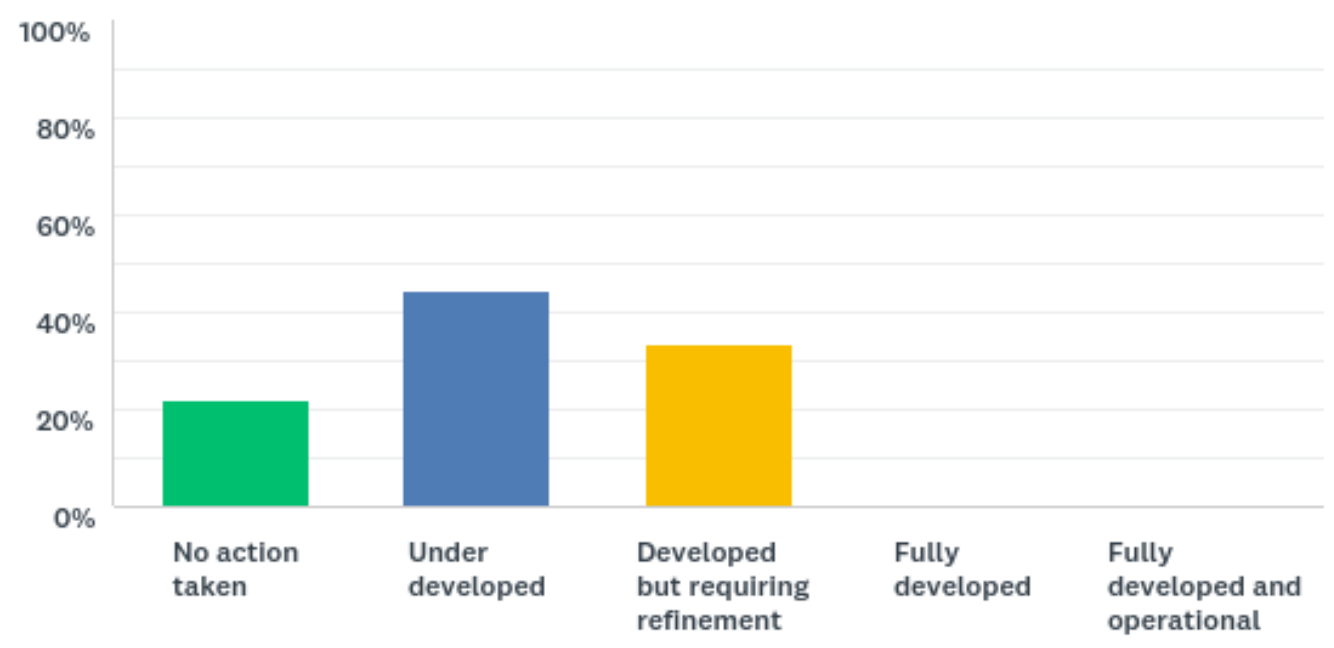

There was general agreement that this was an objective that required further work to make it fully developed and operational (See Figure 35). With one Strategic Lead [SL8] adding they had seen no evidence of a communication plan and another commenting that a communication plan had not been disseminated to the community [SL4].

FIGURE 36: Distribution of strategic leads to $\mathbf{5}$ score options rating by objective SLQ 12 - Training on children's rights for all staff (appropriate to context and role that a member of staff performs) has been prioritised

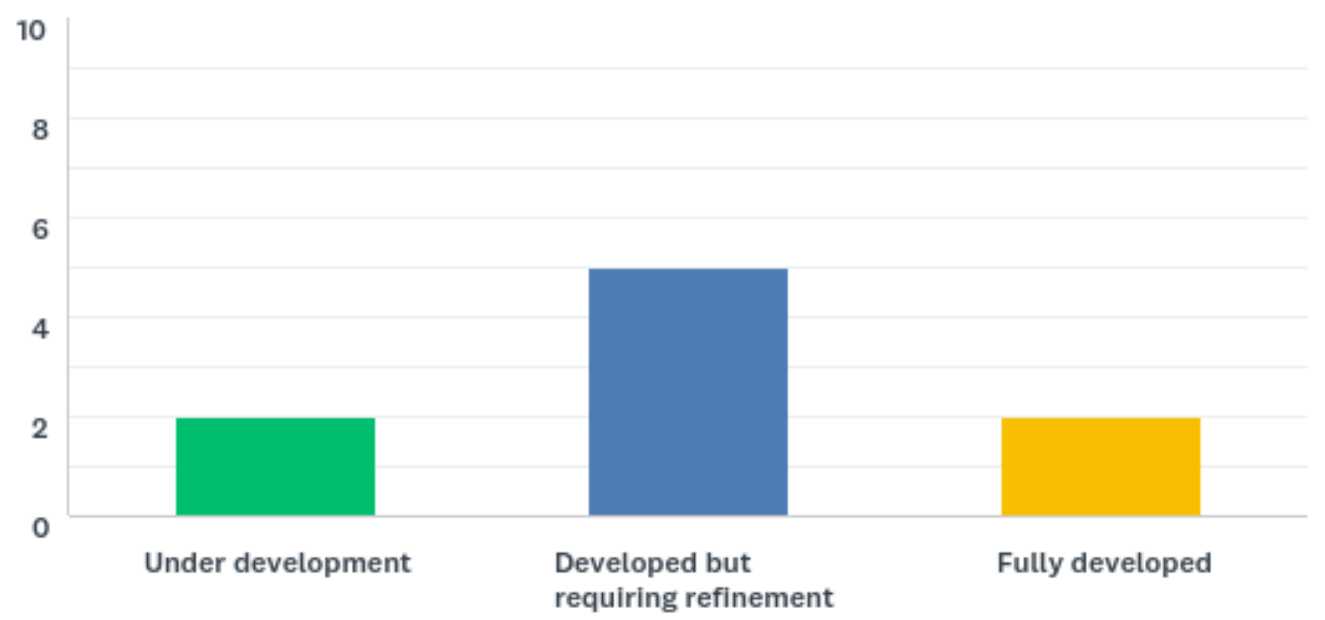


With regards to children's rights training being prioritised, 2 Strategic Leads believed this standard to be under development, 5 believed it to be developed but requiring refinement, and 2 fully developed, demonstrating a difference of opinion on the implementation of this objective (See Figure 36). One Strategic Lead commented that there has been "Limited training external to Children's Services - as those areas do not recognise their responsibilities" [SL8] this was reinforced by another Strategic Lead who agreed there was a "need to widen the scope", and others who commented that the "Main focus has been on acute setting/ staff"[SL4] and "This needs to be refined in respect of areas that do not provide direct care to but are accessed by children \& young people" [SL5].

FIGURE 37: Percentage of health profession respondents by training they have received

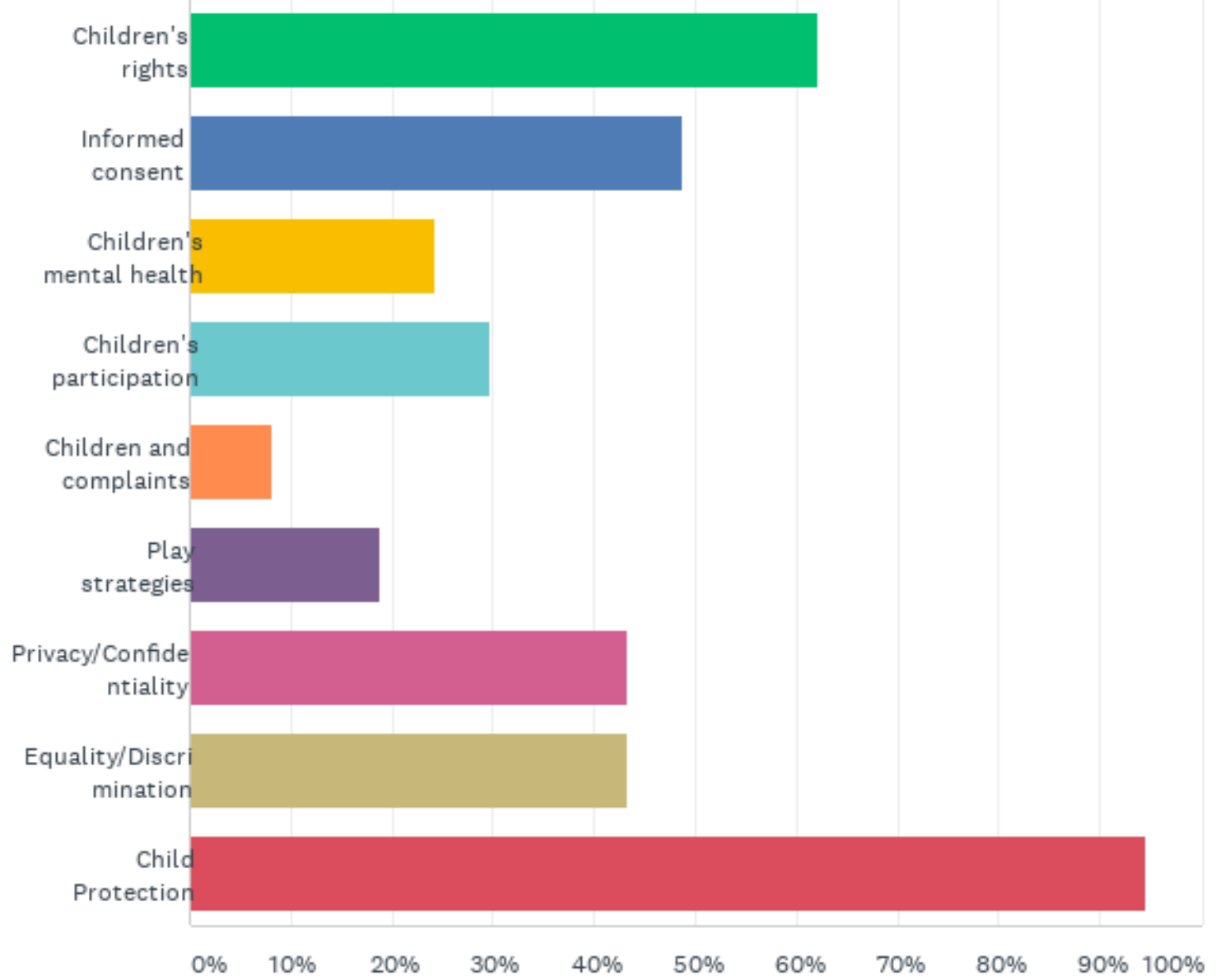

$94.5 \%,(35)$ of health professionals had received training on child safeguarding/child protection. This is a positive finding because it is compulsory when working with 
children, and the majority of this sample work directly with children. $62.1 \%$ (23) had also received training on children's rights and $48.7 \%$ (18) on informed consent. Only $29.7 \%$ (11) of professionals had received training in children's participation in treatment processes, $24.3 \%$ (9) of professionals had received training in supporting children with mental health issues, $18.9 \%$ (7) of professionals supporting children with play strategies in clinical settings. Only $8.1 \%$ (3) of professionals had received training in relation to complaints (See Figure 37 above). This indicates that further research may be required in this area as the above training requirements should be considered essential to effectively supporting the fulfilment of children's rights in health settings. Also, a larger sample of health professionals should be consulted on whether they have received training to increase the validity of findings.

FIGURE 38: Percentage of health professionals who would like to receive training on children's rights

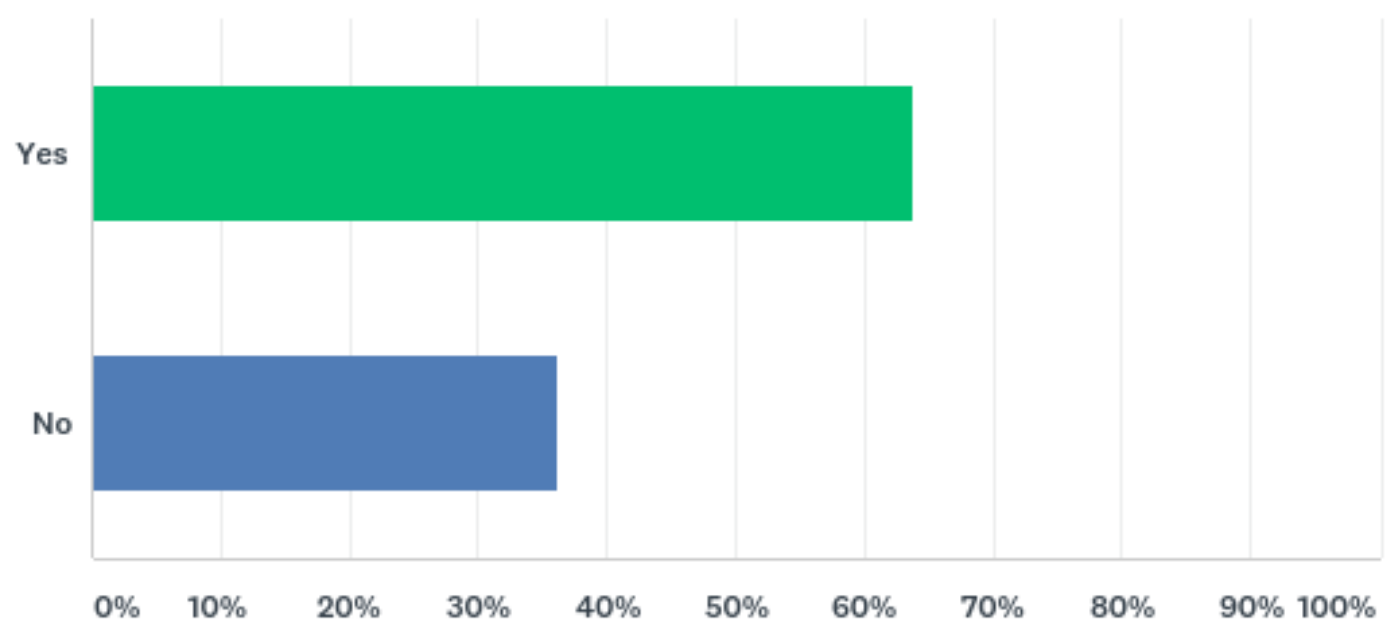

$63.9 \%$ (23) of health professionals responded that they would like to receive training on children's rights (See Figure 38). There were several additional comments as reported below:

"Ensure consistency with all grades of staff." [HP27]

"I would like to know about the continuing growth of the charter and I am keen to know further information about embedding children's rights in everything we do." [HP18] 
"Regular training and updates." [HP16]

“Training on consent." [HP11]

"Training should be at ward level and annually." [HP10]

"Received via service group." [HP9]

"Training for whole child development team perhaps at one of our multidisciplinary team cpd meetings." [HP8]

"E learning or presentation on a clinical governance day." [HP3]

In addition, a Strategic Lead commented,

"Add it to the agenda of every meeting in every dept. Make it part of the mandatory e learning for every member of staff." [SL3].

These responses provide helpful suggestions regarding the implementation of a comprehensive training programme on children's rights tailored to the needs of different staff members. As one of the health professionals commented they want to learn about the Charter but also how they can embed children's rights in everything they do, which is the challenge recognised by other country contexts that have adopted charters.

With regards to the delivery of training, the Head of Nursing and the Manger of the Neath Port Talbot Children's Rights Unit reported, that with support from Neath Port Talbot Children's Rights Unit, ABMU has been able to deliver some training on children's rights to some staff members. Funding for Neath Port Talbot Children's Rights Unit comes from ABMU's charitable funds and not core funding. Since 2018 the manager of the Neath Port Talbot Children's Rights Unit has delivered 45-minute introductory children's rights awareness raising sessions to over 700 primarily nursing staff as a part of mandatory training for women and children's services. However, the Manager indicated that these training sessions are a basic introduction and do not help health professionals to understand how to apply a CRA in their day-to-day practice. In addition, she has delivered some longer workshops to community nursing staff, however, these are not mandatory and with only her as the training resource it 
is challenging to be able to deliver them across the Health Board. The Head of Nursing has also delivered some training sessions to multi-professional teams at Morriston Hospital and Singleton Hospital. ${ }^{1119}$

\subsubsection{Reflections}

The evidence indicates that the Strategic Leads were not always in agreement regarding how effectively some of the CRA standards and objectives had been implemented. A Communication Plan for all staff regarding the implementation of children rights is critical and should be shared with all staff members across the Health Board. As General Comment No. $5^{1120}$ and Article 42 make clear, adults that are around children must be made aware of and understand the Convention to be able to respect their human rights obligations towards children. This suggests that the current lack of compliance with the CRA is because there is a lack of knowledge and to address this, it is essential that it is brought to the centre of everyone's attention, and everyone has the knowledge to make sure they are meeting children's rights appropriately. As one strategic lead expressed "Education and communication" [SL1] should be the main strategy in implementing a children's rights approach. $100 \%$ of health professionals across the three local authority areas believed that children's rights training was the most important strategy to implement the Children's Rights Charter. This was reinforced by one of the Strategic Leads in response to what strategies are required to implement a CRA:

"Mandatory children's rights awareness training \& updates for all staff including Executive Board and a process to monitor application that is led by young people." [SL5]

This sample suggests that almost two thirds of the health professionals were certainly interested in receiving more training on children's rights. The health authority needs to respond to these requests by ensuring that training is offered to staff across the Health Board. The evidence suggests a need for ongoing and further research across all health services to learn what training health professionals are receiving and what

\footnotetext{
${ }^{1119}$ Two hospitals in the Swansea Local Authority Area

${ }^{1120}$ UN Committee on the Rights of the Child, General Comment No. 5 General Measures of Implementation of the Convention on the Rights of the Child CRC/C/GC/5/2003
} 
training support they require. This would support the UN Committee on the Rights of the Child's own recommendations in General Comment No.5 and General Comment No.15.1121 The Health Board needs to allocate core funding to develop a comprehensive training programme tailored to the needs of its staff.

\subsubsection{Accountability to children: children's rights monitoring}

Monitoring how far children's rights are being realised in health care contexts is essential to assist with determining if children's rights are being respected, protected and fulfilled and also if there are breaches, what action needs to be taken and who needs to be held to account. ${ }^{1122}$ Proofing all policies and budgets in advance is considered essential as well as ensuring that children's rights are embedded in job descriptions and performance indicators. The surveys were designed to ask questions to consider how successfully the ABMU Health Board was meeting these objectives of a CRA.

FIGURE 39: Distribution of strategic leads to 5 score options rating by objective SLQ 13 - An initial and then regular audit of all significant policy statements or other documents has been carried out to assess compliance with the Children's Rights Charter

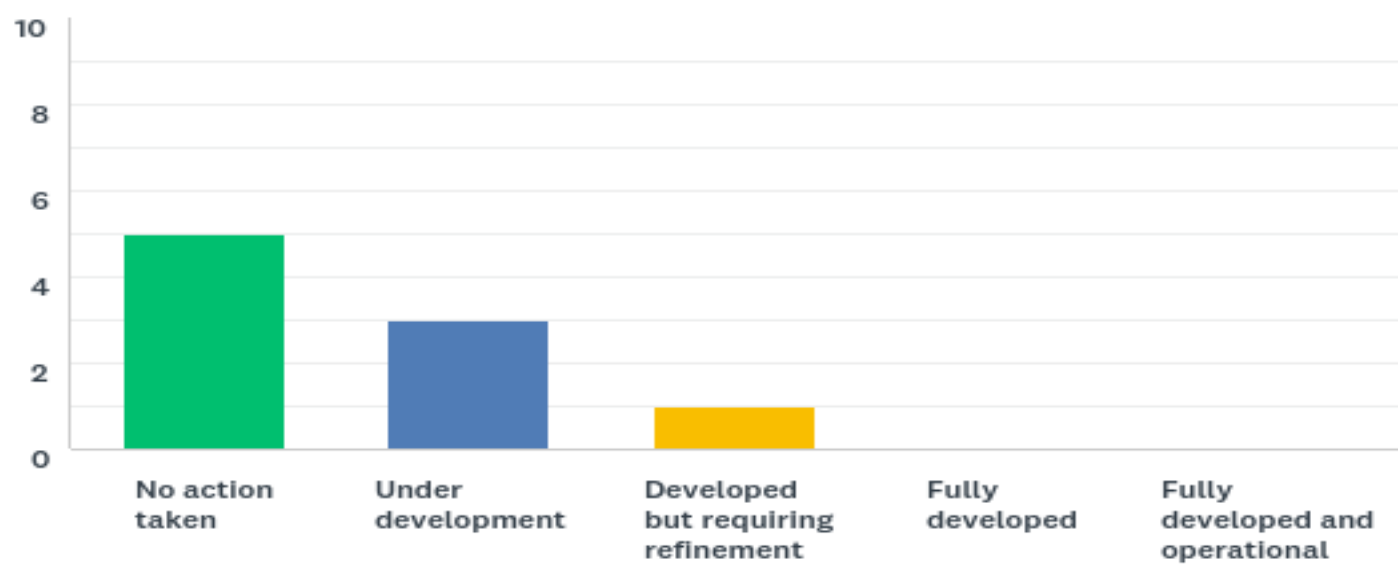

\footnotetext{
${ }^{1121}$ UN Committee on the Rights of the Child, General Comment No. 5 General Measures of Implementation of the Convention on the Rights of the Child $\mathrm{CRC} / \mathrm{C} / \mathrm{GC} / 5 / 2003$; UN Committee on the Rights of the Child, General Comment No.15 on the right of the child to the enjoyment of the highest attainable standard of health $\mathrm{CRC} / \mathrm{C} / \mathrm{GC} / 15 / 2013$

${ }^{1122}$ UN Committee on the Rights of the Child, General Comment No. 5 General Measures of Implementation of the Convention on the Rights of the Child $\mathrm{CRC} / \mathrm{C} / \mathrm{GC} / 5 / 2003$
} 
5 Strategic Leads agreed that no action had been taken to carry out an initial and regular audit of all significant policy statements or other documents to assess compliance with the Charter, 3 believed it to be under development and one believed it to be developed but requiring refinement (See Figure 39). One Strategic Lead commented that they were unaware of this being carried out [SL8] and another commented that this had not been extended to within community/therapies settings." [SL4].

\section{FIGURE 40: Distribution of strategic leads to $\mathbf{5}$ score options rating by}

objective SLQ 14 - Annual reports are published on performance against children's rights indicators and the findings disseminated widely

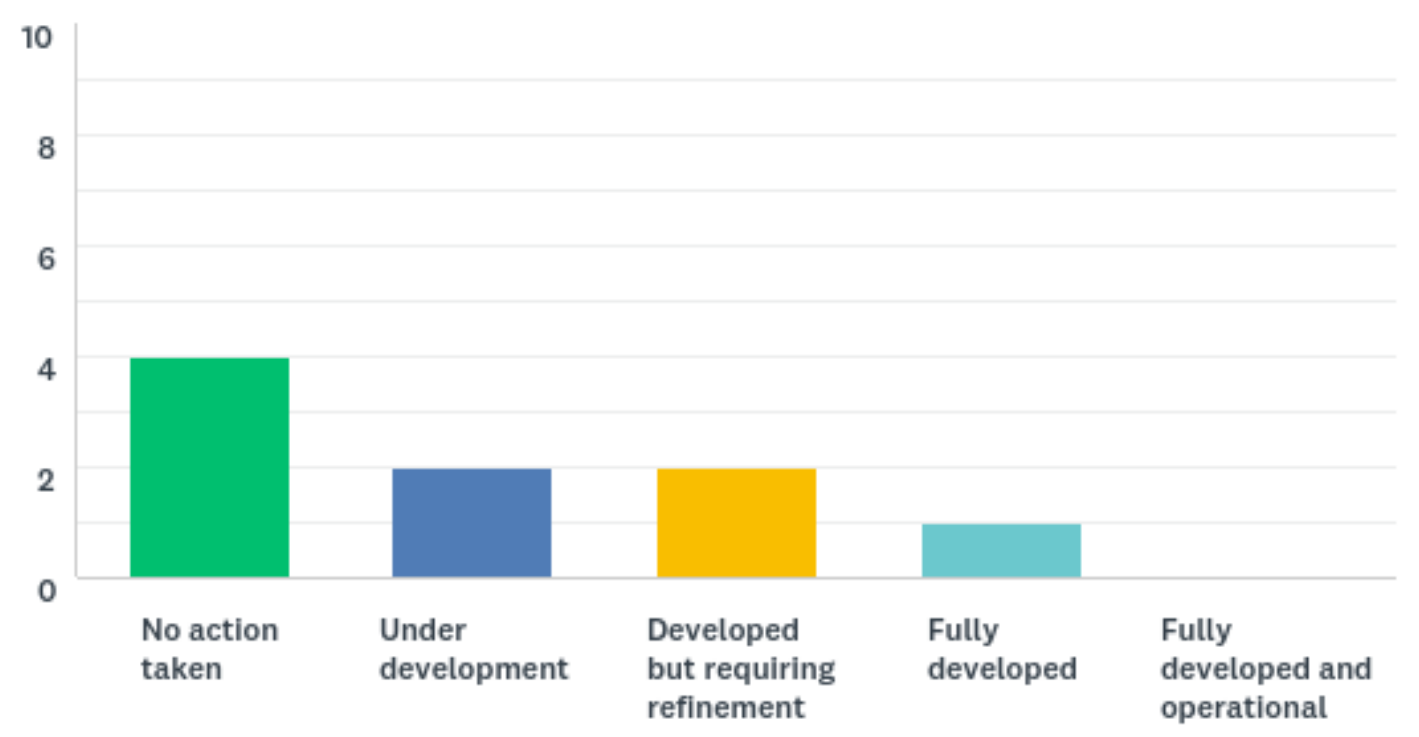

4 Strategic Leads said that no action had been taken to publish annual reports on performance against children's rights indicators and the findings disseminated widely, 2 believed it to be under development, and two developed but requiring refinement and one believed this objective to be fully developed (See Figure 40). One Strategic Lead added that "not been viewed by community/ therapy teams but new structure may facilitate this" [SL4]. 
FIGURE 41: Distribution of strategic leads to $\mathbf{5}$ score options rating by objective

SLQ 15 - There is external monitoring of performance against children's rights standards, including by involving children in monitoring and/or review/inspection

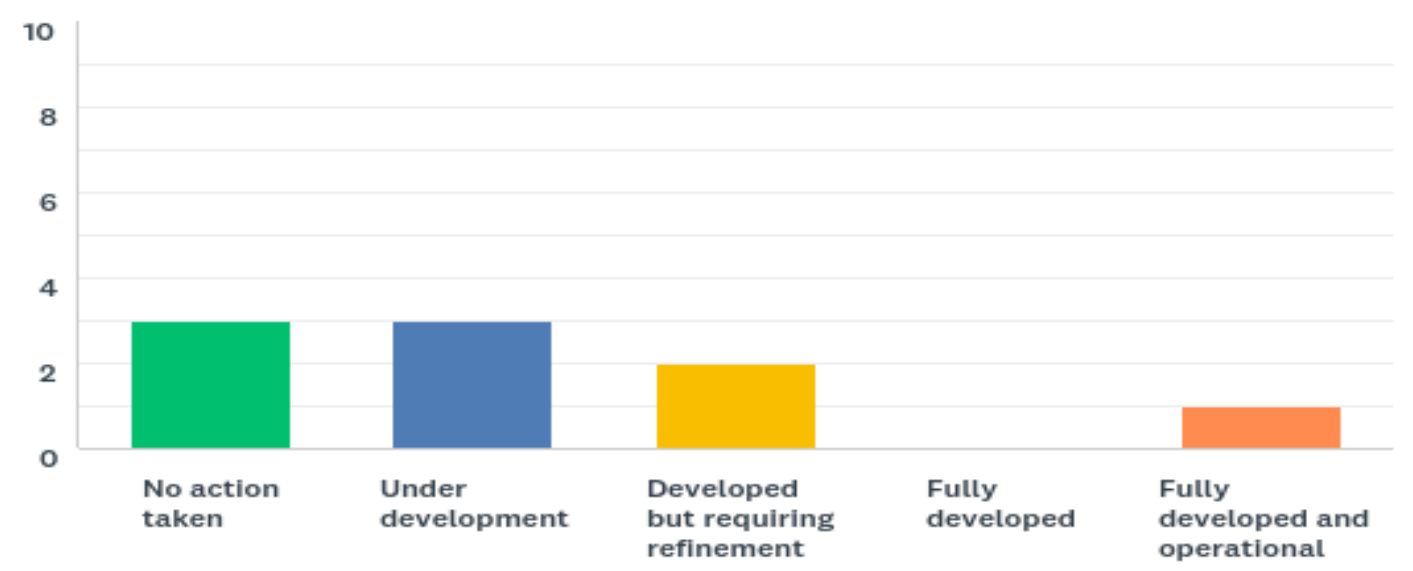

There was again a difference of opinion on the delivery of this objective regarding external monitoring of performance against children's rights standards, with the majority of strategic leads believing it was an area that had no action taken or required further development but one strategic lead believing it to be fully developed and operational (See Figure 41). One strategic lead said they were "Not aware of any monitoring" [SL5] and another Strategic Lead, commented "Previously no/limited involvement of children with disabilities" [SL4]

FIGURE 42: Distribution of strategic leads to $\mathbf{5}$ score options rating by objective SLQ 17 - Children's rights impact assessments are used to proof any policy and budgetary decisions for their direct or indirect impact on children

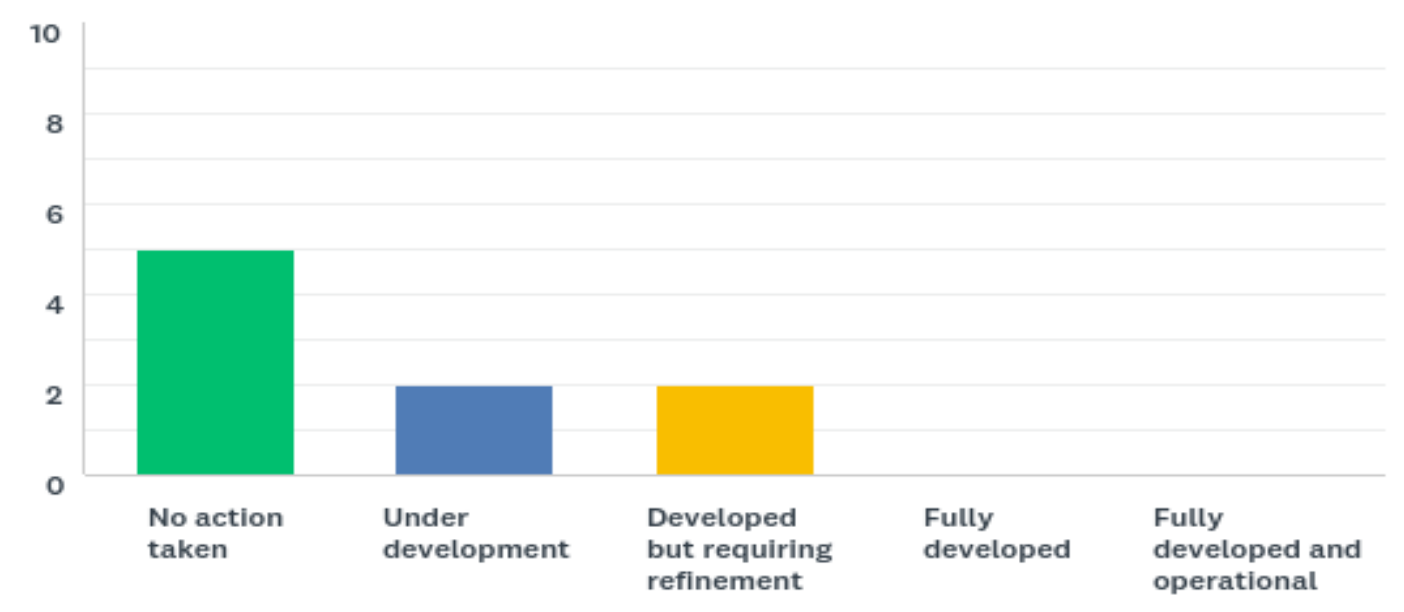


The majority of the Strategic Leads believed that Children's Rights Impact Assessments had not yet been fully implemented (See Figure 42). As outlined in Chapter 6, if a CRA is to be successfully embedded the impact of policy and budgets, must be examined through the lens of children rights. This is a specific requirement of the General Comment No. 5, No 14, No.15 of the UN Committee on the Rights of the Child. ${ }^{1123}$

\section{FIGURE 43: Distribution of strategic leads to 5 score options rating by}

objective SLQ 5 - Staff supervision and performance management includes individual responsibility for children's rights, including performance indicators in job descriptions

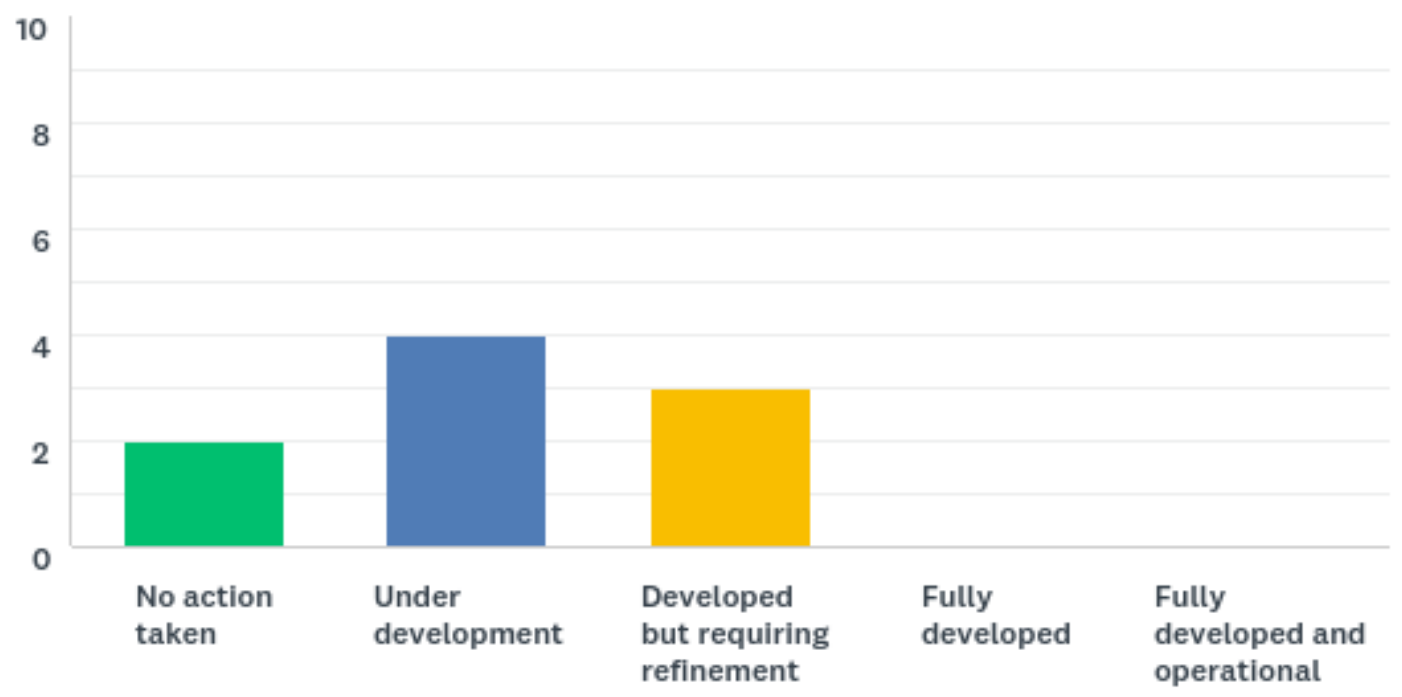

Although general agreement that this was an objective for further development; there was confusion regarding the existence of staff performance indicators rooted in the UNCRC. One Strategic Lead, believed that this is happening in "Children's Services Only", [SL6] another thought that this was "Currently covered under HB Values discussion not UNCRC specific" [SL5] and another believed it, to be "not present in

\footnotetext{
${ }^{1123}$ UN Committee on the Rights of the Child, General Comment No. 15 on the right of the child to the enjoyment of the highest attainable standard of health $\mathrm{CRC} / \mathrm{C} / 15 / 2013$ para $106 \mathrm{~d}$, UN Committee on the Rights of the Child, General Comment No. 14 on the right of the child to have his or her best interests taken as a primary consideration $\mathrm{CRC} / \mathrm{C} / \mathrm{GC} / 14 / 2013$ para 35 ; UN Committee on the Rights of the Child, General Comment No. 5 on the General Measures of Implementation CRC/C/GC/5/2003 para 45
} 
paeds therapies" [SL4]. Again, this emphasised a lack of understanding with regards to the implementation of the Charter across the ABMU workforce from Strategic Leads.

FIGURE 44: Percentage of health professional respondents who have job descriptions that include performance indicators relating to the Children's Rights Charter

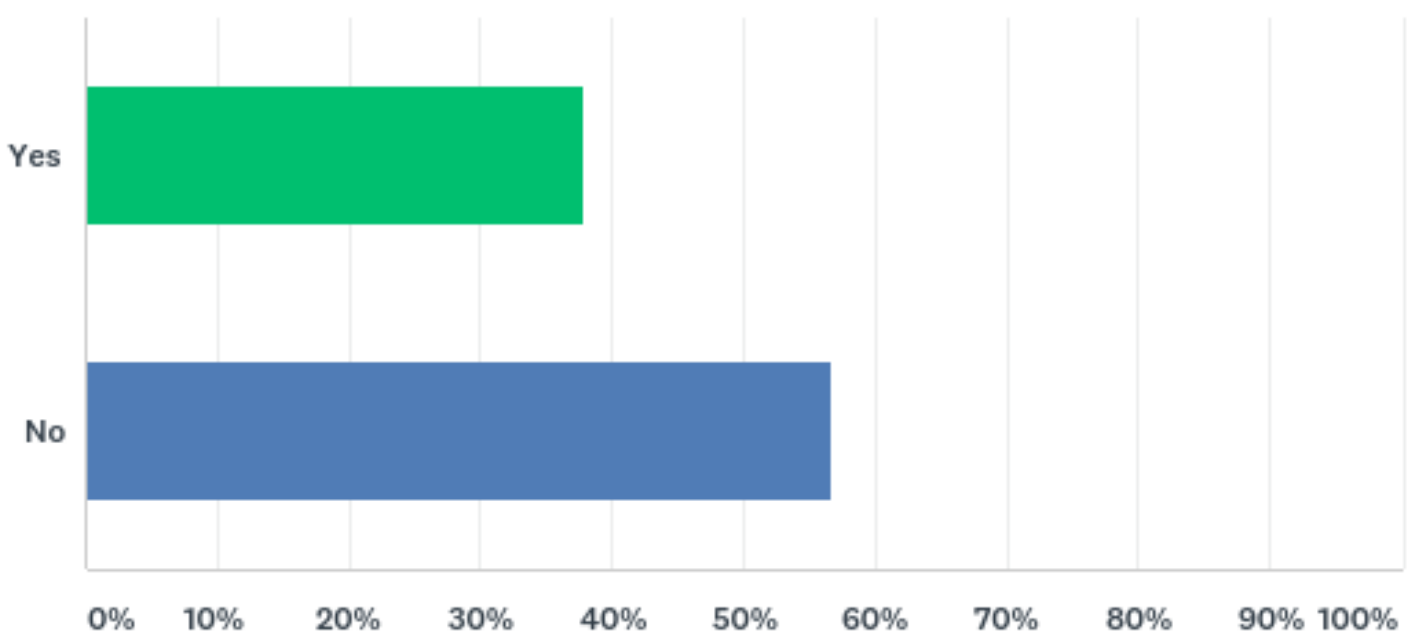

$56.8 \%(21)$ of the health professionals said they did not have performance indicators relating to children's rights in their job descriptions. One health professional [HP32] added that their job description was written before the Charter was established and interestingly another professional added, "My job description is currently under revision. The new JD does have reference to children's rights," [HP18] which may indicate that work had begun to review job descriptions for compliance with the Charter and children's rights.

The Head of Nursing reported that she had successfully managed to secure a Health Board commitment to children's rights in all nursing staff's job descriptions in the area of children's services. This will contribute to the CRA objective of embedding children's rights into job descriptions, and will help staff to be more accountable to children and their children's rights obligations in their day to day practice. However, this now needs to be included in all staff job descriptions. 


\subsubsection{Reflections}

With regards to monitoring children's rights standards within the organisation, there was general agreement from the Strategic Leads that this had not yet happened effectively. This demonstrates that the principle of accountability is not being effectively adhered to and the health authority needs to establish better systems of reporting and accountability across the health authority. The health authority needs to be better aware of how they are performing against children's rights standards. As the UN committee emphasises it is essential to collect data on children's lives and to develop indicators that monitor and evaluate the implementation of children's rights and children's right to health. ${ }^{1124}$ It is also important that this monitoring takes into consideration the changing capacities and needs of children across the life course so that services are developed appropriately. ${ }^{1125}$

The Head of Nursing and Children's Services said as a starting point she would like to secure a commitment from the Health Board to repeat the monitoring assessment that has been delivered as a part of this thesis, to learn how far a CRA is being implemented every 2 years, to learn what they can do to make improvements and to flag up areas of concern for more in-depth research. She also recognised the need to secure funding to launch participatory research to gain the perspectives of the younger child population and ethnographic research to be carried out in the neo-natal unit and/or funding for research with caregivers of children in neo-natal care.

The was no evidence of children's rights impact assessments happening, which if implemented would help to ensure that at the level of Health Board policy and budgetary decision-making children's rights are always given consideration. These assessments would assist the health authority to ensure compliance with the UNCRC and to promote the visible integration of children in all strategic plans and sensitivity to their rights. ${ }^{1126}$

\footnotetext{
${ }^{1124}$ Ibid para 48

${ }^{1125} \mathrm{UN}$ Committee on the Rights of the Child, General Comment No. 15 on the right of the child to the enjoyment of the highest attainable standard of health $\mathrm{CRC} / \mathrm{C} / 15 / 2013$ paras $96-101$

${ }^{1126}$ UN Committee on the Rights of the Child, General Comment No. 5 General Measures of Implementation of the Convention on the Rights of the Child $\mathrm{CRC} / \mathrm{C} / \mathrm{GC} / 5 / 2003$ para 47
} 


\subsubsection{Equality and non-discrimination: equality and non-discrimination to children throughout service delivery}

As has been discussed in a number of chapters (Chapter 4, 5, and 6) in this thesis, children and specific groups of children face discrimination when interacting with public services (including health services) and experience challenges accessing services. This is a breach of Article 2 of the UNCRC which forcefully challenges any discrimination against children and disaggregated groups of children on any grounds. Children should not be discriminated against in any policy, planning and practice decisions. The surveys aimed to consider whether children and young people were facing discrimination when interacting with health services at ABMU and what their experiences were of accessing services.

FIGURE 45: Distribution of strategic leads to 5 score options rating by objective SLQ 19 - Data is collected, including disaggregated data, to enable identification of discrimination or inequalities in the realisation of children's rights to identify children who are being or may be discriminated against

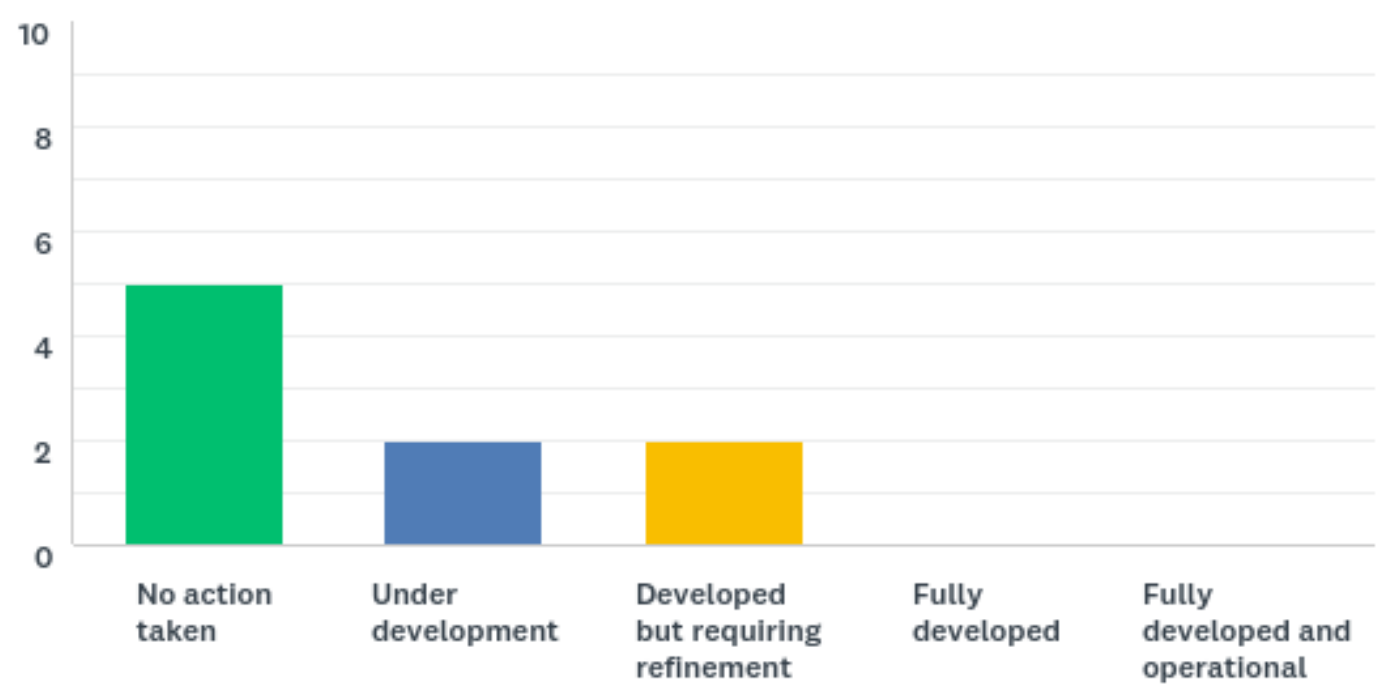

With regards to disaggregated data collected to identify discrimination two Strategic Leads suggested that work had begun whereas one believed no action had been taken (See Figure 45). One strategic lead commented that this is not achieved in all areas of the Health Board [SL8]. 
FIGURE 46: Distribution of strategic leads to $\mathbf{5}$ score options rating by objective

SLQ 20 - Services and resources are reviewed to identify barriers to children's access, including in collaboration with children as service users, in particular in relation to services to excluded/marginalised or disadvantaged social groups

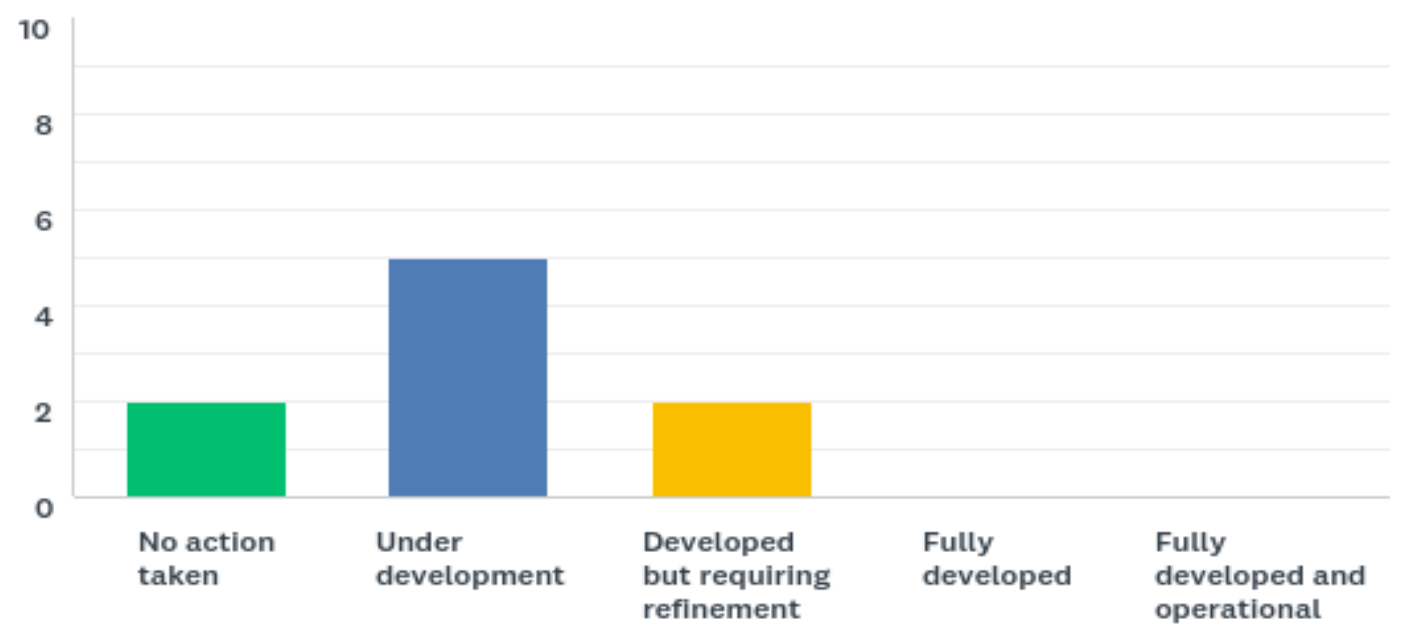

In relation to services being reviewed to identify barriers to children's access and appropriate priorities targets and programmes to eliminate discrimination it was agreed that this required a lot more work [SL5].

FIGURE 47: Distribution of strategic leads to $\mathbf{5}$ score options rating by objective SLQ 21 - Appropriate priorities, targets and programmes have been developed to eliminate discrimination against excluded, socially marginalised, disadvantaged and vulnerable groups and to promote equality for these groups

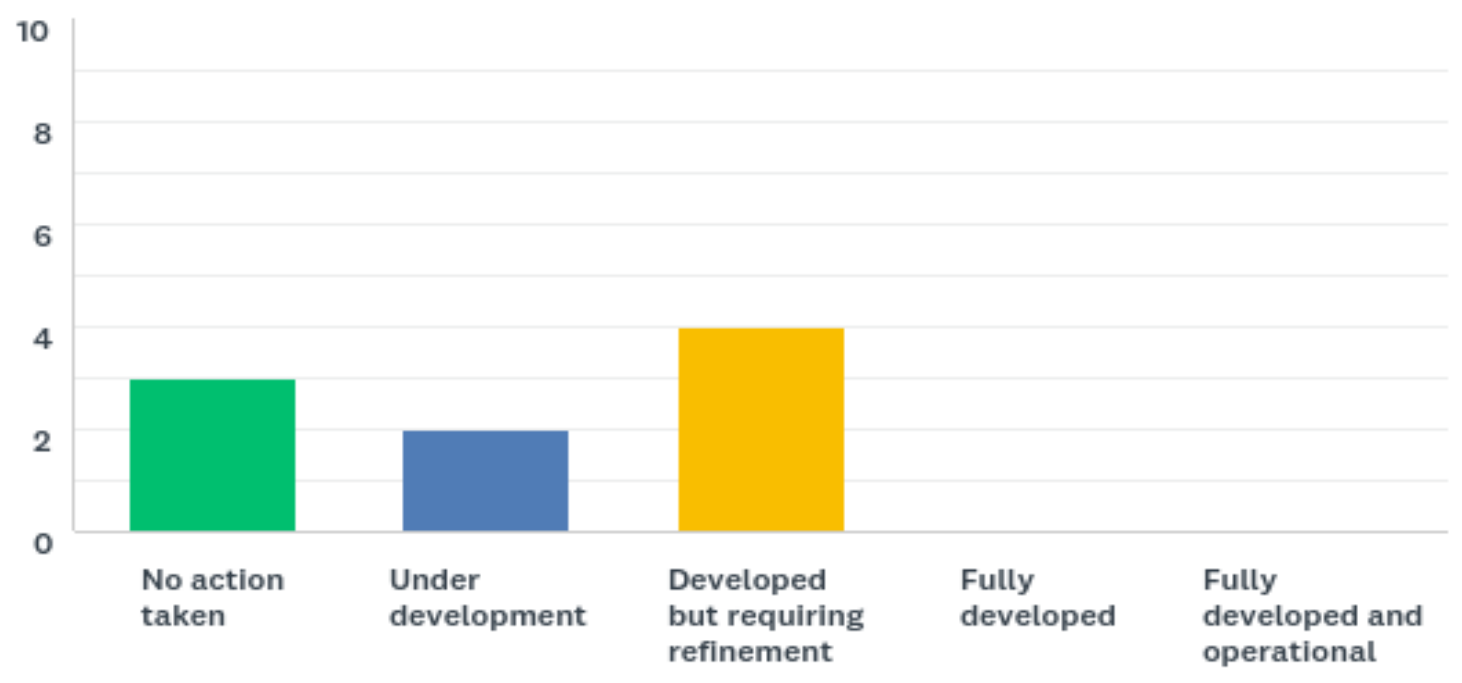


There was also agreement that priorities, targets and programmes to eliminate discrimination required more work [See Figure 46].

FIGURE 48: Distribution of strategic leads to $\mathbf{5}$ score options rating by objective SLQ 22 - All buildings are compatible with Disability Discrimination Legislation requirements

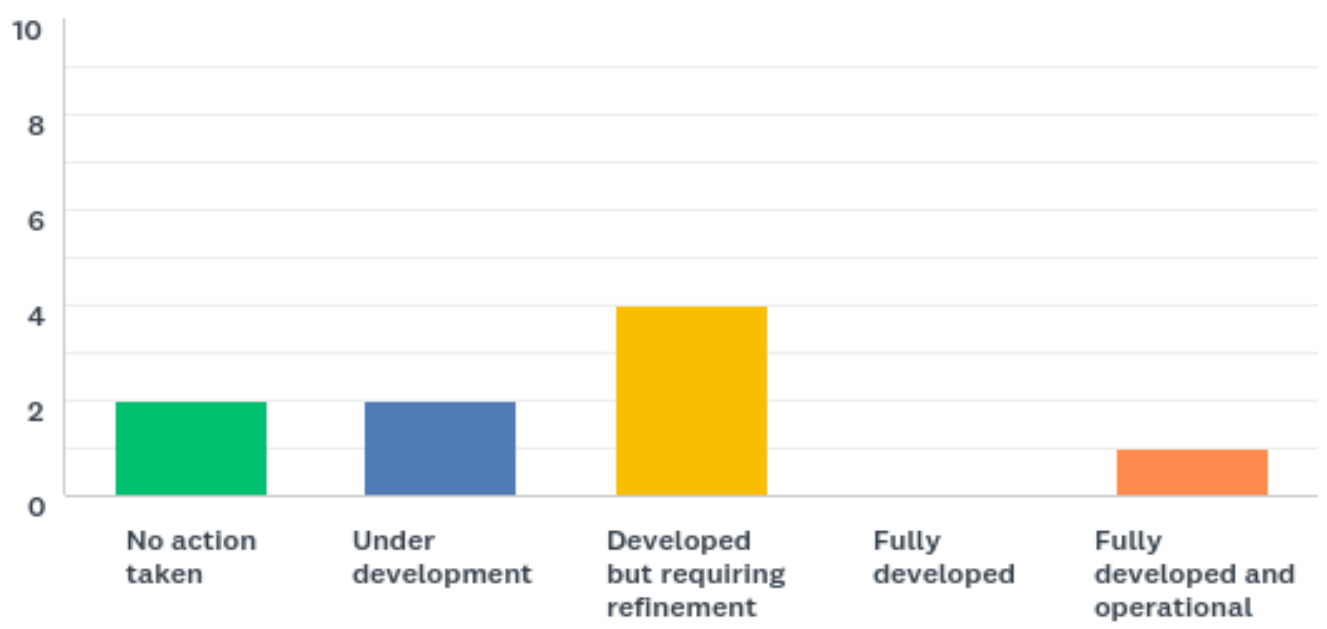

There was a difference of opinion with regards to buildings being Disability Discrimination Act compatible; with one Strategic Lead claiming that this objective was fully developed and operational (see Figure 47) and one Strategic Lead concerned that "Not all areas meet this particularly some community venues" [SL5].

FIGURE 49: Distribution of strategic leads to $\mathbf{5}$ score options rating by objective SLQ 23 - All children have access to professional interpreters when required

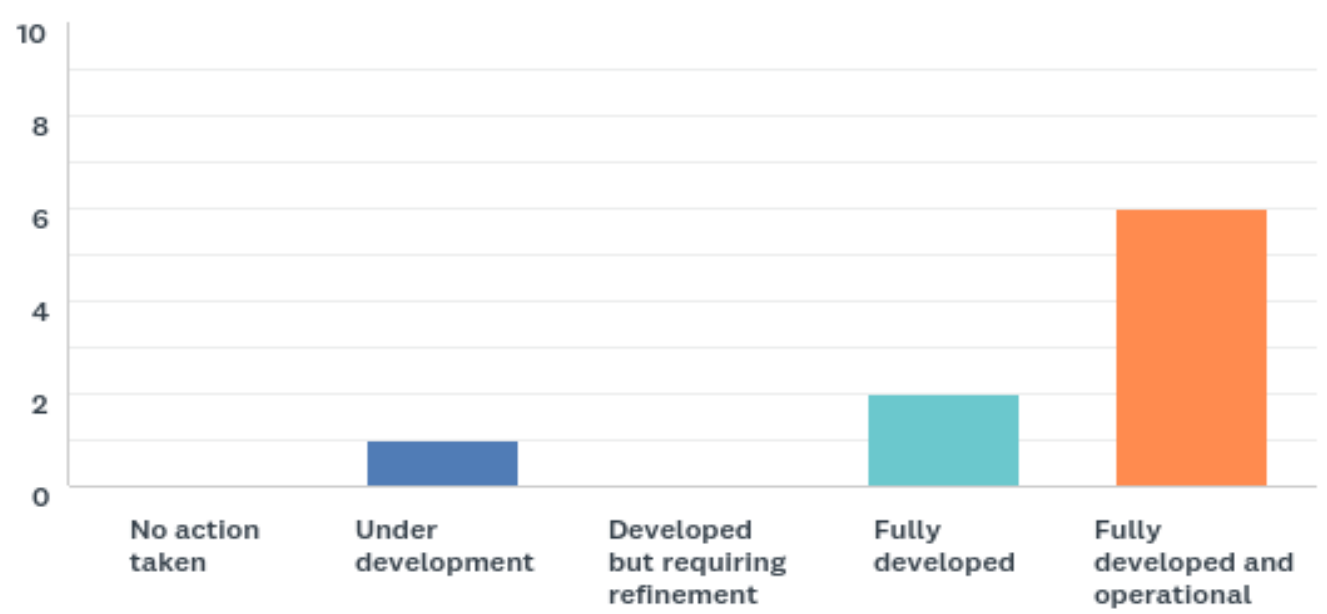


With regards to access to interpreters, the majority of strategic leads believed this to be working well (See Figure 49) and failing access to interpreters "Language line is available" [SL5].

FIGURE 50: Percentage of health care professional respondents that have timely access to professional interpreters

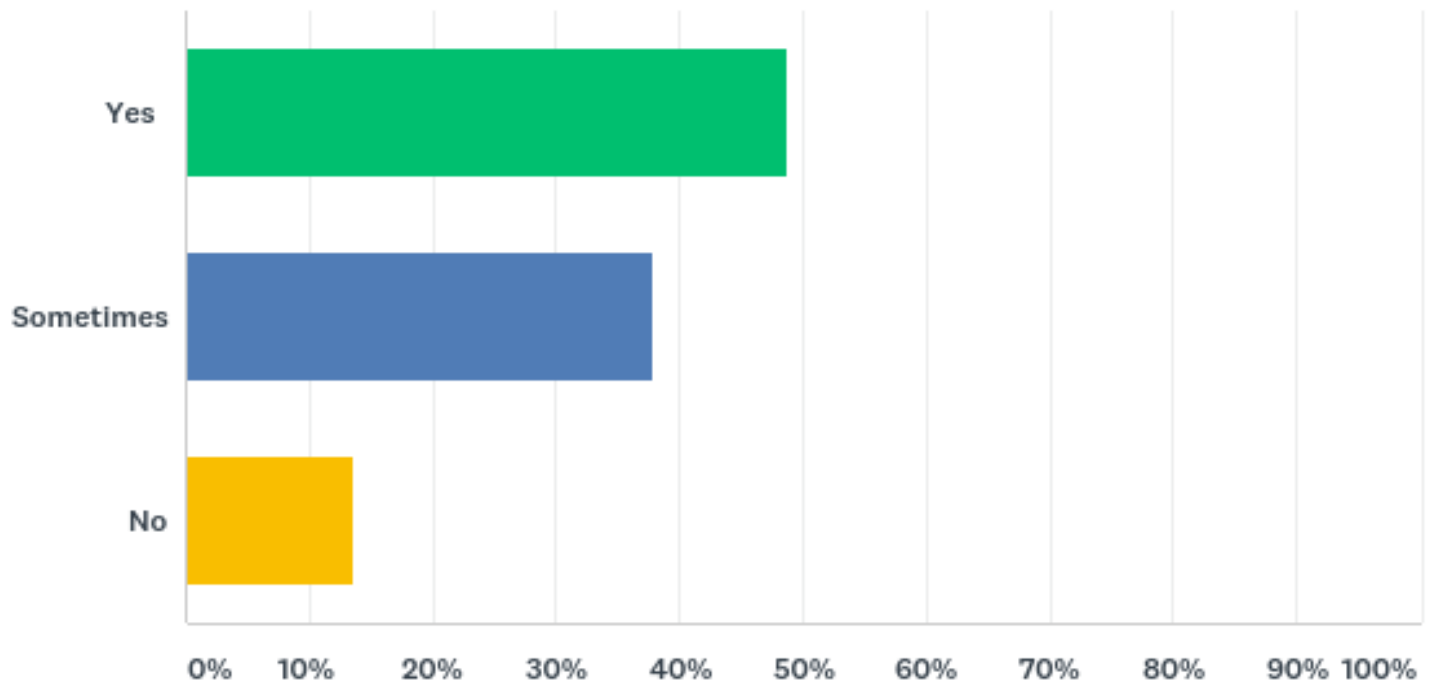

$48.7 \%$ (18) of the health professionals responded that they could access a professional interpreter when needed. However, 37. 9\% (14) responded only sometimes. Two health professionals added additional comments saying that they use (See Figure 50):

“Language Line." [HP 36]

Others reported, that

"Google translate is helpful when communicating short information, however language line is also used and interpreters can be booked for home visits." [HP 32]

"Difficulty in accessing some documentation including consent forms in foreign languages." [HP33] 
These findings suggest that at service delivery level, health professionals are not having easy access to interpreters and are utilising mechanisms like Google Translate/Language line to make do. Strategic Leads should be made aware of this.

FIGURE 51: Distribution of strategic leads to 5 score options rating by objective SLQ 24 - All information is provided to children in a language or format appropriate to their age, culture, gender or disability

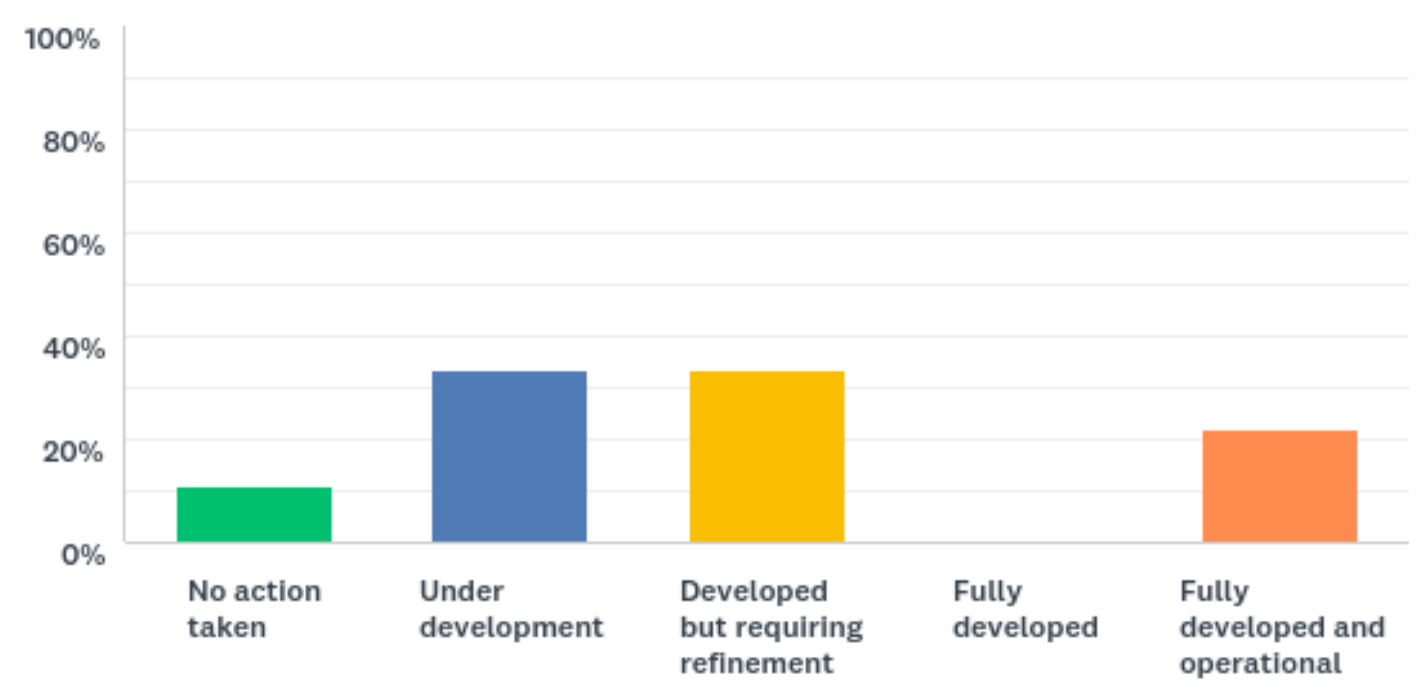

Information being provided to children in a language and format appropriate to their age, gender, disability and culture was met again with some divergence of opinion. With some believing it to be an objective that is fully developed and operational (See Figure 51) and one believing no action had been taken in this area and being concerned that "Information is provided to adults only in some areas outside of Children's Services" [SL8].

Research undertaken by Grooten-Wiegers, Hein and Staphorst concurs with this finding explaining that 'a fundamental problem arises as oral communication and textual information are often primarily directed at adults or aimed at minors but not connected to their perspective'. ${ }^{1127}$ Another Strategic Lead added, "Not all ethnic minority or special needs are catered for and few 'child friendly' versions of documents outside of acute services" [SL5].

${ }^{1127}$ Grootens-Wieger P, Hein I and Staphorst M, 'Using Children's Voice to Optimize Pediatric Participation in Medical Decision Making', The American Journal of Bioethics', 2018 18:3, 14-15 
FIGURE 52: Percentage of health care professional respondents who ensure that all information they provide to children is in a format that they understand

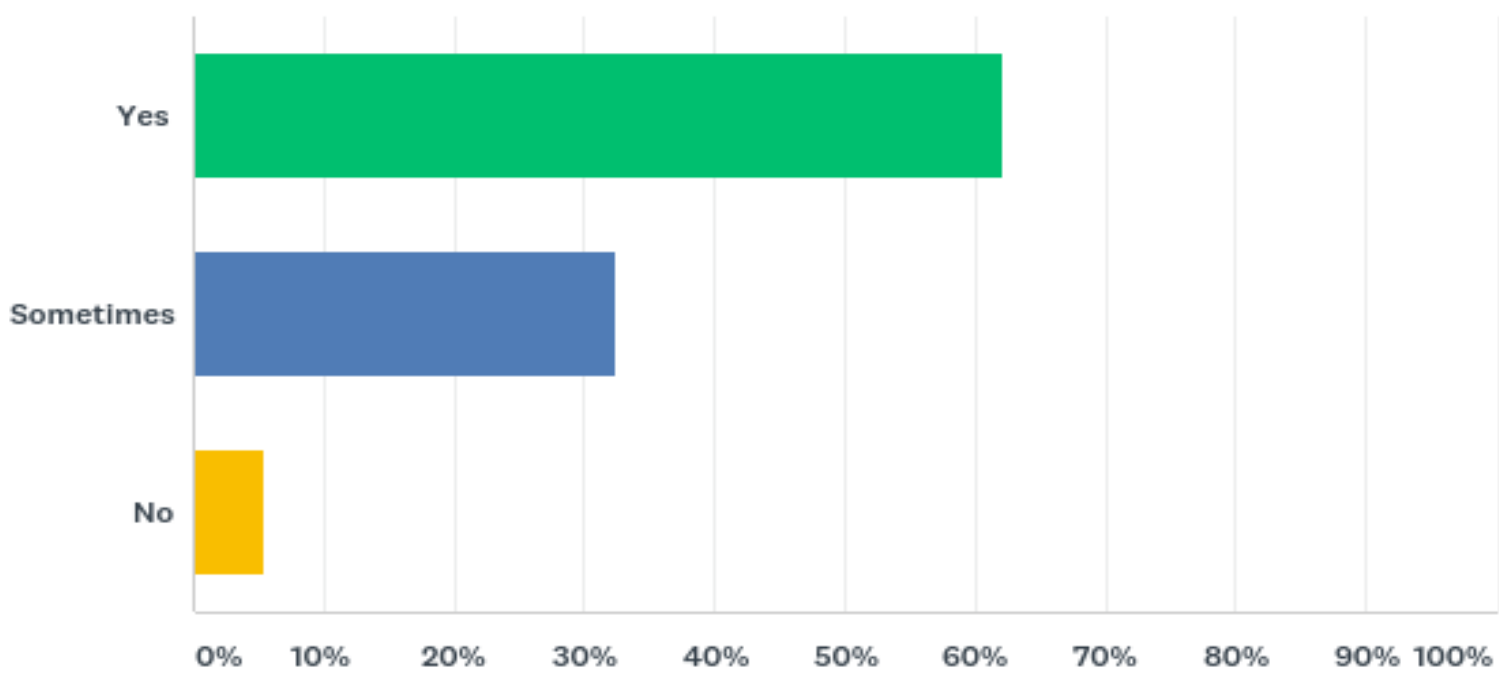

$62.2 \%$ (23) of the health professionals responded (See Figure 52) that they ensure that all the information they provide to children is in a format they understand (e.g., appropriate to age, capacity, gender, disability, culture, language etc.). However, some health professionals added additional comments regarding the challenges, evidencing that some health professionals were concerned that more needs to be done to support children with limited communication or cognition. One commented that it is challenging,

"Having the information in the right format - age or language."

Others reported,

"I am a slt [Speech and Language Therapy] so always ensure this but do not think language/cognitive skills are catered for appropriately by others." [HP24]

"when possible." [HP18]

"this needs to be improved for children with limited or no communication." [HP9] 
"many of the children I see have profound learning disability or communication difficulties and very many are very young." [HP8]

"ensuring those with no or limited communication and low cognition are included and represented." [HP3]

This as well as the Strategic Lead's evidence suggests that more specific work should be done to ensure that children with special needs and requirements are provided with tailored information that helps them to understand their human rights in these settings. This supports research undertaken by Hoole and Morgan in 2010 whereby children with intellectual disabilities were requesting fairness and equality. ${ }^{1128}$

\subsubsection{Young people perspectives}

FIGURE 53: Percentage distribution of young people respondents when seeing a health professional believe they have been treated unfairly by protected characteristic

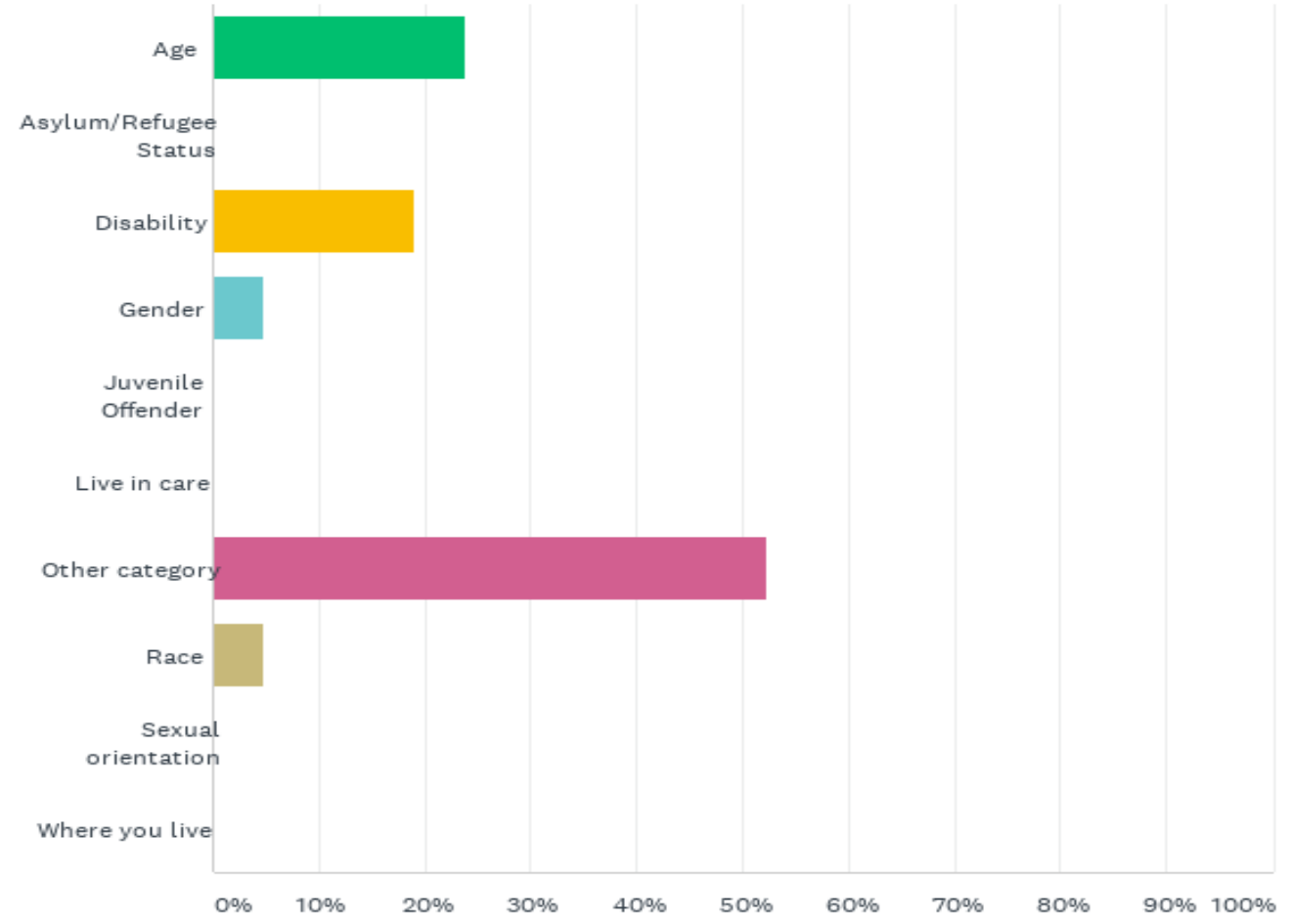

\footnotetext{
${ }^{1128}$ Hoole L and Morgan S, 'It's only right that we get involved': Service-user perspectives on involvement in learning disability services, British Journal of Learning Disabilities (2010) 39, 5-10
} 
$81 \%$ (22) of young people who answered this question ( $\mathrm{N}=27)$ responded that they had been treated unfairly. 18.5\% (5) young people said they had been treated unfairly because of their Age. $3.7 \%$ (1) said because of their Gender and because of their Race $(3.7 \%, 1)$ and $14.8 \%$ (4) young people said they had been treated unfairly because of their Disability. $40.7 \%$ (11) young people said they had been treated unfairly because of an 'other' category (Figure 53 ).

\subsubsection{Young people's illustrative examples}

The data presented the opportunity to bring together different elements of a young person's experience of visiting a health professional. These have been aggregated into a number of illustrative examples. To collate the data for these examples, I reviewed all the individual responses from those young people who had been treated unfairly and through the identification of consistent themes chose a number of these young people to develop illustrative examples. Using the full range of each young person's responses to individual questions, the aggregated data developed a picture of their overall experience of interacting with health services.

The identified examples show evidence of human rights not being fully respected across a range of services, CAMHS, GP Surgery, Accident and Emergency, Hospital Out-patients and Children's Centre in the Health Board Area and across the gender and age category of young people. What these indicate is where young people were being treated unfairly the young person did not know their rights, and furthermore, most of these young people did not know how to make a complaint (see later section on Complaints). Some were not only being treated unfairly but were reporting that their rights to privacy and being asked to consent to treatment were also not being respected. One young person said she had to fight to get doctors to believe her. This is consistent with research undertaken by Savage and Callery in $2007^{1129}$ who also reported that children with cystic fibrosis spoke of health professionals not believing what they had to say and were marginalised in the decision-making process as compared to adults.

\footnotetext{
${ }^{1129}$ Savage E and Callery P, 'Clinic consultations with children and parents on the dietary management of cystic fibrosis', Social Science and Medicine' (2007) 64, 363- 374
} 
Collectively, these experiences reflect some of the health professionals' own concerns and the Strategic Leads' own evidence that more needs to be done at a corporate wide level to address discrimination and other children's rights breaches that young people may experience. Illustrative examples 1 - 4 can be found below.

\section{Illustrative Example 1: Discrimination because of Race [YP15]}

A 16 year old female who lived in Swansea had visited a health professional, 4 or more times in 2018-19 and was answering the survey based on her experience of visiting Accident and Emergency. She responded that she had been treated unfairly because of her Race. She did not know her rights when she visited a health professional and had never seen the Children's Rights Charter before. She responded that she understands everything health professionals have to say; however they only listen to what she has to say sometimes and ask her questions sometimes, and she never helps to choose how she can get better. She had always been asked her consent to treatment, but her privacy had been respected only sometimes. She said she would never tell a health professional if she was worried or upset and did not know how to complain and needed more information. She responded to make a visit to a health professional better there should be "shorter waiting times and more autonomy over treatment".

\section{Illustrative Example 2: Discrimination because of Age [YP48]}

A 13 year old female who lived in Swansea and had visited a health professional 4 or more times in 2018-19 and was answering the survey based on her experience of visiting a Children's Centre responded that she had been treated unfairly because of her age. She commented that she had to, "fight for drs to diagnose and believe condition - CFS ME". She responded that she did not know her rights when visiting a health professional and needed more information and had never seen the Children's Rights Charter before. She responded that health professionals 'mostly talk to the person you came with'. She answered that health professionals only listen to what you have to say sometimes, ask you questions sometimes, and she only understands what they have to say sometimes. She said she had always been asked to consent to 
treatment but her privacy was respected only sometimes. She responded that she does not trust health professionals and would never tell them if she was worried or upset. She said she did not know how to complain and needed more information and said she had never before been asked her views on how to make a visit to a health professional better.

\section{Illustrative Example 3: Discrimination because of Disability [YP31]}

A 15 year old female who lived in Swansea and had visited a health professional 4 or more times in 2018-19 answered the survey based on her experience of visiting a health professional in hospital. She said she had been treated unfairly because of her disability. She said she did not know her rights and had never seen the Children's Rights Charter before. She said that health professionals listen to what she has to say sometimes, give her the opportunity to ask questions sometimes and she only understands everything they have to say sometimes. She said she is never given the opportunity to help to choose how she can get better. She said she always finds it difficult to get to see a health professional and responded "make it easier to make appointments".

\section{Illustrative Example 4: Discrimination because of Learning needs [YP9]}

A 13 year old male who lived in Swansea and had visited a health professional 4 or more times in 2018-19 and was answering the survey based on his experience of visiting a hospital offered additional information saying that he had been treated unfairly; "because of my behaviour. Learning needs". He responded that he did not know his rights when visiting a health professional and had never seen the Children's Rights Charter before. He responded that health professionals listen to what he has to say, but do not give him the opportunity to ask questions and he does not understand everything that they are saying. He responded that he learns about staying healthy from his family and did not tick any other responses on this list. He had never been asked his views before on how to make a visit to see a health professional better. He did not respond to the open -ended questions (Q22 and Q24) one may suspect because these questions demanded a more detailed written response and did not support his learning need requirements. 
These examples demonstrate that some young people are experiencing discrimination and breaches of some of their human rights when visiting a health professional. It is important that further research is carried out with a larger sample of young people to learn whether this may be the case for more young people using the Health Board's services.

\subsubsection{Children's perspectives 7-12 years}

Even though there was no question that asked the younger children directly about whether they had been treated unfairly, one child reported that the doctor never speaks to them in Welsh,

"Dydy'r doctor byth wedi siarad Cymraeg a fi"/ . The doctor never speaks to me in Welsh." [C18]

This is evidence of a child being treated unfairly or discriminated against because their first language is Welsh, inhibiting their ability to understand what the doctor or nurse is saying to them, being able to ask questions and to confidently refuse or consent to treatment. As part of further research, it will be important to learn how many children would prefer to speak to doctors and nurses in their first language, and as we are in a bilingual country, services should be adapted accordingly.

\subsubsection{Child friendly resources}

A third $(34.02 \% .33)$ of children responded that they did not have the opportunity to play. It was a significant theme of the data that this age group of children wanted older more age-appropriate toys or resources to play with. The research indicated that children in the 7-12 years age group were not being catered for as the toys and resources were perceived to be more suitable for younger children. See some of the examples of the children's responses below:

A 9 year old boy who lived in Cowbridge and had visited a health professional 1 time in 2018-19 answered the survey from his experience of visiting a hospital said:

"Aethon ni i'r Ysbyty Bridgend. Byddon gwell i cael mwy tegennau am plentyn hena / We went to the hospital in Bridgend. It would be better if there were more toys for older children." [C98] 
A 7 year old girl who lived in Swansea and had visited a doctor or nurse 4 or more times in 2018-19, answered the survey from her experience of visiting a hospital said:

"More things for older children to do when waiting to be seen." [C91]

A 9 year old boy who lived in Neath-Port Talbot and had visited a doctor or nurse 4 or more times in 2018-19 answered the survey from their experience of visiting a hospital responded:

"More toys for older children." [C44]

This theme of a lack of child friendly and age-appropriate resources was reinforced by a health professional, who responded that there is a lack of compliance with a CRA because:

\begin{abstract}
"Lack of money to provide the correct equipment and physical space to offer privacy to YP especially in a children's ward. Lack of toys in our setting and a very unsuitable waiting room as the toddlers and teenagers have to wait in the same area." [HP34]
\end{abstract}

Other research reviewed in Chapter 4 also suggests, play, resources and recreation and other activities are highlighted as important to children across a range of health settings ${ }^{1130}$ and children report that this is not done adequately enough. ${ }^{1131}$ Additionally, children have reported on the need for developmentally appropriate facilities, for example bright and colourful decor, age-appropriate furniture and separate adolescent units $^{1132}$, as well as child friendly settings appropriate for younger children. ${ }^{1133}$

\footnotetext{
${ }^{1130}$ Lambert V, Coad J, Hicks P and Glacken M, 2010, Physical Places and Social Spaces for Young Children in Hospital Dublin (National Paediatric Hospital Project 2010); Koller D, Nicholas D, Gearing R and Kalfa O, Paediatric Pandemic planning: Children's perspectives and recommendations. Health and Social Care in the Community (2010) 18, 396-377; National Children's Bureau, Children and Young People's Views on Health and Health Services: A Review of the Evidence. (London:

National Children's Bureau 2005)

${ }^{1131}$ Kilkelly U, Child friendly health care: The views and experiences of children and young people in the Council of Europe (Strasbourg: Council of Europe 201)

1132 Kikelly U, 'Health and Children's Rights', In Vandenhole W, Desmet E, Reynaert D, and Lembrects S (eds) International Handbook of Children's Rights Studies (Routledge 2015)

${ }^{1133}$ Lambert V, Coad J, Hicks P and Glacken M, 2010, Physical Places and Social Spaces for Young Children in Hospital. Dublin (National Paediatric Hospital Project 2010)
} 
The findings of this research indicate that more should be done to tailor services and provide appropriate resources to children. Children as service users should be invited to collaborate in designing child friendly services across the health authority.

\subsubsection{Accessing services and waiting}

FIGURE 54: Percentage of young people respondents who find it difficult to get to see a health professional

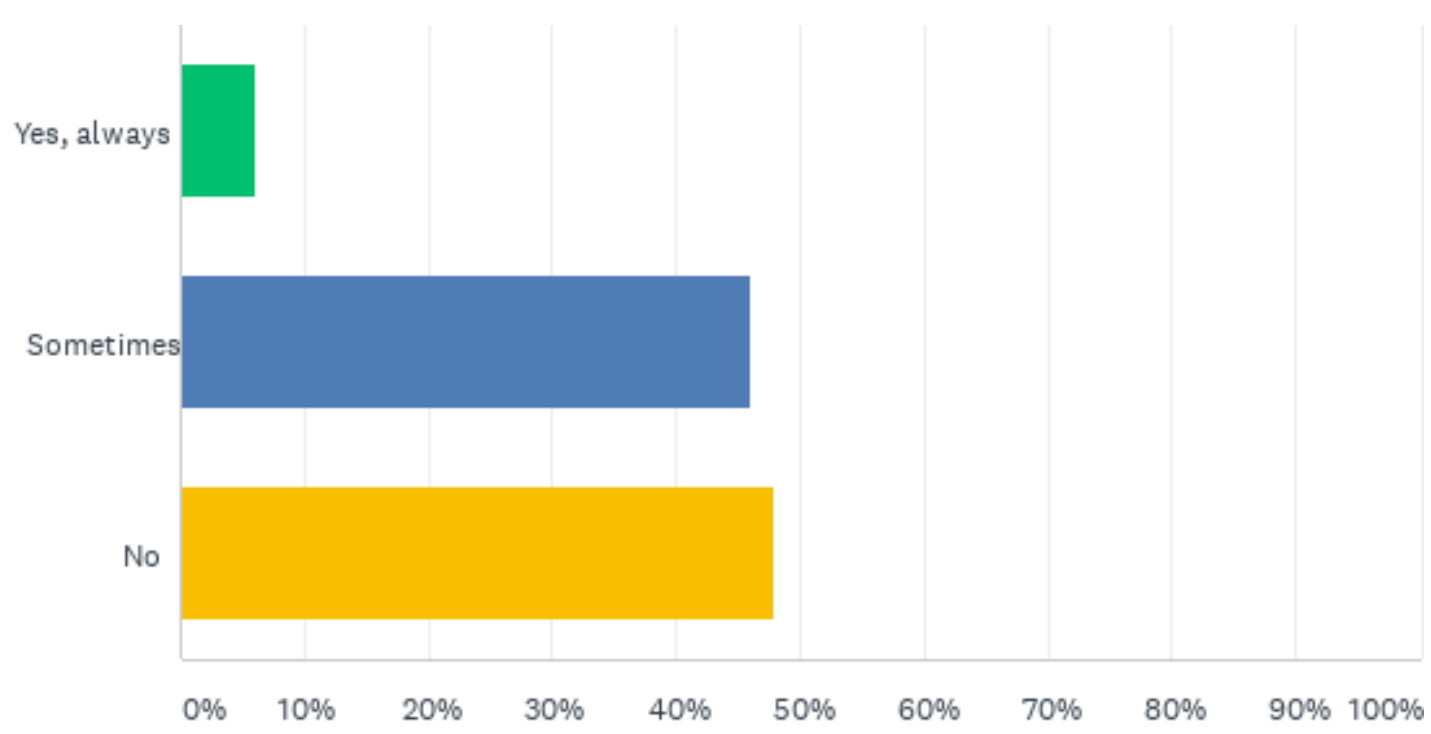

Almost half $48 \%$ (24) of the young people said they did not find it difficult to get to see a health professional, however almost half $(46 \%, 23)$ said sometimes and 3 children who did find it difficult offered additional information responding that they found it "difficult to get appointments" [YP37] one young person responded,

"You can't always get an appointment. It can be embarrassing to tell the receptionist what you need to speak to the doctor about." [YP16]

This complements other research that reports that adolescents are often embarrassed to speak to adults about their personal issues and want privacy. ${ }^{1134}$

Another young person said,

${ }^{1134}$ International Institute for Child Rights and Development, CRED Pro Child Rights Curriculum for Health Professionals (IICRD2008) 
"appointments take time and waiting lists." [YP8]

Again, this question was not asked directly of the children, however the children's open-ended responses identified the theme of waiting for long periods of time as a major issue for many children, and having easy access to services they needed. For example,

An 8 year old girl who lived in Bridgend and had visited a doctor or nurse 1 time in 2018-19 answered the survey from their experience of visiting a hospital responded,

"Not to wait for so long and play with toys." [C2]

A 7 year old boy who lived in Neath Port Talbot and had visited a doctor or nurse 4 or more times answered the survey from their experience of visiting a hospital responded,

"Just wish cleft lip service was available in port Talbot hospital so wouldn't need to travel as far." [C38]

A 9 year old boy who lived in Swansea and had visited a doctor or nurse 4 or more times in 2018-19 answered the survey from their experience of visiting a hospital responded,

"Because of my issues with walking not having to walk to far for my appointments." [C75]

As Kilkelly reports children want 'accessible, flexible and integrated services that allow for continuity of care'. ${ }^{1135}$

\subsubsection{Reflections}

Addressing discrimination towards children and specific groups of children as identified by the findings outlined above is an area that requires further development. It is concerning that any young people or children are reporting experiences of discrimination, as this is a significant breach of their human rights under Article 2 of the UNCRC. It emphasizes that children's right to health should be available to all

\footnotetext{
${ }^{1135}$ Kilkelly U, 'Health and Children's Rights', In Vandenhole W, Desmet E, Reynaert D, and Lembrects S (eds) International Handbook of Children's Rights Studies (Routledge 2015) 226
} 
children without discrimination. ${ }^{1136}$ Children and young people should not be expected to face any discrimination when interacting with health services. Further research across the Health Board should be conducted to ascertain whether these experiences of discrimination that young people and children have reported are more widespread. The UN Committee on the Rights of the Child recommends, there must be sufficient collection of reliable data on children, 'disaggregated to enable identification of discrimination and/or disparities in the realisation of rights.' ${ }^{1137}$ The Strategic Leads reported that this programme of work has begun but needs to be further developed.

It is also concerning that some children are struggling to access services, and better focus should be given to tailoring services to be age appropriate and child friendly. Article 24 'imposes a strong duty of action by States parties to ensure that health and other relevant services are available and accessible to all children, with special attention to under-served areas and populations' and all barriers should be identified and eliminated. ${ }^{1138}$ As the UN Committee on the Rights of the Child makes clear as part of their AAAQ framework in General Comment No.15 there should be 'functioning children's health facilities, goods, services and programmes in sufficient quantity"1139 made accessible to all children ${ }^{1140}$ and services should be designed to take full account of children's needs and reach especially vulnerable groups of children. ${ }^{1141}$ Services should also be delivered in a timely and appropriate manner ranging from preventative, rehabilitative, palliative, health promotion and curative services. ${ }^{1142}$ In addition, health workers must work in a child sensitive manner ensuring that they do not deny children services that they are entitled to. ${ }^{1143}$

\footnotetext{
${ }^{1136}$ UN Committee on the Rights of the Child, General Comment No. 15 on the right of the child to the enjoyment of the highest attainable standard of health $\mathrm{CRC} / \mathrm{C} / 15 / 2013$ para 8

${ }^{1137}$ UN Committee on the Rights of the Child, General Comment No.5 on General Measures of Implementation, $\mathrm{CRC} / \mathrm{GC} / 2003 / 5$ para 48

${ }^{1138}$ Ibid paras 28, 29

${ }^{1139}$ UN Committee on the Rights of the Child, General Comment No. 15 on the right of the child to the enjoyment of the highest attainable standard of health $\mathrm{CRC} / \mathrm{C} / \mathrm{GC} / 15$ para 113

${ }^{1140}$ UN Committee on the Rights of the Child, General Comment No. 15 on the right of the child to the enjoyment of the highest attainable standard of health $\mathrm{CRC} / \mathrm{C} / \mathrm{GC} / 15$ para $114 \mathrm{a}, \mathrm{b}, \mathrm{c}, \mathrm{d}$

${ }^{1141}$ UN Committee on the Rights of the Child, General Comment No. 15 on the right of the child to the enjoyment of the highest attainable standard of health $\mathrm{CRC} / \mathrm{C} / \mathrm{GC} / 15$ para 115

${ }^{1142}$ Ibid para 2

${ }^{1143}$ Ibid para 27
} 
Health professionals also reported their concerns regarding ensuring information was in the right age, language or format or being able to provide information that supported the limited communication capacity and cognitive needs of children who were facing complex challenges. The UN Committee on the Rights of the Child explain that 'children's needs, expectations, cultures, views and languages,' must be taken into account when delivering services. ${ }^{1144}$

Strategic Leads overall, reported limited progress with regards to the Equality and Non-Discrimination CRA objectives. Adhering to the objectives relating to Equality and Non-Discrimination that are laid out in the CRA assessment tool are a starting point, i.e., identifying discrimination and developing appropriate policies and programmes and resources to address it. The UN Committee on the Rights of the Child comments that educational measures are needed to change attitudes. ${ }^{1145}$ Offering training on understanding discrimination towards children and specific groups of children should be included in mandatory training on children's rights for all staff members.

\subsubsection{Participation of children: children can actively participate in decisions about their own health}

As noted in earlier chapters, the UNCRC is clear that children must have a say in all decisions that affect them (Article 12 of the UNCRC). This includes health care decision making. ${ }^{1146}$ The most important human right to children across all age groups in health care settings according to research undertaken by Bensted et al is Article 12. ${ }^{1147}$ As outlined in Chapter 4, the research suggests that this human right is not always respected across health services. Of critical importance is that staff who have a clinical role have appropriate training, to communicate effectively with children, listen to children, involve them in treatment planning and diagnosis, encourage them to ask questions and ensure their views are given due weight (See Chapter 6). As Grootens-

\footnotetext{
${ }^{1144}$ Ibid

${ }^{1145}$ UN Committee on the Rights of the Child, General Comment No.5 on General Measures of Implementation, $\mathrm{CRC} / \mathrm{GC} / 2003 / 5$ para 12

${ }^{1146}$ UN Committee on the Rights of the Child, General Comment No. 15 on the right of the child to the enjoyment of the highest attainable standard of health $\mathrm{CRC} / \mathrm{C} / \mathrm{GC} / 15$ para 19

${ }^{1147}$ Bensted R, Hargreaves D S, Lombard J, Kilkelly U and Viner R M, 'Comparison of healthcare priorities in childhood and early/late adolescence: Analysis of cross-sectional data from eight countries in the CoEChild-friendly Health Care Survey, 2011,' Child Care, Health and Development (2014) $1-6$.
} 
Wiegers, Hein \& Staphorst explain 'we, as professionals working in paediatric health care, should take due account of and actively incorporate children's perspectives in paediatric care.' ${ }^{\prime 148}$

FIGURE 55: Distribution of strategic leads to $\mathbf{5}$ score options rating by objective SLQ 25 - Children are encouraged to exercise their right to participate in the decisions being made about their health or condition, encouraged to express their views freely, ask questions and their views are given due weight

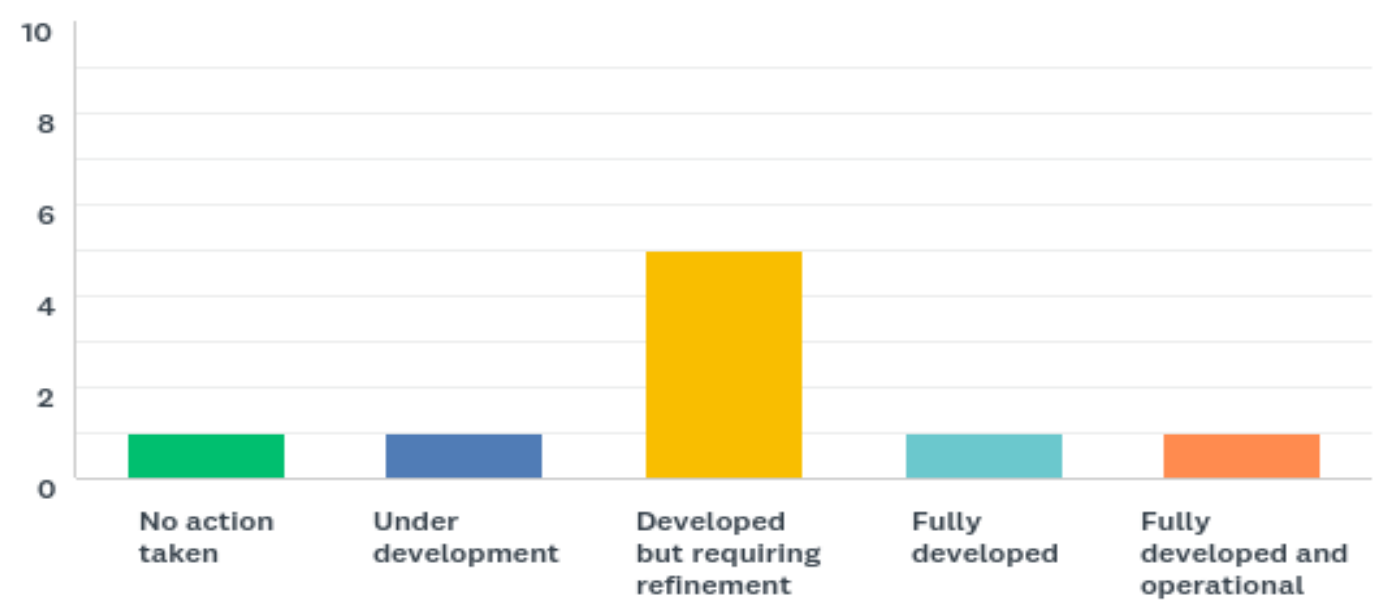

To date ABMU like most other health boards have not assessed how effectively their health professionals are meeting this expectation (See Objective in Figure 55). It is concerning that even one Strategic Lead considers that no action had been taken in the delivery of the objective. One Strategic Lead added that there is "No evidence of this external to Children's Services" [SL8] and this was reinforced by another who said "Not adhered to in all areas" [SL5]. However, two strategic leads considered it to be fully developed/fully developed and operational. There is a clear diversity of opinion.

\footnotetext{
${ }^{1148}$ Grootens-Wieger P, Hein I and Staphorst M, 'Using Children's Voice to Optimize Pediatric Participation in Medical Decision Making', The American Journal of Bioethics (2018) 18:3, 15
} 
FIGURE 56: Percentage of health professional respondents by rating their ability to involve children according to their age and capacity in clinical decisions

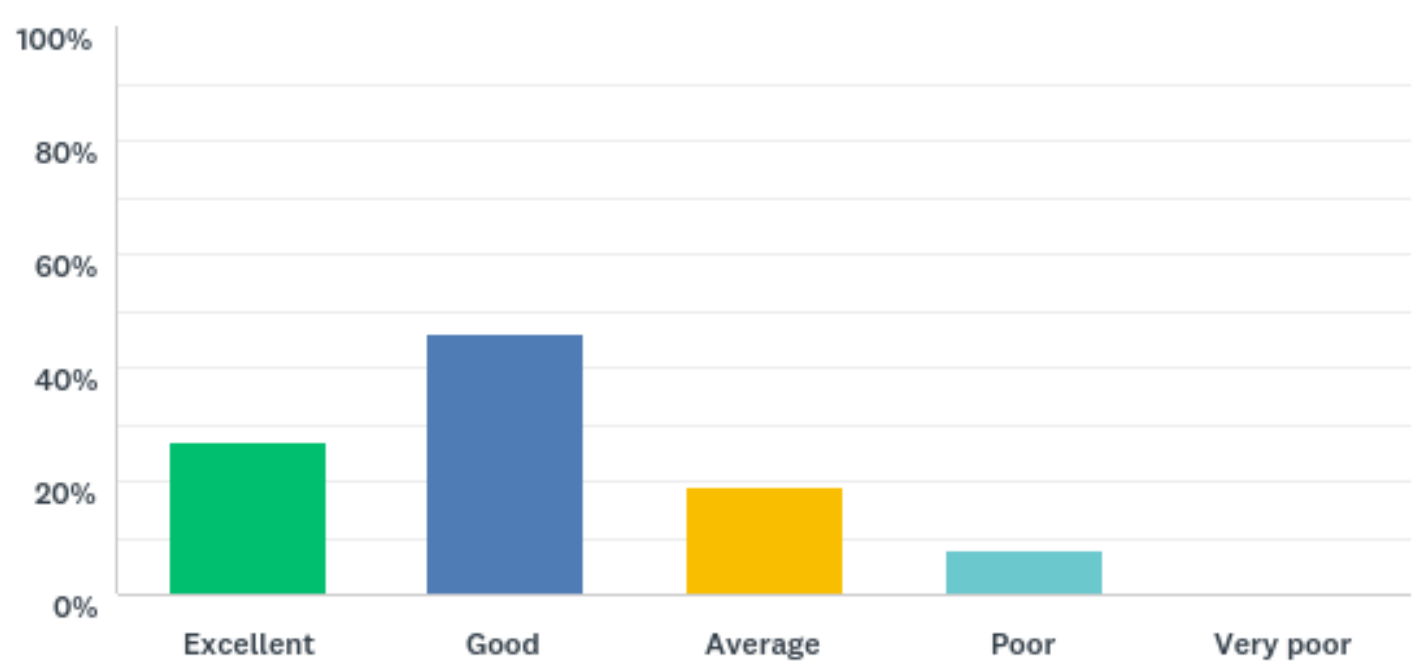

$27 \%$ (10) of the health professionals in rating their ability to involve children according to their age and capacity in clinical decisions believed they were Excellent and $46 \%$ (16) rated their ability as Good. One would hope that by 2021 that $100 \%$ of health professionals were reporting their ability was at least Good as it an essential requirement of a CRA and a fundamental human right of all children to have their Article 12 of the UNCRC right, fully respected. One health professional responded identifying one of the main challenges to complying with the Charter, was the

"right to information, right to have your say difficult to implement in younger children." [HP12]

Other research suggests that professionals often believe that younger children are not as capable as older children to participate in health care decision making ${ }^{1149}$ despite research that demonstrates that younger children are much more capable of communicating about their health condition than adults believe. ${ }^{1150}$ This perception

\footnotetext{
${ }^{1149}$ Kilkelly U and Donnelly M (2006) The child's right to be heard in the health care setting: perspectives of children, parents and health professionals (Dublin: Office of the Minister for children 2006)

${ }^{1150}$ Garth B, Murphy G C and Reddihough D S et al, 'Perceptions of participation: Child patients with a disability in the doctor-parent-child partnership', Patient Education and Counselling, (2009) 74, 45-52; Savage E and Callery P, 'Clinic consultations with children and parents on the dietary management of cystic fibrosis', Social Science and Medicine (2007) 64, 363-374; Alderson P and
} 
needs to be challenged and indeed health professionals need to be supported to ensure they are facilitating younger children's right to information and to have their say if children want this to happen.

Another health professional additionally commented that they found it difficult to adequately address the:

"Conflict between health needs of the child and parents/guardians wishes/beliefs". [HP12]

As addressed in earlier chapters this is a significant tension identified by the wider research and it is highly probable that this is also an issue for health professionals working at ABMU and at other health boards across Wales. As Kilkelly eloquently advises:

They [health professionals] need to understand the significance of treating the child as a rights-holder in the healthcare process and to develop special skills to balance the right of parents to decide what is in their child's interests with their own professional understanding of the child's needs and rights. ${ }^{1151}$

Further research should be developed to explore how to best support health professionals to best translate a children's rights perspective into their daily practice.

Montgomery J, Health care choices: Making decisions with children (London. Institute for Public Policy Research 1996)

${ }^{1151}$ Kikelly U, 'Health and Children's Rights', In Vandenhole W, Desmet E, Reynaert D, and Lembrects S (eds) International Handbook of Children's Rights Studies (Routledge 2015) 228 


\subsection{Young people's perspectives (13-17 years)}

FIGURE 57: Percentage of young people respondents who think that health professionals are friendly

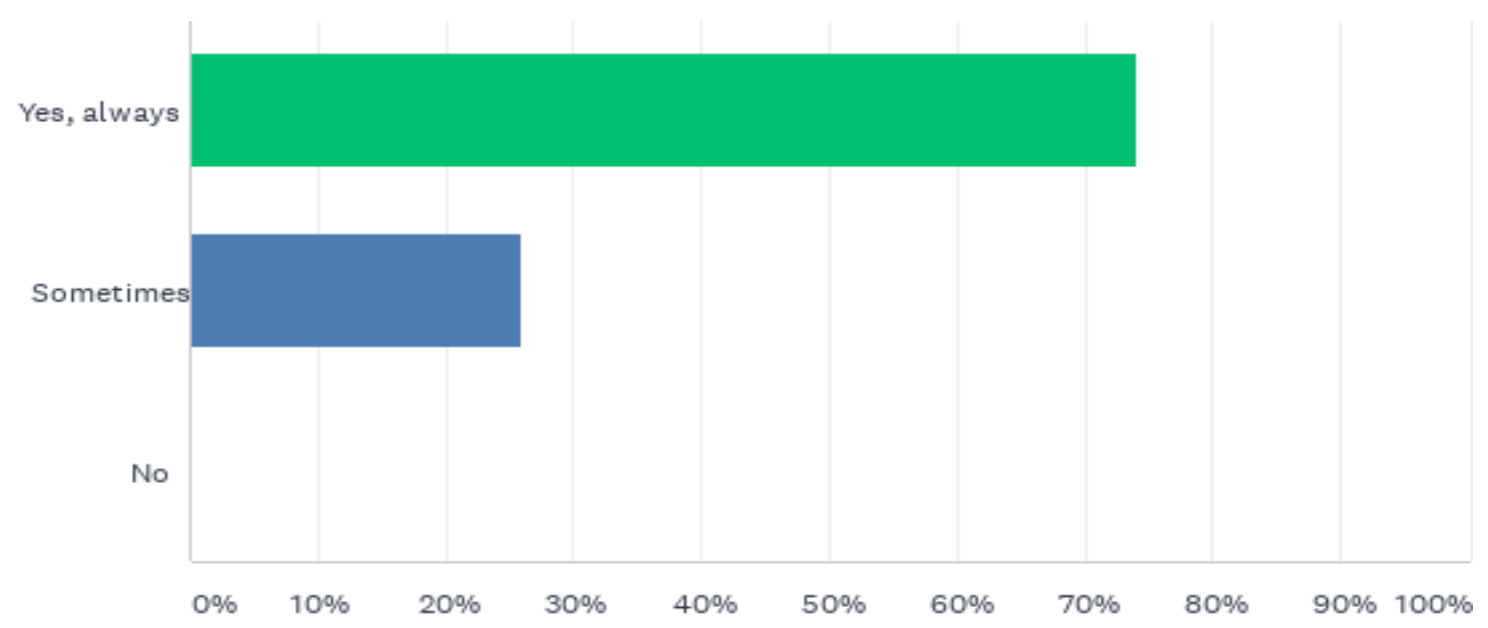

The majority of $(74 \%, 37)$ young people perceived the health professionals as friendly (Figure 57). Other research by Savage and Callery noted that health professionals may have been perceived by children to be friendly and communicated to them about social components to their lives however talking to them about their health experiences was more limited. ${ }^{1152}$

${ }^{1152}$ Savage E and Callery P, 'Clinic consultations with children and parents on the dietary management of cystic fibrosis', Social Science and Medicine (2007) 64, 363- 374 
FIGURE 58: Percentage of young people respondents who think that health professionals only talk to them, only talk to the person they came with, or talk to both them and the person they came with

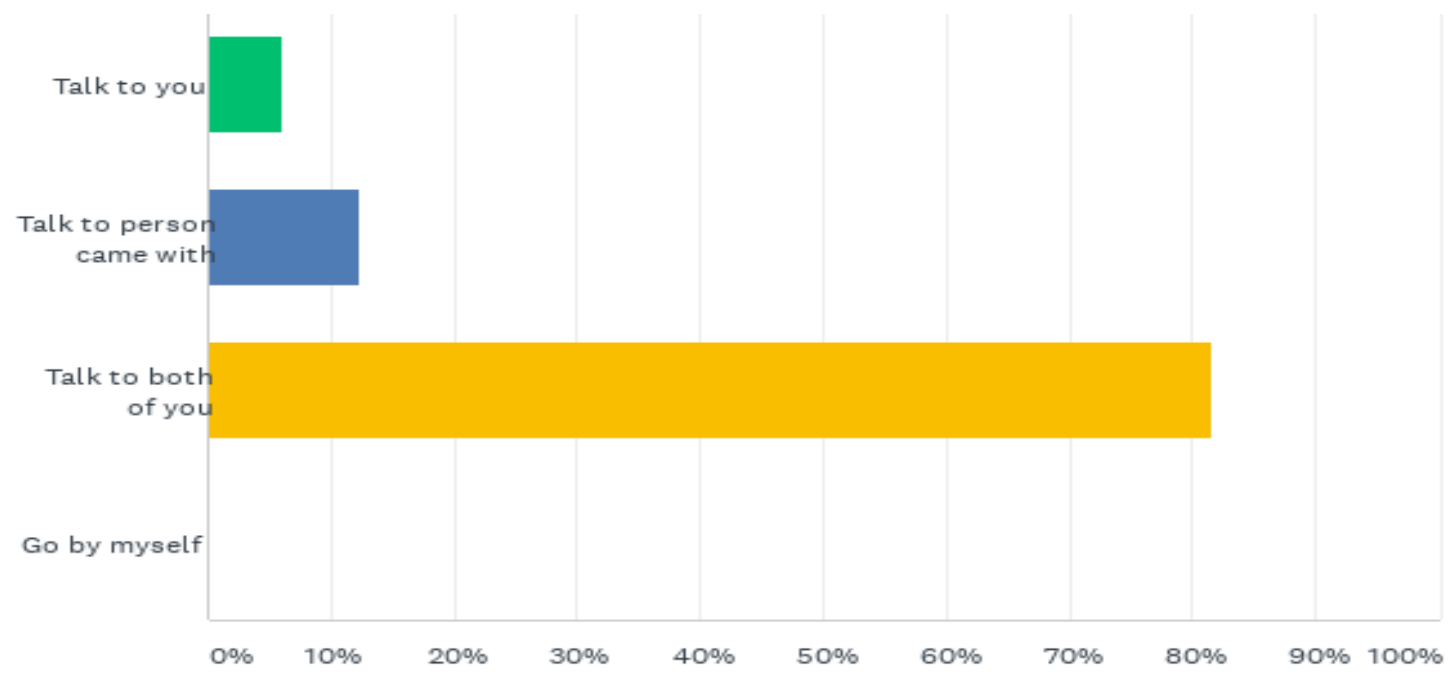

$81.6 \%(40)$ young people said that the health professional 'mostly talks to them and the person they came with', $12 \%$ (6) said they 'mostly talk to the person that they came with' and 6\% (3) said that 'they mostly talked to them' (See Figure 58). Other research suggests that children can become passive bystanders in medical consultation. ${ }^{1153} \mathrm{It}$ is reassuring that the majority of the children in this sample were spoken to directly with their parent/carer as this will help them to better understand what is happening and agree to any treatment or procedures that may be proposed. ${ }^{1154}$

\footnotetext{
${ }^{1153}$ Lambert V, Glacken M. and McCarron M, 'Communication between children and health professionals in a child hospital setting: A child transitional communication model', Journal of Advanced Nursing (2010) 67, 569-582.

${ }^{1154}$ Moore L and Kirk S, 'Literature review of children's and young people's participation in decisions relating to health care', Journal of Clinical Nursing, (2010) 19, 2215-2225
} 
FIGURE 59: Percentage of young people respondents who think that health professionals listen to what they have to say

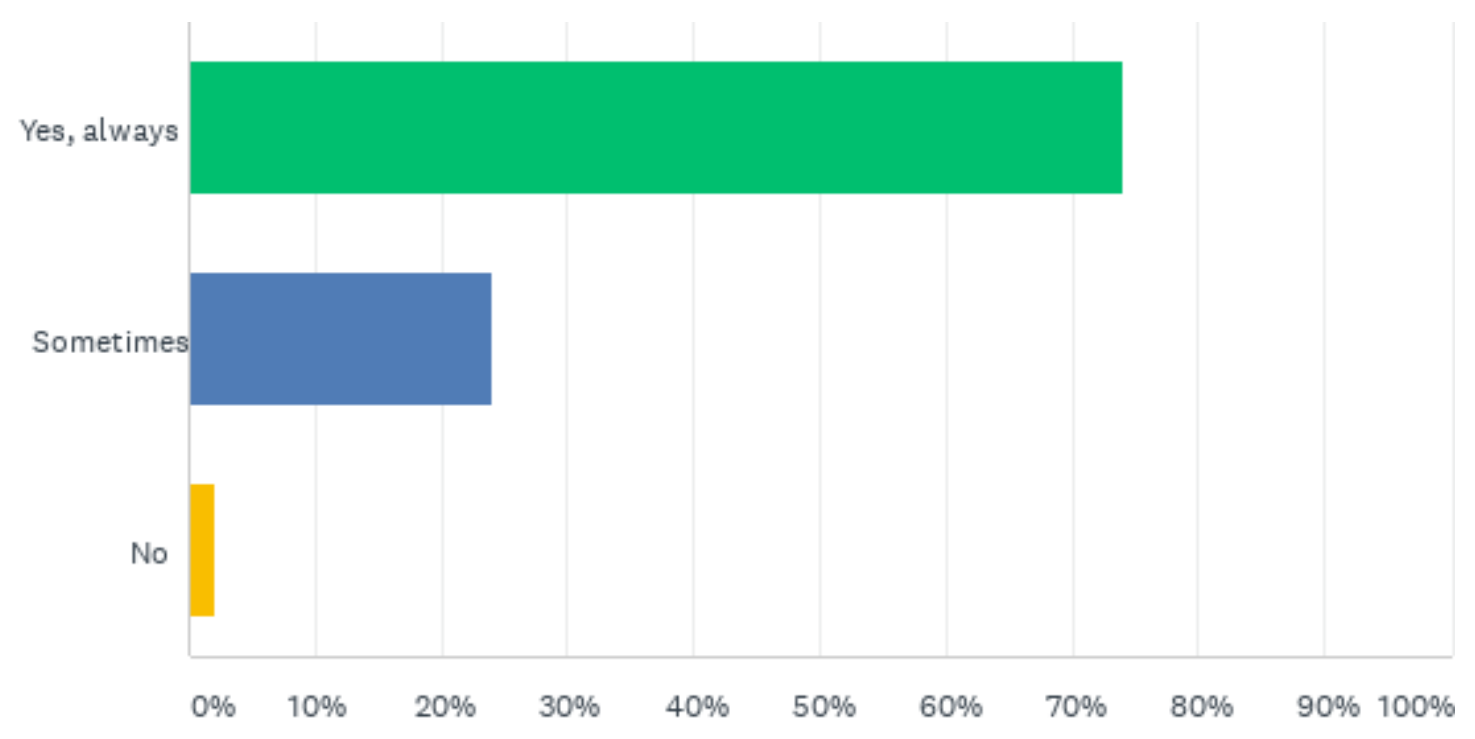

FIGURE 60: Proportion of young people respondents who think health professionals give them a chance to ask questions

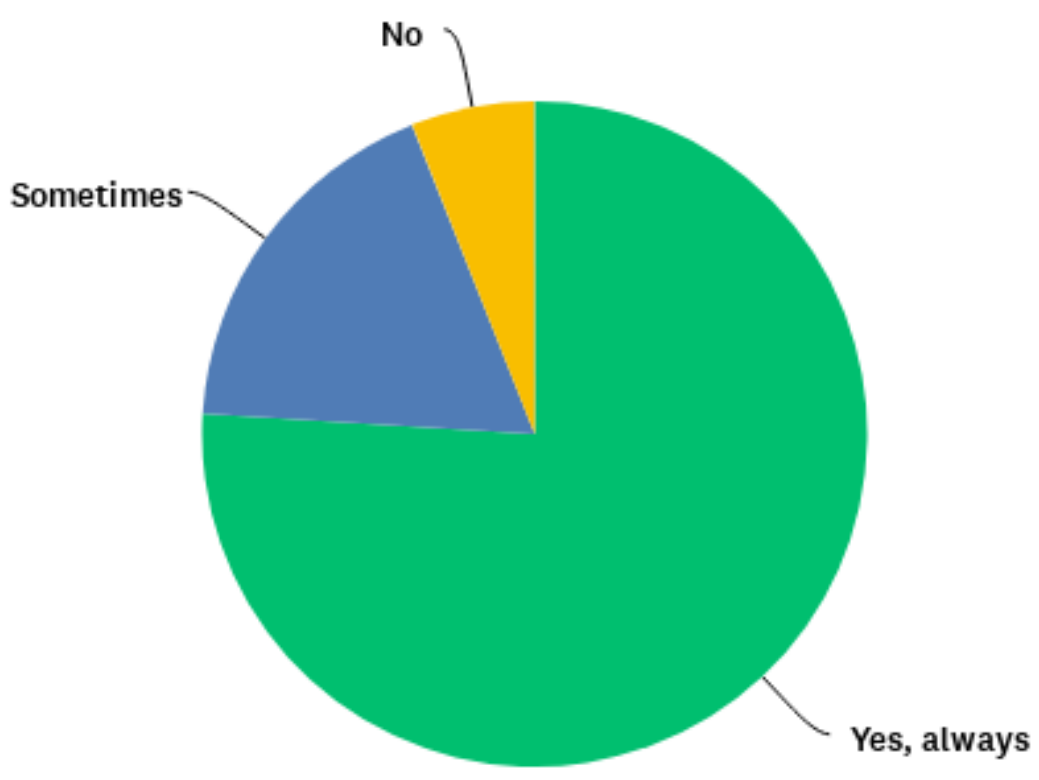


$74 \%$ (37) of young people said that health professionals listened to what they have to say. $24 \%$ (12) said sometimes (See Figure 59 ). The majority of young people ( $76 \%$, 38 ) also responded that they were given the chance to ask questions, whereas $18 \%$ (9) said only sometimes (See Figure 60).

FIGURE 61: Proportion of young people respondents who understand everything health professionals say to them

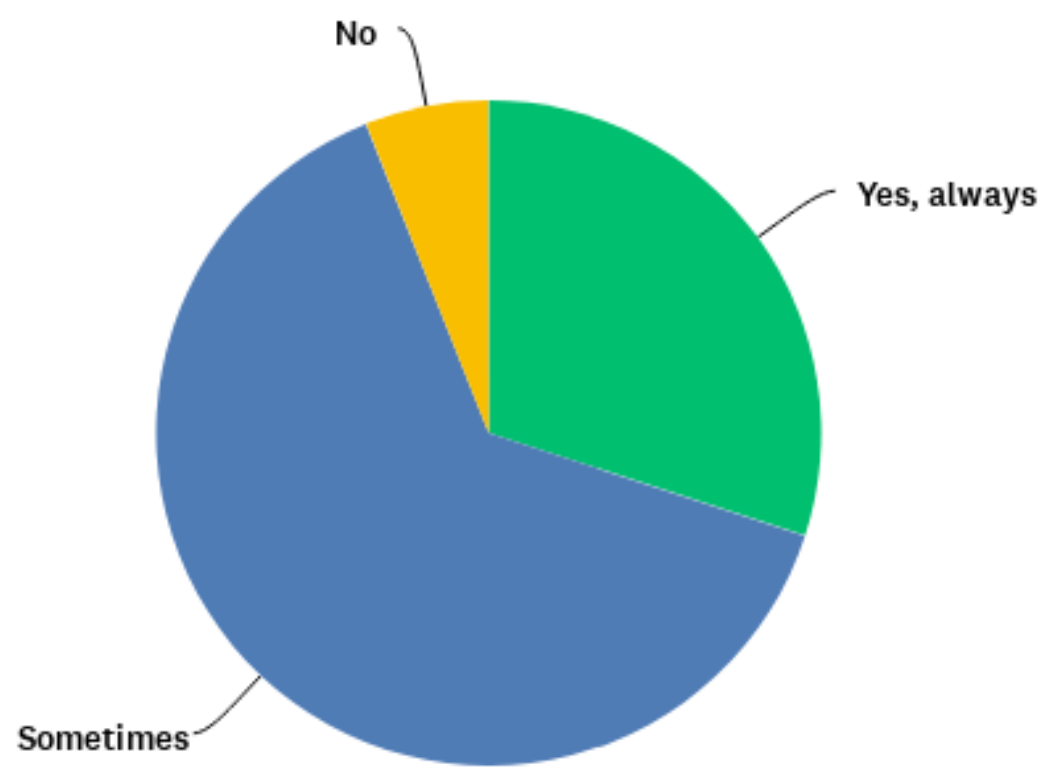

Fewer young people $(30 \%, 15)$ said that they always understand what health professionals say to them, with $64 \%$ (32) of young people saying they only understand sometimes (Figure 61). In other research, children have recognised the importance of information that is communicated to them in child-friendly language they can 
understand that does not use medical jargon ${ }^{1155}$ and uses age-appropriate terminology as they get older. ${ }^{1156}$

FIGURE 62: Proportion of young people respondents who help to choose how they can get better

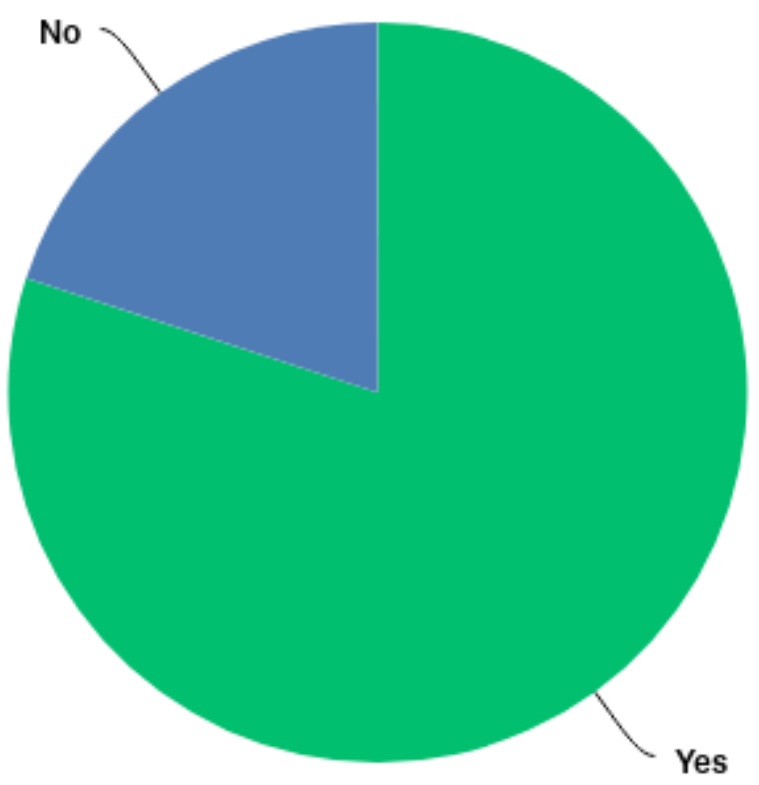

The majority of the $(80 \%, 40)$ young people said that they help to choose how they can get better (See Figure 62). Children being involved in the treatment and planning process is an expected component of Article 12 of the UNCRC. Children being involved in all decisions that impact on them has been demonstrated by other research to have a positive impact on treatment outcomes. ${ }^{1157}$

\footnotetext{
${ }^{1155}$ Mitchell-Lowe M. and Eggleston M, 'Children as consumer participants of child and adolescent mental health services', Australasian Psychiatry (2009) 17, 287-290; Kilkelly U and Donnelly M, Participation in Health Care: A report commissioned by the Ombudsman for Children (Dublin: Ombudsman for Children (2011); Coyne et al, Giving children a voice: Investigation of children's experiences of participation in consultation and decision making in Irish hospitals (Dublin: office of the Minister for Children 2006)

${ }^{1156}$ Gibson F, Aldiss S, Horstman M, Kumpunen S, Richardson A, 'Children and young people's experiences of cancer care: A qualitative research study using participatory methods', International Journal of Nursing Studies (2010) 47, 1397-1407.

${ }^{1157}$ Angst and Deatrick, 'Involvement in health care decisions: Parents and Children with Chronic Illness', Journal of Nursing May 11996
} 
FIGURE 63: Proportion of young people respondents who would tell a health professional if they were worried or upset

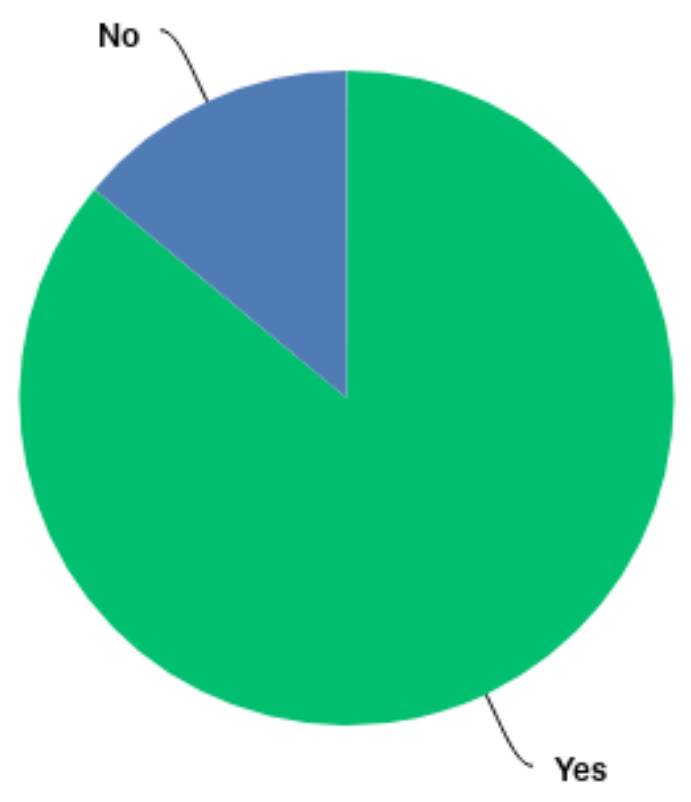

FIGURE 64: Percentage of young people respondents who trust health professionals

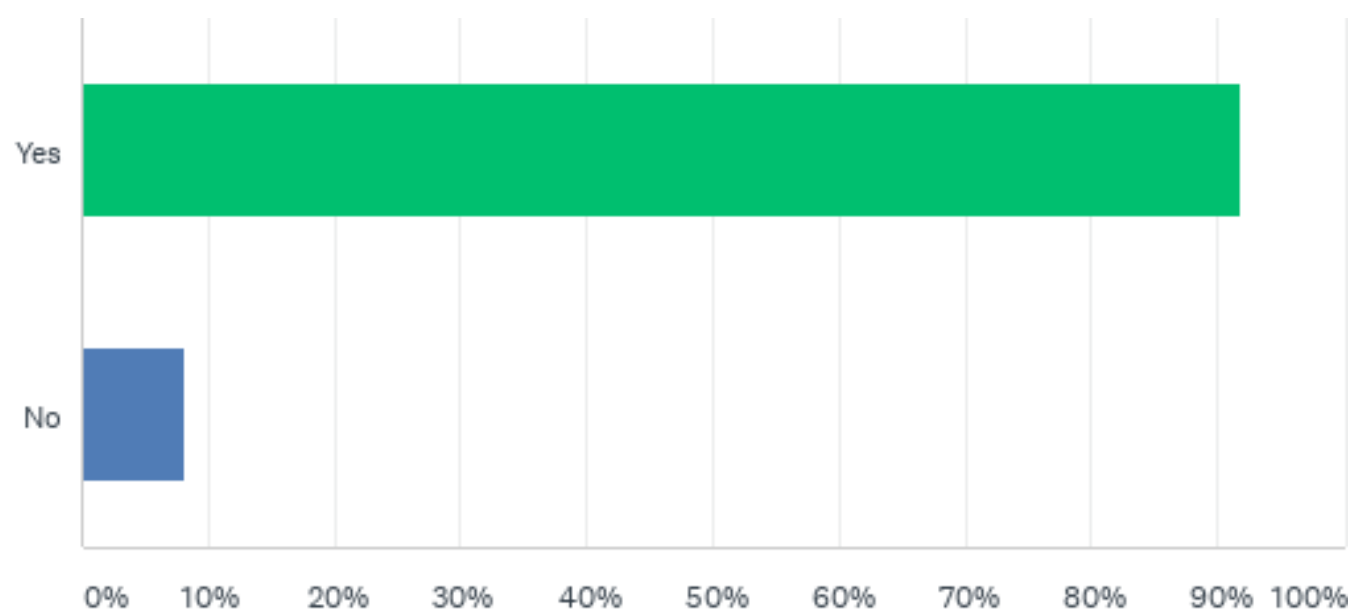

$86 \%$ (43) of the young people said they would tell a health professional if they were worried or upset (See Figure 63 ) and the majority $(90 \%, 45)$ of young people said that they trust health professionals (See Figure 64). 
FIGURE 65: Percentage of young people respondents who said they knew that health professionals have to keep their information private but health professionals have to pass their information on if they consider them to be unsafe

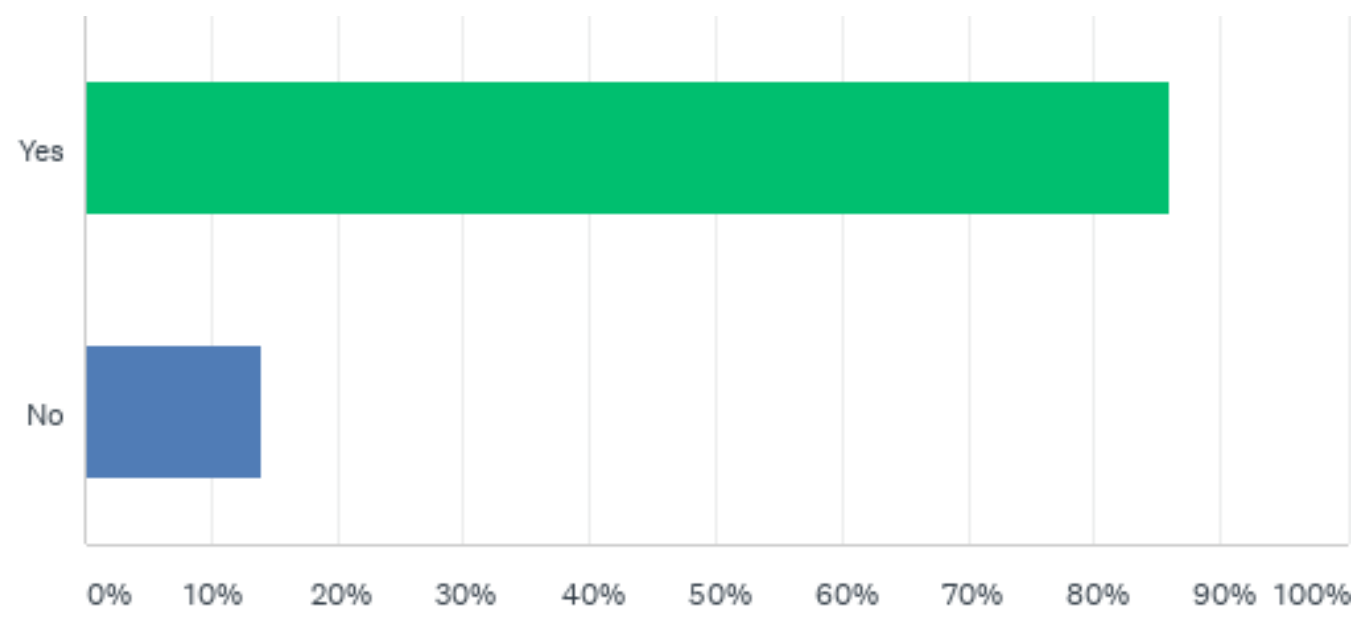

$86 \%$ of (43) the young people said they knew that health professionals have to keep their information private (Figure 65) but if they consider the young person not to be safe they will have to pass the information on. One young person offered additional information saying that,

"they don't always pass info on though" [YP4].

FIGURE 66: Percentage of young people respondents who feel safe when they visit a health professional

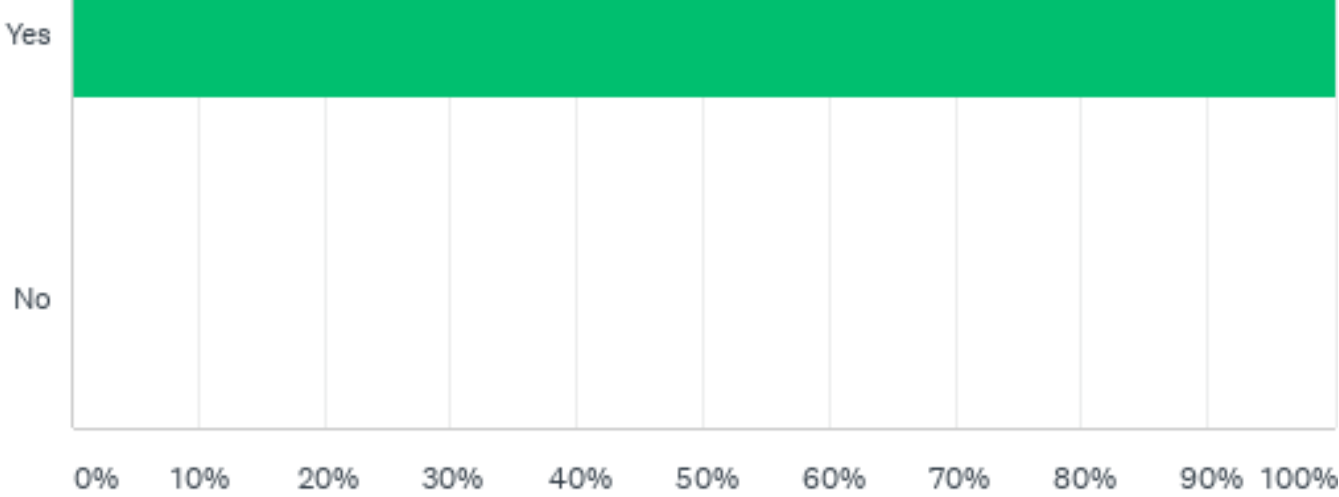


$100 \%(50)$ of young people said they feel safe when they visit a health professional (Figure 66) which shows evidence of good practice by the Health Board and compliance with the Charter's guarantee to children 'to work effectively on your behalf and do everything we can to make you feel safe and protected when you use our service.'1158

FIGURE 67: Percentage of young people respondents who feel their privacy is respected when they visit a health professional

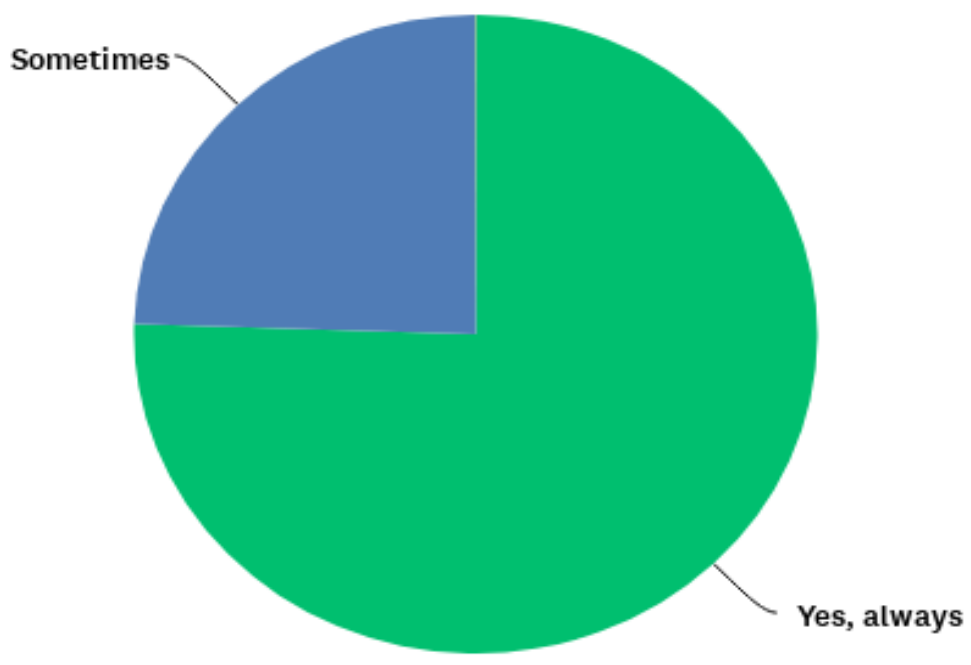

$75.5 \%$ (37) of young people said that their privacy was respected when they see a health professional (Figure 67) however $24.5 \%$ (12) said only sometimes. Other research has demonstrated that older children would like health care environments to be designed that support their privacy in consultation and treatment procedures. ${ }^{1159}$

\footnotetext{
${ }^{1158}$ See number 9 of the Charter, The right to be safe. www.wales.nhs.uk/sitesplus/documents/863/Bilingual\%20Children $\% 27 \mathrm{~s} \% 20$ Rights $\% 20$ Charter.pdf accessed January 2020

1159 Tylee A, Haller D, Graham T, et al 'Youth friendly primary care services: How are we doing and what more needs to be done?' Lancet (2007) 369 (9572), 1565-1573; National Children's Bureau, Children and Young People's Views on Health and Health Services: A Review of the Evidence (London: National Children's Bureau (2005); Boylan P, Children's Voices Project. Feedback from Children and Young People about their experiences and expectations of Health Care (Commission for Health improvement National Health Service 2004)
} 
FIGURE 68: Percentage of young people respondents who think health professionals ask for their permission before treating them

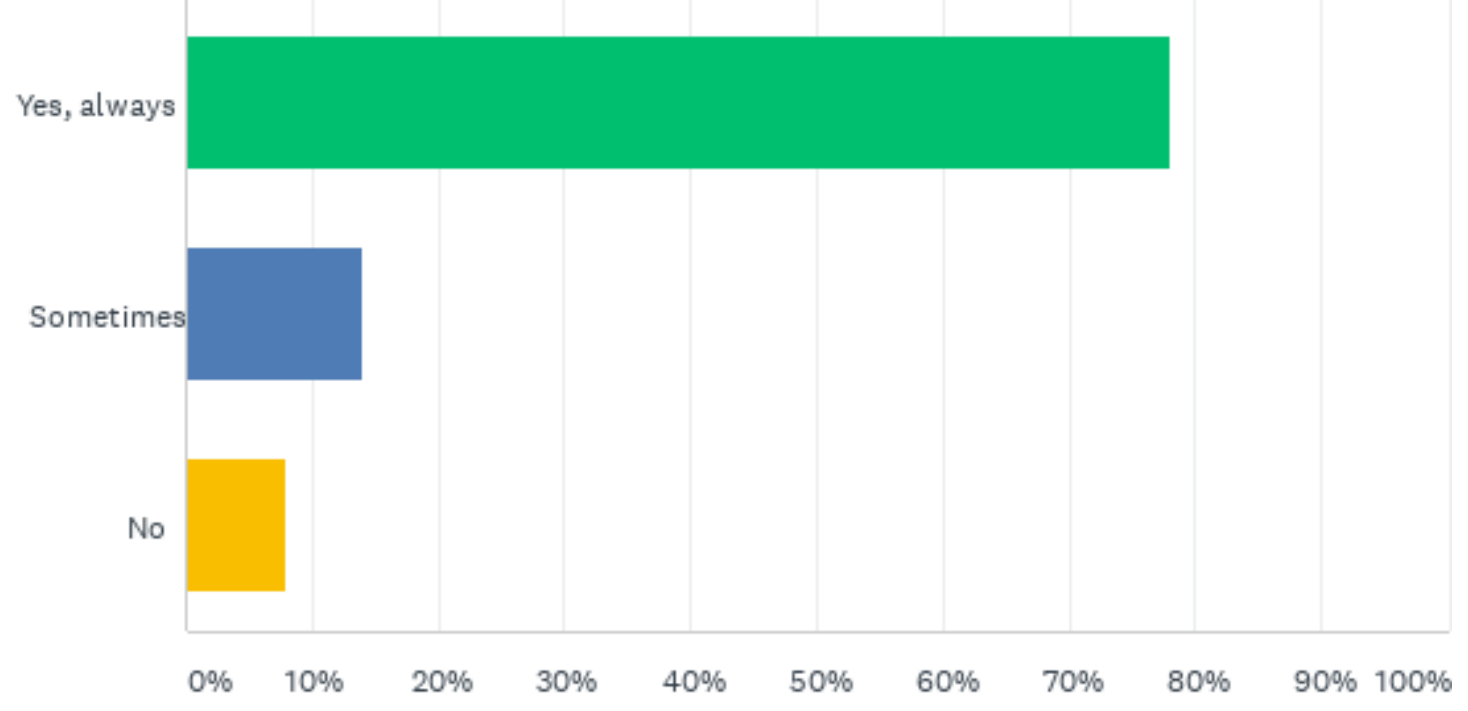

$78 \%$ (39) young people said that they are always asked for permission/consent before treatment, $14 \%$ (7) responded sometimes and $8 \%$ (4) said that their permission was not asked for (See Figure 68). Although it is positive that the majority of the young people's permission has been asked for, it is concerning that even 7 young people responded only sometimes, and 4 young people responded that their permission was not asked for, before treating them. Even these small numbers suggest that children's rights may be being breached. One health professional [HP 13] also talked about the issue of consent being a challenge to complying with the Charter. Earlier chapters to this thesis discussed the complexities of consent (See in particular Chapter 4, 6, 8) and recommended further research on this subject.

\subsection{Young people's illustrative examples of visiting a health professional}

See below illustrative examples from this research that indicate that some young people are not given full opportunities to participate in the treatment process, are not listened to and do not always understand what the doctor is saying to them. In some of these examples, consent was only asked for sometimes and privacy respected only sometimes. It is reassuring that the evidence coming from young people suggests that from the majority of young people's perspective many of the guarantees as laid out in the Children's Rights Charter are being adhered to. However, in any human rights 
analysis, if 4 young people are saying that their consent was not asked for this equates to four children's individual human rights being breached, likewise regarding children's privacy not being always respected. Illustrative examples $5-7$ can be found below.

\title{
Illustrative Example 5: "Less formal. Ensure you understand. Ask me what I think is wrong" [YP37]
}

A 16 year old female who lived in Neath-Port Talbot who had visited a health professional 4 or more times in 2018-19 answered the survey based on her experience of visiting a health professional in hospital. She responded that she did not know her rights when visiting a health professional and needed more information. She had never seen the Children's Rights Charter before. She said that health professionals are friendly only sometimes and they mainly talk to the person you came with. However they always listen to what she has to say, and she has the chance to ask questions. She only understands what they say sometimes and she only helps to choose how to get better sometimes. She answered that she trusts health professionals and feels safe when she visits them and she would tell them if she was worried. They only ask her for her consent sometimes and only respect her privacy sometimes. She answered that she does not know how to make a complaint and she needs more information. She has never been asked before what would make a visit to a health professional better, but she thinks it would be better if it was "less formal. Ensure you understand. Ask me what I think is wrong."

\section{IIlustrative Example 6: "I didn't know that I had the right to information in health} or the right to have my say. I thought that the doctor's word was final." [YP16]

\begin{abstract}
A 17 year old female who lived in Neath-Port Talbot and had visited a health professional 4 or more times in 2018-19 and answered the survey based on her experience of visiting a GP surgery responded that she did not know what her rights were when visiting a health professional and needed more information. She also had never seen the Children's Rights Charter before. She answered that health professionals are friendly only sometimes, they listen to what you have to say sometimes, they do not give you the chance to ask questions, and she does not understand everything that they are saying and she does not help to choose how she can better. She does not always trust health professionals, "because of past
\end{abstract}


experience with health professionals and family members being mis-diagnosed or not diagnosed at all". Health professionals only ask for her consent sometimes and her privacy is only respected sometimes. She sometimes finds it difficult to get to see the health professional, explaining that "You can't always get an appointment. It can be embarrassing to tell the receptionist what you need to speak to the doctor about." She would not tell a health professional if she was worried or upset and she did not know how to complain and needs more information. She has never been asked before on what would make a visit to see a health professional better.

Illustrative Example 7: "Better attitude. They have secretive meetings about my care without me knowing" [YP34]

A 13 year old female who lived in Swansea had visited a health professional 4 or more times in 2018-19 answered the survey based on their experience of visiting a health professional in a hospital responded that she knows what her rights are when she visits a health professional and she had seen the Children's Rights Charter before. She responded that health professionals are friendly sometimes; she trusts them and feels safe. They listen to what she has to say sometimes, they always give her the chance to ask questions but she does not always understand everything they are saying and she does not help to choose how to get better. She has been treated unfairly but did not disclose how she had been treated unfairly. She is only asked for her consent sometimes and her privacy is only respected sometimes. She would tell a health professional if she was worried or upset, but she did not know how to complain and needed more information. She had never been asked before what would make a visit to see a health professional better.

These illustrative examples indicate that some young people are struggling to assert their human rights in the health setting. It would be important to carry out research with a larger sample of young people to learn whether this is the case for more young people across the Health Board. 


\subsection{Children's perspectives 7-12 years}

FIGURE 69: Percentage of child respondents who like visiting a doctor or nurse

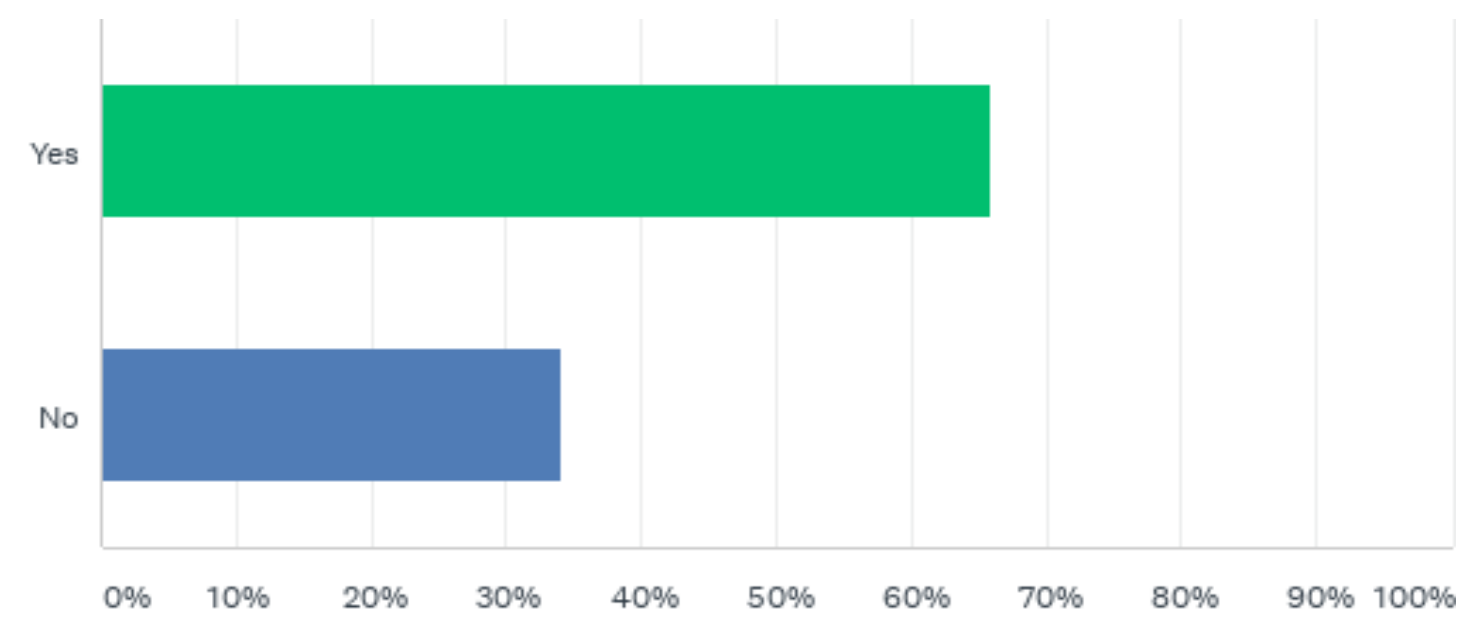

Over a third (32.9\%) of children said they did not like visiting the doctor or nurse (Figure 69). This could have been primarily due to illness or the condition that the children were experiencing at that time. However, 21 children responded with additional comments that demonstrated a level of anxiety when visiting the doctor, with children using words like "scared and nervous". When visiting the doctor, "I get scared the reason why I get scared is because I worry about what they gonna do" [C94]. This supports research undertaken by Kilkelly and Donelly 2011 and Alderson 2014 ${ }^{1160}$, that suggests that if children have things explained to them in advance, they become less scared. Another child was concerned they were going to get into trouble "i feel like im gonna get in trouble", [C74] as Kilkelly notes if children have too limited information, they may construct inaccurate mental representations of what might happen and these in themselves can be frightening. ${ }^{1161}$

One child said they did not like visiting the doctor or nurse "because it is boring" [C66]. Other children did not like visiting the doctor or nurse because of the other ill people,

\footnotetext{
${ }^{1160}$ Kikelly U and Donelly M 'Participation in healthcare: The views and experiences of children and young people', International of Journal of Children's Rights (2011) 19, 107-125, 19, 107-125

Alderson P, 'Children as patients', In Melton G, Ben-Arieh A, Casmore J, Goodman G and Worley N (eds) The Sage Handbook of Child Research (London: Sage 2014)

${ }^{1161}$ Kikelly U, 'Health and Children's Rights', In The International Handbook of Children's Rights Studies (eds) Vandenhole W, Desmet E, Reynaert D and Lembrects S (Routeledge 2015) 225
} 
"NO. because other people here arent very well" [C16] and another child said "i am shy and all depends what im seeing them for" [C14].

These responses give us a flavour of some of the children's anxiety about visiting a doctor or nurse. The young people did not freely offer the same concerns with regards to visiting a health professional, which may suggest that children who are younger are generally more anxious when visiting a doctor or nurse and this should be taken into consideration by health professionals.

FIGURE 70: Proportion of child respondents who think doctors and nurses are friendly

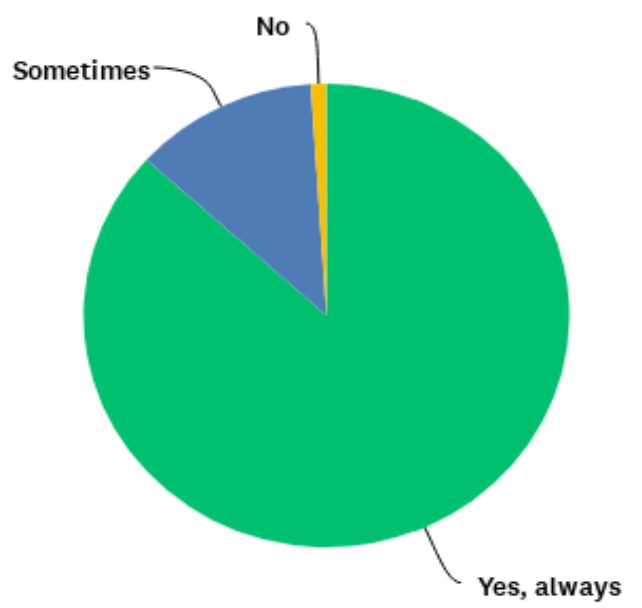

FIGURE 71: Proportion of child respondents who feel safe when they visit a doctor or nurse

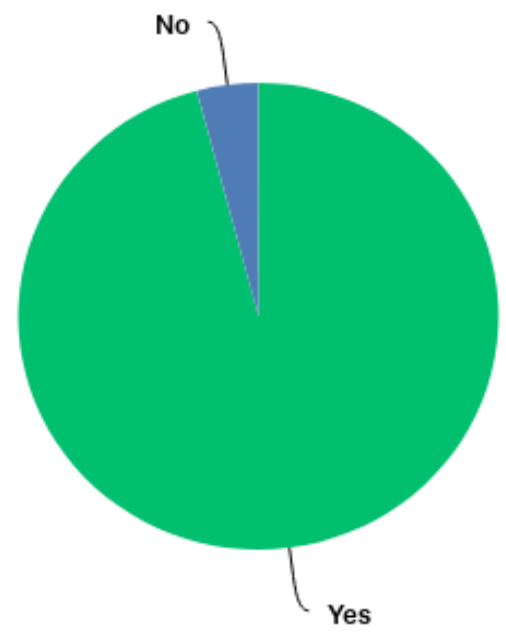


The majority of children $(86.7 \%, 85)$ said that in their experience doctors and nurses are friendly (See Figure 70 ) and the majority of children like the young people $(95.8 \%$, 93) said they feel safe (see Figure 71) when they visit a doctor or nurse, 4 said they do not. These 4 children offered additional information which echoed the anxieties recorded in the responses to whether they like visiting the doctor or nurse,

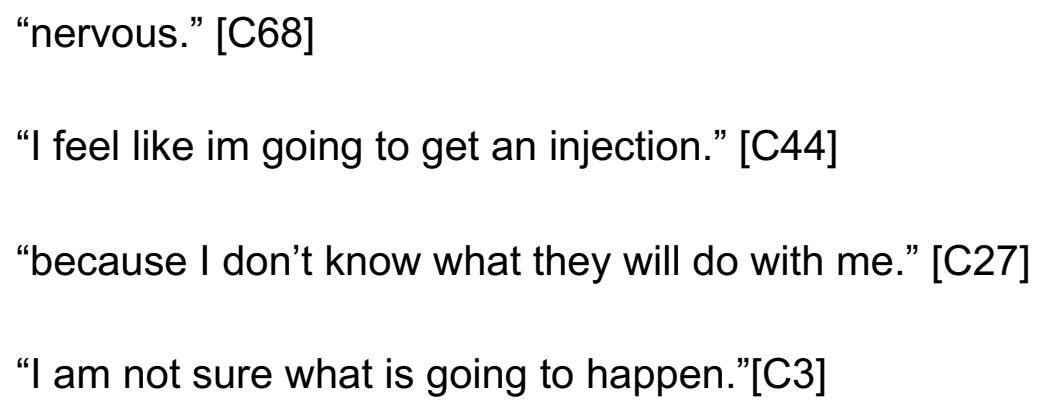

Kikelly and Donelly's own research suggests that children (5-11 years) are generally dissatisfied with how they are informed about impending procedures such as injections and that the practice of informing children was both inconsistent and unplanned. Janniste et al, explain that professionals are themselves uncertain about how best to communicate to children about procedures and propose a framework for how best to do this. ${ }^{1162}$

\section{FIGURE 72: Percentage of child respondents who are happy to tell the doctor or nurse if they are worried or upset}

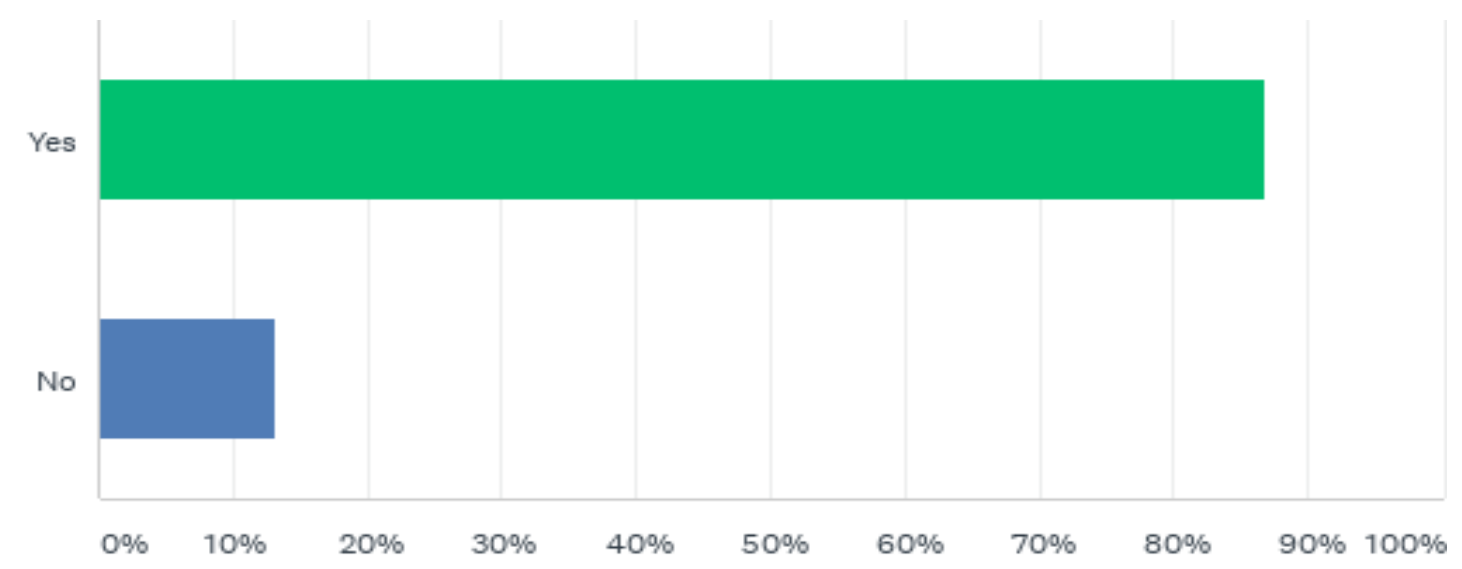

1162 Janniste T, Hayes B and Von Baeyer C L, 'Providing children with information about forthcoming medical procedures: A review and synthesis', Clinical Psychology Science and Practice (2007) 12, $124-143$ 
The majority of children $(86.7 \%, 85)$ said they would be happy to tell the doctor or nurse if they were worried or upset (See Figure 72 ). $13.3 \%$ (13) of the children that said they would not be happy, one child offered additional information; again saying "that they get nervous" [C34].

FIGURE 73: Proportion of child respondents who understand what doctors and nurses say to them

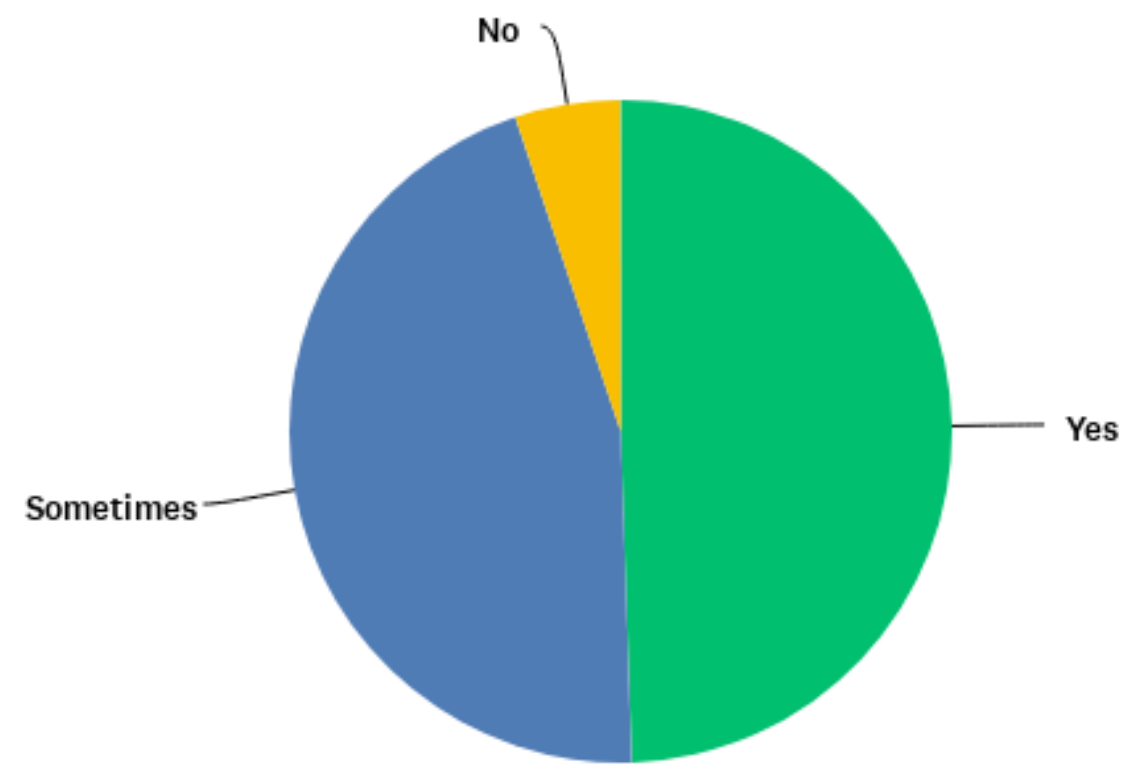

Just less than half the children responded that they only understand what doctors or nurses say to them $(45.4 \%, 44)$ sometimes, and 5 said they do not understand what doctors and nurses say to them (See Figure 73). This, like the young person's survey suggests some children may be struggling to understand what doctors/nurses are trying to communicate to them about their condition. This is in line with other research where professionals use medical language rather than child-friendly language which can become a barrier to the child participating in the decision-making process. ${ }^{1163}$

\footnotetext{
${ }^{1163}$ Mitchell-Lowe M. and Eggleston M, 'Children as consumer participants of child and adolescent mental health services,' Australasian Psychiatry (2009) 17, 287-290; Kilkelly U and Donnelly M Participation in Health Care: A report commissioned by the Ombudsman for Children (Dublin: Ombudsman for Children 2011); Coyne et al, Giving children a voice: Investigation of children's experiences of participation in consultation and decision making in Irish hospitals (Dublin: office of the Minister for Children 2006)
} 
FIGURE 74: Percentage of child respondents who think that doctors and nurses give them the chance to ask questions

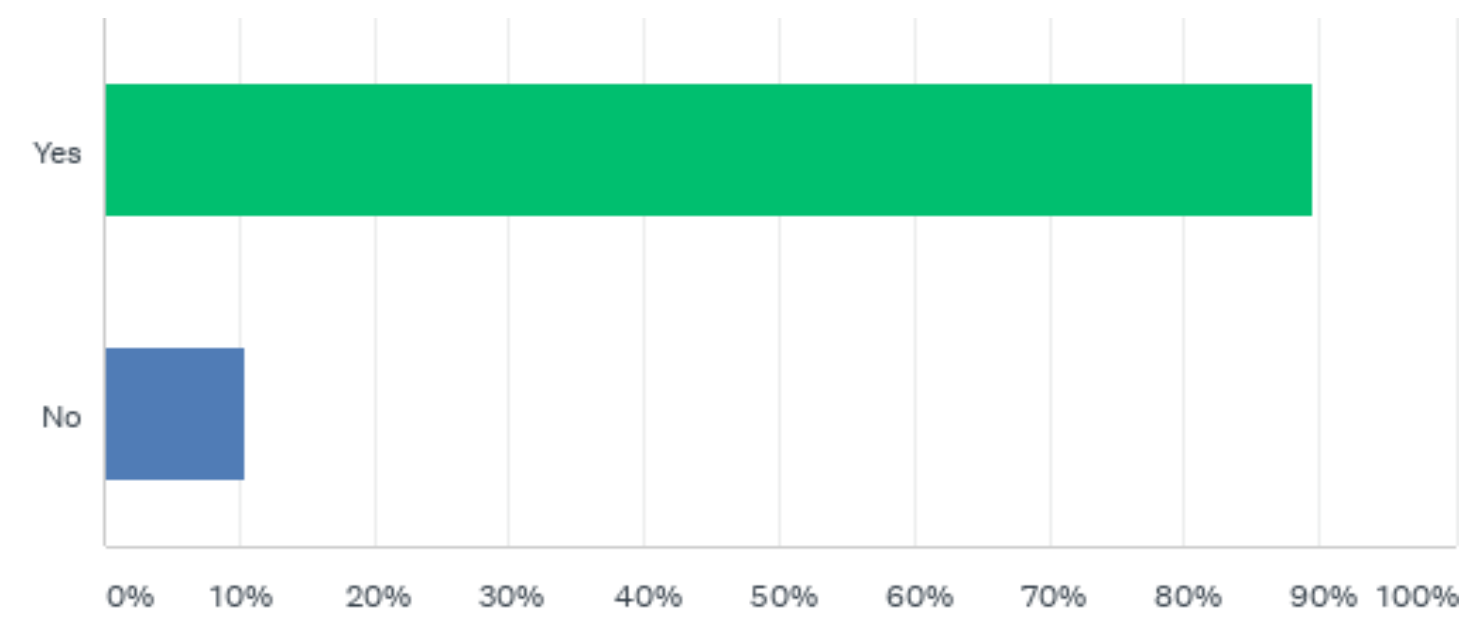

FIGURE 75: Percentage of child respondents who think that doctors and nurses listen to what they have to say

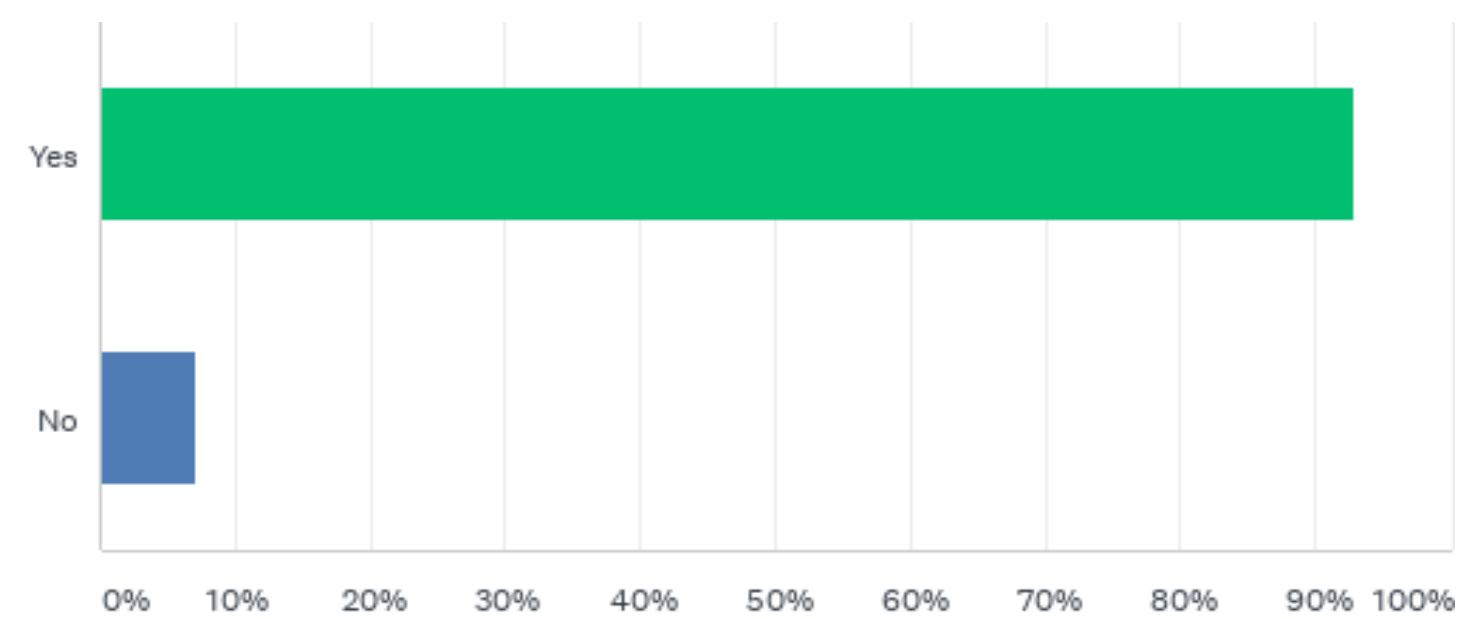

The majority of children said that doctors and nurses gave them the chance to ask questions $(89.6 \%, 86)$ (see Figure 74$)$ and the majority of children $(92.8 \%, 90)$ responded that doctors and nurses listen to what they have to say (See Figure 75).

9.3.6.1.4 Children's (7-12 years) illustrative examples of visiting a doctor or nurse

Akin to the data collected from the young people, the children's data generated an opportunity to bring together different elements of a child's experience of visiting a 
doctor or nurse. These have been brought together in a number of illustrative examples that indicate that a number of children's rights are not being fully respected when visiting a doctor or nurse. They show evidence of challenges to realising children's rights across the age and gender category and across services in different local authorities within the Health Board area. All of these children either did not know what their rights were when visiting a doctor or nurse and needed more information or had not seen the Charter before. Illustrative examples 8 - 12

\section{IIlustrative Example 8: "If I didn't need so many blood tests and they told me more what they are doing" [C87]}

A 7 year old girl who lived in Bridgend and had visited a doctor or nurse 3 or more times in 2018-19 answered the survey from her experience of visiting a hospital. She responded that she did not know what her rights are when she visits a doctor or nurse and needed more information. She had also not seen the Children's Rights Charter before. She said that she does not like visiting the doctor or nurse and thinks that doctors and nurses are friendly sometimes. She responded that she only understands what doctors and nurses say sometimes and she does not have the chance to ask questions. Doctors and nurses do however listen to what she has to say. She responded that she feels safe when she visits the doctor and nurse and she has the chance to play. She would tell a doctor or nurse if she was worried or upset. She responded that a visit to the doctor or nurse would be better if "If I didn't need so many blood tests and they told me more what they are doing". 
Illustrative Example 9: "I get scared the reason why $i$ get scared is because $i$ worry about what they gonna do" [C94]

A 10 year old girl who lived in Swansea and had visited a doctor or nurse 2 or more times in 2018-19 answered the survey from her experience of visiting a hospital. She responded that she did not know what her rights were when she visits a doctor or nurse and needed more information. She had also not seen the Children's Rights Charter before. She said that she does not like visiting the doctor or nurse "I get scared the reason why i get scared is bescause i worry about what they gonna do". However, she responded that doctors and nurses are always friendly, they listen to what she has to say and they give her the chance to ask questions but she only understands what they are saying sometimes. She responded that she feels safe when she visits the doctor or nurse and would tell a doctor or nurse if she was upset.

\section{IIlustrative Example 10: "More things my age to take my nerves away" [C72]}

A 9 year old girl who lived in Bridgend and had visited a doctor or nurse 4 or more times in 2018-19 answered the survey from her experience of visiting a GP surgery. She responded that she knows what her rights are when visiting a doctor or nurse but she had not seen the Children's Rights poster before. She responded that she does not like visiting the doctor or nurse because "I get nervous". She responded that doctors and nurses are friendly, they listen to what she has to say and they give her the chance to ask questions, however she only understands what they say sometimes. She responded that she feels safe when she visits a doctor or nurse and would tell them if she was worried or upset. However, she responded she does not have the chance to play and a visit to the doctor or nurse would be better if there were "More things my age to take my nerves away." 
IIlustrative Example 11: "I think that the doctor needs to listen to the children a bit more" [C13]

A 10 year old boy who lived in Swansea and had visited a doctor or nurse 4 or more times in 2018-19 answered the survey from his experience of visiting a hospital. He responded that he did not know what his rights are when visiting a doctor or nurse and had not seen the Children's Rights poster before. He responded that doctors and nurses are always friendly and he understands what they are saying, however they do not listen to what he has to say or give him the chance to ask questions. He responded that he does not have the chance to play when he visits a doctor or nurse. He would however tell a doctor or nurse if he was worried or upset and always felt safe when visiting a doctor or nurse. He responded that to make a visit to the doctor or nurse better "I think that the doctor needs to listen to the children a bit more".

\section{IIlustrative Example 12: "If they understand my needs" [C29]}

A 11 year old boy who lived in Swansea and had visited a doctor or nurse 4 or more times in 2018-19 answered the survey from his experience of visiting a hospital. He responded that he did not know what his rights are when visiting a doctor or nurse and had not seen the Children's Rights Poster before. He responded that he does not like visiting the doctor or nurse and they are not friendly. He answered he does not understand what they are saying; they do not listen what he has to say and do not give him the chance to ask questions. He also does not have the chance to play when he visits a doctor or nurse. He does feel safe when he visits a doctor or nurse but he would not tell a doctor or nurse if he was worried or upset. He said to make a visit to see a doctor or nurse better, he responded "If they understand my needs". 


\subsubsection{Participation of children: children involved in the design, monitoring and evaluation of service delivery}

The UN Committee on the Rights of the Child strongly advocates for children to be involved in the design, monitoring and evaluation of service delivery. Children, according to the General Comment No. 15 on health, should be encouraged to give their views on all:
aspects of health provision, including, for example, what services are needed, how and where they are best provided, barriers to accessing or using services, the quality of the services and the attitudes of health professionals. ${ }^{1164}$

As outlined in Chapter 5 this is further supported by the Welsh Government's Prudent Health Care principles that emphasise the importance of coproducing services, stating 'Achieve health and well-being with the public, patients and professionals as equal partners through co-production'. ${ }^{1165}$ However, children and young people on the whole seem to be a neglected population group in becoming equal partners in coproduction. According to the $\mathrm{RCPCH}$, children in Wales are not consistently asked for their perspective regarding their experience of being a patient. ${ }^{1166}$

\footnotetext{
${ }^{1164}$ UN Committee on the Rights of the Child (2013) General Comment No. 15 on the right of the child to the enjoyment of the highest attainable standard of health $\mathrm{CRC} / \mathrm{C} / 15 / 2013,19$

${ }^{1165}$ Prudent Health Care, Prudent Health Care; Securing Health and Well-Being for Future Generations http://www.prudenthealthcare.org.uk/wp-content/uploads/2016/02/Securing-Health-andWellbeing-for-Future-Generations1.pdf accessed January 2020

${ }_{1166}$ Royal College of Paediatrics and Child Health, State of Child Health: 2017 Recommendations for Wales (RCPCH 2017); RCPCH State of Child Health: 2018 Recommendations for Wales (RCPCH 2018)
} 
FIGURE 76: Distribution of strategic leads to $\mathbf{5}$ score options rating by objective

SLQ 26 - Children are directly involved in the development, monitoring and evaluation of service delivery

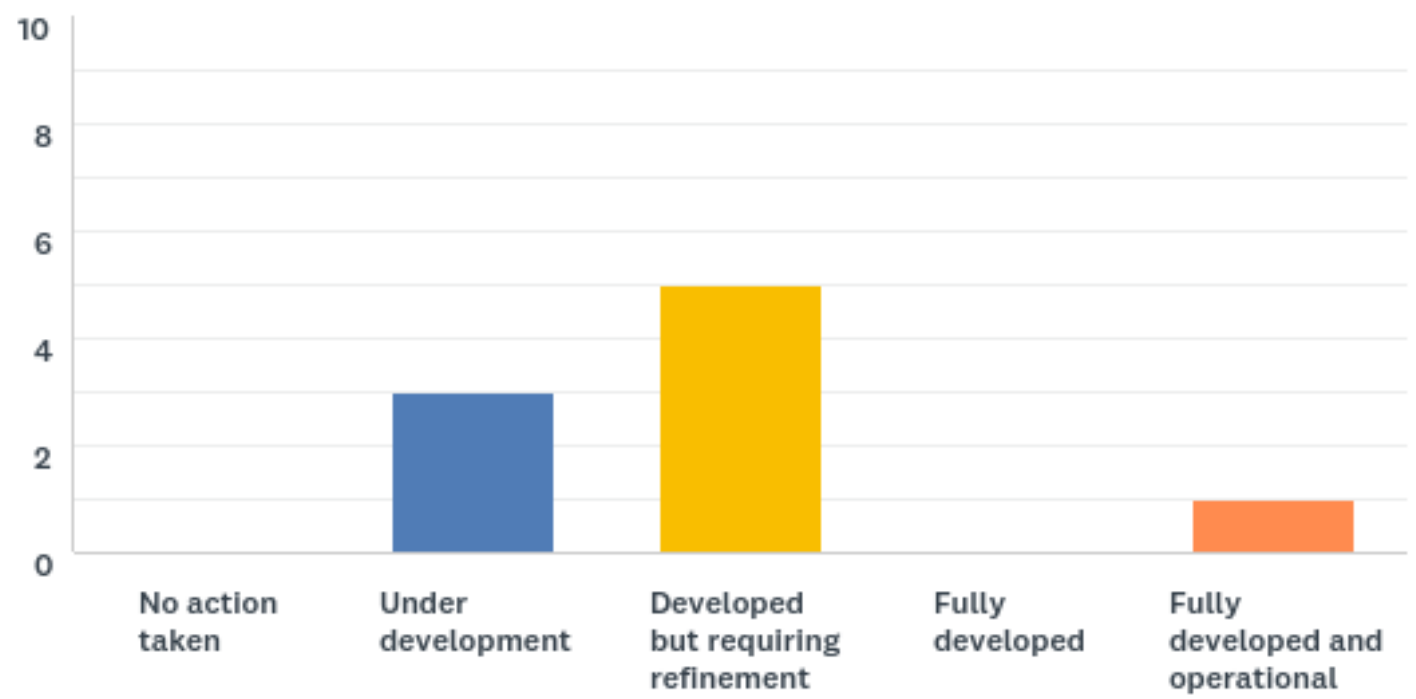

Strategic Leads again demonstrated a difference of opinion with some strategic leads believing this objective to be under development to one Strategic Lead considering children being involved in the monitoring and evaluation of service delivery to be fully developed and operational.

FIGURE 77: Distribution of strategic leads to $\mathbf{5}$ score options rating by objective SLQ 27 - A process has been established in all ABMU health service areas to collect and act on Child Patient Feedback

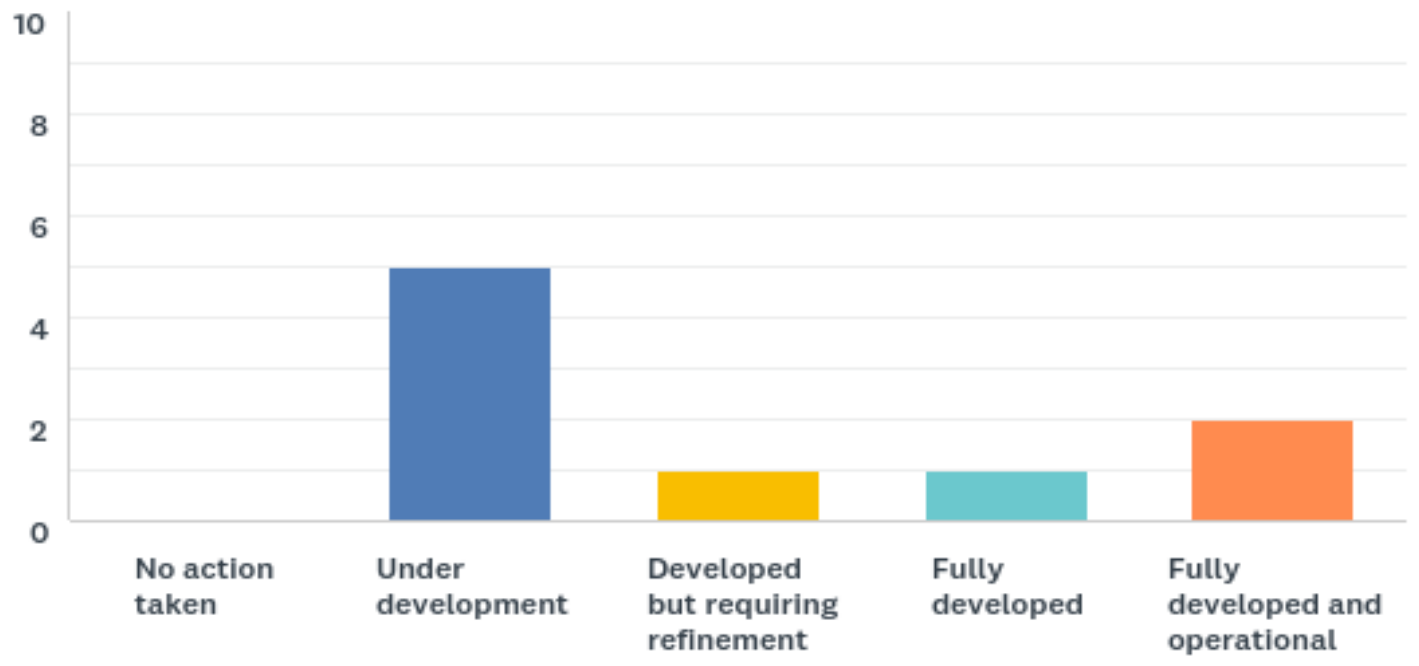


5 Strategic Leads considered this objective to be under development, one considered it to be developed but requiring refinement, one fully developed and one fully developed and operational (See Figure 77). This conveyed yet again a discrepancy of opinion on the delivery of this objective. One Strategic Lead added that "A lot more work to do before this is in place in all service areas [SL5].

FIGURE 78: Proportion of health professional respondents who provide children with opportunities to give patient feedback

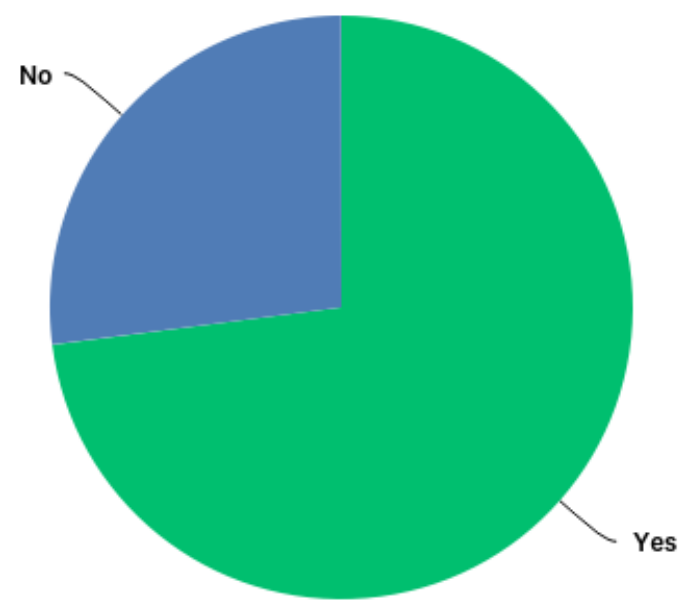

$73 \%$ (27) of health professionals responded that they did give children opportunities for child patient feedback (See Figure 78). A number of health professionals added a mix of responses to this question and how feedback was acted on,

"usually receive feedback verbally or in the form of cards. One other example is where a child requested that nursing staff did not escort him to school in uniform as it caused him to stand out - this has since been implemented into all schools where children require a HCSW to attend to their health needs at school." [HP32]

"As far as it relates to the health promotion we can provide." [HP30]

"Bring comments to all service meetings." [HP27]

" 15 steps looks at the ward from a young person's view point and comments they make are acted upon and implemented when possible." [HP18] 
"Always interact with a child before and after an operation to assess their concerns." [HP4]

FIGURE 79: Proportion of young people respondents who have been asked what would make a visit to a health professional better

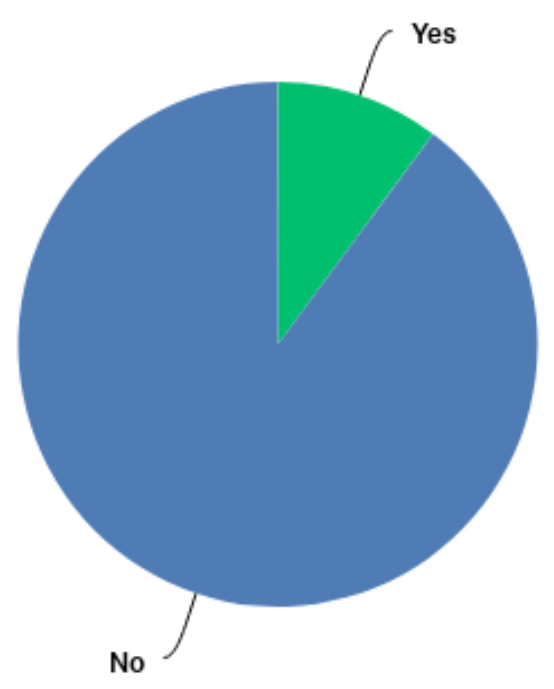

Although the health professional and the strategic lead responses were fairly positive with regards to providing opportunities for child patient feedback, the majority of the young people $(88 \%, 44)$ said they had never been asked before how to make a visit to a health professional better. This evidence reinforces findings in the $2011 \mathrm{CoE}$ study that found that the majority of children had never been asked for their views on their patient experience or health policy making. ${ }^{1167}$

The dedicated ABMU Patient Experience Coordinator has been running the programme what is referred to as 'What is top?' and What is pants?' to learn about children's experiences and perspectives regarding in-patient hospital services. These questions are asked of children about their stay at wards across hospitals in the Health Board area. This information is given to the Patient Experience Coordinator who reviews and tries to implement changes that the children suggest. It is apparent from this sample that it has not successfully been extended to child out-patients and this

\footnotetext{
${ }^{1167}$ Kilkelly U, Child Friendly Healthcare: The Views and Experiences of Children and Young People in the Council of Europe (Strasbourg: Council of Europe 2011)
} 
supports some strategic lead's concerns that child patient feedback is not happening across all services.

The Patient Experience Coordinator also collects child patient stories that address a significant issue that can support wider learning regarding the shortcomings of service delivery. These patient stories are reported to the Children's Strategy Group to share lessons and discuss what improvements should be made. However, from observations over the three-year period it did not always appear that these suggested improvements were having an impact on Board level decision making.

\subsection{ABM Youth Board}

ABM Youth are a young people expert advisory group, of approximately twenty 14-25 year olds. The first young people expert advisory group to influence the work of a health board in Wales. ${ }^{1168}$ They were established in 2017 and have been involved in the development, monitoring and evaluation of service delivery.

They are supported by the Neath Port Talbot Children's Rights Unit. The development of the ABM Youth is a positive step in the Health Board's commitment to supporting the embedding of a CRA and to help ensure that young people's voices are heard and perspectives are taken into consideration.

As referred to above by one of the health professional respondents, ABM Youth have been using what is known as the 15 steps a quality assessment tool to assess what the care is like at a ward or department in the health authority. ${ }^{1169}$ These 15 steps range from assessing, whether a ward/department is friendly and welcoming, whether staff talk directly to children, to whether a ward/department is clean and hygienic. ABM Youth go into wards and departments to speak to child patients and staff. This assessment conducted by the young people gives an invaluable young person's perspective that often differs from the perspectives of staff. The young people then write up their report and make their recommendations and revisit the ward/department

\footnotetext{
${ }^{1168}$ Cardiff and Vale Health Board set up their own young people's advisory group in 2018 ${ }^{1169}$ NHS Institute for Innovation and Improvement, The 15 Steps Challenge: Quality from a Patient's Perspective (NHS Institute for Innovation and Improvement 2012) https://hic.org.au/wpcontent/uploads/2019/10/Health-Issues-Centre-15-steps-challenge-toolkit.pdf; Abertawe Bro Morgannwg Health Board, Annual Quality Statement 2018 (ABMU 2018) 27-28
} 
in 12 months to learn whether the recommendations have been implemented. This was reported as having a significant impact on the development of services because it was an area of work that was led and controlled by children's services. At the time of the research, they were hoping to be the first young people in the UK to roll this approach out to GP services.

\section{ABM Youth Project work}

ABM Youth have been involved in a number of different projects and met with the Welsh Government Health Minister Vaughn Gething MS in 2018, to bring attention to their advisory group and present their views on health services. However, the young people at the time of the research had never been invited to attend an ABMU Board meeting to present their work or to input into Board level decision making.

Projects ABM Youth were involved in 2017 -2019:

- $A B M$ Youth were involved in the redesign of the floor plan/design of the building that affects children at Morriston hospital that was not fit for purpose in 2018.

- Advised from a young person's perspective on the development of the Health Boards' early intervention mental health service.

- Design2Smile - ABM youth have given their feedback on a dental poster campaign.

- Patient Questionnaires - ABM youth have given feedback on the content of patient questionnaires for children and young people.

- Zero tolerance Poster - developed a Zero Tolerance Poster for Children's Wards.

- Represented ABMU at various conferences/forums - e.g. CNO; Lighting the Future; All Wales Listening and Learning; Children's Commissioner for Wales Annual Child Health seminar, $30^{\text {th }}$ Anniversary of the UNCRC conference.

- $\mathrm{RCPCH}-\mathrm{A}$ number of ABM youth members took part in an $\mathrm{RCPCH}$ takeover challenge day where young people informed the work of $\mathrm{RCPCH}$ and were given the opportunity to give their opinion and develop ideas on how to improve healthcare for children and young people. This has now been developed into an action plan. 
- Some ABM Youth members are Community Ambassadors for the Children's Commissioner for Wales.

- Written an article for Royal College of Paediatrics and Child Health in Wales.

Although not part of this evaluation it can be suggested that ABM Youth have been given some opportunities to influence strategies internally at Health Board level but also externally at the national level with regards to changes for children and young people patients across Wales. However, there was a perception from the young people that adults were very willing to consult them for their ideas and opinions but were less inclined to present them with feedback regarding what changes they had made based on their input. This is contrary to the expectations of the UN Committee on the Rights of the Child that recommends that decision makers should always give feedback to children regarding the outcome of a decision-making process and how the child's views were given consideration. ${ }^{1170}$

FIGURE 80: Distribution of strategic leads to $\mathbf{5}$ score options rating by objective SLQ 29 - Children have been given opportunities to act collectively to develop ideas and proposals, to take action and to influence decisions e.g. ABM Youth Board

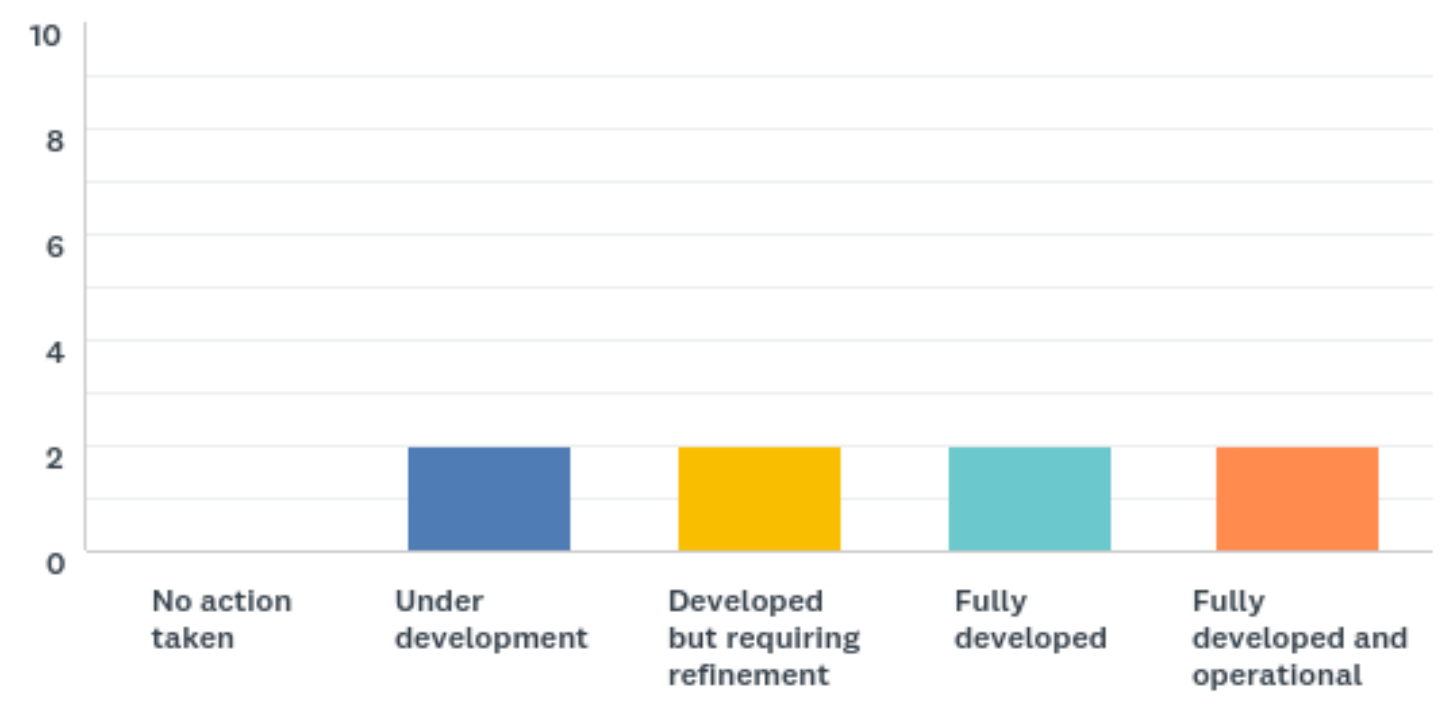

There was a divergence of opinion about the degree to which children have been supported to act collectively e.g., a youth board being implemented. 2 Strategic Leads

\footnotetext{
${ }^{1170} \mathrm{UN}$ Committee on the Rights of the Child, General Comment No. 12: The right of the child to be heard, $\mathrm{CRC} / \mathrm{GC} / 12 / 2009$ paras 30 and 45
} 
considered this to be under development, 2 developed but requiring refinement, 2 fully developed, 2 fully developed and operational, 1 person not responding. One Strategic Lead commented that there was "potential to broaden membership to children with disabilities" [SL4].

ABM Youth are said to play a role in the recruitment of nursing staff across children's health services and have received training from the Neath Port Talbot Children's Rights Unit to become young interviewers.

FIGURE 81: Distribution of strategic leads to 5 score options rating by objective SLQ 28 - Children are involved in the recruitment of staff that directly work with children

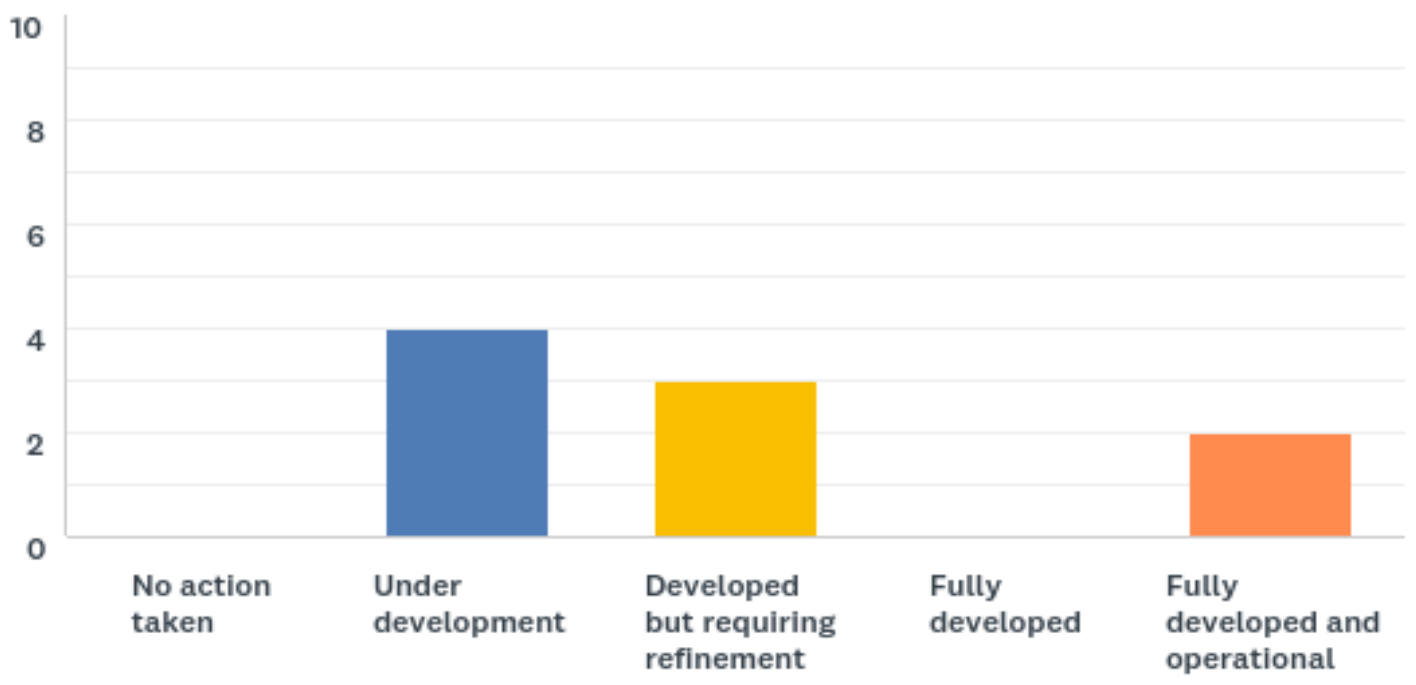

With regards to children involved in the recruitment of staff, 4 Strategic Leads believed this to be under development, 3 believed the standard to be developed but requiring refinement and 2 believed it to be fully developed and operational (see Figure 28). 2 Strategic Leads added that standard is being adhered to in "Children's Services" [SL8] but "not applied in all service areas" [SL5].

\subsection{Reflections}

On the whole, the sample of young people (13-17 years) reported that health professionals were friendly, that they trusted them, and they felt safe. Also, their right to be heard, listened to, to ask questions, being able to choose to get better, being talked to as well as their carer and being given the opportunity to consent to treatment 
was being respected. Fewer young people said they were able to understand what doctors are saying and this may indicate that more work should happen to empower young people to understand what is happening when they visit a health professional.

However, it is concerning that even small numbers of young people are not being asked for their consent to treatment, their privacy is only respected sometimes, that they are not being talked to directly, listened to and opportunities to help to choose to get better are not being respected. This suggests that a more detailed study with a larger sample of young people should be carried out to discern if there are larger numbers of young people across the Health Board that may be experiencing these human rights breaches.

The sample of children (7-12 years) also indicated a positive response in terms of being listened to; being able to ask questions but again more children reported that they only understand the doctor or nurse sometimes. Many children consistently reported feeling anxious and scared when visiting a doctor or nurse and this anxiety maybe being heightened if they do not understand what is happening and in advance of procedures and consultations. The UN Committee on the Rights of the Child comments that children should always be provided with information about proposed treatments, including in formats appropriate and accessible to children and children with disabilities. ${ }^{1171}$

It is concerning that some of the Strategic Leads did not believe that children's Article 12 human right is respected in medical decision making as a matter of course and also that they have not actively and routinely assessed how well children and young people's right to be heard is being respected within medical decision making. As the UN Committee on the Rights of the Child in General Comment No. 12 and 15 makes clear, no matter the age of the child, the views of children must always be taken into account in clinical decision making. ${ }^{1172}$

\footnotetext{
${ }^{1171} \mathrm{UN}$ Committee on the Rights of the Child, General Comment No. 12: The right of the child to be heard, $\mathrm{CRC} / \mathrm{C} / \mathrm{C} / 12$ para 100

${ }^{1172}$ UN Committee on the Rights of the Child, General Comment No. 12: The right of the child to be heard, CRC/GC/12/2009; UN Committee on the Rights of the Child, General Comment No. 15 on the right of the child to the enjoyment of the highest attainable standard of health $\mathrm{CRC} / \mathrm{C} / 15 / 2013$
} 
With regards to Child Patient Feedback, there is the programme 'What is top and what is pants?' and other health professionals reported that they were supporting Child Patient Feedback. However, the research revealed that the majority of young people out-patients had never been asked for their views, on making a visit to see a health professional better. This suggests the need for more research across the Health Board and a more consistent approach to securing children and young people's perspectives as service users should be embedded across all services that impact on children.

The UN Committee's General Comment on health states that children's views should be taken into account in the evaluation of services, what services are needed, what are the barriers to access, the quality of services and the attitudes of health professionals. ${ }^{1173}$ Nolan et al argue that a key component of the right to health is that children are not only included in individual health decision making but at the systematic level of health policy and service delivery. ${ }^{1174}$

The work of ABM Youth is pioneering and leading the way in Wales in securing young people to advise on many different aspects of health care decision making across the Health Board and at the national level. ABM Youth now needs to be funded as part of core funding, rather than charitable endowment, so the Health Board demonstrates its long-term commitment to ensuring a young person's perspective to the design, monitoring and evaluation of service delivery. ABM Youth also needs to be better integrated into reporting their findings and views into Board level decision making.

Finally, it is also positive that young people are involved in the recruitment of nursing staff. This approach needs to be rolled out to all professionals who directly work with children across the Health Board.

\footnotetext{
${ }^{1173}$ UN Committee on the Rights of the Child, General Comment No. 15 on the right of the child to the enjoyment of the highest attainable standard of health $\mathrm{CRC} / \mathrm{C} / 15 / 2013$ para 19

${ }^{1174}$ Nolan A, Yamin AE and Meier BM, Submission on the Content of a Future General Comment on the Right of the Child to the Enjoyment of the Highest Attainable Standard of Health (art. 24) (OHCHR)
} 


\subsubsection{Empowering children: child friendly complaints mechanism}

Having a child friendly complaints system is a critical method of empowering children as child service users with an appropriate mechanism to complain and is recommended by the UN Committee on the Rights of the Child in General Comment No. 12 and No.15 ${ }^{1175}$ However, in Chapter 4, other research ${ }^{1176}$ indicated children are not being made aware of or given opportunities to complain that are child friendly and tailored to the needs of the child. In Chapter 5 it was reported that Stats Wales collect data on the number of complaints made against each health board across a number of variables. However, there is no data collected that demonstrates the number of complaints made by children and what their complaints concern. The questions in the surveys were designed to learn from young people, professionals and strategic leads how successfully young people and indeed children are able to complain when using ABMU health services.

FIGURE 82: Distribution of strategic leads to $\mathbf{5}$ score options rating by objective SLQ 30 - Children and their carers are provided with accessible information on the process for making complaints and for holding the authority, or individual staff to account

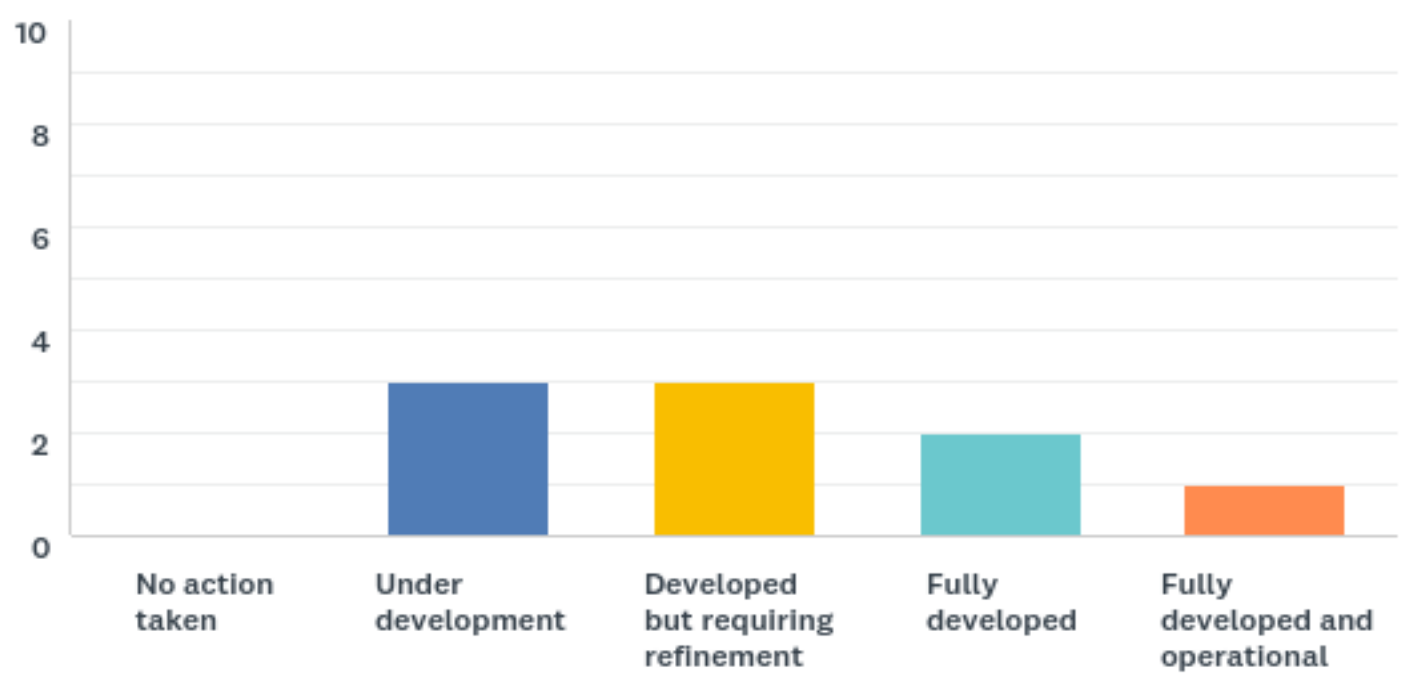

${ }^{1175}$ UN Committee on the Rights of the Child, General Comment No. 12: The right of the child to be heard, CRC/GC/12/2009 para 20; UN Committee on the Rights of the Child, General Comment No. 15 on the right of the child to the enjoyment of the highest attainable standard of health $\mathrm{CRC} / \mathrm{C} / 15 / 2013$, para 119

${ }^{1176}$ Children's Commissioner for England, Child Friendly Complaints Processes in Health Services, Principles, Pledges and Progress (CCfE 2013) 
There was a lack of agreement by Strategic Leads with regards to whether child friendly complaints were available; with some considering it to be under development and others considering it to be fully developed and operational (See Figure 82). One Strategic Lead added that, "Parents and carers are catered for but not children and young people" [SL5].

FIGURE 83: Percentage of health professional respondents who know how to support a child to make a complaint

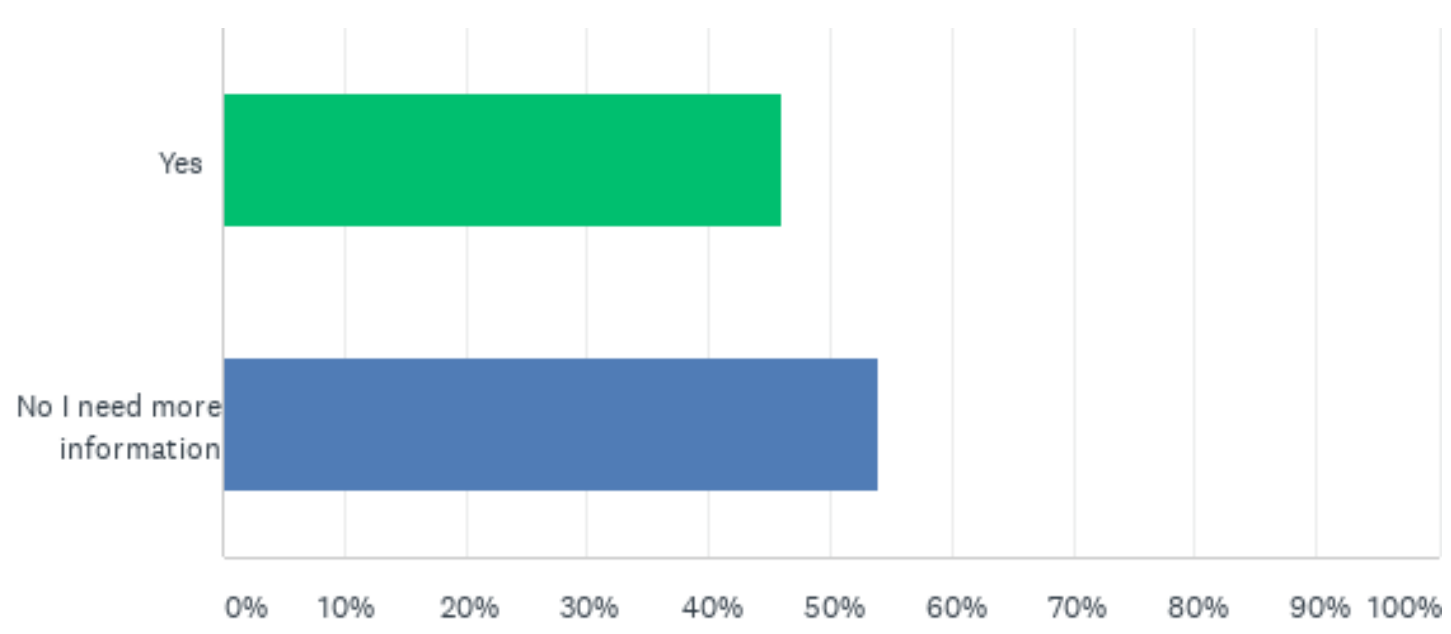

Just over half of the $(54 \%, 37)$ health professionals said that they did not know how to support a child to make a complaint and they needed more information. Only 3 health professionals had received any training on supporting children to make complaints (see Figure 38 above). 
FIGURE 84: Proportion of children health professional respondents have supported to make a complaint in 2018

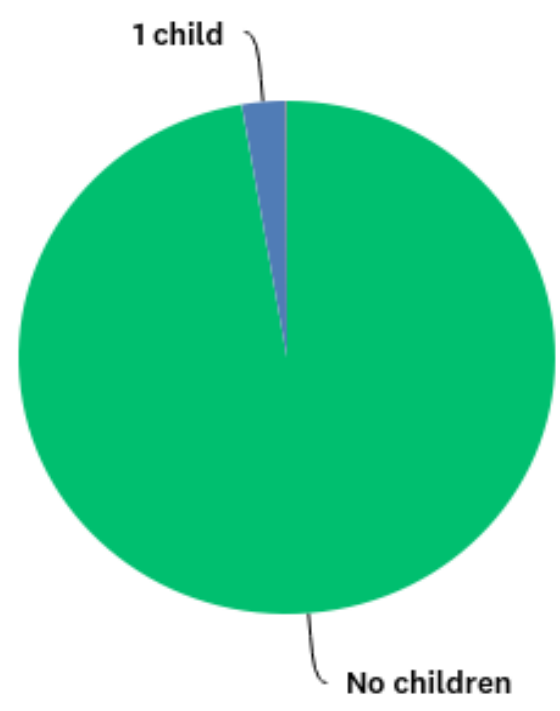

Only one health professional who worked in Swansea health services had supported one child to make a complaint in 2018. This may indicate that there was only one genuine complaint, or it could indicate that many young people do not know how to complain as suggested by this sample.

FIGURE 85: Proportion of young people respondents who know how to complain

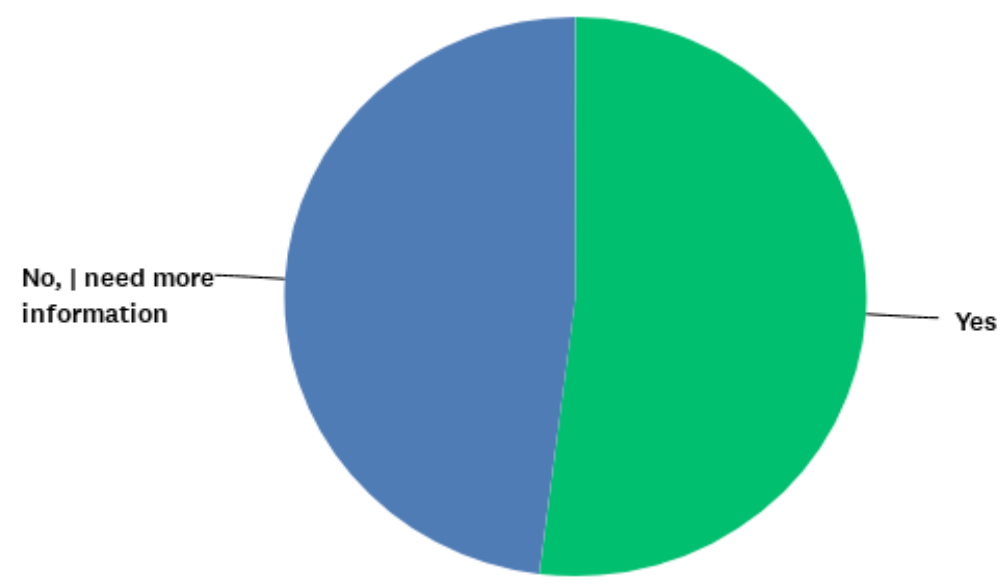

Just less than half $(48 \%, 24)$ of the young people said they do not know how to make a complaint and would need more information (See Figure 84). Eleven 13 year olds said that they did not know how to complain and needed more information; this age 
category, the youngest age category in the age range had the most responses who said they did not know how to complain. $62.5 \%$ (15) children who said they did not know how to complain also said they did not know their rights and $95.8 \%(23)$ of the young people who responded that they did not know how to complain had never been asked for their views on visiting a health professional before. $79.1 \%$ (19) of the young people who said they did not know how to complain responded that they get their information on how to stay healthy from their family.

3 young people responded that they had not been asked for their permission/consent before treatment and 4 who responded that their permission had only been asked sometimes, also responded that they did not know how to complain and needed more information. 9 young people who did not know how to complain responded that their privacy had only been respected sometimes. 4 young people who responded that they had been treated unfairly because of their Age, one because of their Gender and Age one because of their Race, also said they did not know how to complain. These findings are concerning because of the young people who had experienced human rights breaches they did not know how to make a complaint.

\subsubsection{Young people's illustrative examples who did not know how to complain}

Please see below two illustrative examples where young people did not know how to complain. The first young person was a CAMHS out-patient and did not know her rights when visiting a health professional and needed more information and was reliant on her mother to make a complaint. She reported that her privacy was only respected sometimes, as well as being asked for permission before being treated.

The second young person believed he had been treated unfairly because of his age and gender, had not been asked for this consent and his privacy was only respected sometimes. He also said that health professionals mainly talk to the person he came with, do not listen what he has to say and he does not help to choose how he can get better. This supports research undertaken by Lambert et al that children/young people can become 'passive bystanders' when health care professionals communicate 
directly to their parents and not the child. ${ }^{1177}$ This young person did know his rights when visiting a health professional however he did not know how to make a complaint and had never before been asked for his view on how to make a visit to a health professional better. Illustrative examples 12 and 13 can be found below.

\section{Illustrative Example 12: “Tell Mam" [YP3]}

One 15 year female who lived in Swansea and had visited CAMHS 4 or more times in 2018-19 responded she would "Tell Mam" when asked if she knew how to make a complaint. This young person did not know her rights when she visited a health professional and said she needed more information. She had also never seen the Charter before. She responded that health professionals are friendly and helpful sometimes and it depends on the person whether she trusts them. She responded that health professionals listen to what you have to say and ask you questions only sometimes. She responded that she only understands what the health professional says sometimes, and she never helps to choose how she can get better. She said she would tell a health professional if she was worried or upset. She said that her privacy is respected only sometimes, and she is asked for her consent only sometimes. She responded that the main place where she gets information about being healthy is from her family and secondly the internet.

\section{Illustrative Example 13: Health professionals should "stop looking down on you" [HP4]}

A 17 year old male who lived in Neath-Port Talbot and had visited a health professional 2 or more times in 2018-19 answered the survey based on his experience of visiting a GP surgery reported that he had been treated unfairly because of this Age and Gender. He responded that he knew is rights when visiting a health professional and had seen the Children's Rights Charter before. He responded that health professionals are friendly and helpful only sometimes. He responded that health professionals 'mainly talk to the person you came with' and they do not listen to what you have to say. He responded they give you the

${ }^{1177}$ Lambert V, Glacken M. and McCarron M, 'Communication between children and health professionals in a child hospital setting: A child transitional communication model', Journal of Advanced Nursing (2010) 67, 569-582 
opportunity to ask questions sometimes, he only understands everything they say sometimes, and he does not get to help to choose how he can get better. He said he does not trust health professionals and they do not ask his permission or consent before treatment. He said his privacy is only respected sometimes. He responded that he knew that health professionals had to keep your information private and pass it on if they are concerned you are not safe, however he commented "that they do not always pass info on though". He said he did not know how to make a complaint and needed more information. He said if health professionals "stopped looking down on you" then this would make a visit better. He has never been asked his view before regarding what would make visit to see a health professional better before.

\subsubsection{Reflections}

Many health professionals in this sample did not know how to assist children how to make a complaint and had not received training on supporting children to make a complaint. Only one health professional supported one child to make a complaint in 2018. This was reinforced by the Head of Nursing, who is the lead for complaints for children, reporting that she had indeed only received 2 complaints from children in 2018. Young people reported that they do not know how to make a complaint, and they also do not know what their rights are when visiting a health professional. The research revealed that some young people had been treated unfairly because of their age, gender, race, and other categories etc (see section Equality and NonDiscrimination) and did not know how to make a complaint. As the UN Committee on the Rights of the Child recommends, effective remedies should be accessible to the child when any decision making process has not adhered to appropriate standards, including making child friendly complaints mechanisms accessible. ${ }^{1178}$ It therefore concerning that young people or indeed children are not aware of and do not have access to a child friendly mechanism to make a complaint and when necessary to hold the health authority to account for a breach of their human rights.

\footnotetext{
${ }^{1178}$ UN Committee on the Rights of the Child, General Comment No. 15 on the right of the child to the enjoyment of the highest attainable standard of health $\mathrm{CRC} / \mathrm{C} / 15 / 2013$ para 119
} 
The Head of Nursing reported that they do have a leaflet that tells children about their right to complain and there is the standard 'Putting it right' leaflet for caregivers, but as the staff member who is responsible for children's complaints, she is still concerned that children do not know or understand what it means to complain and how to do it. They want to establish a process so that children understand how to make complaints and the Health Board can learn from children directly, how to improve health services for children. They also want to ensure appropriate redress when children's rights have been violated. Children and young people should be consulted on the development of a child friendly complaints mechanism that would support them to make complaints.

\subsubsection{Empowering children: health promotion and children's rights information and advocacy for children and carers}

Health promotion is critical to equipping children with basic knowledge on how to take action to stay or become healthy and is an important component of Article 24 (e) of the UNCRC, and Article 17 with regards to the accessing of appropriate information. It is also an important aspect of empowering children to take advantage and exercise their human rights in health care settings. Children and their carers should always be able to access information about human rights. Furthermore, to support children to exercise their human rights, they must also be able to access advice, such as advisory services, human rights advocacy services or professional legal advice. The surveys were designed to learn to what degree this is happening at $A B M U$ from the perspective of Strategic Leads and health professionals as well as getting an indication from young people where they learned about being healthy. 
FIGURE 86: Distribution of strategic leads to $\mathbf{5}$ score options rating by objective

SLQ 31 - Children are provided accessible information on how to access advice, such as advisory services, human rights advocacy services or professional legal advice

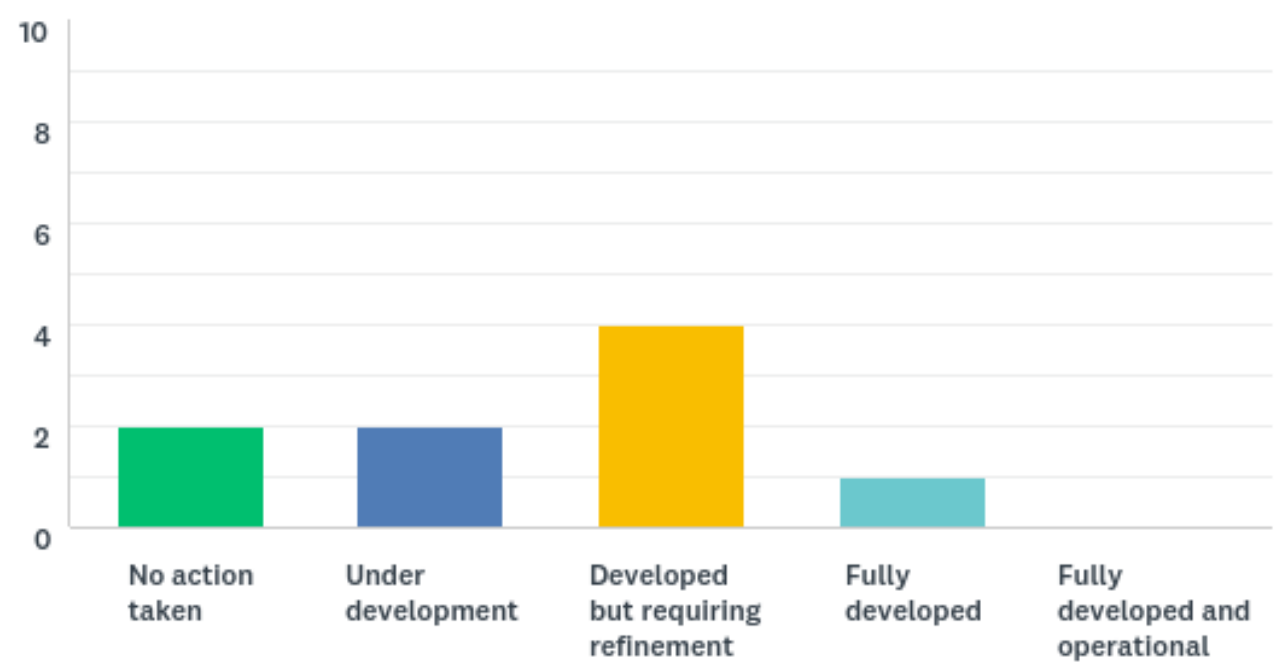

There was also a discrepancy of opinion with regards to whether children and young people are able to access advisory services, advocacy and legal advice, with 2 Strategic Leads believing no action had been taken whereas another Strategic Lead believed it to be fully developed area of work (See Figure 86). One Strategic Lead added that this was "Not available in all service areas particularly primary care/GP" [SL5].

FIGURE 87: Distribution of strategic leads to 5 score options rating by objective SLQ 32 - Children and their carers are able to access age, gender, disability and culturally appropriate information about how to stay healthy and how to take action to become healthy

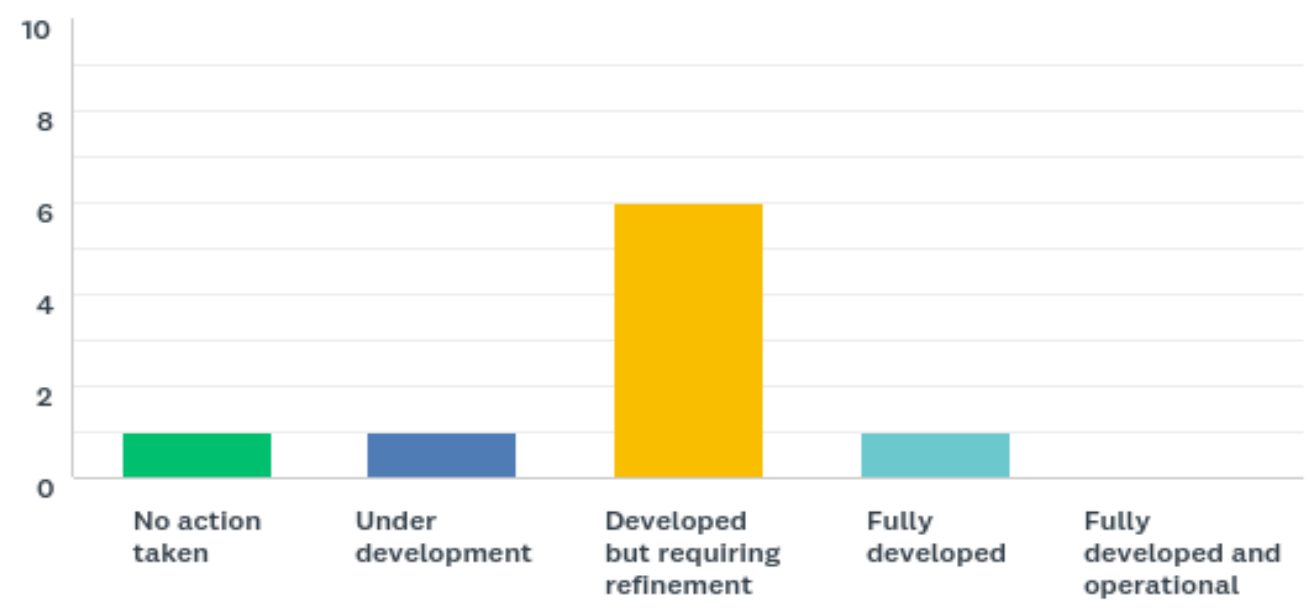


One Strategic Lead believed that no action had been taken in the delivery of this standard and one believed that it was under development, 6 Strategic Leads believed that it was developed but requiring refinement and one believed it to be fully developed (See Figure 87).

FIGURE 88: Distribution of strategic leads to 5 score options rating by objective SLQ 34 - Materials providing information about preventative health and health rights are designed in collaboration with children

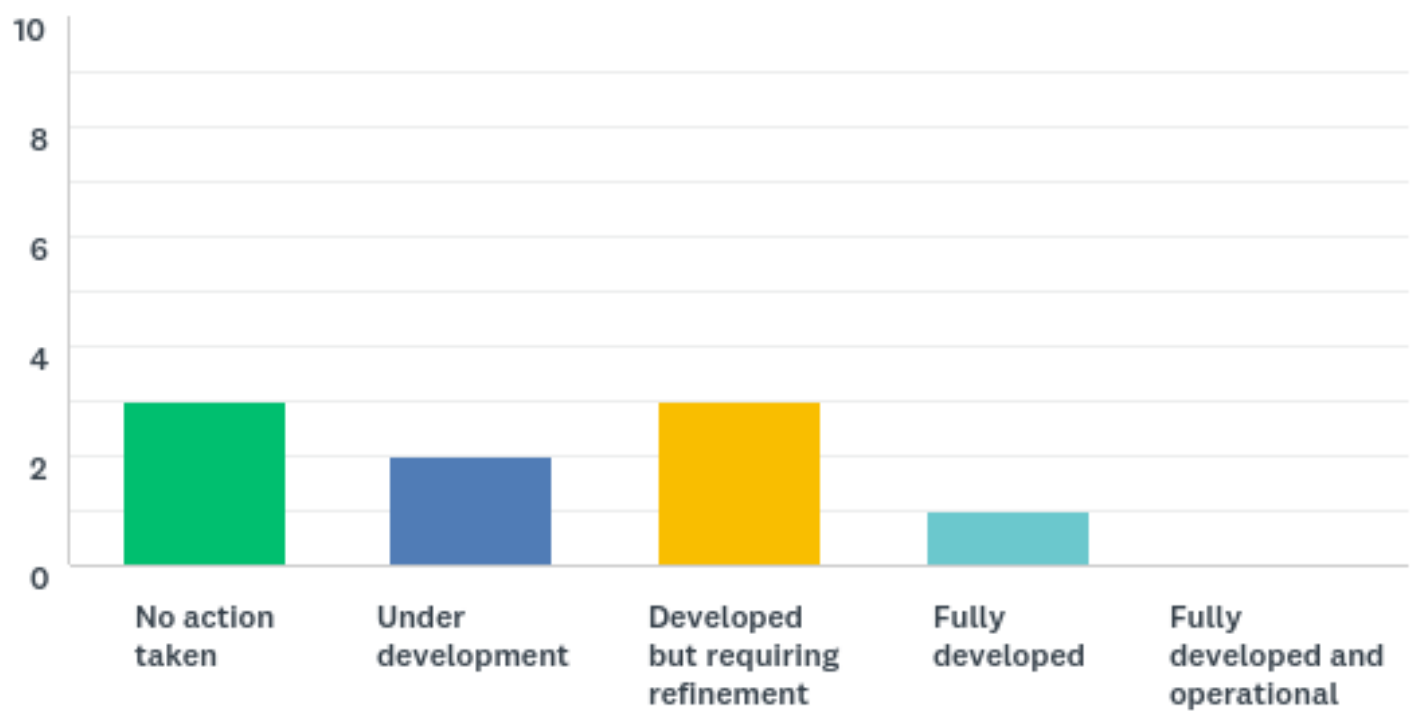

As indicated by Figure 88, a difference of opinion was seen when the Strategic Leads were asked whether children and their carers are being provided with appropriate information about their health rights and whether the information was designed in collaboration with children. One Strategic Lead added that "they were not aware of any collaboration in this respect" [SL5]. 
FIGURE 89: Distribution of health professional respondents who provide health promotion or health rights information by subject categories listed

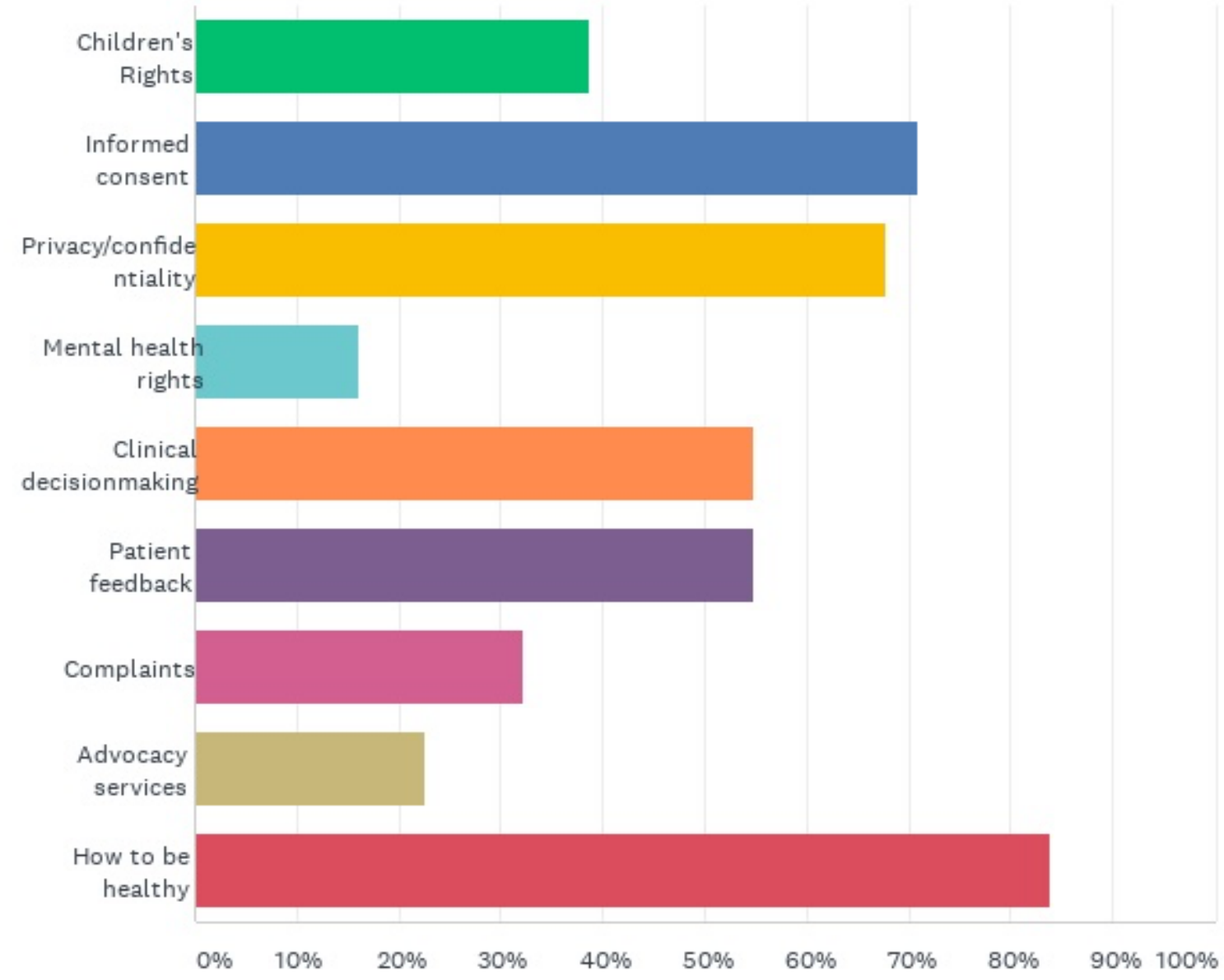

$79 \%$ (26) of the health professionals responded (See Figure 89 above) that they provide children with information regarding 'how to be healthy', $66.7 \%$ (22) provide children information about 'informed consent', $66.6 \%$ (21) 'rights regarding privacy and confidentiality', $51.5 \%$ (17) right to give patient feedback and rights to be involved in clinical decision making. Just over a third $(36.4 \%, 12)$ of health professionals provided general information on children's rights in health care settings and a third $(30.3 \%, 10)$ of health care professionals had ever provided children information regarding the right to complain. Even fewer health professionals $(21.2 \%, 7)$ provided information about other services that the child could access for help (e.g., advocacy, advisory, legal advice). Only $15.2 \%$ (5) of health professionals had provided children information about their mental health rights (See Figure 90).

A surgeon offered additional comments explaining, 
"None formally and not always appropriate in a peri-operative setting but addressed if appropriate on a case by case basis". [HP4]

A nurse clarified that she provides:

"Verbal information only." [HP32]

Other health professionals explained that in order to comply with the Charter there should be,

"Information, resources and access to specialist play therapy. Child friendly information about treatment and informed consent. Information for health professionals regarding mental health for children." [HP11]

This is a small sample of health professionals; however, it may indicate areas where there is need for further research regarding learning what health professionals require to make sure they are themselves providing appropriate information and resources to children.

FIGURE 90: Distribution of young people respondent's responses by where they learn most about being healthy

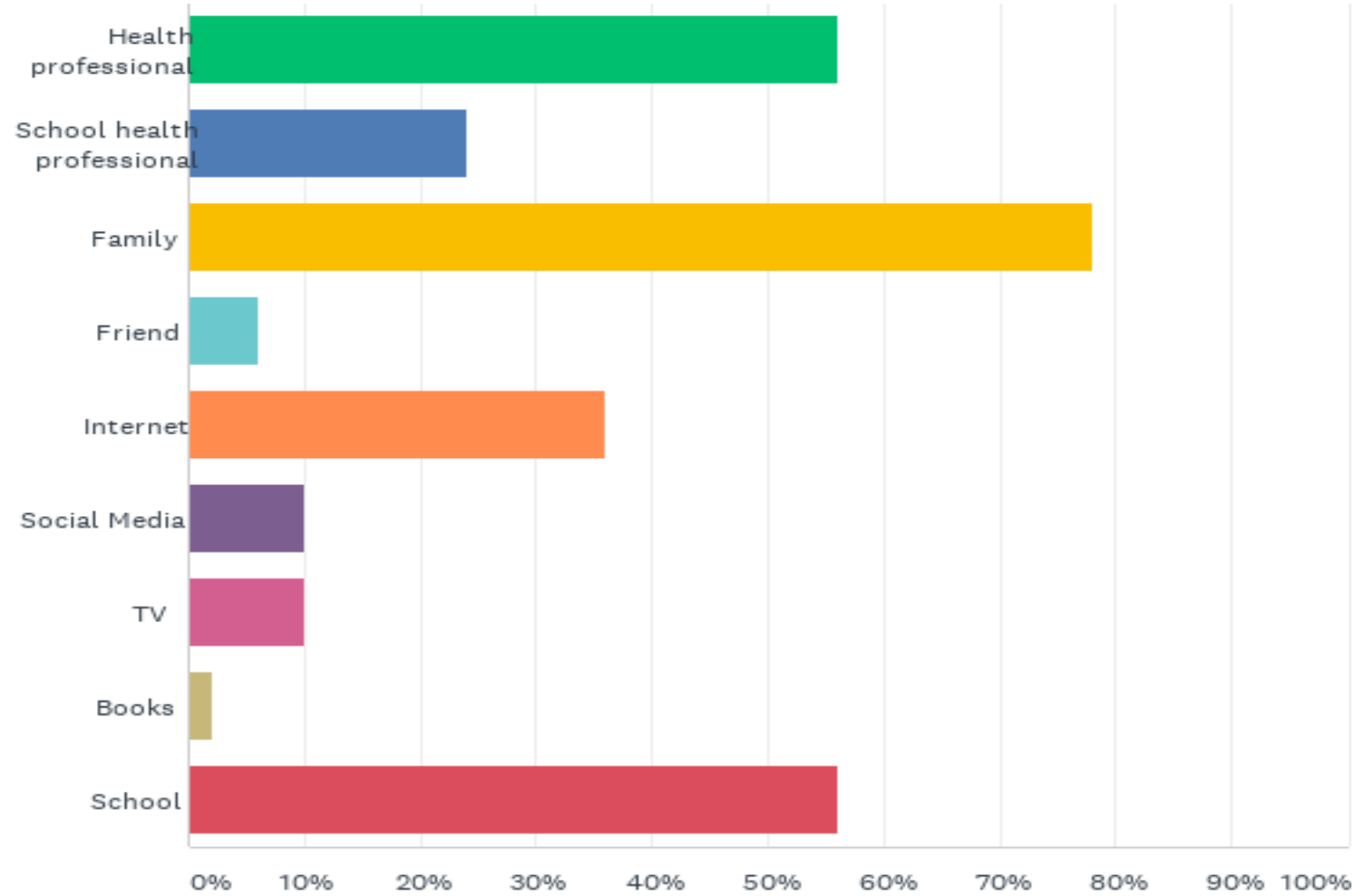


Young people reported that the main places they learned about being healthy were firstly their family $(78 \%, 39)$ secondly school $(56 \%, 28)$ and from a health professional $(56 \%, 28)$ thirdly on the internet $(36 \%, 18)$ and fourthly from a health professional in school $(24 \%, 12)$. Only one young person said from books. There were 5 responses recorded for being healthy from the TV and 5 from other social media.

\subsubsection{Reflections}

These findings indicate that young people in this sample learned about taking action to stay healthy primarily from family members. The Health Board should ensure that parents/carers, young people and children receive copies of the Charter when attending appointments and other resources regarding what the Charter means for children and young people in practice as well as health promotion materials. Also, the Charter and the UNCRC and what both mean for young people in health care settings should be taught in schools across the Health Board area, and health professionals should continue to offer resources and advice to children about what it means to be healthy. Young people thirdly referred to accessing information on the internet and other research demonstrates that young people do actively seek out information online; regarding health and health care matters in their own time and space. ${ }^{1179}$ Over an 18 month period the Children's First for Health website in the UK had 2, 865 hits from children but mostly adolescents on information relating to their health. ${ }^{1180} \mathrm{Health}$ information should be made available to young people in an accessible way on line by the Health Board.

Children and young people should be involved collaboratively in the design of resources so that any resources can be better tailored to their needs. It is essential that children and young people understand what is happening in the health care setting. As mentioned throughout this chapter many younger children are scared and nervous when visiting a doctor or nurse, they should be given opportunities to

\footnotetext{
${ }^{1179}$ Kikelly U, 'Health and Children's Rights', In Vandenhole W, Desmet E, Reynaert D, and Lembrects S (eds) International Handbook of Children's Rights Studies (Routledge 2015) 225

${ }^{1180}$ Franck L, Noble G and McEvoy M. 'Enquiring minds want to know: Topics requested by users of a children's health information website', Patient Education and Counseling (2008) 72, 168-171
} 
understand the consultation and treatment process and how they can better participate.

As an 8 year old girl who lived in Neath-Port Talbot who had visited a doctor or nurse 3 or more times in 2018-19 and answered the survey from her experience of visiting a GP surgery responded,

"leaflets to explain what some wirds mean and when your ill so it easier for me to know whats happen." [C4]

A health professional also commented:

"The wording of the charter on the poster is aimed at the older child and the wording would mean nothing to younger children. It should be made clear that the parent advocates for the child if the child is unable to understand and that the info is therefore given to the parent in that capacity. I am doubtful that a child will read the charter if given in outpatient setting and therefore, is actually aimed at parents?"[HP4]

In autumn 2019 this concern was addressed in part when Swansea Bay Health Board designed a version of the Charter that was more age appropriate for younger children. From attending meetings and conversations with staff, some innovative resources for children have been developed. For example, an innovative video whereby children did a physical journey from their perspective through the children's ward at Morriston Hospital and another video from a child's perspective about going into theatre to have surgery. There is a hope to secure more resources to do more of these short videos to explain how the different services work from a child's perspective. The Head of Nursing is also hoping to secure funding to develop resource materials for all age groups that explain specific elements of the Charter and what it means for children and additionally ensure that these materials are age appropriate, disability and culturally appropriate. A copy of the Charter is also being enclosed in the personal files of disabled child outpatients by community nursing staff.

Since the research was conducted, links have been made with school nursing teams and school nurses have committed to integrate children's rights into their educational strategy for schools by raising awareness of the Charter and children's rights in 
Personal Social Education (PSE) lessons that that they deliver. The Head of Nursing has also delivered training in some of the specialist schools in the Health Board area. However, more funding is required to develop resources and it is incredibly challenging for the Head of Nursing to deliver this kind of support in addition to her current work plan.

\subsection{Conclusion}

It is clear from the above findings and analysis the Health Board has made a good start by making a health authority wide commitment to the UNCRC through adopting a Charter, by delivering some children's rights training to health professionals and by supporting ABM Youth to offer a young person's perspective to the design, monitoring and evaluation of health services delivery. However overall, the findings of the four surveys give a strong indication that there is still a long way to go until all the standards and objectives of a CRA to health services and the Charter guarantees are successfully embedded.

\subsubsection{Future research}

The next step on this journey for the Executive and Non-Executive Board members should be to offer senior level direction and to consider the findings of this research and to agree on a draft plan to implement the standards and objectives of a CRA and the Charter. To continue to monitor progress on the implementation of a CRA the Board should dedicate additional resource to repeat the research in 2021 . The monitoring tools should be amended based on the learning from this research and the research repeated with larger samples of strategic leads, health professionals, children and young people across all health services (not just outpatients) that can generalise into the population as a whole. For the 2021 assessment, a monitoring tool should be developed for 2-6 year olds, children with learning disabilities or cognitive impairment, caregivers and an ethnographic study of the neo-natal ward conducted. There should be more in-depth research that explores:

- Children and young people's experiences of discrimination when interacting with health services. 
- To what degree children and young people's participation in medical decision making is respected and learning from children why they struggle to understand what health professionals are communicating to them.

- Children and young people's experiences of consenting and dissenting to treatment.

- Children and young people's experiences of making complaints.

- Children and young people's experiences regarding their right to privacy being respected or disrespected.

- Children and young people's views on improvements to health services and when their views are collected, monitoring the impact they are having over the design and delivery of services.

- What training support health professionals require in relation to translating a CRA into practice.

- The proportion of expenditure on child health services as compared to adult health services.

\subsubsection{Embedding children's rights: health authority wide commitment, children's rights strategy, children's training, children's rights monitoring}

Throughout the analysis of the findings, it became evident, that much of the focus on the implementation of the Charter and the embedding of a CRA has been focused on acute/hospital-based children's services and not other services that children use. The Strategic Leads consistently commented that the Charter should not be solely for Children's Services but should be the responsibility of the whole organisation. Areas like therapy services, primary care, general surgery, ENT orthopaedic do not sit within Children's Services and yet many children use these services. Strategic Leads were also concerned there has yet been no implementation plan, developed across all health services and recommended that an implementation plan is required. Any plan should strive to implement the standards and the objectives of the CRA across all health services.

There was no clear evidence to demonstrate the proportion of expenditure by the health authority on children and the findings of the case study suggest that only minimum resources have been dedicated to the implementation of a CRA and the 
Charter. There is a critical need to develop a programme of support. This can only be achieved with senior level commitment and core funding. At the time of writing there was not a Non-Executive Champion at Board level to promote compliance with children's rights across the health authority. This position should be reinstated as it will help to harness senior level commitment to children, ensuring children are not invisible and neglected in board level or service level decision making.

It is also evident that communication, awareness raising and indeed training is also required for Strategic Leads, Health Professionals, Young People and Children, so that everyone understands the Charter and what children rights means in practice for them. This was seen to be the most important strategy for implementing the Charter by health professionals. Strategic Leads recommended that education and communication is essential and a Strategic Lead proposed that there should be mandatory children's rights awareness and updates for all staff (including the Executive Board) and a process to monitor its application led by young people. $100 \%$ of health professionals believed children's rights training was the best strategy to implement a CRA. As noted above (see Children's Rights Training section) health professionals also suggested several excellent ideas regarding training and awareness-raising for health professionals on children's rights.

\subsubsection{Accountability to children: children's rights monitoring}

The Health Board could be doing more work to monitor whether children's rights are being respected, protected and fulfilled across health services. As recommended as an objective of a CRA, there should be annual reports that demonstrate how successfully the health authority is meeting children's rights standards and children's rights impact assessments should be used to proof all policies and budgets for compliance with children's rights. Health budgets also need to be transparently monitored for the proportion of expenditure on children. It is also imperative that performance indicators for children's rights are included in all staff job descriptions that impact on children as well as their work plans. 


\subsubsection{Equality and non-discrimination: equality and non-discrimination throughout service delivery}

It is concerning that the research revealed that some young people were being treated unfairly and discriminated against on a range of different grounds. There is a critical requirement to carry out more research and monitoring and to learn whether more young people and children are being discriminated against when interacting with services across the health authority. If further instances are identified, they must be urgently addressed with training for health professionals and a comprehensive programme to eliminate discrimination. Services should also be developed that are children friendly and age-appropriate and consider the needs and human rights of children and young people.

\subsubsection{Participation of children: children's participation in their own health}

It was a positive finding that for the most part, children and young people trusted and perceived health professionals to be friendly. They also believed that health professionals listened to them, gave them the chance to ask questions and help them to choose how to get better. More children and young people responded that they did not always understand what health professionals were saying to them. There is certainly a need as reinforced by other research, for the health authority to consider how they better train their health professionals to communicate with the younger population. There were also a small number of children and young people who believed that they could have been better empowered to participate in medical decision making (as concluded across the range of responses regarding children and young people's participation) as well as young people who believed their rights to consent and right to privacy were not respected or only respected sometimes.

Younger children suggested that they were scared and nervous when visiting doctors and nurses and it is recommended that they are supported with information in advance of appointments and procedures. This indicates that there could be room for improvement and more research to ascertain across a wider sample, to what degree children and young people's participation in medical decision making is guaranteed. 


\subsubsection{Participation of children: children's participation in the monitoring, evaluation and design of service delivery}

Positively, there was evidence of mechanisms that supported child patient feedback. However, this was primarily in-patient or acute services and this case study indicated that the majority of young people had not been asked before for their views on improving a visit to a health professional. Children and young people across the full range of services should be given opportunities to give feedback on their patient experience.

ABM Youth is a pioneering example of a young people collectively offering a young person's perspective on the Health Board's services internally and health services nationally. However, for this structure to continue and to be able to influence in a meaningful way, this structure should become embedded, supported by core funding and integrated into the system of reporting and Health Board decision making.

It was also positive that children were being involved in the recruitment of nursing staff, but it should be extended to the recruitment of all health professionals whose work impacts on children.

\subsubsection{Empowering children: children's rights complaints mechanism}

It is concerning that a number of young people's human rights have been identified as being breached and yet these young people did not know how to complain. A child/young person friendly complaints and advice system must be developed so that children and young people have a mechanism to claim their human rights and to hold health authorities to account. Any mechanism must be designed and coproduced with the children and young people as service users. Health professionals must also be trained in how to support children and young people to use this system. The Health Board must strive to learn from the shortcomings of their organisation and ensure changes are implemented and provide adequate and timely redress to children and young people. 


\subsubsection{Empowering children: health promotion and children's rights information and advocacy for children and carers}

Child and young people friendly information on children's rights and health should be designed in collaboration with children and young people. It is critical that resources are developed that support the specific needs of younger children, older children, children with learning or cognitive impairment, children with other disabilities and children of different ethnic groups. Health professionals need to be supported to be able to effectively share information with children in a format that each child and young person understands. It is unacceptable that not all ethnic minority or special needs are catered for and there are few 'child friendly' versions of documents outside of acute services. All children should have equal opportunities to access information that helps them claim and assert their human rights and information that supports their ability to survive and develop to their maximum potential. There also needs to be more allocated resources for health promotion education and children's rights being taught in education institutions. Children's capacities must be strengthened so they are better able to take advantage of rights, and to engage with, influence and hold accountable those individuals and institutions that affect their lives. It is also essential that children have access to advocacy and professional legal advice at all times.

\subsubsection{A children's rights team}

Further work needs to happen to ensure that the principles, standards and objectives of a CRA to health services and indeed the Charter are fully implemented at ABMU. As suggested above the Health Board needs to first take the opportunity to learn whether in 2021 there has been further progress in achieving a CRA.

However, it is evident from conducting this case study and engaging with the health authority over a three-year period, achieving a CRA requires a commitment to children and to ensuring that dedicated resources are allocated to ensuring children's rights are respected, protected and fulfilled. Instead of health practitioners trying to deliver on a CRA in addition to their day job, a team should be established to deliver the CRA across the health authority. This is one of the objectives of a CRA and it is suggested to respond to the shortcomings and areas for improvement identified in this conclusion, that roles in the team could include: 
- Children's Rights Manager to manage the children's rights team, to coordinate the Children's Strategy Multi-Agency Meetings, to support the Champions to report to the Board on progress on children's rights implementation; to develop a Communication Plan and Implementation Plan regarding the delivery of children's rights across the health authority and commissioned services; to organise the selection of children's rights champions in every service area of the health authority and develop a system of reporting and accountability.

- Children's Rights Researcher with expertise in children's rights to conduct CRA research and analysis and further research on identified areas of concern, to write up annual reports that monitor the health authority's commitment to children's rights; to carry out CRIA's on the development of policy, budgets, service delivery guidelines and commissioned contracts.

- Children's Rights Trainer with expertise in children's rights to develop and deliver training to all health professionals, strategic leads and children and young people across the Health Board area and to develop health promotion materials in collaboration with children and young people.

- A Human Resources Officer to review all job descriptions and work plans for compliance with CRA and the Charter, to ensure children and young people are involved in the recruitment of any strategic lead or health authority professional whose work directly or indirectly impacts on children and young people.

- Children's Rights and Participation expert to consistently gather child patient feedback and compile reports and influence the Health Board to make relevant changes; support ABM Youth to influence the monitoring, evaluation, design of health services delivery and advise on any participatory research to be conducted with children and young people that supports the coproduction of child friendly services and health promotion resources.

- Child Friendly Advice and Complaints Officer to develop a mechanism in collaboration with children and young people, to advertise the mechanism to children and their carers, to sign post children and young people and their carers to other advocacy and advisory services, to educate health professionals and children regarding how to use the child friendly advice and complaints system. 


\section{CHAPTER 10 CONCLUSION}

\subsection{Introduction}

This thesis set out to consider what should be included in a CRA for health services in the Welsh context. The thesis reviewed the literature, the international human rights framework and its jurisprudence and the policy and legislative environment in Wales, to develop a principled and practical conceptual framework that was best suited to the Welsh context. From this detailed review, monitoring tools were developed to test a health authority's institutional approach to implementing a CRA. Using ABMU Health Board as the case study, it demonstrated how the monitoring tools can be successfully used to gain a base line understanding of how far a CRA has been embedded in health services and what strategies were required to make a CRA fully operational.

The tools were determined to be effective non-resource intensive methods (with some minor amendments) that can be used to test a health board's progress on implementing a CRA. The results of the primary research also presented opportunity for reflections, regarding how to better embed a CRA to health services as well as recommendations regarding future research. Based on the findings of the ABMU Case Study (what was the largest health board in Wales), it is reasonable to question whether other health boards in Wales and possibly in the UK more widely, are properly implementing children's rights and/or applying a CRA to health services. In order to provide further evidence on this issue, it would be advantageous to carry out a Waleswide study using the tools developed for this thesis. This would not only provide additional insights into progress (or lack of) on children's rights in the context of health services in Wales but would also provide an opportunity to disseminate a fully justified CRA to health service providers to support implementation of children's rights, accompanied by appropriate monitoring and evaluation tools.

This final chapter seeks to summarise some critical and transferrable lessons from the research. While recognising that many of the issues dealt with in preceding chapters may be context specific, there are many issues that are likely to arise for other health boards seeking to give effect to children's rights. In discussions with health partners for this research, they requested that the main findings be summarised as succinctly as possible so that they can be easily communicated to health colleagues within 
$A B M U$ and may be disseminated to other health partners. Therefore, this final section draws together critical reflections in three key areas (from the literature and the international human rights framework discussed in Part 1, and the ABMU case study in Part 2). These reflections provide transferrable learning for health authorities striving to realise children's rights in health services.

\subsection{Critical reflections}

\subsubsection{The national policy and legislative environment needs to support a children's rights approach}

Wales is attempting through policy and law reform to address the socioeconomic determinants of poor child health and child health inequalities. The right to health is a fundamental human right. It is an inclusive right which includes not only the right to health services, but to a wide range of factors e.g., services, resources, information, advice, that help children achieve the highest attainable standard of health. Achievement of the right is also influenced by wider social determinants, i.e., the conditions in which we are born, we grow and age and in which we live and work. The evidence reviewed for this thesis relating to these factors and determinants in Wales (See Chapter 5) presents challenges for many children who face health inequality and whose rights under the UNCRC are not guaranteed.

Post 2011, a focus on children became lost as part of the agenda for integrated service provision for children and adults and resources were not being sufficiently assigned to tackle the full range of children's rights violations. ${ }^{1181}$ Fiscal austerity increased public expenditure cuts, with funding that was often short-term and opportunistic and vulnerable to political re-prioritisation. There has also been a longer history of insignificant priority given to ring fencing funding for children's services (See Chapter 5). In Wales there is an inadequate paediatric workforce, with there being a shortfall of 74 paediatric consultants and insufficient investment in the paediatric academic workforce. ${ }^{1182}$ Additionally, there has been a continued trend of providing insufficient

\footnotetext{
${ }^{1181}$ Croke R and Williams J (eds) Wales UNCRC Monitoring Group report to the UN Committee on the Rights of the Child (Swansea University 2015)

1182 Royal College of Paediatrics and Child Health, Facing the Future: Standards for Paediatric Services (RCPCH 2010)
} 
investment in community child health ${ }^{1183}$ (See Chapter 5). This raises concerns when the Strategic Leads in the ABMU Case study suggested that there is need for a CRA to be embedded in the community and across the full range of health services (See Chapter 9). This can only happen with additional resources for implementation.

Where there are general health policies much more could be done to ensure integration and application to the importance of children's rights. The $\mathrm{RCPCH}$ commented in 2017 there should be an overarching evidenced based strategy for children's health and well-being that covers all of childhood. ${ }^{1184}$ The RCPCH also argue that there should be a 'Child health in all policies' approach to decision-making, policy making and service design'. However, as suggested in Chapter 5 , there instead needs to be a CRA to all policy decision-making and service design, and an overarching strategy for children's rights, with health and well-being an indivisible part of such an approach.

A CRA to health aims to support better and more sustainable outcomes for children by addressing the roots of inequalities, discriminatory practices and unjust power relationships which are at the root of challenges to children's rights in relation to health services. A CRA emphasises that the ultimate goal of all health policies, strategies and programmes should be to further advance the realisation of the right to the highest attainable standard of health and other related and inter-connected children's rights, as guaranteed by international human rights law. Health policy making and programming should be guided by children's rights standards and should aim to develop the capacity of those delivering health services to meet their obligations and aim to empower children as rights-holders to effectively claim their human rights. Once the concept of empowerment is introduced into the context of policymaking, the rationale of eliminating health inequality no longer derives merely from the fact that children facing health inequalities have needs, but also from the fact that they have human rights-entitlements that give rise to legal obligations on the part of duty bearers. The children's rights perspective which is made manifest in a CRA draws attention to the fact that health inequalities confirm incomplete realisation of human

${ }^{1183}$ Royal College of Paediatrics and Child Health and British Association for Community Child Health, Covering all bases - Community Child Health: A paediatric workforce guide (RCPCH 2017)

${ }^{1184}$ Royal College of Paediatrics (2017) State of Child Health: 2017 Recommendations for Wales 
rights, so that the adoption of public health or child health strategies, that aim to reduce health inequality is not just desirable but obligatory for delivery agents active in States which have ratified international human rights instruments, including the UNCRC. ${ }^{1185}$

The UN Committee on the Rights of the Child and the UN Committee on Economic, Social and Cultural Rights have issued General Comments relating to the right to the highest attainable standard of health. Both emphasise the importance of preventative, timely and appropriate health care, the importance of responding to the underlying determinants of health and coordinated multi-agency action to effectively realize the right to health (See Chapter 2, 6, 9). Similarly, General Comments explain that the four elements of Availability, Accessibility, Acceptability and Quality (AAAQ) are essential to the enjoyment of the right to health by all children (See Chapters 2 and 6). There should be 'functioning children's health facilities, goods, services and programmes in sufficient quantity'1186, made accessible to all children without discrimination ${ }^{1187}$, and services should be designed to take full account of children's needs and reach especially vulnerable groups of children. ${ }^{1188}$ Implementing a CRA would help to ensure that all these essential priorities are met.

Wales is committed to striving towards 'a society in which people's physical and mental well-being is maximised and in which choices and behaviours that benefit future health are understood.'1189 With regards to the international human rights framework's interpretation of the right to health, the majority of policies in Wales do address some of the important aspects of prevention and the social determinants of health, but none of the policies go far enough to integrate other important aspects of a CRA, i.e. empowering the child, service accountability to children and enforcement of socio-

\footnotetext{
${ }^{1185}$ Text in this paragraph has been adapted from the OHCHR Principles and Guidelines for a human rights based approach to poverty reduction (HR/PUB/06/12 2004) para 19 to make it pertinent to health inequalities

${ }^{1186}$ UN Committee on the Rights of the Child, General Comment No. 15 on the right of the child to the enjoyment of the highest attainable standard of hth $\mathrm{CRC} / \mathrm{C} / \mathrm{GC} / 15$ para 113

${ }^{1187}$ UN Committee on the Rights of the Child, General Comment No. 15 on the right of the child to the enjoyment of the highest attainable standard of $h \mathrm{CRC} / \mathrm{C} / \mathrm{GC} / 15$ para $114 \mathrm{a}, \mathrm{b}, \mathrm{c}, \mathrm{d}$

${ }^{1188}$ UN Committee on the Rights of the Child, General Comment No. 15 on the right of the child to the enjoyment of the highest attainable standard of hth $\mathrm{CRC} / \mathrm{C} / \mathrm{GC} / 15$ para 115

${ }^{1189}$ The Well-Being and Future Generations Act (Wales). 2015 Goal 2.

http://www.legislation.gov.uk/anaw/2015/2/contents/enacted accessed on 22 December 2020)
} 
economic rights. Wales does not currently have the strength of the accountability framework of the international human rights framework that visualises access to quality health services in terms of enforceable social and economic rights and does not sufficiently address how children can be empowered to claim their health rights. A CRA would help to ensure that all service delivery efforts are anchored in a system of human rights and corresponding obligations established by international human rights law. A CRA presents a mechanism to ensure a consistent approach to implementation of the UNCRC across health bodies.

LHBs need more direction and guidance on their obligations and to be held to account to ensure children's rights become integral to their decision making. This thesis reflected on Tobin's interpretation of a CRA which argues that there is a necessity to have a clear conceptual framework based on a principled approach and to demonstrate explicitly their connection to the international human rights treaties ${ }^{1190}$ and Darrow et al's approach that argued that there should be a seamless link between principles, standards and objectives with regards to achieving implementation ${ }^{1191}$ (See Chapter 3 ). This serves to create a balance between legalising human rights norms so that duty bearers can be held to account and challenged to address human rights violations but also capture in a simple and accessible way through principles the 'underlying values and spirit of the law' to become more central to an institution's decision-making process. ${ }^{1192}$

It is a positive development that Wales has passed legislation in the form of the WellBeing and Future Generations Act 2015, with clear commitments to health and equality. Furthermore, building on the CRA research and guide developed by Hoffman and Croke, the Children's Commissioner for Wales and the Future Generations Commissioner for Wales have developed guidance for public bodies regarding a CRA to the implementation of the Well-Being goals. The guidance provides practical tools

\footnotetext{
${ }^{1190}$ Tobin J, 'Understanding a human rights based approach to matters involving children: conceptual foundations and strategic considerations,' In Invernizzi A and Williams J (eds) The Human Rights of Children: From Visions to Implementation (Farnham: Ashgate 2011)

${ }^{1191}$ Darrow, Mac and Tomas, Amparo 'Power, Capture, and Conflict: A Call for Human Rights Accountability in Development Cooperation', Human Rights Quarterly 2005

${ }^{1192}$ Sadeleer N, Environmental principles; from political slogans to legal rules (Oxford University Press 2002) 234
} 
and examples to help public bodies consider children's rights across each of the wellbeing goals and the five ways of working under the Well-Being of Future Generations Act. ${ }^{1193}$ The ABMU Health Case Study is included as an example of a health board making strides in relation to children's rights and the well-being goal in relation to health. ${ }^{1194}$ In addition, the work on Adverse Childhood Experiences has been recognised as a priority for action by the Future Generations Commissioner with the focus on improving the well-being of future generations by preventing harm in early childhood. ${ }^{1195}$ The guidance recommends that Public Service Boards (PSB) should pay due regard to the CRC when addressing the Well-Being Goals and in the development of their Well-Being Plans. The importance of prioritising children when a PSB considers the implementation of the Well-Being goals is emphasised, as well as envisioning children as rights holders with the capabilities to take advantage of their human rights. ${ }^{1196}$ This is a significant and positive step towards helping public bodies to consider children in the context of the health and well-being objectives. However, framing the Well Being legislation in terms of well-being objectives and not enforceable human rights does not help in strengthening the legal enforceability of children's health rights. Similarly, Kilkelly with reference to the international Sustainable Development Goals which also makes commitments to health and inequality (SDG Goal 3) expresses disappointment that they are not articulated as legal rights and describes this as a 'missed opportunity'. ${ }^{197}$

Furthermore, although it is also positive that legislation in the form of the Rights of Children and Young Persons (Wales) Measure 2011 has been passed that requires Welsh Ministers to have due regard to the rights of the child in the exercise of all their functions; the duty of due regard does not extend to other public bodies in Wales. In

\footnotetext{
${ }^{1193}$ Children's Commissioner for Wales and Future Generations Commissioner, The Right Way: A Wales Future Fit for Children 2017 https://www.childrensrightsplanning.wales/wpcontent/uploads/2018/06/CCFW-FGCW-Report-_English_01.pdf accessed on 21 December 2020. ${ }^{1194}$ Ibid.

${ }^{1195}$ Wallace J, 'Wales: Wellbeing as Sustainable Development,' In Well-Being and Devolution: Reframing the Role of Government in Scotland, Wales and Northern Ireland (Cham: Palgrave Pivot 2019) 73-101.

${ }^{1196}$ Children's Commissioner for Wales and Future Generations Commissioner, The Right Way: A Wales Future Fit for Children 2017 https://www.childrensrightsplanning.wales/wpcontent/uploads/2018/06/CCFW-FGCW-Report- English 01.pdf accessed on 21 December 2020. ${ }^{1197}$ Kilkelly U, Health rights of Children. In The Oxford Handbook of Children's Rights. Edited by Jonathan Todres and Shani M. King. Oxford: Oxford University Press, 378
} 
Chapter 6, it was recommended that there should be a public sector duty placed on all public authorities (including health authorities) to have due regard to the UNCRC, with dedicated resources that make its implementation possible. Without this domestic legal requirement, it will certainly be more challenging to secure senior level commitment from health boards across Wales to have due regard to the UNCRC. Adding a legal requirement will make it more likely that health boards, will look for guidance on how to discharge their duty and furthermore, presents the opportunity to introduce CRA across health bodies in Wales. The research presented in this thesis provides the mechanism by which 'due regard' can be implemented by health bodies, as well as the tools to monitor and evaluate its implementation.

An obligation to have due regard to the UNCRC in relation to health services could be further underpinned by a requirement that each health board introduce Children's Schemes, similar to the Children's Scheme under the Rights Measure (see Chapter 5 ) which would compel them to develop arrangements for discharging this duty. Having a legal requirement is essential to raising the status of the UNCRC and to ensure that obligations to the UNCRC are better met. An obligatory Children's Scheme at health board level, like WG Children's Scheme could also be developed according to the 5 principles of a CRA, with standards and objectives aligned to each principle as suggested by the conceptual framework for a CRA in Chapter 6 . It will help to ensure that senior level management deliver a corporate-wide approach to the UNCRC.

A National Inquiry into Children's Rights led by the Welsh Parliament Children and Young People and Education Committee in 2020 reported that children's rights across Wales were still not being realised. ${ }^{1198}$ As a result of the research undertaken for this thesis and confirmed through further evidence collated for the Inquiry on behalf of the Children's Hospital for Wales Research Unit; it was concluded that there is limited consideration of children's rights in health policy decision making and often a lack of

\footnotetext{
${ }^{1198}$ Welsh Parliament, National Inquiry into Children's Rights 2020 https://senedd.wales/laid\%20documents/cr-ld13405-r/cr-ld13405-r-e.pdf accessed on 10 December 2020
} 
compliance with the Rights of Children and Young Persons (Wales) Measure 2011. ${ }^{1199}$ On this basis, in addition to a duty of due regard to be placed on public bodies, the introduction of a compliance duty was proposed to strengthen legal enforceability of children's rights in Wales. This means that all public bodies in Wales would have to comply with the principles and provisions of the UNCRC. ${ }^{1200}$ A compliance duty is similar to the duty to act compatibly with the ECHR (Section 3 (1) Human Rights Act 1998). Kilkelly argues that 'indirect incorporation falls short of giving substantive protection to children's rights at a constitutional level.' ${ }^{1201}$ However, she suggests that 'relatively weak measures of implementation can help to build momentum in favour of stronger measures'. ${ }^{1202}$ This has been observed in both Scotland and Sweden with both countries having recently directly incorporated the UNCRC. A compliance duty was supported by the Children's Commissioner for Wales who also gave evidence to the National Children's Rights Inquiry. ${ }^{1203}$ Positively, the Welsh Government in a plenary debate in 2021 reported that they were in the process of strengthening equality and human rights legislation. ${ }^{1204}$

\subsubsection{Embedding a CRA requires leadership, commitment to children's rights training and allocation of resources}

This top-down approach needs to be supported by health professionals and managers at service delivery level, understanding how to apply a CRA to their work. Research in this thesis into the realisation of a CRA illustrated that much more needs to be done with regards to educating and developing the capacity of health professionals and

\footnotetext{
${ }^{1199}$ Connor, $\mathrm{P}$, Croke R*, Thomas-Turner R, Access to medicines and good quality paediatric research: children's human rights implications and considerations for the Welsh context (September 2019)http://senedd.assembly.wales/mgIssueHistoryHome.aspx?IId=25724 accessed January 2020

${ }^{1200}$ Connor P, Croke R*, Edwards M, Thomas-Turner R, and Tuthill D, "Submission to the Senedd Children and Young People Education Committee in advance of the Senedd's Plenary Debate on Children's Rights", November $5^{\text {th }} 2020$ Available online: https://business.senedd.wales/documents/s109280/Additional\%20information\%20from\%20Noahs\%20Ark $\% 2$ accessed February 172021

${ }^{1201}$ Kilkelly U, 'The UN convention on the rights of the child: Incremental and transformative approaches to legal implementation', The International Journal of Human Rights 2320197

1202 Ibid 327

${ }^{1203}$ Children's Commissioner for Wales, Children's Rights Inquiry Response 5th November 2020 https://business.senedd.wales/documents/s109281/Additional\%20information $\% 20$ from $\% 20$ Childrens $\% 20$ Commissioner $\% 20$ for $\% 20$ Wales $\% 20$ regarding $\% 20$ Welsh $\% 20$ Governments $\% 20$ response $\% 20$.pdf accessed on 2 March 2021

${ }^{1204}$ Welsh Parliament, Record of Proceedings. January $20^{\text {th }} 2021$

https://record.assembly.wales/Plenary/11172 accessed on 3 February 2021.
} 
managers to effectively embed and implement it. The adoption of charters by ABMU and other health authorities globally, is a good first step but without a commitment to raising awareness of children's rights and in-depth training regarding how health professionals and strategic leads can apply it to their work, it is impossible for a CRA to become embedded. As one Strategic Lead commented, "Although we have the Children's Rights Charter it is not fully embedded in all policy statements/documents throughout the organisation" [SL8] and a health professional also stated, "I would like to know about the continuing growth of the Charter and I am keen to know further information about embedding children's rights in everything we do" [HP18].

As Tosten argues the entire organisation needs to have the 'requisite skills to infuse every intervention with a child rights perspective'1205 and as an evaluation of UNICEF revealed; senior leadership and staff who truly believed the value of a CRA to their work internalised and successfully applied it. ${ }^{1206}$ As health professionals advocated in the ABMU case study children's rights must become everybody's responsibility (See Chapter 9).

The UN Rapporteur for Health Paul Hunt suggests it is impossible for health professionals/managers to understand complex legal provisions and apply them in practice; they need practical guidance and support ${ }^{1207}$ and as the UN Committee on the Rights of the Child recommends, children's rights should be included in health curricula ${ }^{1208}$ and continuing professional development. ${ }^{1209}$ Strategic Leads and Health professionals were both in agreement in the ABMU Case study that education, communication and training is essential in helping professionals to understand how to embed a CRA in practice.

\footnotetext{
1205 Tostensen A, Stokke H, Trygged S and Halvorsen K, Supporting Child Rights: Synthesis of Lessons Learned in Four Countries (SIDA 2011), 96

${ }^{1206}$ Vandenhole W, 'Failures and Successes of Human Rights-Based Approaches to Development: Towards a Change Perspective, Nordic Journal of Human Rights, 2014 Vol. 32

${ }^{1207}$ Hunt P, 'Interpreting the International Right to Health in a Human Rights-Based Approach to Health', Health and Human Rights Journal 2016 Dec 18(2) 115

${ }^{1208}$ UN Committee on the Rights of the Child (2013) General Comment No. 15 on the right of the child to the enjoyment of the highest attainable standard of health $\mathrm{CRC} / \mathrm{C} / 15 / 2013$

${ }^{1209}$ Williams J, 'The Role of the Professions in Effective Implementation of the CRC', In (eds) Liefaard T and Sloth-Nielsen J (eds) The United Nations Convention on the Rights of the Child: Taking Stock After 25 years (Brill Publishing 2017).
} 
As reported in Chapter 9, one Strategic Lead proposed there should be, "Mandatory children's rights awareness training \& updates for all staff including Executive Board and a process to monitor application that is led by young people" [SL5]. $100 \%$ of the health professionals believed that children's rights training would be the best tool to effectively implement a CRA. Training of health professionals is an important aspect of delivering on the commitment of Article 42 of the UNCRC. Revisiting the CRA guidance developed with Hoffman and Croke, for the Children's Commissioner for Wales in 2016, a CRA based on five principles is helpful to support implementation of children's rights but does not go far enough to specify action in key areas, such as training (See Chapter 6). More is required to help practitioners and managers to understand the explicit connections to the international human rights treaties (in particular, the UNCRC) so that they can better understand how to deliver their obligation to respect, protect and fulfil children's rights in day-to-day practice. While this is implicit in, e.g., the embedding principle, it must be noted that this (and indeed other principles) require practitioners to determine how best to take account of the principle, including through the allocation of resources, training and day-to-day practices. This is not suggested as a weakness of the proposed CRA, but rather as a reality which accompanies implementation of children's rights, i.e., that implementation is complex and multi-faceted.

In response to the National Children's Rights Inquiry by the Welsh Parliament's Children and Young People and Education Committee, the then WG Deputy Health and Social Services Minister committed to make children's rights training mandatory for Welsh Government officials and Ministers in their exercise of their duty to have due regard to the Convention nationally. ${ }^{1210}$ As recommended by the standards of a CRA, it would introduce consistency across all public services, if training was made mandatory for all public sector workers, including health professionals and managers, whose work directly or indirectly impacts on children. Alongside this, performance indicators, workplans and job descriptions should include children's rights standards. ABMU have already adopted this approach for their nursing staff (See Chapter 9). It is important that this extends to health professionals across Wales so that children's

\footnotetext{
${ }^{1210}$ National Assembly Children and Young People Education Committee Children's Rights Inquiry, Evidence Session with Deputy Minister for Health and Social Services November $6^{\text {th }} 2019$
} 
rights standards are integral to how each professional performs their role. As Williams argues, the 'CRC should be internalised in professional culture so that professionals absorb the value and requirements of the Convention. ${ }^{1211}$ London argues ethics codes for health professionals must integrate stronger human rights language. ${ }^{1212}$ The Welsh Government when exercising their functions regarding regulation of the professions, (including medical practitioners) should give due regard to the Convention and consider how the medical profession can have a more positive impact on children's rights. ${ }^{1213}$

Lessons learned from across the research and the ABMU Case study, indicated that without senior level commitment and champions for human rights at Executive and Non-Executive level it is very challenging to create a culture that embeds a CRA. $A B M U$ who had pledged their commitment to the UNCRC, did not have a NonExecutive Champion for children at board decision making level. As a Strategic Lead argued "Community services and children's centres etc. would benefit from champions i.e., greater support to embed this [SL4]." This, according to research undertaken by the $\mathrm{RCPCH}$ in 2019, is also the case for 4 out of the 7 Welsh health boards, that also did not have a Non-Executive Champion for children's rights. ${ }^{1214}$ This certainly reduces opportunities for children to have their voices heard and their human rights respected in health authority decision making. There also needs to be a team of staff in each health board (outlined as an objective of the conceptual framework and further discussed in Chapter 9) that can support a CRA to become embedded. This all requires dedicated resource allocation.

\footnotetext{
${ }^{1211}$ Williams J, 'The Role of the Professions in Effective Implementation of the CRC', In (eds) Liefaard T and Sloth-Nielsen J (eds) The United Nations Convention on the Rights of the Child: Taking Stock After 25 years (Brill Publishing 2017).

${ }^{1212}$ London L 'What is a human rights based approach to health and does it matter?' Health and Human rights (2008) vol. 10, no. 1

${ }^{1213}$ Williams J, 'The Role of the Professions in Effective Implementation of the CRC', In (eds) Liefaard T and Sloth-Nielsen J (eds) The United Nations Convention on the Rights of the Child: Taking Stock After 25 years (Brill Publishing 2017).

${ }^{1214}$ Workforce census: Focus on Wales (2019) Royal College of Paediatrics and Child Health (2019) An Executive Summary https://www.rcpch.ac.uk/resources/workforce-census-focus-wales2019\#downloadBox accessed January 2020
} 


\subsubsection{Children must no longer be invisible, neglected or devalued in health care decision making}

Children's rights champions will help to communicate and represent children's voices in health care decision making. However, health boards that do not have youth advisory groups and children integrally involved in the monitoring and evaluation of service delivery through children's rights impact assessments, patient feedback processes, or effective child friendly complaints systems are inadvertently creating a culture whereby children's voices and opinions are neglected and devalued. Charles and Haines comment that 'children's voices are still not universally heard in policy and operational discourses'. ${ }^{1215}$ As Wall argues, children remain the poorest and most exploited social group because they are not given equal opportunity to participate in decisions that impact on them. ${ }^{1216}$ Liebel explains that children experience discrimination, because they are 'prevented from having equal status, equal access to resources, equal access to decision-making, or to exercising rights in an equal manner' simply because they belong to a social group categorised as 'children'1217 Webb comments that children can be relegated to the status of non-persons, not even seen as the part of core business or service.1218 Denburg et al report that 'social spending in a broad cross-section of advanced nations tilts heavily toward older populations and away from children'. ${ }^{1219}$ These factors can have a significant bearing on the allocation of resources with as Kennedy argues, adult services often being prioritised over children's services. ${ }^{1220}$

One of the Well-Being and Future Generations Act 2015 seven goals is for a more equal Wales, a 'society that enables people to fulfil their potential whatever their

\footnotetext{
${ }^{1215}$ Charles A and Haines K, 'Engaging young people as partners for change: The UR Community Project', The International Journal of Children's Rights, Volume 27: Issue 116 February 2019

${ }^{1216}$ Wall J, 'Democratising democracy: the road from women to children's suffrage', International Journal Human Rights: Vol 18 (2014) Issue 6

${ }^{1217}$ Liebel M, 'Adultism and Age Based Discrimination against children' In, Kutsar D and Warming $\mathrm{H}$ (eds) Children and non-discrimination, inter-disciplinary textbook (University of Estonia press 2014) 120

${ }^{1218}$ Webb E, 'An exploration of the discrimination-rights dynamic', In Invernizzi A and Williams J (eds) The Human Rights of Children: From Visions to Implementation (Farnham: Ashgate 2011)

${ }^{1219}$ Denburg AE, Giacomini M, Ungar WJ, Abelson J. 'The Moral Foundations of Child Health and Social Policies: A Critical Interpretive Synthesis'. Children. 2021; 8(1):43

${ }^{1220}$ Kennedy I Getting it right for children and young people: Overcoming cultural barriers in the NHS so as to meet their needs (Department of Health 2010) 8
} 
background or circumstances'. ${ }^{1221}$ A good starting point would be to invest equally in children as compared to older populations. Additionally, if children were better included in decisions about health service delivery, then perhaps, we would see better allocation of resources to children, instead of a pattern of health policy making favouring adult services (See Chapter 5).

This also requires, as the UN Committee on the Rights of the Child strongly recommends a commitment from duty bearers to clearly and transparently demonstrate their proportion of expenditure on children. It is a specific requirement of the UN Committee on the Rights of the Child, in General comment No. 5 on the General Measures of Implementation ${ }^{1222}$, General Comment No. 14 on Best Interests ${ }^{1223}$, General comment No. 15 on the Right to Health ${ }^{1224}$, and most recently in General Comment No. 19 on Public Budgeting. ${ }^{1225}$ Budgetary decisions must be consistently assessed for compliance with the UNCRC. Detailed CRIAs of all health budgets would demonstrate how they are having a positive or a negative impact on children's rights in health. Under Article 4 of the UNCRC, duty bearers have a clear obligation to demonstrate whether they're fulfilling children's rights to health to the maximum extent of available resources. Transparent evidence on spending on children in relation to health is an essential tool in both meeting this obligation and evidencing how planned spending and indeed spending cuts are impacting on the health outcomes for children. ${ }^{1226}$ Budgets that impact on children should be consistently assessed for their impact on children and their rights. As was made clear by the ABMU Case Study, it is not clear what the proportion of spending is on children as compared to the adult population, and if children are being discriminated against or not in budgetary decision making (See Chapter 9). Adopting the principles and standards of a CRA (see Chapter 6: conceptual framework) will encourage services

\footnotetext{
${ }^{1221}$ The Well-Being and Future Generations Act (Wales) 2015 Goal 3, http://www.legislation.gov.uk/anaw/2015/2/contents/enacted accessed on 22 December 2020 ${ }^{1222}$ UN Committee on the Rights of the Child, General Comment No. 5 General Measures of Implementation of the Convention on the Rights of the Child $\mathrm{CRC} / \mathrm{C} / \mathrm{GC} / 5 / 2003$

${ }^{1223}$ UN Committee on the Rights of the Child, General Comment No. 14 on the right of the child to have his or her best interests taken as a primary consideration $\mathrm{CRC} / \mathrm{C} / \mathrm{GC} / 14 / 2013$

${ }^{1224} \mathrm{UN}$ Committee on the Rights of the Child, General Comment No.15 on the right of the child to the enjoyment of the highest attainable standard of health $\mathrm{CRC} / \mathrm{C} / \mathrm{GC} / 15 / 2013$

${ }^{1225}$ UN Committee on the Rights of the Child, General Comment No.19 on public budgeting for the realization of children's rights $\mathrm{CRC} / \mathrm{C} / \mathrm{GC} / 19 / 2016$

1226 Ibid
} 
to monitor spending on children and be more accountable to respect, protect and fulfil their rights.

As already mentioned, CRIAs are an important part of any CRA, planning in advance how policies and services positively or negatively impact on children and are strongly recommended by the UN Committee on the Rights of the Child. ${ }^{1227}$ CRIA allows the impact of policies and programmes on children to be predicted, monitored and, if necessary, avoided or mitigated, or indeed strengthened. These have been implemented at the national level via the WG Children's Scheme ${ }^{1228}$, but have not yet been adopted consistently by other public bodies or indeed ABMU (See Chapter 9). The Children's Commissioner for Wales has produced a standard CRIA for public bodies. ${ }^{1229}$ If CRIA's were adopted by all public bodies as recommended by the CRA, it would help to make children more visible in all public body decision making. CRIA's also require that children themselves are consulted as part of the process of considering any impact on children.

An important aspect of the CRA is to ensure that children are able to participate in all decision making that affects them. The WG Prudent Health Care Principles state that the public must be equal partners through co-production in health services delivery. In a UK Parliamentary Review of Health and Social Care Services in Wales, 2018, they recommended:

Put the people in control strengthen individual and community involvement, through voice and control in health and care, and ensuring all ages and communities have equal involvement. The public rightly want a modern

\footnotetext{
${ }^{1227}$ UN Committee on the Rights of the Child, General Comment No.15 on the right of the child to the enjoyment of the highest attainable standard of health CRC/C/15/2013 106, para $106 \mathrm{~d}$, UN Committee on the Rights of the Child, General Comment No. 14 on the right of the child to have his or her best interests taken as a primary consideration $\mathrm{CRC} / \mathrm{C} / \mathrm{GC} / 14 / 2013$ para 35; UN Committee on the Rights of the Child, General Comment No. 5 on the General Measures of Implementation $\mathrm{CRC} / \mathrm{C} / \mathrm{GC} / 5 / 2003$ para 45

${ }^{1228}$ Welsh Government, Children's Rights Scheme (Welsh Government 2014) https://senedd.wales/Laid\%20Documents/GEN-LD9732\%20\%20Children's\%20Rights\%20Scheme\%202014-22042014-255569/gen-ld9732-e-English.pdf accessed February 102021

${ }^{1229}$ Children's Commissioner for Wales, Children's Rights Impact Assessment. n.d. Available online: https://www.childcomwales.org.uk/resources/childrens-rights-approach/right-way-childrensrights-approach-wales/ (accessed on 6 December 2020)
} 
service in which they have much better information about health and care, shared decision making in treatment, choice of care and setting, and peer support. ${ }^{1230}$

However, as was outlined in Chapter 4, children in Wales are not consistently asked for their perspective regarding their experience of being a patient. ${ }^{1231}$ Similarly in Europe, the CoE study found that the majority of children had never been asked for their views on their patient experience or health policy making. ${ }^{1232}$ With regards to children's primary care experience in England and Wales, children under-16 years do not get asked their views in patient experience surveys. The majority of young people in the ABMU case study had also not been asked their views on their experience of visiting a health professional (See Chapter 9). However, it is positive that ABM Youth Advisory group has been established to influence health services delivery and there has been the introduction of child patient feedback processes, but these need further resource to become an embedded and integral part of health board decision making (See Chapter 9).

One of the standards of a CRA, is to ensure that children are not discriminated against throughout health services delivery. However, the ABMU Case study and other research in this thesis has reported that children as a group face discrimination as well as specific groups of children (see Chapter 4, 6 and Chapter 9). A Strategic lead commented that, "Not all ethnic minority or special needs are catered for and few 'child friendly' versions of documents outside of acute services" [SL5]. The UN Committee on the Rights of the Child explain that 'children's needs, expectations, cultures, views and languages,' must be taken into account when delivering services. ${ }^{1233}$ Children should be given equal opportunities to engage with health services and not be discriminated on any grounds (Article 2 of the UNCRC). It was therefore concerning that some children in the ABMU Case Study had been discriminated because of their

${ }^{1230}$ UK Parliament, Parliamentary Review of Health and Social Care in Wales: A revolution from within: transforming health and care in Wales (UK Parliament January 2018) 8 Recommendation 4.

${ }^{1231}$ Royal College of Paediatrics and Child Health, State of Child Health: 2017 Recommendations for Wales (RCPCH 2017); RCPCH State of Child Health: 2018 Recommendations for Wales (RCPCH 2018).

${ }^{1232}$ Kilkelly U, Child Friendly Healthcare: The Views and Experiences of Children and Young People in the Council of Europe (Strasbourg: Council of Europe 2011)

${ }^{1233}$ Ibid 
race, gender, age and disability and they also did not know their rights or how to complain (See Chapter 9). So, that children and their experiences do not go unnoticed; it is important that disaggregated data is consistently collected that tells the story of their health care experience and programmes and training for professionals are designed to address this discrimination.

It is also fundamental that children are made aware of their rights in health care and child-friendly complaints systems are adopted urgently by all health boards. The Welsh Government in response to the National Inquiry on Children's Rights has committed to a child-friendly complaints mechanism; this should also be embraced by every health authority and public body in Wales. ${ }^{1234}$ Many of the young people in the ABMU Case study did not know how to make a complaint, only two children between 20182019, were assisted to make a complaint by a health professional (See Chapter 9). Many health professionals did not know how to assist children how to make a complaint and had not received training on supporting children to make a complaint. Children need to understand how to exercise their human rights and have a route to seek a remedy if their rights have been breached when interacting with health services. Such interventions would help to empower children to exercise their human rights in health care settings and encourage services to be accountable to children.

This thesis recognised that there are attitudes across services that conceptualise children being first and foremost vulnerable, incompetent and in need of protection and not capable of autonomous decision making (See Chapter 4, 6, 8). As the UN Committee makes clear, 'there are often serious discrepancies regarding such autonomous decision making, with children who are particularly vulnerable to discrimination often less able to exercise this autonomy.' ${ }^{1235}$ However, on the contrary, the developing jurisprudence of the UNCRC instead envisions children as human rights holders who should be presumed capable and competent (See Chapter 6). It argues that children must no longer be discriminated against and must be empowered

\footnotetext{
${ }^{1234}$ Welsh Government, Deputy Minister Health and Social Services. Letter to Chair of Welsh Parliament Children and Young People and Education Committee' $23^{\text {rd }}$ September 2020 https://business.senedd.wales/documents/s105741/Welsh\%20Government\%20response\%20$\% 2023 \% 20$ Sept accessed February 172021

${ }^{1235}$ UN Committee on the Rights of the Child, General Comment No.4 Adolescent health and development in the context of the Convention on the Rights of the Child $\mathrm{CRC} / \mathrm{C} / \mathrm{GC} / 4 / 2003$ para 32
} 
as a social group to make and influence decisions and participate in all matters that affect them, including health care decision making (See Chapter 6).

The ABMU Case Study indicated, that younger children must be supported with access to child friendly information well in advance of interacting with health services, so the experience of visiting a health professional is not so intimidating, as one child described,

"When visiting the doctor, "I get scared the reason why I get scared is because I worry about what they gonna do" [C94].

As one young person commenting on her health consultation responded, make it, "Less formal. Ensure you understand. Ask me what I think is wrong" [YP37], and another disabled young person, expressing frustration at not being fully included in the decision-making process responded, health professionals need a "Better attitude. They have secretive meetings about my care without me knowing" [YP34]. Children's and young people's capacity for autonomous decision making can be supported by providing them with information and resources to help them to claim their human rights. In the $21^{\text {st }}$ Century it is no longer acceptable that any child or young person says,

"I didn't know that I had the right to information in health or the right to have my say. I thought that the doctors word was final." [YP16]

The very idea that children have human rights is as Tobin describes 'a transformative concept that reconceptualises the power relationship between children, adults and the state.' ${ }^{1236}$ The power of a CRA recognises that children are active subjects with human rights that they are entitled to claim. It makes clear that children can no longer be ignored, devalued or neglected under the guise that adult decision makers will automatically know what is in their best interests.

${ }^{1236}$ Tobin J, 'Understanding a human rights based approach to matters involving children: conceptual foundations and strategic considerations' In Invernizzi A and Williams J (eds) The Human Rights of Children: From Visions to Implementation (Farnham: Ashgate 2011) 89 
This is a complex and political project that demands that individuals and institutional cultures must change. Safarty ${ }^{1237}$ and Tobin ${ }^{1238}$ argue that those who seek to advocate and help institutions to internalise a human rights approach fail to succeed because they do not demonstrate how it has synergy with their own value base. However, as was outlined in the first reflection in this section, the values that underpin the NHS in Wales are not dissimilar to the fundamental principles of a HRBA. It is now about ensuring that, children's rights principles are also given equal priority and no longer seen as an afterthought. All public bodies, including health bodies, should translate a CRA into the practice of their organisations.

${ }^{1237}$ Safarty G, 'Why culture matters in international institutions: the marginality of human rights at the World Bank', American Journal of International Law (2009)103 (4), 647-83

${ }^{1238}$ Tobin J, 'Understanding a human rights based approach to matters involving children: conceptual foundations and strategic considerations', In Invernizzi A and Williams J (eds) The Human Rights of Children: From Visions to Implementation (Farnham: Ashgate 2011) 


\section{APPENDICES}

\section{Appendix 1: Assessing the 5 principles of a CRA and giving consideration to the UNCRC: Annabel's story}

The following is an illustrative example of a child's life story adapted from the BBC "When I Worry About Things" which is a collection of animated films that use personal testimony to explore mental health issues from the perspective of children. ${ }^{1239}$ Annabel faced mental health challenges and the adapted story below describes her experience of using health services and suggests what should have been considered if a children's human rights approach was being implemented. It uses the lens of the 5 principles of a CRA. I developed this illustrative example to help students at the

Swansea University International Children's Rights Summer School understand a children's human rights approach to health services.

\section{Annabel's story}

Annabel (12 years of age) was a happy, bright intelligent girl doing well at school, when her step-father left. She moved house with her mother and moved school half way through year five, aged 9. Annabel does not deal well with change. She did not really fit in at the new school and she was bullied and felt very alone.

She developed a tic (essentially a noise she made through her nose). When she was really stressed she would also develop a twitch in her eyes. It made her feel strange and she worried everyone would notice. She felt very embarrassed. She then developed the habit of repeating an activity many times because if she did not do it she felt something bad would happen to her or her family. She would rearrange her books many times and her teddies and rewrite lists until they were perfect. This gradually became worse over a three year period. She felt depressed and not good enough

\footnotetext{
1239 BBC Teach "When I worry about things" https://www.bbc.co.uk/programmes/articles/5QM6H01X6b3jTQF85GLgbFl/when-i-worry-about-things accessed January 2020
} 
and believed that she was responsible for making everyone leave her (her biological father died when she was 2 yrs old).

Annabel and her mother live in rural Wales, quite some distance from the nearest GP (General medical practitioner in local health surgery) and Annabel's mum does not have a car. Her mother, who had become increasingly worried about Annabel but did not know how to help her, decided to take the long trip on public transport to see the GP. They could not get an out of school hours' appointment, so Annabel's mum first had to travel to Annabel's school. The school secretary came to get her from her class, announcing loudly, "could Annabel please come because her mother was waiting to take her to the doctors". Annabel felt so embarrassed.

When they arrived at the health centre, they waited a long time in the waiting room; there was nothing there for her to do, so this made her even more anxious. On seeing the doctor, he only really talked to her mum, so Annabel was not given the opportunity to really explain how she felt in the 10 minute GP appointment.

She felt scared and awkward in the doctor's room and wanted to get out of there as fast as possible. Annabel believed that this doctor did not really know how to talk to children. He told her mum that he would "take some bloods" to see if she was "run down". He did not ask her if she was ok with needles and proceeded with the injection. This terrified Annabel, silent tears fell down her face.

The doctor said there was not really any further support that they could give Annabel, until the blood results. A week later, she tried to take her life and ended up in hospital.

The text below gives consideration to what the rights of the child (according to the United Nations Convention on the Rights of the Child) are in this case and how the 5 principles, Embedding, Participation, Empowerment, Equality and Non-discrimination and Accountability of the Children's Human Rights Approach should be applied in practice: 
- Embedding human rights - this doctor has not been sufficiently trained to understand the rights of the child, child health or child development (Article 24, 42 UNCRC). He did not extrapolate enough information to learn about Annabel's mental health condition and therefore did not give an appropriate diagnosis (Article 3, 12, 24). If he had made an appropriate diagnosis then Annabel would have been appropriately referred to child and adolescent mental health services, therefore adhering to a coordinated service response (Article $3,4,24$ of the UNCRC). All primary care should be established to be accessible and non-stigmatising for children (Article 2, 24, AAAQ framework UNCRC) as this may be the first point of contact for younger people where early identification and intervention must be a key priority for service providers. It is apparent that the UNCRC is not core to all decision making at this health service (Article 4, 24, 42 of the UNCRC) and it may also indicate that children's human rights are also not embedded within Annabel's school (Article 2, 29,42). There is also a strong indication that Annabel's mother has no understanding or awareness of Annabel's human rights and therefore was unable to advocate and help Annabel to claim them (Article 5, 42, 18, 24). All caregivers should also be educated in understanding what children's human rights are when interacting with services.

- Empowering the child - it is very concerning that this child has not been empowered to understand or tackle what she is facing. This also demonstrates that there was an inappropriate service response from her school (Article 3, 6, $12,24,29)$. It demonstrates the need for early intervention and psychological support within the school environment. Annabel has probably not been given any support to understand how to become or stay mentally healthy (Article 3 , $6,24)$. Annabel at an early age has experienced the loss of her biological father and the separation of her step-father from her mother. It is not reported in the case study but it is possible that Annabel has never had any bereavement support or psychological support to deal with her mother and step-father's break up (Article 3, 6, 39). Annabel has not been supported or empowered to understand or exercise her rights or how to speak out to claim them (Article 12, 42). 
- Annabel should feel safe in her school environment but this right (Article 19) was breached as the story notes she has been subjected to bullying.

- Annabel's right to privacy (Article 16) was also breached when the secretary brought attention to her doctor's appointment in front of the class. For a child who is already experiencing mental health challenges this contributes to her feelings of stigmatisation and disempowerment.

- With regards to consenting or refusing treatment, in England and Wales for example, you can consent to medical treatment if you are 16 or older or if you are under 16 and understand what is going on. This corresponds with what is referred to as Gillick competence,1240 if a child is determined to have "sufficient understanding and maturity" therefore they have been deemed competent and to have capacity to make decisions then the child is able to make a decision independently of their parents. The acquisition of capacity is a developmental continuum, and children over 12-14 years of age may have near-adult capacity. Annabel was not given any information regarding her right to consent or refuse treatment (Article 2, 3, 5, 12, 13) and was not empowered to consent to or refuse treatment. All children should be listened to, given information and supported to exercise choice and control according to their age and understanding (Article 2, 3, 5, 12, 13).

- GP service was also not child-friendly, this contributed to Annabel's heightened anxiety in the waiting room and consultation room (Articles $2,3,12)$.

- Participation of the Child - The doctor did not support any of Annabel's participative rights to take part in the treatment process. He did not give her appropriate information to influence the decisions being made or opportunity to contribute to discussion concerning her treatment and to ask questions. He did

\footnotetext{
${ }^{1240}$ Gillick v West Norfolk \& Wisbeck Area Health Authority [1986] AC 112 House of Lords. "The parental right to determine whether or not their minor child below the age of 16 will have medical treatment terminates if and when the child achieves a sufficient understanding and intelligence to enable him or her to understand fully what is proposed'. [Lord Scarman on the Gillick Case, House of Lords,].
} 
not give Annabel's views due weight (denial of Article 3,12, 13 rights). It is very concerning that the doctor had no basic skills in communicating to Annabel. He only spoke directly to her mother and not to her. In this way she was completely disregarded, and was discriminated against just because she was a child (Article 2). She was also not given any opportunity to give patient feedback (Article 12).

- Equality and non-discrimination - Annabel's experience demonstrates how poor quality medical services can have a dramatic impact on a child's health (see Article 2, 24 and AAAQ framework). If Annabel had seen another medical professional who had skills in communicating and working with children and an understanding of children's mental health, the outcome may have been very different (Article 2, 3). Annabel's case also highlights how so often services are not built around the needs of the child, and Annabel had to leave school to attend an appointment (Article 2, 3, AAAQ framework). The appointment is also limited to 10 minutes and children often need longer to feel comfortable, to be given appropriate information according to their age and understanding and to help to build a relationship with the medical professional, who often from a child's perspective can be perceived to be unfriendly or intimidating. Additionally it was challenging for Annabel and her mother to get to the appointment as they live in a rural area with poor public transport, this calls into question the availability and accessibility and acceptability of the service. (Article, 2, AAAQ Framework).

- Accountability - Services will often respond that there is lack of resources to support all of these needs. However the State/Government that delivers these services has an Article 4 obligation to be transparent about how they are spending on children to the maximum extent of available resources (see also AAAQ framework). Annabel and her mother should also exercise their right to complain. The doctor did not deal with Annabel's case appropriately and put her at risk. There should be a child friendly complaints mechanism at the GP Service and Annabel and her mother should have been made aware of it (Article 3,12 of the UNCRC). This complaint needs to be responded to in a timely manner, recommendations made and responded to urgently so that it does not happen again. It is incredibly important that this case is reported and any further 
cases are also reported so that there is a full picture of what is happening with regards to violations of children's human rights at the GP service in question (Article 4 UNCRC).

- This story illustrates how the many culminating factors that contribute to Annabel's right to survival and development (Article 6), her (Article 24) right to the highest attainable standard of health and what was in her best interests (Article 3) were threatened and ultimately were severely breached. It also demonstrates the importance when implementing a children's human rights approach how children's human rights are interrelated and indivisible and therefore a holistic and coordinated service response is required. 


\section{Appendix 2: Strategic Leads children's rights organisational self- assessment}

\section{Information and consent}

ABMUHB would like to find out from staff who have a strategic role how you are currently working to implement the ABMUHB Children's Rights Charter and any recommendations you have for future improvement in your service areas and corporate wide. We are at the beginning of the journey of implementing the Charter at $A B M U H B$ and are trying to generate a baseline understanding to learn how we can improve. We will repeat this assessment in 2 years time.

To see the Charter please click on Children's Rights Charter

We hope you will be willing to participate in a short 13 minute on-line survey. The data from the survey will be aggregated and anonymised for analysis purposes and individual participants will not be identified in the research findings and any final reports.

The data will only be used as part of a PhD submission and to inform ABMU service planning, policy and delivery and better implementation of the Children's Rights Charter.

Any data will be archived and stored under compliance with data protection legislation for a period of 3 years post the delivery of the research. We will share our report with you in 2019.

The next page will have a number of children's rights standards. Please rate how far you believe ABMUHB has achieved the implementation of each standard according to the scale provided.

$1=$ No action taken $2=$ Under development $3=$ Developed but requiring refinement 4 $=$ Fully developed $5=$ Fully developed and operational

If you are willing to voluntarily participate in the survey. Please consent by pressing $\mathrm{OK}$ and go to the questions below. 


\section{$\underline{\text { Questions }}$}

\section{Monitoring questions}

1: How old are you?

- 18-24 years

- 25-34 years

- 35-44 years

- 45-54 years

- 55-64 years

- $65+$

2. What gender are you?

- Male

- Female

- Transgender

- Non-binary (Not exclusively male of female)

- Prefer not to answer

\section{Health authority wide commitment to the UNCRC}

3. Reference has been made to the United Nations Convention on the Rights of the Child as the framework for service planning and delivery in all significant policy statements or other documents setting out the health authority's vision or key objectives (e.g. a Children's Rights Charter).

- No action taken

- Under development

- Developed but requiring refinement

- Fully developed

- Fully developed and operational

What evidence/comments do you have to support this rating? 
4. Leaders and staff, who are required to put the Children's Rights Charter into practice, are aware of this commitment.

- No action taken

- Under development

- Developed but requiring refinement

- Fully developed

- Fully developed and operational

What evidence/comments do you have to support this rating?

5. Children as service users and their carers are made aware of the commitment to the UNCRC and the Children's Rights Charter.

- No action taken

- Under development

- Developed but requiring refinement

- Fully developed

- Fully developed and operational

What evidence/comments do you have to support this rating?

\section{Develop a children's rights strategy}

6. A strategy has been developed to ensure the UNCRC/Children's Rights Charter is taken into account at all levels of decision-making across all health services and there is clear coordination with other agencies.

- No action taken

- Under development

- Developed but requiring refinement

- Fully developed

- Fully developed and operational

What evidence/comments do you have to support this rating?

7. Protection of children's rights has been prioritised through the commissioning cycle. 
- No action taken

- Under development

- Developed but requiring refinement

- Fully developed

- Fully developed and operational

What evidence/comments do you have to support this rating?

8. Key individuals and/or a team with responsibility to promote children's rights within the health authority has been established

- No action taken

- Under development

- Developed but requiring refinement

- Fully developed

- Fully developed and operational

What evidence/comments do you have to support this rating?

9. There is clear and transparent evidence to demonstrate that the maximum extent of available resources has been allocated to support the organisation to implement the children's human rights strategy.

- No action taken

- Under development

- Developed but requiring refinement

- Fully developed

- Fully developed and operational

What evidence/comments do you have to support this rating?

\section{Raise awareness and deliver training on children's rights}

10. Initial and on-going evaluation of levels of knowledge and understanding of children's human rights amongst staff at all levels has been carried out.

- No action taken 
- Under development

- Developed but requiring refinement

- Fully developed

- Fully developed and operational

What evidence/comments do you have to support this rating?

11. A communication plan for staff has been developed setting out how the health authority intends to develop awareness and understanding of implementing children's human rights.

- No action taken

- Under development

- Developed but requiring refinement

- Fully developed

- Fully developed and operational

What evidence/comments do you have to support this rating?

12. Training on children's rights for all staff (appropriate to context and role that a member of staff performs) has been prioritised

- No action taken

- Under development

- Developed but requiring refinement

- Fully developed

- Fully developed and operational

What evidence/comments do you have to support this rating?

\section{Under take children's rights monitoring}

13. An initial and then regular audit of all significant policy statements or other documents has been carried out to assess compliance with the Charter.

- No action taken

- Under development 
- Developed but requiring refinement

- Fully developed

- Fully developed and operational

What evidence/comments do you have to support this rating?

14. Annual reports are published on performance against children's rights indicators and the findings disseminated widely.

- No action taken

- Under development

- Developed but requiring refinement

- Fully developed

- Fully developed and operational

What evidence/comments do you have to support this rating?

15. There is external monitoring of performance against children's rights standards, including by involving children in monitoring and/or external review/inspection.

- No action taken

- Under development

- Developed but requiring refinement

- Fully developed

- Fully developed and operational

What evidence/comments do you have to support this rating?

16. Staff supervision and performance management includes individual responsibility for children's rights, including performance indicators in job descriptions.

- No action taken

- Under development

- Developed but requiring refinement

- Fully developed

- Fully developed and operational 
What evidence/comments do you have to support this rating?

17. Children's rights impact assessment are used to proof any policy and budgetary decisions for their direct or indirect impact on children.

- No action taken

- Under development

- Developed but requiring refinement

- Fully developed

- Fully developed and operational

What evidence/comments do you have to support this rating?

18. Children are consulted as part of the Children's Rights Impact Assessment process or Equality Impact Assessment process.

- No action taken

- Under development

- Developed but requiring refinement

- Fully developed

- Fully developed and operational

What evidence/comments do you have to support this rating?

\section{Equality and non-discrimination throughout service delivery}

19. Data is collected, including disaggregated data, to enable identification of discrimination or inequalities in the realisation of children's rights to identify children who are being or may be discriminated against.

- No action taken

- Under development

- Developed but requiring refinement

- Fully developed

- Fully developed and operational

What evidence/comments do you have to support this rating? 
20. Services and resources are reviewed to identify barriers to children's access, including in collaboration with children as service users, in particular in relation to services to excluded/marginalised or disadvantaged social groups.

- No action taken

- Under development

- Developed but requiring refinement

- Fully developed

- Fully developed and operational

What evidence/comments do you have to support this rating?

21. Appropriate priorities, targets and programmes have been developed to eliminate discrimination against excluded, socially marginalised, disadvantaged and vulnerable groups and to promote equality for these groups.

- No action taken

- Under development

- Developed but requiring refinement

- Fully developed

- Fully developed and operational

What evidence/comments do you have to support this rating?

22. All buildings are compatible with Disability Discrimination Act requirements.

- No action taken

- Under development

- Developed but requiring refinement

- Fully developed

- Fully developed and operational

What evidence/comments do you have to support this rating?

23. All children have access to professional interpreters when required.

- No action taken 
- Under development

- Developed but requiring refinement

- Fully developed

- Fully developed and operational

What evidence/comments do you have to support this rating?

24. All information is provided to children in a language or format appropriate to their age, culture, gender or disability.

- No action taken

- Under development

- Developed but requiring refinement

- Fully developed

- Fully developed and operational

What evidence/comments do you have to support this rating?

\section{Children can actively participate in decisions about their own health}

25. Children are encouraged to exercise their right to participate in the decisions being made about their health or condition, encouraged to express their views freely, ask questions and their views are given due weight.

- No action taken

- Under development

- Developed but requiring refinement

- Fully developed

- Fully developed and operational

What evidence/comments do you have to support this rating?

Children are directly involved in the development, monitoring and evaluation of service delivery

26. Children are directly involved in the development, monitoring and evaluation of service delivery. 
- No action taken

- Under development

- Developed but requiring refinement

- Fully developed

- Fully developed and operational

What evidence/comments do you have to support this rating?

27. A process has been established in all ABMU health services areas to collect and act on Child Patient Feedback.

- No action taken

- Under development

- Developed but requiring refinement

- Fully developed

- Fully developed and operational

What evidence/comments do you have to support this rating?

28. Children are involved in the recruitment of staff that directly work with children.

- No action taken

- Under development

- Developed but requiring refinement

- Fully developed

- Fully developed and operational

What evidence/comments do you have to support this rating?

29. Children have been given opportunities to act collectively to develop ideas and proposals, to take action and to influence decisions e.g. ABM Youth Board

- No action taken

- Under development

- Developed but requiring refinement

- Fully developed 
- Fully developed and operational

What evidence/comments do you have to support this rating?

\section{Child friendly advice and complaints mechanism}

30. Children and their carers are provided with accessible information on the process for making complaints, and for holding the authority, or individual staff to account.

- No action taken

- Under development

- Developed but requiring refinement

- Fully developed

- Fully developed and operational

What evidence/comments do you have to support this rating?

Health promotion, children's rights information and advocacy for all children and carers

31. Children are provided accessible information on how to access advice, such as advisory services, human rights advocacy services or professional legal advice.

- No action taken

- Under development

- Developed but requiring refinement

- Fully developed

- Fully developed and operational

What evidence/comments do you have to support this rating?

32. Children and their carers are able to access age, gender, disability and culturally appropriate information about how to stay healthy and how to take action to become healthy.

- No action taken

- Under development

- Developed but requiring refinement 
- Fully developed

- Fully developed and operational

What evidence/comments do you have to support this rating?

33. Children and their carers are given information that is age, gender, culture and disability appropriate regarding how to access their rights in health care

- No action taken

- Under development

- Developed but requiring refinement

- Fully developed

- Fully developed and operational

What evidence/comments do you have to support this rating?

34. Materials providing information about preventative health and health rights are designed in collaboration with children.

- No action taken

- Under development

- Developed but requiring refinement

- Fully developed

- Fully developed and operational

What evidence/comments do you have to support this rating?

\section{Strategies for improvement}

35. What would be your main strategy (s) to translate children's rights into the working practice of ABMU health services for children? 


\section{Appendix 3: Health professionals' views - survey}

As part of an ongoing programme to implement the ABMUHB Children's Rights Charter, ABMUHB would like to find out from health professionals how you are currently working to implement the Charter and any recommendations you have for future improvement in your service areas.

\section{To see the Charter please click $\underline{\text { Children's Rights Charter }}$}

We hope you will be willing to participate in a short 8 minute on-line survey. The data from the survey will be aggregated and anonymised for analysis purposes and individual participants will not be identified in the research findings and any final reports.

The data will only be used as part of a PhD submission and to inform ABMU service planning, policy and delivery and better implementation of the Children's Rights Charter. This is our baseline assessment we will repeat this assessment in 2 years to monitor progress.

Any data will be archived and stored under compliance with data protection legislation for a period of 3 years post the delivery of the research. We will share our report with you in early 2019.

If you are willing to voluntarily participate in the survey. Please consent by pressing OK and go to the NEXT Page.

\section{Questions}

1. What gender are you?

- Male

- Female

- Transgender

- Non-binary (Not exclusively male of female)

- Prefer not to answer

2. What age are you? 
- 18-24 years

- 25-34 years

- 35-44 years

- 45-54 years

- 55-64 years

- $65+$

3. Which area do you work in?

- Bridgend

- Neath-Port Talbot

- Swansea

4. Which service area do you work in?

- Children's Services only

- Children's Services only

- Children's and Adult's Services

5. Which health professional are you?

- Doctor/Surgeon

- Nurse

- Psychologist

- Psychiatrist

- Therapist (e.g. speech, podiatry, audiology, podiatry etc)

6. Do you have a medical specialisation in child health or special training in providing care for children?

- Yes

- No

- If Yes, please specify

7. Is the ABMU Children's Rights Charter displayed in the service area where you work?

- Yes 
- No

- Don't know

- Any further comments?

8. How would you rate your knowledge of the ABMU Children's Rights Charter?

- Excellent

- Good

- Average

- Poor

- Very poor

- Any further comments

9. Do you have access to guidance on how the ABMU Children's Rights Charter can be implemented in your area of work?

- Yes

- No, I need guidance

- Don't know

- Any further comments

10. Does your job description include performance indicators relating to the $A B M U$ Children's Rights Charter?

- Yes

- No

- Any further comments?

11. Is there a named person in your service area responsible for all service delivery complying with the ABMU Children's Rights Charter?

- Yes

- No

- Don't know

- Any further comments

12. Please tick which training you have received below 
- Children's rights

- Children's informed consent to treatment

- Supporting children with mental health issues

- Ensuring children's views are always taken into account and given due weight

- Supporting children to make a complaint

- Using play strategies with younger children in clinical settings

- Respecting children's privacy and confidentiality

- Equality and discrimination in relation to children

- Child protection/safeguarding

- Any further comments?

13. How would you rate your ability to involve children according to their age and capacity in the clinical decisions that affect them?

- Excellent

- Good

- Average

- Poor

- Very poor

- Any further comments

14. Do you provide children with opportunities to give patient feedback?

- Yes

- No

- If you answered Yes, do you have any examples of how child patient feedback has improved services for children?

15. Do you know how to support a child to make a complaint?

- Yes

- No, I need more information

- Any further comments?

16. How many children have you supported to make a complaint in 2018 ? 
- No children

- 1 child

- 2 children

- 3 children

- More than 4 children

- If you have supported a child to make a complaint, please tell us if this has resulted in improving services for children?

17. Do you have timely access to professional interpreters when needed?

- Yes

- Sometimes

- No

- Any further comments?

18. Do you ensure that all the information you provide to children is in a format they understand? (e.g. appropriate to age, capacity, gender, disability, culture, language etc.)

- Yes

- Sometimes

- No

- If no, please specify why you find this challenging?

19. Please tick which health promotion or health rights information you provide to children below.

- Children's rights in health care settings

- Informed consent

- Rights to privacy and confidentiality

- Mental health rights

- Right to be involved in clinical decision making

- Right to give patient feedback and how to do it

- Right to make a complaint and how to do it 
- Information about other services that can help the child e.g. advocacy/advisory services/legal advice

- How to be healthy (i.e. preventative health information)

- Any further comments?

20. Would you like to receive training on children's rights and how to implement the ABMU Children's Rights Charter in your work?

- Yes

- No

- If you selected yes, what are your training needs?

21. What do you consider to be the main challenges to complying with the $A B M U$ Children's Rights Charter in your service area? Please read the Children's Rights Charter. (Open-ended)

22. What do you think are the main strategies required to implement the ABMU Children's Rights Charter. Please tick the 3 below that you consider to be the most important.

- Ensuring there are appropriate financial resources to implement the Children's Rights Charter.

- Ensuring there is training for all health professionals relating to implementing the Children's Rights Charter.

- Ensuring that all job descriptions include performance indicators related to implementing the Children's Rights Charter

- Ensuring there is ongoing senior level commitment to implementing the Children's Rights Charter.

- Ensuring there is a positive culture and ethos towards implementing the Children's Rights Charter. 


\section{Appendix 4: Young people - Your views on health services - survey Information and Consent}

We want to ask some questions to learn about your experience of visiting health professionals.

A health professional is a person who looks after your health for example they could be a doctor, a nurse, a physiotherapist, a psychologist, a speech therapist etc.

When you visit a health professional they should make sure you feel: Respected, Listened to, Happy to give your own opinion, happy to say how you feel.

We want to help to make young people's visits to see a health professional better.

We will write a report and tell you the results of our survey in early 2019.

We don't need to know your name, the survey is anonymous.

You can choose whether you want to take part in this survey or not, it is YOUR choice.

If you are happy to answer our 8 minute survey about going to see a health professional, please press OK!

If you would like any further advice or information about children's rights, please see links to organisations below who can offer you advice and support.

- Children's Commissioner for Wales https://www.childcomwales.org.uk/

- Children's Legal Centre https://childrenslegalcentre.wales/

- MEIC https://www.meiccymru.org/

- Childline https://www.childline.org.uk

- NSPCC https://www.nspcc.org.uk/ 
1. How old are you?

2. What is your gender?

- Male,

- Female,

- Transgender,

- Non-binary (not exclusively masculine or feminine),

- Prefer not to answer

3. How many times have you visited a health professional in 2018 ?

- 1 time

- 2 times

- 3 times

- More than 4 times

4. Please tell us whether you are answering this survey based on your experience of visiting a

- Hospital

- GP (local doctor's surgery our Out of Hours)

- Children's centre (e.g. speech therapy, audiology, physiotherapy, psychology etc)

- Accident and Emergency

5. Which area do you live in?

- Bridgend

- Neath-Port Talbot

- Swansea

- Other please specify

6. Do you know what rights are when you visit a health professional?

- Yes,

- No, I need more information.

- Any further comments

7. Have you seen this poster before today?

- Yes,

- No,

- If yes, please tell us where you have seen this poster?

8. Are health professionals friendly? 
- Yes, always

- Sometimes

- No.

- Any further comments

9. When talking to a health professional do you think that?

- They mostly talk to you

- They mostly talk to the person you came with

- They talk to you and the person you came with

- I go by myself

- Any further comments

10. Do health professionals listen to what you have to say?

- Yes, always

- Sometimes

- No.

- Any further comments?

11. Do health professionals give you the chance to ask them questions?

- Yes, always,

- Sometimes

- No.

- Any further comments?

12. Do you understand what health professionals say to you?

- Yes, always,

- Sometimes,

- No.

- Any further comments?

13. Do you help to choose how you can get better?

- Yes

- No

- Any further comments?

14. Do you trust health professionals?

- Yes

- No 
- Any further comments?

15. Do health professionals ask for your permission before treating you? ((i.e. your consent)

- Yes, always

- Sometimes,

- No.

16. When seeing a health professional do you think you have ever been treated unfairly because of ?

- Your age,

- Your gender,

- Your race (this includes, your skin colour, ethnic or national origin)

- Your sexual orientation (e.g. gay, lesbian, bisexual, heterosexual)

- Your disability

- Where you live

- Your asylum or refugee status

- You live in care

- You are in a juvenile offender institution

- If you would like to say why you were treated unfairly please say why in the box below

17. Do you find it difficult to get to see a health professional?

- Yes, always,

- Sometimes

- No.

- If yes or sometimes, please say why in the box below?

18. Would you tell a health professional if you were worried or upset?

- Yes,

- No,

- If No, why not?

19. Health professionals keep what you tell them private. However if they are worried that you are not safe, they might have to talk to somebody else about what you have told them. Did you know this?

- Yes

- No 
- Any further comments?

20. Do you feel safe when you visit a health professional?

- Yes

- No,

- If No, why not?

21. Do you feel that your privacy is respected when you visit health professionals?

- Yes, always

- Sometimes,

- No.

22. Where do you learn most about being healthy? (Please ONLY tick 3 answers below)

- A health professional

- A health professional in school

- Your family

- Your friends

- The internet

- Other social media

- Television

- Books

- In school

- Other, please specify

23. If you visited a health professional and something happened that you did not like, would you know how to complain?

- Yes,

- No, I need more information

- Any further comments

24. What do you think would make a visit to see a health professional better? Please tell us your ideas.

25. Has a health professional ever asked you question number 24 before?

- Yes

- No 
26. Please take a few minutes to read the Children's Rights Charter (please click on this link Children's Rights Charter). Have you learnt anything you did not know before? Please tell us below. Many thanks. 


\section{Appendix 5: Children - Your views on health services - survey}

\section{Parental consent}

We want to ask some questions to learn about what your child thinks about doctors and nurses.

When your child visits a doctor or a nurse they should make sure your child feels: Respected, Listened to, Happy to give their own opinion, Happy to say how they feel.

We want to know this so we can help to make children's visits to see a doctor or nurse better.

We will write a report about what we have found out in 2019.

You can choose whether you want your child to take part in this 5 minute survey or not, it is YOUR choice.

We don't need to know your name or your child's name, the survey is anonymous. So if you are happy to support your child to answer a small number of questions about going to see a doctor or nurse please press OK.

If you would like any further advice or information about children's rights, please see links to organisations below who can offer you advice and support.

Children's Commissioner for Wales https://www.childcomwales.org.uk

Children's Legal Centre https://childrenslegalcentre.wales

MEIC https://www.meiccymru.org/

Childline https://www.childline.org.uk/

NSPCC https://www.nspcc.org.uk/

OK?

PROCEED TO SURVEY 


\section{Information for children}

We want to ask some questions to learn about what you think about doctors and nurses.

When you visit a doctor or a nurse they should make sure you feel: Respected, Listened to, Happy to give your own opinion, Happy to say how you feel.

We want to know this so we can help to make children's visits to see a doctor or nurse better.

We will write a report about what we have found out in 2019. You can choose whether you want to take part in this survey or not, it is YOUR choice. We don't need to know your name, so if you are happy to answer a small number of questions about going to see a doctor or nurse and so is your parent or carer please press OK!

If you would like any further advice or information about children's rights please see links to organisations below who can offer you advice and support. Children's Commissioner for Wales https://www.childcomwales.org.uk/

Children's Legal Centre https://childrenslegalcentre.wales/

MEIC https://www.meiccymru.org/

Childline https://www.childline.org.uk/

NSPCC https://www.nspcc.org.uk/

OK

Questions:

1. How old are you?

- 7

- 8

- 9

- 10

- 11 
- 12

2. Are you a girl or a boy?

- Girl

- Boy

3. Which area do you live in?

- Bridgend

- Neath-Port Talbot

- Swansea

- Other please specify

4. How many times have you visited a doctor in 2018 ?

- 1 time

- 2 times

- 3 times

- 4 or more times

5. Are you answering these questions from visiting a

- Hospital

- GP (Local Doctor's Surgery our Out of Hours)

- Children's Centre (Audiology, speech therapy, physiotherapy, psychology, podiatry etc).

- Accident or Emergency

6. Do you know what your rights are when you visit a doctor or nurse?

- Yes,

- No, I need more information.

7. Have you seen this poster before?

- If yes, where have you seen it?

8. Do you like visiting the doctor or nurse?

- Yes,

- No,

- If No, why not?

9. Are doctors and nurses friendly?

- Yes, always

- Sometimes 
- No.

10. Do you understand what doctors and nurses say to you?

- Yes

- No

11. Do doctors and nurses give you the chance to ask questions?

- Yes

- No

12. Do doctors and nurses listen to what you have to say?

- Yes

- No

13. Do you have the chance to play when you visit the doctor or nurse?

- Yes

- No

14. Do you feel safe when you visit a doctor or a nurse?

- Yes

- No,

- If No, why not?

15. Are you happy to tell the doctor or nurse if you are worried or upset?

- Yes

- No,

- If No, why not?

16. What do you think would make a visit to the doctor or nurse better? Please tell us your ideas in the box below. 


\section{Appendix 6: College of Law and Criminology Ethics Review Form, Swansea University}

\section{LIGHT-TOUCH ETHICAL REVIEW FORM}

To be completed for all research involving human participants or datasets

\begin{tabular}{|c|c|}
\hline Name of PI or Student & Rhian Chamberlain \\
\hline Supervisors* & Dr Simon Hoffman \\
\hline Date Submitted & April $4^{\text {th }} 2019$ \\
\hline Title of Project & $\begin{array}{l}\text { A case study investigation into a children's huma } \\
\text { rights approach to health services }\end{array}$ \\
\hline Name of Funder / Sponsor & Part sponsored by ABMU \\
\hline \multicolumn{2}{|l|}{ Finance Code / Reference ${ }^{*}$} \\
\hline Duration of Project & Thesis duration 2016-2019 \\
\hline
\end{tabular}

* Complete if appropriate

Risk evaluation: Does the proposed research involve any of the follow?

$\checkmark$ Tick those boxes for which the answer is YES

$X$ Cross those boxes for which the answer is NO

$x$ Will the study involve recruitment of patients or staff through the NHS or the use of NHS data or premises and/or equipment? If this is the case,the project must be reviewed by the NHS NRES. (http://www.hra.nhs.uk/research-community/before-youapply/determine-whether-your-study-is-research/

$x$ Does the study involve participants aged 16 or over who are unable to give informed consent? (e.g. people with learning disabilities: see Mental Capacity Act 2005. All research that falls under the auspices of the Act must be reviewed by the NHS NRES.) 
$x$ Does the research involve other vulnerable groups: children, those with cognitive impairment or in unequal relationships? (e.g. your own students). This may require review by the NHS NRES.

$x \quad$ Will the study require the co-operation of a gatekeeper for initial access to the groups or individuals to be recruited? (e.g. students at school, members of self-help group or residents of nursing home?)

X Will it be necessary for participants to take part in the study without their knowledge and consent at the time? (e.g. covert observation of people in non-public places)

x Will the study discuss sensitive topics? (e.g. sexual activity or drug use)

x Are drugs, placebos or other substances (e.g. foods or vitamins) to be administered to study participants, or will the study involve invasive, intrusive or potentially harmful procedures of any kind? (If any substance is to be administered, this may fall under the auspices of the Medicines for Human Use (Clinical Trials) Regulations 2004, and require review by the NHS NRES.)

X Will tissue samples (including blood) be obtained from participants? (This would fall under the terms of the Human Tissue Act 2004. All research that falls under the auspices of the Act must be reviewed by the NHS NRES.)

$\mathrm{X}$ Is pain or more than mild discomfort likely to result from the study?

$x$ Could the study induce psychological stress or anxiety or cause harm or negative consequences beyond the risks encountered in normal life?

$\mathrm{x} \quad$ Will the study involve prolonged or repetitive testing?

YES Will the research involve administrative or secure data that requires permission from the appropriate authorities before use?

$x$ Is there a possibility that the safety of the researcher may be in question? (e.g. in international research: locally employed researchers)

$x$ Does the research involve members of the public in a research capacity (e.g. participant research)? 
$x \quad$ Will the research take place outside the UKwhere there may be issues of local practice and political sensitivities?

$x \quad$ Will the research involve respondents to the Internet or other visual/vocal methods where respondents may be identified?

$x$ Will research involve the sharing of data or confidential information beyond the initial consent given?

$\mathrm{x}$ Will financial inducements (other than reasonable expenses and compensation for time) be offered to participants?

$x$ Are you aware of any other significant ethical risks or concerns associated with the research proposal? (If yes, please outline them below.)

1. Briefly describe the main aims of the research you wish to undertake, including a statement of the intended benefits of the research. Please use non-technical language wherever possible.

I wish to access aggregated and anonymised datasets held by Abertawe Bro Morgannwg University Health Board. These datasets have only recently become available and I wish to consider whether they may usefully add to my analysis.

2. Briefly describe the overall design of the project

The PhD thesis, which is part sponsored by ABMU, included the development of policy tools for use by ABMU to monitor the effectiveness of its 'Child Rights 
Approach' to health services. The relevant research for the thesis was on concepts and practices to inform the development of these tools. Ethical approval was not required for this work under the NHS ethical approval protocol (confirmed by the NHS), or under SU or SoL policy (the research did not involve access to datasets or human participants). The tools are designed to survey the following groups on their experience of ABMU regarding how children's rights are realised through health services:

- Strategic managers employed by ABMU.

- Healthcare professionals employed by ABMU.

- Children as users of ABMU services.

The policy tools were handed over to ABMU in 2018 together with guidance on confidentially and informed consent. ABMU started to use them in order to monitor their implementation of their child rights charter (child rights approach). I have been informed by the ABMU lead official for this work that they have acquired data from the first application of the monitoring tools.

I am currently in the writing up phase of my thesis. I have discussed the availability of the above data with my supervisor. It was not anticipated that data from application of these tools would be included in the thesis. However, my supervisor and I are in agreement that the data might shed useful insights into how effective the policy tools have been or are likely to be to ABMU about the impact of its child rights approach in practice (e.g. response rates, gaps, respondent coverage, questions left unanswered, freehand comments relevant to 'useability' of the tools, et.).

ABMU have confirmed that they are content to provide me with access to the data which is aggregated and anonymized. Access would be directly to ABMU held datasets through the provision of a login password. The data would not be downloaded from source and would at all times remain subject to access control by ABMU. 
3. Briefly describe the methods of data collection and analysis. Please describe all measures to be employed. If questionnaire or interviews are to be used, please provide the questionnaire / interview questions and schedule - if available.

I wish to access data held by ABMU.

4. Please highlight any ethical concerns or risk potential to research participants or investigators.

None.

If the answer to $\underline{\mathbf{A N Y}}$ of the questions is $\underline{\mathbf{Y E S}}$, then a Full Ethical Reviewis required.

If the project involves none of the above, complete the Declaration and send this form with a copy of the proposal to the Research Hub Manager. Research may only commence once approval has been given.

Declaration: The project will be conducted in compliance with the ethical policy of the University and the College. This includes securing informed consent from participants, minimizing the potential for harm and compliance with dataprotection obligations. Any significant change in the purpose, design or conduct of the research will be reported to the Chair of the CLC-REC and, if appropriate, a new application for ethical approval will be made.

\section{Signature of PI or Student}

Signature of first supervisor (if appropriate)

Decision of CLC-REC 


\begin{tabular}{|l|l|}
\hline $\begin{array}{l}\text { Signature of CLC-REC Chair } \\
\text { Date }\end{array}$ & \\
\hline $\begin{array}{l}\text { CLC-REC Reference number } \\
\text { (office use only) }\end{array}$ & \\
\hline
\end{tabular}

Once completed, please print this form, sign the hard copy, scan the form in pdf format and submit as required.

Approval granted by Chair CLC REC via e-mail April $4^{\text {th }} 2019$ 


\section{BIBLIOGRAPHY}

\section{INTERNATIONAL HUMAN RIGHTS TREATIES}

- CEDAW https://www.ohchr.org/EN/ProfessionalInterest/Pages/CEDAW.aspx accessed January 2020

- CRPDhttps://www.ohchr.org/EN/HRBodies/CRPD/Pages/ConventionRightsPersons WithDisabilities.aspx accessed January 2020

- ICCPR https://www.ohchr.org/en/professionalinterest/pages/ccpr.aspx accessed January 2020

- ICERD https://www.ohchr.org/EN/ProfessionalInterest/Pages/CERD.aspx accessed January 2020

- ICESCR https://www.ohchr.org/en/professionalinterest/pages/cescr.aspx accessed January 2020

- ICRMW https://www.ohchr.org/EN/ProfessionalInterest/Pages/CMW.aspx accessed January 2020

- UNCAT https://www.ohchr.org/EN/ProfessionalInterest/Pages/CAT.aspx accessed May 2019

- UNCRC https://www.ohchr.org/EN/ProfessionalInterest/Pages/CRC.aspx accessed May 2019

- UNDHR https://www.un.org/en/universal-declaration-human-rights/index.html accessed May 2019

\section{UN PUBLICATIONS (including General Comments)}

- Commission on Human Rights, Guidelines on HIV/AIDS and human rights, UN Doc. E/CN.4/1997/37 (1996)

- Office of the High Commissioner on Human Rights (1989) HUMAN RIGHTS COMMITTEE Thirty-seventh session Adopted: 10 November 1989 General Comment No. 18 Non-discrimination HRI/GEN/1/Rev.9 (Vol. I)

- Office of the High Commissioner on Human Rights, Human Rights and Poverty Reduction: A conceptual framework (New York: United Nations 2004).

- Office of the High Commissioner for Human Rights, Frequently Asked Questions on a Human Rights-Based Approach to Development Cooperation (United Nations, Geneva 2006)

- Office of the High Commissioner on Human Rights, Scenario and Talking Points for High Commissioner on Human Rights Event to Launch the Technical Guidance on the Application of a Human Rights Based Approach to the Implementation of Policies 2012

- Office of the High Commissioner on Human Rights, Analytical study on the relationship between climate change and the human right of everyone to the enjoyment of the highest attainable standard of physical and mental health. A/HRC/32/23 (UN General Assembly May 2016)

- Office of the High Commissioner for Human Rights, Special Rapporteur for Health https://www.ohchr.org/EN/Issues/Health/Pages/SRRightHealthIndex.aspx accessed January 2020

- Office of the High Commissioner on Human Rights and the World Health Organisation, Fact Sheet No. 31: The Right to Health 
https://www.ohchr.org/Documents/Publications/Factsheet31.pdf accessed January 2020

- Office of the High Commissioner on Human Rights, Fact Sheet No.10 (Rev.1), The Rights of the Child https://www.ohchr.org/Documents/Publications/FactSheet10rev.1en.pdf accessed January 2020

- Maastricht Guidelines on violations of Economic, Social and Cultural Rights (later reissued as UN document E/C.12/2000/13)

- Limburg Principles on the Implementation of the International Covenant on Economic, Social and Cultural Rights, UN Doc. E/CN.4/1987/17

- UN Committee on Economic, Social and Cultural Rights (CESCR), General Comment No. 3: The Nature of States Parties' Obligations (Art. 2, Para. 1 of the Covenant), E/1991/23 (December 14, 1990).

- UN Committee on Economic, Social and Cultural Rights (CESCR) General Comment Number 9 (Nineteenth Session, 1998), Report of the Committee on Economic, Social and Cultural Rights, UN doc.E/1999/22

- UN Committee on Economic, Social and Cultural Rights (CESCR) General Comment No.14: the Right to the Highest Attainable Standard of Health. E/C.12/2000/4.

- UN Committee on Economic, Social and Cultural Rights (CESCR) General Comment No. 20 Non-Discrimination on Economic, Social and Cultural Rights (art 2. Para. 2) E/C.12/GC/20/2009

- UN Committee on Economic, Social and Cultural Rights (CESCR) General Comment No. 22 on the right to sexual and reproductive health (article 12 of the International Covenant on Economic, Social and Cultural Rights) E/C.12/GC/22/201

- UN Committee on the Elimination of Discrimination Against Women (CEDAW) General Recommendation No. 24: Article 12 of the Convention (Women and Health) 1999 A/54/38/Rev.1, chap. I

- UN Committee on the Rights of the Child, Reporting Guidelines for Periodic Reports, General Guidelines regarding the form and contents of periodic reports to be submitted by States Parties under Article 44, (b) of the Convention, adopted by the Committee on the Rights of the Child at its $343^{\text {rd }}$ meeting ( $13^{\text {th }}$ session) 11 October 1996

- UN Committee on the Rights of the Child, General Comment No. 3: HIV/AIDS and the Rights of the Child CRC/GC/2003/3

- UN Committee on the Rights of the Child, General Comment No.4 Adolescent health and development in the context of the Convention on the Rights of the Child $\mathrm{CRC} / \mathrm{C} / \mathrm{GC} / 4 / 2003$

- UN Committee on the Rights of the Child, General Comment No. 5 on the General Measures of Implementation $\mathrm{CRC} / \mathrm{C} / \mathrm{GC} / 5 / 2003$

- UN Committee on the Rights of the Child, General Comment No.7 on implementing the child rights in early childhood CRC/C/GC/7/Rev.1 2006

- UN Committee on the Rights of the Child, General Comment No. 9: The rights of children with disabilities $\mathrm{CRC} / \mathrm{C} / \mathrm{GC} / 9 / 2006$

- UN Committee on the Rights of the Child, General Comment No.11 on the rights of indigenous children $\mathrm{CRC} / \mathrm{C} / \mathrm{GC} / 11 / 2009$

- UN Committee on the Rights of the Child, General Comment No. 12: The right of the child to be heard, $\mathrm{CRC} / \mathrm{GC} / 12 / 2009$ 
- UN Committee on the Rights of the Child, General Comment No. 14 on the right of the child to have his or her best interests taken as a primary consideration $\mathrm{CRC} / \mathrm{C} / \mathrm{GC} / 14 / 2013$

- UN Committee on the Rights of the Child, General Comment No. 15 on the right of the child to the enjoyment of the highest attainable standard of health $\mathrm{CRC} / \mathrm{C} / 15 / 2013$

- UN Committee on the Rights of the Child, General Comment No.19 on public budgeting for the realization of children's rights $\mathrm{CRC} / \mathrm{C} / \mathrm{GC} / 19 / 2016$

- UN Committee on the Rights of the Child, General Comment No. 20 on the implementation of the rights of the child in adolescence CRC/C/GC/20 2016

- UN Committee on the Rights of the Child, Concluding Observations: United Kingdom of Great Britain and Northern Ireland, 9 October 2002, CRC/C/15/Add.188

- UN Development Group, UN Statement of Common Understanding on Human Rights based approaches (UNDG 2003) https://unsdg.un.org/sites/default/files/6959The_Human_Rights_Based_Approach_to_Development_Cooperation_Towards_a_C ommon_Understanding among UN.pdf accessed January 2020

- UN Development Group, Human Rights and the Millennium Development Goals (UNDP 2006)

http://www.undp.org/content/dam/aplaws/publication/en/publications/povertyreduction/poverty-website/human-rights-and-the-millennium-developmentgoals/Human\%20Rights\%20and\%20the\%20MDGs.pdf accessed January 2020

- UNDP Human Development Report 2000: Human Rights and Human Development (Oxford University Press. New York 2000)

- UNDP Section 1 Human Rights and Development: An emerging nexus; human rights and development: the International Framework www.undp.org/rbap/rights/Nexus.htm accessed May 2017

- UN General Assembly Report of the Open Working Group of the General Assembly on Sustainable Development Goals, 2014 A/68/970accessed 22 ${ }^{\text {nd }}$ Nov 16

- UN General Assembly Council, Annual report of the United Nations High Commissioner for Human Rights and reports of the Office of the High Commissioner and the Secretary-General, Mental health and Human Rights. UN General Assembly Human Rights Council (November 2017) A/HRC/34/32

- UNHCR, Guidelines on Determining the Best Interests of the Child (UNHCR 2008)

- UNICEF, 'Global Evaluation of the Application of the Human Rights-Based Approach to UNICEF Programming'. Final Report - Volume I (UNICEF, 2012), www.unicef.org/policyanalysis/rights/files/UNICEF_HRBAP_Final_Report_Vol_I_1 1June_copy-edited_translated.pdf accessed May 2018

- UNICEF, Mapping the UNCRC against the Sustainable Development Goals, https://www.unicef.org/media/60231/file accessed January 2020accessed January 2020

- UNICEF https://www.unicef.org/child-rights-convention/what-is-the-convention accessed January 2020

- UN Secretary-General MDG Gap Task Force Report 2013: The Global Partnership for Development: The Challenge We Face 2013

- UN System Task Team, Post-2015 UN Development Agenda Towards Freedom from Fear and Want: Human Rights in the Post 2015 Agenda 


\section{WORLD HEALTH ORGANISATION PUBLICATIONS}

- Declaration of Alma-Ata, International Conference on Primary Health Care, AlmaAta, USSR, September 1978 http://www.euro.who.int/en/publications/policydocuments/declaration-of-alma-ata,-1978 accessed February 2020

- WHO Constitution 1948 http://www.who.int/governance/eb/who_constitution_en.pdf accessed January 2020

- WHO, Informal Consultation on Health and Human Rights, (WHO Geneva, December 4-5, 1997) WHO and OHCHR, Report of the High-Level Working Group on Health and Human Rights of Women, Children and Adolescents (2017) Leading the realisation of human rights to health and through the health http://www.ohchr.org/Documents/Issues/Women/WRGS/Health/ReportHLWGhumanrights-health.pdf accessed January 2020

- WHO Eleventh General Programme of Work (2006-2015) https://apps.who.int/iris/bitstream/handle/10665/20611/B117 16en.pdf? sequence $=1 \&$ isAllowed $=\mathrm{y}$ accessed January 2020

- WHO Medium-Term Strategic Plan (MTSP) 2008-2013 https://apps.who.int/gb/ebwha/pdf_files/MTSP2009/MTSP1-en.pdf accessed January 2018

- WHO and Commission on the Social Determinants of Health, Closing the gap in a generation: health equity through action on the social determinants of health (World Health Organisation and Commission on the Social Determinants of Health 2008)

- WHO global programme, 'Make medicines child size' https://www.who.int/childmedicines/en/ accessed January 2020

- WHO and OHCHR, A human rights-based approach to health https://www.who.int/hhr/news/hrba_to_health2.pdf accessed January 2020 ?

- WHO Linkages between health and human rights https://www.who.int/hhr/HHR\%20linkages.pdf accessed January 2020.

\section{CASES}

- Sachs J, M v The State Case CCT 53/06 (26 September 2007) para.16

- Gillick v West Norfolk \& Wisbeck Area Health Authority [1986] AC 112 House of Lords

- $\quad \mathrm{R}$ (on the application of Axon) v. Secretary for State for Health and Another [2006] EWHC 37

\section{UK PRIMARY LEGISLATION}

- Age of Criminal Responsibility Act (2019) http://www.legislation.gov.uk/asp/2019/7/contents/enacted accessed January 2020

- Children's Commissioner for Wales Act (2001) http://www.legislation.gov.uk/ukpga/2001/18/contents accessed January 2020

- Child Poverty Act (2010) http://www.legislation.gov.uk/ukpga/2010/9/pdfs/ukpga_20100009_en.pdf accessed January 2020

- Equality Act 2010 http://www.legislation.gov.uk/ukpga/2010/15/contents accessed January 2020 
- Government of Wales Act (2006)

http://www.legislation.gov.uk/ukpga/2006/32/contents accessed February 2020

- NHS Wales Act (2006) http://www.legislation.gov.uk/ukpga/2006/42/contents accessed January 2020

\section{WALES PRIMARY LEGISLATION}

- Children and Families (Wales) Measure 2010

http://www.legislation.gov.uk/mwa/2010/1/contents accessed January 2020

- Rights of Children and Young Persons (Wales) Measure 2011 http://www.legislation.gov.uk/mwa/2011/2/contents accessed January 2020

- Public Health (Wales) Act http://www.legislation.gov.uk/anaw/2017/2/contents/enacted16 accessed January 2020

- Social Services and Well-Being Act (Wales) 2014 http://www.legislation.gov.uk/anaw/2014/4/contents accessed January 2020

- Well-Being and Future Generations Act (Wales) 2015 http://www.legislation.gov.uk/anaw/2015/2/contents/enacted accessed January 2020

\section{UK PARLIAMENT PUBLICATIONS}

- All Party Parliamentary Group on Inclusive Growth 2019 Report https://www.inclusivegrowth.co.uk/ accessed November 2019

- UK Parliament, Public Accounts Committee Report (UK Parliament July 2019) https://publications.parliament.uk/pa/cm201719/cmselect/cmpubacc/1751/175102.htm accessed January 2020

- UK Parliament, Parliamentary Review of Health and Social Care in Wales: A revolution from within: transforming health and care in Wales (UK Parliament January 2018) https://gov.wales/sites/default/files/publications/2018-01/Reviewhealth-social-care-report-final.pdf accessed January 2020

\section{UK GOVERNMENT PUBLICATIONS}

- Department of Health, Lost in care: Report of the Tribunal of Inquiry into the Abuse of Children in Care in the Former County Council Areas of Gwynedd and Clwyd since 1974 (Department of Health 1999)

https://webarchive.nationalarchives.gov.uk/20130124064403/http:/www.dh.gov.uk/pr od_consum_dh/groups/dh_digitalassets/documents/digitalasset/dh_134777.pdf accessed January 2020

- Department of Health, Human Rights a Framework for local Action (Department of Health 2008)

http://webarchive.nationalarchives.gov.uk/20130124044024/http://www.dh.gov.uk/pr od consum_dh/groups/dh_digitalassets/@dh/@en/documents/digitalasset/dh_088972. pdf accessed January 2020

- Department of Health, Reference Guide to Consent for Examination or Treatment (2nd edn Department of Health 2009)

- Kennedy I, Getting it right for children and young people: Overcoming cultural barriers in the NHS so as to meet their needs (Department of Health 2010) 


\section{NATIONAL ASSEMBLY FOR WALES PUBLICATIONS}

- Lord Carlisle, The Review of Safeguards for Children and Young People Treated and Cared for by the NHS in Wales, "Too Serious a Thing" (National Assembly for Wales 2001) http://www.wales.nhs.uk/publications/English text.pdf accessed February 2019

- National Assembly for Wales, Health in Wales, Everybody's Business (National Assembly for Wales 2001) http://www.wales.nhs.uk/document/111047/info/ accessed March 2017

- National Assembly for Wales, Barnett Formula: Funding the Devolved Administrations (National Assembly for Wales 2008) http://www.assembly.wales/NAfW\%20Documents/09-012.pdf\%20\%2026032009/09-012-English.pdf accessed January 2020

- National Assembly for Wales Children, Young People and Education Committee, Inquiry into Child and Adolescent Mental Health Services, November 2014, National Assembly for Wales, http://www.senedd.assembly.wales/documents/s34408/Report\%20November $\% 20201$ 4.pdf accessed March 2018

- National Assembly for Wales Children and Young People Education Committee Children's Rights Inquiry, Evidence Session with Deputy Minister for Health and Social Services November $6^{\text {th }} 2019$

- National Assembly for Wales Children and Young People and Education Committee, Inquiry into Children's Rights October $6^{\text {th }} 2019$ http://senedd.assembly.wales/mgIssueHistoryHome.aspx?IId=25724 accessed January 2020

- National Assembly for Wales Cross Party Group on Medical Research Fourth meeting of 2019, First Inquiry Session: Patient and public involvement. November $19^{\text {th }} 2019$

- National Assembly Research Service, Health Policy a Topic Brief, National Assembly Research Service 2007 http://www.assembly.wales/NAfW\%20Documents/tb-08003.pdf\%20-\%2028072009/tb-08-003-English.pdf accessed February 2020

\section{WELSH PARLIAMENT PUBLICATIONS}

- Welsh Parliament, National Inquiry into Children's Rights 2020 https://senedd.wales/laid\%20documents/cr-ld13405-r/cr-ld13405-r-e.pdf accessed on 10 December 2020

- Welsh Parliament, Record of Proceedings, January $20^{\text {th }} 2021$ https://record.assembly.wales/Plenary/11172 accessed on 3 February 2021.

\section{WELSH ASSEMBLY GOVERNMENT (1999-2006) AND WELSH GOVERNMENT PUBLICATIONS (2007+)}

- Welsh Assembly Government, Children and Young People: Rights to Action (Welsh Assembly Government 2004)

- Welsh Assembly Government, Children and Young People: Rights to Action. Guidance on local cooperation under the Children Act 2004 (Welsh Assembly Government 2004) 
- Welsh Assembly Government, National Service Framework for Young People and Maternity Services (Welsh Assembly Government 2005)

http://www.wales.nhs.uk/sites3/home.cfm?OrgID=441 accessed January 2020

- Welsh Assembly Government, One Wales: A progressive agenda for the government of Wales, (Welsh Assembly Government 27 June 2007)

- Welsh Government, School Education Effectiveness Framework (Welsh Government 2008)

http://gov.wales/topics/educationandskills/publications/guidance/schooleffectivenessf ramework/?lang=en accessed February 2018

- Welsh Government, Patient Consent to Examination and Treatment-Revised Guidance, Welsh Health Circular, (WHC 2008,10, February 29)

http://www.wales.nhs.uk/sites3/Documents/465/WHC\%282008\%29010.pdf accessed January 2020

- Welsh Government, A Framework for a School Nursing Service for Wales (Welsh Government 2009)

- Welsh Government, National Action Plan on Children's Rights (Welsh Government 2009) http://dera.ioe.ac.uk/10867/1/091117gettingitrighten.pdf accessed January 2020

- Welsh Government, Our Healthy Future: Technical Working Paper (Welsh Government 2009) http://gov.wales/docs/phhs/publications/100527technicalen.pdf accessed January 2020

- Welsh Government, Thinking positively: emotional health and wellbeing in schools and early years settings (Welsh Government 2010)

http://gov.wales/topics/educationandskills/publications/guidance/thinkingpositively/?1 ang=en accessed January 2020

- Welsh Government, Setting the Direction: Primary and Community Services Community Delivery Plan (Welsh Government 2010)

- Welsh Government, Together for Health: A Five Year Vision for the NHS in Wales (Welsh Government 2011)

- Welsh Government, Building a brighter future: early years and childcare plan (Welsh Government 2013) http://gov.wales/topics/people-andcommunities/people/children-and-young-people/early-years/building-a-brighterfuture-early-years-and-childcare-plan/?lang=en accessed January 2020

- Welsh Government, Delivering local healthcare, accelerating the pace of change (Welsh Government 2013) http://gov.wales/docs/dhss/publications/130625localhealthcareen.pdf accessed January 2019

- Welsh Government, Child Poverty Strategy for Wales (revised) (Cardiff: Welsh Government 2015)

- Welsh Government, Children and young people's wellbeing monitor for Wales 2015: Summary https:/gov.wales/sites/default/files/statistics-and-research/2019-07/151211-childrenyoung-people-wellbeing-monitor-2015-summary-en.pdf accessed January 2020

- Welsh Government, Children's Scheme (Welsh Government 2014) http://www.assembly.wales/Laid\%20Documents/GEN-LD9732\%20\%20Children's\%20Rights\%20Scheme\%202014-22042014-255569/gen-ld9732-eEnglish.pdf accessed January 2020

- Welsh Government, 2013/14 Health Behaviour in School-aged Children (HBSC) Wales: key findings (Welsh Government 2015) 
https://gov.wales/docs/caecd/research/2015/151022-health-behaviour-schoolchildren-2013-14-key-findings-en.pdf accessed January 2020

- Welsh Government, Programme for Government for Children (Welsh Government 2015) https://gov.wales/sites/default/files/publications/2019-06/seven-core-aims-forchildren-and-young-people.pdf

- Welsh Government, Child Poverty Strategy: Assessment of Progress 2016. Summary report (Welsh Government 2016)

https://gov.wales/docs/dsjlg/publications/cyp/161212-child-poverty-strategy-progressreport-2016-en.pdf accessed January 2020

- Welsh Government and NHS Wales, Prudent Health Care; Securing Health and Well-Being for Future Generations (Welsh Government and NHS Wales 2016) http://www.prudenthealthcare.org.uk/wp-content/uploads/2016/02/Securing-Healthand-Wellbeing-for-Future-Generations1.pdf accessed January 2020

- Welsh Government, A Healthier Wales: Out Plan for Health and Social Care 2018 (Welsh Government 2018) www.basw.co.uk/system/files/resources/180608healthierwales-mainen.pdf accessed January 2020

- Welsh Government, In brief: A Healthier Wales: Our plan for health and social care (Welsh Government 2018) https://gov.wales/docs/dhss/publications/180611ltpinbriefen.pdf accessed December 2018

- Welsh Government, Compliance report on the Rights of Children and Young Persons (Wales) Measure 2011 (Welsh Government 2018) https://gov.wales/rights-childrenand-young-people-compliance-report accessed February 2020

- Welsh Government, All Wales Breast Feeding Action Plan 2019 -2024 (Welsh Government 2019) https://gov.wales/breastfeeding-plan-2019-2024 accessed March 2020

- Welsh Government, Deputy Minister Health and Social Services. Letter to Chair of Welsh Parliament Children and Young People and Education Committee' 23 ${ }^{\text {rd }}$ September 2020 https://business.senedd.wales/documents/s 105741/Welsh\%20Government\%20respons e\%20-\%2023\%20Sept accessed February 172021

\section{NHS PUBLICATIONS}

- NHS England and British Youth Council, A bitesize guide to setting up a youth forum in services across England (NHS England 2015) https://www.england.nhs.uk/wpcontent/uploads/2015/02/how-to-guid-yth-forum.pdf accessed January 2020

- NHS England, Healthcare Play Specialist Education Trust Children's Environments of Care Report, Exploring the impact environments have on children and young people's experience of healthcare: a review of the literature for NHS England (NHS England May

https://www.hpset.org.uk/downloads/research_development/HPSET_CEC\%20Report. pdf accessed January 2020

- NHS Digital, Mental Health of Children and Young People in England (2017 NHS, PAS) https://digital.nhs.uk/data-and-information/publications/statistical/mentalhealth-of-children-and-young-people-in-england/2017/2017 accessed January 2020

- NHS England, Children and Young People's Survey http://www.cqc.org.uk/publications/surveys/children-young-peoples-survey-2016 accessed January 2020 
- NHS Institute for Innovation and Improvement, The 15 Steps Challenge: Quality from a Patient's Perspective (NHS Institute for Innovation and Improvement 2012) https://hic.org.au/wp-content/uploads/2019/10/Health-Issues-Centre-15-stepschallenge-toolkit.pdf

- NHS Performance Complaints https://statswales.gov.wales/Catalogue/Health-andSocial-Care/NHS-Performance/Complaints accessed June 2018

- NHS Wales, Improving health in Wales: A Plan for the NHS with its Partners (NHS Wales 2001)

- NHS Wales, Designed for Life (NHS Wales May 2005) http://www.wales.nhs.uk/documents/designed-for-life-e.pdf accessed January 2020

- NHS Wales ABMU Children's Rights Charter http://www.wales.nhs.uk/sitesplus/documents/863/Bilingual $\% 20$ Children $\% 27 \mathrm{~s} \% 20 \mathrm{Ri}$ ghts $\% 20$ Charter.pdf

- NHS Wales Putting it Right, NHS Wales integrated process for complaints http://www.wales.nhs.uk/governance-emanual/putting-things-right accessed January 2020

- NHS Wales, Health in Wales http://www.wales.nhs.uk/nhswalesaboutus/structure accessed January 2020

- NHS Wales Governance E Manual http://www.wales.nhs.uk/governanceemanual/primary-legislation accessed February 2020

- NHS and Welsh Government (2012) Working differently, working together: A framework to support the development of a fully integrated healthcare organisation.

- NHS Wales and Welsh Government, An overview to the Healthy Child Wales Programme (2019) https://gov.wales/sites/default/files/publications/2019-05/anoverview-of-the-healthy-child-wales-programme.pdf accessed January 2020

\section{ROYAL COLLEGE OF PAEDIATRICS AND CHILD HEALTH PUBLICATIONS}

- Royal College of Paediatrics and Child Health, Good Medical Practice in Paediatrics and Child Health: Duties and Responsibilities of Paediatricians (Royal College of Paediatrics and Child Health, London 2002)

- Royal College of Paediatrics and Child Health, Facing the Future: Standards for Paediatric Services (Royal College of Paediatrics and Child Health 2010)

- Royal College of Paediatrics and Child Health, Working party of the Royal College of Paediatrics Guidance on clinical research involving infants, children and young people: an update for researchers and research ethics committees (RCPCH 2014)

- Royal College of Paediatrics and Child Health, Child Health Matters, A Vision for 2016 in Wales (Royal College of Paediatrics and Child Health 2016)

- Royal College of Paediatrics and Child Health, State of Child Health: 2017 Recommendations for Wales (Royal College of Paediatrics and Child Health 2017)

- Royal College of Paediatrics and Child Health and British Association for Community Child Health, Covering all bases - Community Child Health: A paediatric workforce guide (Royal College of Paediatrics and Child Health 2017) www.rcpch.ac.uk/resources/covering-all-bases-community-child-health-paediatricworkforce-guide accessed January 2020

- Royal College of Paediatrics and Child Health in Wales, Mortality Indicators https://www.rcpch.ac.uk/resources/state-child-health-1-mortality-indicators accessed January 2020 
- Royal College of Paediatrics and Child Health, Turning the tide-five years on (Royal College of Paediatrics and Child Health 2018) https://www.rcpch.ac.uk/sites/default/files/2018-03/turning the tide_five years on_2018-03.pdf accessed January 2020

- Royal College of Paediatrics and Child Health (2019) Workforce census: Focus on Wales: An Executive Summary (Royal College of Paediatrics and Child Health 2019) https://www.rcpch.ac.uk/resources/workforce-census-focus-wales2019\#downloadBox accessed December 2019

- Royal College of Paediatrics and Child Health, 'Worrying lack of children's doctors in Wales could damage health of future generations, say medical experts,' (May 10 2019) https://www.rcpch.ac.uk/news-events/news/worrying-lack-childrens-doctorswales-could-damage-health-future-generations-say accessed January 2020

- Royal College of Paediatrics and Child Health, One year on Score Card https://www.rcpch.ac.uk/sites/default/files/2018-02/state of child health wales one year on scorecard english 2018-01.pdf accessed March 2018

- Royal College of Paediatrics and Child Health, State of Child Health Report 2020: Mental Health Services https://stateofchildhealth.rcpch.ac.uk/evidence/mentalhealth/services/ accessed March 2020

- Royal College of Paediatrics and Child Health, State of Child Health 2020: Wales (RCPCH 2020)

\section{PUBLIC HEALTH WALES PUBLICATIONS}

- Public Health Wales NHS Trust, Child Measurement Programme for Wales 2016/17 (Public Health Wales NHS Trust 2018)

http://www.wales.nhs.uk/sitesplus/documents/888/12743\%20PHW\%20CMP\%20Rep ort $\% 20 \% 28$ Eng\%29.pdf accessed January 2020

- Public Health Wales Observatory, Tobacco and health in Wales (Public Health Wales Observatory 2012)

- Public Health Wales Observatory, Health of Children and Young People, (Public Health Wales NHS Trust 2013) http://www.wales.nhs.uk/sitesplus/922/page/69313 accessed January 2020

- Public Health Wales Observatory, Health and its Determinants in Wales - Informing Strategic Planning (Public Health Wales NHS Trust 2018) http://www2.nphs.wales.nhs.uk:8080/PubHObservatoryProjDocs.nsf/85c50756737f7 9ac80256f2700534ea3/99a9490d2e6d05268025820b005851de/\$FILE/Health\&determ inantsinWales_Report_Eng.pdf accessed January 2020

- Public Health Wales NHS Trust, Welsh Adverse Childhood Experiences Study (Public Health Wales Trust 2015) http://www.cph.org.uk/wp-content/uploads/2016/01/ACEReport-FINAL-E.pdf accessed January 2020

- Public Health Wales, Pregnancy and childhood surveillance tool (Public Health Wales Trust 2017) http://www.publichealthwalesobservatory.wales.nhs.uk/pregnancychildhood accessed February 2020 


\section{SECONDARY SOURCES (Books, journals, reports, newspaper articles,}

websites)

- Abertawe Bro Morgannwg University Health Board, Children and Young Person's Strategy (ABMU September 2017)

- Abertawe Bro Morgannwg Health Board, Annual Quality Statement 2018 (ABMU 2018)

- Acheson D, Independent Inquiry into Inequalities in Health (London: The Stationery Office; 1998)

- Aisling P, Children and International Human Rights Law: The Right of the Child to be heard (Routledge 2013)

- Alanen L, Brooker E, Mayall B (eds.) Childhood with Bourdieu (Palgrave, Macmillan 2015)

- Alderson P, 'Children's Consent and 'Assent' to Healthcare Research,' In Freeman M (eds) Law and Childhood Studies: Current Legal Issues Volume 14 (Oxford Scholarship online 2012)

- Alderson P, Listening to children: children, ethics and social research (London: Barnardos)

- Alderson P and Montgomery J, Health care choices, making decisions with children (IPPR 1996)

- Alderson P, Children's Consent to Surgery (Open University Press, Buckingham 1993) 154-63

- Alderson P, 'Children as Researchers. The Effects of Participatory Rights on Research Methodology', In Christensen P and James A (eds) Research with Children. Perspectives and Practices, 241-257. (London: Routledge Falmer 2000)

- Alderson P, Hawthorne J and Killen M 'The participation rights of premature babies', International Journal of Children's Rights (2005) 13/1-2

- Alston P 'The Historical Origins of the Concept of "General Comments", In Human Rights Law,' In Laurence Boisson de Chazournes and Vera Gowlland-Debbas (eds), The International Legal System in Quest of Equity and Universality: Liber Amicorum Georges Abi-Saab (MartinusNijhoff, 2001)

- Alston, $\mathrm{P}$ 'The Legal Framework of the Convention on the Rights of the Child', Bulletin of Human Rights, 91/2 1992 1-15

- American Academy of Pediatrics Committee on Bioethics, 'Informed consent, parental permission, and assent in pediatric practice', Pediatrics (1995) 95:314-317. [PubMed]

- Angst and Deatrick, 'Involvement in health care decisions: Parents and Children with Chronic Illness', Journal of Nursing May 11996

- Anwar E, Barr B, Law C, Taylor-Robinson D, 'Poverty and child health in the UK: using evidence for action', BMJ Archives of Diseases of Childhood, (2016) Vol 101, Issue 8

- Archard D, Children: Rights and childhood (2nd edn London: Routledge 2004)

- Archard D and Skivenes M. 'Deciding best interests: general principles and the cases of Norway and the UK,' Journal of Children's Services (2010) 5 (4), 43-54

- Arie de Bruin, 'Children's Rights in Health Care and the Legacy of Janusz Korczak', In Children's Rights and Health Care (eds) Doek and Dorscheist (Brill Publications 2018) 
- Aspinwall T and Croke R, 'Policy Advocacy Campaigns: the collective voices of children's NGOs in Wales,' In Williams J (eds) The UNCRC in Wales (University of Wales Press 2013)

- Aynsley-Green A, Barker M, Burr S, Macfarlane A, Morgan J, Sibert J, Turner T, Viner R, Waterston T, Hall D, 'Who is speaking for children and adolescents and for their health at the policy level?' BMJ (2000)

- Baines P, 'Assent for children's participation in research is incoherent and wrong', Archives of Diseases in Childhood, Volume (2011) 96. Issue 10.

- Balen R, Blyth E, Calabretto H, Fraser C, Horrocks C, and Manby M, 'Involving children in health and social research: "Human becomings" or "active beings"?' Childhood (2006) 13(1)

- Baude W, 'Making Doctrinal Work More Rigorous: Lessons from Systematic Reviews', University of Chicago Law Review 37 (May 2017)

- BBC Teach 'When I worry about things' https://www.bbc.co.uk/programmes/articles/5QM6H01X6b3jTQF85GLgbF1/when-iworry-about-things accessed January 2020

- Beazley H, Bessell S, Ennew J \& Waterson R, The right to be properly researched: research with children in a messy, real world, Children's Geographies 2009, 7:4, 365 378

- Bell J, 'Understanding Adultism: A Major Obstacle to Developing Positive YouthAdult Relationships,' Youth Build USA (1995)

- Bensted R, Hargreaves D S, Lombard J, Kilkelly U\$ and Viner R M, 'Comparison of healthcare priorities in childhood and early/late adolescence: analysis of crosssectional data from eight countries in the CoE Child-friendly Healthcare Survey 2011,' Child Care, Health and Development (2015) Jan;41(1):160-5

- Berger R, 'Now I see it, now I don't: Researcher's position and reflexivity in qualitative research', Qualitative Research, 15(2), 2013 219-234

- Bester, J and Kodish E, 'Children Are Not the Property of Their Parents: The Need for a Clear Statement of Ethical Obligations and Boundaries,' The American Journal of Bioethics Volume 17 (2017) - Issue 11

- Biesta G, Pragmatism and the philosophical foundations of mixed methods research. In Handbook of Mixed Methods in Social and Behavioral Research, 2nd ed. Tashakkori A and Teddlie C (Thousand Oaks: Sage 2010)

- Birrell D, The impact of devolution on social policy (Bristol: Policy Press 2009)

- Black D, Inequalities in Health (London: Penguin; 1980)

- Bourdieu P, Distinction: A Social Critique of the Judgment of Taste, translated by Nice R Nice (Harvard University Press:1984 [1979])

- Bourdieu P, Language and Symbolic Power (Harvard University Press 1991)

- Boyden J and Ennew J, Children in Focus - a manual for participatory action research with children, Radda Barnen (Swedish Save the Children, Stockholm 1997)

- Boylan J and Dalrymple J, Understanding Advocacy for Children and Young People (Mcraw Hill Education UK 2009)

- Boylan P, Children's Voices Project. Feedback from Children and Young People about their experiences and expectations of Health Care (Commission for Health improvement National Health Service 2004)

- Braun V and Clarke V, Thematic Analysis; Handbook of Research Methods in Health Social Sciences (Springer 2019) 843-860.

- Brannick T and Coghlan D, "In Defense of Being "Native": The Case for Insider Academic Research', Sage Journals, January 1, 2007 
- Brewer J and Hunter A, Multi-method Research: A Synthesis of Styles (London: Sage 1998)

- Bristol Royal Infirmary, Learning from Bristol: The Report of the Public Inquiry into Children's Heart Surgery at the Bristol Royal Infirmary 1984-1995 Command Paper CM 5207 (Bristol Royal Infirmary Inquiry, Bristol 2001).

- Broberg M and Sano H, 'Strengths and weaknesses in a human rights-based approach to international development - an analysis of a rights-based approach to development assistance based on practical experiences,' The International Journal of Human Rights, (2018) 22:5, 664-680

- Bryant C G A, and Jary D, Coming to terms with Anthony Giddens, In Bryant C and Jary D (eds.) Giddens' theory of structuration: A critical appreciation (New York, NY: Routledge 1991).

- Bryman A, Quantity and Quality in Social Research (London: Routledge, $1^{\text {st }}$ ed 1998); Bryman (2004) Quantity and Quality in Social Research (London: Routledge, $2^{\text {nd }}$ ed 2004)

- Butler D L, 'Investigating self-regulated learning using in-depth case study', In Zimmerman B J and Schunk D H (eds.), Handbook of self-regulation of learning and performance (346-360) (New York, NY: Routledge 2011)

- Buchen L, 'Science in court: Arrested development,' Nature News, International weekly journal of science (2012) Volume 484, Issue 7394

- Burnett S, Bird G, Moll J, Frith C and Blakemore S, J, 'Development during adolescence of the neural processing of social emotion', Journal of Cognitive Neuroscience (2009) 1736-1750

- Burns J H and Hart H L A (eds) The collected works of Jeramy Bentham: An Introduction to the Principles and Morals of legislation (London: The Athlone Press, 1982)

- Bustreo F and Hunt P, Women's and children's health: Evidence of impact of human rights (Geneva: World Health Organization, 2013) http://apps.who.int/iris/bitstre am/10665/84203/1/9789241505420 eng.pdf. 15 accessed January 2020

- Butler 1 and Drakeford M, 'Children's rights as a policy framework in Wales,' In Williams J (eds) The UNCRC in Wales (Wales University press 2013)

- Cameron C, "Access to health services: Care leavers and young people "in difficulty", ChildRight (2007) 238: 22-25

- Cantwell N, 'Are children's rights still human?' In Invernizzi A and Williams J (eds), The Human Rights of Children: From Visions to Implementation (Farnham: Ashgate 2011)

- Cantwell N, "Are the "Best Interests" a Pillar or a problem for Implementing Human Rights of Children?' In Liefaard T, Sloth-Nielsen J (eds.): The United Nations Convention on the Rights of the Child. Taking Stock after 25 Years and Looking Ahead (Leiden/Boston, Brill 2017)

- Care Quality Commission, Regulations for Health and Social Care (Care Quality Commission 2014) https://www.cqc.org.uk/sites/default/files/20150416_our_human_rights_approach.pdf

- Care International, 'Accountability and Transparency', https://www.careinternational.org/who-we-are-1/accountability-transparency accessed January 2018

- Cave E, Young People who refuse life sustaining treatment: A briefing paper on current law and the need for reform (University of Leeds 2013)

- Chandni M J, Baird J, Barker M, Cooper C and Hanson M, The Importance of a Life Course Approach to Health: Chronic Disease Risk from Preconception through 
Adolescence and Adulthood (Institute of Development Studies, University of South Hampton) accessed January 2020

- Chapman A, 'The Foundations of a Human Right to Health: Human Rights and Bioethics in Dialogue', Health and Human Rights Journal (2015) Vol. 1 Issue 17

- Charles A and Haines K, 'Engaging young people as partners for change: The UR Community Project, The International Journal of Children's Rights, Volume 27: Issue 116 February 2019

- Chase, E and A. Knight, et al, 'The emotional well-being of unaccompanied young people seeking asylum in the UK,' London, British Association for Adoption and Fostering (BAAF 2008) 51-56 Cited in Listening to children's views on health provision (NCB 2013)

- Cheah P Y, and Parker M 'Research consent from young people in resource-poor settings,' Archives of Disease in Childhood (2015) 100(5): 438-40

- Chae-Young K, Sheehy K, Kerawalla L, Developing children as researchers: $A$ practical guide to help children do social research. (London: Routledge 2017)

- Children's rights knowledge centre, A discussion of commonly encountered tensions and possible solutions based on international best interests and policy strategies since 2004: A study of the Children's Knowledge Centre (Commissioned by the Flemish Government Division of Youth, 2014)

- Children's Commissioner for England, Child, Friendly Complaints Processes in Health Services, Principles, Pledges and Progress (CCfE 2013)

- Children's Commissioner for England, It takes a lot of courage - Children and young people's experiences of complaints procedures for services for mental health and sexual health including those provided by GPs' (CCfE 2012) 84-85

- Children's Commissioner for Wales, The Right Way: A Children's Human Rights Approach (Children's Commissioner for Wales 2017) https://www.childcomwales.org.uk/wp-content/uploads/2017/04/The-Right-Way.pdf accessed January 2020

- Children's Commissioner for Wales, Charter for Change: Protecting Welsh Children from the Impact of Poverty, https://www.childcomwales.org.uk/a-charter-for-changeprotecting-welsh-children-from-the- impact-of-poverty-2/ accessed January 2020

- Children's Commissioner for Wales, Children's Rights Impact Assessment. n.d. Available online: https://www.childcomwales.org.uk/resources/childrens-rightsapproach/right-way-childrens-rights-approach-wales/ accessed on 6 December 2020

- Children's Commissioner for Wales and Future Generations Commissioner, The Right Way: A Wales Future Fit for Children 2017

https://www.childrensrightsplanning.wales/wp-content/uploads/2018/06/CCFWFGCW-Report-_English_01.pdf accessed on 21 December 2020.

- Children's Commissioner for Wales, Children's Rights Inquiry Response 5th November 2020

https://business.senedd.wales/documents/s 109281/Additional $\% 20$ information $\% 20$ fro m\%20Childrens $\% 20$ Commissioner $\% 20$ for $\% 20$ Wales $\% 20$ regarding $\% 20$ Welsh $\% 20 \mathrm{Go}$ vernments $\% 20$ response $\% 20$.pdf accessed on 2 March 2021

- Choudhury S, 'Culturing the adolescent brain: what can neuroscience learn from anthropology?' Social Cognitive and Affective Neuroscience, (2010) Volume 5, Issue 2-3, 1 June 159-167

- Citizens Advice Bureau, Children's Consent https://www.citizensadvice.org.uk/wales/health/nhs-healthcare/nhs-services-in-walesw/nhs-patients-rights-in-wales-w/\#h-children-and-consent accessed January 2020 
- Clark A, Understanding Research with Children and Young People (Published in association with The Open University 2013)

- Clark V, Braun V and Hayfield N, 'Thematic Analysis', In Smith J A (eds) Qualitative Psychology: A Practical Guide to Research Methods (Sage 2015)

- Clements K, Opening the door to better health care: Ensuring General practice is working for children and young people (NCB 2013)

- Clutton S, 'Devolution and the language of children's rights in the UK', In Invernizzi A and Williams J (eds), Children and Citizenship (London: Sage) 171-81.

- Coad J and Evans R, 'Reflections on Practical Approaches to Involving Children and Young People in the Data Analysis Process', Children and Society 2008 22(1): 41-5

- Commission to the European Parliament and Council, State of Paediatric Medicines in the EU 10 years of the EU Paediatric Regulation (COM 2017 626)

https:/ec.europa.eu/health/sites/health/files/files/paediatrics/docs/2017 childrensmedi cines report en.pdf accessed January 2020

- Connor P, Croke R*, Thomas-Turner R, Access to medicines and good quality paediatric research: children's human rights implications and considerations for the Welsh contexthttp://senedd.assembly.wales/documents/s94526/CYPE5-28-19\%20\%20Paper\%202.pdf accessed January 2020.

- Connor P, Croke R*, Edwards M, Thomas-Turner R, and Tuthill D, Submission to the Senedd Children and Young People Education Committee in advance of the Senedd's Plenary Debate on Children's Rights November $5^{\text {th }} 2020$ Available online: https://business.senedd.wales/documents/s 109280/Additional\%20information\%20fro m\%20Noahs\%20Ark\%2 accessed February 172021

- Corbin Dwyer S and Buckle J L, 'The Space Between: On Being an Insider-Outsider in Qualitative Research', Sage Journals, March 1, 2009

- Council for Disabled Children (2011), 'Managing My way', cited in Clements K, Opening the door to better health care: Ensuring General practice is working for children and young people (NCB 2013)

- Council of Europe, Child Friendly Guidelines to HealthCare (COE 2011) https://rm.coe.int/guidelines-of-the-committee-of-ministers-of-the-council-of-europeon-c/16808c3a9f accessed January 2020

- Council of the European Union, EU Action Plan on Human Rights and Democracy (Luxembourg 2015), https://eeas.europa.eu/human_rights/docs/eu_action_plan_on_human_rights_and_dem ocracy en.pdf accessed October 2017

- Coyne I, Regan G, Hayes E, Gallagher P, Giving children a voice: Investigation of children's experiences of participation in consultation and decision making in Irish hospitals (Dublin: office of the Minister for Children 2006)

- Coyne I, 'Accessing children as research participants: examining the role of gatekeepers', Childcare, health and development', Vol 36 Issue 4 (2010)

- Coyne I and Gallagher P, 'Participation in communication and decision-making: children and young people's experiences in a hospital setting', Journal of Clinical Nursing (2011)

- CRIN 'Guide to non-discrimination and the CRC' (Child Rights Information Network 2009) http://www.crin.org/Discrimination/CRC/index.asp accessed January 2020

- Creswell J W, Research design: Qualitative, quantitative and mixed methods approaches (London: Sage Publications 2003)

- Creswell J W and Plano Clark V L, Designing and Conducting Mixed Methods Research, 2nd Edition (Sage Publications, Los Angeles 2011). 
- Croke $\mathrm{R}$ and Crowley A (eds) Righting the wrongs: the reality of children's rights in Wales (Save the Children UK 2006).

- Croke R and Crowley A (eds) Stop, Look, Listen: the road to realising children's rights in Wales. (Save the Children UK 2007)

- Croke R and Crowley A, 'Human Rights and Child Poverty in the UK', In Invernizzi A and Williams J (eds), The Human Rights of Children: From Visions to Implementation (Farnham: Ashgate 2011) 267

- Croke R, on behalf of the Wales UNCRC Monitoring Group, POLICY BRIEFING 25th Anniversary of the United Nations Convention on the Rights of the Child: Welsh Government action needed to support effective structures and legislation that respects and protects children's human rights (Wales UNCRC Monitoring Group 2014)

- Croke $\mathrm{R}$ (eds) Rights here, right now: What is the reality of children's rights in Wales? (Save the Children UK 2013)

- Croke R and Williams J (eds) Wales UNCRC Monitoring Group report to the UN Committee on the Rights of the Child (Swansea University 2015) https://www.swansea.ac.uk/media/WalesUNCRCReport v3.pdf accessed May 2016

- Croke R, A new Youth Assembly for Wales? A comparative exploration into the best practice elements of 17 youth parliaments in the UK, Europe and globally (CYPAW 2016

- Croke R and Williams J, Our rights, our parliament: The story of the campaign for the children and young people's assembly for Wales 2014-2018 (Swansea University 2018)

- Crowley A, 'Is anyone listening? The impact of children's participation on public policy', International Journal of Children's Rights (2014) 23 (3):571-590

- Daly A, 'Assessing Children's Capacity: Reconceptualising our Understanding through the UN Convention on the Rights of the Child', International Journal of Children's Rights, 2020 Volume 28 Issue 3

- Danish Institute of Human Rights, The Human Rights Guide to the Sustainable Development Goals. http://sdg.humanrights.dk/en/targets2?goal[]=72 accessed January 2020

- DANIDA online lessons in understanding what a human rights approach is. http://humanrightseducation.dk/HRBA_elearning/Lesson_4\%20/story html5.html accessed January 2020

- Darrow M and Tomas A, 'Power, Capture, and Conflict: A Call for Human Rights Accountability in Development Cooperation', Human Rights Quarterly (2005) 27 486-487

- Davidson S, Human Rights (law and political change) (McGraw-Hill Education 16 May 1993)

- de Leeuw E D, Improving data quality when surveying children and adolescents cognitive social development and its role in questionnaire construction and pretesting (Report prepared for the annual meeting of the academy of Finland: Research Programmes, Public Health Challenges and Health and Welfare of Children and Young People 2011)

- De Vries M and Rings E, 'Children's Rights in Paediatric Practice' In, Doek and Dorscheist (eds) Children's rights in Health Care (Brill Publications 2018)

- De Vries M C, Wit J M, Engberts D P, Kaspers G J L, Van Leeuwen E, 'Norms versus Practice: Pediatric Oncologists' Attitudes towards Involving Adolescents in Decision Making concerning Research Participation', Pediatr Blood Cancer. 2010; 55:123-128. 
- Declaration on the Rights of the Child https://blogs.lse.ac.uk/lsehistory/2017/03/08/eglantyne-jebb-and-the-respectedprotected-the-rights-of-children-exhibition/ accessed May 2019

- De Beco G, 'Measuring Human Rights: Underlying Approach', (2007) E.H.R.L.R., Issue 3: 266-278

- De Laet D, 'Genital Autonomy, children rights and competing rights claims in international human rights law', The International Journal of Children's Rights (2012) 20(4), 554-583

- Denburg AE, Giacomini M, Ungar WJ, Abelson J, 'The Moral Foundations of Child Health and Social Policies: A Critical Interpretive Synthesis', Children. 2021; 8(1):43

- Denzin N K and Lincoln Y S, 'Introduction: The discipline and practice of qualitative research', In K. Denzin NK and Lincoln Y S (eds.) The Sage handbook of qualitative research (4th ed 1-20) (Thousand Oaks, CA: Sage Publications 2011)

- Dietrick S A, Commentary on the United Nations Convention on the Rights of the Child (The Hague: Brill/Nijhoff 1999)

- Dobbs, T and Duncan J 'Children's Perspectives on Physical Discipline: A New Zealand Example', Journal Child Care in Practice (2004) Volume 10, 2004 - Issue 4

- Doek J, 'Children's rights in health care and the General Principles of the CRC', In Doek J and Dorscheist M (eds) Children's Rights in Health Care (Brill Publications 2018)

- Doek J, 'The CRC General Principles,' In (eds) Connors J, Zermatten J, Panayotidis A, 18 Candles: The Convention on the Rights of the Child reaches majority (Geneva: Institut international des droits de l'enfant 2007) 31-32

- Donnelly M and Kilkelly U, 'Child-friendly health care: delivering on the right to be heard', Medical Law Review (2011) Volume 19 Issue 1, Winter

- Dowdle M W, 'Public accountability: conceptual, historical and epistemic mappings', In Dowdle M W (ed) Public Accountability, Designs, Dilemma and Experiences (New York: Cambridge University Press)

- Downie A, 'Consent to Medical Treatment -- Whose View of Welfare? Family Law Journal' (1999) 29818 commenting on Re W [1992] 4 All ER 627.

- Drisko J W, 'Constructivist research in social work', In A. E. Fortune, Reid W J and Miller R L (eds) Qualitative research in social work (pp. 81-106) (New York, NY: Columbia University Press 2013)

- Dupuy R (ed), Le Droit à la santé entant que droit de l'homme / The right to health as a human right (Amsterdam: Sijthoff and Noordhoff, 1979

- Dura Kuper A, Lingard L, Levinson W, 'Critically appraising qualitative research', BMJ 2008;337: a1035n et al 2006

- Duran R P, Eisenhart M A, Erickson F D, Grant C A, Green J L, Hedges L V, Schneider B L, Standards for reporting on empirical social science research in AERA publications: American Educational Research Association. Educational Researcher, 2006 35(6), 33-40.

- EACH, https://www.each-for-sick-children.org/each-charter.html accessed January 2020

- Edwards A and Talbot R, The Hard-pressed Researcher: Research Handbook for the Caring Professions (Longman 1999)

- Eekelaar J, 'The Emergence of Children's Rights', Oxford Journal of Legal Studies 6, 1986, no. 2

- Eekelaar J 'The Interests of the Child and the Child's Wishes: The Role of Dynamic Self-Determinism', International Journal of Law Policy and the Family 8, 1994 no. 1 
- Eichstellar G 'JanuszKorczak - His Legacy and its Relevance for Children's Rights Today', The International Journal of Children's Rights, Volume 17, Issue 3, (2009)

- Eurochild, 'A Child rights to child poverty: Discussion paper' (2007) https://www.eurochild.org/fileadmin/public/05 Library/Thematic priorities/01 Child rens Rights/Eurochild/Eurochild discussion paper_child rights poverty.pdf accessed January 2020

- EU working paper 13880/04, Commission staff working document, Proposal for a Regulation of the European parliament and of the Council on medicinal products for paediatric use and amending Council Regulation (EEC) No 1786/92, Directive 2001/83/EC and Regulation (EC) No 726/2004

- Every Child, The Global Strategy for Women's, Children's and Adolescents' Health, 2016-2030 (Every Child 2015) http://www.who.int/countries/moz/areas/human_rights/en/ accessed January 2020

- Federle K H, 'Rights, Not Wrongs,' International Journal of Child Rights (2009) 17

- Feinburg J, Rights, Justice and the bounds of liberty (Princeton University Press 1980)

- Felizer M, 'Doing Mixed Methods Research Pragmatically: Implications for the Rediscovery of Pragmatism as a Research Paradigm', Journal of Mixed Methods Research January 2010 4(1):6-16

- Flasher J, 'Adultism,' Adolescence (1978) 13 (51): 517-523

- Fortin J, Children's Rights and the Developing Law, ( $3^{\text {rd }}$ edn Cambridge University Press 2009)

- Franck L, Noble G and McEvoy M, 'Enquiring minds want to know: Topics requested by users of a children's health information website', Patient Education and Counseling (2008) 72, 168-171

- Franklin B, 'Children's political rights', In Franklin B (ed) The rights of children (New York Basil Blackwell 1986)

- Freeman M, The Moral Status of Children: Essays on the Rights of the Children (1 ${ }^{\text {st }}$ ed Springer, 1997)

- Freeman M, 'Beyond Conventions - towards Empowerment', In Freeman M (ed) The Moral Status of Children: Essays on the Rights of the Child (The Hague, The Netherlands/ The Kluwer Law International 1997)

- Freeman M, 'Why It Remains Important to Take Children's Rights Seriously,' The International Journal of Children's Rights (March 2007) 15 (1): 5-23

- Freeman M, Article 3: Best interests of the child (Leiden: MartinusNijhoff 2007)

- Freeman M, 'Upholding the Dignity and Best Interests of Children: International Law and the Corporal Punishment of Children' (2010) 73 Law and Contemporary Problems, 213-53

- Freeman M, 'The Value and Values of Children's Rights, In Invernizzi A and Williams J (eds), The Human Rights of Children: From Visions to Implementation (Farnham: Ashgate 2011)

- Future Generations Commissioner, The Right Way: A Wales Future Fit for Children (Future Generations Commissioner 2019) https://futuregenerations.wales/resources_posts/the-right-way-a-wales-future-fit-forchildren/ accessed January 2020

- Future Generations Commissioner and Children's Commissioner Guidance, The Right Way, http://www.childrensrightsplanning.wales/wp-content/uploads/2018/06/CCFWFGCW-Report- English_01.pdf accessed January 2020 
- Gallagher M, Haywood S, Jones M, and Milne S 'Negotiating informed consent with children in school-based research: A critical review', Children and Society (2010) 24, 471482

- Garth B, Murphy G C and Reddihough D S, 'Perceptions of participation: Child patients with a disability in the doctor-parent-child partnership,' Patient Education and Counselling (2009) 74, 45-52

- Gavrieldes T, 'Ethnicity and Inequalities in Health and Social Care' 4.1 (2011) 28-37.

- Gearty C and Mantouvalou V, Debating Social Rights (Hart Publishing 2010)

- Geertz C, Thick description: Toward an interpretive theory of culture. In The interpretation of cultures: Selected essays, 3-30 (New York: NY: Basic Books 1973)

- Generation R https://generationr.org.uk/about/ accessed January 2020

- George R L, The NHS in Scotland and Wales: The Ideas and Development of Devolved Health Policy, 1999-2011 (Thesis PhD, Swansea University, College of Arts Humanities 2015)

- Gerber P, KyriaKakis J and O'Byrne K, 'General Comment 16 on State Obligations Regarding the Impact of the Business Sector on Children's Rights: What is its Standing, Meaning and Effect?' Melbourne Journal of International Law, Vol. 14, No. 1 (2013)

- Gibson F, Aldiss S, Horstman M, Kumpunen S and Richardson A, 'Children and young people's experiences of cancer care: A qualitative research study using participatory methods,' International Journal of Nursing Studies, 47, 1397-1407

- Giddens A, Central problems in social theory: Actions, structure and contradiction in social analysis (Contemporary Social Theory 1979).

- Giddens A, 'Structuration theory: past, present and future', In Bryant C G A and Jary D (eds) Giddens, Theory of Structuration: A Critical Appreciation (London: Routledge: 1991) 204

- Giesbertz N A A, Bredenoord A L and Delden van J J M, 'Clarifying assent in pediatric research', European Journal of Human Genetics (2014) volume 22, 266269

- Goldhagen and Mercer, 'Child Health Equity: From Theory to Reality, In Invernizzi A and Williams J (eds) The Human Rights of Children: From Visions to Implementation (Farnham: Ashgate 2011) 307

- GMC, GMC 0-18 Guidance (GMC 2007)

- Goodenough T, Williamson E, Kent J and Ashcroft R, 'What did you think about that? Researching children's perceptions of participation in a longitudinal genetic epidemiology study', Children and Society (2003) 17, 113-125

- Goodwin W L and Goodwin L D, Understanding quantitative and qualitative research in early childhood education (New York, NY: Teachers College Press 1996)

- Gostin L and Lazzarini Z, Human rights and public health in the AIDS pandemic (New York: Oxford University Press, 1997) xv.

- Green, M, 'What We Talk About When We Talk About Indicators: Current Approaches to Human Rights Measurement', Human Rights Quarterly (2001) 23(4): 1062-109

- Greer Scott L, Four Way Bet: How Devolution Has Led to Four Different Models for the NHS (February 2004, The Constitution Unit)

- Greig A and Taylor J, Doing Research with Children (London: Sage 1999)

- Grisso T and Vierling L, 'Minors' Consent to Treatment: A Developmental Perspective', ProfPsych (1978) 9: 412-427 
- Grootens-Wieger P, Hein I and Staphorst M, 'Using Children's Voice to Optimize Pediatric Participation in Medical Decision Making', The American Journal of Bioethics (2018) 18:3 14- 15

- Gruskin S, Bogecho D, and Ferguson L, 'Rights-based approaches' to health policies and programs: Articulations, ambiguities, and assessment,' Journal of Public Health Policy 31/2 (2010), 129-145

- GTZ German Federal Ministry for Economic Cooperation and Development, Human Rights in German Development Policy - Strategy (BMZ Strategy Paper 4 - 2011) health.bmz.de/what_we_do/Gender_and_human_rights/Policies_and_concepts/Huma n_Rights_in_German_Development_Policy_Strategy_Paper/BMZ-StrategiepapierHealth_and_Human_Rights.pdf accessed January 2020

- Hagen-Zanker J and Mallett R, How to do a rigorous, evidence focused literature review in international development: A Guidance Note (Overseas Development Institute. London 2013).

- Hammerberg T, Belembaogo A, Children's Rights, turning principles into practice. (Stockholm, Save the Children Sweden 2006)

- Hanson K and Lundy L, 'Does exactly what it is says on the tin? A critical analysis and alternative conceptualisations of the So-called "General Principles" of the Convention on the Rights of the Child', The International Journal of Children's Rights (2017) (25 (2)285-306

- Harris D, The development of socio-legal studies in the United Kingdom (Cambridge University Press: January 2018)

- Hart H L A 'Bentham on Rights', In Simpson AW (ed.) Oxford Essays in Jurisprudence, (Oxford, Oxford University Press, 1973)

- Hart R A, Children's Participation - From Tokenism to Citizenship (Florence, Italy: UNICEF 1992)

- Hart R, Children's participation: the theory and practice of involving young citizens in community development and environmental care (UNICEF and Earthscan1997)

- Hayward T, 'On Prepositional Duties', Ethics (2013) 123: 264-91

- Health Research Authority, UK Policy Framework for Health and Social Research (HRA 2017)

- Health Research Authority, Health research approval one year on (HRA 2017) https://www.hra.nhs.uk/about-us/news-updates/hra-approval-one-year/ accessed January 2020

- Health Research Authority, Health Authority Decision Making Tools http://www.hradecisiontools.org.uk/research/docs/DefiningResearchTable_Oct2017-1.pdf accessed January 2020

- Health Research Authority, Qualitative Protocol Tool (HRA 2017) 5 https://www.hra.nhs.uk/documents/324/qualitative-protocol-developaccessed January 2020

- Health Research Authority, Research Ethics Committee Review, What approvals and decisions do I need https://www.hra.nhs.uk/approvals-amendments/what-approvalsdo-i-need/research-ethics-committee-review/ accessed January 2018

- Hein I M et al, 'Accuracy of the MacArthur competence assessment tool for clinical research (MacCAT-CR) for measuring children's competence to consent to clinical research' JAMA Pediatrics 168, 2014, no. 12, 1147-1153

- Hein I M, De Vries M C, Troost P W, Meynen G, Johannes B, Van Goudoever J B and Lindauer R J L, 'Informed consent instead of assent is appropriate in children from the 
age of twelve: Policy implications of new findings on children's competence to consent to clinical research', BMC Med Ethics (2015) 16: 76

- Hellawell D, 'Inside-out: Analysis of the insider-outsider concept as a heuristic device to develop reflexivity in students doing qualitative research', Teaching in Higher Education, 11(4) 2006: 483-494.

- Herring J, Medical Law and Ethics (6 ${ }^{\text {th }}$ edn Oxford: Oxford University Press 2016)

- Hill A, 'UK children's health 'harmed by gap with adult services' Guardian Online $\left(28^{\text {th }}\right.$ April 2019) https://www.theguardian.com/society/2019/apr/28/uk-childrens-healthharmed-by-gap-with-adult-services accessed January 2020

- Hill M, 'Research Review: Participatory research with children', Child and Family Social Work 2: 1997 171-183.

- Hill M, Davis J, Prout A, and Tisdall K, 'Moving the participation agenda forward,' Children and Society (2004) 18, 77-96

- Hobbes T, Leviathan (London: Penguin 1981)

- Hodgson D, 'The historical development and "Internationalisation" of the Children's Rights Movement,' Australian Journal of family law quarterly (1992)

- Hoffman S and Croke R, 'A Children's Human Rights Statement and Guide' prepared for the Children's Commissioner for Wales (Swansea University 2016)

- Hoffman S and Williams, J, 'Accountability,' In, Williams, J (eds) The UNCRC in Wales, (University of Wales Press 2013)

- Holland S, Renold E, Ross N, Hillman A, Rights 'right on' or the right thing to do? A critical exploration of young people's engagement in participative social work research (Cardiff University, ESRC Centre for Research Methods 2008)

- Holt J, Escape from Childhood (Boston: E. P. Dutton.1975)

- Hood S, Kelley P and Mayall B, 'Children as research subjects: a risky enterprise. Children and Society', (1996) 10, 117-128

- Hoole L and Morgan S, 'It's only right that we get involved: Service-user perspectives on involvement in learning disability services', British Journal of Learning Disabilities (2010) 39, 5-10.

- Huber M, Stanciole A, Wahlbeck K, Tasma N, Torres F, Jelfs E and Bremner J, Equality in and Equality of Access to Health Care Services (Brussels: European Commission 2008)

- Hudson C, 'Socioeconomic Status and Mental Illness: Tests of the Social Causation and Selection Hypotheses,' American Journal of Orthopsychiatry, Foundation (2005) Vol. 75, No. 1, 3-18

- Hunt P, 'Interpreting the International Right to Health in a Human Rights-Based Approach to Health', Health and Human Rights Journal (2016) Dec 18(2)

- Information Commissioner's Office, Processing Children's Data https://ico.org.uk/fororganisations/guide-to-data-protection/key-data-protection-themes/children/ accessed January 2020

- Information Commissioner's Office, Consultation Children and the GDPR Guidance 2017 https://ico.org.uk/media/about-theico/consultations/2172913/children-and-thegdpr-consultation-guidance-20171221.pdf accessed January 2017

- Institute for Fiscal Studies, Living standards, poverty and inequality in the UK: 201718 to 2021-22 (Institute for Fiscal Studies 2017)

https://www.ifs.org.uk/uploads/publications/comms/R136.pdf accessed January 2020

- Integrated Research Assessment Application system

https://www.myresearchproject.org.uk/ accessed January 2018 
- International Council on Human Rights Policy, Taking Duties Seriously: Individual Duties in International Human Rights Law (International Council on Human Rights Policy 1999), www.ichrp.org accessed February 2020

- International Institute for Child Rights and Development, CRED Pro Child Rights Curriculum for Health Professionals (IICRD2008)

- James A and Prout A (eds) Constructing and Reconstructing Childhood: Contemporary Issues in the Sociological Study of Childhood (London: Falmer 1997)

- Janniste T, Hayes B and Von Baeyer C L, 'Providing children with information about forthcoming medical procedures: A review and synthesis,' Clinical Psychology Science and Practice (2007) 12, 124-143

- Jans M, 'Children as citizens: Towards a contemporary notion of child participation', Childhood, (2004) 11 (1): 27-44.

- Johnson J, 'Are children's perspectives valued in changing contexts? Revisiting a rights-based evaluation in Nepal,' Journal of International Development (2010) 1076 $-1089$

- Jones P, Rights (Palgrave Macmillan, 1994)

- Jonsson U, Human Rights Approach to Development Programming (UNICEF 2003)

- Joshi A, Review of impact and effectiveness of transparency and accountability initiatives Annex 1, Service Delivery (Sussex UK. IDS. 2010)

- Keller H and Grover L, 'General Comments of the Human Rights Committee and Their Legitimacy,' In Keller H and Ulfstein G (eds), UN Human Rights Treaty Bodies: Law and Legitimacy (Cambridge University Press, 2012) 116

- Kellett M 2010, 'Small Shoes, Big Steps! Empowering Children as Active Researchers', Journal of Community Psychology 2010, Vo1.46. Issue 1-2

- Kennedy I, Treat me right: essays in medical law and ethics (Oxford: Clarendon Press 2001)

- Kirby P, Involving children in research, In The New Handbook of Children's Rights: Comparative Policy and Practice, Franklin B (ed.) (London: Routledge 2002)

- Kilkelly U and Donnelly M, The child's right to be heard in the health care setting: perspectives of children, parents and health professionals (Dublin: Office of the Minister for children 2006)

- Kilkelly U, Child Friendly Healthcare: The Views and Experiences of Children and Young People in the Council of Europe (Strasbourg: Council of Europe 2011)

- Kikelly U and Donelly M, 'Participation in healthcare: The views and experiences of children and young people', International of Journal of Children's Rights' (2011) 19, 107-125

- Kilkelly U and Savage E, Child friendly health care; A report commissioned for the ombudsman for children (Ombudsman for Children 2013)

- Kikelly U, 'Health and Children's Rights', In The International Handbook of Children's Rights Studies (eds) Vandenhole W, Desmet E, Reynaert D and Lembrects S (Routeledge 2015)

- Kilkelly U, 'The UN convention on the rights of the child: Incremental and transformative approaches to legal implementation'. The International Journal of Human Rights 232019

- Koller D, Nicholas D, Gearing R and Kalfa O, 'Paediatric Pandemic planning: Children's perspectives and recommendations,' Health and Social Care in the Community (2010) 18, 396-377 
- Lambert V, Glacken M, and McCarron M, "Visible-ness": the nature of communication for children admitted to a specialist children's hospital in the Republic of Ireland', Journal of Clinical Nursing (2008) 17, 3092-3102

- Larkins C, Thomas N, Carter B, Farrelly J, Judd D, Beatrice D and Lloyd J, 'Support for Children's Protagonism: Methodological Moves towards Critical Children Rights Research Framed from Below', International Journal of Children's Rights 232015 (2)

- Lambert V, Coad J, Hicks P and Glacken M, 2010, Physical Places and Social Spaces for Young Children in Hospital (Dublin: National Paediatric Hospital Project 2010)

- La Valle I, Payne L with Gibb J and Jelicic H, Listening to the views of children, $A$ rapid review of the evidence (NCB 2012)

- Landman T, 'Measuring Human Rights, Practice and Policy', Human Rights Quarterly (2004) vol. 26: 906-931

- Lang R, Kett M, Groce N, Trani J F, 'Implementing the United Nations Convention on the rights of persons with disabilities: principles, implications, practice and limitations', Alter Volume 5, Issue 3, July-September 2011, 206-220

- Lansdown G, The evolving capacities of the child, Innocenti Research Centre (UNICEF/Save the Children, Florence 2005)

- Landsdown G, 'The Realisation of Children's Participation Rights - Critical Reflections,' In Percy Smith B. and Thomas N (eds), A Handbook of Children and Young People's Participation: Perspectives from Theory and Practice (London and New York, 2010)

- Landsdown G, Every Child's Right to be Heard: A resource guide to the UN Committee on the Rights of the Child's General Comment No. 12 (UNICEF 2011) 93

- Lansdown G, Lundy L, Goldhagen J, 'The UN Convention on the Rights of the Child: relevance and application to pediatric clinical bioethics perspectives in biology and medicine', Baltimore 58.3 (Summer 2015)

- Larkin M, Health and well-being across the life course (2013 Sage Publications)

- Lavis P and Hewson L, 'How many times do we have to tell you?' Young Minds Magazine 2010 109: 30-31

- Law Wales, Helping you to understand Welsh law https://law.gov.wales/publicservices/health-services/what-is-devolvedhealth/?lang=en\#/publicservices/health-services/what-is-devolvedhealth/?tab=overview\&lang=en accessed January 2020

- Leikin SL, 'A Proposal Concerning Decisions to Forgo Life Sustaining Treatment for Young People,' JPediatr (1989) 108:17-22

- Leibenberg S, 'The value of human dignity in interpreting socio-economic rights,' South African Journal of Human Rights (2005), 21 (1) 1-31

- Lexy R, 'Legal reasoning and rational discourse', Ratio Juris 51992143 et seq (145)

- Liebel M, 'Adultism and Age Based Discrimination against children,' In Kutsar, D and Warming, $\mathrm{H}$ (eds) Children and non-discrimination, inter-disciplinary textbook. (University of Estonia press 2014)

- Liebel, Luhamaa, Gornischeff, 'Introduction' In, Kutsar D and Warming H (eds) Children and non-discrimination, inter-disciplinary textbook (University of Estonia press 2014)

- Lindsay M, Highlight: An Introduction to Children's Rights (London: National Children's Bureau 1992) 
- Liston C, Watts R, Tottenham N, Davidson M C, Niogi S, Ulug A M, Casey B J, 'Frontostriatal microstructure modulates efficient recruitment of cognitive control' Cerebal Cortex (2006) Apr 16(4):553-60, Epub 2005 Jul 20

- Locke J, The Second Treatise of Civil Government and a Letter Concerning Toleration (Oxford, Blackwell, 1946)

- London L, 'What is a human rights based approach to health and does it matter?' Health and Human rights (2008) vol. 10, no. 1

- Longley M, Riley N, Davies P, Hernandez-Quevedo C, United Kingdom (Wales), Health system review Health Systems in Transition, Vol 14 (11) http://www.euro.who.int/_ data/assets/pdf_file/0006/177135/E96723.pdf accessed January 2020

- Lorant V, Croux C, Weich S, Deliege D, Mackenbach J and Ansseau M, 'Depression and socio-economic risk factors: 7-year longitudinal population study', British Journal of Psychiatry (2007) 190 (4), 293-298

- Lundy L, 'Voice is not enough, conceptualising Article 12 of the United Nations Convention on the Rights of the Child', British Educational Research Journal (2007) $33 / 6$

- Lundy L, McEvoy L, \& Byrne B, 'Working With Young Children as Co-Researchers: An Approach Informed by the United Nations Convention on the Rights of the Child', Early Education and Development 2011 22(5), 714-736

- Lundy L, Kikelly U, Byrne B, King J, The UN Convention on the Rights of the Child: A Study of Legal Implementation in 12 Countries (Queens University Belfast and UNICEF 2012)

- Lundy L, ‘A Lexicon for Research on International Children's Rights in Troubled Times', International Journal of Children's Rights Volume 27 Issue 42019

- Macleod C M, 'Constructing Children's Rights,' In Drerup J, Graf G, Shickhart C and Shweiger G (eds) Justice, Education and the Politics of Childhood (Springer 2016)

- Madden L, Woolfall K, Sowden E, Smyth, R L, Williamson P R, Young B 'Questioning assent: how are children's views included as families make decisions about clinical trials?' Child: Care, Health and Development Volume 42 (2016) Issue 6

- Madigan J H, Truth, Politics, and Universal Human Rights (Palgrave Macmillan, New York 2007) 45-54

- Mainey A, Ellis A and Lewis J, Children's views of services: a rapid review. (London. National Children's Bureau 2009)

- Marmot M, Allen J, Goldblatt P, Boyce T, McNeish D, Grady M, and Geddes I, Fair society, healthy lives: Strategic review of health inequalities in England post 2010 (Marmot Review 2010)

- Marmot M, Allen J, Boyce T, Goldblatt P, Morrison J, Health equity in England: The Marmot Review 10 years on (London: Institute of Health Equity 2020)

- Marshall K, Children's Rights in the Balance: The Participation-Protection Debate (Stationary Office 1997)

- Mason, J, 'The legal context', In Fraser S, Lewis V, Ding S, Kellett M and Robinson C (Eds.) Doing research with children and young people (London: Sage Publications 2004) 43-58

- Mason J and Hood S, 'Exploring issues of children as social actors in research', Children and Youth Services Review, Volume 33, Issue 4, April 2011, 490-49

- Mauthner M, 'Methodological Aspects of Collecting Data from Children: Lessons from Three Research Projects', Children \& Society 1997 11: 16-28 
- Mayall B, 'The sociology of childhood in relation to children's rights,' The International Journal of Children's Rights (2000) 8: 243-259

- McConville M and Wing H (eds) Research Methods for Law (Edinburgh University Press 2017)

- McIntosh N and Hull D 'Guidelines for the ethical conduct of medical research involving children', Royal College of Paediatrics, Child Health: Ethics Advisory Committee' Archives of Diseases of Childhood (2000) Volume 82

- Meier B, 'Global health governance and the contentious politics of human rights: Mainstreaming the right to health for public health advancement,' Stanford Journal on International Law 46/1 (2010)

- Melhuish E, 'The impact of poverty on child development and adult outcomes: the importance of early years education,' In Judge L, Ending child poverty by 2020 (Child Poverty Action Group 2012)

- Merriam S B, 'Qualitative research: A guide to design and implementation. Revised and expanded from qualitative research', Practical Assessment, Research \& Evaluation, Vol 25 No 22009

- Michael P, Public Health in Wales 1800-2000: A brief history. This work was commissioned by the Chief Medical Officer for Wales to mark the Faculty of Public Health Conference held in Cardiff on June 3-5, 2008.

- Migone M, McNicholas F and Lennon R, 'Are we following the European charter? Children, parents and staff perceptions', Child Care, Health and Development (2008)

- Milennium Cohort Study https://cls.ucl.ac.uk/cls-studies/millennium-cohort-study/ accessed January 2020

- Miller S, 'Researching children: issues arising from a phenomenological study with children who have diabetes mellitus', Journal of Advanced Nursing (2000) 31, 12281234

- Mitchell-Lowe M and Eggleston M, 'Children as consumer participants of child and adolescent mental health services,' Australasian Psychiatry (2009) 17, 287-290

- Modi N, 'Top paediatrician says it's time to give parents extra votes for their children' Guardian Online (January 23 $3^{\text {rd }} 2018$ ) https://www.theguardian.com/society/2018/jan/23/top-paediatrician-says-its-time-togive-parents-extra-votes-for-theirchildren accessed January 2020

- Modi N, Vohra J, Preston J, Elliott C, Van't Hoff W, Coad J, Gibson F, Partridge L, Brierley J, Larcher V, Greenough A, 'Guidance on clinical research involving infants, children and young people: an update for researchers and research ethics committees', Archives of Disease in Childhood (2014) 99(10): 887-91

- Moore L and Kirk S, 'Literature review of children's and young people's participation in decisions relating to health care', Journal of Clinical Nursing, (2010) 19, 2215 2225

- Morgan D L, 'Paradigms lost and pragmatism regained methodological implications of combining qualitative and quantitative methods', Journal of mixed methods research 2007 no. 1 (1):48-76

- Morgan M, Gibbs S, Maxwell K, and Britten N, 'Hearing children's voices: methodological issues in conducting focus groups with children aged 7-11 years', Qualitative Research 2002 2(5): 5-20

- Morrow V, and Richards M, 'The ethics of social research with children: an overview', Children \& Society (1996) 10, 90-105

- Mullender A, Hague G, Imam U, Kelly L, Malos E and Regan L, Children's Perspectives on Domestic Violence (London: Sage 2002) 
- Munro L A, 'Human Rights Based Approach to Programming: A contradiction in terms,' In (eds) Hickey S and Mitlin D, Rights Based Approaches to Development: Exploring the Potentials and the Pitfalls (Kumarian Press USA 2009)

- Naskou - Perraki P, 'An Introduction to International Protection of Human Rights, In Kutsar D and Warming H (eds) Children and non-discrimination, inter-disciplinary textbook (University of Estonia press 2014)

- National Children's Bureau, Children and Young People's Views on Health and Health Services: A Review of the Evidence. (London: National Children's Bureau 2005)

- National Evaluation of Flying Start: Impact Report, Social Research No. 74/2013 December 2013

- Neefjes P, 'Current Developments in Global Child Health Care: Unicef Data and Experiences', In Doek J and Dorscheist M (eds) Children's Rights in Health Care (Brill Publications 2018)

- Newell P and Hodgkin R, Implementation handbook for the Convention on the Rights of the Child, (UNICEF 2002)

- Nkansah L A, Chimbwanda V, Interdisciplinary Approach to Legal Scholarship: A Blend from the Qualitative Paradigm', Asian Journal of Legal Education. December 24, 2015

- Nolan A, Yamin A E and Meier B M, Submission on the Content of a Future General Comment on the Right of the Child to the Enjoyment of the Highest Attainable Standard of Health (art. 24) http://www2.ohchr.org/english/bodies/crc/callsubmissionsCRC_received.htm.

- Nolas M, 'Children's Participation, Childhood Publics and Social Change: A Review', Children and Society, Volume 29, (2015)

- Nuffield Council of Bioethics, Children and Clinical Research: Ethical Issues (Nuffield Bioethics 2015)

- Nuffield Council of Bioethics, Statement of aspiration: improving research by involving children and young people (Nuffield Council of Bioethics 2015)

- Nyamu-Musembi, Celestine and Cornwall, Andrea 'What is the "rights-based approach" all about? Perspectives from international development agencies', IDS Working Paper (2004) Brighton: Institute of Developmental Studies, 2

- O'Malley, Children and Young People Participating in PRSP Processes: Lessons from Save the Children's experiences (London: Save the Children 2004)

- Office of National Statistics Data 2017 https://www.ons.gov.uk/peoplepopulationandcommunity/healthandsocialcare/childhe alth/articles/ukdropsineuropeanchildmortalityrankings/2017-10-13 accessed January 2020

- Office of National Statistics, Child mortality in England and Wales 2016 (Office of National Statistics)

- Olson E A, Collins P F, Catalina H J, Muetzel R, 'White Matter Integrity Predicts Delay Discounting Behavior in 9- to 23-Year-Olds: A Diffusion Tensor Imaging Study,' Journal of Cognitive Neuroscience 21, (2009) 1406-1421

- Organisation for Economic Co-operation and Development, Reviews of Health Care Quality: United Kingdom (OECD 2016)

- Oulton K, Gibson F, Sell D, Williams A, Pratt L, Wray J, 'Assent for children's participation in research: why it matters and making it meaningful', Child Care, Health and Development' (2016) Vol. 42, Issue 4 
- Oxfam, 'Our Commitment to Human Rights', https://www.oxfam.org/en/ourcommitment-human-rights accessed January 2020

- Oxford online dictionary, https://en.oxforddictionaries.com/definition/us/principle

- Pais M, The Convention on the rights of the child, In Manual on Human Rights reporting under six major international human rights instruments, Office of the High Commissioner for Human Rights, Geneva: United Nations 1997 Institute for Training and Research, United Nations Staff College Project Turin. 424 cited In, Newell P and Hodgkin R Implementation handbook for the Convention on the Rights of the Child, (UNICEF 2002)

- Parliamentary Assembly Council of Europe, Ensuring access to healthcare for all children in Europe, Report1 Committee on Social Affairs, Health and Sustainable Development Rapporteur: Ms Stella KYRIAKIDES, Cyprus, Group of the European People's Party (2016)

- Partington R, 'Inequality is it rising and can we reverse it,' Guardian Online (September 2019) https://www.theguardian.com/news/2019/sep/09/inequality-is-itrising-and-can-we-reverse-it accessed January 2020

- Parton, N, Safeguarding Childhood: Early Intervention and Surveillance in Late Modern Society (Basingstoke: Palgrave Macmillan 2006)

- Peel K L, 'A beginner's guide to applied educational research using thematic analysis', Practical Assessment, Research \& Evaluation 2020 25(2)

- Peleg N, 'Reconceptualising the Child's Right to Development: Children and the Capability Approach', The International Journal of Children's Rights, 2013 21(3), 523-542

- Pemberton S, Gordon D, Nandy S, Pantazis C, Townsend P Child Rights and Child Poverty: Can the International Framework of Children's Rights Be Used to Improve Child Survival Rates? PLOS Medicine, Published: October 23, (2007)

- Pillas D, Marmot M, Naicker K, et al. 'Social inequalities in early childhood health and development: a European-wide systematic review', Pediatr Res (2014)

- Pillay N, UN High Commissioner for Human Rights Human Rights in the Post-2015 Agenda 2013 Open letter to all Permanent Missions in New York and Geneva

- Piron L and Sano H, Lessons learned on DANIDA's human rights based approachAn Evaluation (Ministry for Foreign Affairs Denmark/DANIDA 2016)

- Piron L and Watkins F, DFID Human Rights Review - A Review of How DFID Has Integrated Human Rights Into Its Work (London: Overseas Development Institute,2004) https://www.odi.org/sites/odi.org.uk/files/odi-assets/publicationsopinion-files/2289.pdf accessed October 2017

- Popay J, Roberts H, Sowden A, Petticrew M, Arai L, Rodgers M and Duffy S, Guidance on the conduct of narrative synthesis in systematic review. A product from the ESRC methods programme (Version 1 Oxford: ESRC 2006)

- Pope C, Ziebland S and Mays N, 'Qualitative research in health care; Analysing qualitative data', BMJ (2000) Jan 8; 320 (7227)

- Powell M A, Fitzgerald R M, Taylor N, Graham A, International literature review: ethical issues in undertaking research with children and young people (Southern Cross University ePublication@SCU 2012)

- Powell M, and Smith A B, 'Children's participation rights in research', Childhood (2009) 16, 124-142.

- Quennerstedt A, 'Children's Rights Research Moving into the Future - Challenges on the Way Forward', The International Journal of Children's Rights 2013 21(2) 
- Rees O \& Williams J, 'Framing Asymmetry: Devolution and the United Kingdom's Four Children's Commissioners', The International Journal of Children's Rights 24(2), 408-433

- Robson C, Real world research: a resource for social scientists and practitionerresearchers (Malden, Blackwell Publishing 2002)

- Robinson S, 'Children and young people's views of health professionals', England Journal of Child Health Care (2010)14, 310-326

- Roche J, 'Children: Rights, Participation and Citizenship', Childhood 19996 (4): 475-493

- Rosga A and Satterthwaite M, 'The Trust in Indicators: Measuring Human Rights', Berkeley Journal of International Law (2009) vol. 27, Number 2: 253-31

- Rousseau J, Social Contract and the Discourses (London: J M Dent and Sons 1973)

- Royal College of Nursing, The role of children and young people's nurses in commissioning and planning service (Royal College of Nursing 2014)

- Sabatini F, The Human Rights Approach to Programming; what have we learnt.

- Sadeleer N, Environmental principles; from political slogans to legal rules (Oxford University Press 2002) 234

- Safarty G, 'Why culture matters in international institutions: the marginality of human rights at the World Bank', American Journal of International Law (2009)103 (4), 647-83

- SAIL data bank, https://saildatabank.com/ accessed January 2020

- Sandelowski M, 'Rigor or rigor mortis: the problem of rigor in qualitative research revisited', Adv Nurs Sci 1993; 16:1-8.

- Santos Pais M, Child Participation Documentacao e Direito Comparado, nos 81/82 (2000) 93

- Saunders M N K 'Gatekeeper', In Sage Dictionary of Social Research Methods (2006) http://srmo.sagepub.com/view/the-sage-dictionary-of-social-researchmethods/n85.xml accessed 20 January 2020

- Savage E and Callery P, 'Clinic consultations with children and parents on the dietary management of cystic fibrosis', Social Science and Medicine' (2007) 64, 363- 374

- Save the Children Sweden, Child rights programming: How to apply rights based approaches to programming: A handbook for Save the Children International Alliance Members (Save the Children International 2005)

- Save the Children UK, Eglatyne Jebb, 1923 recorded in the history of Save the Children UK https://www.savethechildren.org.uk/about-us/our-history accessed January 2020

- Schrag F, 'Children and Democracy: Theory and Policy', Politics, Philosophy and Economics no. 3 (2004): 371

- Scottish Human Rights Commission, NHS in Scotland, the Health and Social Care Alliance in Scotland, Human Rights: Human Rights in Health and Social Care, putting it into practice (April 2016) http://www.scottishhumanrights.com/media/1408/shrc_case_studies_report.pdf accessed March 2018

- Scott J, 'Children are respondents: The Challenge for Quantitative Methods' In, (eds) Christensen P, and James A, Research with Children: Perspectives and Practices $\left(2^{\text {nd }}\right.$ edn Routledge London and New York 2008) 88

- Sen A, Development as Freedom (Alfred A Knopf, New York, 1999) 
- Shier H, Pathways to participation: openings, opportunities and obligations. Children and Society Vo1. 15 Issue 2. April (2001) 107-117

- SIDA, Human Rights Based Approach at Sida https://www.sida.se/English/partners/methods-materials/human-rights-basedapproach-at-sida/ accessed January 2020

- Slevin E, 'Enhancing the truthfulness, consistency, and transferability of a qualitative study: using a manifold of two approaches', Nurse Res 2002; 7:79-197

- Theis J, Promoting rights based approaches; Experiences and ideas from Asia and the Pacific. Bankok (Save the Children Sweden 2004)

- Simonelli F and Guerreiro A and Task Force on Health Promotion for Children and Adolescents in and by Hospitals and Health Services, The Respect of Children's Rights in Hospital: An Initiative of the International Network of Health Promoting Hospitals and Health Services (Final Report of the implementation process of the implementation of the Self-evaluation Model and Tool on the Respect for Children's Rights in Hospital (International Network of Health Promoting Hospitals and Health Services - WHO Collaborative Centre 2010).

- Stats Wales, percentage of children living in poverty 2015-16 to 2017-18 https://statswales.gov.wales/Catalogue/Community-Safety-and-SocialInclusion/Poverty/householdbelowaverageincome-by-year accessed January 2020

- Stoecklin D, Bonvin, J M (eds) Children's rights and the capabilities approach (Springer 2014)

- Sullivan G M, and Artino A R jnr 'Analyzing and Interpreting Data From Likert-Type Scales', J Grad Med Educ. 2013 Dec; 5(4): 541-542

- Tait A, Voepel-Lewis T, Malviya S, 'Do they understand? (Part II) Assent for children participating in clinical anesthesia and surgery research,' Anaesthesiology (2003)

- Tashakkori A and Teddlie C, Mixed Methodology: Combing Qualitative and Quantitative Approaches (London: Sage 1998)

- Theis J, Promoting rights based approaches - Experiences and Ideas from Asia and the Pacific (Save the Children Sweden 2004)

- Thomas N, Interpreting children's needs: contested assumptions in the provision of welfare. In Goddard J, McNamee S, James A, James A (eds) The Politics of Childhood: International Perspectives, Contemporary Developments (Palgrave Macmillan. 2005)

- Thomas M D et al, 'Utilising insider-outsider research teams in qualitative research,' Qualitative Health Research 2000 Nov

- Thomas N, 'Towards a theory of children's participation', International Journal of Children's Rights (2007) 15, 199-218

- Thomas R, Kuruvilla S, Hinton R, Jensen S L B, Magar V and Bustreo F, 'Assessing the Impact of a Human Rights-Based Approach across a Spectrum of Change for Women's, Children's and Adolescents', Health and Human Rights Journal 17/2 (Published December 10, 2015)

- Thurmond V A, 'The point of triangulation', The Journal of Nursing Scholarship (2001) Volume 33 Issue 3

- Tobin J, 'Understanding a human rights based approach to matters involving children: conceptual foundations and strategic considerations,' In Invernizzi A and Williams J (eds) The Human Rights of Children: From Visions to Implementation (Farnham: Ashgate 2011)

- Tobin J, 'Understanding Children's Rights: A Vision beyond Vulnerability', Nordic Journal of International Law (2015) (28) 155-182 
- Toebes $\mathrm{B}$, The right to health as a human right in international law (Cambridge: Intersentia, 1999).

- Together for Children and Young People, http://www.goodpractice.wales/t4cyp accessed January 2020

- Tostensen A, Stokke H, Trygged S and Halvorsen K, Supporting Child Rights. Synthesis of Lessons Learned in Four Countries (SIDA 2011) www.cmi.no/publications/file/3947-supporting-childrights.pdf accessed January 2020

- Treseder P, Empowering Children \& Young People: Training Manual: Promoting Involvement in Decision-making (Save the Children 1997)

- Tylee A, Haller D, Graham T, et al 'Youth friendly primary care services: How are we doing and what more needs to be done?' Lancet (2007) 369 (9572), 1565-1573

- UK Children's Commissioners, Report of the UK Children's Commissioners UN Committee on the Rights of the Child Examination of the Fifth Periodic Report of the United Kingdom of Great Britain and Northern Ireland (UK Children's Commissioners 2015) http://www.childrenscommissioner.gov.uk/sites/default/files/publications/UNCRC $\% 2$ 0final 0.pdf accessed January 2020

- UK Foundation Programme Office, F2 Career Destinations Report 2018

- Uvin P, Human Rights and Development (Kumarian Press 2004)

- Van Bueren G, 'The International Law on the Rights of the Child', In The International Law on the Rights of the Child (Leiden: Brill Nijhoff 1995)

- Vandenhole W, 'Failures and Successes of Human Rights-Based Approaches to Development: Towards a Change Perspective', Nordic Journal of Human Rights, (2014) Vol. 32

- Van Duffel S, 'In Defense of the Will Theory of Rights', Res Publica 2012 18: 23131.

- Varadan S, 'The Principles of Evolving Capacities under the Convention on the Rights of the Child', International Journal of Child Rights (2019) Volume 27 Issue 2

- Velanova K, Wheeler M E and Luna B. 'Maturational Changes in Anterior Cingulate and Frontoparietal Recruitment Support the Development of Error Processing and Inhibitory Control' Cereb. Cortex 18 (2008) 2505-2522

- Viner RM, Ozer E M, Denny S, Marmot M, Resnick M, Fatusi A, Currie C, 'Adolescence and the social determinants of health,' The Lancet 379 (2012): 164152.

- Wales Audit Office, Health Care Inspectorate for Wales, Estyn, CCSIW (2009). Services for Children and Young People with Emotional and Mental Health Needs https://dera.ioe.ac.uk/11698/1/CAMHS_eng.pdfaccessed April 2018

- Waligora M, 'Is a requirement of personalised assent realistic? A case from the GABRIEL project', European Journal of Human Genetics Volume 22 (2014)

- Wall J, 'Democratising democracy: the road from women to children's suffrage', International Journal Human Rights: Vol 18 (2014) Issue 6

- Wallace J, 'Wales: Wellbeing as Sustainable Development', In Well-Being and Devolution: Reframing the Role of Government in Scotland, Wales and Northern Ireland (Cham: Palgrave Pivot 2019) 73-101

- Webb E, 'An exploration of the Discrimination-Rights Dynamic,' In Invernizzi A and Williams J (eds), The Human Rights of Children: From Visions to Implementation (Farnham: Ashgate 2011) 
- Webb, E, 'Health Inequalities,' In Croke R and Crowley A (eds) Righting the wrongs: the reality of children's rights in Wales (Save the Children UK 2006)

- Weithorn L A and Campbell S B 'The Competency of Children and Adolescents to Make Informed Treatment Decisions', Child Dev (1982) 53: 1589-1598

- Welling, B A J 'International Indicators and Economic, Social, and Cultural Rights', Human Rights Quarterly (2008) vol. 30(4): 933-958

- Welsh Office, Better Health-Better Wales (Welsh Office 1998) http://www.wales.nhs.uk/publications/greenpaper98_e.pdf accessed January 2020

- Wheeler R 'Gillick or Fraser? A plea for consistency over competence in childrenGillick and Fraser are not interchangeable,' BMJ volume 3328 April (2006)

- Wilkson D, 'Dissent about assent in paediatric research', Journal of Medical Ethics (2012) 38(1):2

- Williams C, 'Editorial: The Post-2015 Development Agenda, Human Rights, Evidence, and Open-Access Publishing', Health and Human Rights (2013) vol. 152 , $1-4$

- Willow C, Franklin A and Shaw C, Meeting the obligations of the Convention on the Rights of the Child in England. Children and young people's messages to Government (DCSF 2007)

- Williams J, 'Multi-level governance and CRC implementation', In Invernizzi A and Williams J (eds.) The Human Rights of Children: From Visions to Implementation (Farnham: Ashgate 2011)

- Williams J, 'The Role of the Professions in Effective Implementation of the CRC', In (eds) Liefaard T and Sloth-Nielsen J (eds) The United Nations Convention on the Rights of the Child: Taking Stock After 25 years (Brill Publishing 2017)

- Williams, J 'General legislative measures of implementation: individual claims, 'public officer's law' and a case study on the UNCRC in Wales' The International Journal of Children's Rights 2012 20(2), 224-240

- Williams J (eds) The UNCRC in Wales (University of Wales Press 2013)

- Woods H, 'Examining the implications of Insider- Outsider Positioning'. Published by Heather W June 2019, https://heatherawoods.ca/research/examining-theimplications-of-insider-outsider-positioning/ accessed December 2020

- Yin R K, Case study research: Design and methods (Newbury Park, CA: Sage 1984).

- Youle R, 'This is how a Welsh health board spent £1billion last year', Wales Online (June 5th 2018)

- Young B, Dixon-Woods M, Windridge K, and Heney D, 'Managing communication with young people who have a potentially life-threatening chronic illness: Qualitative study of patients and parents', British Medical Journal, (2003) 326, 1-5

- Young K, Constituting Economic and Social Rights (Oxford: Oxford University Press 2012)

- Zermatten J, The Best Interests of the Child: Literal Analysis, Function and Implementation. (Institut International de droits de l'enfants 2009). 